\title{
Intruder Dose Pathway Analysis for the Onsite Disposal of Radioactive Wastes: The ONSITE/MAXI1 Computer Program
}

Prepared by B.A. Napier, R. A. Peloquin, W. E. Kennedy, Jr., S. M. Neuder

Pacific Northwest Laboratory Operated by

Battelle Memorial Institute

NOTICE

PORTIONS OF THIS REFORT ARE ILEEGRLE.

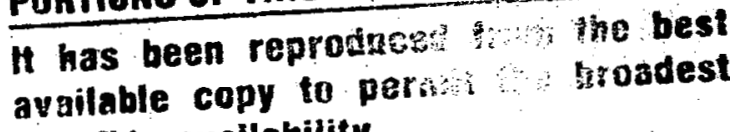
possible avallability.

Prepared for

U.S. Nuclear Regulatory

Commission

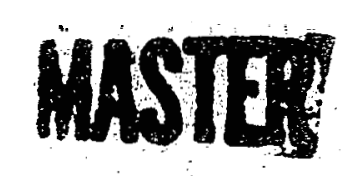




\section{DISCLAIMER}

This report was prepared as an account of work sponsored by an agency of the United States Government. Neither the United States Government nor any agency Thereof, nor any of their employees, makes any warranty, express or implied, or assumes any legal liability or responsibility for the accuracy, completeness, or usefulness of any information, apparatus, product, or process disclosed, or represents that its use would not infringe privately owned rights. Reference herein to any specific commercial product, process, or service by trade name, trademark, manufacturer, or otherwise does not necessarily constitute or imply its endorsement, recommendation, or favoring by the United States Government or any agency thereof. The views and opinions of authors expressed herein do not necessarily state or reflect those of the United States Government or any agency thereof. 


\section{DISCLAIMER}

Portions of this document may be illegible in electronic image products. Images are produced from the best available original document. 


\section{NOTICE}

This report was prepared as an account of work sponsored by an agency of the United States Government. Neither the United States Government nor any agency thereof, or any of their employees, makes any warranty, expressed or implied, or assumes any legal liability of responsibility for any third party's use, or the results of such use, of any information, apparatus. product or process disclosed in this report, or represents that its use by such third party would not infringe privately owned rights.

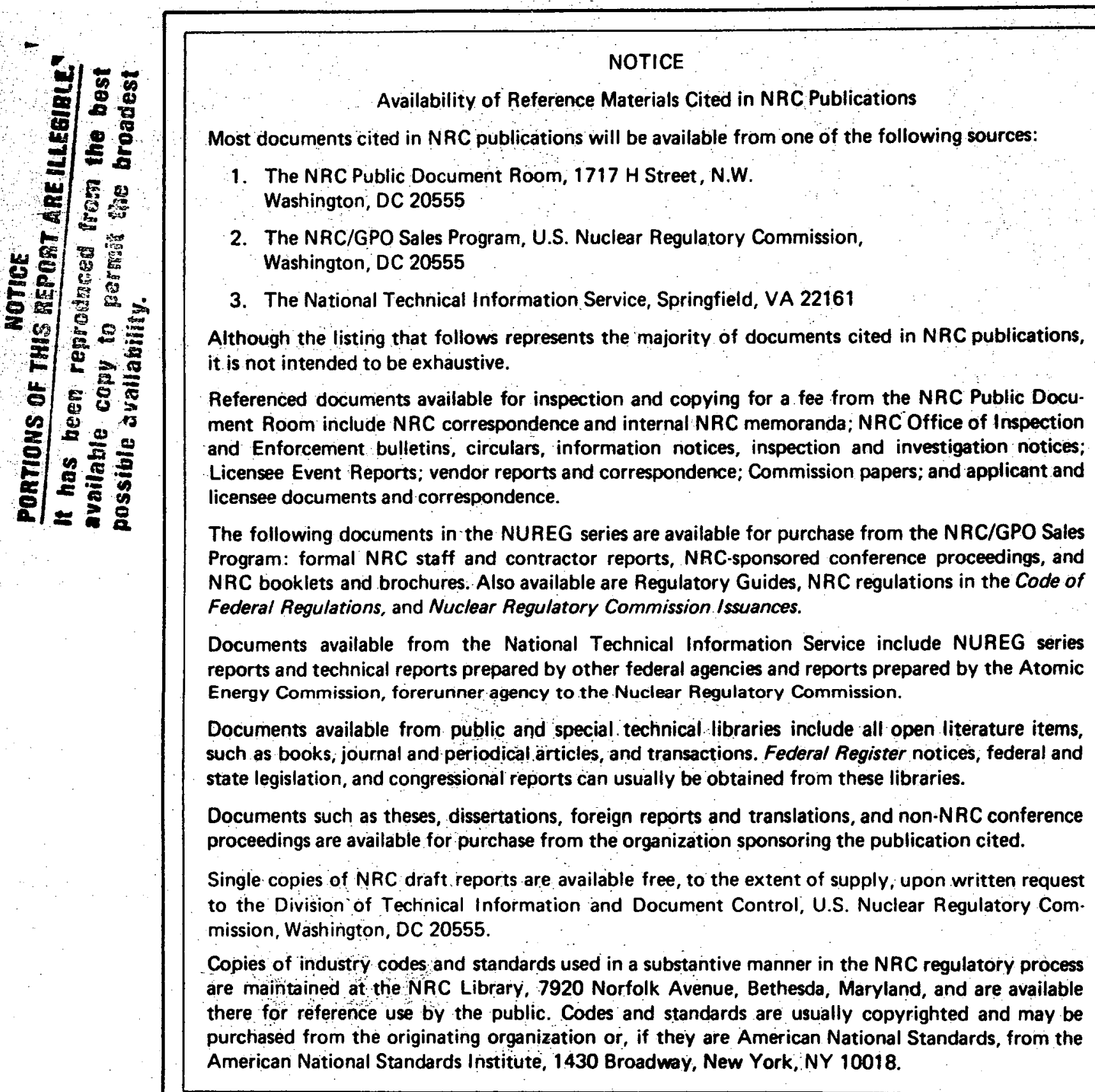

GPO Printed copy price: $\$ 8.50$ 
It has been reprodussis from the best

\title{
Intruder Dose Pathway Analysis for the Onsite Disposal of Radioactive Wastes: The ONSITE/MAXI1 Computer Program
}

Manuscript Completed: June 1984

Date Published: October 1984

Prepared by

B. A. Napier, R. A. Peloquin, W. E. Kennedy, Jr., S. M. Neuder*

Pacific Northwest Laboratory

Richland, WA 99352

*Staff, U. S. Nuclear Regulatory Commission

\author{
Prepared for \\ Division of Waste Management \\ Office of Nuclear Material Safety and Safeguards \\ U.S. Nuclear Regulatory Commission \\ Washington, D.C. 20555 \\ NRC FIN B2478
}

\section{DISCLAIMER}

This report was prepared as an account of work sponsored by an agency of the United States Government. Neither the United States Government nor any agency thereof, nor any of their employees, makes any warranty, express or implied, or assumes any legal liability or responsibility for the accuracy, completeness, or usefulness of any information, apparatus, product, or process disclosed, or represents that its use would not infringe privately owned rights. Reference herein to any specific commercial product, process, or service by trade name, trademark, manufacturer, or otherwise does not necessarily constitute or imply its endorsement, recommendation, or favoring by the United States Government or any agency thereof. The views and opinions of authors expressed herein do not necessarily state or reflect those of the United States Government or any agency thereof. 


\section{ABSTRACI}

Because of uncertainties assoclated with assessing the potential risks from onsite burials of radioactive waste, the U. S. Nuclear Regulatory Commission (NRC) has amended its regulations to provide greater assurance that buried radioactive material will not present a hazard to public health and safety. The amended regulations now require licensees to apply for approval of proposed procedures for onsite disposal pursuant to $10 \mathrm{CFR}$ 20.302. The NRC technically reviews these requests on a case-by-case basis. These technical reviews require modeling potential pathways to man and projecting radiation dose commitments. This document contains a summary of our efforts to develop human-intrusion scenarios and to modify a version of the MAXI computer program for potential use by the NRC in reviewing applications for onsite radioactive waste disposal. The documentation of the ONSITE/MAXI computer program is written for two audiences. The first (Audience A) includes persons concerned with the mathematical models and computer algorithms. The second (Audience B) includes persons concerned with exercising the computer program and scenarios for specific onsite disposal applications. Five sample problems are presented and discussed to assist the user in operating the computer program. Summaries of the input and output for the sample problems are included along with a discussion of the hand calculations performed to verify the correct operation of the computer program.

Computer 1 istings of the ONSITE/MAXIl computer program with an abbreviated data base listing are included as Appendix 1 to this document. Finally, complete listings of the data base with listings of the special codes used to create the data base are included in Appendix 2 as a microfiche attachment to this document. 


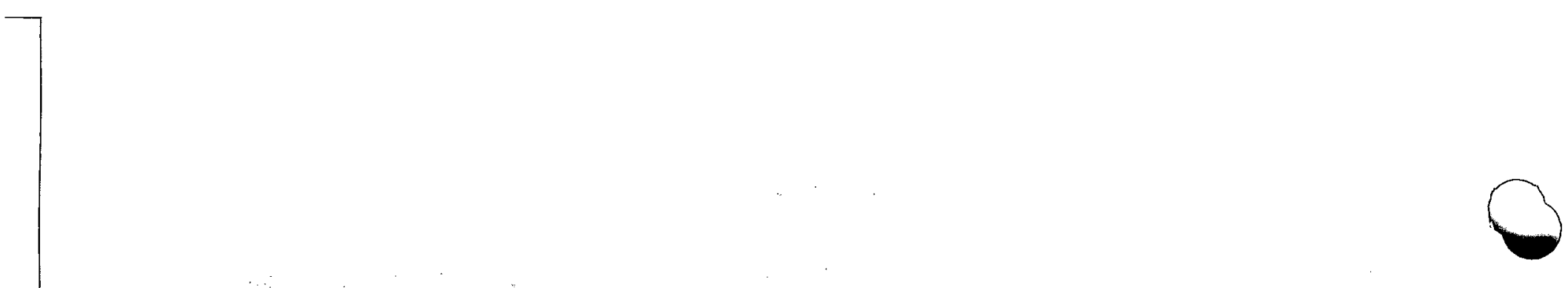

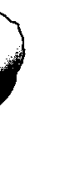

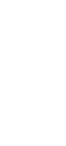




\section{ACKNOWLEDGMENTS}

The authors would like to thank all of those individuals who have helped make this study possible. The historical development of the MAXI computer program included major contributions from Ed Watson, Glenn Hoenes, and Joe Sol dat of Pacific Northwest Laboratory. We greatly appreciate the guidance, assistance, and encouragement offered by these individuals in the development of the methods and philosophy applied in this report. We would also like to thank Norma Van Houten for her contributions in typing, organizing, and correcting the draft and final manuscripts of this document. 

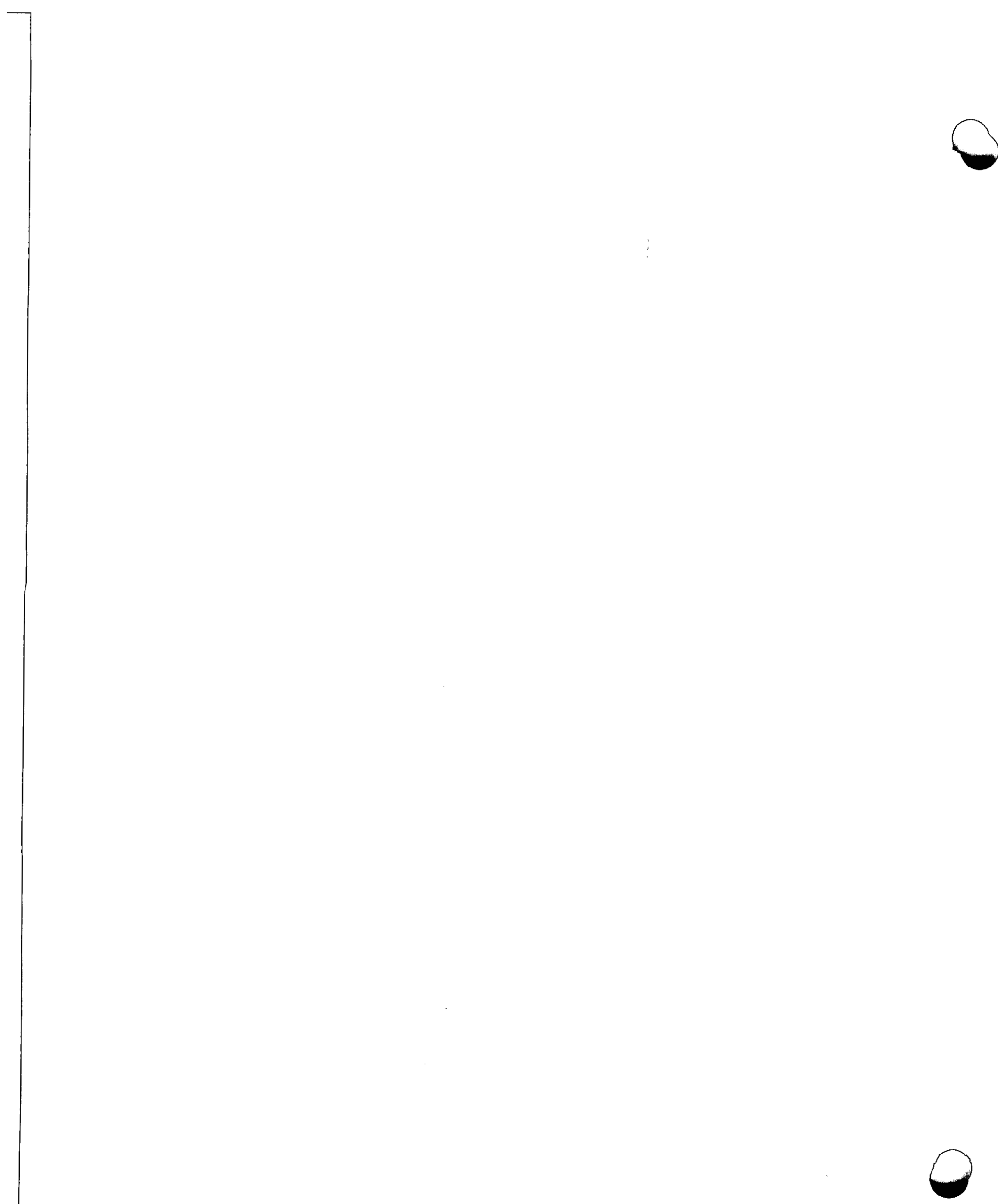
1. INTRODUCTION................................ 1.1

1.1 References............................... 1.2

2. MATHEMATICAL MODELS AND COMPUTER SOFTWARE FOR ASSESSING

ONSITE DISPOSAL IMPACTS........................ 2.1

2.1 Definition and Solution of the Problem............. 2.1

2.1.1 Applying the Pathway Analysis Models........... 2.2

2.1.2 Onsite Disposal "Environment" Description......... 2.3

2.1.3 Onsite Disposal Scenario Descriptions............ 2.6

2.1.4 Mathematical Models...................... 2.7

2.1.4.1 Dose from Ingestion of Food Products.... 2.11

2.1.4.2 Dose from Ingestion of Drinking Water... 2.17

2.1.4.3 Dose from Inhalation............... 2.19

2.1.4.4 Dose from External Radiation.......... 2.20

2.1.4.5 Dose from Ingestion of Aquatic Food .... 2.21

2.2 Computer Implementation....................... 2.24

2.2.1 Computer Programs Descriptions.............. 2.24

2.2.1.1 ONSITE Computer Program Description..... 2.25

2.2.1.2 MAXIl Computer Program Description...... 2.26

2.2.1.3 MAXI2 Computer Program Description...... 2.27

2.2.1.4 MAXI3 Computer Program Description...... 2.27

2.2.2 Operation of the ONSITE/MAXII Software Package... 2.27

2.2.2.1 Levels of Operation................ 2.28

2.2.2.2 Software Process Flow.............. 2.28

2.2.3 Capabilities, Restrictions, and Performance..... 2.29

2.2.3.1 "Environment"/Scenario Definition...... 2.29

2.2.3.2 Exposure Pathway Selection/Parameter

Modification...................... 2.29

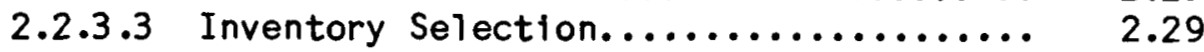

2.2 .3 .4 Organ Selection................... 2.30 
2.3 Data Base................................... 2.30

2.3.1 Radionuclide Master Library - RMDLIB........... 2.3I

2.3.2 Leaf Mechanism Dose Rate Factors - FILE20........ 2.32

2.3.3 Soil Mechanism Dose Rate Factors - FILE21........ 2.33

2.3.4 Soll Surface External Exposure Mechanism Dose Rate Factors............................ 2.34

2.3.5 Inhalation Dose Rate Factors - FILE23.......... 2.35

2.3.6 Aquatic Foods Dose Rate Factors - FILE24........ 2.36

2.3.7 Drinking Water Dose Rate Factors - FILE25....... 2.37

2.3.8 Buried Waste External Dose Rate Factors ........ 2.38

2.4 References.................................... 2.39

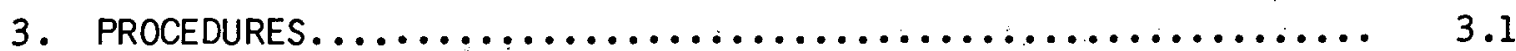

3.1 User. Instructions............................ 3.1

3.1.1 Creating and Executing a Scenario - ONSITE

(Level 1 User)........................... 3.2

3.1.2 Creating an "Environment" - MAXI2 and MAXI3

(Level 2 User)........................... 3.5

3.1.3 Interacting Directly with MAXIl (Level 3 User)... 3.6

3.2 Input Parameters................................ 3.6

3.3 Output Descriptions................................. 3.13

3.4 Sample Problems.................................. 3.14

3.4.1 Sample Problem One.......................... 3.14

3.4 .2 Sample Problem Two............................ 3.14

3.4.3 Sample Problem Three......................... 3.35

3.4 .4 Sample Problem Four.......................... 3.35

3.4 .5 Sample Problem Five....................... 3.57

3.5 Error and Recovery........................... 3.77

3.5.1. Error and Recovery - ONSITE................ 3.77

3.5.2 Error and Recovery - MAXII............... 3.77

3.6 References................................... 3.79

4. PROGRAMMING DETAIL. $\ldots \ldots \ldots \ldots \ldots \ldots \ldots \ldots \ldots \ldots \ldots \ldots \ldots \ldots \ldots \ldots \ldots \ldots, 4.1$

4.1 Program Hierarchy and Structure.................... 4.1

4.2 Computer Program Flow................................ 4.6

4.3 Program Data and Data Structures....................... 4.10

4.4 Input File Organization............................ 4.20

4.5 Additional Parameter Descriptions................... 4.22

4.6 CDC Computer Code Installation..................... 4.24 
4.6.1 Command Leve1 Procedures................. 4.25

4.6.2 Software Security...................... 4.26

4.6.3 Computer Code Conversion................. 4.26

4.7 References.............................. 4.26

APPENDIX 1.A - COMPUTER CODE LISTING - MAXI1.............. 1.A-1

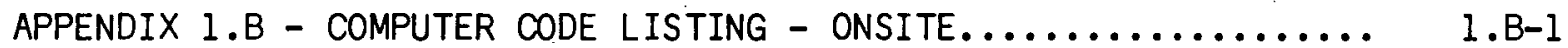

APPENDIX 1.C - ABBREVIATED DATA BASE LISTING.............. 1.C-1

Radionuclide Master Library for MAXIl - RMDLIB.......... 1.C-1

Onsite Disposal Environment FILE20 (Leaf), page 1........ 1.C-7

Onsite Disposal Environment FILE21 (Soi1), page 1....... 1.C-8

Onsite Disposal' Environment Surface Soil PLANSOURC

(External)................................... 1.C-9

Onsite Disposal Environment Stored Wastes ROOM (Externa1). 1.C-11

Onsite Disposal Environment FILE23 (Air), page 1......... 1.C-13

Onsite Disposal Environment FILE24 (Aquatic), page 1...... 1.C-14

Onsite Disposal Environment FILE25 (Drink), page 1....... 1.C-15

Onsite Disposal Environment VOLSOURC (Externa1).......... 1.C-16

Onsite Disposal Environment BURIEDHF (External) .......... 1.C-18

Onsite Disposal Environment BURIEDl (External)........... 1.C-20

Onsite Disposal Environment Selected Radionucl ides -

RMDONS................................... 1.C-22

APPENDIX 1.D - CDC Computer Installation...................... 1.D-1

CDC Command Level Procedures - PROCFIL.................. 1.D-1

CDC Version of the ONSITE module RITFIL.............. 1.D-2

(Appendix 2 is on microfiche)

APPENDIX 2.A - COMPLETE DATA BASE LISTING............... i

Radionuclide Master Library for MAXIl - RMDLIB......... 2.A-1

Onsite Disposal Environment FILE20 (Leaf) .............. 2.A-6

Onsite Disposal Environment FILE21 (Soi1)............... 2.A-92

Onsite Disposal Environment Surface Soil PLANSOURC

(External).................................... 2.A-180

Onsite Disposal Environment Stored Wastes ROOM (External). 2.A-182

Onsite Disposal Environment FILE23 (Air)............. 2.A-184

Onsite Disposal Environment FILE24 (Aquatic)............ 2.A-296

Onsite Disposal Environment FILE25 (Drink)............. 2.A-375

Onsite Disposal Environment VOLSOURC (Externa 1 ).......... 2.A-456

Onsite Disposal Environment BURIEDHF (Externa 1)......... 2.A-458

Onsite Disposal Environment BURIEDl (External).......... 2.A-460

Onsite Disposal Environment Selected Radionuclides -

RMDONS.................................... 2.A-462 
APPENDIX 2.B - MAXI2 COMPUTER CODE................... 2.B-I

MAXI2 Computer Code Listing...................... 2.B

Sample MAXI2 Input File to Create FILE20 and FILE21...... 2.B-23

APPENDIX 2.C - MAXI3 COMPUTER CODE................... 2.C-1

MAXI3 Computer Code Listing...................... 2.C-1

Sample MAXI3 Input File to Create FILE24 and FILE25....... 2.C-20

\begin{tabular}{|c|c|c|}
\hline & DISPOSAL ENVIRONMENT $\ldots \ldots \ldots \ldots \ldots \ldots \ldots \ldots \ldots$ & 2.D-1 \\
\hline $\begin{array}{l}\text { Input } \\
\text { Input } \\
\text { Input } \\
\text { Input }\end{array}$ & 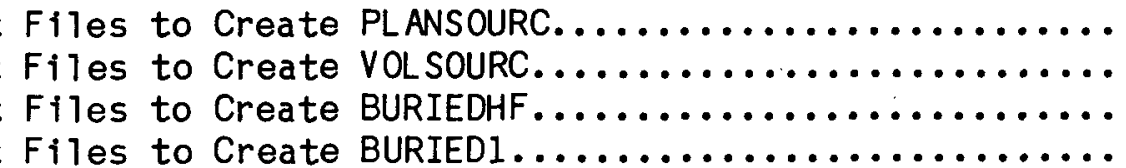 & $\begin{array}{l}2 \cdot D-1 \\
2 \cdot D-5 \\
2 \cdot D-11 \\
2 \cdot D-16\end{array}$ \\
\hline
\end{tabular}

\section{TABLES}

2.1-1 Parameters Used for Calculation of Radiation Dose

Factors from Consumption of Foods.................. 2.4

2.1-2 Parameters Used for Calculation of Radiation Doses from

Drinking Water and Aquatic Foods................... 2.4

2.1-3 Radionuclides Considered in the Onsite Disposal

"Environment"................................. 2.5

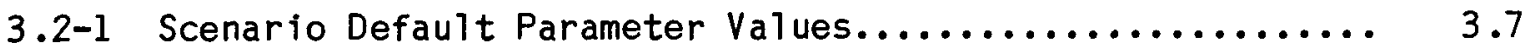

3.2-2 ONSITE/MAXIl Parameter Descriptions................. 3.8

4.1-1 MAXI1 Module Summary.......................... 4.1

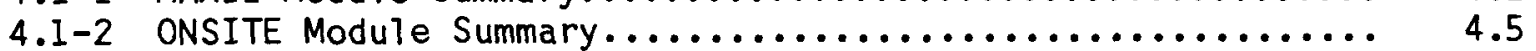

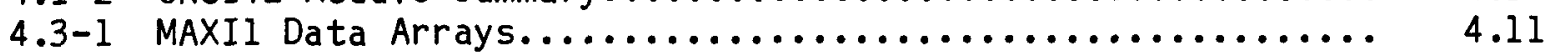

4.3-2 ONSITE Data Arrays............................. 4.13

4.3-3 MAXII Common Block Definition and Usage............... 4.14

4.3-4 ONSITE Common Block Definition and Usage.............. 4.16

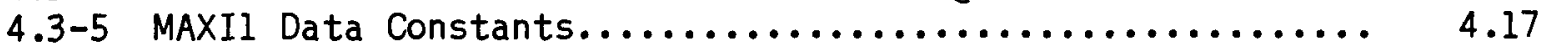

4.3-6 ONSITE Data Constants........................... 4.19

4.4-1 MAXIl Execution File Organization.................... 4.21

4.5-1 Additional Parameter Descriptions - MAXIl.............. 4.22

4.5-2 Organ Selection................................ 4.24

4.6-1 Contents of the ONSITE/MAXI Software Package........... 4.25 
2.1-1 Area Correction Factors for the Ingestion and Inhalation

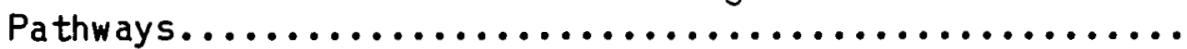

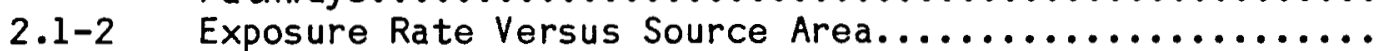

2.1-3 Exposure Rate Ratio Versus Fractional Hectare of Source Area...................................... 2.22

$2.1-4$ Area Correction Factors for External Exposure...........

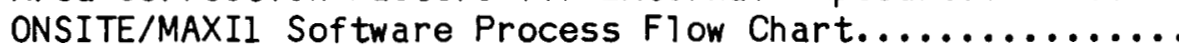

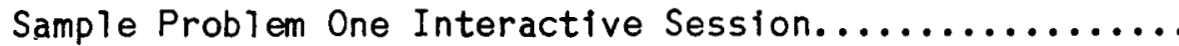

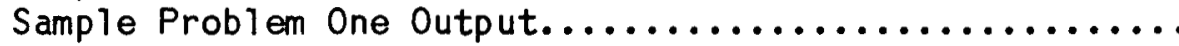

$3.4-5$

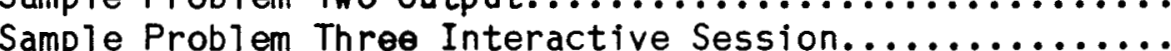


INTRUDER DOSE PATHWAY ANALYSIS FOR THE ONSITE DISPOSAL OF

RADIOACTIVE WASTES: THE ONSITE/MAXII COMPUTER PROGRAM

\section{INTRODUCTION}

In January 1981, the U.S. Nuclear Regulatory Commission (NRC) amended its regulation in order to minimize the risks associated with onsite land disposal of radioactive materials by 1 icensees. Current regulations require that disposal of radioactive materials by 1 icensees, unless otherwise authorized, be specifically approved by the NRC pursuant to Section $20.302(a)$ of 10 CFR Part 20 (1984). This regulation states:

"Any licensee or applicant for a license may apply to the Commission for approval of proposed procedures to dispose of 1 icensed material in a manner not otherwise authorized in the regulations in this chapter. Each application should include a description of the licensed material and any other radioactive material involved, including the quantities and kinds of such material and the levels of radioactivity involved, and the proposed manner and conditions of disposal. The application should also include an analysis and evaluation of pertinent information as to the nature of the environment, including topographical, geological, meteorological, and hydrological characteristics; usage of ground and surface waters in the general area; the nature and locations of other potentialiy affected facilities; and procedures to be observed to minimize the risk of unexpected or hazardous exposures."

The current policy of the NRC is to review all proposed onsite burials on a case-by-case basis. Technical assessments of proposed onsite disposals may at times require modeling of the potential pathways to man and projecting the magnitude of potential radiation dose commitments. The objective of this project is to modify an existing pathway-to-man computer program, MAXI (Napier et al. 1979), for use by the NRC Waste Management staff for conducting human-intrusion, dose-pathway analyses for onsite burial of lowactivity radioactive wastes. As part of this effort, specific human intrusion scenarios have been developed that consider various potential combinations of direct exposure to penetrating radiation, inhalation of airborne radionuclides, ingestion of agricultural products raised in contaminated soil, and ingestion of radionuclides in drinking water. These scenarios are activated by running the ONSITE/MAXIl computer software package.

The ONSITE/MAXIl software package contains four computer codes. ONSITE is the interactive user interface that allows the end-user to simply and efficiently create and use the radiation exposure scenarios. MAXIl is then used with the scenario information to calculate the maximum annual dose to the exposed individual from selected pathways. MAXI2 generates intermediate dose conversion factors for food pathways. These factors are 
stored in data flles. MAXI3 calculates the data files containing intermediate dose conversion factors for aquatic pathways.

In addition, data files are provided that contain inhalation and external dose conversion factors. These factors are calculated using codes external to the ONSITE/MAXII software package. The inhalation dose conversion factors are calculated using the DACRIN (Houston. Strenge and Watson 1974) computer program. The external dose conversion factors for various waste disposal geometries are calculated using the ISOSHLD (Engel, Greenborg and Hendrickson 1966) shielding program.

This report documents the resulting computer software package. The documentation of the ONSITE/MAXIl computer software package has been written for two major audiences. The first audience (Audience A) includes persons concerned with the mathematical models and computer algorithms considered for onsite disposal of radioactive wastes, and the second audience (Audience B) includes persons concerned with exercising the computer program and exposure scenarios to obtain results for specific applications. This document is designed to function both as an instructional and a reference document.

Section 2 contains information useful to Audience A concerning the mathematical models and computer algorithms used in the ONSITE/MAXIl computer programs. Section 3 contains information useful to Audience B concerning the procedures for executing ONSITE/MAXIl computer programs, including a discussion of sample problems and hand calculations performed to verify correct operation of the computer program. Section 4 contains additional detalls on the structure and organization of the computer programs and is provided for individuals who may be interested in such details and those who wish to modify the computer programs. In addition, appendices are provided that present listings of the computer programs, data $1 \mathrm{ibrarles,}$ and dose conversion factors. Page-edge tabs have been provided as reference points for Audiences $A$ and $B$. To use these tabs, simply fan the pages of the document until the appropriate page-edge tab is located.

\subsection{References}

Code of Federal Regulations. 1984. Title 10, Part 20, "Standards for Protection Against Radiation."

Houston, J. R., D. L. Strenge and E. C. Watson. 1974. DACRIN - A Computer Program for Calculating Organ Dose from Acute or Chronic Radionuclide Inhalation. BNWL-B-389, Pacific Northwest Laboratory, Richland, Washington.

Engel, R. L., J. Greenborg, and M. M. Hendrickson. 1966 ISOSHLD - A Computer Code for General Purpose Isotope Shielding Analysis. BNWL-236, Pacific Northwest Laboratory, Richland, Washington. 
Napier, B. A., G. R. Hoenes, W. E. Kennedy, Jr., and E. C. Watson. 1979. "The Maximum Annual Dose Resulting from Residual Radioactive Contamination." Paper presented at the 24th Annual Meeting of the Health Physics Society, July 8-13, 1979, Philadelphia, Pennsylvania. PNL-SA-7496. Pacific Northwest Laboratory, Richland, Washington. 
This section contains descriptions of the radiation-exposure scenarios, mathematical mode1s, computer programs, and data bases for assessing the potential doses to intruders at onsite waste disposal sites using the ONSITE/MAXII computer programs. The information in this section is designed to be useful to Audience $A$, as identified in Section 1 , concerning the ONSITE/MAXIl computer software package. First, the method used for assessing potential doses to intruders is presented, followed by a discussion of the computer implementation of that method, and a description of the associated data base.

\subsection{Definition and Solution of the Problem}

In the Draft and Final Environmental Impact Statements in support of $10 \mathrm{CFR}$ Part 61 (U.S. NRC 1981; U.S. NRC 1982), the NRC modeled the potential exposure pathways to man from buried radioactive wastes. In their analysis, the NRC identified four human-intrusion scenarios to account for the actions of man after the loss of institutional controls (U.S. NRC 1981, App. H, p. $\mathrm{H}-15)$ :

- Intruder-Construction Scenario. An individual excavates at an abandoned disposal site to build a house.

- Intruder-Discovery Scenario. This scenario is a subset of the intruder-construction scenario and also involves excavation into a closed site. The time over which the excavation proceeds is reduced compared to the intruder-construction scenario.

- Intruder-Agriculture Scenario. An individual lives in a house built on a closed disposal site surrounded by contaminated soil resulting from the intruder-construction scenario. The individual consumes vegetables grown in the contaminated soil.

- Intruder-Well Scenario. An individual uses contaminated water from an onsite wel1.

The disposal limits that result are based on an annual 500-mrem total-body dose to the maximally exposed individual who intrudes after 100 years of site control. Of the four human-intrusion scenarios defined, only the intruder-construction and intruder-agriculture scenarios control the determination of disposal limits:

For the assessment of risks associated with onsite disposal, an approach similar to that applied in the DEIS in support of $10 \mathrm{CFR}$ Part 61 is used. That is, radiation-exposure scenarios are established for the maximally exposed individual (an intruder) and a means of determining the resulting radiation dose is provided. 
Five scenarios are identified as being of potential interest in assessing doses to intruders at onsite disposal sites.

(1) External Exposure Scenario. An individual is assumed to work in an area previously used for onsite disposal. Surface soil contamination, wastes buried at depths of $0.5 \mathrm{~m}$ or $1.0 \mathrm{~m}$, or entry into a room (or vault) that is used for waste storage or disposal are considered.

(2) External Exposure Plus Inhalation Scenario. An individual is assumed to work in an area with 1 imited surface-soil contamination.

(3) Agricultural scenario. An individual is assumed to raise his annual diet (or a fraction of it) in soil contaminated by the onsite disposal of radioactive wastes. External exposure and inhalation of resuspended radionuclides in soil are considered.

(4) Irrigation/Drinking-Water Scenario. An individual is assumed to use a water supply contaminated by radionuclides from an onsite disposal site for irrigation and/or drinking. In addition, external exposure and inhalation of resuspended radionuclides that are deposited on the surface of the soil by the irrigation water are considered.

(5) User-Defined Scenario. The user may construct his own scenario by selecting exposure pathways and defining conditions described in the ONSITE/MAXIl computer software package.

This section contains descriptions of the pathway analysis models used for these scenarios with a definition of the required environmental criteria, descriptions of the scenarios as they are implemented, and descriptions of the mathematical models.

\subsubsection{Applying the Pathway Analysis Models}

The above scenarios can be simulated with the pathway analysis mathematical models. When viewed as a collection, the interrelationships of these models are complex. An overview of the pathway analysis methods at this point in the discussion will facilitate understanding of the model application.

Programs in the ONSITE/MAXIl computer software package can be used to calculate dose conversion factors for a given setting or "environment." The MAXIl computer program uses these factors during subsequent scenario simulations to calculate dose to man for selected exposure pathways. An "environment" defines radionuclides that are likely to be present at a waste site, general agricultural and aquatic practices of the geographical area, and the general 1 ifestyle of the intruder. For example, the "environment" might establish that the intruder grows a garden on the disposa 1 site. The amount of produce, including animal products grown on the site and consumed by the maximum individual, would be defined. Scenarios can 
then be defined within the context of the "environment." A scenario indicates pathways of interest, further defines the 11 fe style of the maximum individual, identifies the source and location of the contamination, and quantifies the inventory. A scenarlo modifies the maximum individual's 1 ife style assumptions by indicating amounts of exposure and by applying percentage factors to established dose rates.

The definition of the "environment" is an intermediate step that simplifies scenario creation and streamlines scenario executions. Scenario creations are simplified because the number of parameters that must be defined is substantially reduced. Scenarios execute more efficiently because many repetitive calculations have been el iminated. Dose conversion factors that apply to the defined "environment" are created by auxiliary programs in the software package (MAXI2 and MAXI3) and are stored in the data base where they can be accessed during the scenario simulations control led by the main computer program, MAXIl.

The following sections contain discussions of the defined "environment" and the mathematical models to be used for the five intruder scenarios, and the mathematical models to be used for onsite disposal sites.

\subsubsection{Onsite Disposal "Environment" Description}

The "environment" defined for onsite disposal assumes intruder activity at an onsite low-level waste disposal site. The reference "environment" is based on a site with an area of 1 ha; however, area correction factors may be included to consider smaller sites. The intruder may be exposed to radioactive contamination via any of the following pathways: external exposure, inhalation of resuspended contaminants, ingestion of farm products grown on a contaminated site, consumption of drinking water from a contaminated wel 7 , or ingestion of aquatic food products from a contaminated water source. For external exposure, wastes may be located on the surface, buried at 0.5 or 1.0 meter depths, or stored in a room-type structure. The intruder's entire diet for the reference "environment" consists of vegetables, fruits, and animal products grown on the site. Table 2.1-1 contains a 1 isting of the intruder's terrestrial food product diet and Table 2.1-2 contains a listing of the intruder's aquatic food product diet for the reference "environment." The intruder is assumed to drink 1.2 liters of water per day from a contaminated wel1. Contaminated farm products may result from radioactive wastes located on the soil surface or from irrigation with contaminated water. The radionuclides expected to be of interest in the reference "environment" are listed in Table 2.1-3. This 1 ist includes 100 radionuclides that might come from the use of radiopharmaceuticals or industrial sources, or from wastes generated as part of the commercial nuclear fuel cycle. 
Table 2.1-1. Parameters Used for Calculation of Radiation Dose Factors from Consumption of Foods

\begin{tabular}{|c|c|c|c|c|}
\hline Food & $\begin{array}{c}\text { Growing Period } \\
\text { (days) }\end{array}$ & $\begin{array}{r}\text { Yield } \\
\left(\mathrm{kg} / \mathrm{m}^{2}\right) \\
\end{array}$ & $\begin{array}{l}\text { Holdup }(a) \\
\text { (days) }\end{array}$ & $\begin{array}{l}\text { Consumption } \\
(\mathrm{kg} / \mathrm{year})(\mathrm{b})\end{array}$ \\
\hline Leafy vegetables & 90 & 1.5 & 1 & 9.5 \\
\hline $\begin{array}{l}\text { Other aboveground } \\
\text { vegetables }\end{array}$ & 60 & 0.70 & 1 & 9.5 \\
\hline Root vegetables & 90 & 9.0 & 1 & 76 \\
\hline Fruit & 90 & 1.7 & 10 & 42 \\
\hline Wheat and grain & 90 & 0.72 & 10 & 51 \\
\hline Eggs & 90 & $0.84^{(c)}$ & 2 & 19 \\
\hline Milk & 30 & $1.3^{(c)}$ & 2 & $110^{(d)}$ \\
\hline Beef & 90 & $0.84^{(c)}$ & 15 & 39 \\
\hline Pork & 90 & $0.84^{(c)}$ & 15 & 29 \\
\hline Poultry & 90 & $0.84^{(c)}$ & 2 & 8.5 \\
\hline
\end{tabular}

(a) Time between harvest and consumption.

(b) These rates are obtained from Regulatory Guide 1.109 (U.S. NRC 1977) and prorated by food category using the fraction of total consumed by an average individual as calculated from Napier (Table 8 1981).

(c) Yield of animal feeds (i.e., grain or pasture grass).

(d) Units of liters/year.

Table 2.1-2. Parameters Used for Calculation of Radiation Doses from Drinking Water and Aquatic Foods

\begin{tabular}{|c|c|c|c|c|}
\hline Pathway & $\begin{array}{l}\text { Mixing } \\
\text { Ratio }\end{array}$ & $\begin{array}{l}\text { Holdup (a) } \\
\text { (days) }\end{array}$ & Consumption & $\begin{array}{c}\text { Consumption } \\
\text { Units }\end{array}$ \\
\hline sh & 1.0 & 1.0 & $6.9^{(b)}$ & $\mathrm{kg} / \mathrm{yr}$ \\
\hline ing & 1.0 & 1.0 & $438^{(c)}$ & $L / y r$ \\
\hline
\end{tabular}

(a) Time between harvest and consumption.

(b) Rate obtained from Regulatory Guide 1.109 (U.S. NRC 1977).

(c) Rate based on scenario assumption of $1.2 \mathrm{~L} / d$. 
Table 2.1-3. Radionuclides Considered in the ONSITE Disposal "Environment"

\begin{tabular}{|c|c|c|}
\hline Radionuclide & Radionuclide & Radionuclide \\
\hline $\begin{array}{l}{ }^{3} \mathrm{H} \\
14_{\mathrm{C}} \\
22_{\mathrm{Na}}\end{array}$ & $\begin{array}{l}144 \mathrm{Ce}+\mathrm{D} \\
152 \mathrm{Eu} \\
154 \mathrm{Eu}\end{array}$ & $\begin{array}{l}137 \mathrm{~m}_{\mathrm{Ba}} \\
141_{\mathrm{Ce}} \\
15 l_{\mathrm{Sm}}\end{array}$ \\
\hline $\begin{array}{l}32 \mathrm{p} \\
33 \mathrm{p} \\
35 \mathrm{~S}\end{array}$ & $\begin{array}{l}160_{\mathrm{Tb}} \\
185_{\mathrm{Os}} \\
191_{\mathrm{OS}}\end{array}$ & $\begin{array}{l}235_{\mathrm{U}} \\
231_{\mathrm{Th}} \\
231_{\mathrm{Pa}}\end{array}$ \\
\hline $\begin{array}{l}36 \mathrm{Cl} \\
40 \mathrm{~K} \\
{ }^{45} \mathrm{Ca}\end{array}$ & $\begin{array}{l}{ }^{192} \mathrm{Ir} \\
203 \mathrm{Hg} \\
210 \mathrm{~Pb}+\mathrm{D}\end{array}$ & $\begin{array}{l}227 \mathrm{Ac} \\
227 \mathrm{Th} \\
223 \mathrm{Fr}\end{array}$ \\
\hline $\begin{array}{l}{ }^{46} \mathrm{Sc} \\
{ }^{51} \mathrm{Cr} \\
54 \mathrm{Mn}\end{array}$ & $\begin{array}{l}{ }^{226} 6_{\mathrm{Ra}+D} \\
228_{\mathrm{Th}+\mathrm{D}} \\
230_{\mathrm{Th}+\mathrm{D}}\end{array}$ & $\begin{array}{l}223 \mathrm{Ra} \\
237 \mathrm{~Np} \\
233_{\mathrm{Pa}}\end{array}$ \\
\hline $\begin{array}{l}{ }^{55} \mathrm{Fe} \\
{ }^{59} \mathrm{Fe} \\
57 \mathrm{Co}\end{array}$ & $\begin{array}{l}{ }^{23} 2_{T h+D} \\
233_{U+D} \\
234_{U}\end{array}$ & $\begin{array}{l}233_{\mathrm{U}} \\
229 \mathrm{Th} \\
225_{\mathrm{Ra}}\end{array}$ \\
\hline $\begin{array}{l}60 \\
{ }^{69} \mathrm{Co} \\
{ }^{59} \mathrm{Ni} \\
63 \mathrm{Ni}\end{array}$ & $\begin{array}{l}{ }^{235} 5_{U+D} \\
238_{U+D} \\
237_{N p+D}\end{array}$ & $\begin{array}{l}225 \mathrm{Ac} \\
238_{\mathrm{U}} \\
234_{\mathrm{Th}}\end{array}$ \\
\hline $\begin{array}{l}65 \mathrm{Zn} \\
75 \mathrm{Se} \\
{ }^{65} \mathrm{Sr}\end{array}$ & 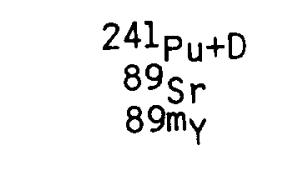 & $\begin{array}{l}234 \mathrm{~m}_{\mathrm{Pa}} \\
234 \mathrm{~Pa} \\
242 \mathrm{Pu}\end{array}$ \\
\hline $\begin{array}{l}90 \mathrm{Sr}_{\mathrm{D}}(\mathrm{a}) \\
93_{\mathrm{Mo}} \\
94_{\mathrm{Nb}}\end{array}$ & $\begin{array}{l}90 \mathrm{Sr} \\
90 \mathrm{Y} \\
99_{\mathrm{MO}}\end{array}$ & $\begin{array}{l}238 \mathrm{~Np} \\
238 \mathrm{Pu} \\
244 \mathrm{Cm}\end{array}$ \\
\hline $\begin{array}{l}106_{\mathrm{Ru+D}} \\
109_{\mathrm{Cd}} \\
110 \mathrm{~m}_{\mathrm{Ag}+\mathrm{D}}\end{array}$ & $\begin{array}{l}{ }^{99 m} \mathrm{Tc} \\
{ }^{99}{ }_{\mathrm{Tc}} \\
103_{\mathrm{Ru}}\end{array}$ & $\begin{array}{l}244 \mathrm{Pu} \\
240 \mathrm{U} \\
240_{\mathrm{Pu}}\end{array}$ \\
\hline $\begin{array}{l}111 \mathrm{In} \\
124 \mathrm{Sb} \\
125 \mathrm{Sb}+\mathrm{D}\end{array}$ & $\begin{array}{l}103 \mathrm{~m}_{\mathrm{Rh}} \\
103 \mathrm{Pd} \\
129_{\mathrm{I}}\end{array}$ & $\begin{array}{l}243 \mathrm{Cm} \\
243 \mathrm{Pu} \\
243 \mathrm{Am}\end{array}$ \\
\hline $\begin{array}{l}125 \mathrm{I+D} \\
131_{\mathrm{I}+\mathrm{D}} \\
137_{\mathrm{Cs}+\mathrm{D}}\end{array}$ & $\begin{array}{l}134 \mathrm{Cs} \\
135 \mathrm{Cs} \\
137 \mathrm{Cs}\end{array}$ & $\begin{array}{l}239 \mathrm{~Np} \\
239 \mathrm{Pu} \\
241_{\mathrm{Pu}}\end{array}$ \\
\hline & & ${ }^{241} \mathrm{Am}$ \\
\hline
\end{tabular}

(a) Where $+D$ means plus short-lived daughters in equilibrium. 


\subsubsection{Onsite Disposal Scenario Descriptions}

Five scenarios are identifled for onsite disposal in Section 2.1.1. They are designed for use in assessing doses to intruders at onsite disposal sites with default site size of 1 ha. These scenarios are defined within the "environment" described in Section 2.1.2. Detailed descriptions of the scenarios as they are parameterized for simulation are given below.

(1) External Exposure Scenario. An individual is assumed to work for $2000 \mathrm{~h} / \mathrm{yr}$ in a 1 ha area previously used for onsite disposal. External exposure factor files are supplied to consider surface-soil contamination, buried wastes at depths of $0.5 \mathrm{~m}$ or $1.0 \mathrm{~m}$, or entry into a room (or vault) that is used for waste storage or disposal. For soil contamination, the inventory is modified by a factor of 0.2 to account for dilution. Only total-body dose is calculated. The user selects the location of the waste (e.g., surface, buried, or stored) and supplies the waste inventory. The user may modify the amount of radioactive decay before exposure, the dilution of the waste (during exhumation activities), the reference site size, and the duration of exposure.

(2) External Exposure Plus Inhalation Scenario. An individual is assumed to work for $2000 \mathrm{~h} / \mathrm{yr}$ in a 1 ha area with surface-soil contamination resulting from a waste exhumation event. Air concentrations of radionuclides are calculated using a resuspension equation by Anspaugh et a). (1975). For the resuspension equation, the age of the contamination at the beginning of the scenario is assumed to be 0.0 and the top 1.0 centimeter of the contaminated surface soil is assumed to be available for resuspension. Doses to total body, bone, 1 ungs, thyroid, and the lower large intestine (LLI) of the GI tract are calculated. The dilution factor (accounting for exhumation activities) applied to the inventory is 0.2 . The user provides the waste inventory. The user may modify the amount of radioactive decay before exposure, the duration of the exposure, the reference site size, and the inventory dilution factor. He may also optionally select a massloading equation, and specify fewer organs. This scenario is similar to the intruder-construction scenario described in the DEIS for 10 CFR Part 61 (U.S. NRC 1981).

(3) Agricultural Scenarie. An individual is assumed to raise his entire diet in a 1 ha area of soil contaminated by the onsite disposal of radioactive wastes. The individual is assumed to be exposed $2000 \mathrm{~h} / \mathrm{yr}$ by external exposure and by inhalation of resuspended radionuclides in soil. Again, the air concentration resulting from resuspension is calculated using the equation by Anspaugh et a1. (1975) with parameters presented for Scenario 2. Doses to total body, bone, 7 ungs, thyroid, and LLI are calculated. The user furnishes the waste inventory to which a dilution factor of 0.2 is applied. Modifications can be made to the amount of radioactive decay before exposure, the duration of the exposure, the fraction of the total diet grown on the 
site, the reference site size, and the dilution of the waste. As in the previous scenarios, the user may substitute the mass-loading model and specify fewer organs. This scenario is similar to the intruderagriculture scenario described in the DEIS for 10 CFR Part 61 (U.S. NRC 1981$)$.

(4) Irrigation/Drinking-Water Scenario. An individual is assumed to use a water supply contaminated by radionuclides from an onsite disposal site for irrigation and/or drinking. The user is required to input the concentration of each radionuclide in the water supply. The expesed individual is assumed to irrigate his field at a rate of 150 $\mathrm{L} / \mathrm{m}^{2} /$ mo during a six-month growing season. The site is assumed to be irrigated with contaminated water for 10 years prior to the beginning of the scenario. The individual obtains his entire diet (or a fraction of it) from a 1 ha irrigated field, and drinks $1.2 \mathrm{~L}$ of water per day from a contaminated water source. In addition, he is assumed to be exposed $2000 \mathrm{~h} / \mathrm{yr}$ by external exposure and inhalation of resuspended radionuclides that are deposited on the surface of the soll by the irrigation water. Doses to total body, bone, I ungs, thyroid and LLI are considered. Irrigation and drinking water may be from the same or separate water supplies. When providing the inventory, the user is asked for radionuclide concentration in drinking and irrigation water separately. Irrigation or drinking water can be individually simulated by entering zero concentrations for the other pathway. The user may modify the irrigation rate, the length of the irrigation season, the time of irrigation prior to the scenario, the fraction of diet grown with contaminated irrigation water, the consumption of drinking water, the times of exposure, the resuspension equation selection, the reference site size, and the organ selection.

(5) User-Defined Scenario. The user may construct his own scenario by selecting exposure pathways and defining conditions associated with each pathway.

\subsubsection{Mathematical Models}

Equations are arranged to aid understanding of the model as a whole. Consequently equations conta in both environment-defined and scenario-defined parameters as distinguished in Section 2.1.1. The origin of the parameters will be discussed when applicable for each equation.

The fundamental relationship for calculating radiation doses to people from any radionuclide exposure pathway is given in Equation 2.1 (Soldat, Robinson, and Baker 1974)

$$
R_{i p r}=C_{i p} U_{p} D_{i p r}
$$


where

$$
\begin{aligned}
& R_{i p r}=\text { the radiation dose equivalent or committed radiation dose } \\
& C_{i p}=\text { concentration of radionuclide } i \text { in the media of exposure }
\end{aligned}
$$
$U_{p}=$ usage parameter (exposure rate or intake rate) associated with exposure pathway $\mathrm{p}(\mathrm{h} / \mathrm{yr}, \mathrm{L} / \mathrm{yr}$, or $\mathrm{kg} / \mathrm{yr}$ )

An analysis of radiation doses from separate exposure pathways requires a determination of the radionuclide concentrations and exposure rate or intake rate associated with each exposure pathway. For external exposure, the concentration of radionuclides and the duration of exposure must be quantified. For ingestion of farm products grown on a contaminated site, the radionuclide concentration in separate food products must be determined by accounting for root transfer from soil, dry deposition from air on leaves, or animal consumption of contaminated forage or feed. The annual diet for the maximally exposed individual, and the holdup time between harvest and consumption must also be determined.

For inhalation, the airborne concentration of resuspended radionuclides can be determined directly from the ground concentration using a mass-loading factor, resuspension factor, or resuspension rate analysis (Anspaugh et a). 1975). Site-specific parameters can be used to determine the exposure pathways and the radionuclide mixture, pathway concentrations, and exposure or intake rates.

Parts of this relationship are calculated in three MAXI codes as follows:

$C_{i p}$ - Concentrations are calculated in MAXI. Some terms in the equations were calculated in MAXI2 (for food pathways) and MAXI3 (aquatic pathways) and the results are located in the data base. These terms will be identified as each equation is discussed.

$U_{p}$ - Default (assumed maximum) usage terms are applied in MAXI2 (food pathways) and MAXI3 (aquatic pathways) and the resulting factors are stored in the data files. A modification factor can be applied to this term in MAXIl to reduce the exposure conditions. 
$D_{\text {ipr }}$ - This term is applied in MAXI2 for food pathways and MAXI3 for aquatic pathways in the generation of the data files accessed by MAXII.

Calculation of the annual dose to an organ of reference by the MAXIl computer program requires the dose equivalent from exposure during the year of interest plus the annual dose resulting from previous years of intake. The general expression for annual dose calculations is deduced by inspecting the annual dose equations for the first three years of continuous exposure. The annual dose for the first year to an organ of reference is simply the summation of the radiation dose equivalents from al 1 internal and external exposure pathways. For the second year, the annual dose is calculated by the following expression (Kennedy et al. 1979):

$$
A_{2}=R_{2}^{*}+\left(R_{1,2}-R_{1,1}\right)
$$

where

$$
\begin{aligned}
& A_{2}=\text { the annual dose during the second year from al } 1 \text { exposure } \\
& \text { pathways to the organ of reference, mrem } \\
& R_{2}^{*}=\text { the radiation dose equivalent in the second year to the organ }
\end{aligned}
$$

The second-year annual dose to an organ of reference ( $A_{2}$ in Equation 2.2) is the summation of the radiation dose equivalents from al 1 exposure pathways during the second year and the dose equivalent delivered during the second year from the radionuclides internally deposited in that organ during the first year. The term in parentheses in Equation 2.2 is the expression for the dose equivalent to the organ of reference from radionuclides deposited in that organ during the first year. It is found by subtracting the first-year dose equivalent, resulting from internal $1 y$ deposited radionuclides, from the second-year committed dose equivalent. The mathematical expression for the annual dose to an organ of reference in the third year of continuous exposure is (Kennedy et al. 1979): 


$$
A_{3}=R_{3}^{*}+\left(R_{1,3}-R_{1,2}\right)+\left(R_{2,2}-R_{2,1}\right)
$$

where

$$
\begin{aligned}
A_{3}= & \text { the annual dose during the third year from all exposure } \\
& \text { pathways to the organ of reference, mrem } \\
R_{3}^{*}= & \text { the radiation dose equivalent in the third year to the organ } \\
& \text { of reference from all internal and external exposure pathways } \\
& \text { from intake and exposure in the third year, mrem. }
\end{aligned}
$$

In Equation 2.3, the terms $R_{1}, R_{1}$ and $R_{2}$ are similar in form, each containing two subscripts. The' first subscript defines the year of intake or exposure after the start of continuous exposure, and the second defines the number of years used in calculating the committed dose equivalent. The quantity in the first parentheses is the dose equivalent to the organ of reference in the third year from radionuclides deposited during the first year of continuous exposure (i.e., the difference between the third-year committed dose equivalent and the second-year committed dose equivalent). The quantity in the second parentheses is the dose equivalent in the third year to the organ of reference from radionuclides deposited during the second year of continuous exposure ( $i . e$. , the difference between the secondyear committed dose equivalent and the first-year committed dose equivalent).

The general expression for calculating the annual dose to an organ of reference during any year after the start of continuous exposure is expressed as (Kennedy et a7. 1979):

$$
A_{t}=R_{t}^{*}+\sum_{i=1}^{t-1} R_{i,(t-i+1)}-R_{i,(t-i)}
$$

where

$$
\begin{aligned}
A_{t}= & \text { the annual dose during the year } t \text { from all exposure pathways to } \\
& \text { the organ of reference, mrem } \\
R_{t}^{*}= & \text { the radiation dose equivalent in year } t \text { to the organ of } \\
& \text { reference from al } 1 \text { internal and external exposure pathways from } \\
& \text { intake and exposure in the year } t, \text { mrem. }
\end{aligned}
$$

The summation term in Equation 2.4 represents the dose equivalent delivered to the organ of reference in year $t$ from radionuclides deposited in the organ from intake in all previous years since the start of continuous exposure. This term is valid only for positive integer values of $t$. For $t$ equal to $l$, the summation term is zero. 
The annual dose. $A_{t}$, to the organ of reference is calculated for each value of $t$ from 1 to 50 , and the maximum annual dose is determined by inspection. Experience with this method to date indicates 50 years to be a sultable maximum value of $t$; however, higher maximum values are not precluded. The radiation dose equivalent terms required by Equation 2.4 are determined from Equation 2.1 using existing radiation dose computer programs for pertinent radiation-exposure pathways. Detalis about the methods of calculating the radionuclide concentrations in various media, $C_{\text {ip }}$ from Equation 2.1, are given in Sections 2.1.4.1 through 2.1.4.5?

No special algorithms or numerical techniques are employed by the ONSITE/ MAXIl computer programs apart from those required to solve Equation 2.4 . However, special formulations for some of the parameters in Equation 2.1 are avaliable in the exposure scenario analysis. Other formulations are directly included in the calculation of the dose conversion factors used by MAXIl. The following sections contain discussions of optional and default equations that are incorporated into the ONSITE/MAXIl software package.

\subsubsection{Dose From Ingestion of Food Products}

The dose conversion factors for the ingestion of food products accessed by the MAXIl computer program are obtained from data files that were generated by the MAXI2 computer program for the onsite disposal environment. The dose from any food pathway is given by Equation 2.1. Radionuclides can be deposited on the leaves of plants directly from the afr or from irrigation water, and can be taken up by the plant roots.

For direct deposition from the air. Equation 2.5 is used to describe the deposition of airborne particulate radionuclides directly onto food products and onto the ground.

$$
d_{i}^{a}=86,400 \bar{x}_{i} \quad v_{d i}
$$

where

$$
\begin{aligned}
d_{i}^{a}= & \text { deposition rate or fiux of radionuclide } i, \mathrm{pCi} /\left(\mathrm{m}^{2} \text {-day }\right) \\
86,400= & \text { dimensional conversion factor, seconds/day } \\
\bar{\chi}_{i}= & \text { average air concentration of radionuclide } i \text { is estimated } \\
& \text { using either the mass-loading or resuspension factor } \\
& \text { as } \mathrm{pCi} / \mathrm{m}^{3} \\
v_{d i}= & \text { deposition velocity of radionuclide } 1, \mathrm{~m} / \text { second, is assumed } \\
& \text { in MAXIl to be } 1 \times 10^{-3} \mathrm{~m} / \mathrm{sec} \text { for all particles. }
\end{aligned}
$$


The MAXIl computer program permits selection of two methods for calculating the average air concentration. These methods are mass-loading and resuspension analysis. The mass-loading method uses the product of the surface soil radionuclide concentration and the average mass-loading of dust or particulate material in the atmosphere. In the absence of data for a particular site, a value of $1 \times 10^{-4} \mathrm{~g} / \mathrm{m}^{3}$ has been suggested for predictive purposes (EPA 1977; Anspaugh et al. 1975). This value is used in this report for the annual average mass-loading factor. Annual arithmetic averages around the United States vary from $9 \times 10^{-6}$ to $7.9 \times 10^{-5} \mathrm{~g} / \mathrm{m}^{3}$ (Anspaugh et a1. 1977).

For resuspension, the average airborne concentration is the product of a resuspension factor and the surface contamination level as shown in Equation 2.6.

$$
\bar{x}=s_{f} s_{A}
$$

where

$$
\begin{aligned}
\bar{X} & =\text { average airborne concentration, } \mathrm{pCi} / \mathrm{m}^{3} \\
S_{f} & =\text { resuspension factor, } \mathrm{m}^{-1} \\
S_{A} & =\text { surface radioactivity, } \mathrm{pCi} / \mathrm{m}^{2} .
\end{aligned}
$$

The MAXIl computer program permits the use of a time-dependent resuspension factor $\left(S_{f}\right)$ as given by Anspaugh et al. (1975):

$$
s_{f}=10^{-4} e^{-\lambda \sqrt{t}}+10^{-9}
$$

where

$$
\begin{aligned}
S_{f}= & \text { resuspension factor, } \mathrm{m}^{-1} \\
10^{-4}= & \text { resuspension factor at time } t=0, \mathrm{~m}^{-1} \\
\lambda= & \text { effective decay constant controlling the availability of } \\
& \text { material for resuspension, } 0.15 \text { day } \\
t= & \text { time after deposition, days } \\
10^{-9}= & \text { resuspension factor after } 17 \text { years, } \mathrm{m}^{-1} .
\end{aligned}
$$


The second term in Equation $2.7\left(10^{-9}\right)$ is added based on the assumption that there is no further measurable decrease in the resuspension factor process after about 17 years, the longest perlod for which data are available.

For deposition on plant leaves or soil from irrigation, the deposition rate in $\mathrm{pCl} / \mathrm{m}^{2}$-day $\mathrm{d}$ for radionuclide $i$ from irrigation water onto the ground, is defined by Equation 2.8 .

$$
d_{i}^{I}=C_{i w} I
$$

where

$$
\begin{aligned}
d_{i}= & \text { deposition rate or } f l u x Q^{f} \text { radionuclides applied with } \\
& \text { irrigation water, }\left(p C i / m^{2} \text {-day }\right) \\
C_{i w}= & \text { concentration of radionuclide } i \text { in the water used for } \\
& \text { irrigation, } p C i / L \\
I= & \text { irrigation rate; the amount of water sprinkled on a unit area } \\
& \text { of field in one day, } L /\left(\mathrm{m}^{2}-\text { day }\right) .
\end{aligned}
$$

The concentration of radioactive material in vegetation resulting from direct deposition onto plant foliage and uptake of radionuclides previously deposited in the soil is determined by Equation 2.9 .

$$
\begin{aligned}
c_{i v}= & {\left[\frac{\left(d_{i}^{a}+d_{i}^{I}\right) r T_{v}\left(1-\exp \left[-\lambda_{E i} t_{e}\right]\right)}{y_{v} \lambda_{E i}}+\frac{\left(d_{i}^{a}+d_{i}^{I}\right) f_{t} B_{v i}\left(1-\exp \left[-\lambda_{i} t_{b}\right]\right)}{p \lambda_{i}}\right.} \\
& \left.+\frac{0.15 f_{t} C_{s i}{ }^{B} v i}{p}+\frac{f_{w} C_{t i}{ }^{B} v i}{\rho}\right] \exp \left(-\lambda_{i} t_{h}\right)
\end{aligned}
$$

where

$$
\begin{aligned}
c_{i v}= & \text { concentration of radionuclide } i \text { in the edible portion of the } \\
& \text { vegetation, } \mathrm{pCi} / \mathrm{kg} \\
d_{i}^{a}= & \text { previously defined (see Equation } 2.5), \mathrm{pCi} /\left(\mathrm{m}^{2}-\right.\text { day) } \\
r= & \text { factor of deposition retained on the vegetation } \\
& \text { (dimensionless); taken to be } 0.25
\end{aligned}
$$




$$
\begin{aligned}
& T_{v}=\text { factor for translocation of externally deposited radio- } \\
& \lambda_{i}=\text { radiological decay constant for radionuclide } i \text {, days }{ }^{-1} \\
& \lambda_{E i}=\text { the effective removal constant for radionuclide } i \text {, days }{ }^{-1} \text {; } \\
& \lambda_{E 1}=\lambda_{i}+\lambda_{w} \\
& \lambda_{w}=\underset{\text { weathering removal constant for vegetation, days }}{ }{ }^{-1} \text {; taken to } \\
& Y_{v}=\text { vegetation yield, } \mathrm{kg} \text { (wet weight) } / \mathrm{m}^{2} \\
& B_{v i}=\text { concentration factor for uptake of radionuclide } i \text { from the } \\
& \text { soil in vegetation } \mathrm{v}, \mathrm{pCi} / \mathrm{kg} \text { (wet weight) } \mathrm{per} \mathrm{pCi} / \mathrm{kg} \\
& \text { soil (dry) } \\
& t_{b}=\text { time for buildup of radionuclides in the soil, days; assumed } \\
& \text { to be } 50 \text { years for irrigation } \\
& t_{e}=\text { time of exposure of aboveground vegetation to contamination } \\
& \text { during growing season, days } \\
& f_{t}=\begin{array}{l}
\text { fraction of the roots in the plow layer of soil } \\
\text { (dimensionless) }
\end{array} \\
& t_{h}=\text { holdup time between harvest and food consumption; days } \\
& p=\text { soil "surface density," } \mathrm{kg} \text { (dry soil)/m²; a value of } \\
& 224 \mathrm{~kg} / \mathrm{m}^{2} \text { is used assuming the contaminated ground is plowed } \\
& \text { to a depth of } 15 \mathrm{~cm} \text { (Napier et al. 1980) } \\
& C_{s i}=\text { concentration of radionuclide } i \text { available for plant uptake } \\
& \text { from the waste contained in the plow layer (top } 15 \mathrm{~cm} \text { of } \\
& \text { soil), } \mathrm{pCi} / \mathrm{m}^{3} \\
& 0.15=\text { plow layer, } m \\
& f_{w}=\text { fraction of the roots that penetrate the waste trenches } \\
& \begin{array}{c}
C_{t i}=\text { concentration of radionuclide } i \text { available for plant uptake } \\
\text { from the subsurface waste zone, } \mathrm{pCi} / \mathrm{m}^{3}
\end{array} \\
& \rho=\text { bulk soil density of subsurface material, } \mathrm{kg} / \mathrm{m}^{3}
\end{aligned}
$$


The first term inside the brackets of Equation 2.9 relates to the concentration resulting from direct deposition of resuspended material and irrigation on follage during the growing season. The second term relates to the plant uptake from the soil and reflects the deposition from irrigation. The third and fourth terms account for uptake of waste material contained in the top $0.15 \mathrm{~m}$ of soll and below this layer, respectively. Specific values used for the parameters in Equation 2.9 located in data libraries are found in Napler et al. (1980).

The following terms of Equation 2.9 are located in the MAXIl computer code:

$$
d_{i}^{a}+d_{1}^{i} \quad d_{f}^{i} f_{t} \quad 0.15 f_{t} \quad f_{w} c_{t i}
$$

The leaf mechanism dose rate factors generated by the MAXI2 computer code are included in the data library and are accessed by MAXIl. The following terms of Equation 2.9 are included in those factors:

$$
\frac{r T_{v}\left(1-\exp \left[-E_{i} t_{e}\right]\right)}{y_{v} \lambda_{E i}}
$$

$$
\frac{B_{v i}\left(1-\exp \left[-\lambda_{i} t_{b}\right]\right)}{P \lambda_{1}}
$$

The soil mechanism dose rate factors generated by the MAXI2 computer code are included in the data library and are accessed by MAXIl. The following terms of Equation 2.9 are included in those factors:

$$
\frac{C_{s i} B_{v i}}{p} \quad\left(\frac{B_{v i}}{\rho}\right) \exp \left(-\lambda_{i} t_{h}\right)
$$

The radionuclide concentration in animal products such as meat, milk, and eggs is dependent on the amount of contaminated forage or feed eaten by the animal. This concentration is described by Equation 2.10.

$$
c_{i a}=s_{i a}\left[c_{i f} a_{f}+c_{i a w} a_{a w}\right]
$$

where

$$
\begin{gathered}
C_{i a}=\text { concentration of radionuclide } i \text { in the animal product, } \mathrm{pCi} / \mathrm{kg} \\
\text { or } \mathrm{pCi} / \mathrm{L}
\end{gathered}
$$




$$
\begin{aligned}
& S_{i a}=\text { transfer coefficient of radionuclide } i \text { from daily intake of } \\
& \begin{aligned}
C_{\text {if }}= & \text { concentration of radionuclide in feed or forage, } \mathrm{pCi} / \mathrm{kg} \text {; } \\
& \text { calculated from Equation } 2.9
\end{aligned} \\
& a_{f}=\underset{k g / d a y}{\operatorname{animal}} \text { consumption rate of contaminated feed or forage, } \\
& C_{\text {faw }}=\text { concentration of radionucl ide } i \text { in the water consumed by } \\
& \text { water, } C_{\text {iw }} \text { (see Equation 2.8) } \\
& \begin{aligned}
a_{\text {aw }}= & \text { consumption rate of the contaminated water by the anima } 1 \text {, } \\
& \mathrm{L} / \text { day. }
\end{aligned}
\end{aligned}
$$

Specific values of the parameters used in Equation 2.10 are given in Napier et a1. (1980).

The dose to an organ of the exposed individual resulting from the ingestion of food products raised in the soll at an onsite disposal site ( $R$ in mrem) is found using a modified version of Equation 2.1. This general relationship is shown in Equation 2.11 .

$$
R_{I r}=U_{p} f_{D} \sum_{i=1}^{n} C_{i p} A_{C}^{I} D_{i p r}
$$

where

$$
\begin{aligned}
f_{D}= & \text { the fraction of the total diet grown on the site } \\
A_{C}= & \text { the area correction factor for internal exposure pathways, } \\
& \text { and where } U_{p}, C_{i p} \text { and } D_{\text {ipr }} \text { are for ingestion and are general } 1 y \\
& \text { defined in Equation } 2.1 .
\end{aligned}
$$

The data libraries for the ONSITE/MAXIl computer program are based on a minimum site area of 1 ha. To account for the 1 imited exposure potential from smaller disposal areas, site area correction factors are required. For example, the amount of agricultural products raised on a site depends upon the intensity of the farming and the types of crops raised. A sma 11 site may produce a large fraction of the seasonal fruit and vegetable diet with intensive farming, but be unable to provide enough forage and grain to support a milk cow or other animals. Thus, while a large fraction of the 
seasonal fruit and vegetable diet may be raised on a small site, the total quantity ralsed may only equal a small fraction of the total annual diet.

In determining area correction factors for the MAXIl computer program, consideration is first given to the default pathway conditions and then to variable exposure conditions as a function of site area. For the default conditions, the individual's entire diet, as defined in Regulatory Guide 1.109 (U.S. NRC 1977), is assumed to be raised on the 1 ha site. This diet consists of fruits and vegetables and meat and animal products. The air concentrations used for the inhalation calculations are for resuspension resulting from large areas of distributed surface contamination.

Because of the large variability that may exist in the exposure conditions at any given site, we have defined default site area correction factors that modify the default exposure pathway assumptions provided in the scenarto analysis.

For the ingestion and inhalation pathway, the correction factors are in the form of a step function as shown in Figure 2.1-1. This function assumes five steps of potential exposure versus site area ranging from small to large sites. The steps of total exposure are: 1) $10 \%$ for sites with areas less than $\left.50 \mathrm{~m}^{2}, 2\right) 25 \%$ for sites with areas between 50 and $200 \mathrm{~m}^{2}$, 3) $50 \%$ for sites with areas between 200 and $\left.1,000 \mathrm{~m}^{2}, 4\right) 75 \%$ for sites with areas between 1,000 and $10,000 \mathrm{~m}^{2}$, and 5) $100 \%$ for sites larger than 10,000 $\mathrm{m}^{2}$ (or $1 \mathrm{ha}$ ).

A step function is used rather than a continuous curve because of the inherent uncertainty in predicting the future actions of individuals. The step function allows consideration of small areas without forcing extreme conservatism on larger areas. That is, it implies that the small areas may be intensely farmed for vegetables, whereas the larger areas may be less efficiently used (i.e., in raising cattle).

\subsubsection{Dose From Ingestion of Drinking Water}

Dose conversion factors for ingestion of drinking water used in MAXIl are calculated using the MAXI3 computer program and the results are stored in the data files. The dose $R_{w r}$ in mrem, from ingestion of water containing radionuclides, is calculated from Equation 2.12 .

$$
R_{w r}=U_{w} \sum_{i=1}^{n} c_{i d w} \exp \left(-\lambda_{i} t_{h}\right) D_{i r} f_{d w}
$$


where

$$
\begin{aligned}
U_{w}= & \text { annual consumption of contaminated drinking water, } L \\
C_{i d w}= & \text { the concentration of radionuclide } i \text { in the drinking water } \\
& \text { (input by user), } p C i / L \\
\lambda_{i}= & \text { radiological decay constant for radionuclide } i \text {, days }-1 \\
t_{h}= & \text { transit time required for radionuclide to reach the point of } \\
& \text { exposure, days } \\
D_{i r}= & \text { radiation dose equivalent factor for ingestion, mrem/pCi } \\
f_{d w}= & \text { drinking water cleanup factor (for municipal water supplies). }
\end{aligned}
$$

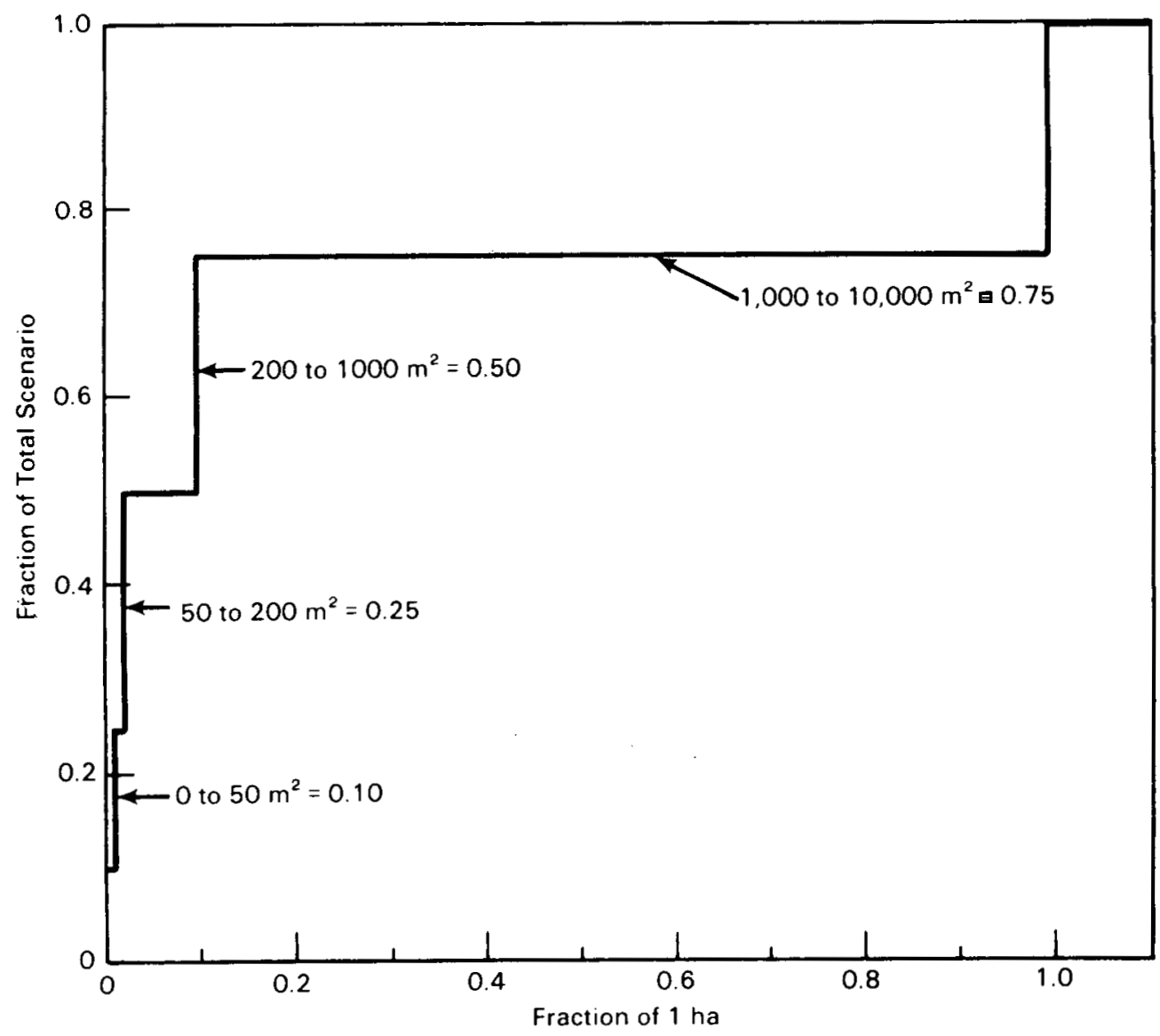

Figure 2.1-1. Area Correction Factors for the Ingestion and Inhalation Pathways 
The drinking-water dose rate factors calculated by the MAXI3 computer code are included in a data library and are addressed by MAXIl. The following terms in Equation 2.11 are included in those factors:

$U_{w} \quad \exp \left(-\lambda_{1} t_{h}\right) D_{i r} f_{d w}$

\subsubsection{Dose From Inhalation}

Dose conversion factors for inhalation used in MAXIl are calculated using the DACRIN (Houston, Strenge, and Watson 1974) computer program and stored in the data files. The inhalation dose, $R_{h r}$ in mrem, is calculated using Equation 2.13.

$$
R_{h r}=v T t_{m} \sum_{i=1}^{n}\left(\bar{x}_{1} \cdot A_{c}^{I}\right) \cdot D_{i r}
$$

where

$$
\begin{aligned}
& V=\text { ventilation rate of exposed individual, } \mathrm{m}^{3} / \mathrm{sec} \\
& T=\text { duration of exposure to the airborne radionuclide concentra- } \\
& \text { tion, seconds. } \\
& t_{m}=\text { modification factor applied to } T \text { to adjust time if exposure } \\
& \text { or breathing rate of } 230 \mathrm{cc} / \mathrm{sec} \text { (ICRP 1975) } \\
& D_{\text {ir }}=\text { radiation dose equivalent factor for inhalation from the } \\
& \text { DACRIN (Houston, Strenge, and Watson 1974) computer code, } \\
& \mathrm{mrem} / \mathrm{pCi}
\end{aligned}
$$

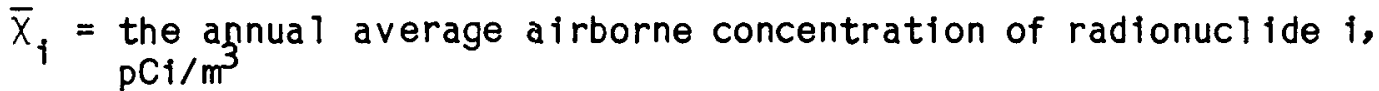

$$
\begin{aligned}
& A_{C}^{I}=\text { the area correction factor for internal exposure pathways as } \\
& \text { discussed in Section 2.1.4.1 and shown in Figure 2.1-1. }
\end{aligned}
$$

The following terms of Equation 2.13 are found in the MAXII computer code:

$$
\bar{x}_{i} \quad t_{m} \quad A_{c}^{I}
$$

The inhalation dose rate factors calculated by the DACRIN (Houston, Strenge, and Watson 1974) computer code are included in a data 1 ibrary and 
are addressed by MAXIl. The fol lowing terms in Equation 2.12 are included in those factors.

Dir VT

\subsubsection{Dose From External Radiation}

Annual doses resulting from exposure to surface- and subsurface-soll contamination or exposure in a reference room (or vault) are calculated using a modified version of Section 2.2.1.2. The modified dose equation for external exposure is shown in Equation 2.14 .

$$
R_{e r}=U_{p} \sum_{i=1}^{n} D_{i r} A_{c}^{E} C_{i p}
$$

where

$$
\begin{aligned}
A_{C}= & \text { the area correction factor for external exposure, and where } U_{P}, \\
& D_{1} \text { ' and } C_{\text {in are for external exposure and are general } 1 \mathrm{y}} \\
& \text { defined in 'Equation } 2.1 .
\end{aligned}
$$

For external exposure, a sensitivity study was conducted for various betagamma emitters to determine the exposure rate versus source area. The results of the calculations are shown in Figure 2.1-2. Since the curves in Figure 2.1-2 are paral1el, there appears to be a uniform correction for reduced site area over a 1 arge range of source energies. Thus, we have determined the ratio of the exposure rates (for small to 1 arge area sources) and plotted the results versus the fractional hectare of source area as shown in Figure 2.1-3. This figure defines the area correction factors for the external exposure pathway. We have approximated this curve in the ONSITE computer program as the sum of four 1 ine segments as shown in Figure 2.1-4.

The dose conversion factors for external exposure model several types of exposure conditions. These include surface-soil contamination (using either plane- or slab-source models), subsurface-soil contamination (using slab sources at depths of 0.5 and $1.0 \mathrm{~m}$ from the soil surface), and a finite disk source of contamination deposited on the floor or a wall in a waste-storage room or vault. These dose conversion factors are in tissue at a point $1 \mathrm{~m}$ above the ground surface. The direct exposure rates encountered by the intruder for various contamination levels in a waste-storage room or vault are calculated using the model developed for decommissioning a reference room at a BWR (Oak et a1. 1980). Al 1 of the external dose equivalent factors are calculated for the radionuclides of concern using the ISOSHLD (Engel et a 1. 1966; Simmons et a 1. 1967) computer program. 


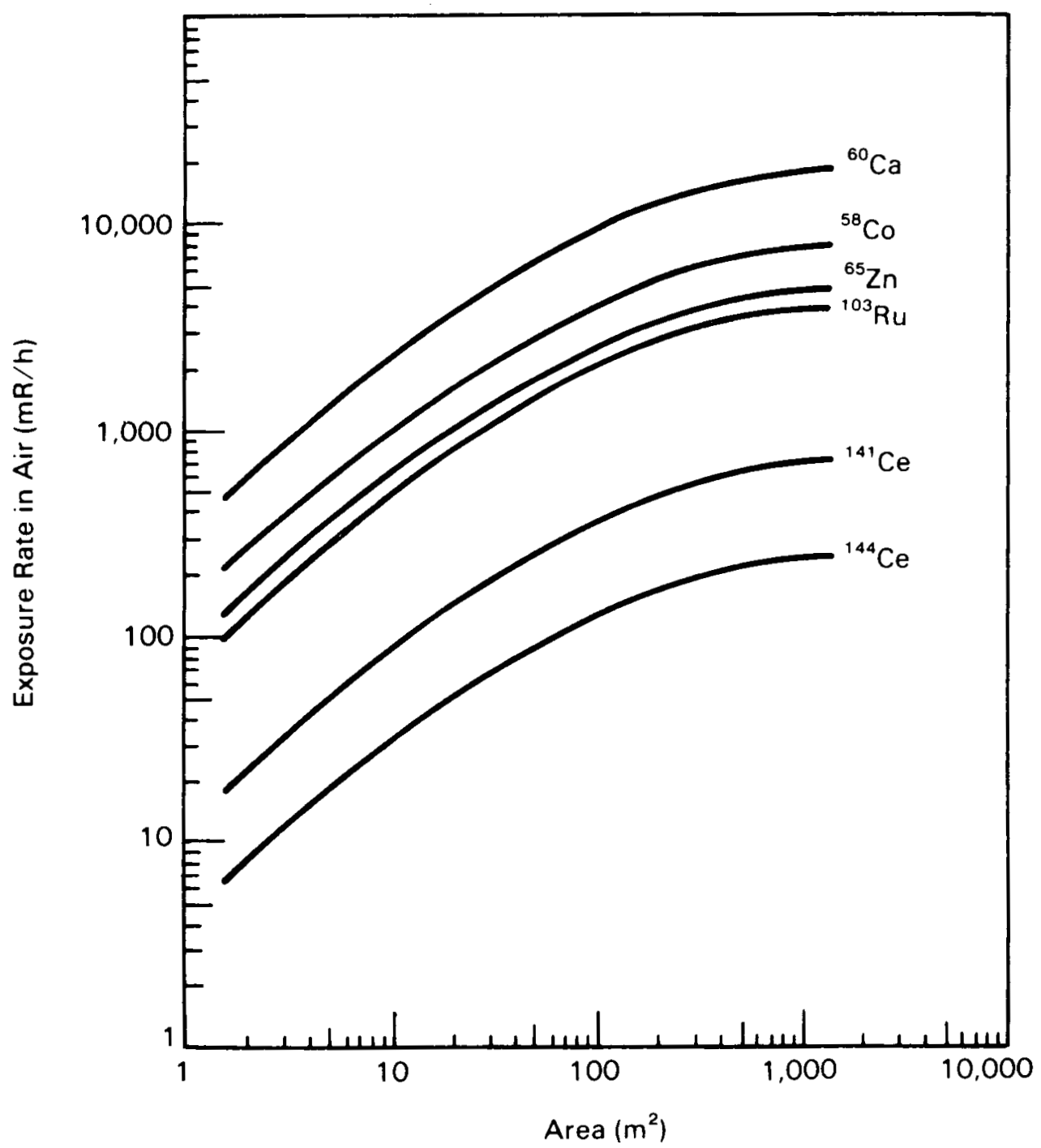

Figure 2.1-2. Exposure Rate Versus Source Area

\subsubsection{Dose From Ingestion of Aquatic Foods}

As an option to the MAXIl computer program, doses resulting from the ingestion of aquatic food products taken from a river contaminated by radionuclides may be considered. These dose factors are calculated using the MAXI3 computer program and stored in the data files. A description of the calculation is included al though none of the default human-intrusion scenarios defined for onsite disposal consider this pathway. 
Concentrations of radionuclides in aquatic foods are directly related to the concentrations of the radionuclides in water. Equilibrium ratios between the two concentrations, cal led bioaccumulation factors, are taken from Soldat, Robinson, and Baker (1974). The dose $\left(R_{a f r}\right)$ in mrem from consumption of aquatic food containing radionuclides is calculated from Equation 2.15.

$$
R_{a f r}=U_{a f} \sum_{i=1}^{n} C_{i w} \exp \left(-\lambda_{i} t_{h}\right) D_{i r}\left[B_{x i}+B_{y i}+B_{z i}\right]
$$

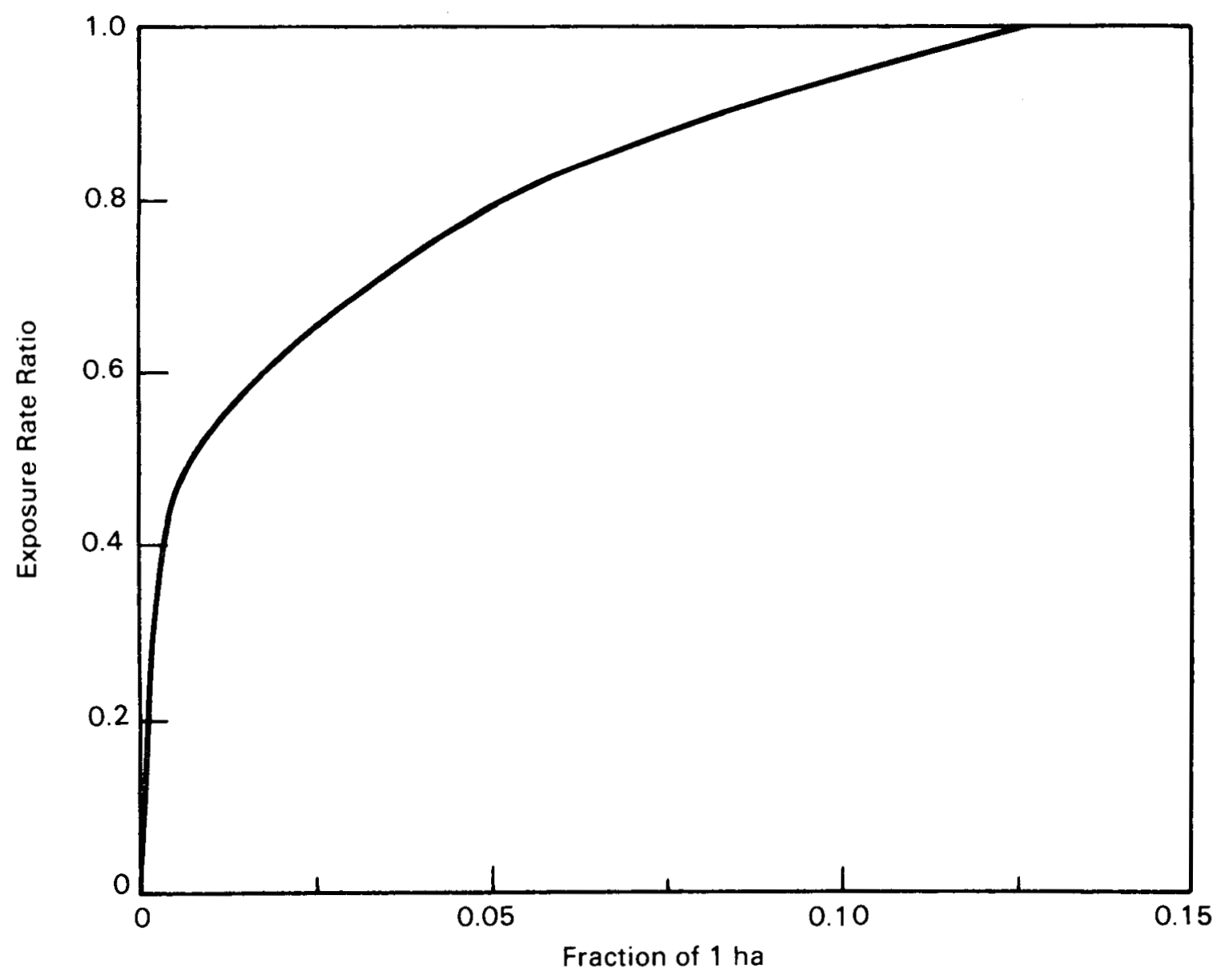

Figure 2.1-3. Exposure Rate Ratio Versus Fractional Hectare of Source Area 
where

$U_{a f}=$ annual consumption of contaminated aquatic foods, $\mathrm{kg}$

$C_{\text {iw }}=$ the concentration of radionuclide $i$ in the water, $p C i / L$

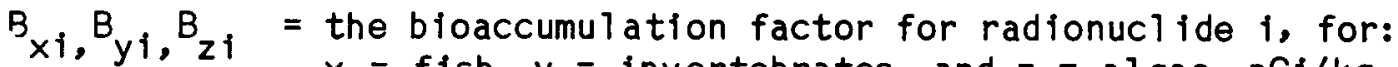
$x=f i s h, y=$ invertebrates, and $z=a 1$ gae, $\mathrm{pCi} / \mathrm{kg}$ per $\mathrm{PCi} / \mathrm{L}$

$D_{i r}=$ radiation dose equivalent factor for ingestion, $\mathrm{mrem} / \mathrm{pCi}$

$\lambda_{i}=$ radiological decay constant for radionuclide $i$, days ${ }^{-1}$

$t_{h}=$ holdup time between harvest and food consumption, days.

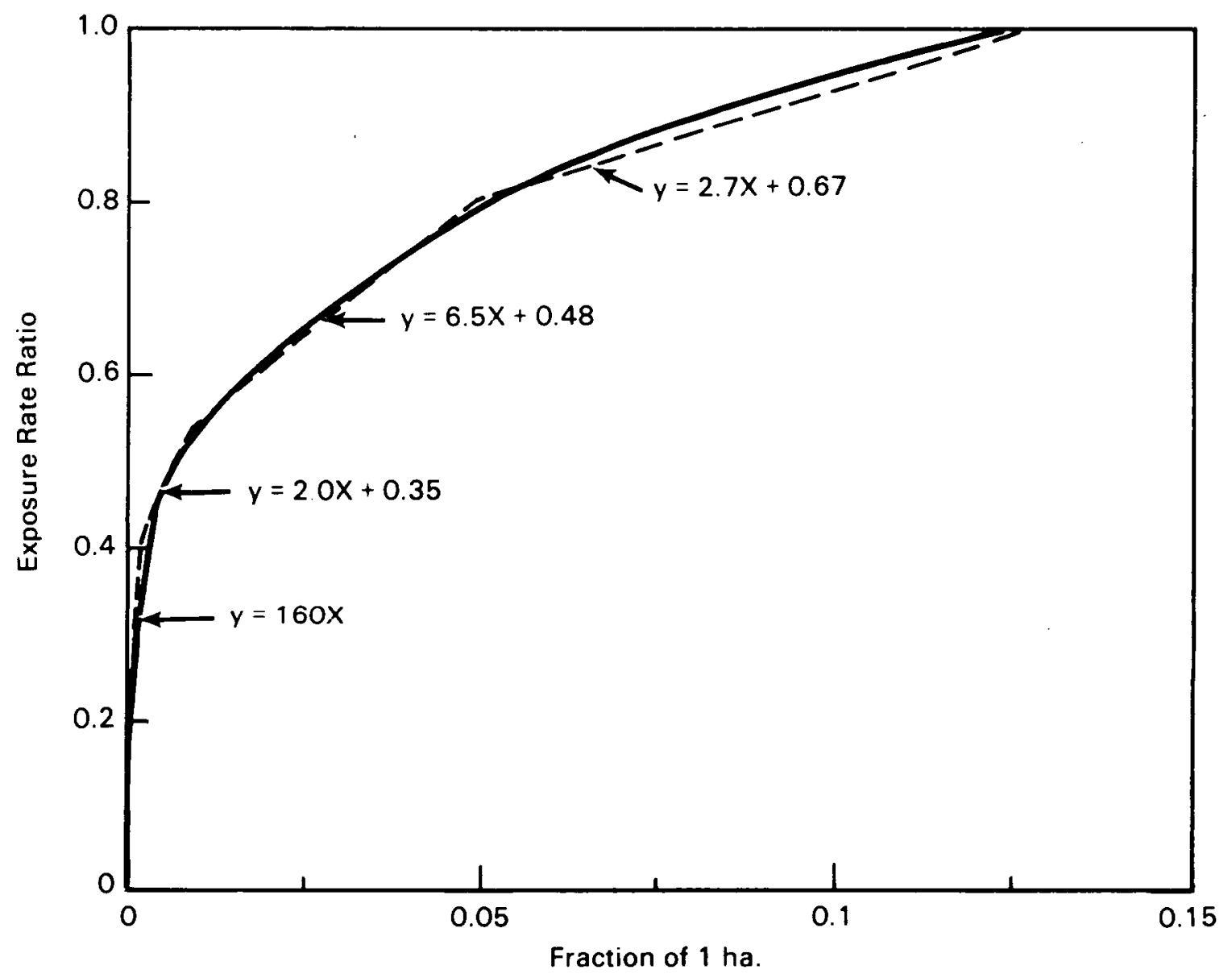

Figure 2.1-4. Area Correction Factors for External Exposure 
The following term in Equation 2.15 is located in the MAXII computer code:

$$
C_{\text {IW }}
$$

Aquatic foods' dose rate factors calculated by the MAXI3 computer code are included in a data 1 ibrary for access by MAXIl. Included in those factors are the following terms of Equation 2.15:

$$
U_{\text {af }} \quad \exp \left(-\lambda_{i} t_{h}\right) D_{i r}\left[B_{x i}+B_{y i}+B_{z i}\right]
$$

\subsection{Computer Implementation}

Estimates of the maximum annual radiation doses resulting from the exposure scenarios described in Section 2.1.1 can be made using environment-specific information and computer codes contained in the ONSITE/MAXIl software. package.

The package contains two primary computer programs, ONSITE and MAXIl, as wel 1 as an extensive data base. Two additional programs, MAXI2 and MAXI3 are included to al low modification of the data base. Figure 2.2-1 depicts the general process flow of the ONSITE/MAXIl software.

The data base contains dose conversion factors applicable to the onsite disposal environment described in Section 2.1.2. This data base is discussed in detail in Section 2.3. The fol lowing sections contain descriptions of the ONSITE/MAXIl computer programs, an overview of software operation and a discussion of capabilities, restrictions, and execution performance of the software.

\subsubsection{Computer Programs Descrjptions}

The ONSITE/MAXIl software package contains four computer codes as shown in Figure 2.2-1. ONSITE is an interactive user interface that al lows the enduser to simply and efficiently create and use the radiation-exposure scenarios. MAXII is then used with the scenario information to calculate the maximum annual dose to an exposed individual from selected pathways. MAXI2 generates intermediate dose conversion factors for food pathways that are stored in the data files. MAXI3 calculates the data files containing intermediate dose conversion factors for aquatic pathways. The following sections contain descriptions of each of the computer codes: 


\subsubsection{ONSITE Computer Program Description}

ONSITE is an interactive computer program that al lows the user to access or create radiation-exposure scenarios used to estimate the dose-to-man resulting from onsite disposal of radioactive wastes. The software solicits scenario information from the user, controls parameter modification, selects the appropriate data libraries for running MAXIl, and constructs the input file for MAXIl. ONSITE was designed to make the creation

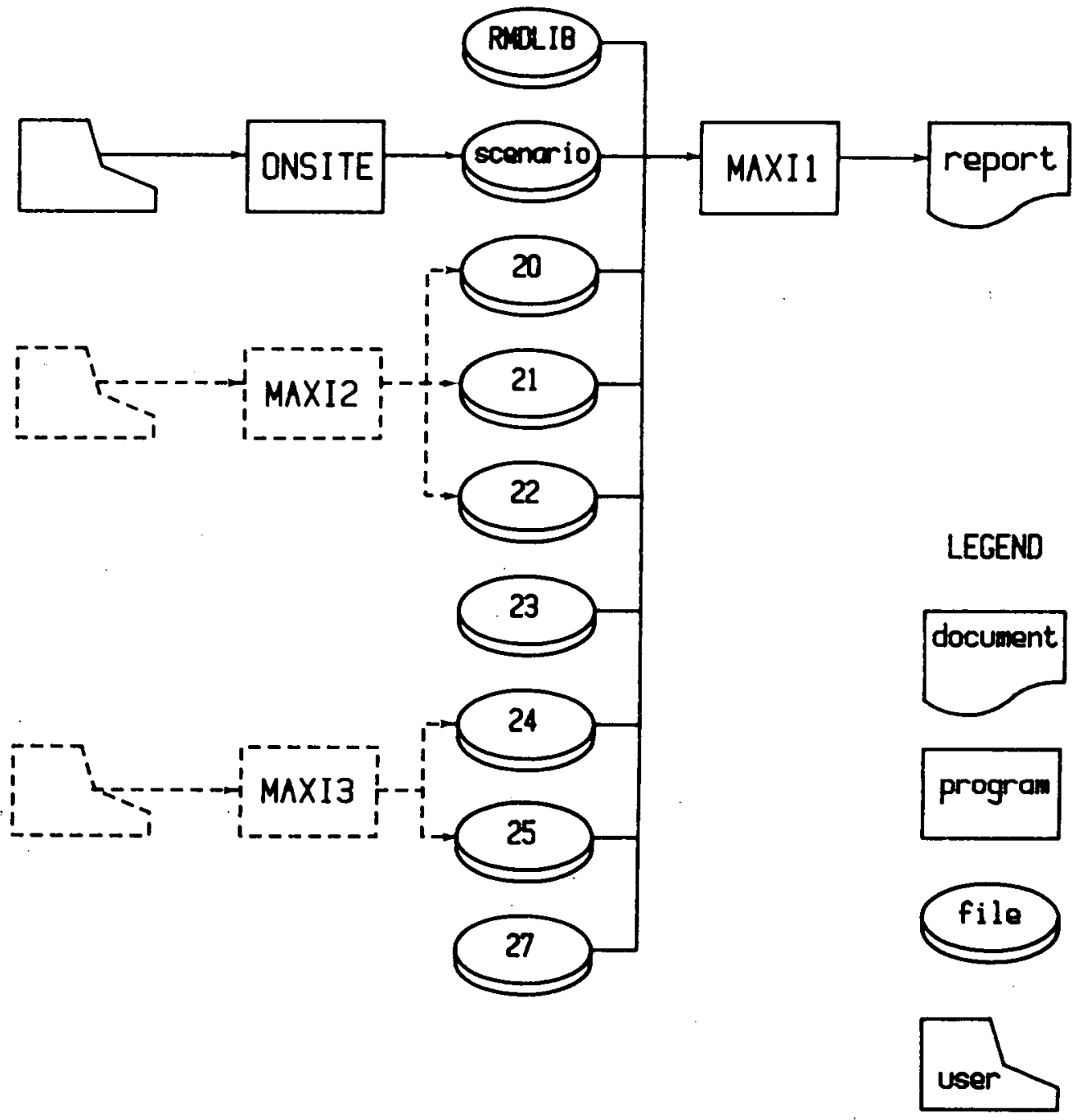

Figure 2.2-1. ONSITE/MAXI1 Software Process Flow Chart 
and execution of a specific scenario as easy for the user as possible. If the default "environment" is used, ONSITE is the only computer program that the user needs to interact with because this interaction automaticaliy produces results from MAXIl. The ONSITE program gives the user the option of changing any parameters of selected pathways used in the radiationexposure scenarios. Each parameter is described in terms that should be meaningful to the end-user. The dimensional units and the upper and lower bounds of each parameter are displayed for each parameter. Each value entered by the user is tested against upper and lower 1 imits when applicable. If the value is not accepted, the user is asked to re-enter the value. Default (or assumed maximum) values and conditions are activated by a null entry (e.g., simply pressing the <return> key on the terminal).

\subsubsection{MAXIl Computer Program Description}

The computer program MAXIl is used to calculate the maximum annual dose to an exposed individual from a large number of exposure pathways. This program uses dose conversion factors from the DACRIN (Houston, Strenge, and Watson 1974) computer program for estimating doses from inhalation of airborne radionuclides. The dose conversion factors from DACRIN are based on the International Commission on Radiological Protection's (ICRP) Task Group Lung Mode1 (TGLM) (Health Phys. 1966). For ingestion pathways, for either food products or drinking water, dose conversion factors from the MAXI2 and MAXI3 computer programs are used by MAXIl. These dose conversion factors a 11 rely on the dosimetry model of ICRP Committee II as reported in ICRP Publication 2 (1959). For external exposure, dose conversion factors from the ISOSHLD (Enge 1 et a 1. 1966; Simmons et a 1. 1967) are used by MAXIl. These factors relate the radionucl ide source strength to the dose rate in tissue $1 \mathrm{~m}$ above an infinite $\mathrm{plane}$ or $\mathrm{slab}$ of contamination. External dose conversion factors are supplied for surface-soll contamination, and for slabs of buried contamination at depths of either 0.5 or $1.0 \mathrm{~m}$. External dose conversion factors from an optional room exposure condition are also available. These factors are intended to model doses to an intruder who may enter a room (or vault) used for storage of radioactive wastes. The room model was originally developed for a study concerning decommissioning of a reference Boiling Water Reactor (BWR) (Oak et al. 1980). A sensitivity analysis for the dose rate response of ${ }^{60}$ Co surface contamination in a room of various sizes indicated a dose rate increase of a factor of two or less from small to large rooms (Oak et al. 1980, p. F-16). Thus, dose factors for a room of $100 \mathrm{~m}^{3}$ volume are assumed to be represented by a plane source that appears to provide a reasonable estimate of the dose resulting in most sizes of rooms that may be encountered.

Exposure pathways that can be modeled include 1) direct external exposure to contaminated soil or building surfaces, 2) inhalation of resuspended materia1, and 3) ingestion of contaminated foods and aquatic products. The time of the maximum dose rate to individual organs of reference is calcu1 ated and the annual dose for that organ is reported. 


\subsubsection{MAXI2 Computer Program Description}

The onsite disposal "environment" (Section 2.1.2) is applicable to all the scenarios presented in Section 2.1.3. MAXI2 need be used only when a different "environment" is defined. MAXI2 generates dose conversion factors to account for deposition on farm or garden soll and crops. Leaf mechanism dose rate factors are written to a computer file assigned to logical unit 20. The computer flle assigned to logical unit 21 , called FILE21, contains dose conversion factors to account for deposition onto soll in which food crops are grown. MAXI2 also generates external dose rate factors for exposure to soll surface contamination. These factors are written to the computer file assigned to logical unit 22, called FILE22. The computer code ISOSHLD (Engel et al. 1966; Simmons et al. 1967) is used to calculate surface external dose rate factors. A 11 sting of the MAXI2 code is found in Appendix 2.B. The input files to MAXI2 that generated the dose conversion factors for the onsite disposal "environment" are included in Appendix 2.B as an example of code usage. MAXI2 is a specialized version of the FOOD (Napier, et al. 1980) computer program. The user is referred to that document for theoretical and operational information. Differences between the MAXI2 and FOOD computer codes are discussed in Section 3.1.2.

\subsubsection{MAXI3 Computer Program Description}

MAXI3 was used to define drinking-water and aquatic food-pathway factors for the onsite disposal "environment" described in Section 2.1.2. This "environment" is applicable to all the scenarios presented in Section 2.1.3. MAXI3 need be executed only when a different "environment" is considered. MAXI3 generates dose conversion factors for contaminated drinking water and aquatic food harvested from contaminated water.

Drinking-water dose conversion factors are written to a computer file assigned to logical unit 24, called FILE24. The computer file assigned to logical unit 25, called FILE25, contains dose conversion factors to account for ingestion of comtaminated aquatic food products. A listing of the MAXI3 code is found in Appendix 2.C. The input files to MAXI3 that generated the dose conversion factors for the onsite disposal "environment" are shown in Appendix 2.C as an example of code usage. MAXI3 is a speclalized version of the ARRRG (Napier, et al. 1980) computer program. The user may reference that document for theoretical and operational information on MAXI3. Differences between the MAXI3 and ARRRG computer programs are discussed in Section 3.1.2.

\subsubsection{Operation of the ONSITE/MAXII Software Package}

Section 3 contains a detailed discussion of the operation of the ONSITE/ MAXIl software package. A theoretical overview of software operation is presented here. Three levels of operation will be defined and the software process flow will be presented. 


\subsubsection{Levels of Operation}

This software package implements the scenarios discussed in Section 2.1.3. The user is asked to supply information specific to the selected scenario and system information as defined in Section 3.1. No further interaction between the user and the software is necessary. The scenario will be executed and a report prepared automatically. This is the principal intended scope of the ONSITE/MAXIl software package. However, the user is allowed to use the software for a wider range of applications. Three levels of operation have been defined to clarify this extended use of the software.

Leve] 1. The ONSITE/MAXII software package is designed to be used for assessing impacts from the onsite disposal of low-level wastes. This is the intended principal use of the software package. The data base contains information on the "environment" described in Section 2.1.2. Five scenarlos have been defined that may be executed with in the context of that "environment." The ONSITE program is used to select and establish parameters for a scenario. The user is assisted during scenario creation by a restricted set of parameters and restricted ranges of values for each parameter.

Level 2. The user may define a different "environment" by using the MAXI2 and MAXI3 computer codes. The ONSITE program can then be used to evaluate the five defined scenarios within the context of the newly created "environment." It is the user's responsibility to determine the validity of the "environment" and the appropriateness of the defined scenarios to this new "environment."

Level 3. The user creates a new "environment" with the MAXI2 and MAXI3 computer codes and establishes scenarios by manipulating MAXIl input parameters directly. This level of operation should not be attempted without a thorough understanding of MAXIl theory and operation because the interrelationships between MAXIl input parameters are complex. The user must determine the validity of the "environment" and the scenarios, and the appropriateness of scenario application to the "environment."

\subsubsection{Software Process Flow}

Figure 2.2-1 depicts the general process flow of the ONSITE/MAXIl software. The process flow details for each of the three levels of operation are discussed blow.

Level 1. The user executes the ONSITE program, inputting scenario selection and inventory. ONSITE allows parameter modification for selected pathways. A computer file that parameterizes the scenario is created by ONSITE. That file, the master radionuclide 1 ibrary, and the files that define the onsite disposal "environment" will be accessed by MAXIl. MAXIl produces a printed report of dose estimates. 
Level 2. The user first defines an "environment" by executing MAXI2 and MAXI3. The computer data files describe the newly created environment. The ONSITE code is then executed as in Level 1.

Level 3. The user defines an "environment" as in Level 2. The user bypasses the ONSITE program and creates the input stream for MAXIl using a system editor.

\subsubsection{Capabilities, Restrictions and Performance}

The capabilities and inherent restrictions of the ONSITE/MAXI computer implementation are discussed for the following areas: "environment"/scenario definition, pathway selection/parameter modification, inventory selection, and organ selection. Capabilities and restrictions vary depending on the level of operation. Operation level are noted with each comment below.

\subsubsection{1 "Environment"/Scenario Definition.}

Levels 1-3. Section 2.2.2.1 defines three levels of ONSITE/MAXIl software usage. User responsibilities concerning definition of the "environment," the scenarios, and their interrelationships are noted at each of the levels.

\subsubsection{Exposure Pathway Selection/Parameter Modification}

Levels 1-2. Five default scenarios have been implemented in this application. The user is allowed to change parameter values for each exposure pathway considered. Default pathways have been established for Scenarios 1-4. Scenario 5 allows the user to select any combination of exposure pathways and exposure conditions.

Level 3. Any of the defined exposure pathways may be selected. Allowable pathways are external exposure from surface and/or buried wastes, ingestion of farm products grown on contaminated soil, ingestion of drinking water from a contaminated source, and ingestion of contaminated aquatic food products. Any associated parameter values may be modified.

\subsubsection{Inventory Selection}

Levels 1-3. No default inventory has been established. Up to a total of 50 radionuclides may be considered. The default libraries for use in Level I contain information on 100 radionuclides. Several of these radionuclides (shown in Table 2.1-3) are listed with a $+D$ (plus daughters) designation. For these radionuclides, the energies of the short-lived daughters in equilibrium with the parent radionuclides are included in the organ dose 
and external dose calculations. For other radionuclides, chain decay calculations are performed and daughters are permitted to reach their equilibrium values.

Leve] 1. The inventory is restricted to radionuclides appearing in Table 2.1-3.

Levels 2-3. Dose conversion factors are created for up to 100 radionuclides defined in the "environment." Different radionuclides than those included in the reference "environment" may be included at this level of operation. Subsequent scenarios are restricted to this set of radionuclides.

\subsubsection{Organ Selection}

Level 1. Doses to the following organs may be considered: total body, bone, lung, thyrold, and the lower large intestine (LLI) of the GI tract.

Levels 2-3. Dose conversion factors are generated for up to five organs defined in the "environment". These organs can be selected from the allowable organs discussed in Section 4.5. Dose conversion factors are based on data for each radionuclide in the radionuclide master 1 ibrary (RMDLIB), the organ data library (ORGLIB) and transfer factor 1 ibraries (FTRANSLIB, GRDFLIB, BIOAC). The user must determine if ORGLIB has sufficient data for each selected organ.

\subsection{Data Base}

The user is assisted in the appropriate use of the data base by the computer program ONSITE. ONSITE asks the user questions that are applicable to the scenario under construction. From the responses to those questions, ONSITE selects the appropriate files from the data base. An understanding of the detailed information which follows is not necessary for the successfur execution of ONSITE/MAXIl. The intended audience is those interested in the organization and content of the data base and Leve 2 and Leve 3 users (defined in Section 2.2.2.1) who are defining a different "environment."

The ONSITE/MAXIl data base is composed of eleven data files. The relationship of the data base to the computer codes is depicted in Figure 2.2-1. RMDLIB is the master radionuclide 1 ibrary containing chain decay and translocation class information. The balance of the files contain dose conversion factors for various pathways. 


\subsubsection{Radionuclide Master Library for MAXIl - RMDLIB}

The radionuclide master data library (RMDLIB) contains all radiological decay data used by MAXI. The library is organized into two sections. The first section contains radionuclides that are not members of decay chains, and also radionuclides singled out from chains with the "+D" ( $p$ lus daughters) designation. Radionuclides in the first section are arranged by increasing atomic number. The second section of the library contains radionuclides organized into decay chains ordered under the radionuclides highest in the chain. RMDLIB contains about 280 entries.

The first record of the 1 ibrary contains 80 characters of descriptive information used as identification in the input data report printed by MAXIl. The balance of the data records have the following information:

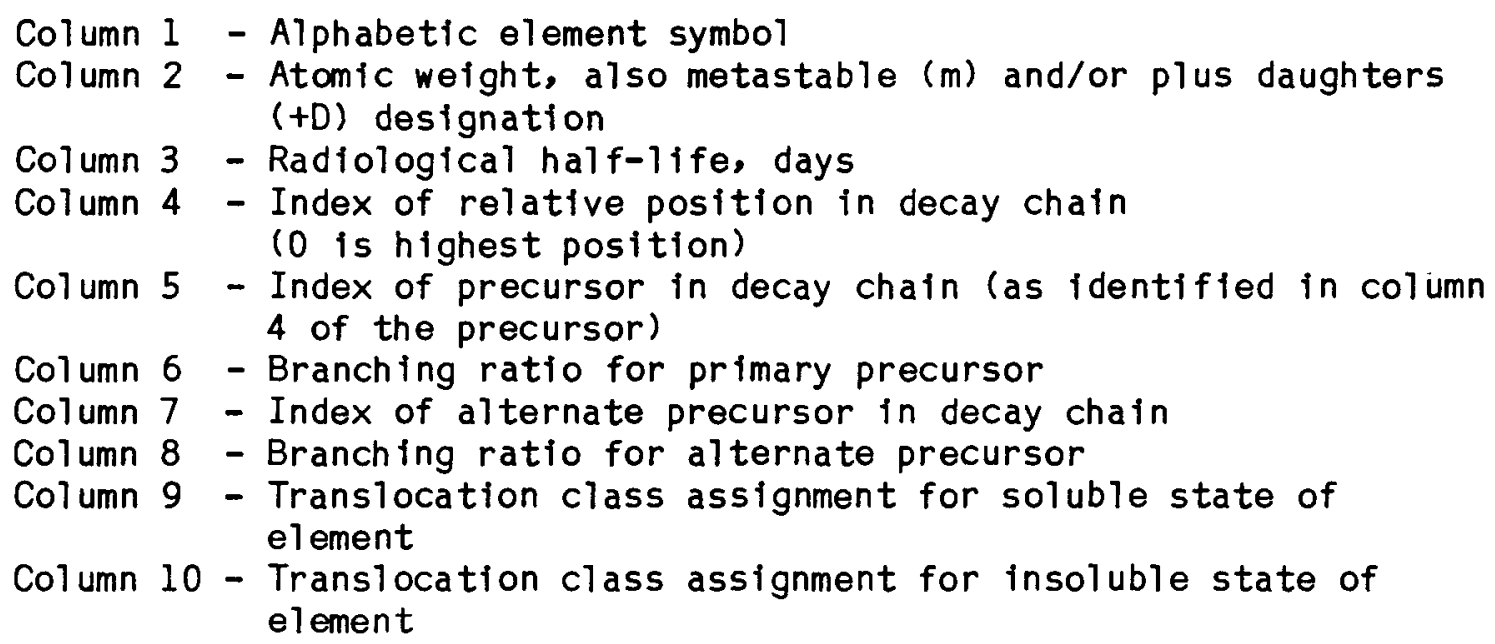

Translocation refers to the rate at which radionuclides are transported by body fluids from the lungs to the blood and GI tract after inhalation. For inhalation calculations, translocation classifications are made for each organ based on the usage of the Task Group Lung Model (ICRP 1966). The translocation indices used in RMDLIB refer to the following classes as defined in ICRP (1966):

Index 1 - Class D Materials. A maximum clearance half-time of less than a day.

Index 2 - Class W Materials. A maximum clearance half-time ranging from a few days to a few months.

Index 3 - Class $y$ Materials. A maximum clearance half-time of from six months to a few years.

ONSITE/MAXIl assumes that for inhalation all elements are insoluble for the lungs and soluble for the other organs. This assumption tends to maximize the organ dose. The translocation classification for soluble and insoluble 
w111 be read by the ONSITE computer code and applied to each organ according to the above assumption. The default translocation assignments may be modified by the user during scenario creation.

The RMDLIB FORTRAN format is (A2, A6, E10.2, 2I2, F7.4, I2, F7.4, 22X,2I1). The parameter in column four is used to signal the end of the data library $(x=0)$. A listing of the library is located in Appendix 1.C. ONSITE reads a shortened version of RMDLIB containing only those radionuciides defined for the onsite disposal environment entitled RMDONS (1isted in Appendices I.C and 2.A).

\subsubsection{Leaf Mechanism Dose Rate Factors - FILE20}

The file assigned to logical unit 20, called FILE20, contains "environment"specific leaf-mechanism dose rate factors for 1 pCi per cubic meter in air. Each record of the file contains dose rate factors of one radionuclide for selected organs. The file is arranged into sets of records for each year. The sets are delimited by a blank record. The file organization, corresponding MAXII variable names, and FORTRAN formats of FILE20, are as follows:

Line 1

Line 2

Line 3
- Descriptive title, TIT20; (20A4).

- Type descriptor, ID; number of years of data, NYRL; number of isotopes. NISOL; number of organs, NORGL; (5X, A4, 3I5).

- Index of organs, KORGLS(i), for $i$ ranging from one to NORGL; (5I5).

The following set of records follows for each year of data $(k)$; a total of NYRL sets:

$$
\begin{aligned}
& \text { Line A } \\
& \text { Next NISOL } 1 \text { ines }
\end{aligned}
$$

- Blank Tine

- One line for each isotope (i) containing: element symbol as in the master radionuclide library, ELTLS( $i)$; atomic number as in the master radionuclide library, AWLS(i); dose rate factor for KORGLS $(j)$ where $j$ ranges from one to NORGL, $\operatorname{DINCL}(k, i, j)$; $(A 2, A 6,5 E 12.2)$.

FILE20 contains dose rate factors for five organs for 100 radionuclides for fifty years. The organs are total body, bone, lungs, thyroid, and the lower large intestine of the GI tract. Consumption parameters included in 
the dose conversion factors are listed in Table 2.1-1. The radionuclides considered are 1isted in Table 2.1-3. The first page of this default file is printed in Appendix 1.C. A complete listing of the default file is given in Appendix 2.A.

When creating a new "environment," the computer code MAXI2 is used to generate this file. MAXI2 is a special version of the FOOD computer code (Napier et al. 1980). The user is referred to that document for detailed information. Instructions for executing MAXI2 are given in Section 3.1.2. MAXI2 outputs leaf-mechanism dose rate factors to the file assigned to logical unit 20. The MAXI2 input file that generated FILE20 for the onsite disposal "environment" is 1 isted in Appendix 2.B.

\subsubsection{Soil Mechanism Dose Rate Factors - FILE21}

The file assigned to logical unit 2l, called FILE2l, contains "environment" -specific soil-mechanism dose rate factors for $1 \mathrm{pCi}$ per square meter in soil. Each record of the file contains dose rate factors of one radionuclide for selected organs. The file is arranged into sets of records for each year.

The sets are delimited by a blank record. The file organization, corresponding MAXIl variable names, and FORTRAN formats of FILE2l is as follows:
Line 1
- Descriptive title, TIT21; (20A4).
Line 2
- Type descriptor, ID;
number of years of data, NYRS;
number of isotopes, NISOS;
number of organs, NORGS; $(5 X, A 4,315)$.
Line 3
- Index of organs, KORGLS(i),
for i ranging from one to NORGS; (5I5).

The following set of records follows for each year of data. $(k)$; a total of NYRS sets:

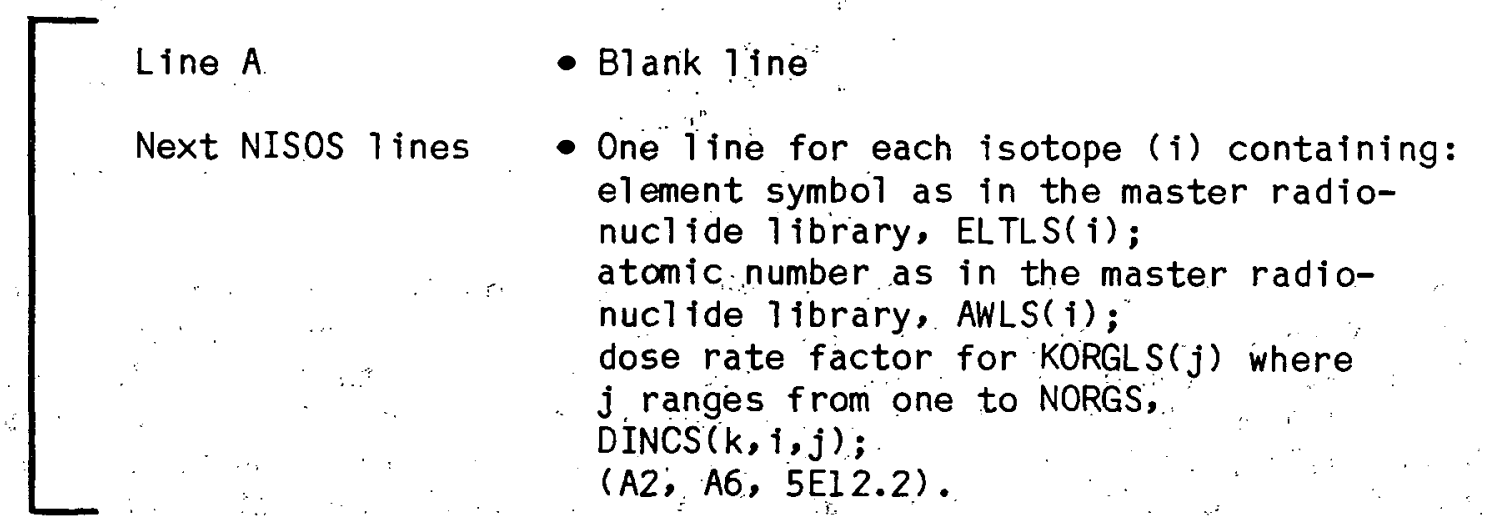


FILE21 contains dose rate factors for five organs for 100 radionuclides for fifty years. The organs are total body, bone, lungs, thyrold, and the lower large intestine of the GI tract. Consumption parameters included in the dose conversion factors are listed in Table 2.1-1. The radionuclides considered are listed in Table 2.1-3. The first page of this file is printed in Appendix 1.C. A complete listing of the file is in Appendix 2.A.

MAXI2, a special version of the FOOD computer (Napier et al. 1980), generates this file. The user is referred to the FOOD program documentation for detalled information. Instructions for executing MAXI2 are located in Section 3.1.2. The input submitted to MAXI2 to generate the FILE2I is given in Appendix 2.B. MAXI2 prints a report of input parameters and outputs soil-mechanism dose rate factors to the file assigned to logical unit 21 in the format described above.

\subsubsection{Surface External Exposure Mechanism Dose Rate Factors}

The file assigned to logical unit 22 contains external dose rate factors. Two files are available for considering surface contamination in the onsite disposal "environment." These files are based on the location of the waste. The files are:

$$
\begin{aligned}
& \text { "PLANSOURC" - An infinite plane of soll contamination, } \\
& \text { "ROOM" } \\
& \begin{array}{l}
\text { - } \\
\text { of a room. }
\end{array}
\end{aligned}
$$

The organization, corresponding MAXIl variable names, and FORTRAN formats of these files are as follows:
Line 1
- Descriptive title, TIT22; (20A4).
Line 2
- Type descriptor, ID; number of isotopes, NISOX; (5X, A4, I5).
Next NISOX lines
- For each isotope (i):
element symbol as in master radionuclide library, ELTX(i); atomic number as is master radionuclide library, $\operatorname{AWX}(i)$; external exposure dose rate factor, $\operatorname{DFXT}(i)$; $C A 2, A 6, E 7.1)$.

The data files "PLANSOURC" and "ROOM" are printed in Appendices 1.C and 2.A. When establishing a new "environment," the user may use the ISOSHLD (Engel et a1. 1966; Simmons et a1. 1967), MAXI2, or other compatible computer programs to generate external dose rate factors. A file in the above format will probably have to be hand-generated from the results of the shielding calculations. MAXIl anticipates external dose rate factors in 
units of $\mathrm{mrem} / \mathrm{yr}$ per $\mathrm{pCi} / \mathrm{m}^{2}$. Both "PLANSOURC" and "ROOM" were generated using the ISOSHLD computer program.

\subsubsection{Inhalation Dose Rate Factors - FILE23}

The file assigned to logical unit 23 called FILE23, contains inhalation dose rate factors for $1 \mathrm{pCi}$ per cubic meter of air. The file is arranged into sets of records for each isotope. Each isotope set contains three solubility class subsets. Each solubility class subset is comprised of a variable number of records, one record per year. Each record contains data on up to five organs. The file organization, corresponding MAXIl variable names, and FORTRAN formats of FILE23 are as follows:

Line 1

- Number of radionuclides in 1 ibrary, NDI; descriptive t1t1e, TIT23; (I5, 15X,15A4).

Line 2

- Index of organs, IDORG( 1 ),

for $i$ ranging from 1 to $5, i=0$ indicates data

for less than five organs; (5I5).

This set of records follows for each radionuclide(k); a total of NDI sets:

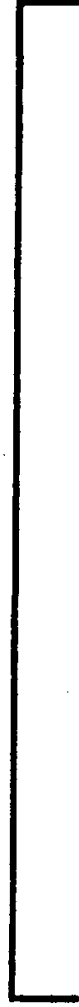
Line $A$
- Element symbol as in the master radio- nuclide library, ELTD;
atomic number as in the master radionuclide library, AWD;
number of years of data solubility
class $1, \mathrm{Nl}$;
number of years of data solubility
class 2, N2;
number of years of data solubility
class $3, \mathrm{~N} 3$;
(A2, $A 6,2 X, 3 I 5)$.
Next NI lines
- For translocation class 1 , one record con- tains inhalation dose rate factors for five organs $(j), \operatorname{DIN}(1, i, j)$; $(10 x, 5 E 10.2)$.
Next N2 1ines
- For translocation class 2, one record con- tains inhalation dose rate factors for five organs $(j), \operatorname{DIN}(2, i, j) ;(10 x, 5 E 10.2)$.
Next N3 lines
- For translocation class 3 , one record con- tains inhalation dose rate factors for five organs $(j), \operatorname{DIN}(3,1, j) ;(10 x, 5 E 10.2)$.
The file contains dose rate factors of 130 radionuclides for five organs for a varying number of translocation classes and a varying number of years. The organs are total body, bone, lungs, thyroid, and the lower 
large intestine of the GI tract. Dose rate factors are based on a breathing rate of $230 \mathrm{cc} / \mathrm{sec}$. The first page of this file is printed in Appendix 1.D.5. A complete listing is located in Appendix 2.A. FILE23 is created by a special version of the computer code DACRIN (Houston, Strenge, Watson. 1974). This library is not "environment"-specific and consequently should not need to be recreated by the user. The input to DACRIN that created FILE23 is shown in Appendix 2.D.

\subsubsection{Aquatic Foods Dose Rate Factors - FILE24}

The file assigned to logical unit 24, called FILE24, contains "environment" -specific aquatic foods dose rate factor for 1 pCi per 1 iter of river water. Each record of the file contains dose rate factors of one radionuclide for selected organs. The file is arranged into sets of records for each year. The sets are delimited by a blank record. The file organization, corresponding MAXIl variable names, and FORTRAN formats of FILE24 are as follows:
Line 1
- Descriptive title, TIT24; (20A4).
Line 2
- Type descriptor, ID;
number of years of data, NYRA;
number of isotopes, NISOA;
number of organs, NORGA; $(5 X, A 4,3 I 5)$.
Line 3
- Index of organs, KORGA(i),
for $i$ ranging from one to NORGA; (5I5).

The following set of records follows for each year of data $(k)$; a total of NYRA sets:

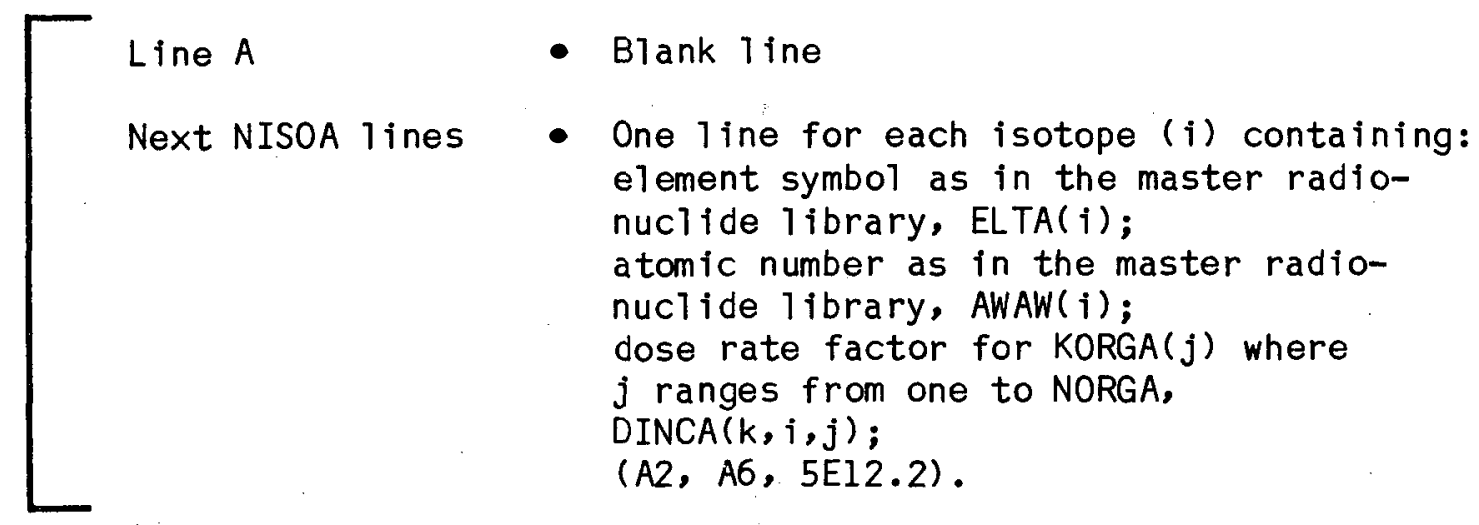

FILE24 contains dose rate factors for five organs for 100 radionuclides for fifty years. The organs are total body, bone, lungs, thyroid, and the lower large intestine of the GI tract. Consumption rates are given in 
Table 2.1-2. Radionuclides included are listed in Table 2.1-3. The first page of this file is printed in Appendix 1.C. A complete listing of the file is located in Appendix 2.A.

FILE24 is generated by the MAXI3 computer code. MAXI3 is a special version of the ARRRG computer code (Napler et a1. 1980). The user is referred to that document for detalled information. Instructions for executing MAXI3 are given in Section 3.1.2. The input to MAXI3 that generated the aquatic foods dose rate factors in FILE24 is given in Appendix 2.C.

\subsubsection{Drinking-Water Dose Rate Factors - FILE25}

The file assigned to logical unit 25, called FILE25, contains "environment" -specific drinking-water dose rate factors for $1 \mathrm{pCi}$ per 1 iter of drinking water. Each record of the file contains dose rate factors of one radionuclide for selected organs. The file is arranged into sets of records for each year. The sets are delimited by blank records. The file organization, corresponding MAXIl variable names, and FORTRAN format of FILE25 are as follows:

Line 1

Line 2

Line 3
- Descriptive tit7e, TIT25; (20A4).

- Type descriptor, ID; number of years of data, NYRW; number of isotopes, NISOW; number of organs, NORGW; (5X, A4, 3I5).

- Index of organs, KORGW(i), for $i$ ranging from 1 to NORGW; (5I5).

The following set of records follows for each year of data (k); a total of NYRW sets:

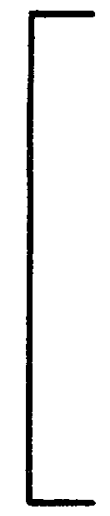

Line A

Next NISOW 1 ines
- Blank line

- One line for each isotope (i) containing: element symbol as in the master radionuclide library, ELTW(i); atomic number as in the master radionuclide library, $A W W(i)$; dose rate factor for $\operatorname{KORGW}(j)$ where $j$ ranges from one to NORGW, $\operatorname{DINCW}(k, i, j)$;

(A2, $A 6,5 E 12.2)$.

FILE25 contains dose rate factors for five organs for 100 radionuclides for fifty years. The organs are total body, bone, lungs, thyroid, and the lower large intestine of the GI tract. Consumption rates are given in 
Table 2.1-2. The radionuclides considered are listed in Table 2.1-3. The first page of this file is printed in Appendix 1.C. A complete listing of the file is in Appendix 2. A.

The computer code MAXI3 generates FILE25. MAXI3 is a special version of the ARRRG computer code (Napier et al. 1980). The user is referred to that document for detailed information. Instructions for executing MAXI3 are given in Section 3.1.2. The MAXI3 input file that generated the dose rate factors in FILE25 is given in Appendix 2.C.

\subsubsection{Buried Waste External Dose Rate Factors}

Three files are available for considering burled waste in the onsite disposal "environment." The files are based on the location (relative depth from the surface) of the waste. The three optional files are:

$$
\begin{aligned}
& \text { "VOLSOURC" - infinite surface slab source (waste thickness of } 1 \mathrm{~m} \text { ) } \\
& \text { "BURIEDHF" - infinite slab source buried in soll with an overburden } \\
& \text { "BURIEDI" - } \begin{array}{l}
\text { infinite slab source buried in soil with an overburden } \\
\text { depth of } 1.0 \text { meters (waste thickness of } 1 \mathrm{~m} \text { ) }
\end{array}
\end{aligned}
$$

ONSITE assigns the appropriate file to logical unit 27 based on the waste location selected by the user. The factors in these files relate the radionuclide source strength to the dose rate in tissue $1 \mathrm{~m}$ away. These factors are for $1 \mathrm{pCi}$ per cubic meter for the waste. Each record of the file contains dose rate factors for one radionuclide. The file organization, corresponding MAXIl variable names, and FORTRAN formats of the optional files are as follows:

$$
\begin{array}{ll}
\text { Line } 1 & \text { - } \\
\text { Line } 2 & \text { Descriptive title, TIT27; (20A4). } \\
\text { Next NISODX 1ines } & \text { Type descriptor, ID; } \\
& \text { number of isotopes, NISODX; (5X, A4, I5). } \\
& \text { For each isotope (i) } \\
& \text { element symbol as in master radionuclide } \\
& \text { library, ELTDX( } i) ; \\
& \text { atomic number as is master radionuclide } \\
& \text { library, AWDX( } i) ; \\
& \text { dose rate factor in air, DFDXT(i); } \\
& (A 2, A 6, E 7.1)
\end{array}
$$

The three onsite disposal "environment" files are 1 isted in Appendices 1.C and 2.A. These files are created by the ISOSHLD (Engel et al. 1966; Simmons et a7. 1967) computer program. 


\subsection{References}

Anspaugh, L. R., J. H. Shinn, P. L. Phelps and N. C. Kennedy. 1975. "Resuspension and Redistribution of Plutonium in Soils." Health Phys. 29:571-582.

Engel, R. L., J. Greenborg, and M. M. Hendrickson. 1966. ISOSHLD - A Computer Code for General Purpose Isotope Shielding Analysis. BNWL-236, Pacific Northwest Laboratory, Richland, Washington.

Houston, J. R., D. L. Strenge and E. C. Watson. 1974. DACRIN - A Computer Program for Calculating Organ Dose from Acute or Chronic Radionuclide Inhalation. BNWL-B-389, Pacific Northwest Laboratory, Richland, Washington.

International Commission on Radiological Protection (ICRP). 1959. Report of ICRP Committee II on Permiss ib le Dose for Internal Radiation. ICRP Publication 2, Pergamon Press, New York.

International Commission on Radiological Protection (ICRP). 1966. "Deposition and Retention Models for Internal Dosimetry of the Human Respiratory Tract." Health Phys. 12:173-207.

Kennedy, W. E., Jr., E. C. Watson, G. R. Hoenes, and B. A. Napler. 1979. "A Method for Determining Acceptable Residual Radioactive Contamination Levels." Paper presented at the 24th Annual Meeting of the Health Physics Society, July 8-13, 1979, Philadelphia, Pennsyivania.

Napier, B. A., R. L. Roswe1 1, W. E. Kennedy, Jr. and D. L. Strenge. 1980. ARRRG and FOOD - Computer Programs for Calculating Radiation Dose to Man from Radionuclides in the Environment. PNL-3180, Pacific Northwest Laboratory, Richland, Washington.

Napier, B. A. 1981. Standardized Input for Hanford Environmental Impact Statements - Part I. PNL-3509, Part 1, Pacific Northwest Laboratory, Richland, Washington

Oak, H. D., G. M. Holter, W. E. Kennedy, Jr., and G. J. Konzek. 1980. Technology, Safety and Costs of Decommissioning a Reference Bolling-Water Reactor Power Station. NUREG/CR-0672, Vo1. 1 and 3. Prepared for the U.S. Nuclear Regulatory Commission by Pacific Northwest Laboratory, Richland, Washington.

Simmons, G. L. et a7. 1967. ISOSHLD II Code Revision to Include Calculation of Dose Rate from Shielded Bremsstrahlung Sources. BNWL-236 Supplement 1, Pacific Northwest Laboratory, Richland, Washington.

Soldat, J. K., N. M. Robinson and D. A. Baker. 1974. Models and Computer Codes for Evaluating Environmental Radiation Doses. U.S. AEC Report BNWL-1754, Pacific Northwest Laboratory, Richland, Washington. 
U.S. Environmental Protection Agency (EPA). 1977. Proposed Guidance on Dose Limits for Persons Exposed to Transuranium Elements in the General Environment. EPA 520/4-77-016, U.S EPA, Washington, D.C.

U.S. Nuclear Regulatory Commission (NRC). 1977. Calculation of Annual Doses to Man From Routine Releases of Reactor Effluents for the Purpose of Evaluating Compliance with 10 CFR Part 50, Appendix I. Regulatory Guide 1.109, Rev.1, U.S. NRC, Wash ington, D.C.

U.S. Nuclear Regulatory Commission. 1981. Draft Environmental Impact Statement on 10 CFR Part 61, "Licensing Requirements for Land Disposal of Radioactive Waste." NUREG-0782, Vols. 1-4, Washington, D.C.

U.S. Nuclear Regulatory Commission. 1982. Final Envirenmental Impact Statement on 10 CFR Part 61 "Licensing Requirements for Land Disposal of Radioactive Waste." NUREG-0945, Washington, D.C. 


\section{PROCEDURES}

User instructions and technical details on use of the ONSITE/MAXIl software package are presented in this section. Instructions are given for user interaction with each of the computer codes. Detailed information on input parameters is included for reference. Outputs from the computer programs are described. Five sample problems are included with a discussion of the hand calculations performed to verify the correct operation of the computer code. Program-generated error messages and corresponding corrective actions for the ONSITE and MAXII computer codes are also listed.

This section is written primarily for the user who interacts with the ONSITE program to execute one of the scenarios presented in Section 2.1.3. Before interacting directly with the other codes in the software package, the user should be familiar with Section 2.2, Computer Implementation.

The following conventions will be used in this manual to distinguish exact user input from instructions and from computer program displays.

$\langle c r\rangle$

boldface

CAPITAL LETIERS

lower-case letters
- These symbols indicate that the keyboard key labeled RETURN should be pressed when encountered in the manual. This is analogous to the carriage return for those of you more familiar with typewriters than computers.

- Boldface print designates information entered at the terminal by the user. NOTE: In the appendices, information entered by the user is underl ined.

- When capital letters in boldface type are encountered, the user should type in the boldface letters exactly as shown.

- When lower-case letters are encountered in boldface type, the user should substitute scenario-specific information or a unique name.

\subsection{User Instructions}

The ONSITE/MAXIl software package is installed on the Brookhaven CDC 6600 MFA and 7600 MFZ computers. It is necessary to obtain an account name, password, and problem number to use this computer. The user is responsible for obtaining the above privileges to access the ONSITE/MAXIl software.

Three levels of software operation are presented in Section 2.2.2. At Leve1 1 , the ONSITE program is used to establish and exercise a scenario 
within the context of the "environment" described in Section 2.1.2. At Level 2, a different "environment" can be established with the MAXI2 and MAXI3 programs. At Leve1 3, the user interacts directly with the MAXII program to set up scenarios for an "environment" created with MAXI2 and MAXI3 programs.

The following three subsections correspond to these levels, respectively.

\section{I.I Creating and Executing a Scenario - ONSITE (Leve 1 User)}

To establish and execute a scenario, the user need only type

\section{ATTACH,PROCFIL, ID=0NSITE, MR=1 〈Cr > BEGIN, ON 〈Cr>}

to access the interactive program.

ONSITE first introduces itself and displays general instructions on use of the program. A menu describing the available scenarios is displayed. The five scenarios are:

(1) External-Exposure Scenario

(2) External-Exposure Plus Inhalation Scenario

(3) Agricultural Scenarios

(4) Irrigation/Drinking-Water Scenario

(5) User-Defined Scenario

A brief description of the selected scenario is displayed. The user may change the scenario selection at this point. This allows the user to interactively review al 1 scenario descriptions before making a final decision for a specific simulation.

The user is queried for a descriptive title, the start time of the simulation, and the level of detail presented in the output reports. The user may execute the scenario as it was described in Section 2.1 .3 or modify parameters associated with exposure pathways included in the selected scenario. If changes are to be made, ONSITE will set parameter values based on the user's response to questions. Default values are displayed for each parameter, and the user's input is tested to determine if it is within bounds. Before the user is asked to supply the inventory, an opportunity is provided to review all of the entered parameters. This enables the user to correct any mistakes or make changes.

When the user is satisfied with the parameter selection, the source term is entered by radionuclide. Radionuclides should be selected from Table 2.1-3. MAXIl accepts radionuclide names only as they appear in RMDONS, 1 isted in 
Appendix 1.C.9. Inhalation exposure calculations require a translocation class assignment for each organ for each radionuclide. Default assignments have been made. The user may review and/or modify these assignments. The concentration of the radionuclides in the source term may be entered in various units selected by the user. A screen report of the inventory is displayed when the user has completed inventory input. The user is then a 1 lowed to 1) modify the displayed inventory, and then 2) add radionuclides to the inventory.

ONSITE provides assistance to the user during scenario creation. This manual should not be necessary during normal executions. The fol 1 owing features are incorporated into the ONSITE software:

- Parameter descriptions and default values for each of the five scenarios are stored in the code.

- Only applicable parameters are reviewed for each scenarto.

- Questions are "English-phrased". A strong effort has been made to refrain from computer jargon. The code attempts to ask questions meaningful to the end user and logically establishes required parameter values.

- Values entered at the terminal by the user are tested against minimum and maximum allowable limits. If a value is determined to be outside the allowable limits, the user is asked to supply another value.

- Default values are installed with a null entry (i.e., pressing the <return> key).

- When a "YES/NO" question is asked of the user, the default condition is always displayed first (e.g., $(N / Y)$ indicates that a null entry is equivalent to a "no" response).

- Review of collections of parameters (e.g., agricultural and/or inhalation pathway parameters may be bypassed during scenario modification).

- Radiological inventory input is tested against a shortened version of the master radionucl ide 1 ibrary, RMDONS. This establ ishes that information is available in the data base for the source term in question and that the user entered the radionuclide name in a recognizable form.

- Radiological inventory input is tested against the previously entered input to ensure that an entry is not dupiicated.

- Upon the completion of input, the radiological inventory is displayed. The user is given the opportunity to first modify and then add to the inventory. 
- Default organ translocation classes are assigned.

- Input is free-formatted as specified in ANSI-FORTRAN-77.

- The user may revfew and/or modify scenario parameters until satisfied with the selection.

Upon completion of the ONSITE program, the user is asked to supply a CDC account name and problem number. This information is used to prepare control statements for the MAXIl execution. The MAXI execution file created by ONSITE will be in the user's work area under the name TAPE7.

The user should then enter the following command:

\section{BEGIN, DONE <cr>}

This command will catalog the execution file, submit the file to the MFZ computer for processing, and prepare the work area for another run.

The user will be prompted to enter a unique filename in the following manner:

\section{F FILENAME FOR SCENARIO: filename 〈cr $\rangle$}

The user is then asked to supply a unique read key for the file as follows:

\section{R READ KEY FOR FILE: readkey 〈cr>}

This key will protect the user's account name and problem number. The MAXIl execution file will be stored as a permanent file under the name specified by the user. The permanent file will have an ID of ONSITE and a retention period of ten days. This two-step procedure allows the user to access the input file prior to execution.

Because of extended core memory requirements, there may be a delay in the MAXIl executions. When the files have been executed, (the job names will appear under OUTPUT FILES in the FILES command response), the user may use the SEND command procedure to direct output to the RJE terminal in SS-056. To start the procedure, enter:

\section{BEGIN,SEND 〈cr>}

The procedure will respond with the following request:

F NAME OF OUTPUT FILE TO BE PRINTED: jobname <cr>

The user should enter the jobname as it appears in the FILES command response. The SEND procedure then requests a name that will be printed on 
the banner page of the output. The user may use any five-character sequence to identify the run. The format of the request is as follows:

\section{N FIVE CHARACTER NAME TO IDENTIFY RUN: name 〈cr>}

\subsubsection{Creating an "Environment" - MAXI2 and MAXI3 (Leve1 2 User)}

MAXI2 is a specialized version of the FOOD (Napier et al. 1980) computer program. MAXI3 is a specialized version of the ARRRG (Napier et a1. 1980) computer code. The user is referred to the ARRRG and FOOD document for user instructions, with the following exceptions:

- Only the following NAMELIST parameters are used by MAXI2:

$\begin{array}{lll}\text { NEXT } & \text { HLDUP } & \text { KORG } \\ \text { KFDTYP } & \text { CON } & \text { T2 } \\ \text { GRWP } & \text { TRNS } & \text { POP } \\ \text { YELD } & \text { EXTIM } & \text { IPOP }\end{array}$

- Onty the following NAMELIST parameters are used by MAXI3:

$\begin{array}{lll}\text { NEXT } & \text { KORG } & \text { USAG } \\ \text { KPTHWY } & \text { PLIFE } & \text { ISALT } \\ \text { T2 } & \text { HLDUP } & \end{array}$

- Release parameter records need only 1 ist the radionuclide name, $\operatorname{ELTI}(i)$ and AWI(i) in FORTRAN A2, A6 format.

- Special versions of the data libraries used by MAXI2 and MAXI3 are included in the ONSITE/MAXI software package. These libraries contain information in the radionuclides listed in Table 2.1-3. The 1ibrary FTRANSL IB contains elemental deposition velocities to account for deposition of resuspended radipactive materials. Transfer coefficients in FTRANL IB for ${ }^{3} \mathrm{H}$ and ${ }^{14} \mathrm{C}$ are taken from Regulatory

Guide 1.109 (U.S. NRC 1977). The libraries included in this package are:
RMDL IB
ORGL IB
BIOAC
GRDFLIB
FTRANSL IB

RMDL IB is also used by MAXIl.

- Files must be assigned to the following logical unit devices to obtain dose rate factor output: 
Logica 1

Unit No.

\section{0}

21

22

24

25
File Description

MAXI2 leaf mechanisms

MAXI2 soll mechanisms

MAXI2 surface external mechanisms

MAXI3 aquatic food-product mechanisms

MAXI3 drinking-water mechanisms
Corresponding

ONSITELMAXI File

FILE20

FILE21

PLANSOURC

FILE24

FILE25

MAXI2 and MAXI3 will print reports of input parameters. Output file organization is presented in Section 2.3. Output reports (as provided by FOOD and ARRRG) are not printed.

Sample input files to MAXI2 and MAXI3 and 1 isted in Appendices 2.B and 2.C, respectively.

The ONSITE/MAXIl data base contains the "environment" described in Section 2.1.2. File names generated by MAXI2 and MAXI3 must not conflict with those currently in the data base. It is suggested that all files be renamed so that the different "environment" can be established without sacrificing the integrity of the ONSITE/MAXI data base.

\subsubsection{Interacting Directly with MAXIl (Level 3 User)}

A user may establish a scenario by interacting directly with the MAXII computer program. Because of the complexity of the MAXIl input parameters, the user must have a thorough understanding of MAXIl theory and coding before attempting this interaction. Al 1 necessary information for MAXIl execution is included in this manual. The user is referred to Sections 2.2, $2.3,3.2,4.4$ and 4.5 for further information on executing MAXIl.

\subsection{Input Parameters}

Information in this section is not necessary for successful execution of the ONSITE program. It is included for reference. The default parameter values assigned to each scenario are given in Table 3.2-1. The input variables for ONSITE/MAXIl are described in Table 3.2-2. The name of each parameter is fol lowed by the number of elements (and specification if it is an array), the data type classification, and a description. The parameter description includes the function of the parameter, the dimensional units, and the minimum and maximum al lowable values if applicable. The parameters are 1 isted in alphabetical order. 
Table 3.2-1. Scenario Default Parameter Values

Pathways:

\begin{tabular}{|c|c|c|c|}
\hline $\begin{array}{l}\text { External } \\
\text { Exposure }\end{array}$ & $\begin{array}{l}\text { External } \\
\text { Exposure and } \\
\text { Inhalation }\end{array}$ & Aoricultural & $\begin{array}{c}\text { Irrigation } \\
\text { Drinking } \\
\text { Matar }\end{array}$ \\
\hline
\end{tabular}

External Exposure to Burfed Waste (IEXT)

1

$$
0
$$

0

0

1

External Exposure to Surface Waste (ISUR)

Food Consumption (IFOD)

Drinking Water

Consumption (IWAT)

Aquatic Food Product Consumption (IARG)

Air Submission

(IAIR)

Hours of Exposure:

To Externa?

To Inhalation

$2000 . \quad 2000$.

02000

2000.

2000 .

2000 .

2000 .

8766.

Waste Dilution

Factor

$\begin{array}{cc}\text { NA } & .2 \\ \text { NA } & \text { Anspaugh } \\ \text { NA } & 1.0 \\ 0.0 & 0.0 \\ 0 & \begin{array}{l}0 \\ \text { Total } \\ \text { body }\end{array} \\ \begin{array}{c}\text { Total body, lungs, } \\ \text { bone, } \\ \text { thyroid, } \\ \text { GI tract }\end{array}\end{array}$

\section{$\begin{array}{ll}1.0 & .2\end{array}$}

Anspaugh

0

Anspaugh

0

Mass loading

$-1$

1.0

1.0

NA
0.0
1.0
1.0

Years of Prior

Irrigation of

Site

Selected Organs
0
Total body, bone, lungs, thyroid, GI tract
10 thyroid, Total body, Total body, thyroid, GI tract GI tract bone, lungs, bone, lungs,

No. of Years

After Waste is

Disposed That:

Scenarlo Begins

Scenar 10 Ends

$\begin{array}{rr}0 & 0 \\ 50 & 50\end{array}$

0

0

0

Site Size (ha)

1.0

1.0

50

50

50

0.05

$1: 0$

1.0 
Table 3.2-2. ONSITE/MAXIl Parameter Descriptions

NAMELIST

Parameter Set/No. Array

Name.

AGE

AREAEX

AREAIN

INPUT

INPUT

INPUT

Rea1

Real

Alpha

$(100)$

INPUT

DEN

ELTI

(100)

FRSIZ

INPUT

Real
I22 INPUT Integer

Data Type

Anspaugh model. Average age of surof the calculation in years.

Area correction factor for external pathways to account for the 1 imited exposure potential from smaller disposal sites. This parameter is calculated by ONSITE based on the size of the site, FRSIZ. (Default value is 1.0 )

Real Area correction factor for internal pathways to account for the 1 imited exposure potential from smaller disposal sites. This parameter is calculated by ONSITE based on the size of the site, FRSIZ. (Default value is 1.0 )

Two-character element symbol of each radionuclide in the source term.

Real Mass-loading model. Soil density in grams per cubic meter. (Default value is $1.0 E+6$ )

Alpha Atomic number of this radionuclide. Input may be up to six characters in length and include metastable ( $m$ ) and daughter ( $+D)$ designation (e.g., TEl27m+D):

Real Disposal site size in terms of fractional hectares. (Default value is 1.0 )

Index of source computer program of the external dose rate factors in the file assigned to logical unit 22:

0 - ISOSHLD

1 - MAXI2 
Table 3.2-2. ONSITE/MAXII Parameter Descriptions - Continued

NAMELIST

Parameter Set/No. Array

Name Elements

Data Type

Description

If I22=0, MAXIl will set XFACT = 5.844E-11. If I22=1, MAXIl will set $X F A C T=1.0 . \quad$ (Default value is 0 )

IARG INPUT Integer Consumption of aquatic food products from a contaminated river pathway:

0 - pathway not selected

1 - pathway selected

IEXT

INPUT

Integer

External exposure and crop root penetration for deeply buried waste:

0 - pathway not selected

1 - pathway selected

IFOD

INPUT

Integer

Farm products ingestion pathway:

0 - pathway not selected

1 - pathway selected

IMO

INPUT

Integer

The number of months per year that crops are irrigated. (Default value is 6)

INHAL

Integer

Inhalation from resuspension pathway:

0 - pathway not selected

1 - pathway selected

ION

INPUT

Integer

Control parameter set to indicate that input was created by the ONSITE program. Used to control parameter printing in QAPAGE. ION is set to 1 by ONSITE. (Default value is 0 )

IOUT

INPUT

Integer

Output class index:

0 - print tables of maximum annual doses per organ with radionucl ide and pathway contribution 
Table 3.2-2. ONSITE/MAXIl Parameter Descriptions - Continued

NAMELIST

Parameter Set/No. Array

Name Elements

IRR

IRS

Integer Index of the selected default scenario:

I - external exposure

2 - external exposure plus inhalation from resuspension

3 - external exposure from agricultural activities

4 - use of contaminated water for irrigation and/or drinking

5 - user-created

ISUR

INPUT

Integer

External exposure to surface contamination:

0 - not selected

1 - selected

If this parameter is set to 0 , XFACT will be set to 1.0 in MAXIl. (Defautt value is 1 )

ITI

INPUT

Integer

The year after waste disposal when intrusion occurs and the annual dose calculation begins. This parameter allows for correct chain decay of source term. (Default value is 1 )

IT2 INPUT Integer Number of years of annual dose calculations. The maximum allowed is $49+\mathrm{ITl}$. (Default value is 50 ) 


\section{Table 3.2-2. ONSITE/MAXIl Parameter Descriptions - Continued}

\begin{tabular}{|c|c|c|c|}
\hline $\begin{array}{l}\text { Parameter } \\
\text { Name } \\
\end{array}$ & $\begin{array}{c}\text { NAMELIST } \\
\text { Set/No. Array } \\
\text { Elements } \\
\end{array}$ & Data Type & Description \\
\hline IWAT & INPUT & Integer & $\begin{array}{l}\text { Drinking water ingestion from well } \\
\text { water pathway: } \\
0 \text { - pathway not selected } \\
1 \text { - pathway selected }\end{array}$ \\
\hline KORG & $\begin{array}{l}\text { INPUT } \\
(5)\end{array}$ & Integer & $\begin{array}{l}\text { Indices of selected organs. } \\
\text { Indices must be arranged in } \\
\text { ascending order as discussed in } \\
\text { Section } 4 \text {. Total body must be } \\
\text { included. }\end{array}$ \\
\hline M3M2 & INPUT & Integer & $\begin{array}{l}\text { Surface source term input: } \\
0 \text { - permits input of } \mathrm{pCi} / \mathrm{square} \\
\text { meter } \\
1 \text { - permits input of } \mathrm{pCi} / \text { cubic } \\
\text { meter } \\
2 \text { - permits input of } \mathrm{pCi} / \mathrm{kilogram} \\
\text { of soi } 1 \\
\text { (Default value is } 1 \text { ) }\end{array}$ \\
\hline NIN & & Integer & $\begin{array}{l}\text { Number of radionuclides in the } \\
\text { source term. ONSITE calculates } \\
\text { this number. }\end{array}$ \\
\hline NORG & INPUT & Integer & $\begin{array}{l}\text { Number of organs to be considered. } \\
\text { Total body must always be con- } \\
\text { sidered as one of the five selected } \\
\text { organs. NOTE: I NORG } \leq 5 \text {. }\end{array}$ \\
\hline Q & $(100)$ & Real & $\begin{array}{l}\text { Contamination deposited on the } \\
\text { site at start of calculation. } \\
\text { Units as specified by M3M2. }\end{array}$ \\
\hline QI & $(100)$ & Real & $\begin{array}{l}\text { Irrigation/river release source } \\
\text { term in units of } \mathrm{PCi} / \mathrm{L} \text {. May be } \\
\text { used in Scenarios } 4 \text { and } 5 \text {. }\end{array}$ \\
\hline QJ & $(100)$ & Real & $\begin{array}{l}\text { Drinking water source term in units } \\
\text { of } \mathrm{PCi} / \mathrm{L} \text {. May be used in Scenarios } \\
4 \text { and } 5 \text {. }\end{array}$ \\
\hline RF1 & INPUT & Real & $\begin{array}{l}\text { The fraction of total roots in top } \\
15 \mathrm{~cm} \text { of the solt. (Default } \\
\text { value is } 1.0 \text { ) }\end{array}$ \\
\hline
\end{tabular}


Table 3.2-2. ONSITE/MAXIl Parameter Descriptions - Continued

NAMELIST

Parameter Set/No. Array
Name Elements

RF2

RINH

INPUT

INPUT

Data Type

Rea 1

Real

RIRR

INPUT

Real

Real

INPUT

RPF

RPF1

INPUT

Rea1

RPF2

INPUT

SRDIL

INPUT

INPUT

Rea 1

XDPT

XF2

Input

\section{Description}

The fraction of total roots entering the buried waste below the top $15 \mathrm{~cm}$ plow layer of soil. (Default value is 0.0 ) Note: RFI+RF $2 \leq 1.0$.

RINH modifies the hours of inhalation per year from 8660 hours per year to case-specific values and modifies breathing rate. ONSITE asks for the number of hours of inhalation per year and computes this number.

Irrigation rate in 1 iters per square meter per month. (Default value is 0.0 - no irrigation)

This parameter value is calculated by ONSITE (RPF = RPFI * RPF 2) unless RPF is zero or unspecified; in that case RPF = RPFl.

This is a ratio of waste concentration in surface to subsurface soils. (Default value is 1.0 )

Real Fraction of the total diet grown on the site. (Default value is 1.0 )

Real Inventory dilution factor. (Default value is 1.0 )

Anspaugh resuspension mode1. Fraction of the soil plow-layer thickness available for resuspension. (Default value is 0.067 )

Number of hours of external exposure to surface contamination. This parameter will modify XFACT by XF2/8766 in MAXIl. (Default value is 2000) 
Table 3.2-2. ONSITE/MAXIl Parameter Descriptions - Continued

\begin{tabular}{|c|c|c|c|}
\hline $\begin{array}{l}\text { Parameter } \\
\text { Name } \\
\end{array}$ & $\begin{array}{l}\text { NAMELIST } \\
\text { Set/No. Array } \\
\text { Elements } \\
\end{array}$ & Data Type & Description \\
\hline$X M L F$ & INPUT & Real & $\begin{array}{l}\text { Mass-loading resuspension model. } \\
\text { Mass-loading factor in grams per } \\
\text { cubic meter. (Default value } \\
\text { is } 1 E-4 \text { ) }\end{array}$ \\
\hline
\end{tabular}

The reference "environment" used to calculate the dose factor files in the data libraries is based on a uniformly contaminated site of 1 ha. To modify the default site area for consideration of smaller sites, the user is asked to enter the site size in terms of fractional hectares. As an example, if we wish to model a site of $150 \mathrm{~m}^{3}$, we would enter a fractional site size of $0.015\left(150 \mathrm{~m}^{2} / 10,000 \mathrm{~m}^{2}\right)$. The site area correction factor automatically applied by the ONSITE computer program to the ingestion and inhalation pathways is 0.25 as shown in Figure 2.1-1. This factor implies that on 1 y $25 \%$ of the total annual diet is raised on a site of $150 \mathrm{~m}^{2}$ and that the local air concentration resulting from resuspension is $25 \%$ of that resulting from a larger ( 1 ha) site. For direct exposure, the site area correction factor applied by the ONSITE computer program for this case is about 0.5 as shown in Figure 2.1-3. This factor implies that the direct exposure source strength from a site of $150 \mathrm{~m}^{2}$ is $50 \%$ of the source strength resulting from an infinite slab or plane. In addition to applying the site area correction factors, the user may still modify the hours of exposure and the other scenario-specific pathway assumptions.

\subsection{Output Descriptions}

ONSITE produces a system execution file containing logical unit/file assignments, the system command to execute MAXIl, and input for MAXIl defining the scenario specified by the user while interacting with ONSITE.

MAXIl generates a printer report that contains a complete description of parameters and their values and tables of maximum annual doses per organ. The user may select from three levels of detail in the results reporting:

- tables of maximum annual doses per organ with radionuclide and pathway contribution

- the tables listed above and a running summary of the annual doses listed by organ and total only

- the above summaries and a.l 1 annual tables by organ, pathway, and radionuclide. 
The parameter IOUT controls printer report selection. Usual 1y IOUT=0 will provide the user with adequate results. Examples of output from MAXIl are included for each of the sample problems in Section 3.4.

\subsection{Sample Problems}

Five sample problems are presented and discussed to assist the user in various types of executions. An attempt has been made to cover a typical range of scenarios for which the code package was intended. The complete set of input and output for each of the sample problems is 1 isted.

\subsubsection{Sample Problem One}

The first sample problem is designed to exercise the external-exposure scenario. For this sample problem, a licensee is assumed to dispose of $500 \mathrm{~m}^{3}$ of radioactive waste in a purial area onsite. The waste is assumed to contain an average of $0.1 \mathrm{Ci} / \mathrm{m}^{3}$ of ${ }^{60}$ Co buried to a depth of $0.5 \mathrm{~m}$ over a 1 ha site. The sample problem is to determine the doses to an intruder 10 years after the wastes are buried. The solution is found by running the ONSITE default external exposure scenario for subsurface waste with default exposure conditions and the ${ }^{60}$ Co waste inventory. A summary of the ONSITE interactive session used to develop the runstream for Sample Problem One is shown in Figure 3.4-1. The output resulting from this sample problem is shown in Figure 3.4-2. The maximum annual total-body dose to the intruder resulting for this sample problem is about $0.04 \mathrm{rem} / \mathrm{yr}$. Hand calculations were performed for this sample problem. The results verified the code operation in calculating radioactive decay, soil concentrations, and totalbody dose for the external-exposure pathway.

\subsubsection{Sample Problem Two}

The second sample problem is designed to exercise the external exposure plus inhalation scenario. For this sample problem, a 1 ifensee is assumed to dispoşe of $500 \mathrm{~m}^{3}$ of waste onsite containing $0.1 \mathrm{Ci} / \mathrm{m}^{3}$ of $60{ } \mathrm{Co}$ and $0.01 \mathrm{Ci} / \mathrm{m}^{3}$ of ${ }^{90} \mathrm{Sr}+\mathrm{D}$. The wastes are assumed to contaminate a 1 ha site. Default conditions for resuspension are assumed except that the intruder is assumed to be exposed for $3000 \mathrm{~h} / \mathrm{yr}$ instead of $2000 \mathrm{~h} / \mathrm{yr}$. Sample Problem Two is to determine the doses to the intruder 10 years after the wastes are buried. The solution is found by running the ONSITE external exposure plus inhalation default scenario with the specified conditions and waste inventory. A summary of the ONSITE interactive session used to develop the runstream for Sample Problem Two is shown in Figure 3.4-3. The output resulting for this sample is shown in Figure 3.4-4. The maximum annual doses resulting for this sample problem are about $16 \mathrm{rem} / \mathrm{yr}$ to total body, $22 \mathrm{rem} / \mathrm{yr}$ to bone, $37 \mathrm{rem} / \mathrm{yr}$ to $1 \mathrm{ung}, 16 \mathrm{rem} / \mathrm{yr}$ to thyroid, and $16 \mathrm{rem} / \mathrm{yr}$ to $G I$ ( $L L I)$. 
This interactive program will assist you in the creation of scenarios for assessment of onsite disposal of lowlevel waste. Doses to man through the specified pathways will be simulated by the computer program MAXI.

The following notes may be of interest:

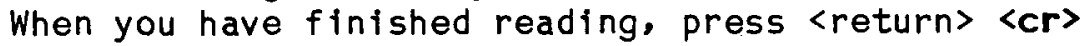

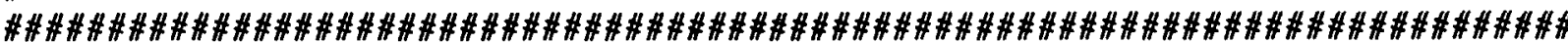

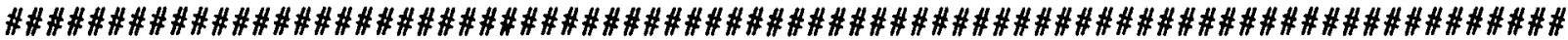

\#

\#

$\#$

\#

\#

\#

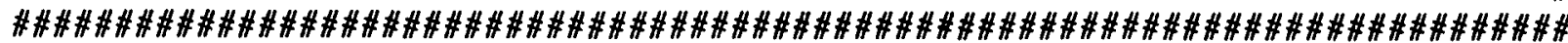

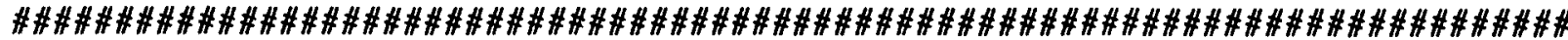
\#

Figure 3.4-1. Sample Problem One Interactive Session

1) If the default condition is selected, you need only press <return>. YES-or-NO questions are designated by $(Y / N)$ and should be answered with a $Y$ or $N$. The default condition is always listed first.

2) The values you enter will be tested against reasonable limits and if they are not accepted you will be asked to supply another value.

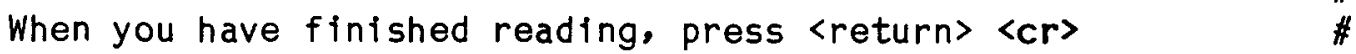

The following scenarios have been defined:

1 - External exposure

2 - External exposure plus inhalation from resuspension

3 - Agricultural activities

4 - Use of well water for irrigation and drinking water

5 - User-created scenario

To select a scenario or for additional information

on a scenario enter $1,2,3,4$, or $5: 1\langle c r\rangle$ 


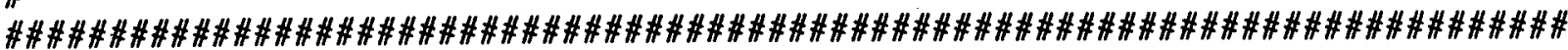

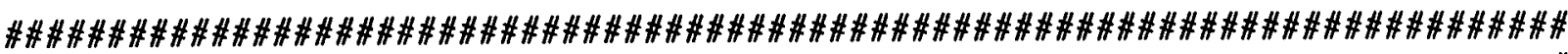

$\#$

$\#$

\#

\#

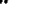

Enter a descriptive title to identify this case:

\section{SAMPLE PROBLEM ONE}

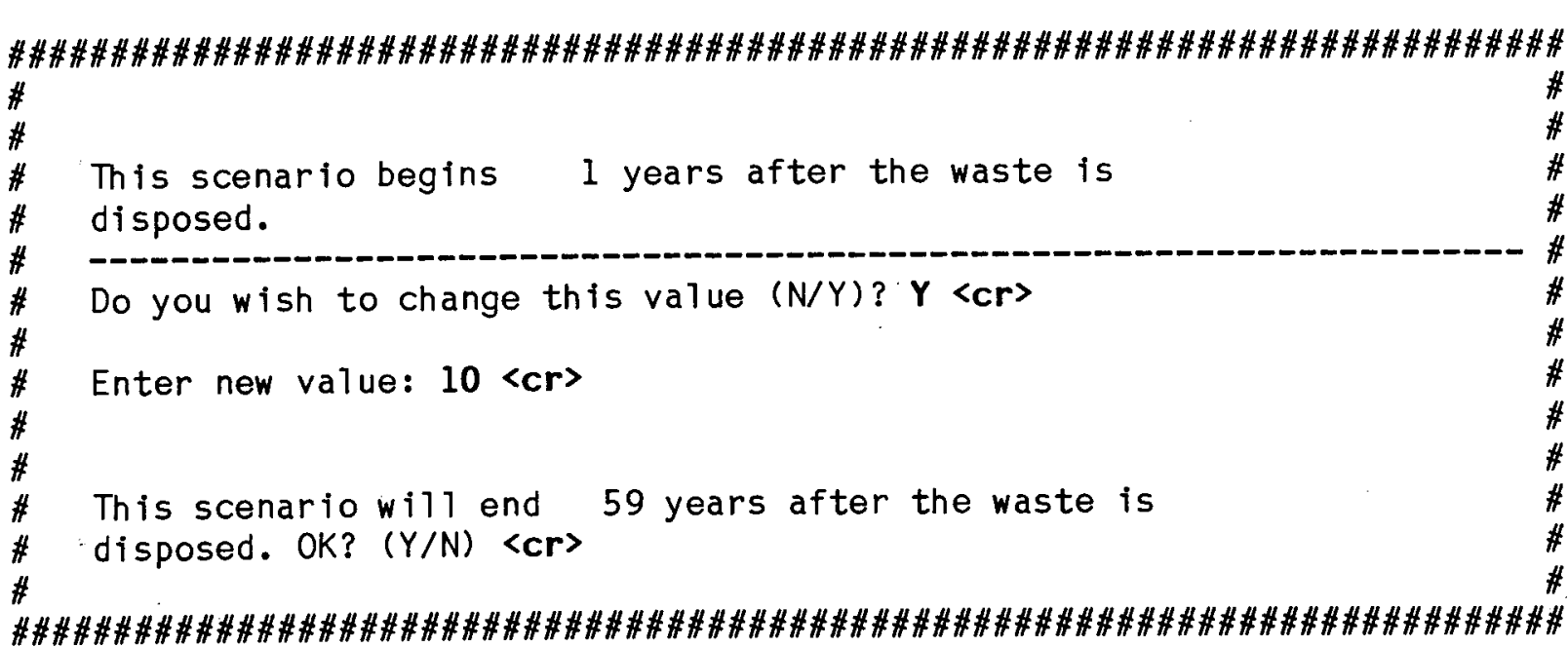

Figure 3.4-1. Sample Problem One Interactive Session (Continued) 


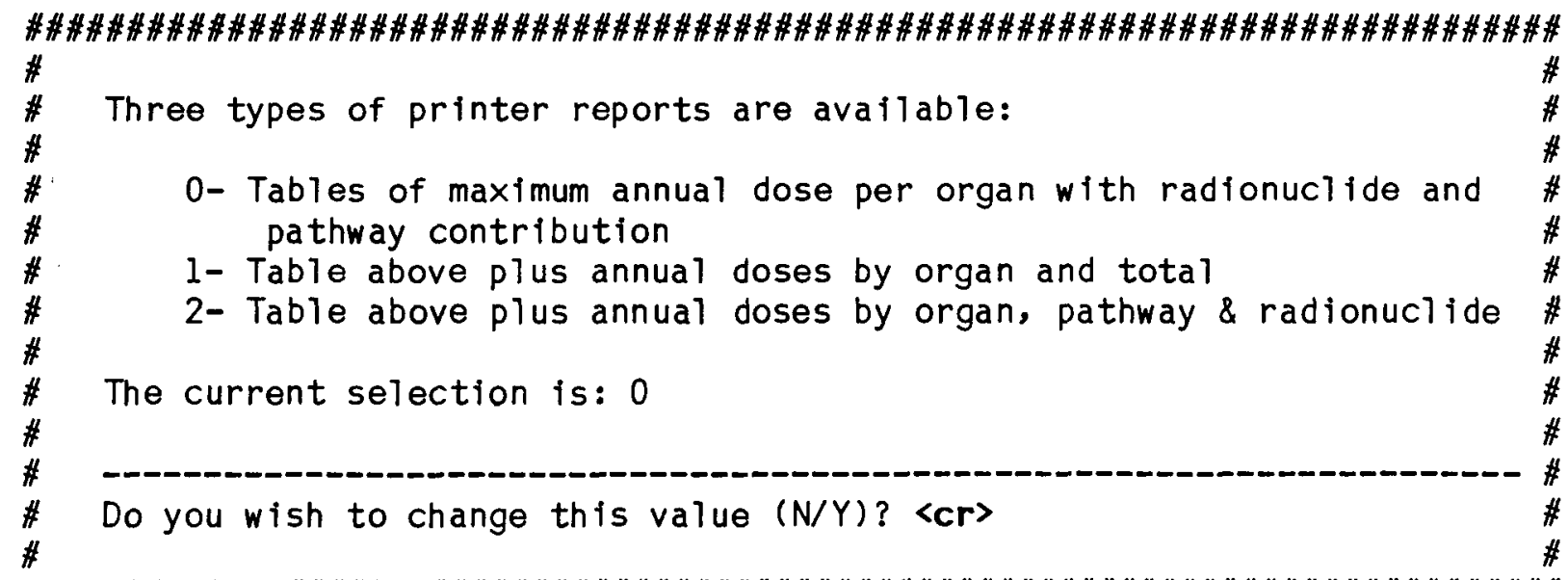

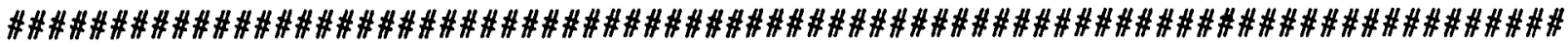

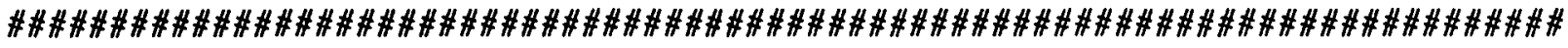

$\#$

In this scenario, wastes may be:

1 -On surface

2 -Buried at $0.5 \mathrm{~m}$

3 -Buried at $1.0 \mathrm{~m}$

4 -Stored waste

The current selection is: 2

Do you wish to change this value $(N / Y)$ ? $\langle c r\rangle$

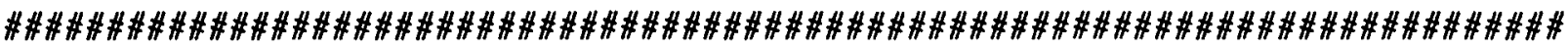

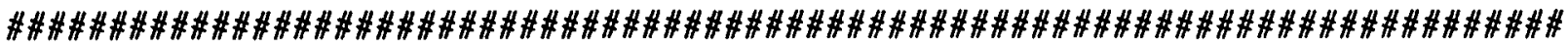

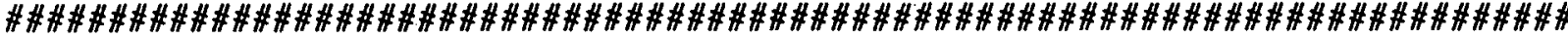

Figure 3.4-1. Sample Problem One Interactive Session (Continued) 
Figure 3.4-1. Sample Problem One Interactive Session (Continued) 
The surface/buried inventory dilution factor is: 0.20 ( range $=0.0$ to $1.0 \mathrm{E}+20$ )

Do you wish to change this value $(N / Y)$ ? $\langle c r\rangle$

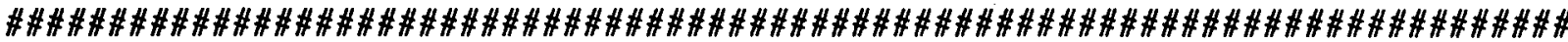

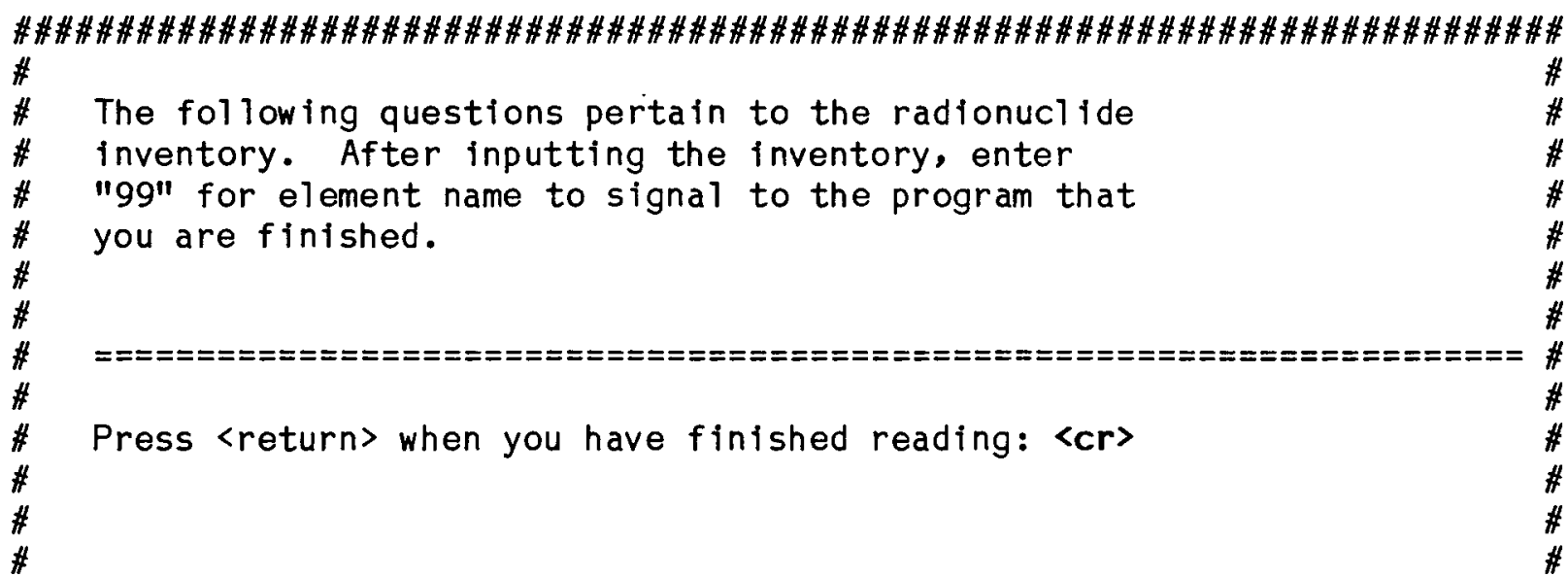

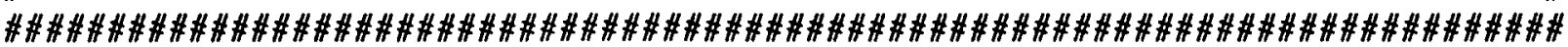

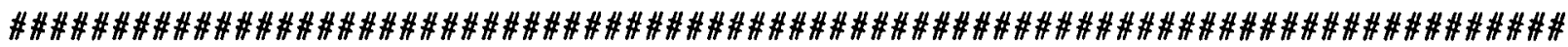

\#

\#

\#

$\#$

\#

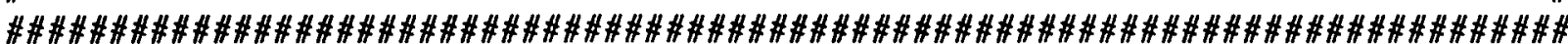

Figure 3.4-1. Sample Problem One Interactive Session (Continued) 


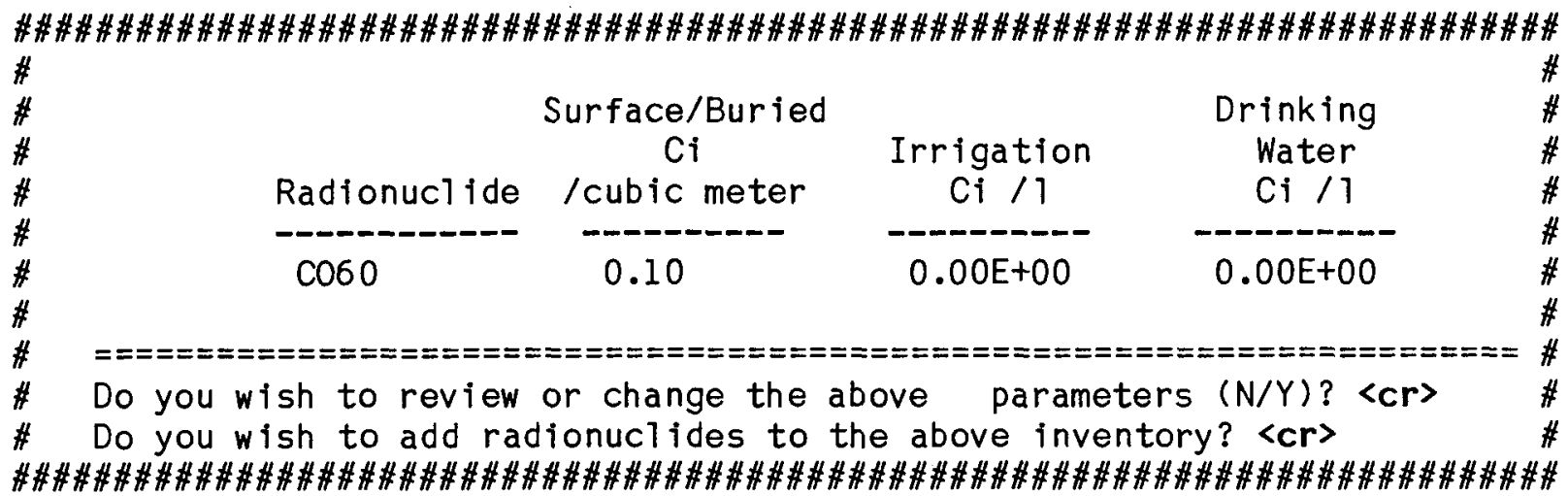

(The above interactive session generates the following file.)

account-name, STMFZ,CM160000,EC400,T177.

ACCOUNT, account-name, prob 7 em-number, problem-number.

ATTACH, TAPE20, F ILE20, ID =ZZRNRC.

ATTACH, TAPE21, FILE21, ID =ZZRNRC.

ATTACH, TAPE24, FILE24, ID=ZZRNRC.

ATTACH, TAPE25, FILE25, ID $=Z Z R N R C$.

ATTACH, TAPE22, PLANSOURC, ID=ZZRNRC.

ATTACH, TAPE27, BURIEDHF, ID =ZZRNRC.

ATTACH, TAPE10, RMDL IB, ID =ZZRNRC.

ATTACH , TAPE23, FILE23, ID =ZZRNRC.

ATTACH, ABS, MAXII ABS, ID =ZZRNRC.

COPY, ABS, LGO.

RE TURN, ABS.

MAP, OFF.

LDSET, PRESET $=$ ZERO.

LGO.

\{eor \}

SAMPLE PROBLEM ONE

\$INPUT NEXT $=1$,

IFOD $=0, I A R G=0, I W A T=0, I E X T=1$,

ISUR $=0$, IAIR $=0$,

RPF $1=0 . \quad, \operatorname{RPF} 2=1.00$,

$\mathrm{RINH}=0.000000, \mathrm{DILF}=1.00, \mathrm{XF2}=.200 E+04$,

$M 3 M 2=1$, INTRUD $=0, I 22=0$,

$I T 1=10, I T 2=59, N O R G=1, \operatorname{KORG}(1)=1$,

SRDIL $=.200 \quad$, FRSIZ $=1.00 \quad$, AREAIN $=1.00$

AREAEX $=1.00$,

IOUT $=0, \quad$ ION $=1$, \$END

10

C060 $113111.00 \mathrm{E}+110 . \quad 0.000$.

\{eor \}

\{eof \}

Figure 3.4-1. Sample Problem One Interactive Session (Continued) 


\section{MAXI - Maximum Annual Dose Calculation Version VAX2.2 25-APR-84 \\ Executed on 3-MAY-84 at $07: 38: 10$.}

Case title: SAMPLE PROBLEM ONE

RADIONUCL IDE CHAIN LTBRARY USED:

DOSE FACTOR FILES USED FOR THIS CASE :

RADIONUCL IDE MASTER DATA LIBRARY /w TRANSLOCATION CLASSES, 6-APR-84 RAP

* 27 ISOSHLD EXTERNAL: ONSITE/BIOPORT EXTERNAL DRFS (BURIED AT 0.5 M) 9-APR

DOSES CALCULATED FROM 10 TO 59 YEARS FOLLOWING TIME ZERO

PATHWAYS INITIAL IZED FOR DOSE CALCULATIONS: FARM PRODUCT INGESTION:
INHALATION OF RESUSPENDED MATERIAL:OFF INHALATION OF RESUSPENDED MATERIAL:OFF

DRINKING WATER INGESTION: OFF

CONTINUING ATMOSPHERIC DEPOSITION OFF

EXTERNAL FROM BURIED WASTES ON

EXTERNAL FROM SURFACE DEPOSITS: OFF

FARM PRODUCT PARAMETERS USED:

FRACTION OF ROOTS IN UPPER SOIL: $0.10 E+01$

FRACTION OF ROOTS IN BURIED WASTE $0.00 E+00$

FRACTION OF TOTAL DIET GROWN ON SITE: $1.00 E+00$

SPECIAL PARAMETERS INITIAL IZED:

INVENTORY DILUTION FACTOR: 2.00E-0

DECAY OF RIVER RELEASE SOURCE TERM NOT PERFORMED

DECAY OF AIR RELEASE SOURCE TERM NOT PERFORMED

SITE X/Q: $\quad 0.00 E+00$

SPECIAL INHALATION MODEL NOT USED

SIZE OF THE SITE: 1.00000 FRACTIONAL HECTARES

INTERNAL PATHWAY AREA CORRECTION FACTOR: $1.00 E+00$ EXTERNAL PATHWAY AREA CORRECTION FACTOR: $1.00 E+00$

EXTERNAL EXPOSURE PARAMETERS USED:

IRRIGATION RATE: $0.00 E+00 \mathrm{~L} / \mathrm{M} * 2 / \mathrm{MO}$

MONTHS PER YEAR IRRIGATED

RIVER DILUTION FACTOR: 1.OOE+OOYR/L

YEARS OF IRRIGATION WITH CONTAMINATED WATER PRIOR TO THE DOSE CALCULATIONS:

RATIO OF EXTERNAL CONTAMINATION IN SURFACE SOIL TO SUBSURFACE SOIL $0.00 E+00$

NUMBER OF HOURS OF EXPOSURE TO EXTERNAL CONTAMINATION 2.00E+03

SURFACE DEPOSITS DRFS FROM ISOSHLD; MODIFICATION FACTOR: $5.844 E-11$

ORGANS FOR WHICH DOSES ARE CALCULATED (SAME OROER AS SOLUBILITIES GIVEN BELOW):

TOTAL BODY

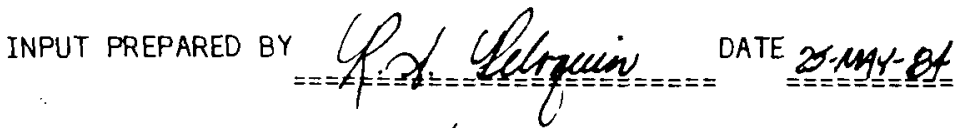

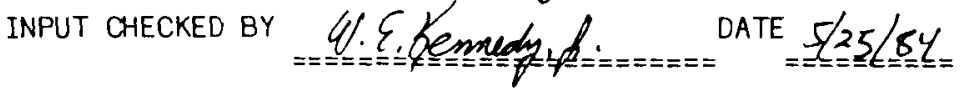

Figure 3.4-2. Sample Problem One Output 


\begin{tabular}{|c|c|c|c|c|c|c|c|}
\hline $\begin{array}{l}\text { RELEASE TERMS } \\
\text { NUCLIDE }\end{array}$ & ORGAN & SOL UBILITY & CLASSES & $\begin{array}{l}\text { SOIL SOURCE } \\
\left(\mathrm{PCI} / M^{* * 3)}\right.\end{array}$ & $\begin{array}{l}\text { IRRIGATATION/AQUATIC } \\
\text { (PCI/L) }\end{array}$ & $\begin{array}{l}\text { DRINKING WATER } \\
(\mathrm{PCI} / \mathrm{L})\end{array}$ & $\begin{array}{l}\text { ATM. RELEASE } \\
(C I / Y R)\end{array}$ \\
\hline 0060 & 1 & 0 & 0 & $2.00 E+10$ & $0.00 E+00$ & $0.00 E+00$ & $0.00 E+00$ \\
\hline
\end{tabular}

\section{$* * * * * * * * * * * * * * * * * *$ *PLESE NOTE ANY SPECIAL CONSIDERATIONS IN THIS SPACE******************** * \\ ****************************************************************************************}

SOIL,AIR, AND WATER CONCENTRATION SUMMARY FOR THE YEAR

$\begin{array}{ccclcc}\text { RADIONUCLIDE } & \begin{array}{c}\text { SURFACE SOIL } \\ \text { PCI/M2 }\end{array} & \begin{array}{c}\text { DEEP SOIL } \\ \text { PCI/M3 }\end{array} & \begin{array}{l}\text { AIR } \\ \text { PCI/M3 }\end{array} & \begin{array}{c}\text { IRRIGATION } \\ \text { PCI/L }\end{array} & \begin{array}{c}\text { DRINKING WATER } \\ \text { PCI/L }\end{array} \\ \text { CO } 60 & 0.00 E+00 & 5.35 E+09 & 0.00 E+00 & 0.00 E+00 & 0.00 E+00\end{array}$

SOIL,AIR, AND WATER CONCENTRATION SUMMARY FOR THE YEAR 59

$\begin{array}{cccccc}\text { RADIONUCLIDE } & \begin{array}{c}\text { SURFACE SOIL } \\ \text { PCI } / M 2\end{array} & \begin{array}{c}\text { DEEP SOIL } \\ \text { PCI/M3 }\end{array} & \begin{array}{l}\text { AIR } \\ \text { PCI/M3 }\end{array} & \begin{array}{c}\text { IRRIGATION } \\ \text { PCI/L }\end{array} & \begin{array}{c}\text { DRINKING WATER } \\ \text { PCI/L }\end{array} \\ \text { CO } 60 & 0.00 \mathrm{E}+00 & 8.38 \mathrm{E}+06 & 0.00 \mathrm{E}+00 & 0.00 \mathrm{E}+00 & 0.00 \mathrm{E}+00\end{array}$

SAMPLE PROBLEM ONE

MAXI, Version VAX2.2 25-APR-84 executed on 3-MAY-84 at $07: 38: 10$

MAXIMUM ANNUAL DOSE SUMMARY FOR THE YEAR 10 FORTOTAL BODY

\begin{tabular}{|c|c|c|c|c|c|c|c|c|c|c|c|}
\hline RADIONUCL IDE & $\begin{array}{l}\text { INGESTION } \\
\text { REM }\end{array}$ & $\begin{array}{l}\text { EXPOSURE } \\
\%\end{array}$ & $\begin{array}{l}\text { PATHWAY } \\
\text { INHAL ATION } \\
\text { REM }\end{array}$ & \% & $\begin{array}{l}\text { EXTERNAL } \\
\text { REM }\end{array}$ & $q$ & $\begin{array}{l}\text { AQUATIC F } \\
\text { REM }\end{array}$ & \% & $\begin{array}{l}\text { DRINKING } \\
\text { REM }\end{array}$ & $\begin{array}{r}\text { NATER } \\
\%\end{array}$ & \\
\hline $\mathrm{cos} 0$ & $0.00 E+00$ & 0 & $0.00 E+00$ & 0 & $3.96 \mathrm{E}-02$ & 100 & $0.00 \mathrm{E}+00$ & 0 & $0.00 E+00$ & 0 & \\
\hline \multirow[t]{2}{*}{ TOTALS } & INGESTION & $\%$ & INHAL ATION & $\%$ & EXTERNAL & $\%$ & AOUATIC & $D \%$ & DRINKING & VATER $\%$ & TOTAL \\
\hline & $0.00 E+00$ & 0 & $0.00 E+00$ & 0 & $3.96 \mathrm{E}-02$ & 100 & $0.00 E+00$ & 0 & $0.00 E+00$ & 0 & $3.96 E-02$ \\
\hline
\end{tabular}

Figure 3.4-2. Sample Problem One Output (Continued) 
This interactive program will assist you in the creation of scenarios for assessment of onsite disposal of lowlevel waste. Doses to man through the specifled pathways will be simulated by the computer program MAXI.

The following notes may be of interest:

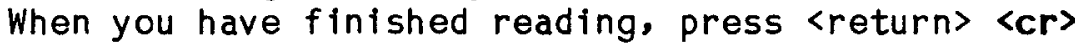

1) If the default condition is selected, you need only press <return>. YES-or-NO questions are designated by $(Y / N)$ and should be answered with a $Y$ or $N$. The default condition is always listed first.

2) The values you enter will be tested against reasonable 1 imits and if they are not accepted you will be asked to supply another value.

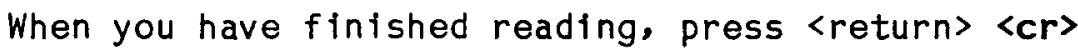

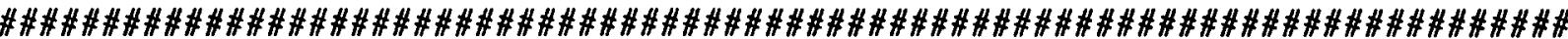

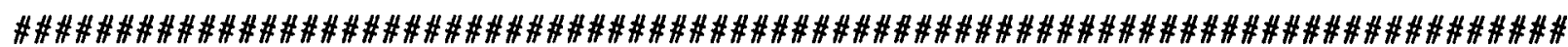

The following scenarios have been defined:

1 - External exposure

2 - External exposure plus inhalation from resuspension

3 - Agricultural activities

4 - Use of well water for irrigation and drinking water

5 - User-created scenario

To select a scenario or for additional information

on a scenario enter $1,2,3,4$, or $5: 2\langle c r\rangle$

\#

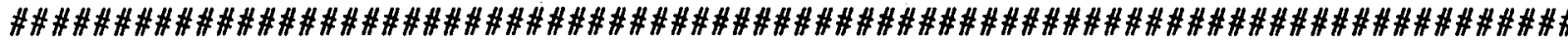

Figure 3.4-3. Sample Problem Two Interactive Session 


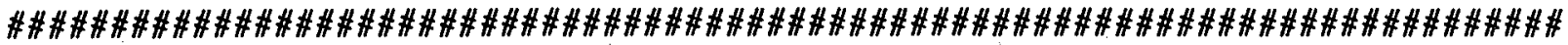

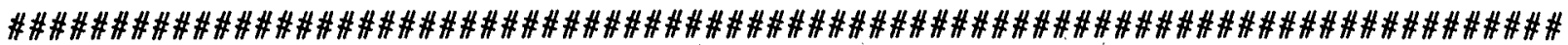

H

$\#$

\#

\#

\#

\#

\#

\#

\#

\#

\#

$\#$

\#

\#\#\#\#\#\#\#\#\#\#\#\#\#\#\#\#\#\#\#\#\#\#\#\#\#\#\#\#\#\#\#\#\#\#\#\#\#\#\#\#\#\#\#\#\#\#\#\#\#\#\#\#\#\#\#\#\#\#\#\#\#\#

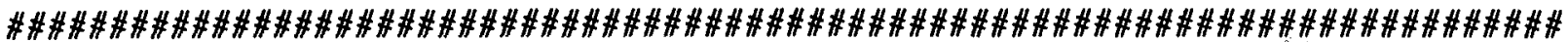

\#

\#

\#

This scenario begins 1 years after the waste is

disposed.

Do you wish to change this value $(N / Y)$ ? $Y\langle c r\rangle$

Enter new value: $10\langle\mathrm{cr}\rangle$

This scenario will end 59 years after the waste is disposed. OK? $(Y / N)\langle C r\rangle$

\section{$\#$}

Enter a descriptive title to identify this case: \#

SAMPLE PROBLEM TWO 〈cr>

Figure 3.4-3. Sample Problem Two Interactive Session (Continued) 
Three types of printer reports are available:

0- Tables of maximum annual dose per organ with radionuclide and pathway contribution

1- Table above plus annual doses by organ and total

2- Table above plus annual doses by organ, pathway and radionuclide\#

The current selection is: 0

Do you wish to change this value $(N / Y)$ ? 〈cr

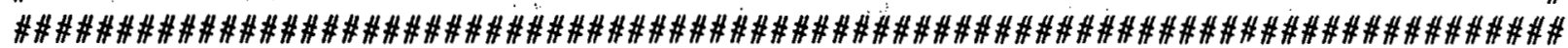

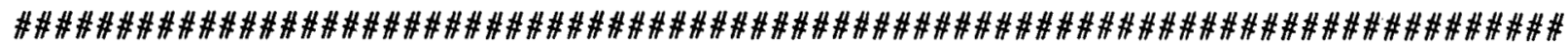

$\#$

$\#$

\#

$\#$

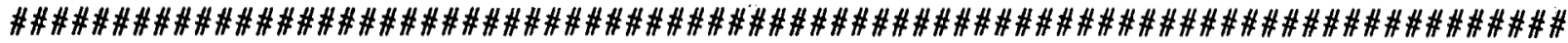

Do you wish to modify any parameter values for Scenario $2(N / Y)$ ? $Y\langle c r\rangle$

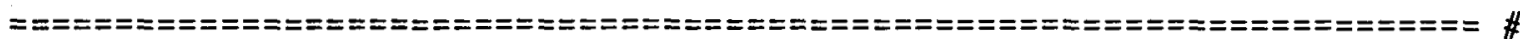

Do you wish to review or change ext. exposure parameters $(N / Y)$ Y $\langle c r\rangle$ \#

Do you wish to review or change ext, exposure parameters

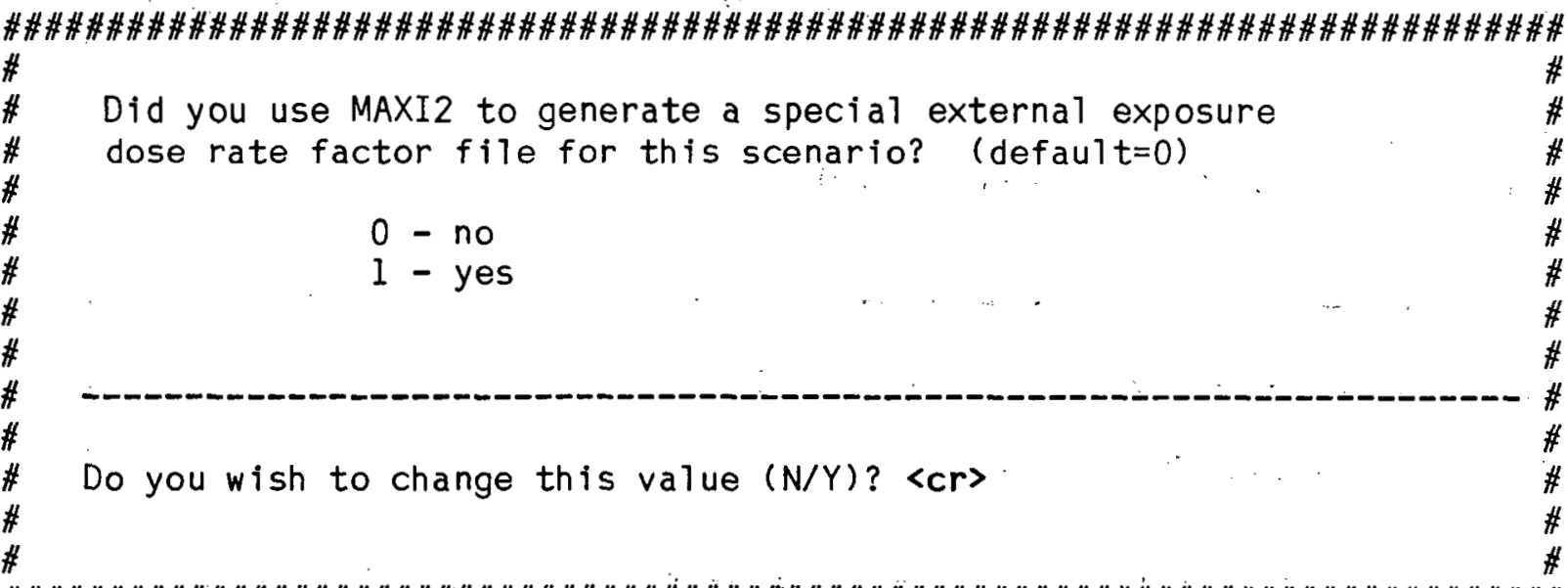

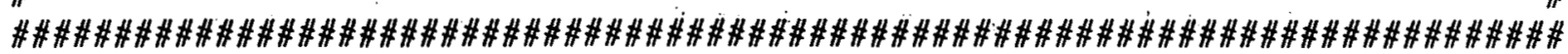

Figure 3.4-3. Sample Problem Two Interactive Session (Continued) 
$\#$

\#

\#

\#

\#

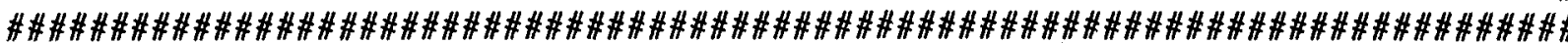

Figure 3.4-3. Sample Problem Two Interactive Session (Continued) 
Two resuspension models are available:

1 - Anspaugh

2 - Mass Loading

The selected model is 1

Do you wish to change this value $(N / Y)$ ? $\langle c r\rangle$

\#

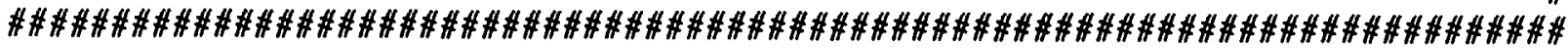

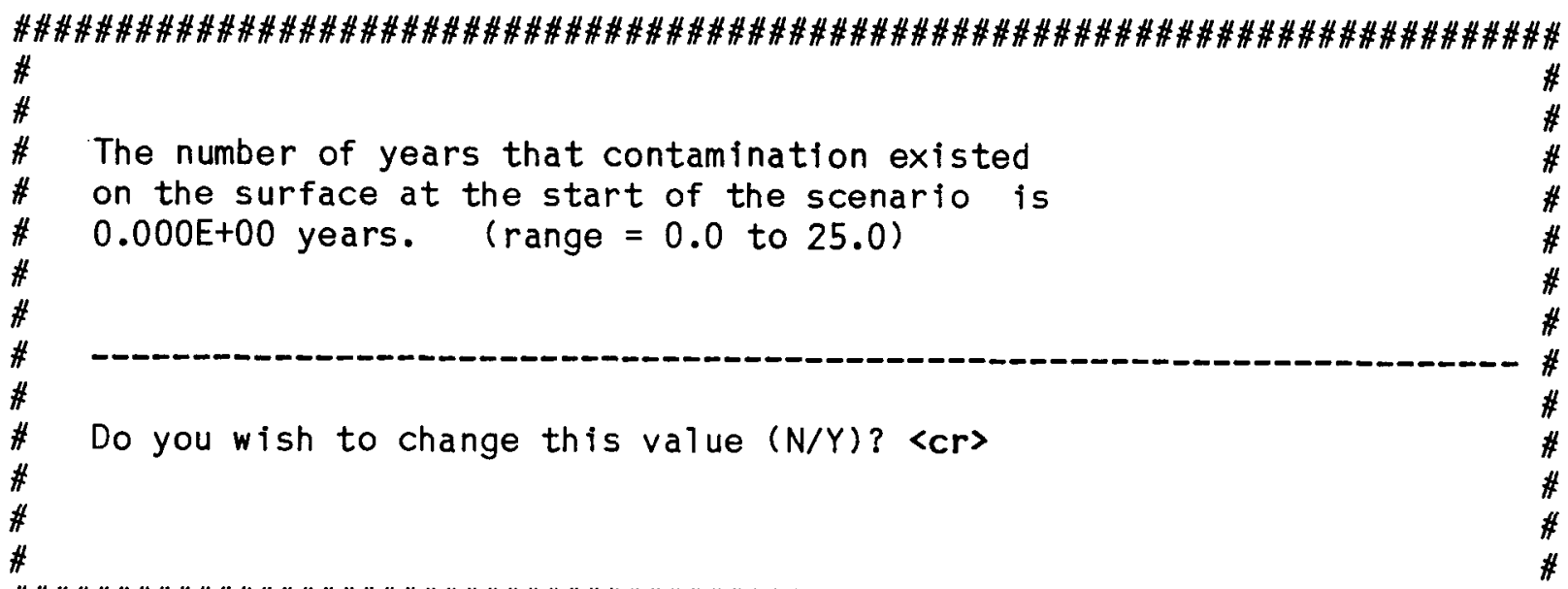

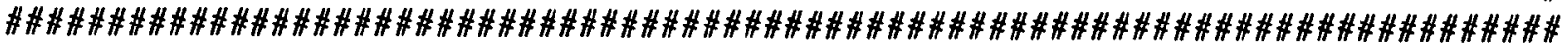

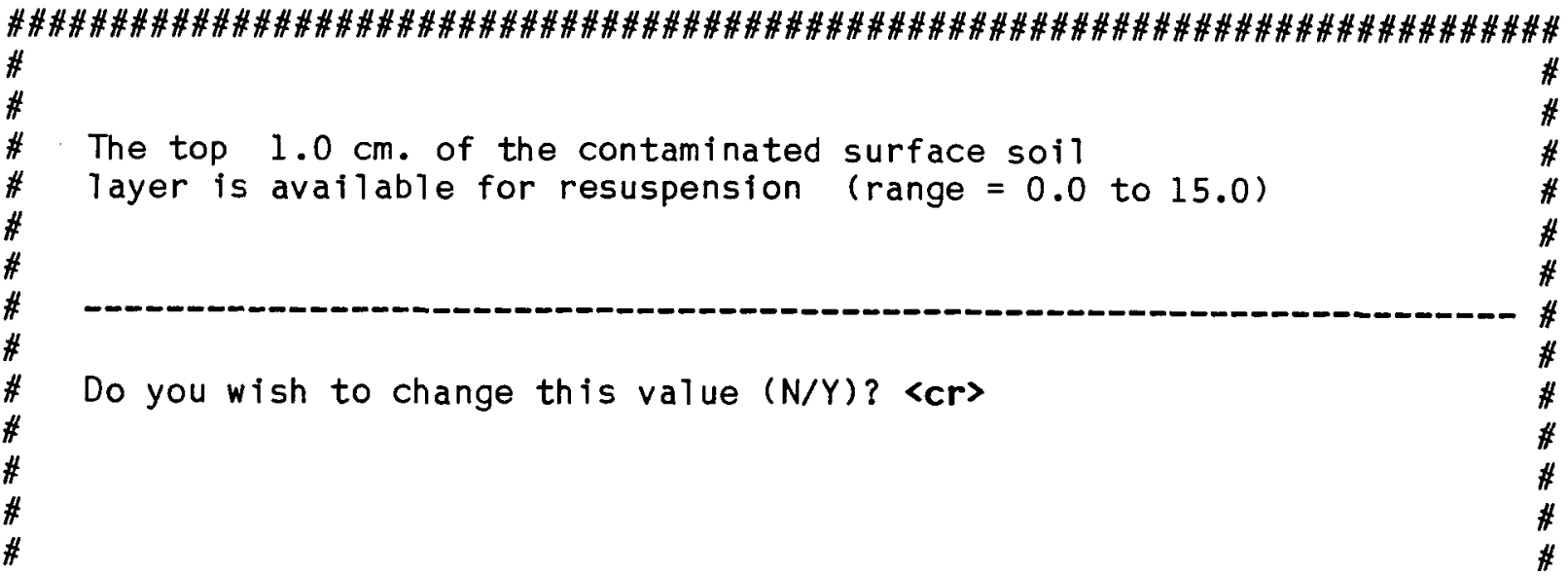

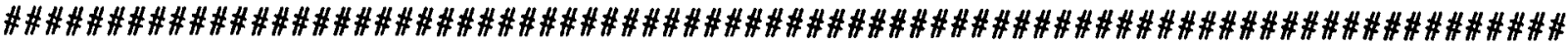

Figure 3.4-3. Sample Problem Two Interactive Session (Continued) 
Do you wish to review or change organ parameters $(N / Y)\langle c r\rangle$

\# The size of the site in terms of fractional hectares

\# (ie., $10000 \mathrm{sq} \mathrm{m}$ ), is 1.00 .

Do you wish to change this value $(\mathrm{N} / \mathrm{Y})$ ? $\langle\mathrm{cr}\rangle$

The inventory will automatically be adjusted by the appropriate area correction factor for each exposure pathway based on a site size of 1.00 hectares.

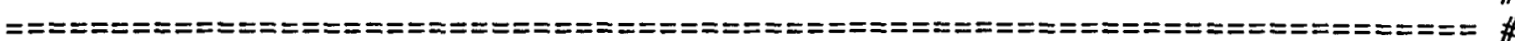

Do you wish to review or change the above parameters $(N / Y)\langle c r\rangle$ \# \#

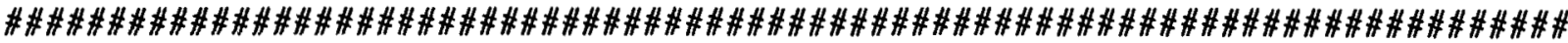

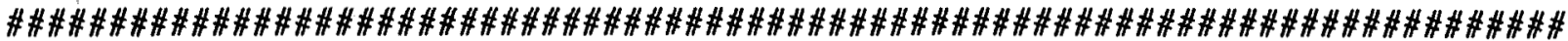

\#

\#

The surface/buried inventory may be entered as:

$$
\begin{aligned}
& 1-\mathrm{pCi} \\
& 2-\mathrm{uCi} \\
& 3-\mathrm{mCi} \\
& 4-\mathrm{Ci}
\end{aligned}
$$

The currect selection is: 1

Do you wish to change this value $(N / Y)$ ? $Y\langle c r\rangle$

Enter new value: $4\langle\mathrm{cr}\rangle$

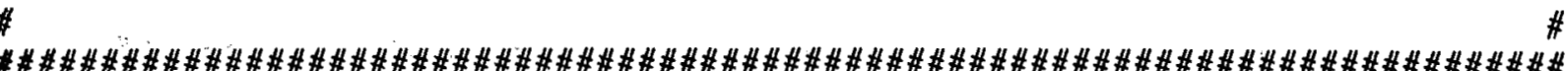

Figure 3.4-3." Sample Problem Two Interactive Session (Continued) 


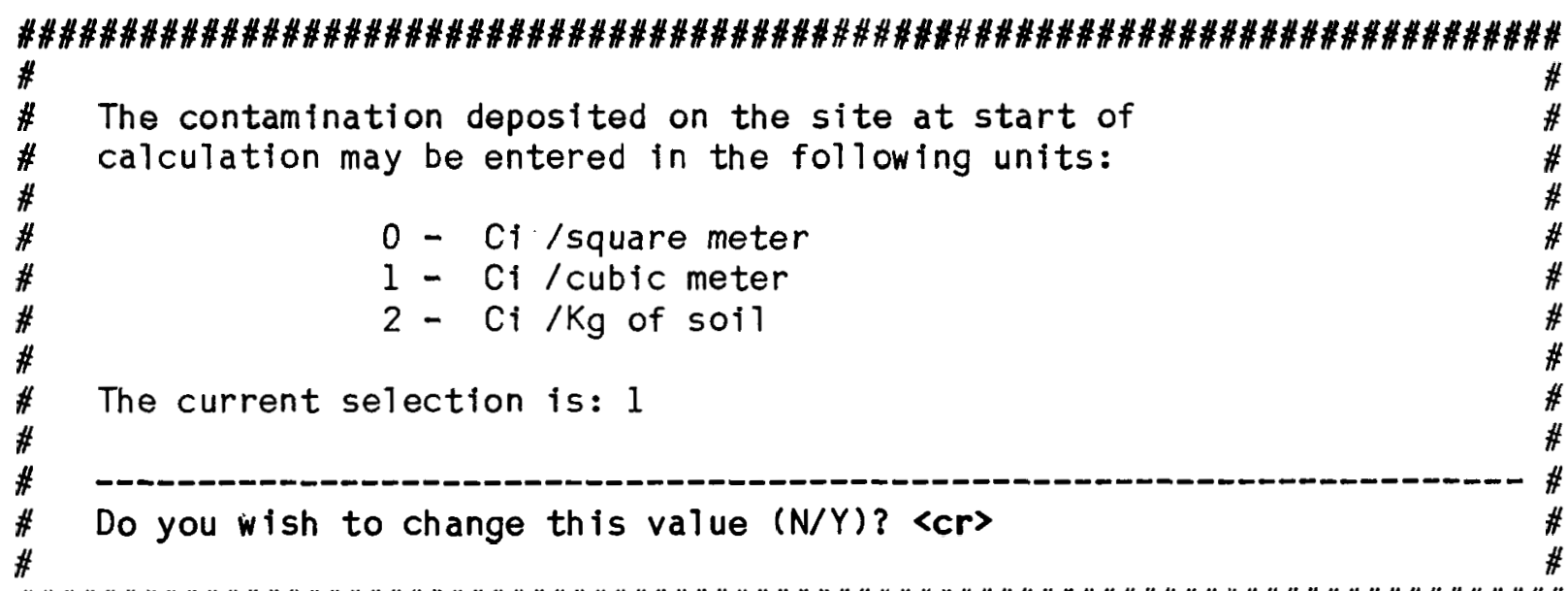

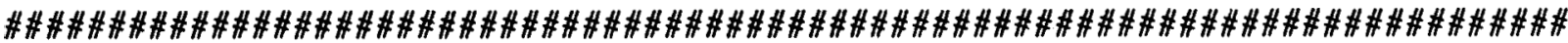

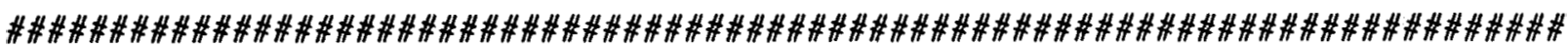

\# \#

\# The surface/buried inventory dilution factor is: 0.20 \#

\# (range $=0.0$ to $1.0 \mathrm{E}+20)$

\#

\# Do you wish to change this value $(N / Y)$ ? <cr> \#

\#

\#

Do you wish to review or change any of the above parameters $(N / Y)\langle c r\rangle$ \#

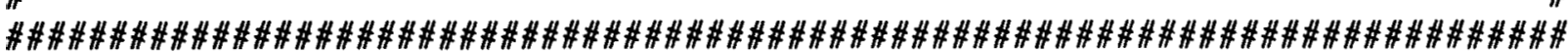

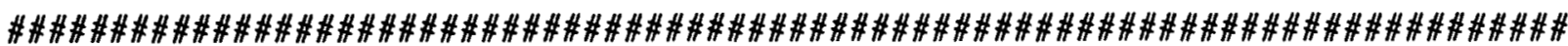

$\#$

\#

\#

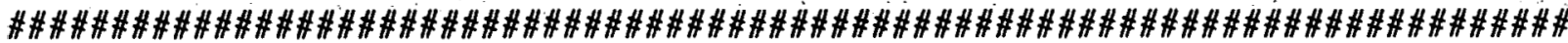

Figure 3.4-3. Sample Problem Two Interactive Session (Continued)

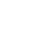




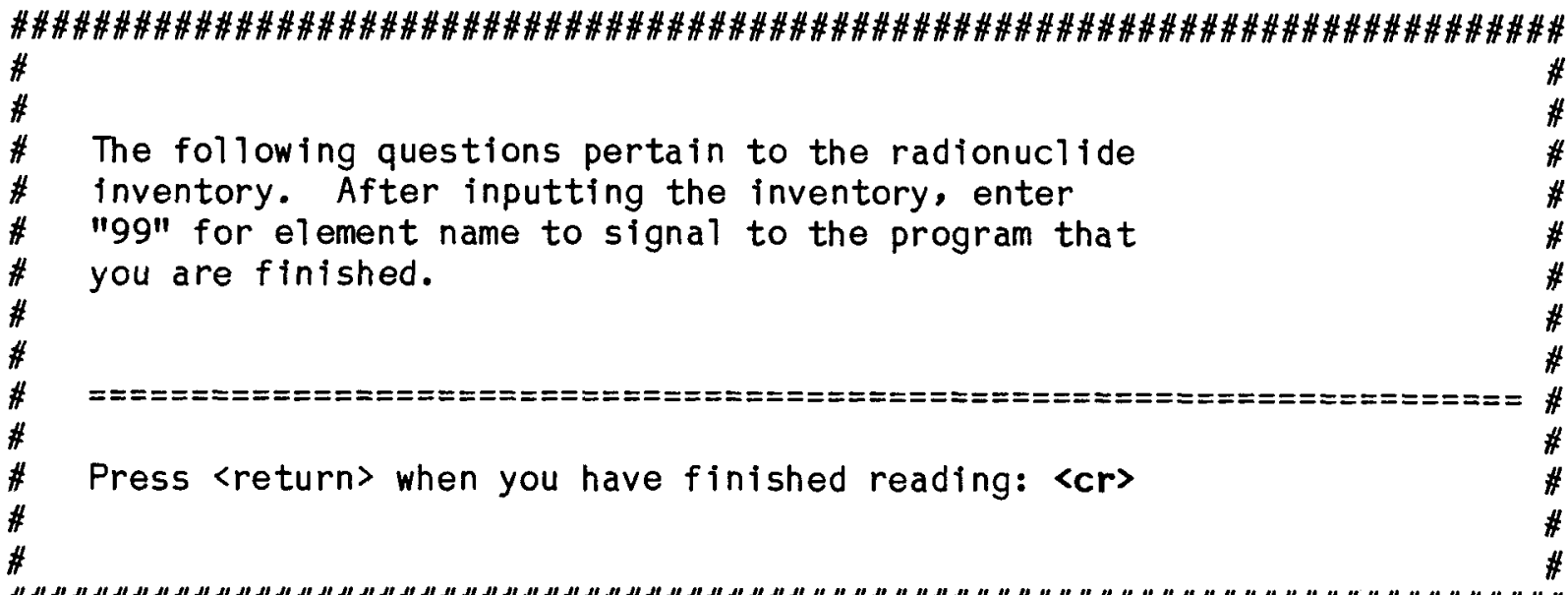

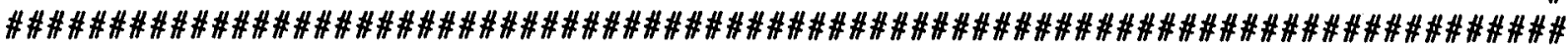

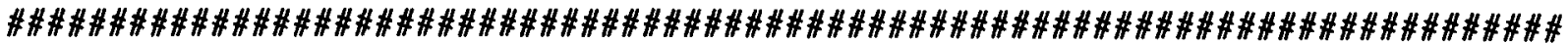

$\#$

\#

$\#$

\#

Enter new 2-character element (99=finished): CO 〈cr

Atomic number input can be up to 6 characters 1 ong.

Include metastable $(M)$ and daughter $(+D)$ designation, (i.e., TE127M+D) \#

Enter atomic number: $60\langle c r\rangle$

Enter the quantity of $\mathrm{CO} 60$ deposited on the site at start of calculation (units: Ci /cubic meter ) : .1 〈cr〉

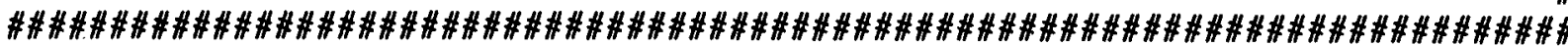

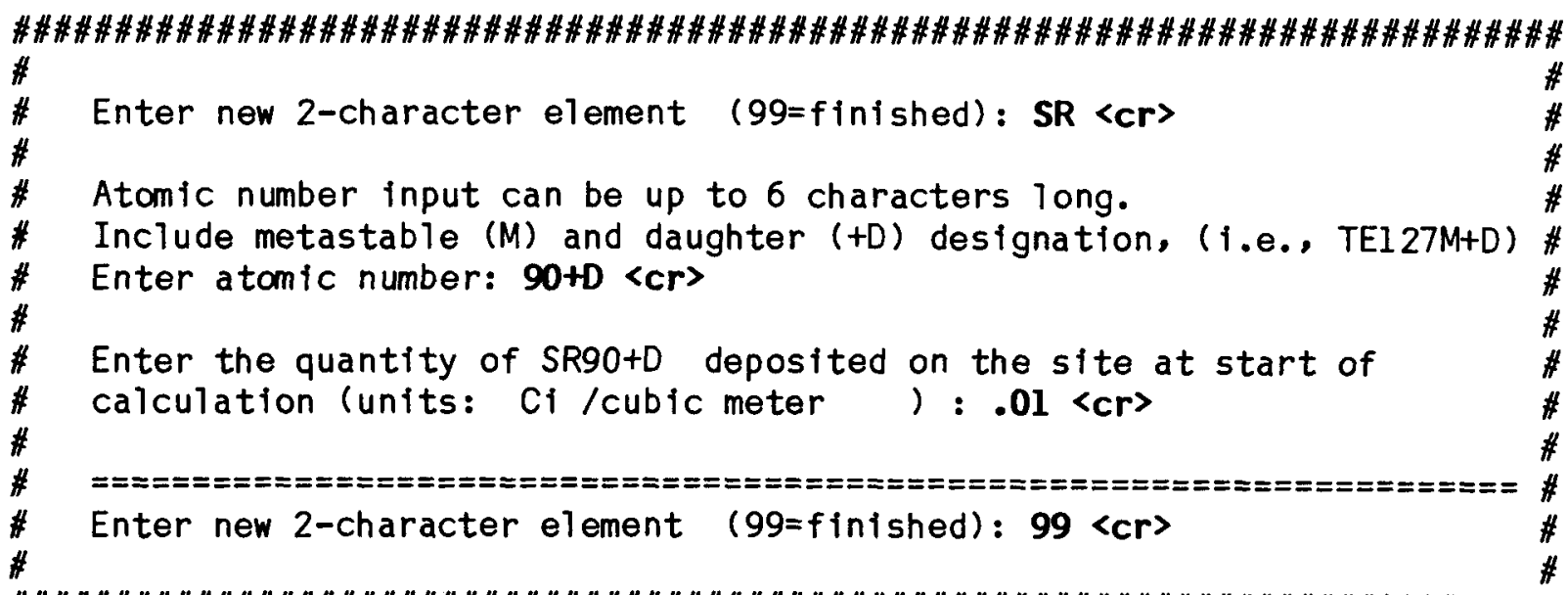

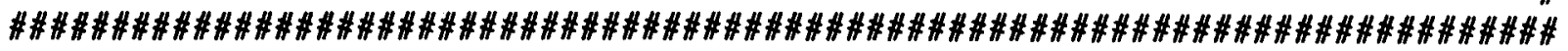

Figure 3.4-3. Sample Problem Two Interactive Session (Continued) 
(The above interactive session generates the following file.)

account-name, STMFZ, CMI60000,EC400,T177.

ACCOUNT, account-name, prob 1 em-number, prob 1 em-number.

ATTACH, TAPE $20, F I L E 20$, ID =ZZRNRC.

ATTACH, TAPE21, FILE21, ID =ZZRNRC.

ATTACH, TAPE24, FILE24, ID =ZZRNRC.

ATTACH, TAPE25, FILE25, ID =ZZRNRC.

ATTACH, TAPE22, PL ANSOURC, ID=ZZRNRC.

ATTACH, TAPE27, VOLSOURC, ID =ZZRNRC.

ATTACH, TAPE 10, RMDL IB, ID=ZZRNRC.

ATTACH, TAPE23, FILE23, ID=ZZRNRC.

ATTACH, ABS, MAXI I ABS, ID=ZZRNRC.

COPY, ABS, LGO.

RETURN, ABS.

$M A P, O F F$.

LDSET, PRESET=ZERO.

LGO.

\{eor \}

SAMPLE PROBLEM TWO

\$INPUT NEXT $=1$,

IFOD $=0$, IARG $=0$, IWAT $=0$, IEXT $=1$, ISUR $=0, I A I R=0, R P F I=0$, RPF $2=1.00$,

$A G E=0 ., X D P T=.670 E-01, R I N H=.342231, D I L F=1.00, X F 2=.300 E+04$,

$M 3 M 2=1, \quad I N T R U D=0, I 22=0$,

$I T I=10, I T 2=59, N O R G=5, \operatorname{KORG}(1)=1,6,8,16,23$,

SRDIL $=.200 \quad$, FRSIZ $=1.00 \quad$, AREAIN $=1.00$,

AREAEX $=1.00$, IOUT $=0$, ION $=1, \$ E N D$

20

$\begin{array}{llllll}\mathrm{C} 060 & 11311 & 1.00 E+11 & 0 . & 0 . & 0 .\end{array}$

SR90+D $113111.00 E+10$ 0. 0.0.

\{eor \}

\{eof \}

Figure 3.4-3. Sample Problem Two Interactive Session (Continued) 
MAXI - Maximum Annual Dose Calculation Version VAX2.2 25-APR-84

Executed on 3-MAY-84 at $07: 40: 56$.

Case title:SAMPLE PROBLEM TWO

RADIONUCLIDE CHAIN LIBRARY USED:

DOSE FACTOR FILES USED FOR THIS CASE:

* 23 DACRIN-INHAL ATION: DOS: DOSE INCREMENT FILE ONSITE/BIOPORT ENV 16-APR-84 RAP

* 27 ISOSHLD EXTERNAL: ONSITE/BIOPORT VOLUME SOURCE SURFACE EXTERNAL DRFS

DOSES CALCULATED FROM 10 TO 59 YEARS FOLLOWING TIME ZERO

PATHWAYS INITIALIZED FOR DOSE CALCULATIONS:

FARM PRODUCT INGESTION: OFF

INHALATION OF RESUSPENDED MATERIAL :ON

AQUATIC FOODS INGESTION: OFF

DRINKING WATER INGESTION: OFF

CONTINUING ATMOSPHERIC DEPOSITION OFF

$\begin{array}{lll}\text { EXTERNAL FROM BURIED WASTES } & \text { ON } \\ \text { EXTERNAL FROM SURFACE DEPOSITS: } & \text { OFF }\end{array}$

FARM PRODUCT PARAMETERS USED:

FRACTION OF ROOTS IN UPPER SOIL: $0.10 E+01$

FRACTION OF ROOTS IN BURIED WASTE $0.00 \mathrm{E}+00$

FRACTION OF TOTAL DIET GROWN ON SITE: $1.00 E+00$

SPECIAL PARAMETERS INITIAL IZED:

INVENTORY DILUTION FACTOR: 2.00E-01

DECAY OF RIYER RELEASE SOURCE TERM NOT PERFORMED

DECAY OF AIR RELEASE SOURCE TERM NOT PERFORMED

SITE X/Q: $\quad 0.00 \mathrm{E}+00$

SPECIAL INHALATION MODEL NOT USED

SIZE OF THE SITE: 1.00000 FRACTIONAL HECTARES

INTERNAL PATHWAY AREA CORRECTION FACTOR: 1.00E+00

EXTERNAL PATHWAY AREA CORRECTION FACTOR: $1.00 E+00$

IRRIGATION RATE: $0.00 \mathrm{E}+00 \mathrm{~L} / \mathrm{M} * * 2 / \mathrm{MO}$

MONTHS PER YEAR IRRIGATED:

RIVER DILUTION FACTOR: 1.00E+0OYR/L

YEARS OF IRRIGATION WITH CONTAMINATED WATER PRIOR TO

THE DOSE CALCULATIONS:

EXTERNAL EXPOSURE PARAMETERS USED

RATIO OF EXTERNAL CONTAMINATION IN SURFACE SOIL TO SUBSURFACE SOIL 1.00E+O0

NUMBER OF HOURS OF EXPOSURE TO EXTERNAL CONTAMINATION $3.00 E+03$

SURFACE DEPOSITS DRFS FROM ISOSHLD; MODIFICATION FACTOR: $5.844 E-11$

INHALATION PARAMETERS USED:

MODIFICATION FACTOR, RINH: $3.42 E-01$

(EQUIVALENT TO BREATHING RATE OF $230 \mathrm{CC} / \mathrm{SEC}$ FOR 3000. HR/YR)

RESUSPENSION MODEL USED FOR CALCULATING AIR CONCENTRATION: ANSPAUGH

AVERAGE AGE OF MATERIAL ON GROUND AT TIME ZERO: $0.00 E+00$ YEARS

TOP $1.0 \mathrm{CM}$ OF THE CONTAMINATED SURFACE LAYER IS AVAILABLE FOR RESUSPENSION.

ORGANS FOR WHICH DOSES ARE CALCULATED (SAME ORDER AS SOLUBILITIES GIVEN BELOW):
TOTAL BODY
BONE
LUNGS
THYROID
GI-LLI ,

Figure 3.4-4. Sample Problem Two Output 


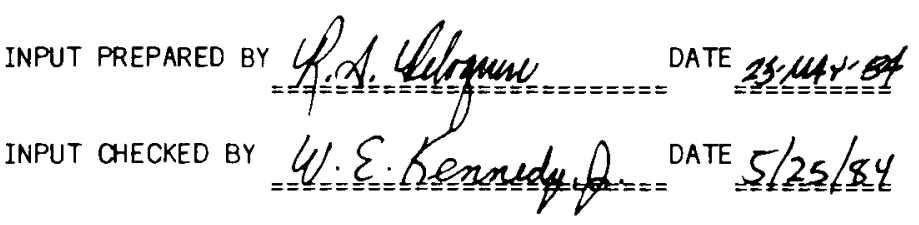

\begin{tabular}{|c|c|c|c|c|c|c|c|}
\hline $\begin{array}{l}\text { RELEASE TERMS } \\
\text { NUCL IDE }\end{array}$ & ORGAN & SOLUBIL IT & TY CLASSES & $\begin{array}{l}\text { SOIL SOURCE } \\
\left(\mathrm{PCI} / M^{* * 3}\right)\end{array}$ & $\begin{array}{c}\text { IRRIGATATION/AQUATIC } \\
\text { (PCI } / \mathrm{L})\end{array}$ & $\begin{array}{l}\text { DRINKING WATER } \\
(P C I / L)\end{array}$ & $\begin{array}{l}\text { ATM. RELEASE } \\
\text { (CI/YR) }\end{array}$ \\
\hline CO 60 & 1 & 1 & 1 & $2.00 E+10$ & $0.00 E+00$ & $0.00 \mathrm{E}+00$ & $0.00 E+00$ \\
\hline SR $90+D$ & 1 & 1 & 1 & $2.00 E+09$ & $0.00 E+00$ & $0.00 E+00$ & $0.00 E+00$ \\
\hline
\end{tabular}

SOIL, AIR, AND WATER CONCENTRATION SUMMARY FOR THE YEAR 10

$\begin{array}{cccccc}\text { RADIONUCLIDE } & \begin{array}{c}\text { SURFACE SOIL } \\ \text { PCI/M2 }\end{array} & \begin{array}{c}\text { DEEP SOIL } \\ \text { PCI } / M 3\end{array} & \begin{array}{l}\text { AIR } \\ \text { PCI/M3 }\end{array} & \begin{array}{c}\text { IRRIGATION } \\ \text { PCI/L }\end{array} & \begin{array}{c}\text { DRINKING WATER } \\ \text { PCI } / L\end{array} \\ \text { C0 } 60 & & & & & \\ \text { SR } 90+D & 2.03 E+08 & 5.35 E+09 & 5.38 E+03 & 0.00 E+00 & 0.00 E+00 \\ & 2.35 E+08 & 1.57 E+09 & 1.58 E+03 & 0.00 E+00 & 0.00 E+00\end{array}$

SOIL,AIR, AND WATER CONCENTRATION SUMMARY FOR THE YEAR 59

$\dot{\omega}$

\begin{tabular}{|c|c|c|c|c|c|}
\hline RADIONUCL IDE & $\begin{array}{c}\text { SURFACE SOIL } \\
\text { PCI /M2 }\end{array}$ & $\begin{array}{l}\text { DEEP SOIL } \\
\mathrm{PCI} / \mathrm{M} 3\end{array}$ & $\begin{array}{l}\text { AIR } \\
\mathrm{PCI} / \mathrm{M3}\end{array}$ & $\begin{array}{l}\text { IRRIGATION } \\
\text { PCI } / \mathrm{L}\end{array}$ & $\begin{array}{c}\text { DRINKING WATER } \\
\text { PCI/L }\end{array}$ \\
\hline$\infty \begin{array}{ll}\infty & 60 \\
& 0\end{array}$ & $1.26 \mathrm{E}+06$ & $8.38 E+06$ & $8.42 \mathrm{E}-05$ & $0.00 E+00$ & $0.00 E+00$ \\
\hline SR $90+D$ & $7.14 \mathrm{E}+07$ & $4.76 E+08$ & $4.78 E-03$ & $0.00 E+00$ & $0.00 E+00$ \\
\hline
\end{tabular}

SAMPLE PROBLEM TWO

MAXI, Version VAX2.2 25-APR-84 executed on 3-MAY-84 at 07:40:56

MAXIMUM ANNUAL DOSE SUMMARY FOR THE YEAR 10 FORTOTAL BODY

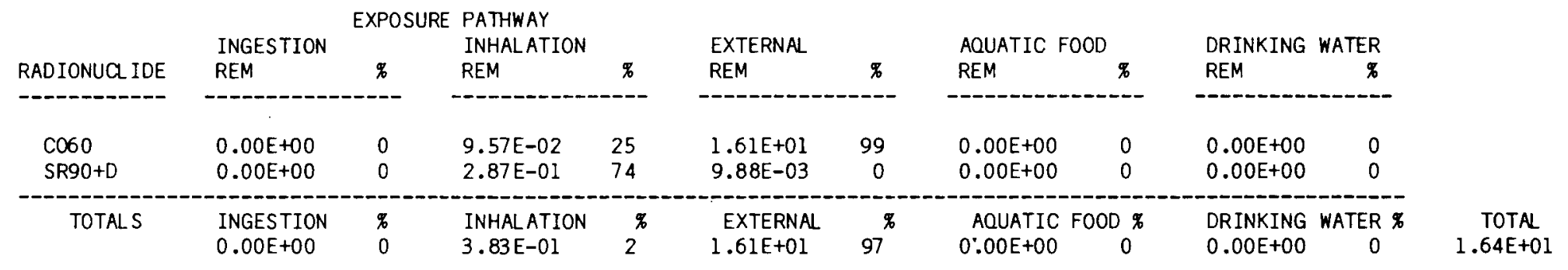

Figure 3.4-4. Sample Problem Two Output (Continued) 
MAXIMUM ANNUAL DOSE SUMMARY FOR THE YEAR 11 FOR BONE

\begin{tabular}{|c|c|c|c|c|c|c|c|c|c|c|c|}
\hline RADIONUCL IDE & $\begin{array}{l}\text { INGESTION } \\
\text { REM }\end{array}$ & $\begin{array}{l}\text { EXPOSURE } \\
x\end{array}$ & $\begin{array}{l}\text { PATHWAY } \\
\text { INHALATION } \\
\text { REM }\end{array}$ & $\mathscr{q}$ & $\begin{array}{l}\text { EXTERNAL } \\
\text { REM }\end{array}$ & $\%$ & $\begin{array}{l}\text { AQUATIC } \\
\text { REM }\end{array}$ & 罗 & $\begin{array}{l}\text { DRINKING } \\
\text { REM }\end{array}$ & $\begin{array}{r}\text { WATER } \\
\%\end{array}$ & \\
\hline $\begin{array}{l}\text { CO60 } \\
\text { SR90+D }\end{array}$ & $\begin{array}{l}0.00 E+00 \\
0.00 E+00\end{array}$ & $\begin{array}{l}0 \\
0\end{array}$ & $\begin{array}{l}0.00 E+00 \\
8.33 E+00\end{array}$ & $\begin{array}{r}0 \\
100\end{array}$ & $\begin{array}{l}1.41 E+01 \\
9.64 E-03\end{array}$ & $\begin{array}{r}99 \\
0\end{array}$ & $\begin{array}{l}0.00 E+00 \\
0.00 E+00\end{array}$ & $\begin{array}{l}0 \\
0\end{array}$ & $\begin{array}{l}0.00 E+00 \\
3.00 E+00\end{array}$ & $\begin{array}{l}0 \\
0\end{array}$ & \\
\hline \multirow[t]{2}{*}{ TOTALS } & INGESTION & $\%$ & INHAL ATION & $\%$ & EXTERNAL & $\%$ & AQUATIC & D \% & DRINKING & WATER $\%$ & TOTAL \\
\hline & $0.00 E+00$ & 0 & $8.33 E+00$ & 37 & $1.41 E+0 I$ & 62 & $0.00 E+00$ & 0 & $0.00 E+00$ & 0 & $2.24 E+01$ \\
\hline
\end{tabular}

MAXIMUM ANNUAL DOSE SUMMARY FOR THE YEAR II FOR LUNGS

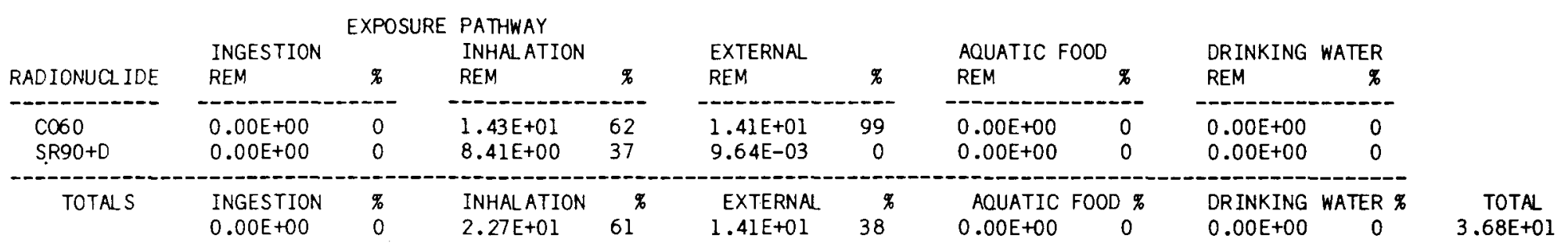

MAXIMUM ANNUAL DOSE SUMMARY FOR THE YEAR 10 FOR THYROID

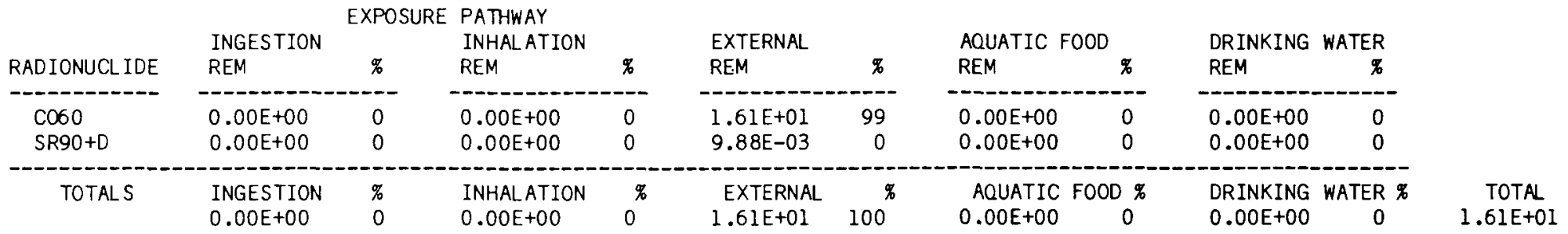

MAXIMUM ANNUAL DOSE SUMMARY FOR THE YEAR 10 FOR LLI

\begin{tabular}{|c|c|c|c|c|c|c|c|c|c|c|c|}
\hline RADIONUCL IDE & $\begin{array}{l}\text { INGESTION } \\
\text { REM }\end{array}$ & XPO & $\begin{array}{l}\text { PATHWAY. } \\
\text { INHALATION } \\
\text { REM }\end{array}$ & $\mathscr{0}$ & $\begin{array}{l}\text { EXTERNAL } \\
\text { REM }\end{array}$ & $\mathscr{\phi}$ & $\begin{array}{l}\text { AQUATIC } \\
\text { REM }\end{array}$ & D & $\begin{array}{l}\text { DRINKING } \\
\text { REM }\end{array}$ & $\begin{array}{r}\text { WATER } \\
\%\end{array}$ & \\
\hline $\begin{array}{l}\mathrm{C} 060 \\
\mathrm{SR} 90+\mathrm{D}\end{array}$ & $\begin{array}{l}0.00 E+00 \\
0.00 E+00\end{array}$ & $\begin{array}{l}0 \\
0\end{array}$ & $\begin{array}{l}8.65 \mathrm{E}-02 \\
4.48 \mathrm{E}-02\end{array}$ & $\begin{array}{l}65 \\
34\end{array}$ & $\begin{array}{l}1.61 \mathrm{E}+01 \\
9.88 \mathrm{E}-03\end{array}$ & $\begin{array}{r}99 \\
0\end{array}$ & $\begin{array}{l}0.00 E+00 \\
0.00 E+00\end{array}$ & $\begin{array}{l}0 \\
0\end{array}$ & $\begin{array}{l}0.00 \mathrm{E}+00 \\
0.00 \mathrm{E}+00\end{array}$ & $\begin{array}{l}0 \\
0\end{array}$ & \\
\hline TOTALS & $\begin{array}{l}\text { INGESTION } \\
0.00 \mathrm{E}+00\end{array}$ & $\begin{array}{l}\% \\
0\end{array}$ & $\begin{array}{l}\text { INHALATION } \\
1.31 \mathrm{E}-01\end{array}$ & 0 & $\begin{array}{l}\text { EXTERNAL } \\
1.61 \mathrm{E}+01\end{array}$ & $99^{\circ}$ & $\begin{array}{l}\text { AQUATIC } \\
0.00 E+00\end{array}$ & $\begin{array}{c}00 \% \\
0\end{array}$ & $\begin{array}{l}\text { DRINKING } \\
0.00 \mathrm{E}+00\end{array}$ & $\begin{array}{c}\text { WATER } \% \\
0\end{array}$ & $\begin{array}{c}\text { TOTAL } \\
1.62 E+01\end{array}$ \\
\hline
\end{tabular}

Figure 3.4-4. Sample Problem Two Output (Continued) 


\subsubsection{Sample Problem Three}

The third sample is designed to exercise the agricultural exposure scenario. For this problem, a licensee is assymed to dispose of $50 \mathrm{~m}^{3}$ of waste containing $0.1 \mathrm{Ci} / \mathrm{m}^{3}$ of both ${ }^{6} \mathrm{Co}$ and ${ }^{3} 3{ }^{\mathrm{Cs}^{+} \mathrm{D}}$, and $0.01 \mathrm{Ci} / \mathrm{m}^{3}$ of $90 \mathrm{Sr}+\mathrm{D}$. Default conditions are assumed except that only 0.05 ha is assumed to be contaminated by the disposal of wastes. Sample Problem Three is to determine the doses to the intruder 10 years after the wastes are buried. The solution is found by running the ONSITE agricultural scenario with the specified conditions and waste inventory. A summary of the ONSITE interactive session used to develop the runstream for Sample Problem Three is shown in Figure 3.4-5. The output resulting for this sample problem is shown in Figure 3.4-6. The maximum annual doses resulting for this sample problem are about $22 \mathrm{rem} / \mathrm{yr}$ to total body, $56 \mathrm{rem} / \mathrm{yr}$ to bone, $20 \mathrm{rem} / \mathrm{yr}$ to 1ungs, $13 \mathrm{rem} / \mathrm{yr}$ to thyroid, and $17 \mathrm{rem} / \mathrm{yr}$ to GI(LLI). Doses to total body, and bone are controlled by ingestion of farm crops, while the doses to lungs, thyroid, and GI(LLI) are controlled by external exposure. Hand calculations verified the code operation in calculating radioactive decay, soil concentrations, air concentrations, external dose, inhalation dose, and ingestion dose from consumption of garden crops.

\subsubsection{Sample Problem Four}

The fourth sample problem is designed to exercise the irrigation/drinkingvater scenario. For this problem, a licensee is assumed to dispose of wastes that result in $60_{C},{ }^{129}{ }_{I}, 90 S r+D$, and $238 \mathrm{U}+D$ in an offsite well. The water concentrations are $10 \mathrm{pCi} / \mathrm{L}$ of each radionuclide. In addition, an offsite river-water concentration of $0.1 \mathrm{pCi} / \mathrm{L}$ of each of these radionuclides is assumed. The individual is assumed to use the well water for drinking and the river water for irrigation. The sample problem is to determine the doses that result to this individual from using these contaminated water sources. The solution is found by running the ONSITE irrigation/drinking-water scenario with the specified conditions and source terms. A summary of the ONSITE interactive session used to develop the runstream for Sample Problem Four is shown in Figure 3.4-7. The output resulting for this sample problem is shown in Figure 3.4-8. The maximum annual doses resulting for Sample Problem Four are about $0.0016 \mathrm{rem} / \mathrm{yr}$ to total body, $0.0077 \mathrm{rem} / \mathrm{yr}$ to bone $8.0 \times 10^{-6} \mathrm{rem} / \mathrm{yr}$ to lungs, $0.028 \mathrm{rem} / \mathrm{yr}$ to thyroid, and $3.5 \times 10^{-4} \mathrm{rem} / \mathrm{yr}$ to $\mathrm{GI}(\mathrm{LII})$. Hand calculations verified the code operation for all of the decay, radionuclide concentrations and dose estimates for all of the exposure pathways considered. 
This interactive program w111 assist you in the creation of scenarios for assessment of onsite disposal of lowlevel waste. Doses to man through the specifled pathways will be simulated by the computer program MAXI.

The following notes may be of interest:

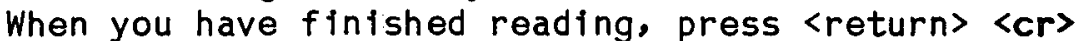

1) If the default condition is selected, you need only press <return>. YES-Or-NO questions are designated by $(Y / N)$ and should be answered with a $Y$ or $N$. The default condition is always listed first.

2) The values you enter will be tested against reasonable limits and if they are not accepted you will be asked to supply another value.

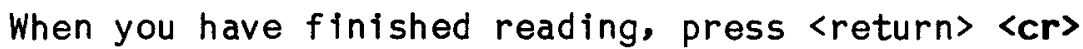

\#

\#

\#

\#

\#

\#

\#

\#

\#

\#

\#

\#

\#

The following scenarios have been defined:

1 - External exposure

2 - External exposure plus inhalation from resuspension

3 - Agricultural activities

4 - Use of well water for irrigation and drinking water

5 - User-created scenario

To select a scenario or for additional information

on a scenario enter $1,2,3,4$, or $5: 3\langle\mathrm{cr}\rangle$

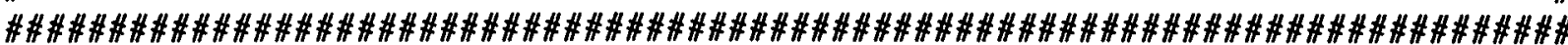

Figure 3.4-5. Sample Problem Three Interactive Session 


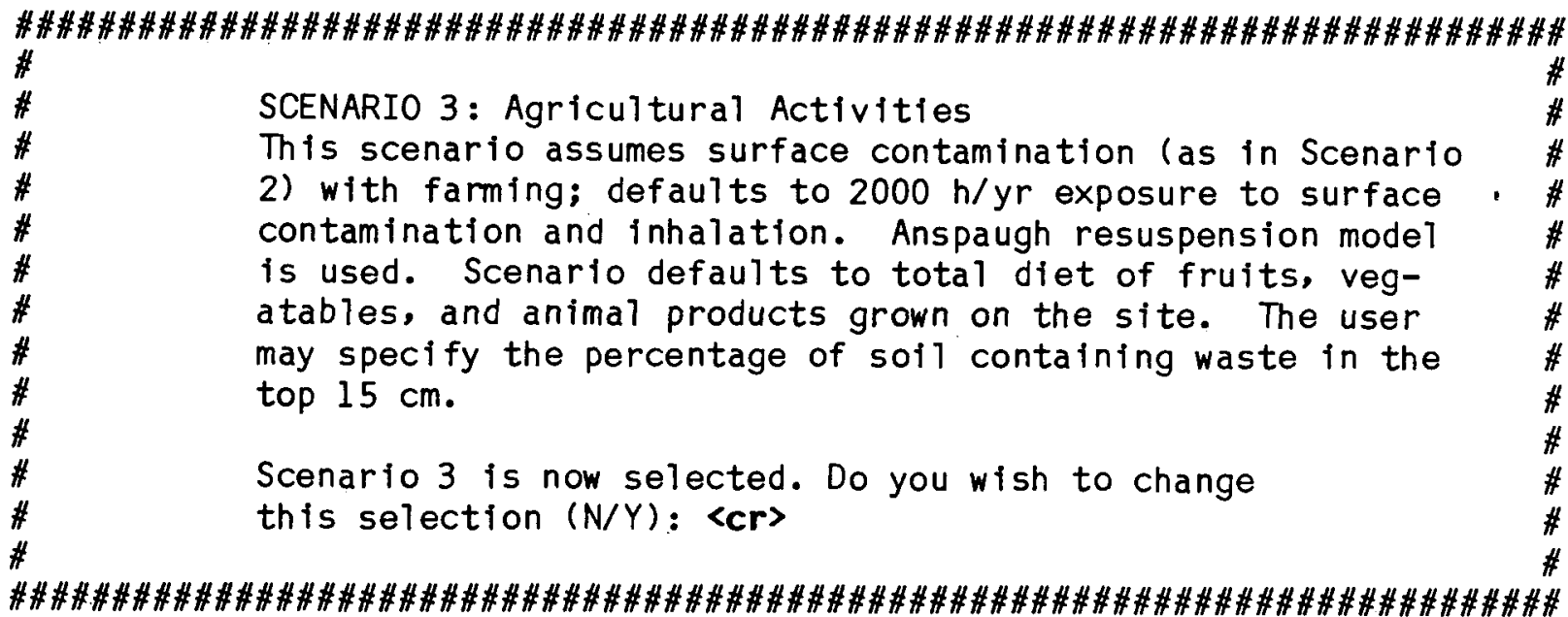

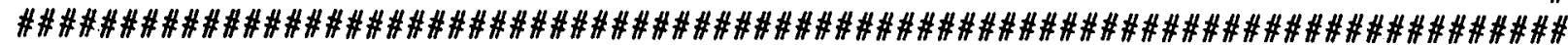

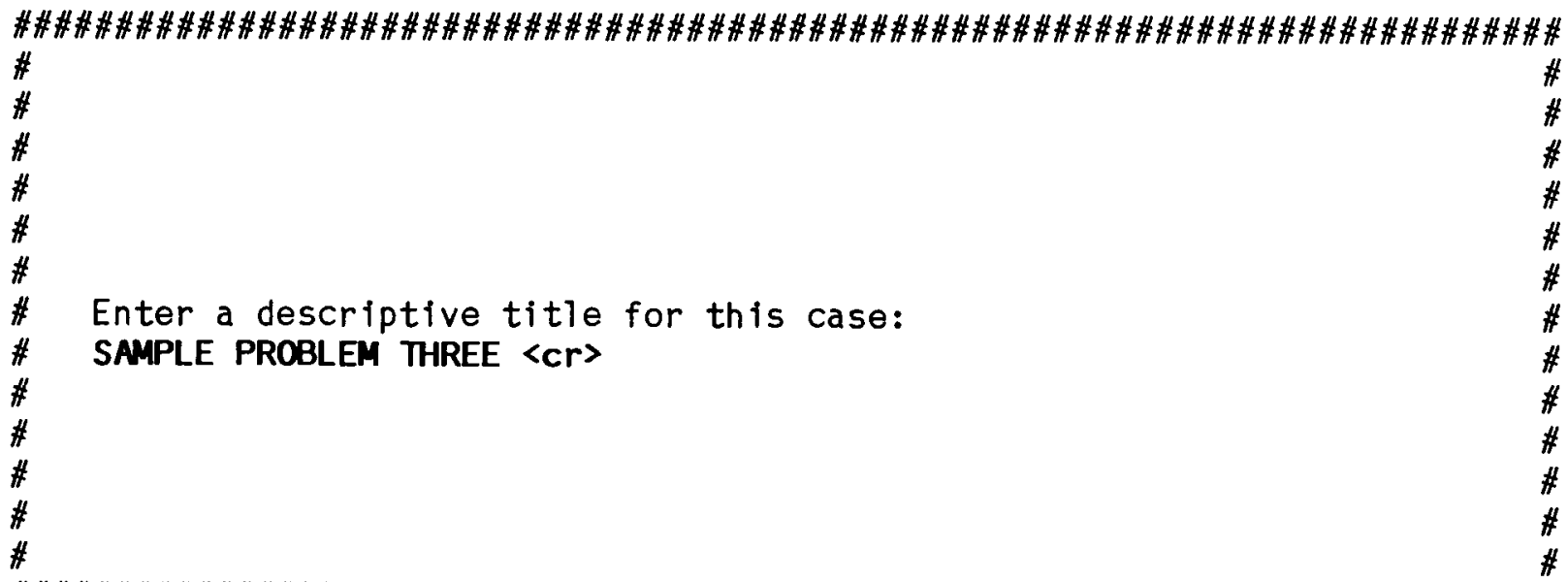

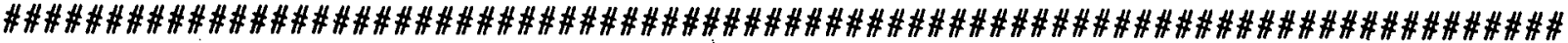

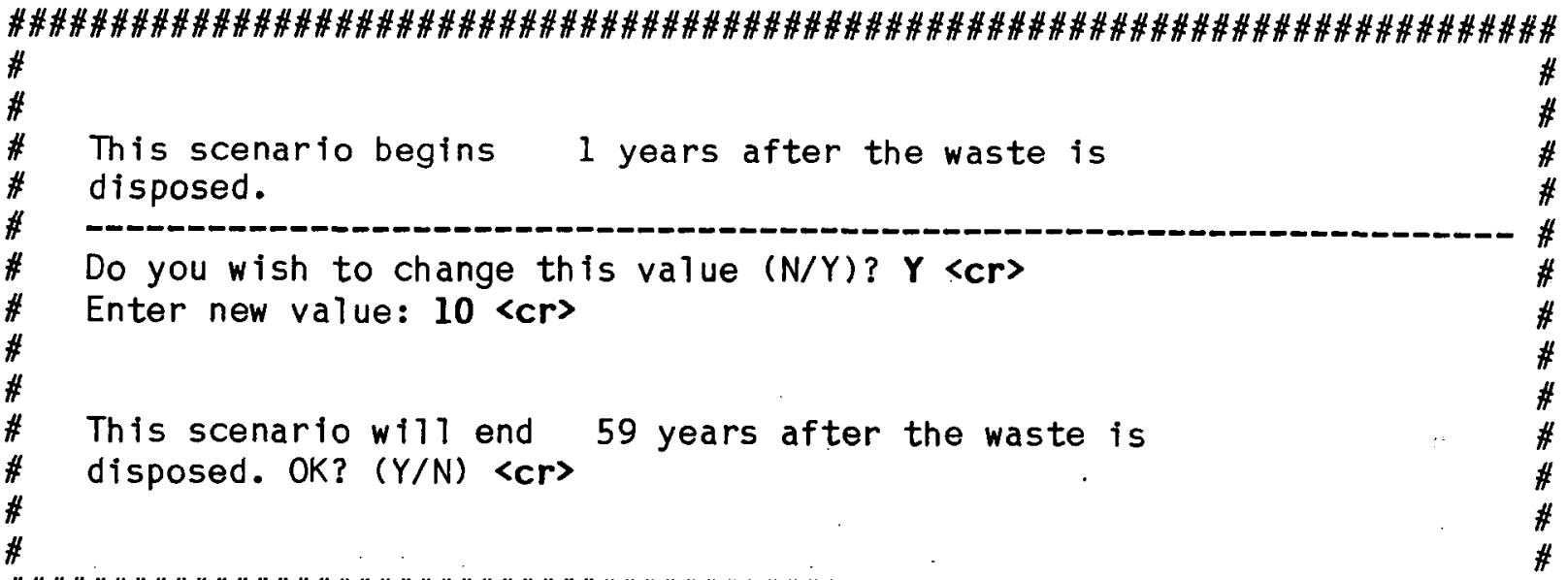

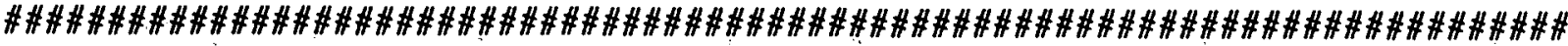

Figure 3.4-5. Sample Problem Three Interactive Session (Continued) 


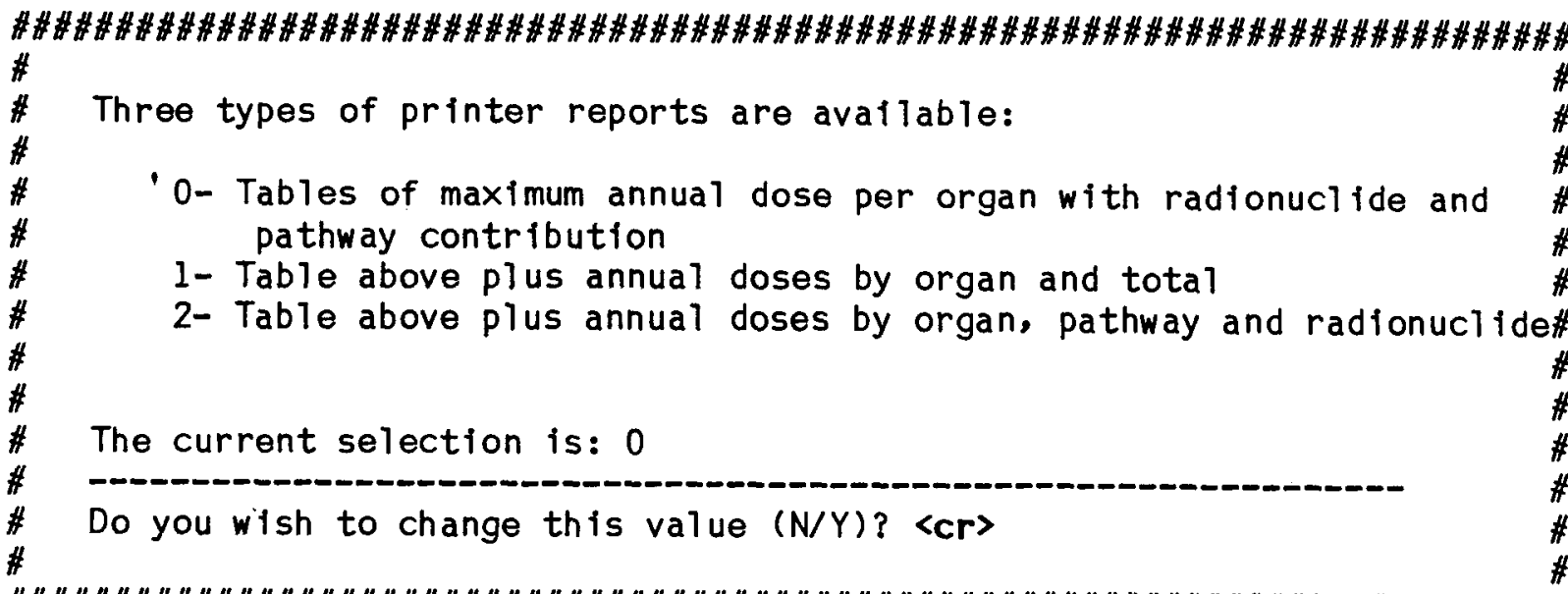

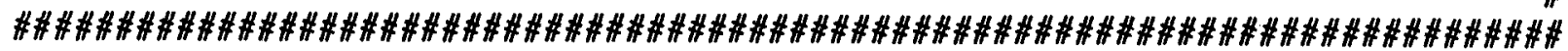

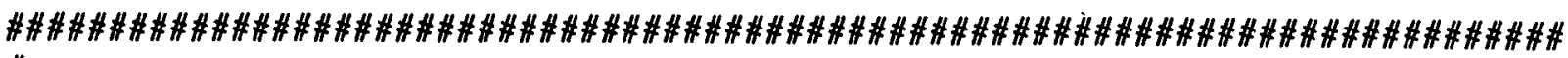

$\#$

\#

Enter new value: .05 <cr

The inventory will automatically be adjusted by the appropriate area correction factor for each exposure pathway based on a site size of 5.000E-02 hectares.

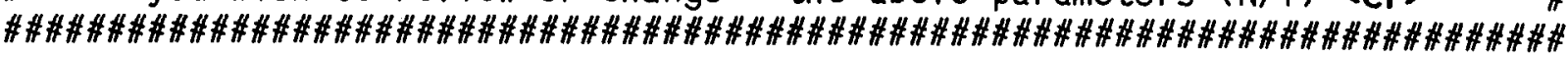

Figure 3.4-5. Sample Problem Three Interactive Session (Continued) 


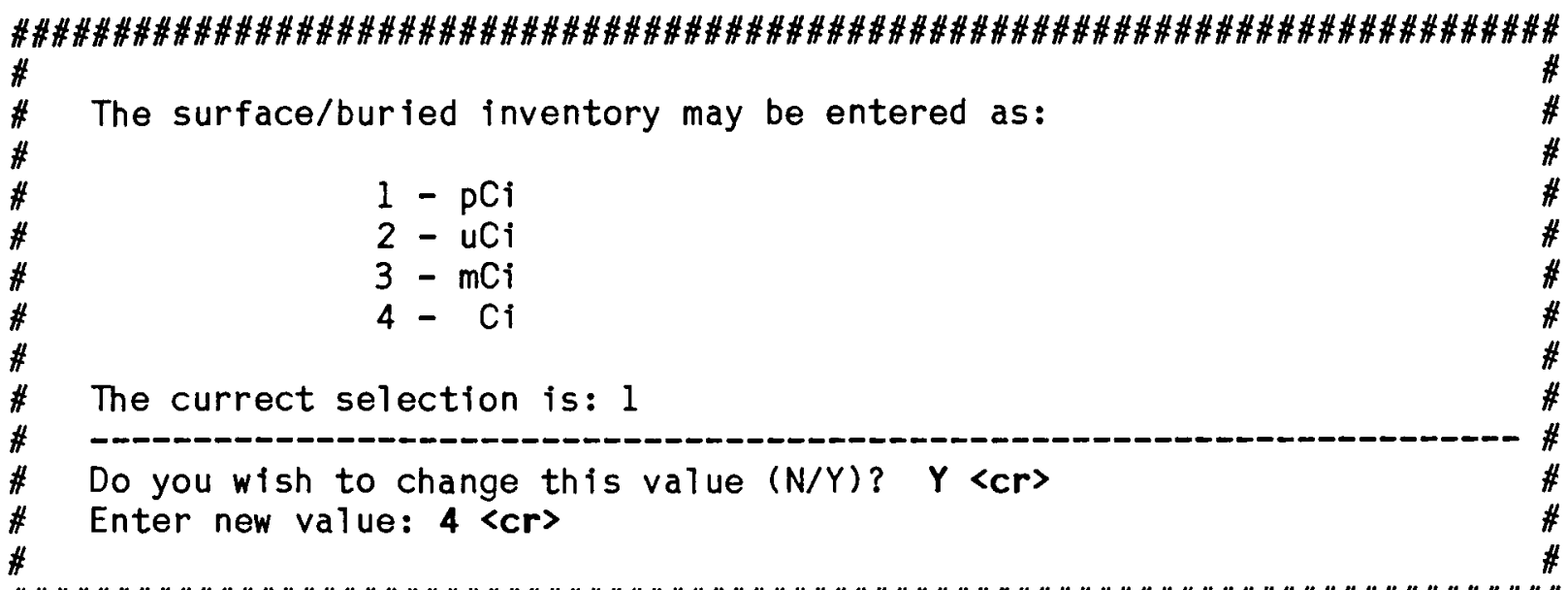

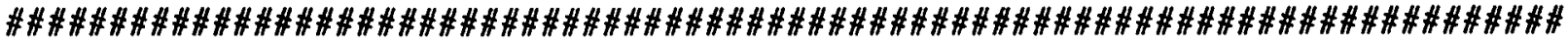

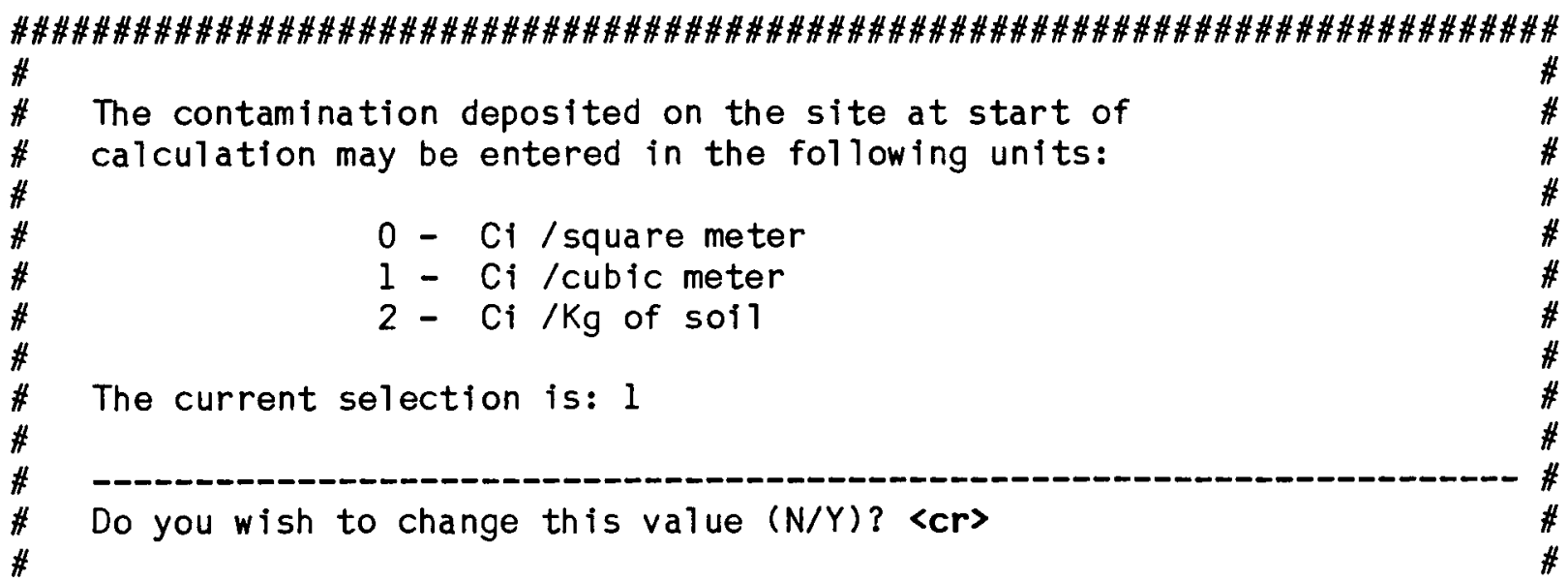

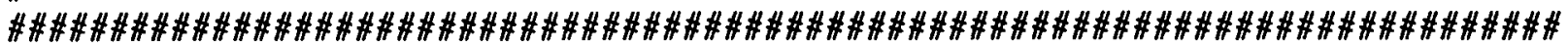

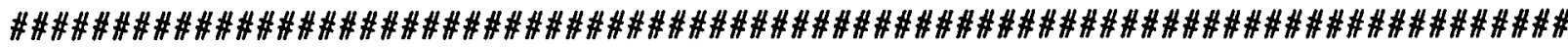

The surface/buried inventory dilution factor is: $\quad 0.20$

(range $=0.0$ to $1.0 \mathrm{E}+20)$

\#

\#

\#

$\#$

$\#$

\#

$\#$

$\#$

\#

\#\#\#\#\#\#\#\#\#\#\#\#\#\#\#\#\#\#\#\#\#\#\#\#\#\#\#\#\#\#\#\#\#\#\#\#\#\#\#\#\#\#\#\#\#\#\#\#\#\#\#\#\#\#\#\#\#\#\#\#\#\#\#\#

Figure 3.4-5. Sample Problem Three Interactive Session (Continued) 


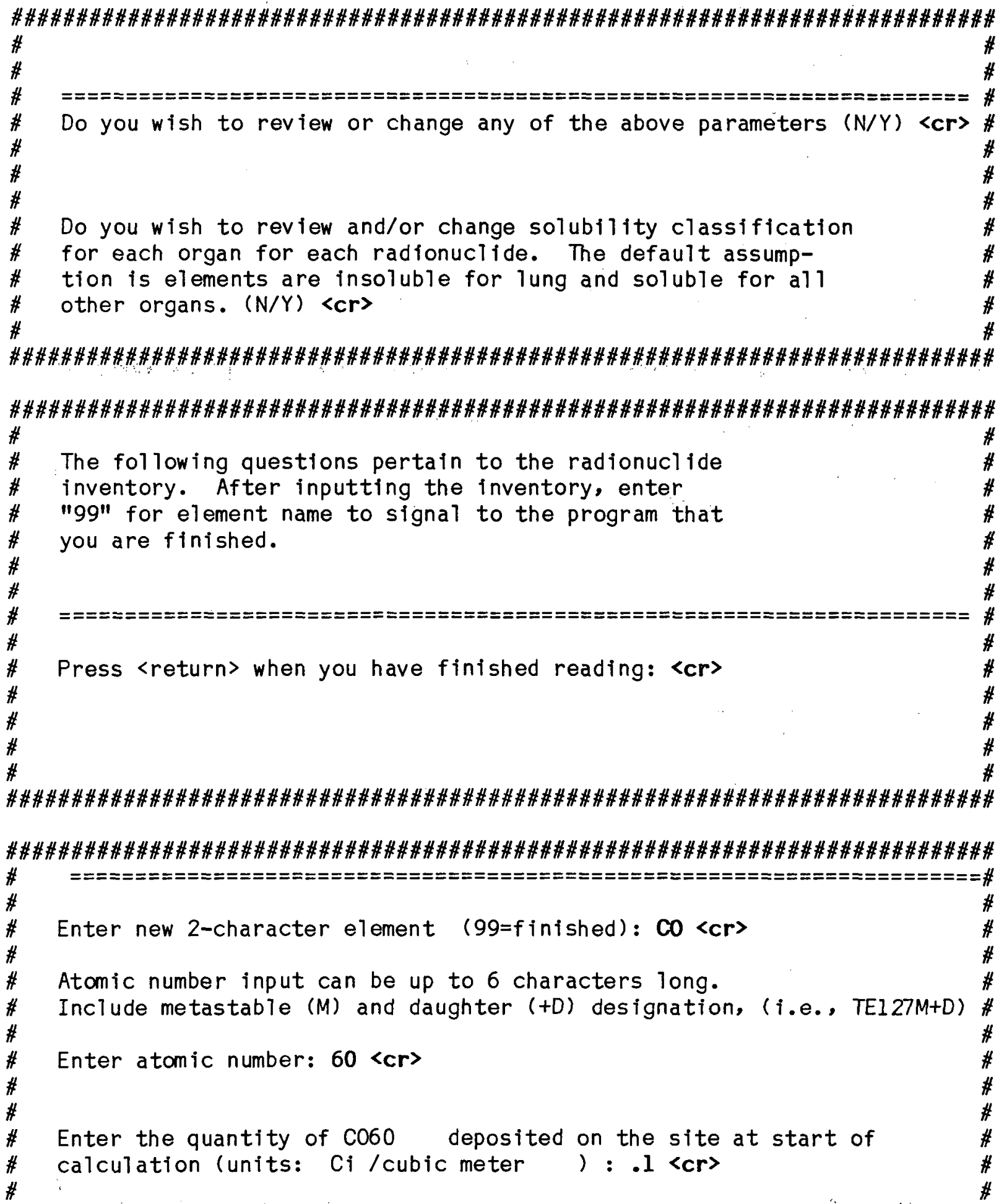

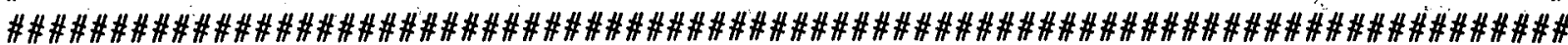

Figure 3.4-5. Sample Problem Three Interactive Session (Continued) 


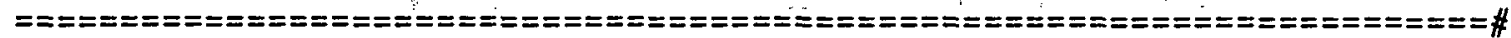

Enter new 2-character element (99=finished): SR 〈cr> \#

Atomic number input can be up to 6 characters long.

Include metastable $(M)$ and daughter ( $+D)$ designation, (i.e., TEl27M+D) \#

Enter atomic number: $\mathbf{9 0 + D}\langle\mathrm{Cr}\rangle$

Enter the quantity of $S R 90+D$ deposited on the site at start of

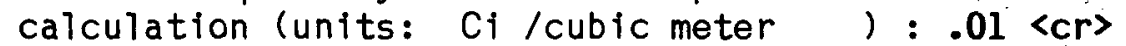

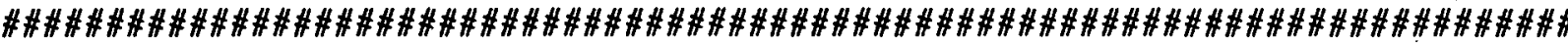

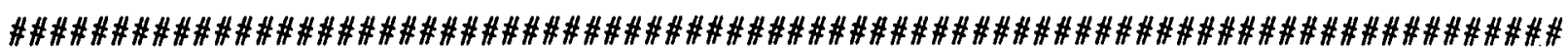

\#

\#

\#

$\#$

$\#$

\#

\#

\#

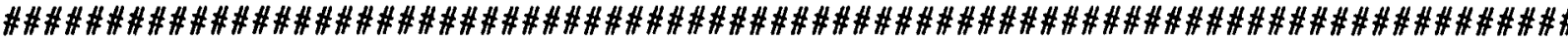

\#\#\#\#\#\#\#\#\#\#\#\#\#\#\#\#\#\#\#\#\#\#\#\#\#\#\#\#\#\#\#\#\#\#\#\#\#\#\#\#\#\#\#\#\#\#\#\#\#\#\#\#\#\#\#\#\#\#\#\#\#\#\#\#\#$$
\#
$$

Surface/Buried

$\mathrm{Ci}$.

Atomic number input can be up to 6 characters long.

Include metastable (M) and daughter (+D) designation, (i.e., TEI27M+D) \#

Enter the quantity of $\operatorname{CS137+D~deposited~on~the~site~at~start~of~\# ~}$ calculation (units: Ci /cubic meter ) : .1 〈cr〉 \#

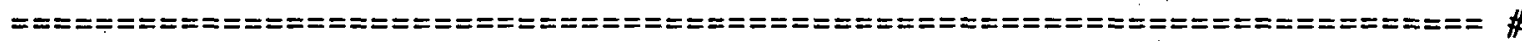

Enter new 2-character element ( $99=$ finished): 99 <cr

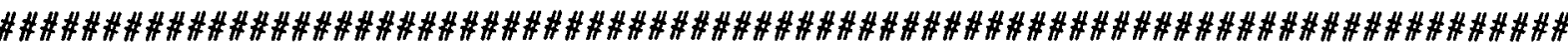

Figure 3.4-5. Sample Problem Three Interactive Session (Continued) 
(This interactive session generates the following file.)

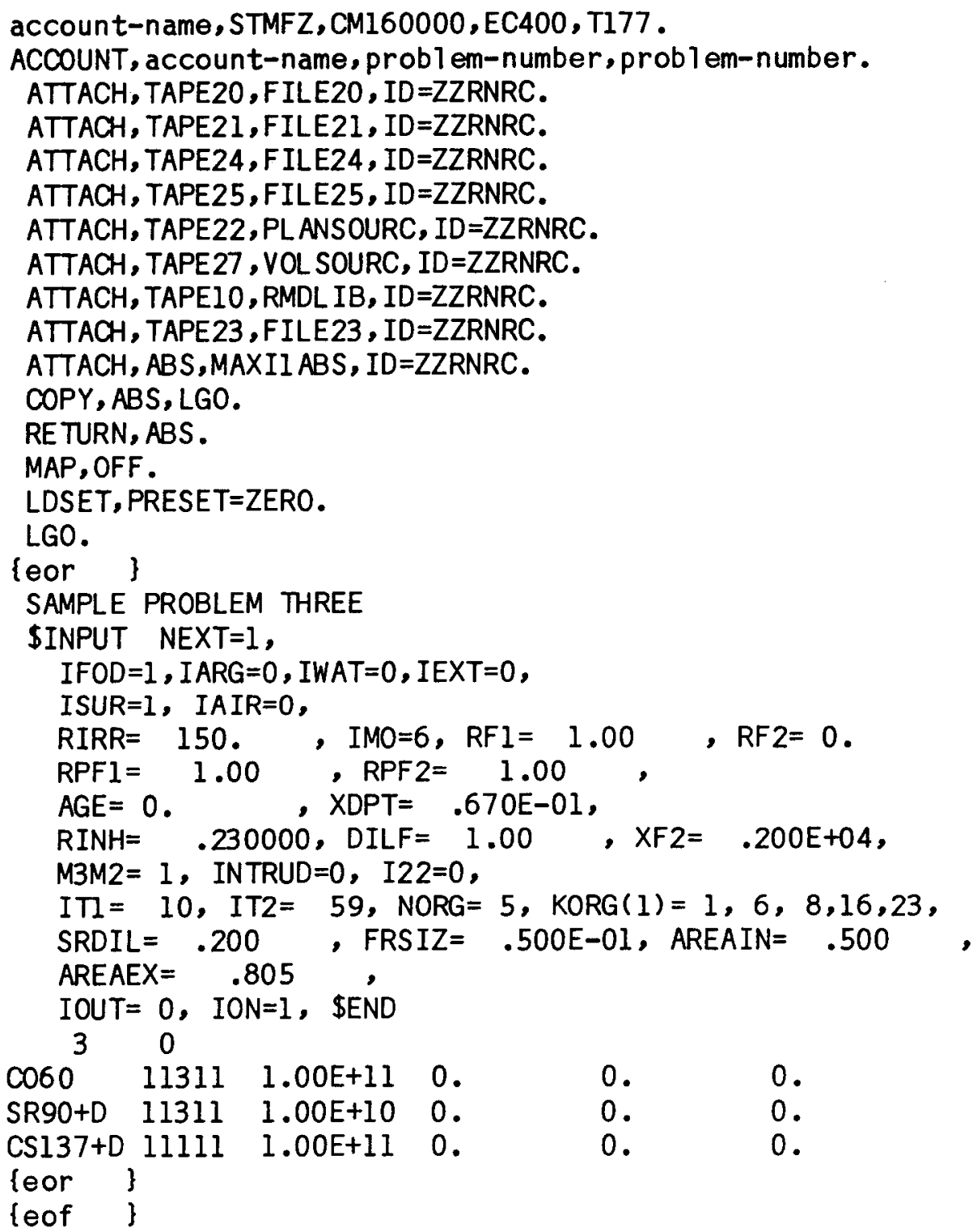

Figure 3.4-5. Sample Problem Three Interactive Session (Continued) 
RADIONUCL IDE CHAIN LIBRARY USED: DOSE FACTOR FILES USED FOR THIS CASE:
*20 FOOD-LEAF
*21 FOOD-SOIL:
Leaf Incremental Dose Factors for the ONSITE/BIOPORT
*22 SHALLOW EXTERNAL:
Soll Incremental Dose Factors for the ONSITE/BIOPORT
*23 DACRIN-INHAL ATION
ONSITE/BIOPORT EXTERNAL DRFS FOR SURFACE (PLANE SOUR
DOS) DOSE INCREMENT FILE ONSITE/BIOPORT ENV. 16-APR-84 RAP

RADIONUCLIDE MASTER DATA LIBRARY / W TRANSLOCATION CLASSES, 6-APR-84 RAP

DOSES CALCULATED FROM 10 TO 59 YEARS FOLLOWING TIME ZERO

PATHWAYS INITIAL IZED FOR DOSE CALCULATIONS :

FARM PRODUCT INGESTION

SPECIAL PARAMETERS INITIAL IZED:

INHALATION OF RESUSPENDED MATERIAL: ON

AOUATIC FOODS INGESTION: OFF

DRINKING WATER INGESTION: OFF

CONTINUING ATMOSPHERIC DEPOSITION OFF

EXTERNAL FROM BURIED WASTES OFF

EXTERNAL FROM SURFACE DEPOSITS: ON

FARM PRODUCT PARAMETERS USED:

FRACTION OF ROOTS IN UPPER SOIL: $0.10 E+01$

FRACTION OF ROOTS IN BURIED WASTE $0.00 E+00$

FRACTION OF TOTAL DIET GROWN ON SITE: $1.00 E+00$

INVENTORY DILUTION FACTOR: 2.00E-01

DECAY OF RIVER RELEASE SOURCE TERM NOT PERFORMED

DECAY OF AIR RELEASE SOURCE TERM NOT PERFORMED

SITE X/Q: $0.00 E+00$

SPECIAL INHALATION MODEL NOT USED

SIZE OF THE SITE: 0.05000 FRACTIONAL HECTARES

INTERNAL PATHWAY AREA CORRECTION FACTOR: 5.00E-01

EXTERNAL PATHWAY AREA CORRECTION FACTOR: 8.05E-01

IRRIGATION RATE: $1.50 \mathrm{E}+02 \mathrm{~L} / M * * 2 / \mathrm{MO}$

MONTHS PER YEAR IRRIGATED: 6

RIVER DILUTION FACTOR: 1.0OE+OOYR/L

YEARS OF IRRIGATION WITH CONTAMINATED WATER PRIOR TO THE DOSE CALCULATIONS:

EXTERNAL EXPOSURE PARAMETERS USED:

RATIO OF EXTERNAL CONTAMINATION IN SURFACE SOIL TO SUBSURFACE SOIL $1.00 E+00$

NUMBER OF HOURS OF EXPOSURE TO EXTERNAL CONTAMINATION 2.00E+03

SURFACE DEPOSITS DRFS FROM ISOSHLD; MODIFICATION FACTOR: $5.844 E-11$

INHALATION PARAMETERS USED:

MODIFICATION FACTOR, RINH: 2.30E-0I

(EQUIVALENT TO BREATHING RATE OF $230 \mathrm{CC} / \mathrm{SEC}$ FOR 2016. HR/YR)

RESUSPENSION MODEL USED FOR CALCULATING AIR CONCENTRATION: ANSPAUGH

AVERAGE AGE OF MATERIAL ON GROUND AT TIME ZERO: $0.00 E+00$ YEARS

TOP $1.0 \mathrm{CM}$ OF THE CONTAMINATED SURFACE LAYER IS AVAILABLE FOR RESUSPENSION.

ORGANS FOR WHICH DOSES ARE CALCULATED (SAME ORDER AS SOLUBILITIES GIVEN BELOW):
TOTAL BODY
BONE
LUNGS
THYROID
GI-LLI

Figure 3.4-6. Sample Problem Three Output 


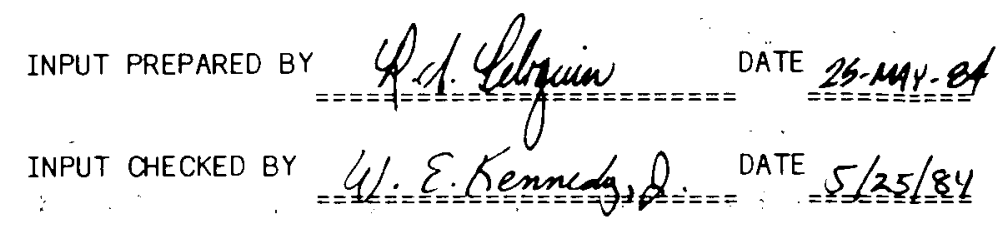

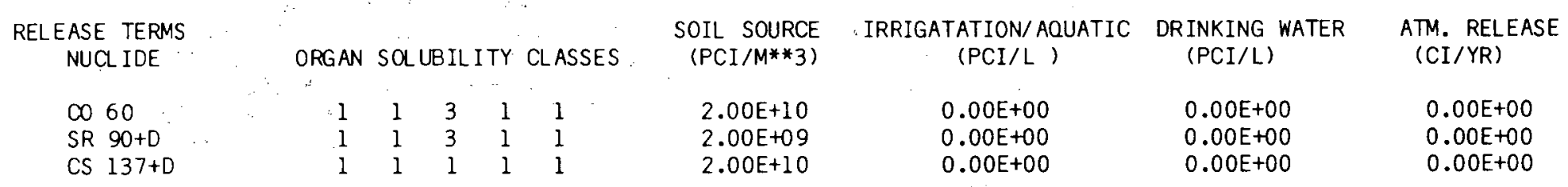

$\stackrel{\omega}{\oplus}$

\section{******************PLEASE NOTE ANY SPECIAL CONSIDERATIONS IN THIS SPACE***************** *

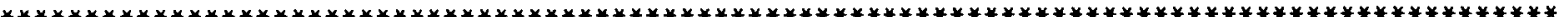
SOIL, AIR, AND WATER CONCENTRATION SUMMARY FOR THE YEAR 10

\begin{tabular}{|c|c|c|c|c|c|}
\hline RADIONUCL IDE & $\begin{array}{c}\text { SURFACE SOIL } \\
\text { PCI/M2 }\end{array}$ & $\begin{array}{l}\text { DEEP SOIL } \\
\text { PCI/M3 }\end{array}$ & $\begin{array}{l}\text { AIR } \\
\mathrm{PCI} / \mathrm{M3}\end{array}$ & $\begin{array}{c}\text { IRRIGATION } \\
\mathrm{PCI} / \mathrm{L}\end{array}$ & $\begin{array}{c}\text { DRINKING WATER } \\
\mathrm{PCI} / \mathrm{L}\end{array}$ \\
\hline CO 60 . & $8.03 E+08$ & $0.00 E+00$ & $5.38 \mathrm{E}+03$ & $\quad 0.00 E+00$ & $0.00 \mathrm{E}+00$ \\
\hline SR $90+D$ & $2.35 E+08$ & $0.00 E+00$ & $1.58 \mathrm{E}+03$ & $0.00 \mathrm{E}+00$ & $0.00 \mathrm{E}+00$ \\
\hline \multirow[t]{2}{*}{ CS $137+D$} & $2.38 E+09$ & $0.00 E+00$ & $1.60 E+04$ & $0.00 E+00$ & $0.00 \mathrm{E}+00$ \\
\hline & SOIL, AIR, & AND WATER CON & TION SUMMARY & Y FOR THE YEAR & 59 \\
\hline RADIONUCL IDE & $\begin{array}{l}\text { SURFACE SOIL } \\
\text { PCI/M2 }\end{array}$ & $\begin{array}{l}\text { DEEP SOIL } \\
\mathrm{PCI} / \mathrm{M3}\end{array}$ & $\begin{array}{l}\text { AIR } \\
\text { PCI/M3 }\end{array}$ & $\begin{array}{l}\text { IRRIGATION } \\
\text { PCI } / L\end{array}$ & $\begin{array}{c}\text { DRINKING WATER } \\
\text { PCI } / L\end{array}$ \\
\hline $\begin{array}{l}\text { CO } 60 . \\
\text { SR }\end{array}$ & $1.26 \mathrm{E}+06$ & $0.00 E+00$ & $\begin{array}{l}8.42 \mathrm{E}-05 \\
4.78 \mathrm{E}-03\end{array}$ & $\begin{array}{l}0.00 E+00 \\
0.00 E+00\end{array}$ & $\begin{array}{l}0.00 E+00 \\
0.00 E+00\end{array}$ \\
\hline $\begin{array}{l}\text { SR } 90+D \\
\text { CS } 137+D\end{array}$ & $\begin{array}{l}7.14 \mathrm{E}+07 \\
7.72 \mathrm{E}+08\end{array}$ & $\begin{array}{l}0.00 E+00 \\
0.00 E+00\end{array}$ & $\begin{array}{l}4.78 \mathrm{E}-03 \\
5.17 \mathrm{E}-02\end{array}$ & $\begin{array}{l}0.00 E+00 \\
0.00 E+00\end{array}$ & $\begin{array}{l}0.00 E+00 \\
0.00 E+00\end{array}$ \\
\hline
\end{tabular}

Figure 3.4-6. Sample Problem Three Output (Continued) 
SAMPLE PROBLEM THREE

MAXI, Version VAX2.2 25-APR-84 executed on 3-MAY-84 at 08:07:59.

MAXIMUM ANNUAL DOSE SUMMARY FOR THE YEAR 10 FORTOTAL BODY

\begin{tabular}{|c|c|c|c|c|c|c|c|c|c|c|c|}
\hline RADIONUCL IDE & $\begin{array}{l}\text { INGESTION } \\
\text { REM }\end{array}$ & EXPO & $\begin{array}{l}\text { PATHWAY } \\
\text { INHALATIO } \\
\text { REM }\end{array}$ & $\%$ & $\begin{array}{l}\text { EXTERNAL } \\
\text { REM }\end{array}$ & $\%$ & $\begin{array}{l}\text { AQUATIC } \\
\text { REM }\end{array}$ & 000 & $\begin{array}{l}\text { DRINKING } \\
\text { REM }\end{array}$ & $\begin{array}{r}\text { WATER } \\
\%\end{array}$ & \\
\hline $\begin{array}{l}\text { CO60 } \\
\text { SR90+D } \\
\text { CS137+D }\end{array}$ & $\begin{array}{l}1.14 \mathrm{E}-01 \\
1.26 \mathrm{E}+00 \\
7.34 \mathrm{E}+00\end{array}$ & $\begin{array}{r}1 \\
14 \\
84\end{array}$ & $\begin{array}{l}3.22 \mathrm{E}-02 \\
9.64 \mathrm{E}-02 \\
3.42 \mathrm{E}-01\end{array}$ & $\begin{array}{r}6 \\
20 \\
72\end{array}$ & $\begin{array}{l}7.41 E+00 \\
4.80 E-03 \\
5.37 E+00\end{array}$ & $\begin{array}{r}57 \\
0 \\
42\end{array}$ & $\begin{array}{l}0.00 \mathrm{E}+00 \\
0.00 \mathrm{E}+00 \\
0.00 \mathrm{E}+00\end{array}$ & $\begin{array}{l}0 \\
0 \\
0\end{array}$ & $\begin{array}{l}0.00 E+00 \\
0.00 E+00 \\
0.00 E+00\end{array}$ & $\begin{array}{l}0 \\
0 \\
0\end{array}$ & \\
\hline TOTALS & $\begin{array}{l}\text { INGEST ION } \\
8.72 E+00\end{array}$ & $\begin{array}{r}\% \\
39\end{array}$ & $\begin{array}{l}\text { INHAL ATIO } \\
4.70 E-01\end{array}$ & $2^{\%}$ & $\begin{array}{r}\text { EXTERNA } \\
1.28 \mathrm{E}+01\end{array}$ & $58^{\%}$ & $\begin{array}{l}\text { AQUATIC } \\
0.00 E+00\end{array}$ & $\begin{array}{c}\text { FOOD \% } \\
0\end{array}$ & $\begin{array}{l}\text { DRINKING } \\
0.00 E+00\end{array}$ & $\begin{array}{c}\text { WATER } \% \\
0\end{array}$ & $\begin{array}{c}\text { TOTAL } \\
2.20 E+01\end{array}$ \\
\hline
\end{tabular}

MAXIMUM ANNUAL DOSE SUMMARY FOR THE YEAR 27 FOR BONE

EXPOSURE PATHWAY

\begin{tabular}{|c|c|c|c|c|c|c|c|c|c|c|c|}
\hline RADIONUCL IDE & $\begin{array}{l}\text { INGESTION } \\
\text { REM }\end{array}$ & $\%$ & $\begin{array}{l}\text { INHAL ATION } \\
\text { REM }\end{array}$ & $\%$ & $\begin{array}{l}\text { EXTERNAL } \\
\text { REM }\end{array}$ & $\%$ & $\begin{array}{l}\text { AQUATIC } \\
\text { REM }\end{array}$ & $x$ & $\begin{array}{l}\text { DRINKING } \\
\text { REM }\end{array}$ & $\begin{array}{r}\text { WATER } \\
\%\end{array}$ & \\
\hline $\begin{array}{l}\text { CO60 } \\
\text { SR90+D } \\
\text { CS137+D }\end{array}$ & $\begin{array}{l}0.00 E+00 \\
5.04 E+01 \\
1.95 E-01\end{array}$ & $\begin{array}{r}0 \\
99 \\
0\end{array}$ & $\begin{array}{l}0.00 \mathrm{E}+00 \\
7.36 \mathrm{E}-01 \\
8.37 \mathrm{E}-06\end{array}$ & $\begin{array}{r}0 \\
99 \\
0\end{array}$ & $\begin{array}{l}7.88 E-01 \\
3.17 E-03 \\
3.63 E+00\end{array}$ & $\begin{array}{r}17 \\
0 \\
82\end{array}$ & $\begin{array}{l}0.00 E+00 \\
0.00 E+00 \\
0.00 E+00\end{array}$ & $\begin{array}{l}0 \\
0 \\
0\end{array}$ & $\begin{array}{l}0.00 E+00 \\
0.00 E+00 \\
0.00 E+00\end{array}$ & $\begin{array}{l}0 \\
0 \\
0\end{array}$ & \\
\hline TOTALS & $\begin{array}{l}\text { INGESTION } \\
5.06 \mathrm{E}+01\end{array}$ & $\begin{array}{r}\% \\
90\end{array}$ & $\begin{array}{l}\text { INHALATION } \\
7.36 \mathrm{E}-01\end{array}$ & $1^{8}$ & $\begin{array}{l}\text { EXTERNAL } \\
4.42 E+00\end{array}$ & $7^{\%}$ & $\begin{array}{r}\text { AQUATIC } \\
0.00 E+00\end{array}$ & $\begin{array}{l}10 \% \\
0\end{array}$ & $\begin{array}{l}\text { DRINKING } \\
0.00 E+00\end{array}$ & $\begin{array}{c}\text { WATER } \% \\
0\end{array}$ & $\begin{array}{c}\text { TOTAL } \\
5.58 \mathrm{E}+01\end{array}$ \\
\hline
\end{tabular}

MAXIMUMM ANNUAL DOSE SUMMARY FOR THE YEAR 11 FOR LUNGS

\begin{tabular}{|c|c|c|c|c|c|c|c|c|c|c|c|}
\hline RADIONUCL IDE & $\begin{array}{l}\text { INGESTION } \\
\text { REM }\end{array}$ & $\begin{array}{l}\text { EXPOSURE } \\
\%\end{array}$ & $\begin{array}{l}\text { PATHWAY } \\
\text { INHALATION } \\
\text { REM }\end{array}$ & $\%$ & $\begin{array}{l}\text { EXTERNAL } \\
\text { REM }\end{array}$ & $\%$ & $\begin{array}{l}\text { AQUATIC } \\
\text { REM }\end{array}$ & $\%$ & $\begin{array}{l}\text { DRINKING } \\
\text { REM }\end{array}$ & $\begin{array}{r}\text { WATER } \\
\not\end{array}$ & \\
\hline $\begin{array}{l}\text { CO60 } \\
\text { SR90+D } \\
\text { CS137+D }\end{array}$ & $\begin{array}{l}0.00 E+00 \\
0.00 E+00 \\
9.19 E-01\end{array}$ & $\begin{array}{r}0 \\
0 \\
100\end{array}$ & $\begin{array}{l}4.81 E+00 \\
2.82 E+00 \\
4.46 E-02\end{array}$ & $\begin{array}{r}62 \\
36 \\
0\end{array}$ & $\begin{array}{l}6.49 E+00 \\
4.68 E-03 \\
5.25 E+00\end{array}$ & $\begin{array}{r}55 \\
0 \\
44\end{array}$ & $\begin{array}{l}0.00 E+00 \\
0.00 E+00 \\
0.00 E+00\end{array}$ & $\begin{array}{l}0 \\
0 \\
0\end{array}$ & $\begin{array}{l}0.00 E+00 \\
0.00 E+00 \\
0.00 E+00\end{array}$ & $\begin{array}{l}0 \\
0 \\
0\end{array}$ & \\
\hline TOTALS & $\begin{array}{l}\text { INGEST ION } \\
9.19 \mathrm{E}-01\end{array}$ & $\begin{array}{l}\% \\
4\end{array}$ & $\begin{array}{l}\text { INHALATION } \\
7.68 \mathrm{E}+00\end{array}$ & $37^{\%}$ & $\begin{array}{l}\text { EXTERNAL } \\
1.17 \mathrm{E}+01\end{array}$ & $57^{*}$ & $\begin{array}{l}\text { AQUATIC } \\
0.00 E+00\end{array}$ & $\begin{array}{c}O D \% \\
0\end{array}$ & $\begin{array}{l}\text { DRINKING } \\
0.00 E+00\end{array}$ & $\begin{array}{c}\text { WATER } \% \\
0\end{array}$ & $\begin{array}{c}\text { TOTAL } \\
2.03 E+01\end{array}$ \\
\hline
\end{tabular}

Figure 3.4-6. Sample Problem Three Output (Continued) 
MAXIMUM ANNUAL DOSE SUMMARY FOR THE YEAR 10 FOR THYROID

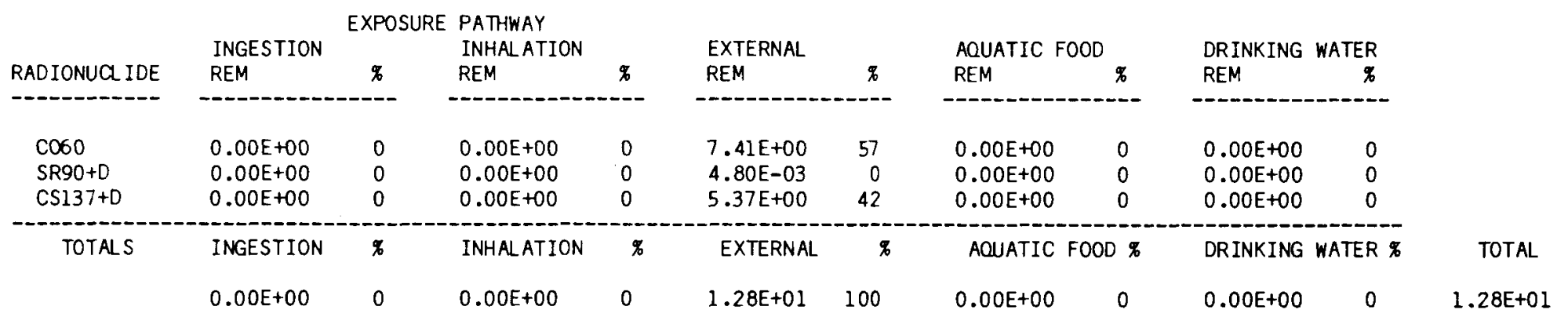

in

MAXIMUM ANNUAL DOSE SUMMARY FOR THE YEAR 10 FOR LLI

\begin{tabular}{|c|c|c|c|c|c|c|c|c|c|c|c|}
\hline RADIONUCL IDE & $\begin{array}{l}\text { INGESTION } \\
\text { REM }\end{array}$ & $\begin{array}{c}\text { EXPOSURE } \\
\end{array}$ & $\begin{array}{l}\text { PATHWAY } \\
\text { INHALATION } \\
\text { REM }\end{array}$ & $\mathscr{q}$ & $\begin{array}{l}\text { EXTERNAL } \\
\text { REM }\end{array}$ & $\%$ & $\begin{array}{l}\text { AQUATIC F } \\
\text { REM }\end{array}$ & $\%$ & $\begin{array}{l}\text { DRINKING } \\
\text { REM }\end{array}$ & $\begin{array}{r}\text { WATER } \\
\%\end{array}$ & \\
\hline - & --- & -- & - & $\cdots$ & $--\infty-\infty$ & --.- & $-\cdots$ & 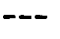 & . & & \\
\hline $\begin{array}{l}\text { CO60 } \\
\text { SR90+D } \\
\text { CS137+D }\end{array}$ & $\begin{array}{l}1.12 E+00 \\
2.21 E+00 \\
4.02 E-01\end{array}$ & $\begin{array}{l}30 \\
59 \\
10\end{array}$ & $\begin{array}{l}2.91 E-02 \\
1.50 E-02 \\
4.61 E-03\end{array}$ & $\begin{array}{r}59 \\
30 \\
9\end{array}$ & $\begin{array}{l}7.41 E+00 \\
4.80 E-03 \\
5.37 E+00\end{array}$ & $\begin{array}{r}57 \\
0 \\
42\end{array}$ & $\begin{array}{l}0.00 E+00 \\
0.00 E+00 \\
0.00 E+00\end{array}$ & $\begin{array}{l}0 \\
0 \\
0\end{array}$ & $\begin{array}{l}0.00 E+00 \\
0.00 E+00 \\
0.00 E+00\end{array}$ & $\begin{array}{l}0 \\
0 \\
0\end{array}$ & \\
\hline \multirow[t]{2}{*}{ TOTALS } & INGESTION & 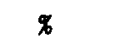 & INHALATION & $\%$ & EXTERNAL & $\%$ & AQUATIC & $0 \%$ & DRINKING & WATER $\mathscr{x}$ & TOTAL \\
\hline & $3.74 E+00$ & 22 & $4.87 \mathrm{E}-02$ & 0 & $1.28 \mathrm{E}+01$ & 77 & $0.00 \mathrm{E}+00$ & 0 & $0.00 E+00$ & 0 & $1.66 \mathrm{E}+0 \mathrm{I}$ \\
\hline
\end{tabular}

Figure 3.4-6. Sample Problem Three Output (Continued) 
This interactive program will assist you in the creation of scenarios for assessment of onsite disposal of lowlevel waste. Doses to man through the specified pathways will be simulated by the computer program MAXI.

The following notes may be of interest:

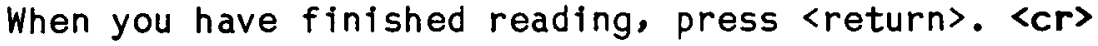

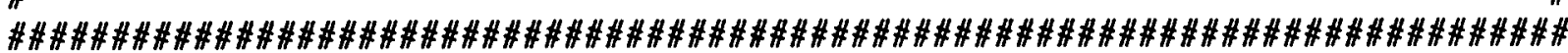

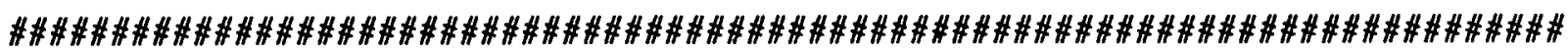

H

\#

\#

\#

\#

\#

$\#$

\#

\#

\#

$\#$

\#

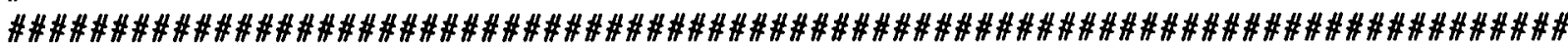

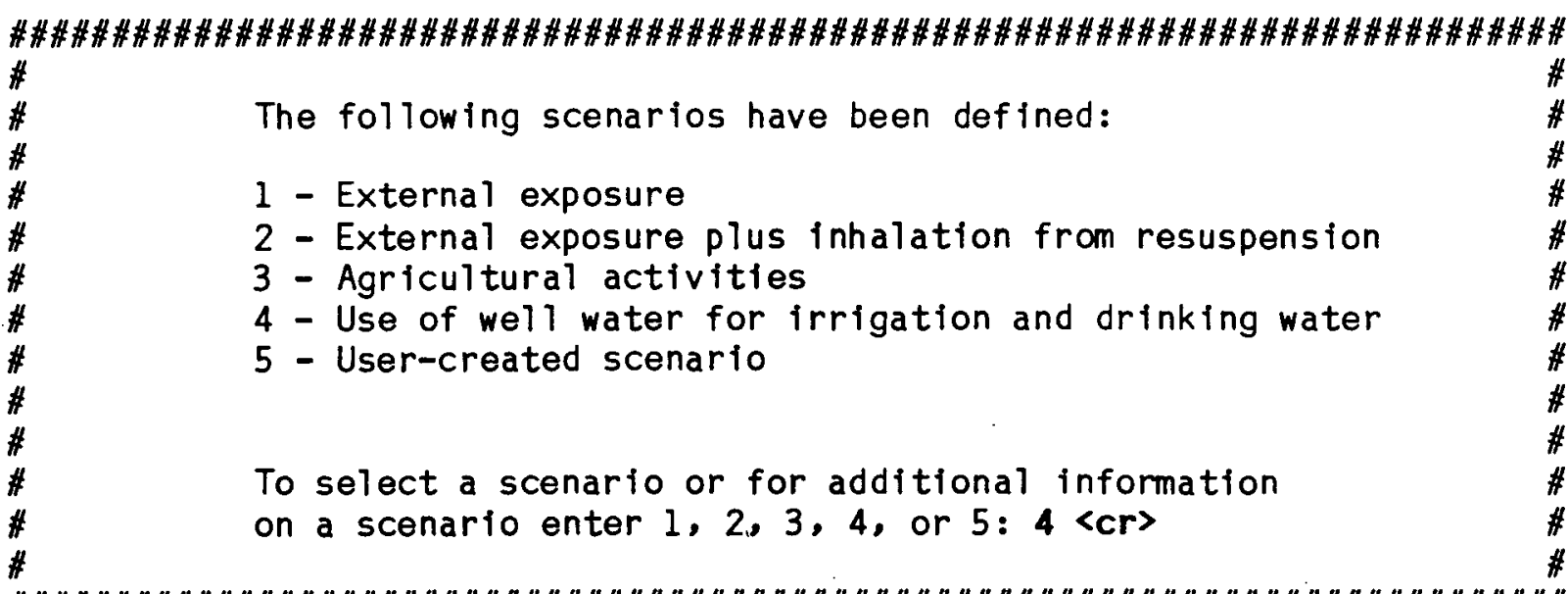

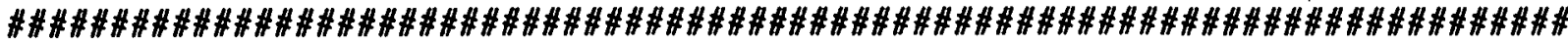

Figure 3.4-7. Sample Problem Four Interactive Session 
This scenarlo accounts for the use of well or river water for irrigation and drinking. Assumes an irrigation rate of $150 \mathrm{l} / \mathrm{sq} \mathrm{m} / \mathrm{mo}$ for 6 months. Defaults to Anspaugh mode 1 for inhalation. Assumes total diet and 1.211 ters/day of drinking water.

Scenario 4 is now selected. Do you wish to change \# this selection $(N / Y)$ : 〈cr> \#

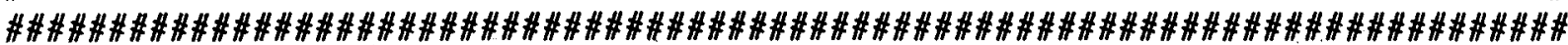

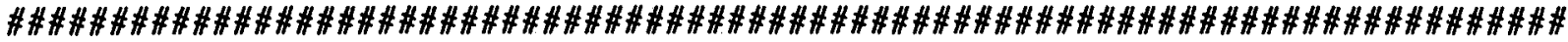$$
\#
$$$$
\#
$$$$
\#
$$

Enter a descriptive title to identify this case:

SAMPLE PROBLEM FOUR 〈cr>

This scenario begins disposed.

1 years after the waste is

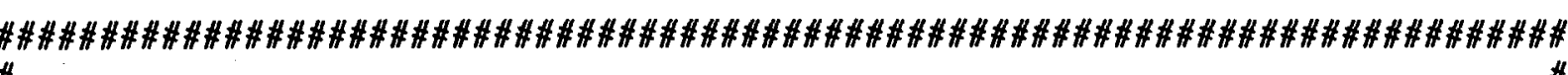

Do you wish to change this value $(N / Y)$ ? $Y\langle c r\rangle$

Enter new value: $10\langle c r\rangle$

This scenario will end 59 years after the waste is disposed. OK? $(\mathrm{Y} / \mathrm{N})\langle\mathrm{Cr}\rangle$

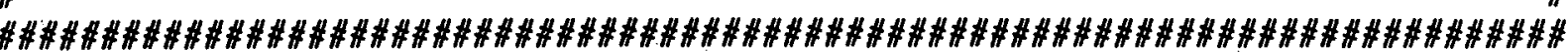

Figure 3.4-7. Sample Problem Four Interactive Session (Continued) 
Three types of printer reports are avallable:

0- Tables of maximum annual dose per organ with radionuclide and pathway contribution

1- Table above plus annual doses by organ and total

2- Table above plus annual doses by organ, pathway and radionuclide\#

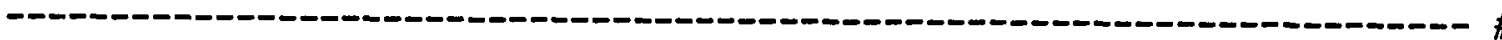

Do you wish to change this value $(N / Y)$ ? 〈cr

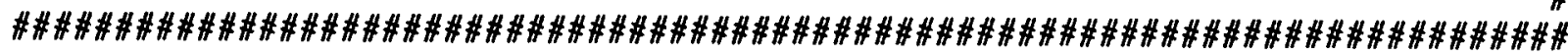

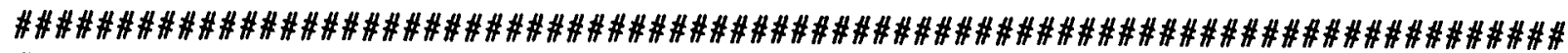

$\#$

\#

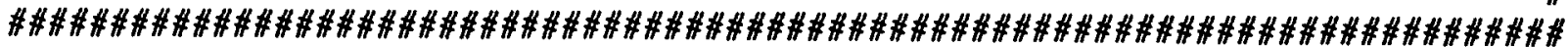
$\#$
$\#$
$\#$
$\#$
$\#$
$\#$
$\#$
$\#$
$\#$
$\#$
$\#$
$\#$
$\#$

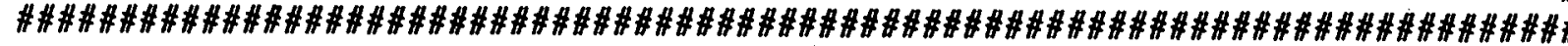

Do you wish to review and/or change solubility classification

for each organ for each radionuclide. The default assump-

tion is elements are insoluble for lung and soluble for all

other organs. $(N / Y)\langle C r\rangle$

Do you wish to modify any parameter values for Scenario 4 ( N/Y) ? <cr>

Do you wish to review or change any of the above parameters $(N / Y)\langle C r\rangle$

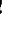
, , Figure 3.4-7. Sample Problem Four Interactive Session (Continued) 
\# The following questions pertain to the radionuclide

\# inventory. After inputting the inventory, enter

\#. "99" for element name to signal to the program that

\# you are finished.

$\#$

$\#$

\#

$\#$

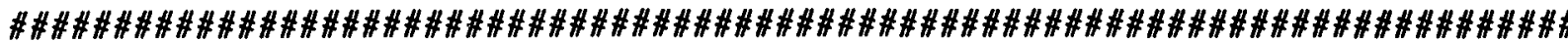

\#\#\#\#\#\#\#\#\#\#\#\#\#\#\#\#\#\#\#\#\#\#\#\#\#\#\#\#\#\#\#\#\#\#\#\#\#\#\#\#\#\#\#\#\#\#\#\#\#\#\#\#\#\#\#\#\#\#\#\#\#\#\#\#\#

\# Enter new 2-character element ( $99=$ finished): $C 0<c r\rangle$ \#

$\#$

\#

\#

$\#$

$\#$

$\#$

$\#$

\#

\#

$\#$

$$
\text { \# }
$$

Atomic number input can be up to 6 characters long.

Include metastable (M) and daughter (+D) designation, (i.e., TEl 27M+D) \#

Enter atomic number: $60\langle\mathrm{cr}\rangle$

To consider only irrigation or only drinking water contamination, \# enter zero quantity for the other pathway.

Enter the concentration of $\mathrm{CO60}$

calculation (units: $\mathrm{pCi} / 1$ iter):

Enter the concentration of 0060

calculation (units: $\mathrm{pCi} / 1$ iter):

in the irrigation water at start of $.1\langle c r\rangle$

in the drinking water at start of \#

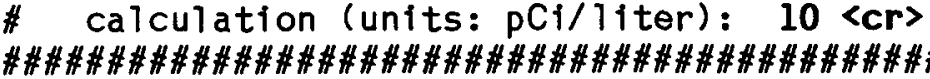

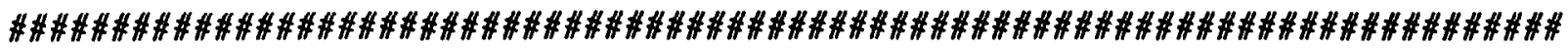

\# Enter new 2-character element ( $99=$ finished): SR 〈cr> \#

$\#$

$\#$

$\#$

$\#$

\#

\#

\#

$\#$

$\#$

$\#$

$\#$

$\#$

Atomic number input can be up to 6 characters long.

Include metastable $(M)$ and daughter ( $D$ ) designation, (1.e., TEl 27M+D) \#

Enter atomic number: $\mathbf{9 0 + D}\langle\mathrm{Cr}\rangle$

To consider only irrigation or only drinking water contamination, enter zero quantity for the other pathway.

Enter the concentration of SR90+D in the irrigation water at start of \# calculation (units: pCi/liter): .1 〈cr>

Enter the concentration of $S R 90+D$ in the drinking water at start of \#

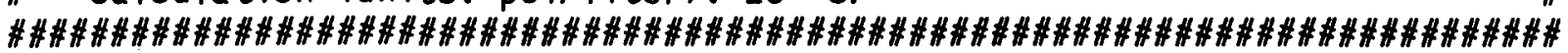

Figure 3.4-7. Sample Problem Four Interactive Session (Continued) 


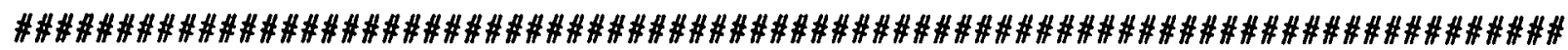

\# Enter new 2-character element $(99=f$ inished): I 〈cr> \#

\#

\# Atomic number input can be up to 6 characters long.

Include metastable $(M)$ and daughter (+D) designation, (i.e., TEI 27M+D) \#

Enter atomic number: 129 〈cr>

To consider only irrigation or only drinking water contamination, \# enter zero quantity for the other pathway.

Enter the concentration of I 129 calculation (units: $\mathrm{pCi} / 1$ iter): calculation cunits: pCi/1iter): .1 <crs Enter the concentration of I 129 in the drinking water at start of calculation (units: $\mathrm{pCi} / 1$ iter): $10<\mathrm{cr}$ )

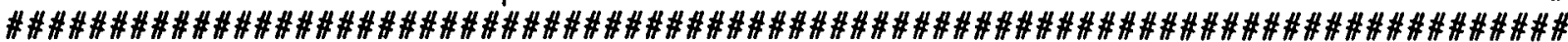

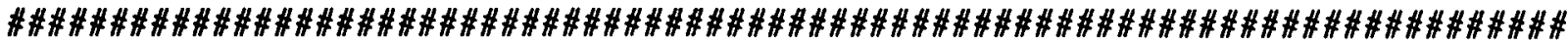

\# Enter new 2-character element ( $99=$ finished): U 〈cr

\# Enter new 2-character element (g9:finished): U <cr

\# Atomic number input can be up to 6 characters long. \#

\# Include metastable (M) and daughter (+D) designation, (i.e., TEl27M+D) \#

\# Enter atomic number: $238+D\langle C r\rangle$

\# To consider only irrigation or only drinking water contamination, \#

\# enter zero quantity for the other pathway. \#

\# Enter the concentration of $U 238+D$ in the irrigation water at start of \#

\# calculation (units: pCi/liter): .1 〈cr> \#

\# Enter the concentration of $U 238+D$ in the drinking water at start of \#

\# calculation (units: $p C 1 / 7$ iter): $10\langle\mathrm{cr}\rangle$

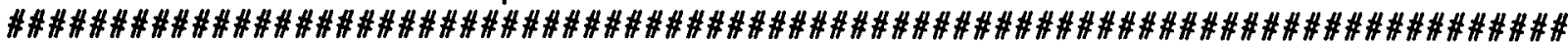

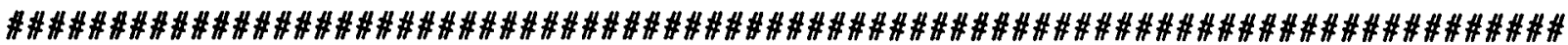

\# Enter new 2-character element (99=finished): 99 〈cr> \#

\# Enter new 2-character element (99=finished):

\# Surface/Buried Drinking \#

\# $\mathrm{pCi}$ Irrigation Water \#

\# Radionuclide /cubic meter $\mathrm{pCi} / 1 \quad \mathrm{pCi} / 1$ \#

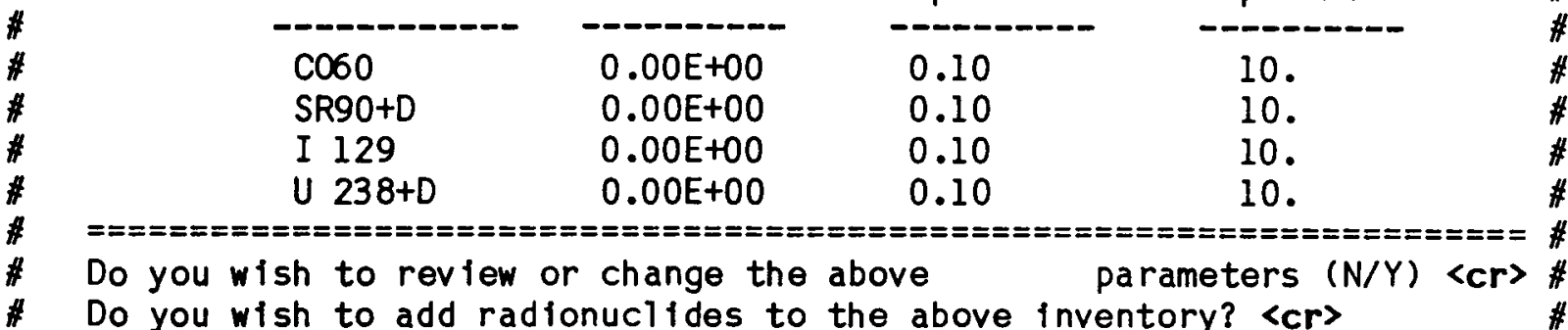

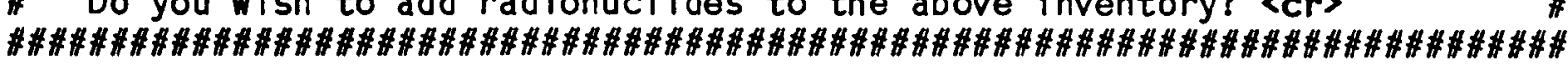

Figure 3.4-7. Sample Problem Four Interactive Session (Continued) 
(This interactive session generates the following flle.)

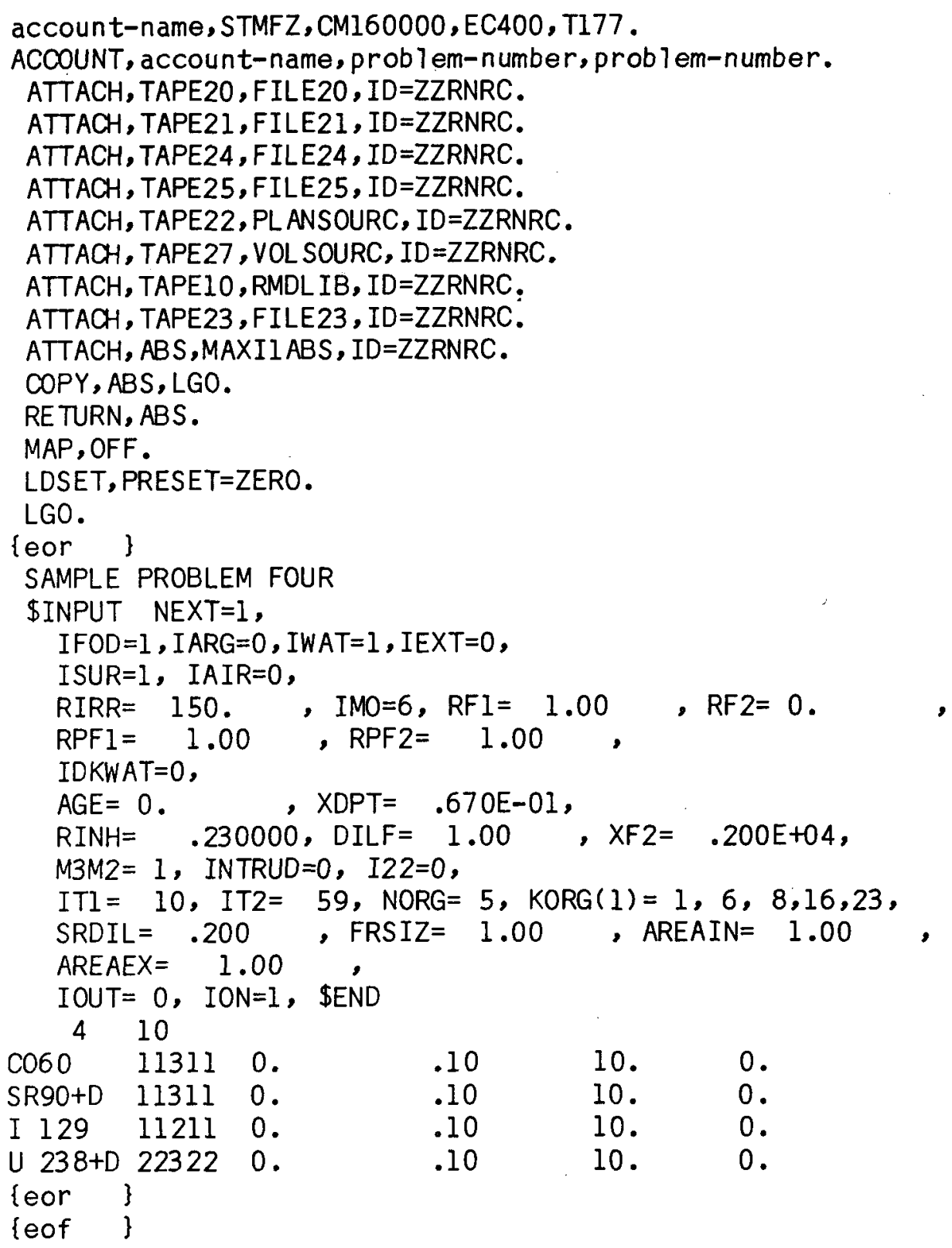

Figure 3.4-7. Sample Problem Four Interactive Session (Continued) 
RADIONUCL IDE CHAIN LIBRARY USED: DOSE FACTOR FILES USED FOR THIS CASE:
* 20 FOOD-LEAF :
*21 FOOD-SOIL:
* 22 SHAL LOW EXTERNAL:
*23 DACRIN-INHAL ATION:
Leaf Incremental Dose Factors for the ONSITE/BIOPORT
Soll Incremental Dose Factors for the ONSITE/BIOPORT
ONSITE/BIOPORT EXTERNAL. DRFS FOR SURFACE (PLANE SOUR
DOS) DOSE INCREMENT FILE ONSITE/BIOPORT ENV. 16-APR-84 RAP
*25 ARRRG-DRINK H20:
Incremental Drinking Water Dose Factors - ONSITE/BIO

DOSES CALCULATED FROM 10 TO 59 YEARS FOLLOWING TIME ZERO

PATHWAYS INITIAL IZED FOR DOSE CALCULATIONS:

FARM PRODUCT INGESTION

AOUATIC FOODS INGESTION: OFF

DRINKING WATER INGESTION: ON

CONTINUING ATMOSPHERIC DEPOSITION OFF

EXTERNAL FROM BURIED WASTES OFF

EXTERNAL FROM SURFACE DEPOSITS: ON

$\omega$

FARM PRODUCT PARAMETERS USED:
FRACTION OF ROOTS IN UPPER SOIL: $0.10 E+01$

FRACTION OF ROOTS IN BURIED WASTE $0.00 E+00$

FRACTION OF TOTAL DIET GROWN ON SITE: $1.00 E+00$

EXTERNAL EXPOSURE PARAMETERS USED:

RATIO OF EXTERNAL CONTAMINATION IN SURFACE SOIL TO SUBSURFACE SOIL $1.00 E+00$

NUMBER OF HOURS OF EXPOSURE TO EXTERNAL CONTAMINATION $2.00 E+03$

SURFACE DEPOSITS DRFS FROM ISOSHLD; MODIFICATION FACTOR: $5.844 \mathrm{E}-11$

INH ALATION PARAMETERS USED:

MODIFICATION FACTOR , RINH: 2.30E-01

(EQUIVALENT TO BREATHING RATE OF $230 \mathrm{CC} / \mathrm{SEC}$ FOR 2016. HR/YR)

RESUSPENSION MODEL USED FOR CALCULATING AIR CONCENTRATION: ANSPAUGH

AVERAGE AGE OF MATERIAL ON GROUND AT TIME ZERO: $0.00 E+00$ YEARS

TOP $1.0 \mathrm{CM}$ OF THE CONTAMINATED SURFACE LAYER IS AVAILABLE FOR RESUSPENSION.

ORGANS FOR WHICH DOSES ARE CALCULATED (SAME ORDER AS SOLUBILITIES GIVEN BELOW):

TOTAL BODY

BONE

LUNGS

THYROID

GI-LLI

Figure 3.4-8. Sample Problem Four Output 


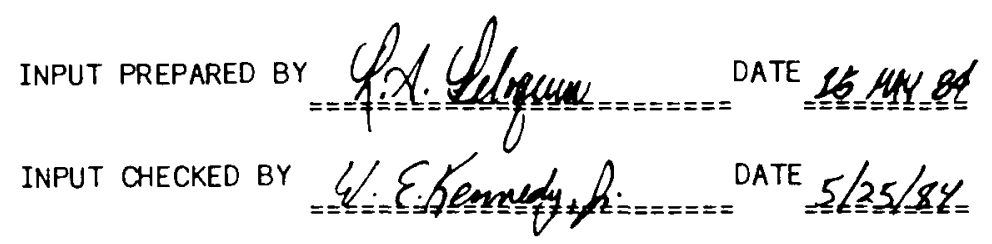

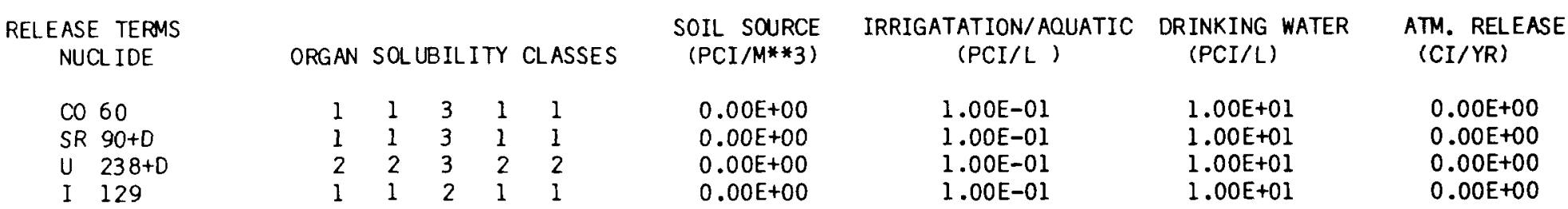

$\underset{\oplus}{\omega}$

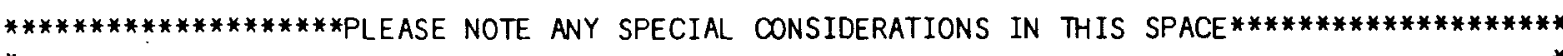
$*$

*

SOIL, AIR, AND WATER CONCENTRATION SUMMARY FOR THE YEAR 10

\begin{tabular}{|c|c|c|c|c|c|}
\hline RADIONUCL IDE & $\begin{array}{l}\text { SURFACE SOIL } \\
\text { PCI/M2 }\end{array}$ & $\begin{array}{l}\text { DEEP SOIL } \\
\mathrm{PCI} / \mathrm{M3}\end{array}$ & $\begin{array}{l}\text { AIR } \\
\text { PCI/M3 }\end{array}$ & $\begin{array}{l}\text { IRRIGATION } \\
\text { PCI } / \mathrm{L}\end{array}$ & $\begin{array}{c}\text { DRINKING WATER } \\
\text { PCI } / L\end{array}$ \\
\hline $\begin{array}{ll}\text { CO } & 60 \\
\text { SR } & 90+D \\
U & 238+D \\
\text { I } & 129\end{array}$ & $\begin{array}{l}4.89 E+02 \\
8.58 E+02 \\
9.90 E+02 \\
9.90 E+02\end{array}$ & $\begin{array}{l}0.00 E+00 \\
0.00 E+00 \\
0.00 E+00 \\
0.00 E+00\end{array}$ & $\begin{array}{l}4.08 E-07 \\
7.15 E-07 \\
8.25 E-07 \\
8.25 E-07\end{array}$ & $\begin{array}{l}1.00 E-01 \\
1.00 E-01 \\
1.00 E-01 \\
1.00 E-01\end{array}$ & $\begin{array}{l}1.00 E+01 \\
1.00 E+01 \\
1.00 E+01 \\
1.00 E+01\end{array}$ \\
\hline & SOIL,AI & AND WATER CONC & ITION SUMMARY & FOR THE YEAR & 59 \\
\hline RADIONUCL IDE & $\begin{array}{l}\text { SURFACE SOIL } \\
\text { PCI/M2 }\end{array}$ & $\begin{array}{l}\text { DEEP SOIL } \\
\text { PCI/M3 }\end{array}$ & $\begin{array}{l}\mathrm{AIR} \\
\mathrm{PCI} / \mathrm{MB}\end{array}$ & $\begin{array}{l}\text { IRRIGATION } \\
\text { PCI/L }\end{array}$ & $\begin{array}{c}\text { DRINKING WATER } \\
\text { PCI /L }\end{array}$ \\
\hline $\begin{array}{ll}C O & 60 \\
\text { SR } & 90+D \\
U & 238+D \\
I & 129\end{array}$ & $\begin{array}{l}6.38 E+02 \\
2.80 E+03 \\
5.40 E+03 \\
5.40 E+03\end{array}$ & $\begin{array}{l}0.00 E+00 \\
0.00 E+00 \\
0.00 E+00 \\
0.00 E+00\end{array}$ & $\begin{array}{l}4.28 \mathrm{E}-08 \\
1.88 \mathrm{E}-07 \\
3.62 \mathrm{E}-07 \\
3.62 \mathrm{E}-07\end{array}$ & $\begin{array}{l}1.00 \mathrm{E}-01 \\
1.00 \mathrm{E}-01 \\
1.00 \mathrm{E}-01 \\
1.00 \mathrm{E}-01\end{array}$ & $\begin{array}{l}1.00 E+01 \\
1.00 E+01 \\
1.00 E+01 \\
1.00 E+01\end{array}$ \\
\hline
\end{tabular}

Figure 3.4-8. Sample Problem Four Output (Continued) 
MAXIMUM ANNUAL DOSE SUMMARY FOR THE YEAR 59 FORTOTAL BODY

\begin{tabular}{|c|c|c|c|c|c|c|c|c|c|c|}
\hline RADIONUCL IDE & $\begin{array}{l}\text { INGESTION } \\
\text { REM }\end{array}$ & $\begin{array}{l}\text { EXPOSURE } \\
\%\end{array}$ & $\begin{array}{l}\text { PATHWAY } \\
\text { INHALATION } \\
\text { REM }\end{array}$ & $\%$ & $\begin{array}{l}\text { EXTERNAL } \\
\text { REM }\end{array}$ & $\%$ & $\begin{array}{l}\text { AQUATIC F } \\
\text { REM }\end{array}$ & क & $\begin{array}{l}\text { DRINKING } \\
\text { REM }\end{array}$ & $\begin{array}{r}\text { WATER } \\
\%\end{array}$ \\
\hline $\begin{array}{l}\text { CO60 } \\
\text { SR90+D } \\
\text { U } 238+D \\
\text { I } 129\end{array}$ & $\begin{array}{l}2.42 \mathrm{E}-07 \\
5.17 \mathrm{E}-04 \\
2.85 \mathrm{E}-06 \\
2.78 \mathrm{E}-06\end{array}$ & $\begin{array}{r}0 \\
98 \\
0 \\
0\end{array}$ & $\begin{array}{l}5.32 \mathrm{E}-13 \\
4.90 \mathrm{E}-10 \\
3.27 \mathrm{E}-10 \\
4.66 \mathrm{E}-12\end{array}$ & $\begin{array}{r}0 \\
59 \\
39 \\
0\end{array}$ & $\begin{array}{l}7.32 \mathrm{E}-06 \\
7.1 \mathrm{IE}-08 \\
3.60 \mathrm{E}-07 \\
3.10 \mathrm{E}-08\end{array}$ & $\begin{array}{r}94 \\
0 \\
4 \\
0\end{array}$ & $\begin{array}{l}0.00 E+00 \\
0.00 E+00 \\
0.00 E+00 \\
0.00 E+00\end{array}$ & $\begin{array}{l}0 \\
0 \\
0 \\
0\end{array}$ & $\begin{array}{l}4.12 E-06 \\
8.99 E-04 \\
1.39 E-04 \\
3.22 E-05\end{array}$ & $\begin{array}{r}0 \\
83 \\
12 \\
3\end{array}$ \\
\hline TOTALS & $\begin{array}{l}\text { INGESTION } \\
5.22 E-04\end{array}$ & $\begin{array}{r}\% \\
32\end{array}$ & $\begin{array}{l}\text { INHALATION } \\
8.21 \mathrm{E}-10\end{array}$ & $0^{*}$ & $\begin{array}{c}\text { EXTERNAL } \\
7.78 \mathrm{E}-06\end{array}$ & $0^{\infty}$ & $\begin{array}{r}\text { AQUATIC } \\
0.00 \mathrm{E}+00\end{array}$ & $\begin{array}{c}O D \% \\
0\end{array}$ & $\begin{array}{l}\text { DRINKING } \\
1.07 \mathrm{E}-03\end{array}$ & $\begin{array}{c}\text { WATER \% } \\
66\end{array}$ \\
\hline
\end{tabular}

TOTAL

MAXIMUM ANNUAL DOSE SUMMARY FOR THE YEAR 59 FOR BONE

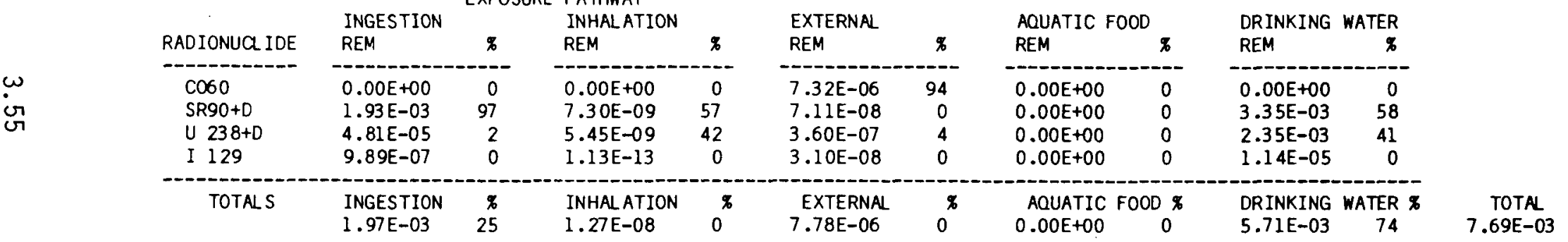

MAXIMUM ANNUAL DOSE SUMMARY FOR THE YEAR 59 FOR LUNGS

\begin{tabular}{|c|c|c|c|c|c|c|c|c|c|c|c|}
\hline RADIONUCL IDE & $\begin{array}{l}\text { INGESTION } \\
\text { REM }\end{array}$ & $\begin{array}{l}\text { EXPOSURE } \\
\%\end{array}$ & $\begin{array}{l}\text { PATHWAY } \\
\text { INHALATION } \\
\text { REM }\end{array}$ & $\%$ & $\begin{array}{l}\text { EXTERNAL } \\
\text { REM }\end{array}$ & $\%$ & $\begin{array}{l}\text { AQUATIC F } \\
\text { REM }\end{array}$ & x & $\begin{array}{l}\text { DRINKING } \\
\text { REM }\end{array}$ & $\begin{array}{r}\text { WATER } \\
x\end{array}$ & \\
\hline $\begin{array}{l}\text { CO60 } \\
\text { SR90+D } \\
\text { U } 238+D \\
\text { I } 129\end{array}$ & $\begin{array}{l}0.00 E+00 \\
0.00 E+00 \\
0.00 E+00 \\
0.00 E+00\end{array}$ & $\begin{array}{l}0 \\
0 \\
0 \\
0\end{array}$ & $\begin{array}{l}2.11 E-10 \\
2.00 E-09 \\
2.29 E-07 \\
2.59 E-11\end{array}$ & $\begin{array}{r}0 \\
0 \\
99 \\
0\end{array}$ & $\begin{array}{l}7.32 \mathrm{E}-06 \\
7.11 \mathrm{E}-08 \\
3.60 \mathrm{E}-07 \\
3.10 \mathrm{E}-08\end{array}$ & $\begin{array}{r}94 \\
0 \\
4 \\
0\end{array}$ & $\begin{array}{l}0.00 E+00 \\
0.00 E+00 \\
0.00 E+00 \\
0.00 E+00\end{array}$ & $\begin{array}{l}0 \\
0 \\
0 \\
0\end{array}$ & $\begin{array}{l}0.00 E+00 \\
0.00 E+00 \\
0.00 E+00 \\
0.00 E+00\end{array}$ & $\begin{array}{l}0 \\
0 \\
0 \\
0\end{array}$ & \\
\hline TOTALS & $\begin{array}{l}\text { INGESTION } \\
0.00 E+00\end{array}$ & $\begin{array}{l}\% \\
0\end{array}$ & $\begin{array}{l}\text { INHAL ATION } \\
2.31 \mathrm{E}-07\end{array}$ & $2^{\%}$ & $\begin{array}{l}\text { EXTERNAL } \\
7.78 \mathrm{E}-06\end{array}$ & 97 & $\begin{array}{l}\text { AQUATIC } \\
0.00 E+00\end{array}$ & $\begin{array}{c}D \% \\
0\end{array}$ & $\begin{array}{l}\text { DRINKING } \\
0.00 \mathrm{E}+00\end{array}$ & $\begin{array}{c}\text { WATER } \bar{x} \\
0\end{array}$ & $\begin{array}{c}\text { TOTAL } \\
8.01 E-06\end{array}$ \\
\hline
\end{tabular}

Figure 3.4-8. Sample Problem Four Output (Continued) 
MAXIMUM ANNUAL DOSE SUMMARY FOR THE YEAR 59 FOR THYROID

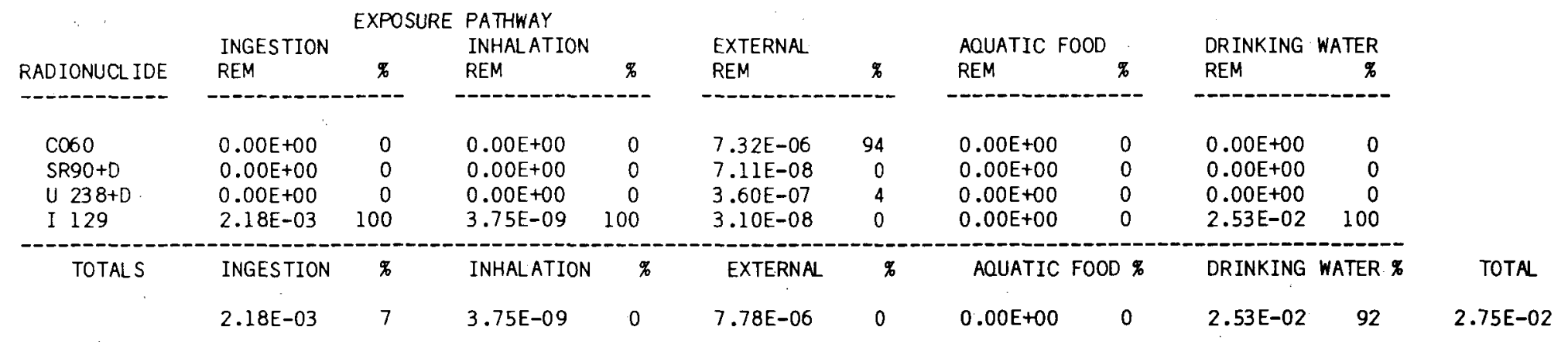

MAXIMUM ANNUAL DOSE SUMMARY FOR THE YEAR 59 FOR LLI

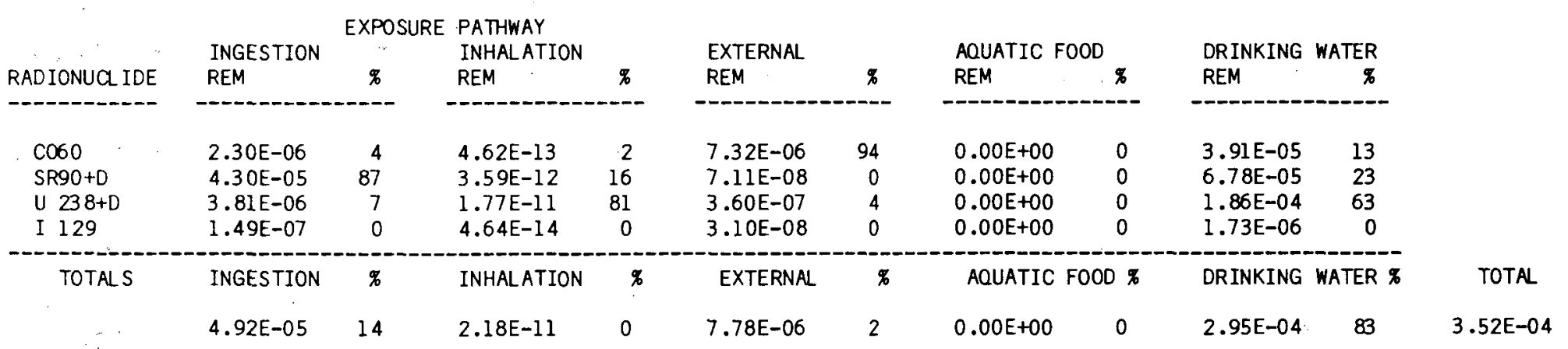

Figure 3.4-8. Sample Problem Four Output (Continued) 


\subsubsection{Sample Problem Five}

The fifth and final sample problem is designed to exercise the user-defined scenario option. This problem is intended to exercise the maximum number of exposure conditions that can be considered by the MAXIl program in a single run. For this problem, the general exposure conditions described in Sample Problem Four are considered with the addition of ingestion of aquatic foods (fish obtained from a river) and root penetration into deeply buried wastes. The radionuclide concentrations in wel 1 and river water defined in Sample Problem Four, are used for the liquid pathways. A deep waste concentration of $0.1 \mathrm{Ci} / \mathrm{m}^{3}$ of each of ${ }^{60} \mathrm{Co},{ }^{129} \mathrm{I}$, and $238 \mathrm{U}+\mathrm{D} \mathrm{pl}$ us $0.001 \mathrm{Ci} / \mathrm{m}^{3}$ of ${ }^{90} \mathrm{Sr+D}$ is al so assumed. The site is assumed to cover 1 ha. The wastes are assumed to be buried for 10 years prior to the start of farming and they are assumed to be located $1.0 \mathrm{~m}$ from the surface. It is further assumed that about $40 \%$ of the roots from the garden crops penetrate to this depth (based on information in Napier 1982). For the user-defined scenario, the air concentration used to estimate inhalation dose is calculated using a mass-loading equation instead of the time-dependent resuspension equation. Also, the individual's total diet is assumed to be grown using the contaminated water supply. The sample problem is to determine the doses to an individual residing on a site containing deeply buried wastes who also uses contaminated water supplies. The solution to this problem is found by running the ONSITE user-defined scenario with the specified source terms and conditions. A summary of the interactive session used to develop the runstream for Sample Problem Five is shown in Figure 3.4-9. The output resulting for this sample problem is shown in Figure 3.4-10. The maximum annual doses resulting for Sample Problem Five are about $1.5 \mathrm{rem} / \mathrm{yr}$ to total body, $6.2 \mathrm{rem} / \mathrm{yr}$ to bone, $2.0 \times 10^{-4} \mathrm{rem} / \mathrm{yr}$ to 1 ungs, $245 \mathrm{rem} / \mathrm{yr}$ to thyroid, and $0.43 \mathrm{rem} / \mathrm{yr}$ to $\mathrm{GI}(\mathrm{LLI})$. Ingestion of farm products whose roots penetrate the deeply buried wastes control the doses to total body, bone, thyroid, and GI(LLI). The dose to 1 ungs is controlled by the external exposure pathway. Hand calculations verified the code operation for the radioactive decay, radionuclide concentrations, and dose estimates for all of the exposure pathways considered. 


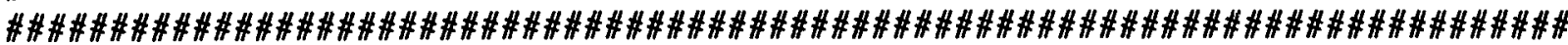

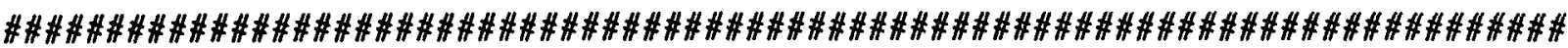

$\#$

$\#$

1) If the default condition is selected, you need only press <return>. YES-Or-NO questions are designated by $(Y / N)$ and should be answered with a $Y$ or $N$. The default condition is always listed first.

2) The values you enter will be tested against reasonable limits and if they are not accepted you will be asked to supply another value.

When you have finished reading, press <return> <cr>

$\#$

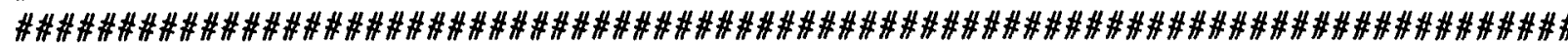

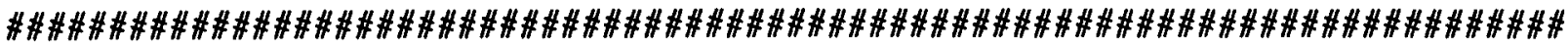$$
\#
$$

The following scenarios have been defined:

1 - External exposure

2 - External exposure plus inhalation from resuspension

3 - Agricultural activities

4 - Use of well water for irrigation and drinking water

5 - User-created scenario

To select a scenario or for additional information on a scenario enter $1,2,3,4$, or $5: 5\langle\mathrm{cr}\rangle$

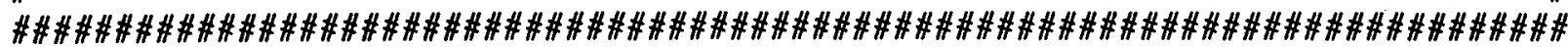

Figure 3.4-9. Sample Problem Five Interactive Session 
SCENARIO 5: User Defined Scenario

This scenario defaults to a full year of exposure to external contamination and a full year of inhalation. The user may specify any parameters to define a scenario.

Scenario 5 is now selected. Do you wish to change this selection $(N / Y):\langle c r\rangle$

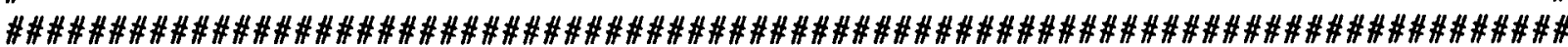

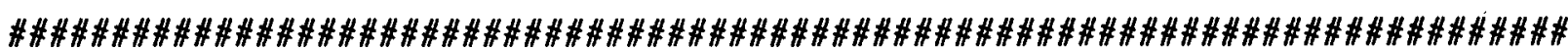

$\#$
$\#$
$\#$
$\#$
$\#$
$\#$
$\#$
$\#$
$\#$
$\#$
$\#$
$\#$
$\#$

Enter a descriptive title to identify this case:

SAMPLE PROBLEM FIVE 〈cr>

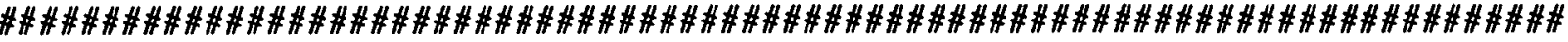

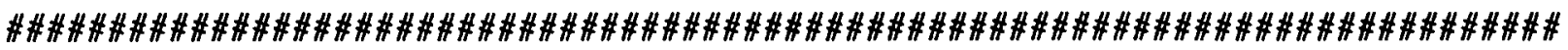

$\#$

This scenario begins 1 years after the waste is disposed.

Do you wish to change this value $(N / Y)$ ? $Y$ <cr

Enter new value: $10\langle\mathrm{cr}\rangle$

This scenario will end 59 years after the waste is

disposed. OK? $(Y / N)<C r\rangle$

\#

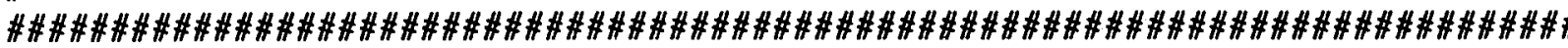

Figure 3.4-9. Sample Problem Five Interactive Session (Continued) 
\# Three types of printer reports are available:

\#

\#

\#

\#

$\#$

\#

\#

\#

\#

\#

\#

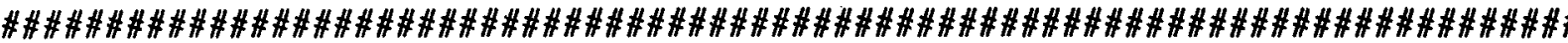

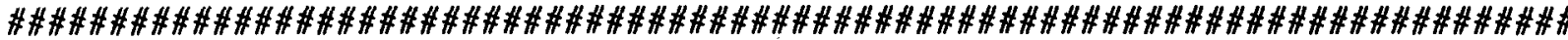

0- Tables of maximum annual dose per organ with radionuclide and pathway contribution

1- Table above plus annual doses by organ and total

2- Table above plus annual doses by organ, pathway and radionuclide\#

The current selection is: 0

Do you wish to change this value $(N / Y)$ ? $\langle c r\rangle$

In this scenario, wastes may be:

1 -On surface

2 -Buried at $0.5 \mathrm{~m}$

3 -Buried at $1.0 \mathrm{~m}$

4 -Stored waste

The current selection is: 1

Do you wish to change this value $(N / Y)$ ? $Y\langle c r\rangle$

Enter new value: $3\langle\mathrm{Cr}>$

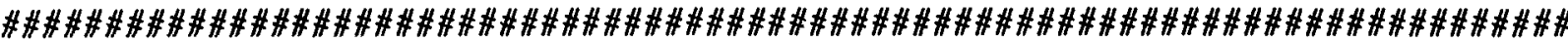

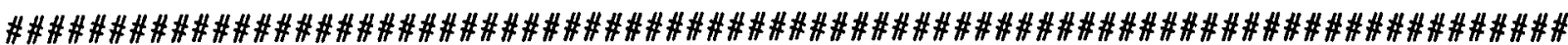

\#

\#

\#

\#

$\#$

\#

\#

\#

\#
Do you wish to consider external exposure to surface contamination? $(\mathrm{Y} / \mathrm{N}) \quad\langle\mathrm{Cr}\rangle$

Do you wish to consider external exposure and crop penetration to deeply buried waste? (Y/N) 〈cr>

Do you wish to consider farm product ingestion? $(Y / N) \quad\langle C r\rangle$

Figure 3.4-9. Sample Problem Five Interactive Session (Continued) 


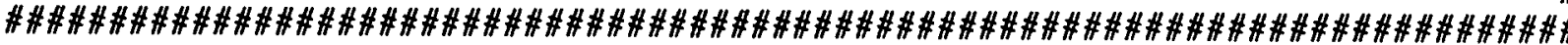

Do you wish to consider consumption of aquatic food from a contaminated river? $(Y / N)$ 〈Cr

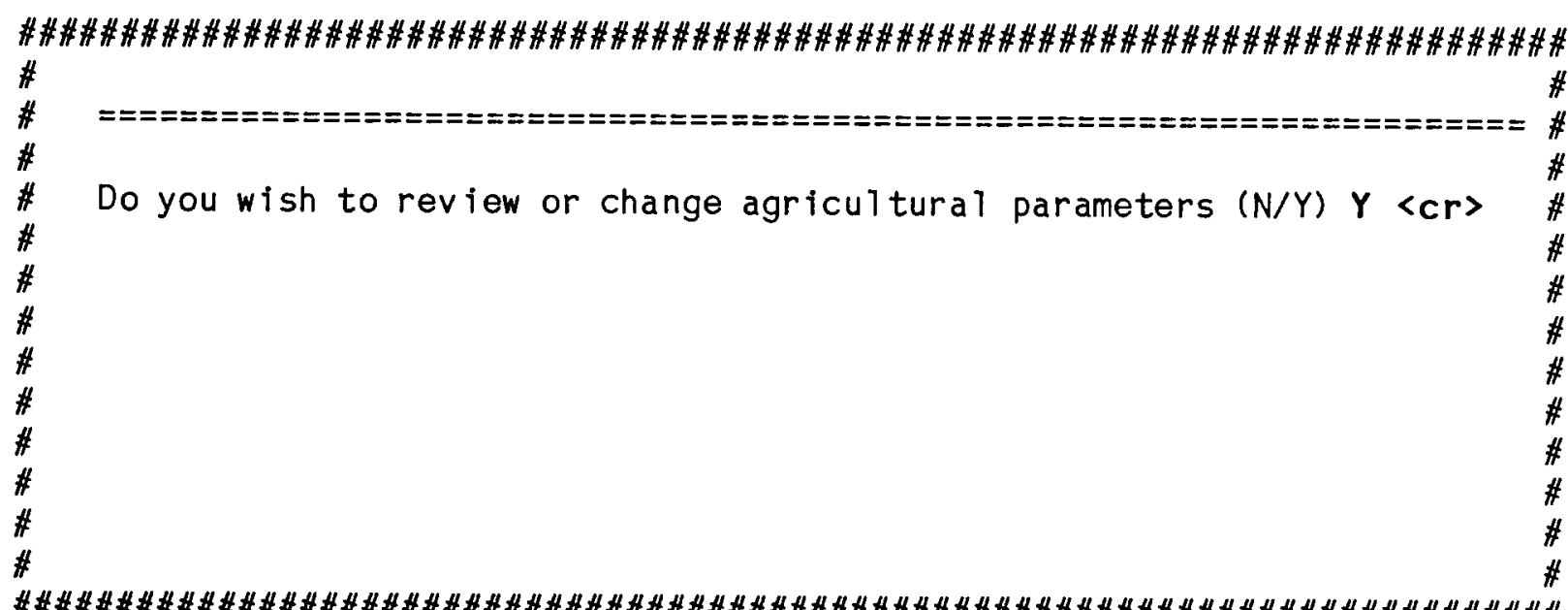

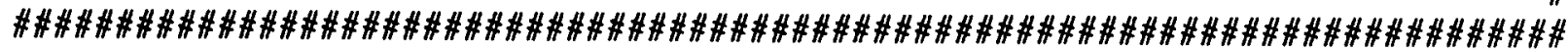

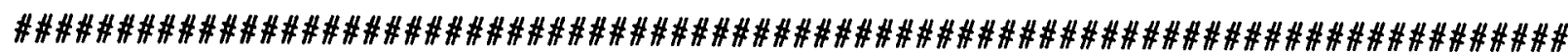

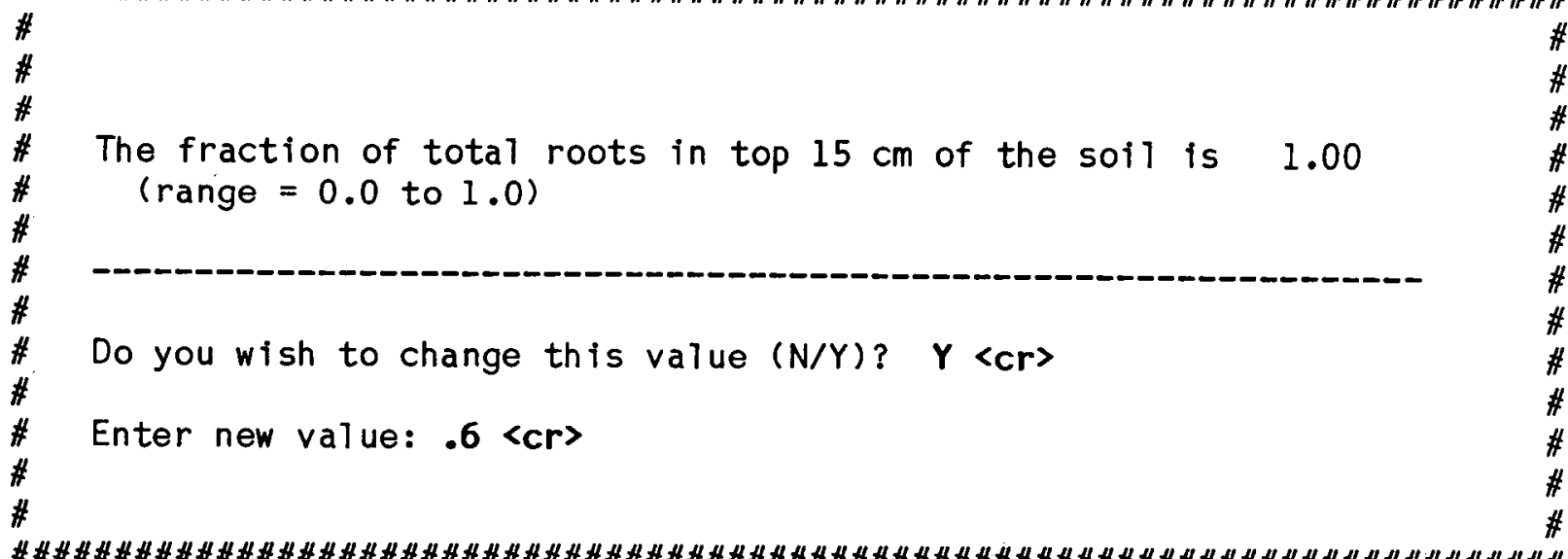

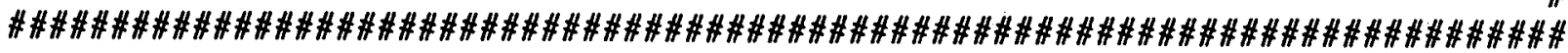

Figure 3.4-9. Sample Problem Five Interactive Session (Continued) 


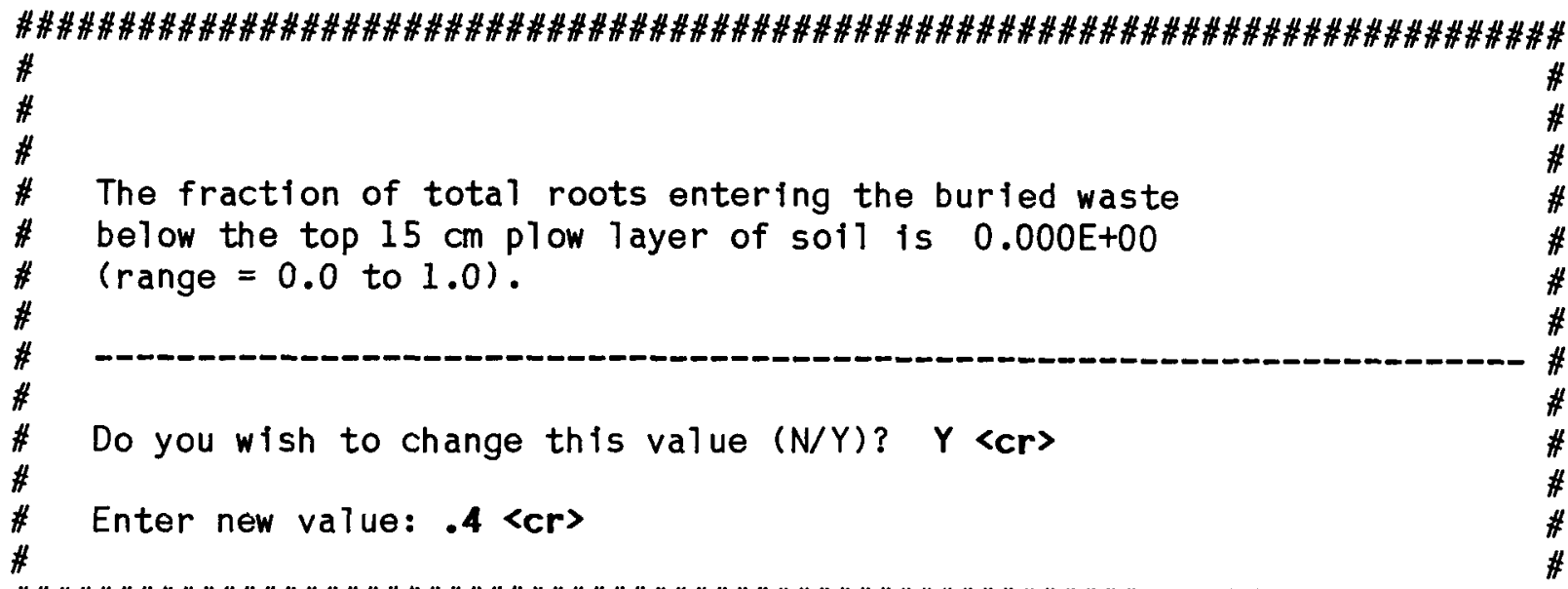

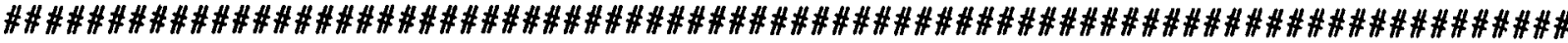

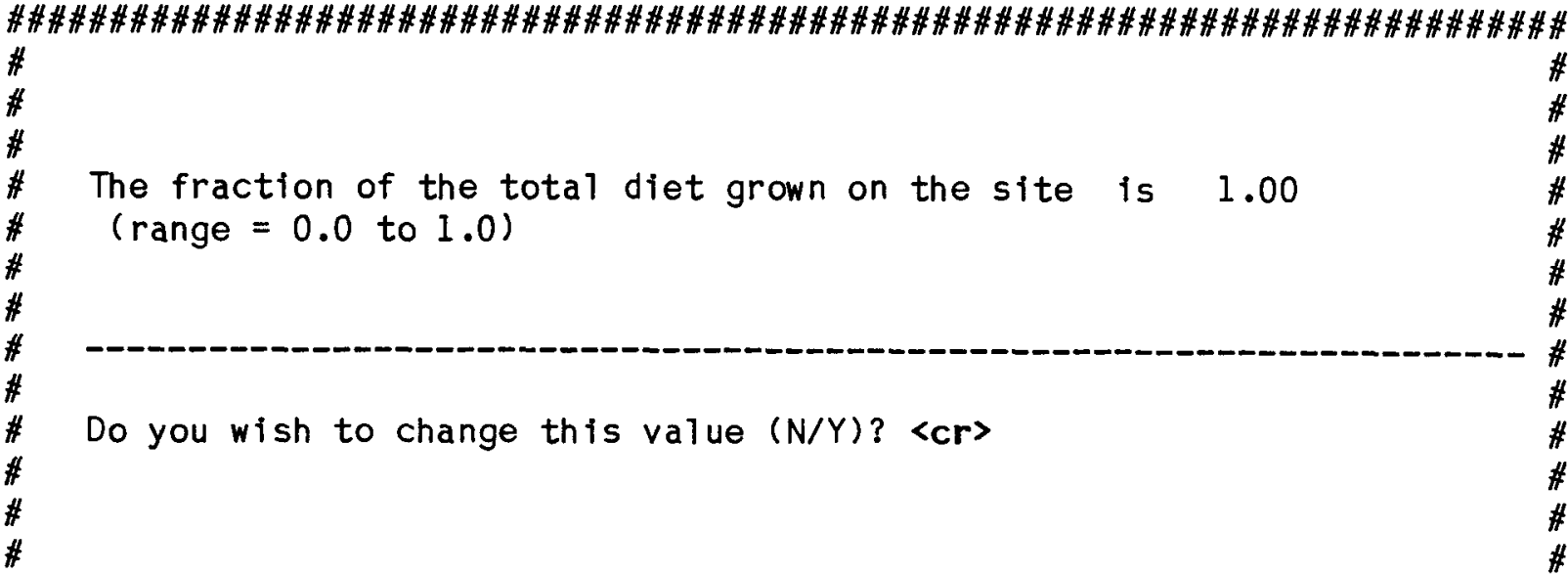

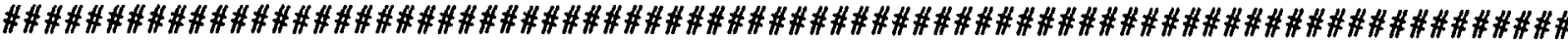

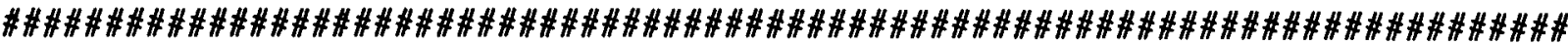

$\#$

The irrigation rate in liters per square meter per month is 150 .

Do you wish to change this value $(N / Y)$ ? $\langle c r\rangle$

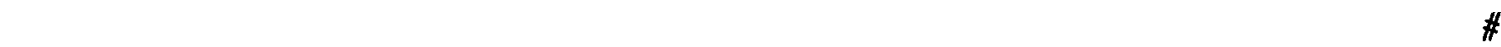

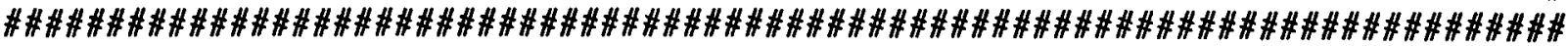

Figure 3.4-9. Sample Problem Five Interactive Session (Continued) 


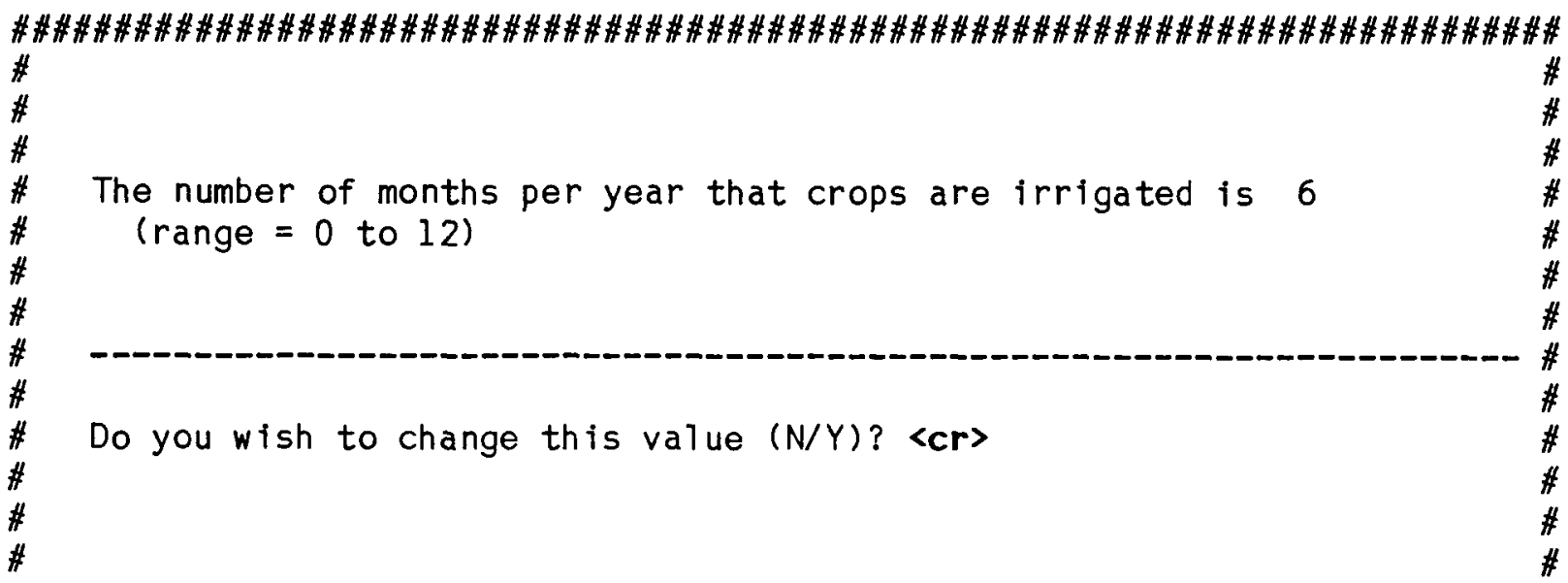

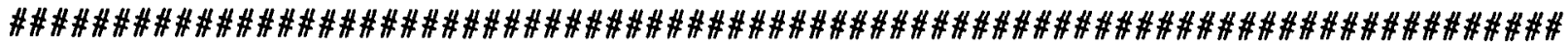

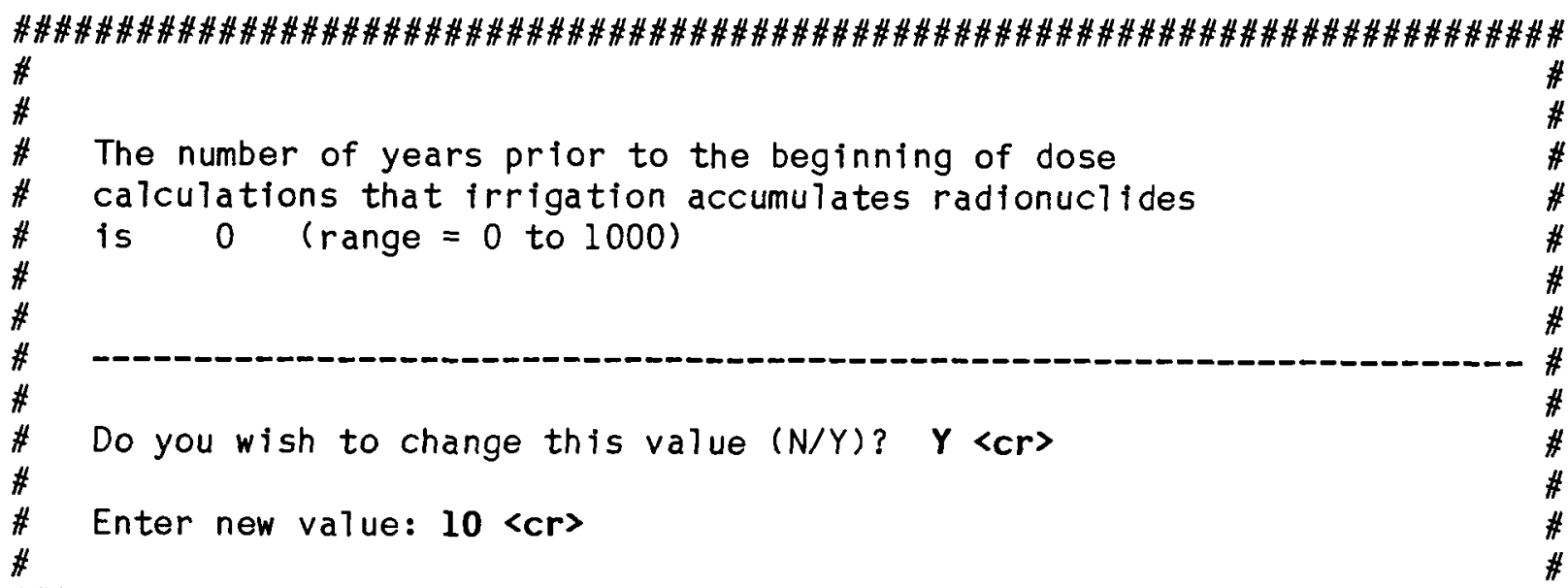

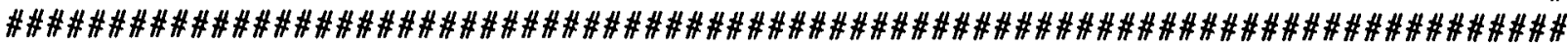

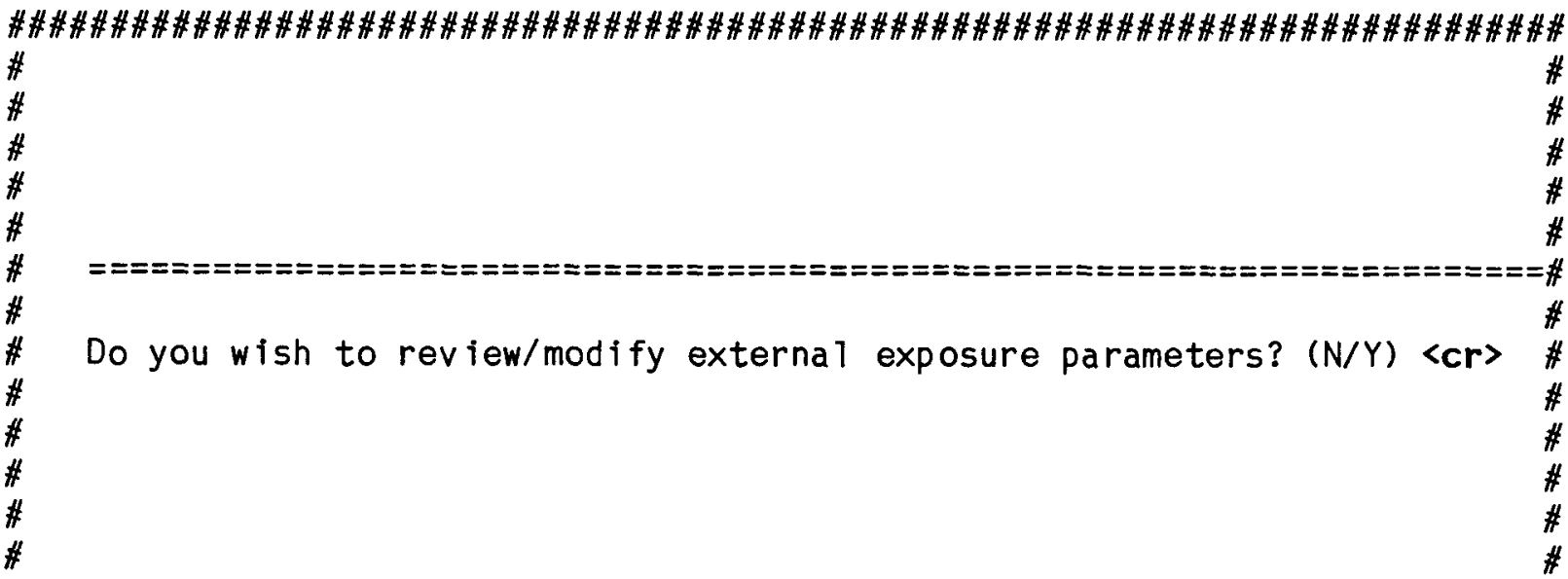

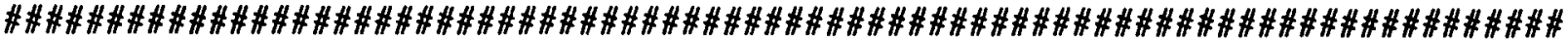

Figure 3.4-9. Sample Problem Five Interactive Session (Continued)

3.63 


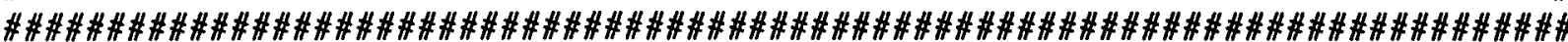

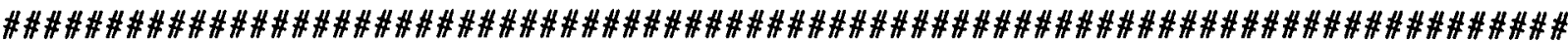$$
\text { \# }
$$$$
\text { \# }
$$$$
\text { \# }
$$$$
\text { \# }
$$$$
\text { \# }
$$$$
\text { \# }
$$$$
\#
$$
\#\#\#\#\#\#\#\#\#\#\#\#\#\#\#\#\#\#\#\#\#\#\#\#\#\#\#\#\#\#\#\#\#\#\#\#\#\#\#\#\#\#\#\#\#\#\#\#\#\#\#\#\#\#\#\#\#\#\#\#\#\#\# Figure 3.4-9. Sample Problem Five Interactive Session (Continued) dose rate factor file for this scenario? (default=0)

$$
\begin{aligned}
& 0 \text { - no } \\
& 1 \text { - yes }
\end{aligned}
$$

Do you wish to change this value $(N / Y)$ ? 〈cr

The number of hours of exposure to external contamination

per year is $8.766 \mathrm{E}+03$ (range $=0.0$ to 8766. )

Do you wish to change this value $(N / Y)$ ? $Y\langle c r\rangle$

Enter new value: $2000\langle c r\rangle$

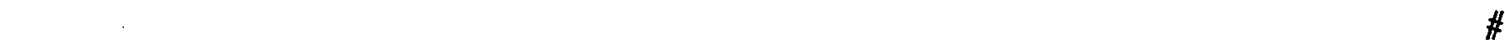

Do you wish to review or change inhalation parameters $(N / Y)$ Y $\langle c r\rangle$ \# $\not$ \#

Did you use MAXI2 to generate a special external exposure 
\# The number of hours of inhalation of contamination

Do you wish to change this value $(N / Y)$ ? $Y\langle c r\rangle$

Enter new value: $2000\langle c r\rangle$

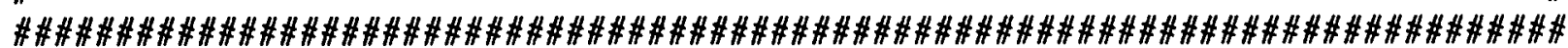

\#\#\#\#\#\#\#\#\#\#\#\#\#\#\#\#\#\#\#\#\#\#\#\#\#\#\#\#\#\#\#\#\#\#\#\#\#\#\#\#\#\#\#\#\#\#\#\#\#\#\#\#\#\#\#\#\#\#\#\#\#\#\#\#\#

$\#$

\#

Two resuspension models are available:

1 - Anspaugh

2 - Mass Loading

The selected model is 2

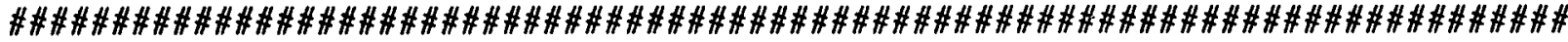

\#\#\#\#\#\#\#\#\#\#\#\#\#\#\#\#\#\#\#\#\#\#\#\#\#\#\#\#\#\#\#\#\#\#\#\#\#\#\#\#\#\#\#\#\#\#\#\#\#\#\#\#\#\#\#\#\#\#\#\#\#\#\#\#\# \#

The density of the soil is (range $=1 . E 5$ to $5.0 E 7$ )

$1.0 E+06$ grams per cubic meter.

\#

$\#$

\#

$\#$

$\#$

Do you wish to change this value $(N / Y)$ ? 〈cr

Figure 3.4-9. Sample Problem Five Interactive Session (Continued) 


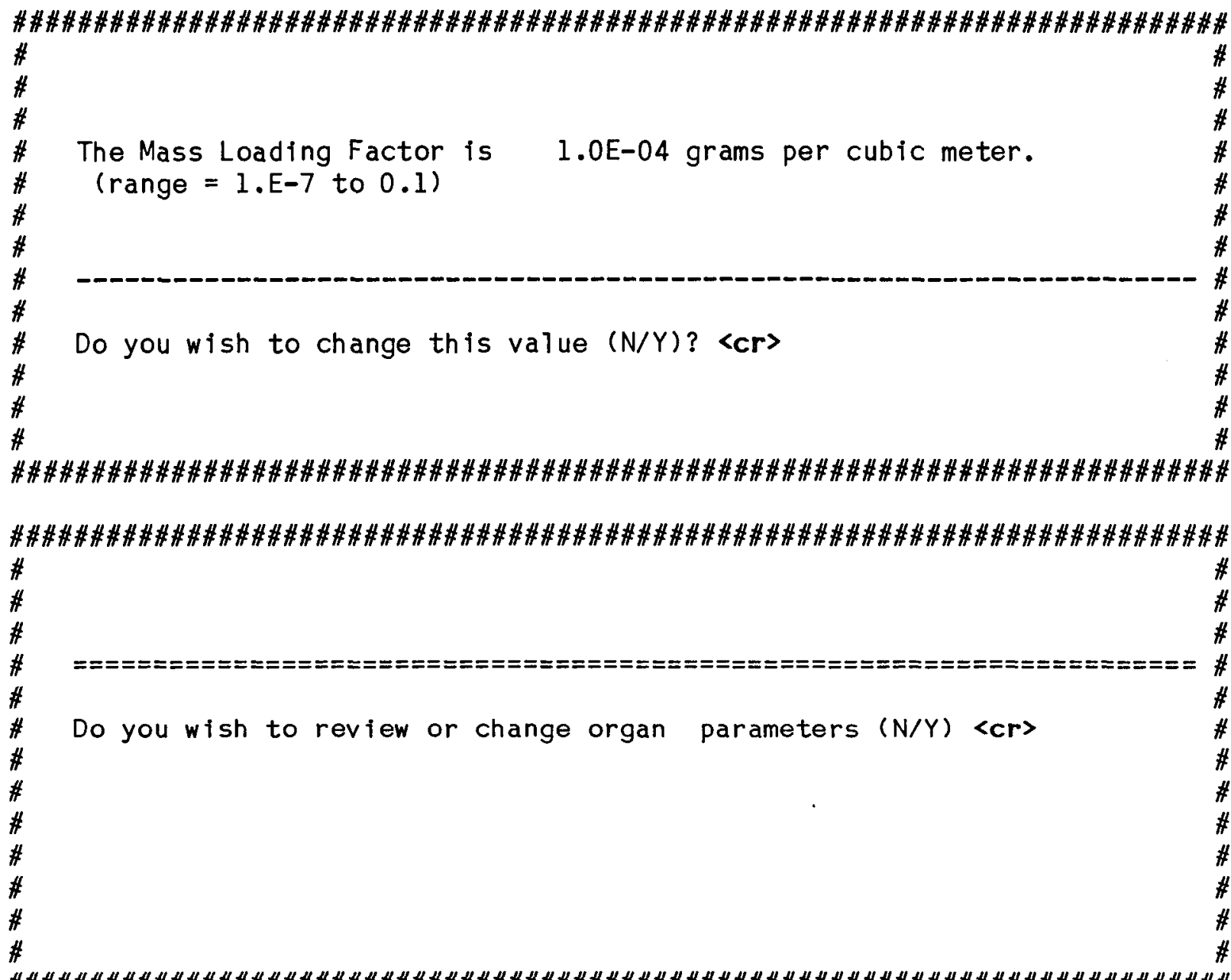

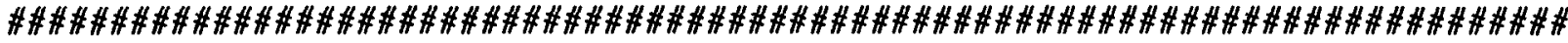

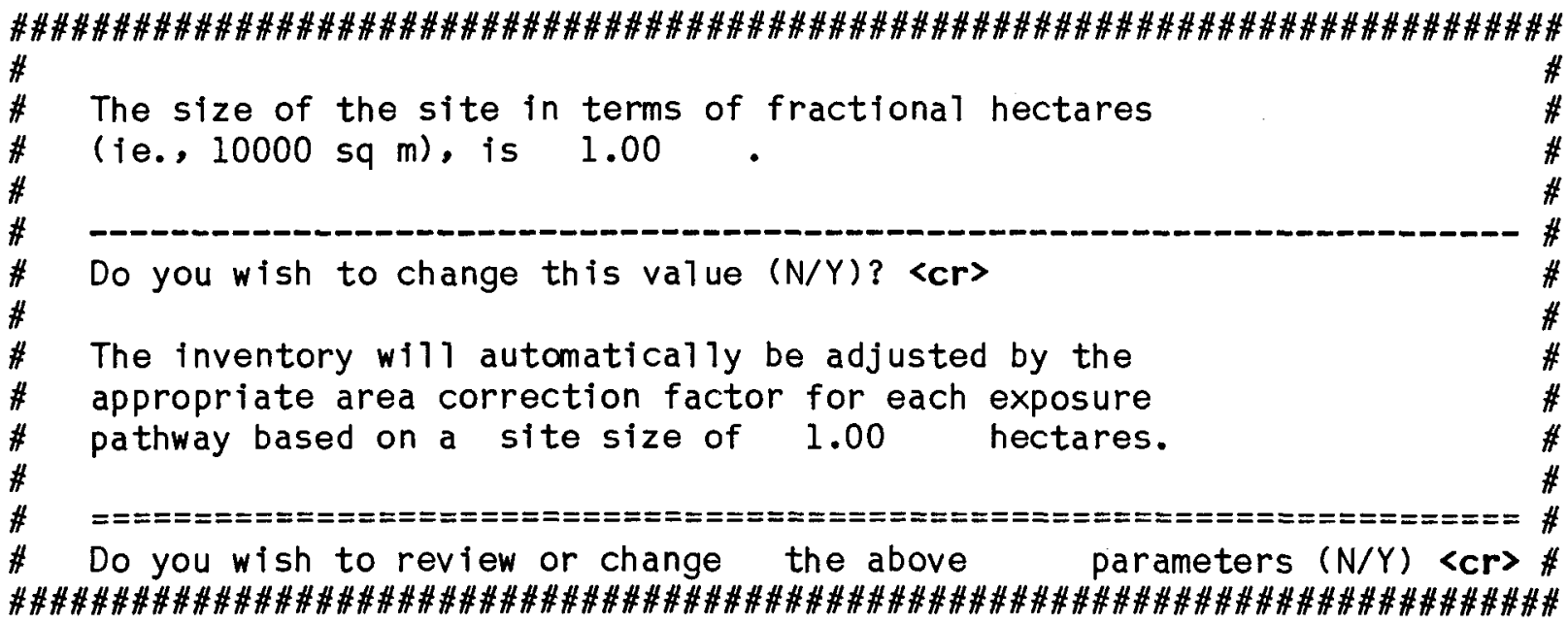

Figure 3.4-9. Sample Problem Five Interactive Session (Continued) 


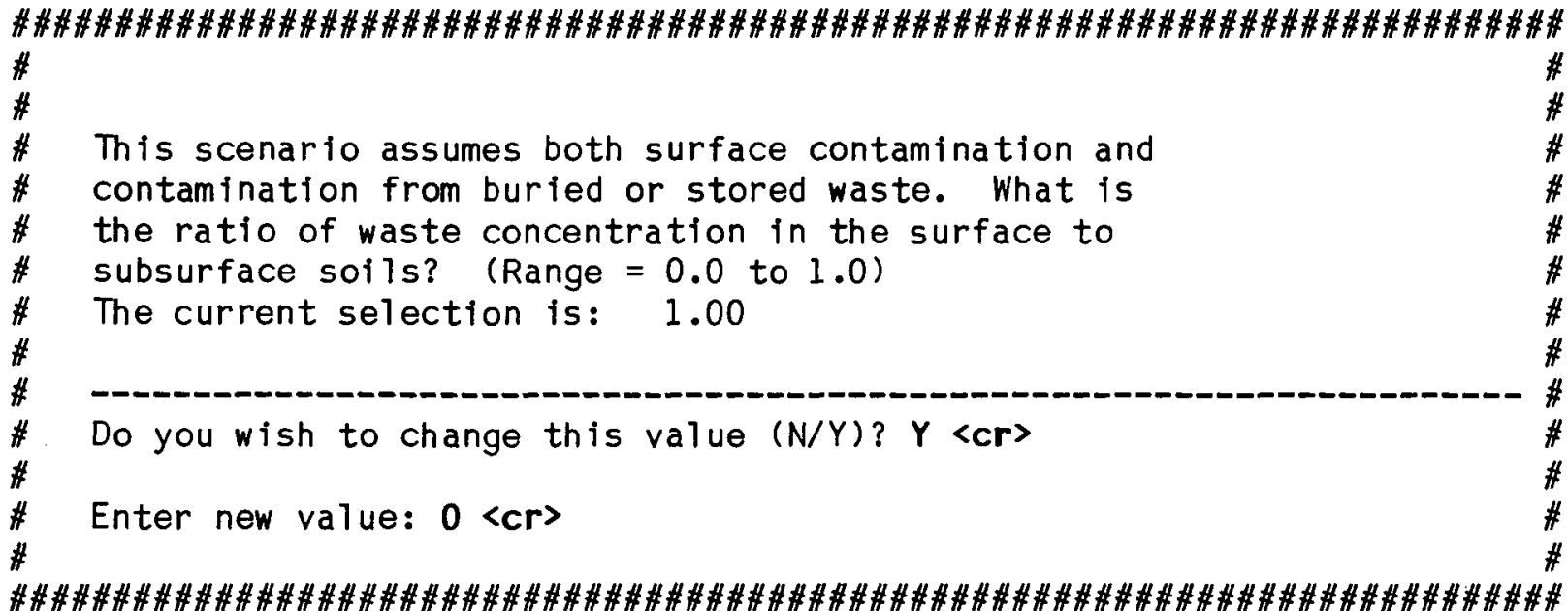

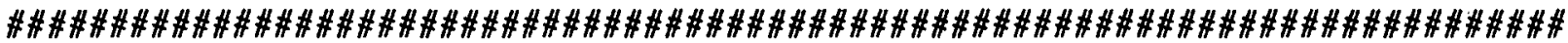

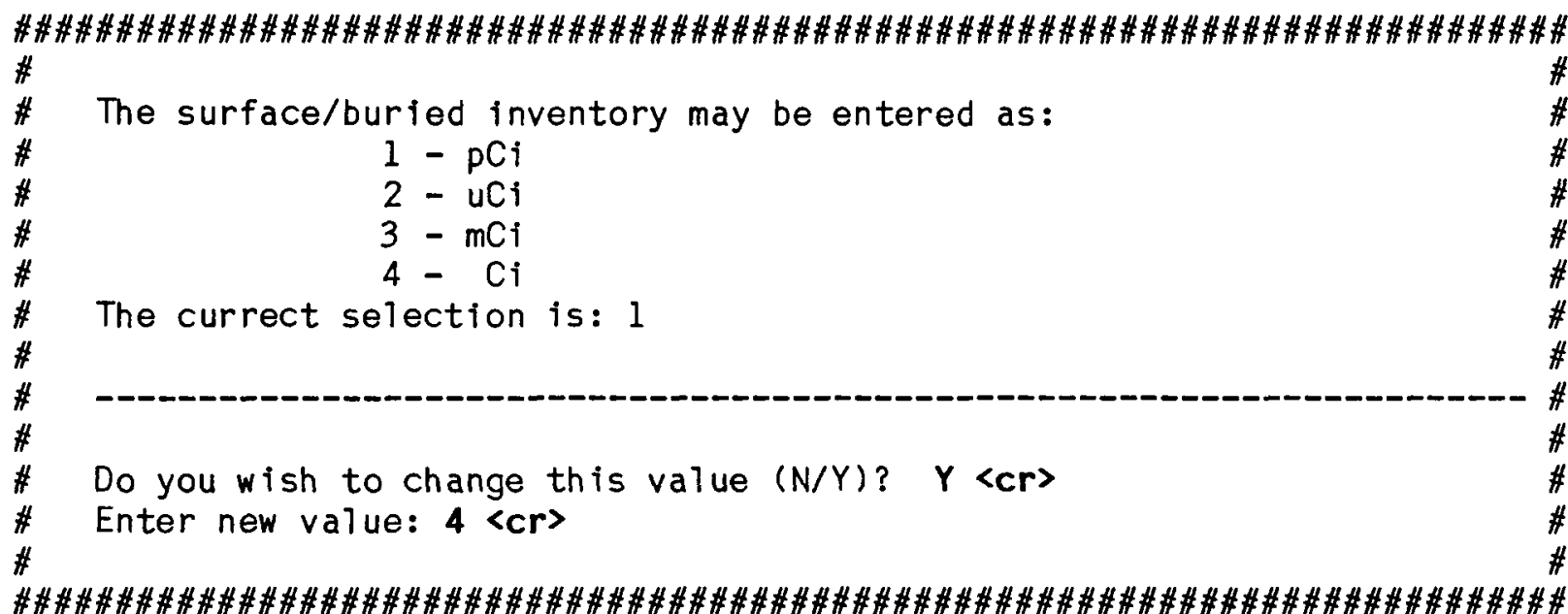

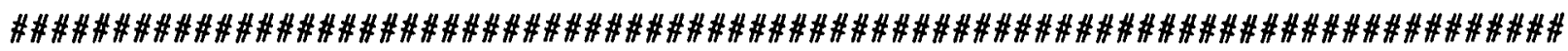

\#

\# The contamination deposited on the site at start of

\# calculation may be entered in the following units:

$\#$

$\#$

\#

$\#$

\#

\#

\#

\#

\#

\#

0 - Ci /square meter

1 - Ci / cubic meter

$2-\mathrm{Ci} / \mathrm{Kg}$ of soil

The current selection is: 1

\#

Do you wish to change this value $(N / Y)$ ? $\langle\mathrm{cr}\rangle$

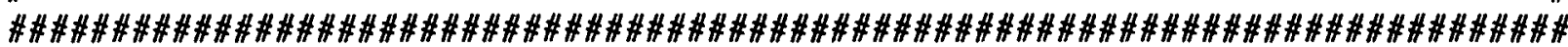

Figure 3.4-9. Sample Problem Five Interactive Session (Continued) 
Do you wish to change this value (N/Y)? <cr>

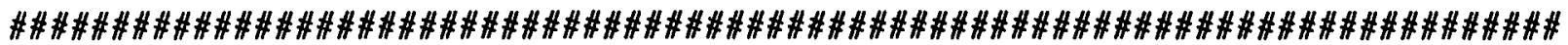

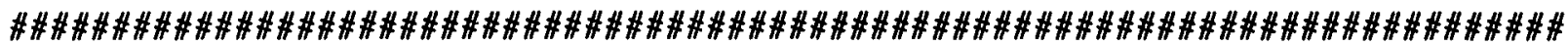
\#

Do you wish to review or change any of the above parameters $(N / Y)\langle c r\rangle$ \#

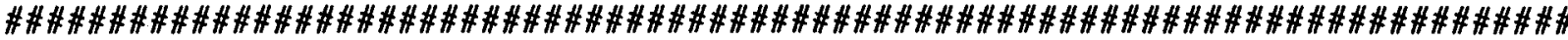

Do you wish to review and/or change solubility classification for each organ for each radionuclide. The default assumption is elements are insoluble for lung and soluble for all other organs. (N/Y) <cr

The following questions pertain to the radionucilide

inventory. After inputting the inventory, enter

"99" for element name to signal to the program that you are finished.

Figure 3.4-9. Sample Problem Five Interactive Session (Continued) 
Enter new 2-character element $(99=f i n i s h e d)$ : $C O\langle c r\rangle$

Atomic number input can be up to 6 characters long.

Include metastable $(M)$ and daughter $(+D)$ designation, (1.e., TEl 27M+D) \#

Enter atomic number: $60\langle\mathrm{cr}\rangle$

Enter the quantity of 0060 deposited on the site at start of

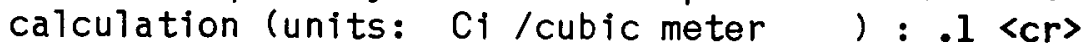

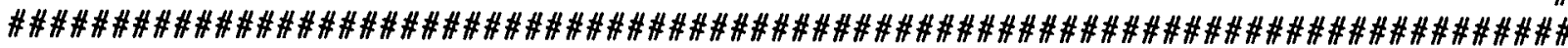

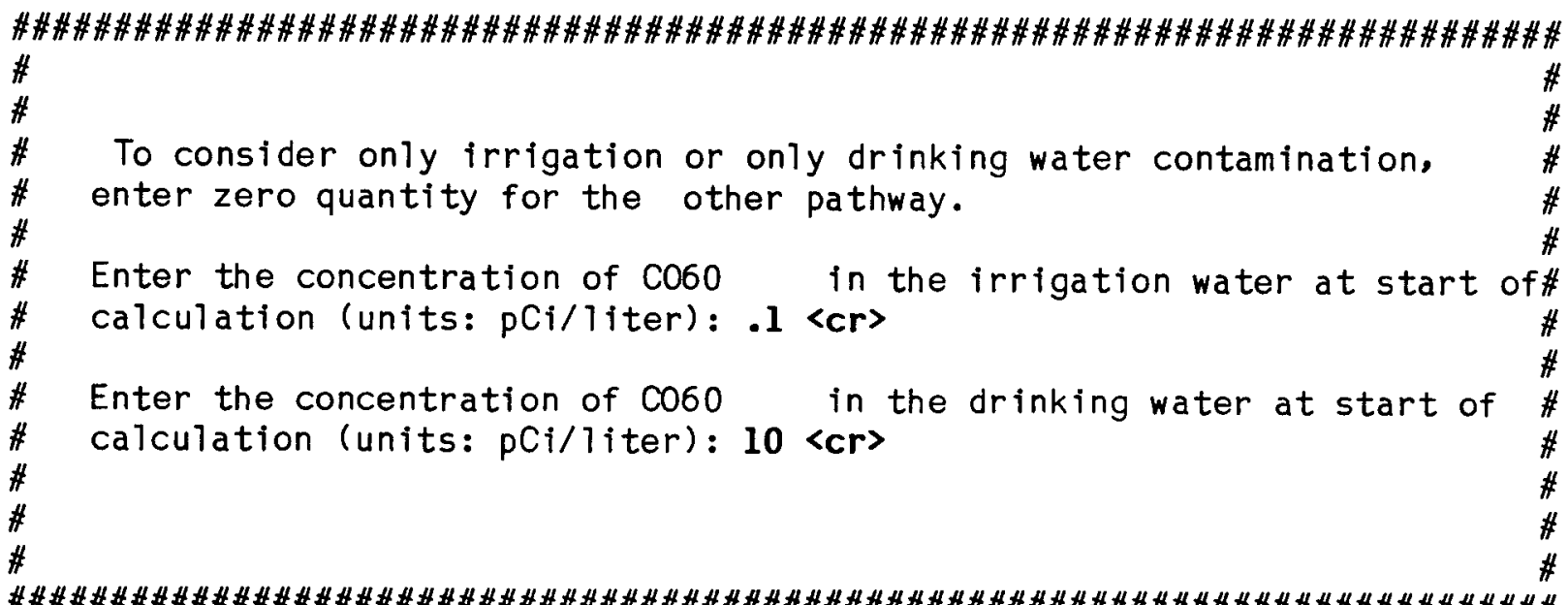

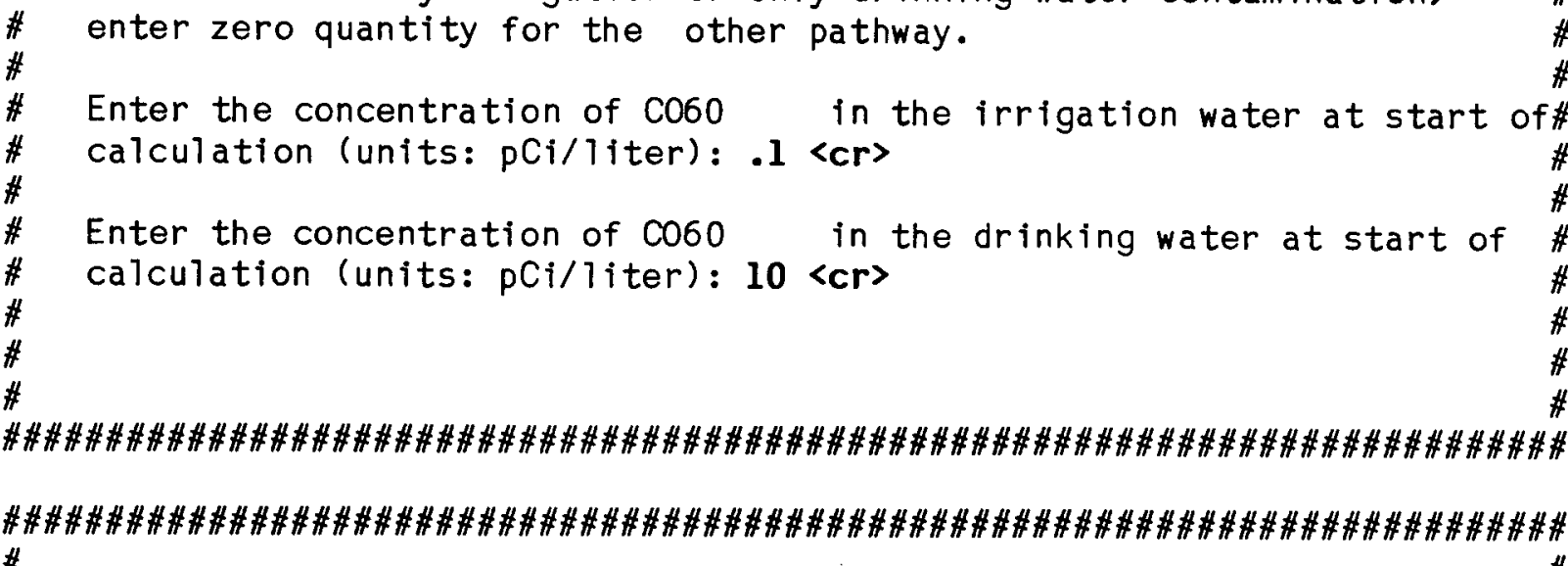

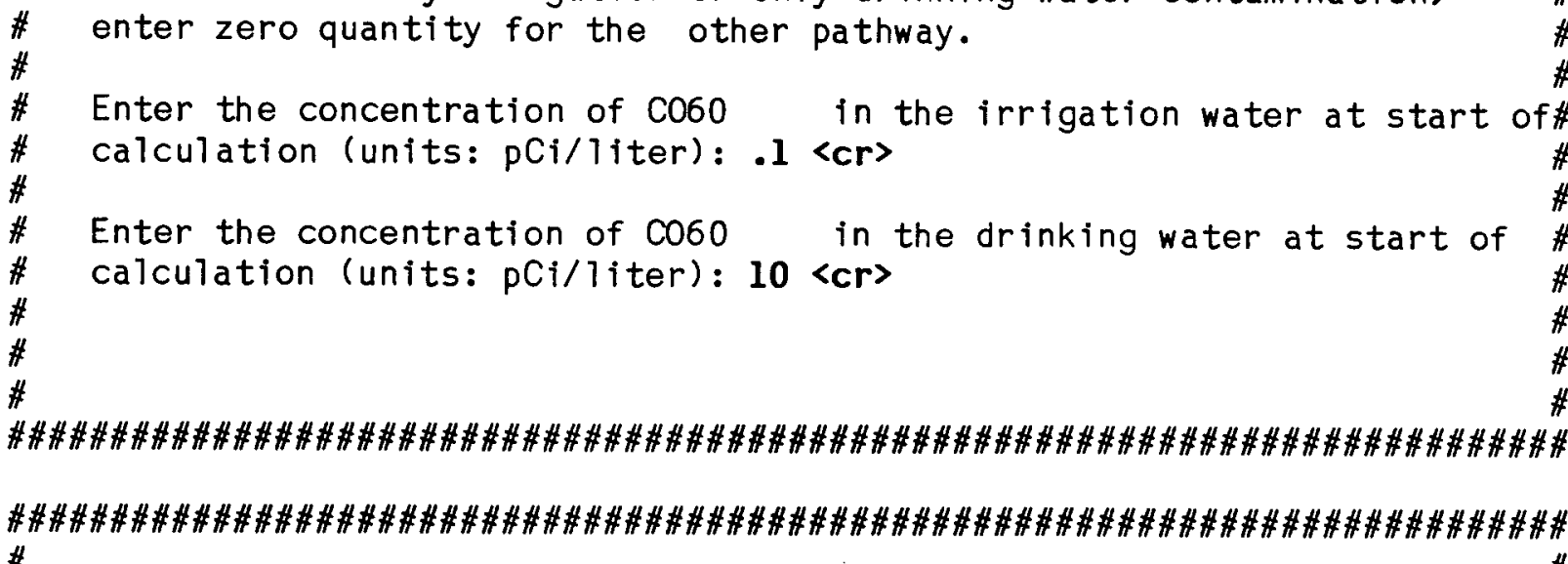

\#

\#) calculation (units: Ci lcubic meter, ):

Enter new 2-character element (99=finished): I 〈cr

Atomic number input can be up to 6 characters long.

Include metastable $(M)$ and daughter $(+D)$ designation, (i.e., TEl $27 M+D)$ \#

Enter atomic number: 129 〈cr> \# \#

Enter the quantity of I 129 deposited on the site at start of

calculation Cunits: Ci lcubic meter, ):

Figure 3.4-9. Sample Problem Five Interactive Session (Continued)

西
(1) 


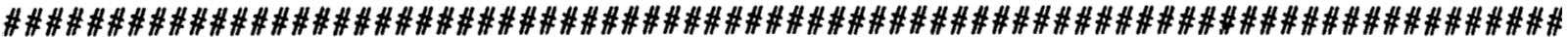

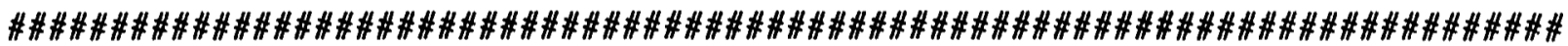

$\#$

\#

\#

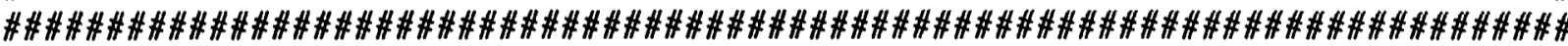

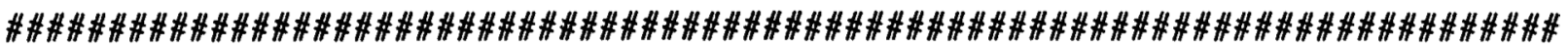

\#

\#

Figure 3.4-9. Sample Problem Five Interactive Session (Continued)

To consider only irrigation or only drinking water contamination, \# enter zero quantity for the other pathway.

Enter the concentration of SR90+D in the irrigation water at start of \# calculation (units: pCi/liter): .1 〈cr

Enter the concentration of SR90+D in the drinking water at start of calculation (units: $\mathrm{pCi} / \mathrm{liter}$ ): $10\langle\mathrm{cr}\rangle$

$\#$
$\#$
$\#$
$\#$
$\#$
$\#$
$\#$
$\#$
$\#$
$\#$
$\#$
$\#$

Atomic number input can be up to 6 characters 10 ng.

Include metastable (M) and daughter (+D) designation, (i.e., TE127M+D) \#

Enter atomic number: $\mathbf{9 0 + D}\langle\mathrm{cr}\rangle$

Enter the quantity of SR90+D deposited on the site at start of calculation (units: Ci /cubic meter ) : .001 〈cr〉 \# . 
Enter new 2-character element $(99=$ finished $): \mathbf{U}\langle c r\rangle$

Atomic number input can be up to 6 characters 10 ng.

Include metastable $(M)$ and daughter ( $+D)$ designation, (i.e., TEl27M+D)

Enter atomic number: $\mathbf{2 3 8 + D}\langle\mathrm{Cr}\rangle$

Enter the quantity of $U 238+D$ deposited on the site at start of

calculation (units: Ci /cubic meter ) : .1 〈cr

\#

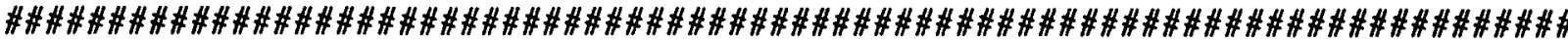

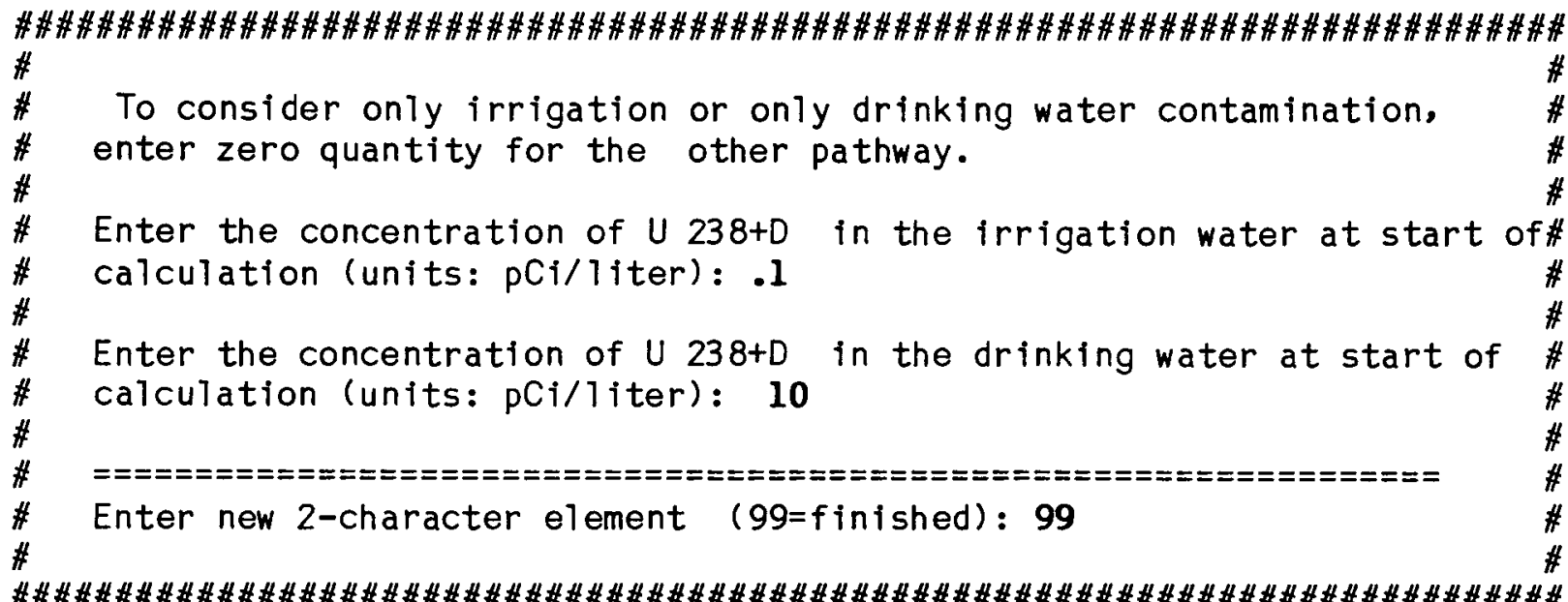

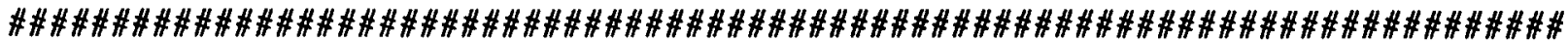

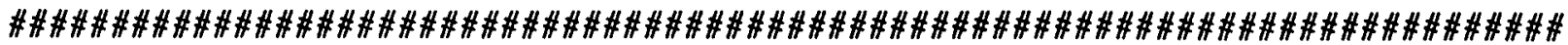

\#

\#

\#

\#

\#

\#

\#

\#

\#

\#

\#

\#

\#

\#

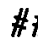

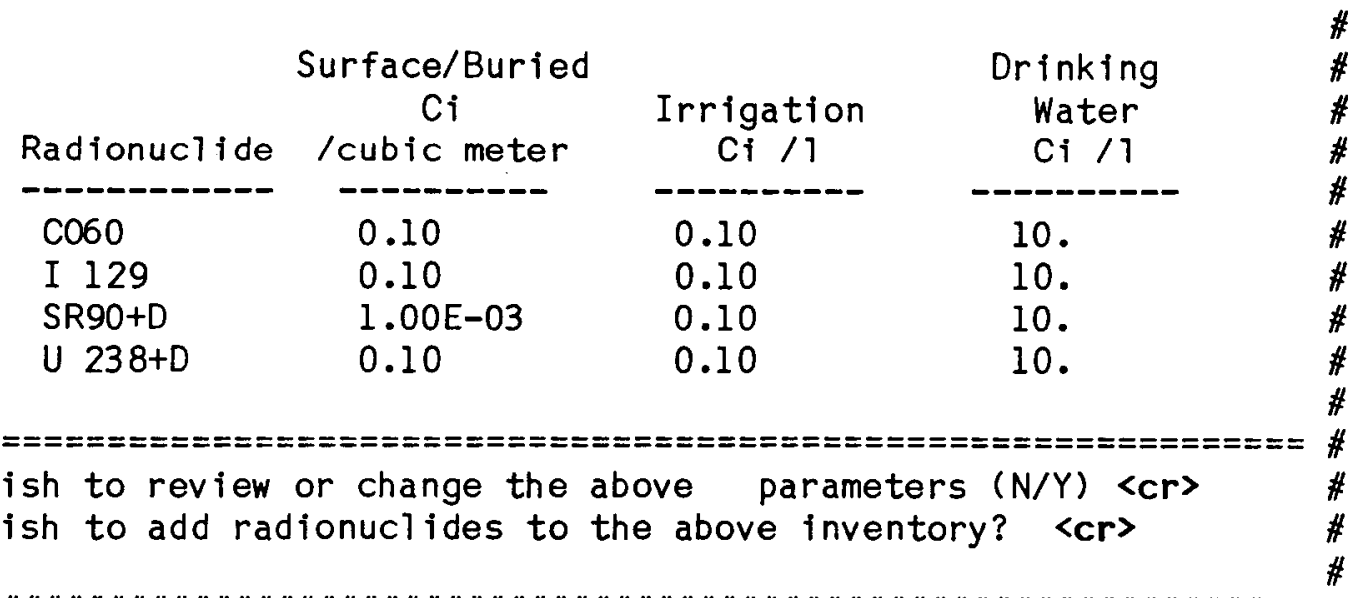

Do you wish to review or change the above parameters $(N / Y)\langle c r\rangle$

Do you wish to add radionuclides to the above inventory? <cr>

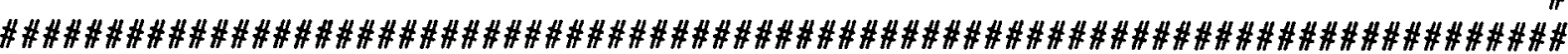

Figure 3.4-9. Sample Problem Five Interactive Session (Continued) 
(This interactive session generates the following file.)

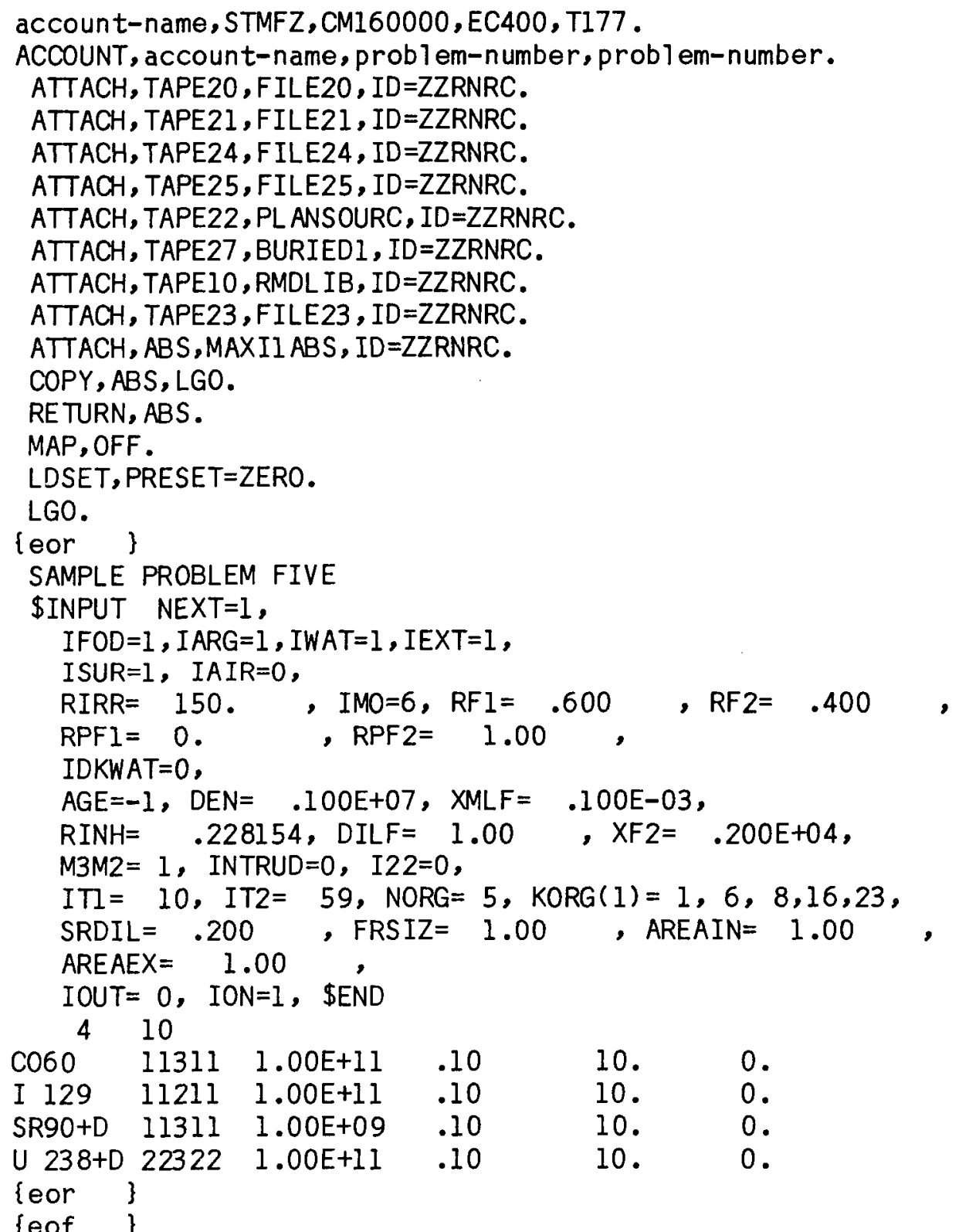

Figure 3.4-9. Sample Problem Five Interactive Session (Continued) 
RADIONUCL IDE CHAIN LIBRARY USED:

DOSE FACTOR FILES USED FOR THIS CASE
* 20 FOOD-LEAF :
*21 FOOD-SOIL:
* 22 SHALlow external:
*23 DACRIN-INHAL ATION
*24 ARRRG-FISH:
*25 ARRRG-DRINK' H20:
Leaf Incremental Dose Factors for the ONSITE/BIOPORT Soll Incremental Dose Factors for the ONSITE/BIOPORT ONSITE/BIOPORT EXTERNAL DRFS FOR SURFACE (PLANE SOUR DOS) DOSE INCREMENT FILE ONSITE/BIOPORT ENV. 16-APR-84 RAP
Incremental Aquatic Foods Dose Factors - ONSITE/BIOP

RADIONUCLIDE MASTER DATA LIBRARY /W TRANSLOCATION CLASSES, 6-APR-84 RAP

DOSES CALCULATED FROM $\cdot 10$ TO 59 YEARS FOLLOWING TIME ZERO

PATHWAYS INITIAL IZED FOR DOSE CALCULATIONS: FARM PRODUCT INGESTION: ON

INHALATION OF RESUSPENDED MATERIAL:ON

AQUATIC FOODS INGESTION:

DRINKING WATER INGESTION: ON

CONTINUING ATMOSPHERIC DEPOSITION OFF

EXTERNAL FROM BURIED WASTES

ON

$\omega$ EXTERNAL FROM SURFACE DEPOSITS: ON

FARM PRODUCT PARAMETERS USED

FRACTION OF RDOTS IN UPPER SOIL: $0.60 E+00$

FRACTION OF ROOTS IN BURIED WASTE $0.40 E+00$

FRACTION OF TOTAL DIET GROWN ON SITE: $1.00 E+00$

SPECIAL PARAMETERS INITIAL IZED

INVENTORY DILUTION FACTOR: $2.00 E-01$

DECAY OF RIVER RELEASE SOURCE TERM NOT PERFORMED

DECAY OF AIR RELEASE SOURCE TERM NOT PERFORMED

SITE X/Q: $0.00 E+00$

SPECIAL INHALATION MODEL NOT USED

SIZE OF THE SITE: 1.00000 FRACTIONAL HECTARES

INTERNAL PATHWAY AREA CORRECTION FACTOR: $1.00 E+00$

EXTERNAL PATHWAY AREA CORRECTION FACTOR: $1.00 \mathrm{E}+00$

IRRIGATION RATE: $1.50 \mathrm{E}+02 \mathrm{~L} / \mathrm{M} * 2 / \mathrm{MO}$

MONTHS PER YEAR IRRIGATED: 6

RIVER DILUTION FACTOR: 1.00E+0OYR/L

YEARS OF IRRIGATION WITH CONTAMINATED WATER PRIOR TO

THE DOSE CALCULATIONS: 10

EXTERNAL EXPOSURE PARAMETERS USED:

RATIO OF EXTERNAL DONTAMINATION IN SURFACE SOIL TO SUBSURFACE SOIL $0.00 E+00$

NUMBER OF HOURS OF EXPOSURE TO EXTERNAL CONTAMINATION $2.00 E+03$

SURFACE DEPOSITS DRFS FROM ISOSHLD; MODIFICATION FACTOR: $5.844 \mathrm{E}-11$

INHAL ATION PARAMETERS USED:

MODIFICATION FACTOR, RINH: 2.28E-01

(EQUIVALENT TO BREATHING RATE OF $230 \mathrm{CC} / \mathrm{SEC}$ FOR 2000. HR/YR)

RESUSPENSION MODEL USED FOR CALCULATING AIR CONCENTRATION: MASS LOADING

SOIL DENSITY, G/M**3: $1.00 \mathrm{E}+06$

MASS LOADING FACTOR, G/M**3: $1.00 E-04$

ORGANS FOR WHICH DOSES ARE CALCULATED (SAME ORDER AS SOLUBILITIES GIVEN BELOW):

TOTAL BODY

BONE

LUNGS

THYROID

GI-LLI

Figure 3.4-10. Sample Problem Five Output 


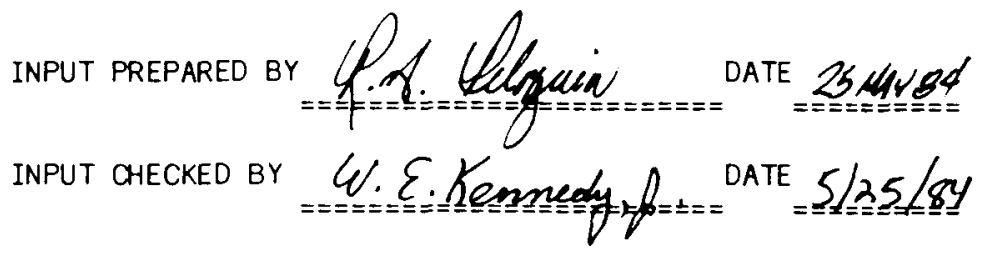

RELEASE TERMS NUCL IDE
$C 060$
SR $90+D$
U $238+D$
I 129

$\begin{array}{ccccc}\text { ORGAN SOLUBILITY } & \text { CLASSE } \\ 1 & 1 & 3 & 1 & 1 \\ 1 & 1 & 3 & 1 & 1 \\ 2 & 2 & 3 & 2 & 2 \\ 1 & 1 & 2 & 1 & 1\end{array}$

IRRIGATATION/AQUATIC

$$
\text { (PCI/L) }
$$

$2.00 E+10$
$2.00 E+08$
$2.00 E+10$
$2.00 E+10$

$1.00 \mathrm{E}-01$
$1.00 \mathrm{E}-01$
$1.00 \mathrm{E}-01$
DRINKING WATER

$(P C I / L)$

$1.00 E+01$
$1.00 E+01$
$1.00 E+01$

ATM. RELEASE

(CI/YR)

$0.00 E+00$

$0.00 E+00$

$0.00 E+00$

$0.00 E+00$

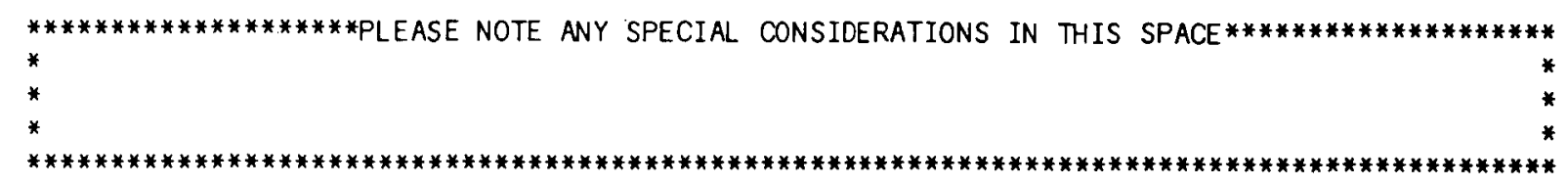

$\stackrel{\omega}{D}$

SOIL, AIR, AND WATER CONCENTRATION SUMMARY FOR THE YEAR

10

RADIONUCL IDE
$\infty 60$
SR $90+D$
U $238+D$
I 129

SURFACE SOIL
PCI /M2
$4.89 \mathrm{E}+02$
$8.58 \mathrm{E}+02$
$9.90 \mathrm{E}+02$
$9.90 \mathrm{E}+02$
DEEP SOIL
$\mathrm{PCI} / \mathrm{MB}$

AIR

PCI/M3

IRRIGATION

PCI/L

DRINKING WATER

PCI/L

$5.35 E+09$
$1.57 E+08$
$2.00 E+10$
$2.00 E+10$

$1.00 \mathrm{E}-01$

$1.00 \mathrm{E}-01$

$1.00 \mathrm{E}-01$

$1.00 E+01$

$1.00 \mathrm{E}+01$

$1.00 E+01$

$9.90 \mathrm{E}+02$

$2.00 \mathrm{E}+10$

$6.60 \mathrm{E}-07$

$1.00 \mathrm{E}-01$

SOIL, AIR, AND WATER CONCENTRATION SUMMARY FOR THE YEAR

$\begin{array}{cccccc}\text { RADIONUCLIDE } & \begin{array}{c}\text { SURFACE SOIL } \\ \text { PCI } / M 2\end{array} & \begin{array}{c}\text { DEEP SOIL } \\ \text { PCI/M3 }\end{array} & \begin{array}{l}\text { AIR } \\ \text { PCI/M3 }\end{array} & \begin{array}{c}\text { IRRIGATION } \\ \text { PCI/L }\end{array} & \begin{array}{c}\text { DRINKING WATER } \\ \text { PCI/L }\end{array} \\ \text { C0 } 60 & 6.38 E+02 & 8.38 E+06 & 4.26 E-07 & 1.00 E-01 & .00 E+01 \\ \text { SR } 90+D & 2.80 E+03 & 4.76 E+07 & 1.87 E-06 & 1.00 E-01 & 1.00 E+01 \\ \text { U 238+D } & 5.40 E+03 & 2.00 E+10 & 3.60 E-06 & 1.00 E-01 & 1.00 E+01 \\ \text { I } 129 & 5.40 E+03 & 2.00 E+10 & 3.60 E-06 & 1.00 E-01 & 1.00 E+01\end{array}$

Figure 3.4-10. Sample Problem Five Output (Continued) 
MAXIMUM ANNUAL DOSE SUMMARY FOR THE YEAR 30 FORTOTAL BODY

\begin{tabular}{|c|c|c|c|c|c|c|c|c|c|c|}
\hline RADIONUCL IDE & $\begin{array}{l}\text { INGESTION } \\
\text { REM }\end{array}$ & $\begin{array}{l}\text { EXPOSURE } \\
\phi\end{array}$ & $\begin{array}{l}\text { PATHWAY } \\
\text { INHALATION } \\
\text { REM }\end{array}$ & $\%$ & $\begin{array}{l}\text { EXTERNAL } \\
\text { REM }\end{array}$ & $\%$ & $\begin{array}{l}\text { AQUATIC F } \\
\text { REM }\end{array}$ & 00 & $\begin{array}{l}\text { DRINKING } \\
\text { REM }\end{array}$ & $\begin{array}{r}\text { WATER } \\
\%\end{array}$ \\
\hline $\begin{array}{l}\text { CO60 } \\
\text { SR90+D } \\
\text { U } 238+D \\
\text { I } 129\end{array}$ & $\begin{array}{l}8.86 E-04 \\
1.08 E+00 \\
1.25 E-01 \\
3.11 E-01\end{array}$ & $\begin{array}{r}0 \\
71 \\
8 \\
20\end{array}$ & $\begin{array}{l}5.16 E-12 \\
2.51 E-09 \\
1.65 E-09 \\
2.36 E-11\end{array}$ & $\begin{array}{r}0 \\
59 \\
39 \\
0\end{array}$ & $\begin{array}{l}2.10 E-05 \\
5.05 E-08 \\
2.27 E-06 \\
1.60 E-08\end{array}$ & $\begin{array}{r}90 \\
0 \\
9 \\
0\end{array}$ & $\begin{array}{l}2.04 E-07 \\
2.55 E-05 \\
1.45 E-06 \\
4.18 E-07\end{array}$ & $\begin{array}{r}0 \\
92 \\
5 \\
1\end{array}$ & $\begin{array}{l}4.12 \mathrm{E}-06 \\
7.60 \mathrm{E}-04 \\
1.39 \mathrm{E}-04 \\
3.22 \mathrm{E}-05\end{array}$ & $\begin{array}{r}0 \\
81 \\
14 \\
3\end{array}$ \\
\hline TOTALS & $\begin{array}{l}\text { INGESTION } \\
1.52 E+00\end{array}$ & $\begin{array}{r}\% \\
99\end{array}$ & $\begin{array}{l}\text { INHAL ATION } \\
\mathbf{4 . 2 0 E - 0 9}\end{array}$ & $0^{\%}$ & $\begin{array}{l}\text { EXTERNAL } \\
2.33 \text { E-05 }\end{array}$ & $0^{*}$ & $\begin{array}{r}\text { AQUATIC } \\
2.76 \mathrm{E}-05\end{array}$ & $\begin{array}{c}000 \% \\
0\end{array}$ & $\begin{array}{l}\text { DRINKING } \\
9.35 \mathrm{E}-04\end{array}$ & $\begin{array}{c}\text { WATER \% } \\
0\end{array}$ \\
\hline
\end{tabular}

MAXIMUM ANNUAL DOSE SUMMARY FOR THE YEAR 30 FOR BONE

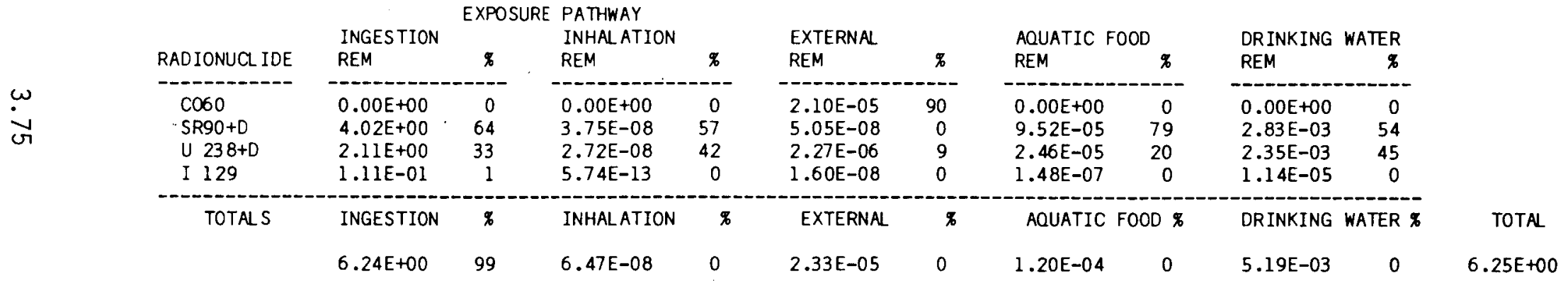

MAXIMUM ANNUAL DOSE SUMMARY FOR THE YEAR 10 FOR LUNGS

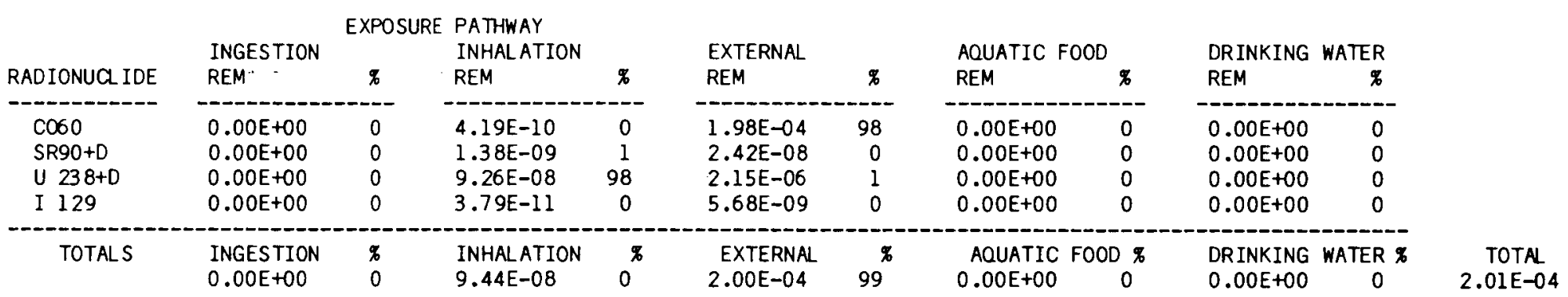

Figure 3.4-10. Sample Problem Five Output (Continued) 
MAXIMUM ANNUAL DOSE SUMMARY FOR THE YEAR 17 FOR THYROID

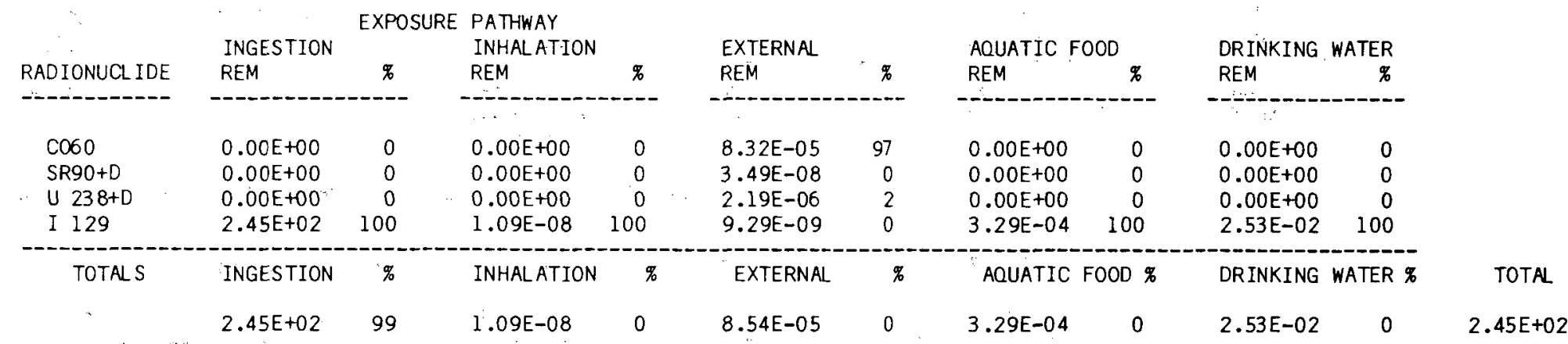

MAXIMUM ANNUAL DOSE SUMMARY FOR THE YEAR IO FOR LLI

\begin{tabular}{|c|c|c|c|c|c|c|c|c|c|c|c|}
\hline RADIONUCL IDE & $\begin{array}{l}\text { INGESTION } \\
\text { REMM }\end{array}$ & $\begin{array}{c}\text { EXPOSURE } \\
\%\end{array}$ & $\begin{array}{l}\text { PATHWAY } \\
\text { INHAL ATION } \\
\text { REM }\end{array}$ & $\%$ & $\begin{array}{l}\text { EXTERNAL } \\
\text { REM }\end{array}$ & $\%$ & $\begin{array}{l}\text { AQUATIC F } \\
\text { REM }\end{array}$ & OD & $\begin{array}{l}\text { DRINKING } \\
\text { REM }\end{array}$ & $\begin{array}{r}\text { WATER } \\
\%\end{array}$ & \\
\hline $\begin{array}{l}C 060 \\
\text { SR90+D } \\
\text { U } 238+D \\
\text { I } 129\end{array}$ & $\begin{array}{l}1.17 \mathrm{E}-01 \\
1.30 \mathrm{E}-01 \\
1.67 \mathrm{E}-01 \\
1.67 \mathrm{E}-02\end{array}$ & $\begin{array}{r}27 \\
30 \\
38 \\
3\end{array}$ & $\begin{array}{l}3.49 \mathrm{E}-12 \\
1.08 \mathrm{E}-11 \\
3.09 \mathrm{E}-11 \\
8.39 \mathrm{E}-14\end{array}$ & $\begin{array}{r}7 \\
23 \\
68 \\
0\end{array}$ & $\begin{array}{l}1.98 \mathrm{E}-04 \\
2.42 \mathrm{E}-08 \\
2.15 \mathrm{E}-06 \\
5.68 \mathrm{E}-09\end{array}$ & $\begin{array}{r}98 \\
0 \\
1 \\
0\end{array}$ & $\begin{array}{l}1.93 \mathrm{E}-06 \\
2.28 \mathrm{E}-06 \\
1.94 \mathrm{E}-06 \\
2.24 \mathrm{E}-08\end{array}$ & $\begin{array}{r}31 \\
36 \\
31 \\
0\end{array}$ & $\begin{array}{l}3.91 \mathrm{E}-05 \\
6.78 \mathrm{E}-05 \\
1.86 \mathrm{E}-04 \\
1.73 \mathrm{E}-06\end{array}$ & $\begin{array}{r}13 \\
23 \\
63 \\
0\end{array}$ & \\
\hline \multirow[t]{2}{*}{ TOTALSS } & INGESTION & $\%$ & INHALATION & $\%$ & EXTERNAL & $\%$ & AQUATIC & $000 \%$ & DRINKING & WATER $\mathscr{\phi}$ & TOTAL \\
\hline & $4.30 E-01$ & 99 & $4.53 E-11$ & 0 & $2.00 \mathrm{E}-04$ & 0 & $6.17 \mathrm{E}-06$ & 0 & $2.95 \mathrm{E}-04$ & 0 & $4.31 E-01$ \\
\hline
\end{tabular}

Figure 3.4-10. Sample Problem Five Output (Continued) 


\subsection{Error and Recovery}

To further ease the user interaction with the ONSITE/MAXIl computer program, error-checking and recovery capabilities have been added. The following paragraphs describe the error and recovery procedures that have been bui $7 t$ into the ONSITE/MAXIl computer program.

\subsubsection{Error and Recovery - ONSITE}

ONSITE has extensive error-checking and interactive recovery capabilities. Most input values are tested against minimum and maximum al lowable limits. If a value does not fall with in the allowable 7 imits, the user is asked immediately to reenter that value.

ONSITE will display error messages if an invalid file name is selected by the user or if the program is enable to locate and access a data base file. The fol lowing messages are displayed by ONSITE. Details of the error condition are discussed and appropriate corrective actions are suggested.

"Error opening radionuclide 1 ibrary." The program could not access the radionuclide library, RMDONS. Refer this problem to the person maintaining the ONSITE/MAXIl computer package.

"Premature end-of-file discovered in library." The program expected additional data in the master radionuclide library, RMDONS. Refer this problem to the person maintaining the ONSITE/MAXIl computer package.

\subsubsection{Error and Recovery - MAXII}

MAXIl generates the fol lowing error messages 1 isted with the source-code module in parentheses. Extended explanations and corrective actions are included, if applicable.

DIAGNOSTIC 1: END OF FILE ON INPUT, STOP (MAIN). The program expected additional input. Suggestion: check use of variable NEXT.

DIAGNOSTIC 2: ERROR ON NAMELIST INPUT (MAIN). The program encountered an error while reading the NAMELIST. Suggestions: check spelling of variable names, check for proper punctuation, verify that column one is blank in each record, and check for "\$END" terminating statement.

DIAGNOSTIC 3: ERROR IN NUMBER OF NUCL IDES. INPUT, NONUC $=n \mathrm{n}$, MAXIMUM ALLOWED IS $n 2$ (MAIN). The program attempts to read NONUC radionuclide data records. Suggestions: verify that NONUC equals the number of radionuclide inventory records, check that NONUC is not greater than the maximum al lowed, and verify format of NONUC record (I5?). 
DIAGNOSTIC 4: END OF INPUT FOR THIS RUN, NORMAL TERMINATION (MAIN). This message is not an error condition; this message is printed to indicate a successful completion of the execution.

DIAGNOSTIC 5: DECAY CHAIN nI HAS IMPROPER ORDER. CURRENT MEMBER INDEX IS n2. (RLIBIN). This message indicates a problem with a decay chain organization while reading the master radionuclide library. Its occurrence indicates that (1) an unsuccessful update was made to the library, or (2) that the file has been corrupted. In either case, refer the problem to the person maintaining the data base.

DIAGNOSTIC 6: IMPROPER NUMBER OF NUCL IDES IN MASTER LIBRARY, NUC $=n$ (RLIBIN). The program expected to find $n$ records in the radionuclide master library. This message indicates that (1) an unsuccessful update was made to the library, or (2) that the file has been corrupted. In either case, refer the problem to the person maintaining the data base.

DIAGNOSTIC 7: END OF FILE ON MASTER LIBRARY UNIT 10. STOP (RLIBIN). The program expected additional records in the master radionuclide library. This message indicates that (1) an unsuccessful update was made to the library, or (2) that the file has been corrupted. In either case, refer the problem to the person maintaining the data base.

DIAGNOSTIC 8: NUMBER OF ISOTOPES FOR DFREAD OUT OF BOUNDS followed by five values which are:
First value - (NISOL) number read in File 20 for leaf DRFs.
Second value - (NISOS) number read in File 21 for soil DRFs.
Third value - (NISOX) number read in File 22 for external-exposure DRFs.
Fourth value - (NISOA) number read in File 24 for aquatic-food DRFs.
Fifth value - (NISOW) number read in File 25 for drinking-water DRFs.

(DFREAD). There is an error in one of the dose rate factor files. The number of isotopes listed in the file does not agree with the specified number also read from the file.

DIAGNOSTIC 9: NUMBER OF YEARS FOR DFREAD OUT OF BOUNDS followed by four values which are:

First value - (NYRL) number read in File 20 for leaf DRFs. Second value - (NYRS) number read in File 21 for soil DRFs.

Third value - (NYRA) number read in File 24 for aquatic-food DRFs. Fourth value - (NYRW) number read in File 25 for drinking-water DRFs.

(DFREAD). One of the dose rate factor files is in error. The number of years listed does not correspond to the number of years specified in the beginning of the file. 
DIAGNOSTIC 10: NUMBER OF ORGANS OUT OF BOUNDS FOR DFREAD fol lowed by four values which are:

First value - (NORGL) number read in File 20 for leaf DRFs. Second value - (NORGS) number read in File 21 for soil DRFs. Third value - (NORGA) number read in File 24 for aquatic-food DRFs.

Fourth value - (NORGW) number read in File 25 for drinking-water DRFs.

(DFREAD). One of the dose rate factor files is in error. The number of organs listed does not correspond to the number of organs specified at the beginning of the file.

DIAGNOSTIC 11: UNIDENTIFIED NUCLIDE name (IDNUC). The program did not find a radionuclide with this name when it checked the master radionuclide 1ibrary. Suggestions: check spelling of name and verify that "name" is included in the master radionuclide library (checking both sections of the 1 ibrary).

DIAGNOSTIC 12: THERE ARE UNIDENTIFIED NUCLIDES, ISTOP $=n$ (IDNUC). This message will appear after Diagnostic 1l, giving the total number $(n)$ of radionuclide names that were not identified in the master radionuclide library. The program will not execute until all name discrepancies have been resolved. Be sure to change the number of radionuclides (NONUC) if any radionuclides are eliminated at this time.

DIAGNOSTIC 13: TOO MANY NUCLIDES ATTEMPTED IN SUBROUTINE SETDAT. INUC $=n$ (SETDAT). More than the maximum allowable number of radionuclides were encountered. This may have been caused by the automatic building in of daughters into the decay chain by the program.

DIAGNOSTIC 14: TEST INUC.NE.NONUC=END - PNTO (PNTO). This error condition occurs when number of radionuclides encountered does not equal the maximum index set.

\subsection{References}

Napier, B. A., R. L. Roswe11, W. E. Kennedy, Jr. and D. L. Strenge. 1980. ARRRG and FOOD - Computer Programs for Calculating Radiation Dose to Man from Radionuclides in the Environment. PNL-3180, Pacific Northwest Laboratory, Richland, Washington.

U.S. Nuclear Regulatory Commission (NRC). 1977. Calculation of Annual Doses to Man From Routine Releases of Reactor Effluents for the Purpose of Evaluating Compliance with 10 CFR Part 50, Appendix I. Regulatory Guide 1.119, Rev.1, U.S. NRC, Washington, D.C. 


\section{PROGRAMMING DETAIL}

The information in this section is not necessary for a theoretical or operational understanding of the ONSITE/MAXIl computer software package. It is included for those who wish to ga in a better understanding of the structure and organization of the computer codes and for the programmer who must maintain or modify the software package.

The organization of the code modules and descriptions of al 1 modules are presented in this section. Flow charts of the program control and simulation control are included. The use of the data arrays, common blocks, and data constants is tabulated for each of the programs. The organization of the input files is presented and the parameters of MAXIl that are not reviewed by ONSITE are identified and described.

\subsection{Program Hierarchy and Structure}

ONSITE/MAXIl is a package of two separate computer codes and a data base. Al1 the computer codes have been designed in modular fashion and are written to meet ANSI-FORTRAN-77 standards. The hierarchical organization of code modules is presented graphically followed by tables describing each module.

MAXIl is controlled by the module named MAIN and calls twenty-one subroutines and one function. The code module hierarchy of MAXIl is presented in Figure 4.1-1. Descriptions of the modules are given in Table 4.1-1.

Table 4.1-1. MAXIl Module Summary

Module Name

ACHAIN

AFACT

AIRDIS

ANDOS

ASUM

\section{Major Function and Description of Module}

Calculates radiological decay for one radionuclide chain. (Subroutine called by SOLCON and WATER.)

Caiculates a resuspension factor using the Anspaugh model. (Subroutine called by PADOS.)

Decays the atmospheric release source term, if necessary. (Subroutine called by PADOS.)

Calculates annual doses. (Subroutine called by MAIN.)

Sums the terms of an array. (Function called by ACHAIN.) 
Table 4.1-1. MAXIl Module Summary (Continued)

Medule Name

DFREAD

DUMMY

IDNUC

INSET

MAIN

MAXDOS

MLOAD

OUTPUT

PADOS

PNTO

QAPAGE

RDSUB

\section{Major Function and Description of Module}

Reads dose rate factor 1 ibraries, except inhalation. (Subroutine called by MAIN)

Reads past unused entries in inhalation dose rate factor library. (Subroutine called by INSET.)

Identifies input radionuclides in the inventory. (Subroutine called by MAIN.)

Reads the inhalation dose rate factor library. (Subroutine called by MAIN.)

Controls 7 ibrary and parameter input, data organization, dose calculations, report printing and successive case handling. (Controlling module.)

Calculates maximum annual dose. (Subroutine called by MAIN.)

Calculates a mass-loading factor. (Subroutine called by PADOS.)

Prints report of results. (Subroutine called by MAIN.)

Calculates pathway doses. (Subroutine called by MAIN.)

Prints the resulting time dependent soil, air, irrigation-water and drinking-water

concentrations. (Subroutine called by PADOS.)

Prints a report of input variables. (Subroutine called by MAIN.)

Initializes inventory arrays and sets input inventory data into arrays. This subroutine is used only when special option is set. (Subroutine cal led by MAIN.) 
Table 4.1-1. MAXIl Module Summary (Continued)

Module Name

RLIBIN

SETDAT

SOLCON

WATER

ZEROI

ZEROR

CHANGE
Major Function and Description of Module

Reads master radionuclide library with chain decay. (Subroutine called by MAIN.)

Stores data for this radionuclide in arrays (Subroutine called by MAIN.)

Calculates the soil concentration accounting for both radioactive decay and deposition of radionuclides in irrigation water. (Subroutine called by PADOS.)

Decays the water release source term, if necessary. (Subroutine called by PADOS.)

Initializes an integer array to zero. (Subroutine called by IDNUC and SETDAT.)

Initializes a real array to zero. (Subroutine cal led by SETDAT, INSET, PADOS, ANDOS, and MAXDOS.)

Query if user requests parameter value change; and if so, input new value, test if within al lowable limits, and repeat if not accepted. (Subroutine cal led by ONSITE, RADIN, QUANTI, and MODIF.) 


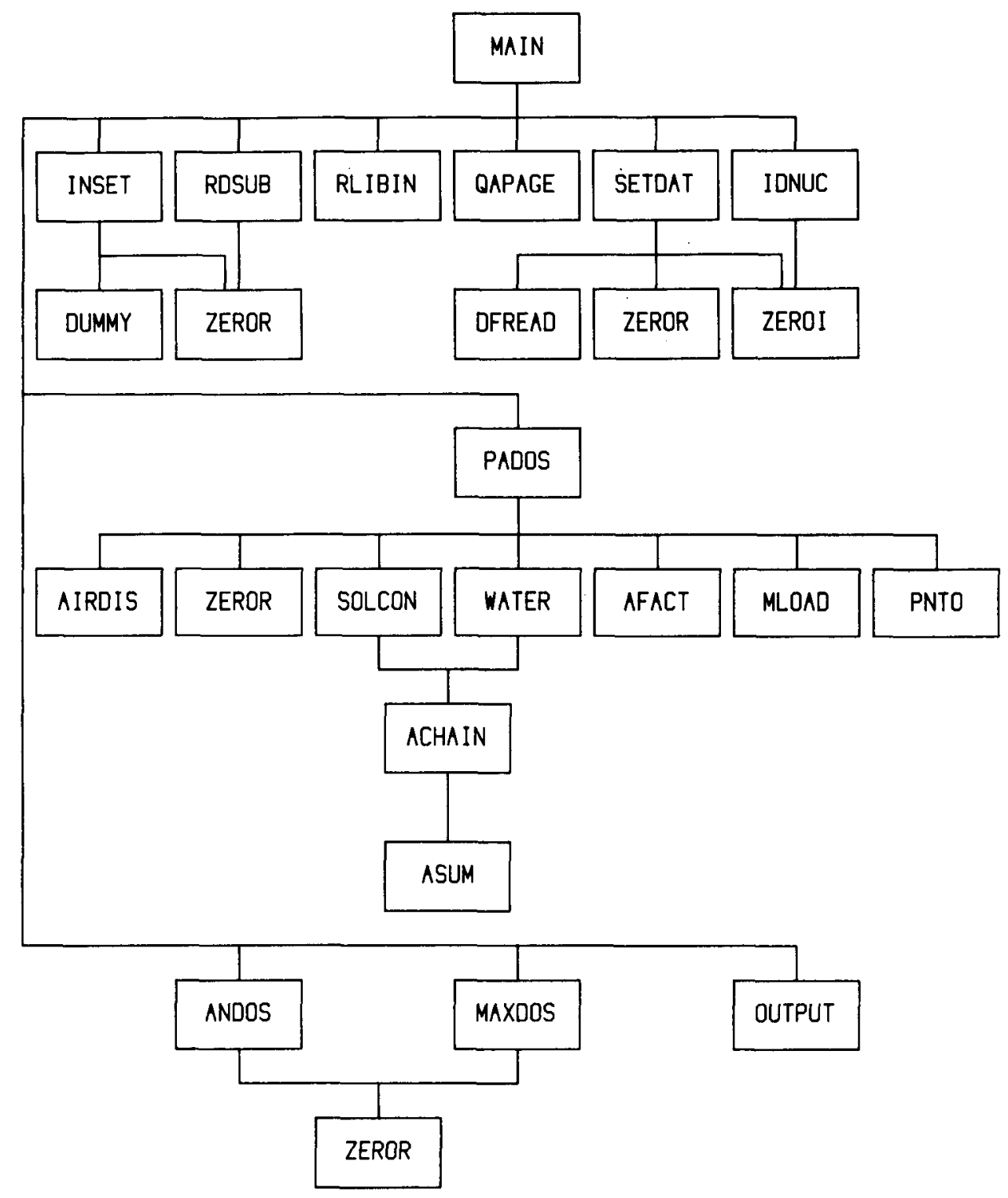

Figure 4.1-1. MAXIl Design Hierarchy

The interactive program ONSITE is organized into twelve modules; ONSITE, the control program, and 11 subroutines. Figure 4.1-2 depicts the module hierarchy of ONSITE. Table 4.1-2 presents a summary of the modules. 


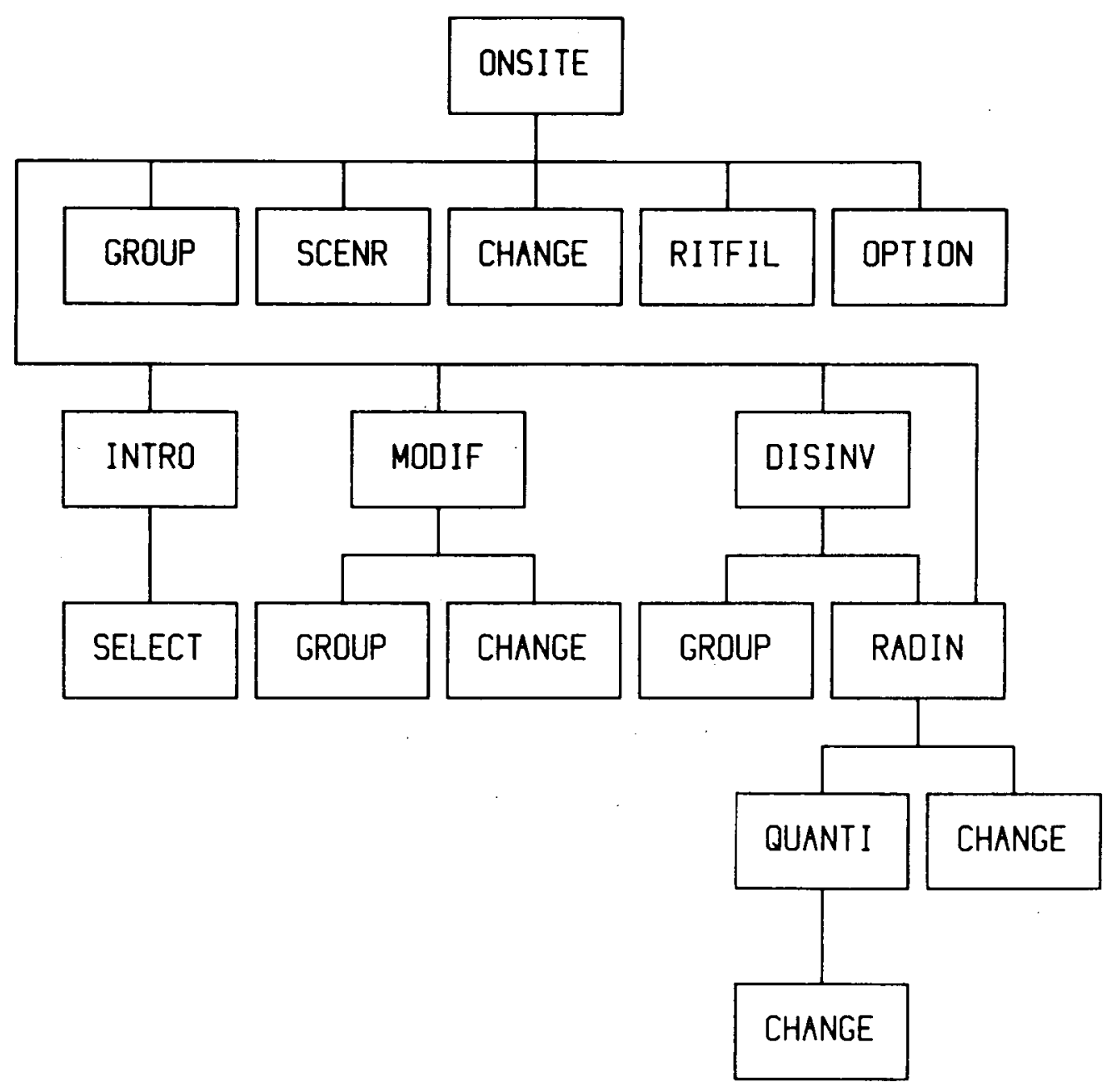

Figure 4.1-2. ONSITE Design Hierarchy

Table 4.1-2. ONSITE Module Summary

Module Name

DISINV

GROUP

INTRO

\section{Major Function and Description of Module}

Display report of radionucl ide inventory and control modification and additions to the inventory. (Subroutine called by ONSITE.)

Query if user wishes to review/modify any of a given collection of parameters. (Subroutine cal led by MODIF, ONSITE, and DISINV.)

Display introductory message, instructions, and scenario descriptions on screen. (Subroutine called by ONSITE.) 
Table 4.1-2. ONSITE Module Summary (Continued)

Module Name

MODIF

ONSITE

OPTION

QUANTI

RADIN

RITFIL

SCENR

SELECT
Major Function and Description of Module

Display for review and/or modification applicable parameters for each scenario; establish modified parameter values. (Subroutine called by ONSITE.)

Control program functions and review general parameters. (Controlling module.)

Allow user to modify selected pathway options in a user-created scenario. (Subroutine called by ONSITE.)

Input source terms for each radionuclide. (Subroutine called by RADIN.)

Input and test radiological source term; allow modification of translocation indices, if selected. (Subroutine called by ONSITE and DISINV.)

Write MAXIl input file. (Subroutine called by ONSITE.)

Establish default parameters for the selected scenario. (Subroutine called by ONSITE.)

Display menu of scenario selection and input user'! choice. (Subroutine called by INTRO.)

\subsection{Computer Program Flow}

The logic of the computer programs in the ONSITE/MAXI software package is depicted using flow-charting techniques described by Chapin (1974). The reader is presented concise overviews of the program control logic and the calculation control logic. Detailed flow charts are not provided for the foll lowing reasons: 1) the codes are modularly designed, 2) the logic within each module is readily apparent, and 3 ) each module is enhanced with comments. Figure 4.2-1 depicts MAXIl program control logic and Figure 4.2-2 summarizes MAXIl dose calculation logic. The program logic of ONSITE is charted in Figure 4.2-3. 


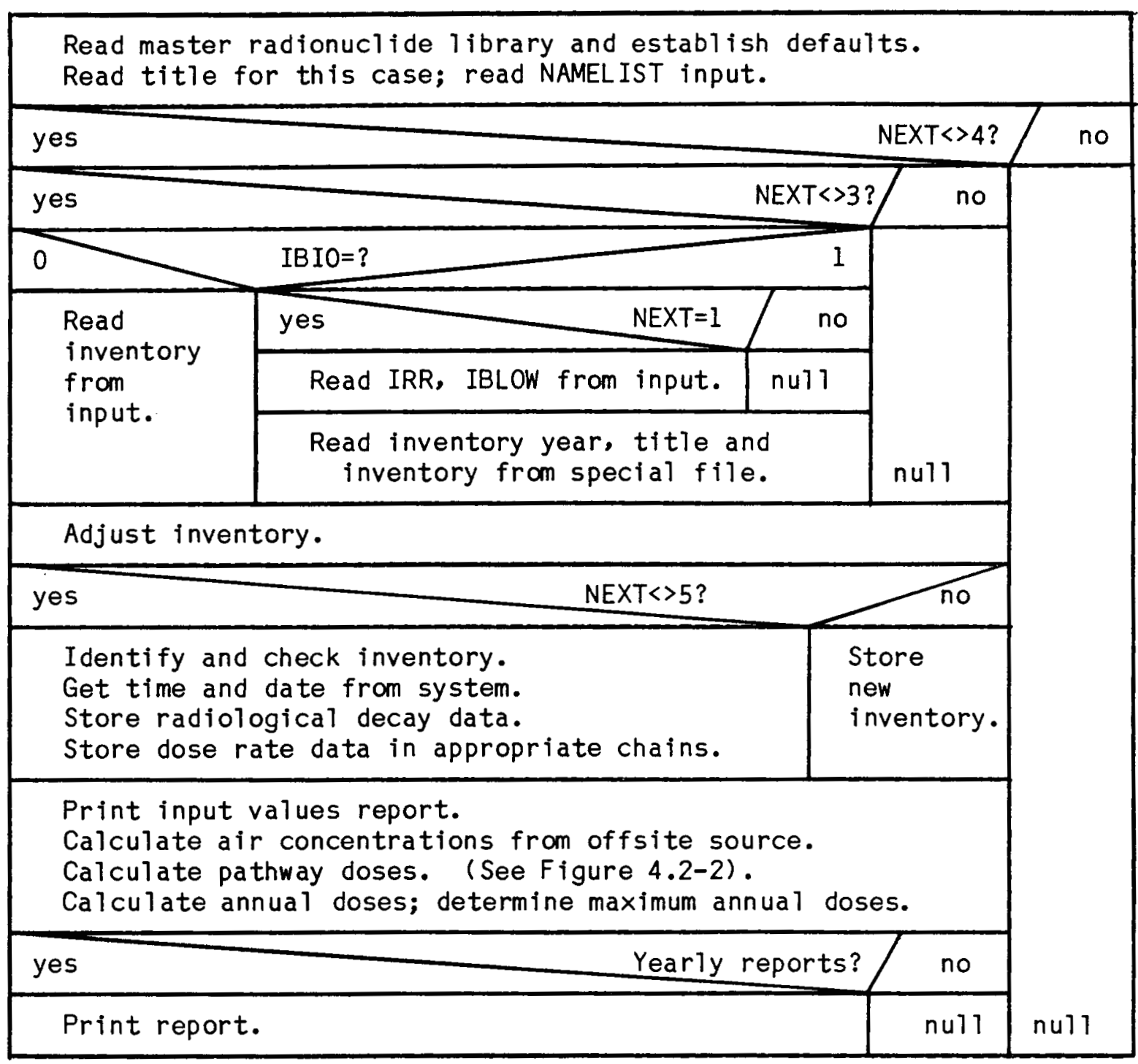

Figure 4.2-1. MAXIl Program Control Flow Chart 
Initialize arrays.

Set time indices.

For each time step:

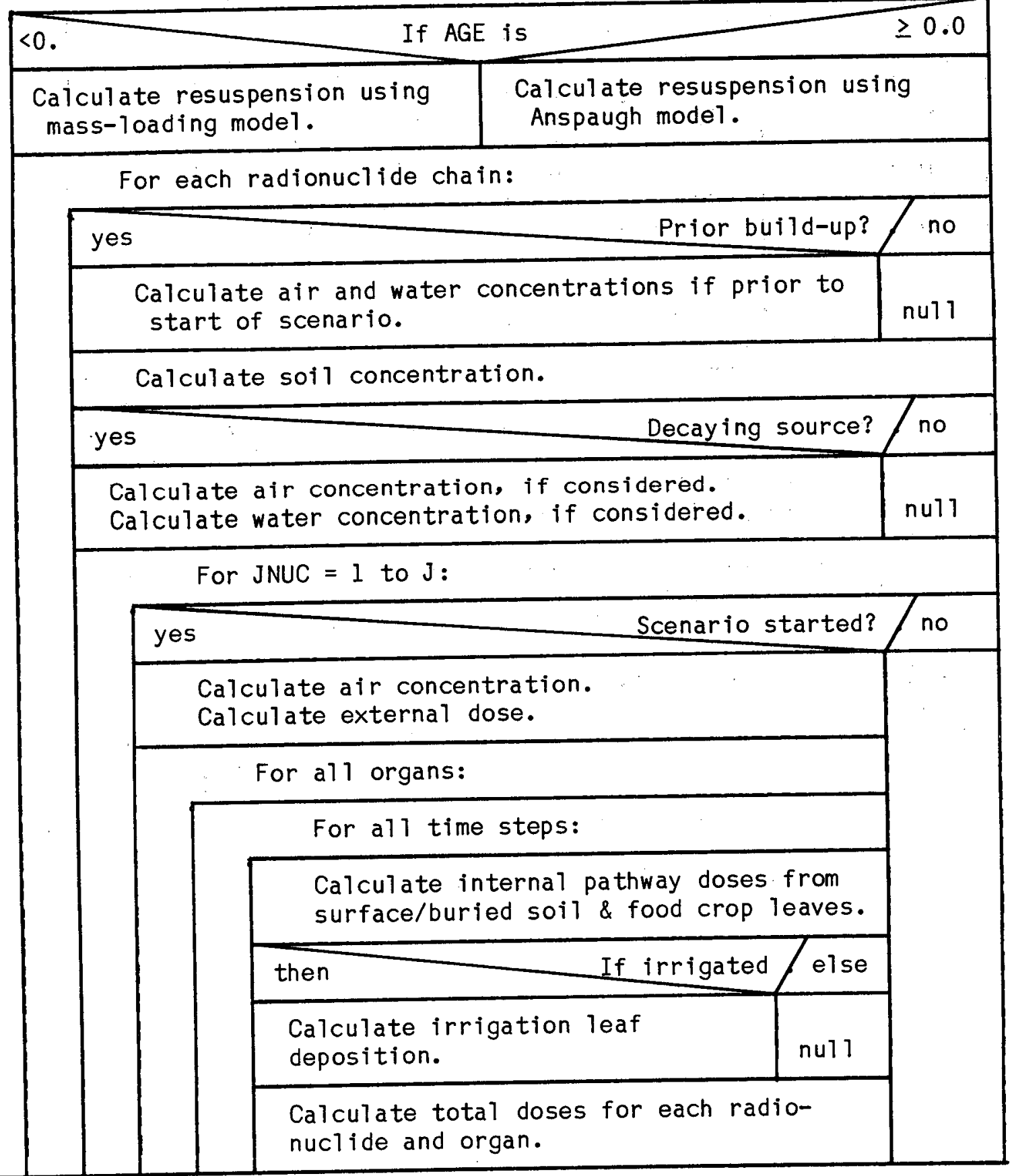

return

Figure 4.2-2. MAXIl Dose Calculation Flow Chart 
Display introductory messages and identify program.

Display menu of scenarios and query for user's choice.

\begin{tabular}{|c|c|c|c|c|}
\hline \multicolumn{4}{|c|}{ Menu selection: } & 4 \\
\hline $\begin{array}{c}\text { Print } \\
\text { Scenario 1 } \\
\text { description. }\end{array}$ & $\begin{array}{c}\text { Scenario 2 } \\
\text { description. }\end{array}$ & $\begin{array}{c}\text { Print } \\
\text { Scenario 3 } \\
\text { description. }\end{array}$ & $\begin{array}{c}\text { Print } \\
\text { Scenario 4 } \\
\text { description. }\end{array}$ & $\begin{array}{c}\text { Print } \\
\text { Scenario 5 } \\
\text { description. }\end{array}$ \\
\hline
\end{tabular}

Do until user is satisfied with scenario selection:

Establish default parameters for selected scenario. Query user for title.

Query for beginning year of calculation.

Display ending year of calculation.

Do until user is satisfied with time period selection:

\begin{tabular}{|c|c|c|}
\hline yes & Scenario 5 ? & no \\
\hline $\begin{array}{l}\text { Display pathway options with defaults. } \\
\text { Query for user's changes. }\end{array}$ & & null \\
\hline
\end{tabular}

Display detail of report option; query for user's changes. Query for location of buried/stored waste.

Query if user wishes to use all default values for scenario.

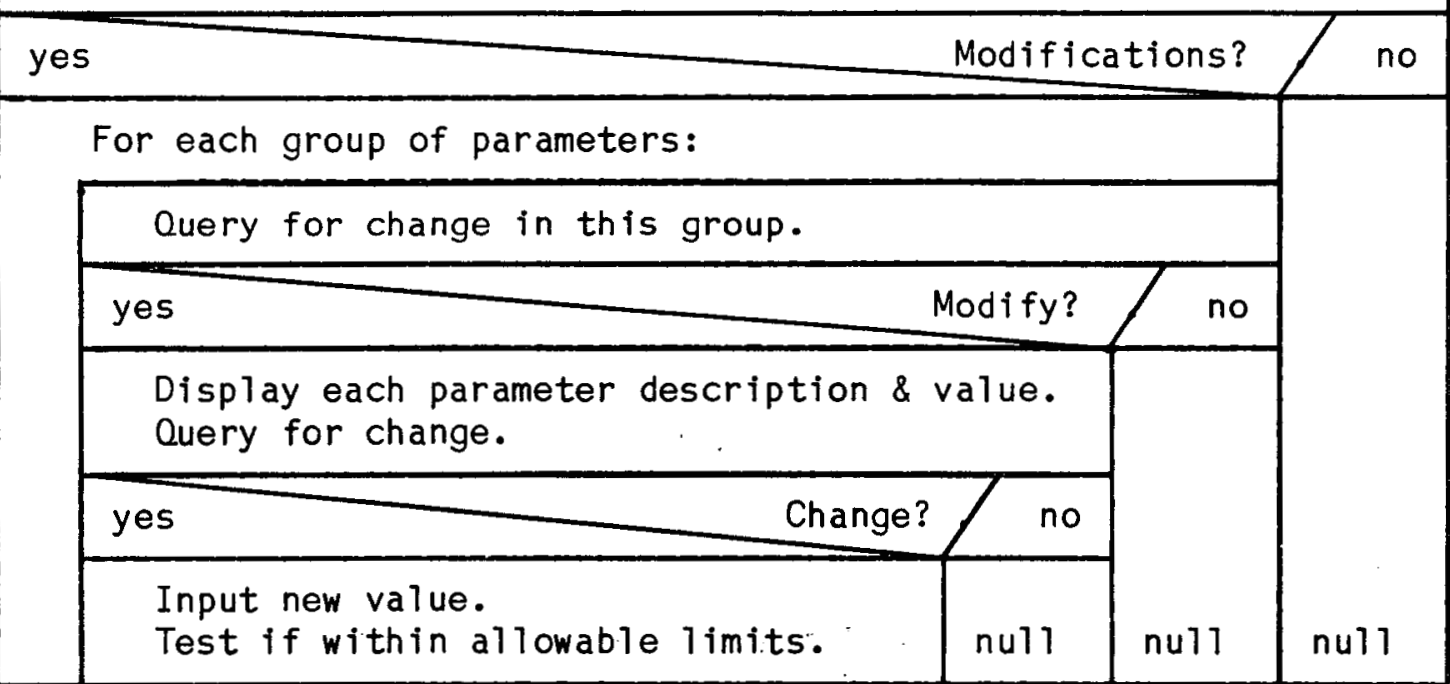

Figure 4.2-3. ONSITE Program Control Flow Chart 


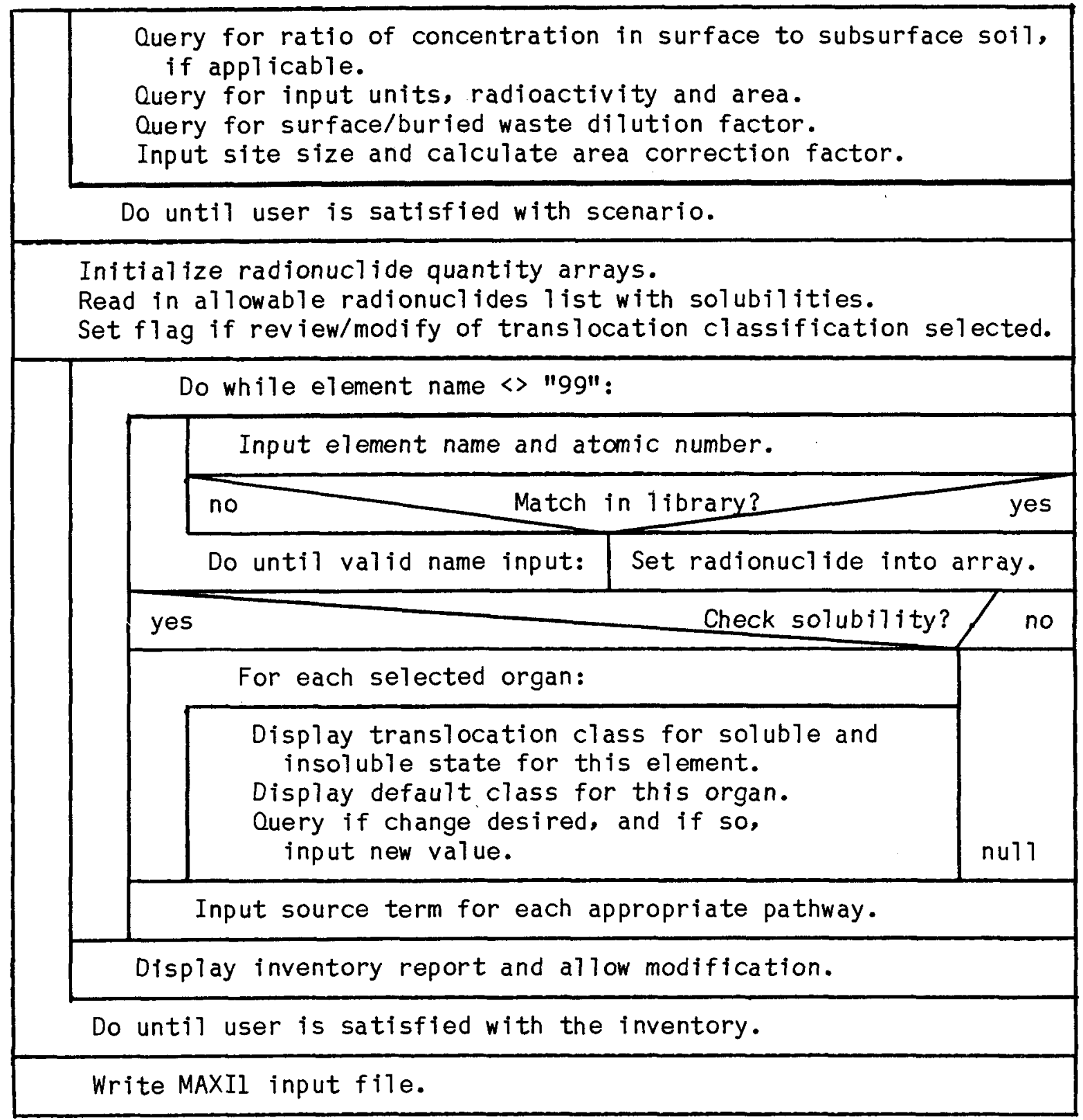

Figure 4.2-3. ONSITE Program Flow Chart (Continued)

\subsection{Program Data and Data Structures}

This section contains tables of the data arrays, common block definition and usage, and data constants for MAXIl and ONSITE. The arrays are identified and their 1ocations given in Tables 4.3-1 and 4.3-2. Common block usage is described in Tables 4.3-3 and 4.3-4. Data constants are identified and the assigned values are 1 isted and described in Tables 4.3-5 and 4.3-6. 
An attempt has been made to use variable and module names consistently throughout the package.

Table 43-1. MAXIl Data Arrays

\begin{tabular}{|c|c|c|c|}
\hline Array Name & $\begin{array}{l}\text { Number of } \\
\text { Elements }\end{array}$ & $\begin{array}{l}\text { Common } \\
\text { Block. }\end{array}$ & Module Location \\
\hline A & $(1)$ & & ASUM, SUMPRD, ZEROR \\
\hline$A$ & $(45)$ & & ACHAIN \\
\hline AARDOS & $(50,5)$ & DOSEI & \\
\hline ADADOS & $(50,5)$ & DOSEl & \\
\hline ADWDOS & $(50,5)$ & DOSEl & \\
\hline AEXDOS & $(50)$ & DOSEI & \\
\hline AFDOS & $(50,5)$ & DOSEl & \\
\hline AIDOS & $(50,50,5)$ & DATA2 & \\
\hline AIRCON & $(50)$ & & PADOS, PNTO \\
\hline AIRFA & $(50)$ & & AFACT, MLOAD, PADOS \\
\hline$A L$ & $(50)$ & DATAl & 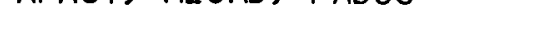 \\
\hline AL & (9) & & ACHAIN \\
\hline AM & $(50)$ & DATAL & \\
\hline AM & (9) & & ACHAIN \\
\hline AMI & $(50)$ & DATAl & PNTO \\
\hline AMJ & $(50)$ & DATAL & PNTO \\
\hline AMK & $(50)$ & & PADOS, WATER, SOLCON \\
\hline AML & $(50)$ & THIRDS & \\
\hline AMM & $(50)$ & & PADOS, SOLCON, AIRDIS \\
\hline AMT & $(50)$ & & PADOS, PNTO, SOLCON \\
\hline$A O$ & (9) & & ACHAIN, PADOS, SOLCON \\
\hline ARDOS & $(50,50,5)$ & DOSEI & \\
\hline ARDW & $(50,50,5)$ & DATA2 & \\
\hline ARGF & $(50,50,5)$ & DATA2 & \\
\hline AW & $(300)$ & $\mathrm{RL} I B$ & IDNUC \\
\hline AWAW & $(100)$ & FREAD & \\
\hline AWDX & $(100)$ & FREAD & \\
\hline AWI & $(50)$ & & MAIN, IDNUC, SETDAT \\
\hline AWLS & $(100)$ & FREAD & \\
\hline AWO & $(50)$ & DATAI & PNTO \\
\hline AWW & $(100)$ & FREAD & \\
\hline AWX & $(100)$ & FREAD & \\
\hline$B$ & (1) & SUMPRD & \\
\hline DADOS & $(50,50,5)$ & DOSEI & \\
\hline DEDXT & $(50,50,5)$ & DATA2 & \\
\hline DEXT & $(50)$ & DATA2 & \\
\hline DFDOS & $(50,50,5)$ & DATA2 & \\
\hline DFDXT & $(100)$ & FREAD & \\
\hline DFXT & $(100)$ & FREAD & \\
\hline DIN & $(3,50,5)$ & & INSET \\
\hline DK & $(2,50)$ & DATAl & \\
\hline
\end{tabular}


Table 4.3-1. MAXII Data Arrays (Continued)

\begin{tabular}{|c|c|c|c|c|}
\hline Array Name & $\begin{array}{l}\text { Number of } \\
\text { Elements }\end{array}$ & $\begin{array}{l}\text { Common } \\
\text { Block. }\end{array}$ & Module Location & \\
\hline DK & $(2,9)$ & & ACHAIN & \\
\hline DKF & $(2,300)$ & $\mathrm{RL} I B$ & & \\
\hline DWDOS & $(50,50,5)$ & DOSEl & & \\
\hline ELT & $(300)$ & RL IB & IDNUC & \\
\hline ELTA & $(100)$ & FREAD & & \\
\hline ELTDX & $(100)$ & FREAD & & \\
\hline ELTI & $(50)$ & & MAIN, IDNUC, SETDAT & \\
\hline ELTLS & $(100)$ & FREAD & & \\
\hline ELTO & $(50)$ & DATAl & PNTO & \\
\hline ELTX & $(100)$ & FREAD & & \\
\hline EXDOS & $(50,50)$ & DOSEl & & \\
\hline EXMO & (9) & & ACHAIN & \\
\hline FADOS & $(50,50,5)$ & & MAIN & \\
\hline FDOS & $(50,50,5)$ & DOSEl & & \\
\hline FR & $(2)$ & & RL IBIN & \\
\hline IDORG & (5) & & INSET & \\
\hline IFR & $(2,300)$ & RL IB & & \\
\hline IFRM & $(2,50)$ & DATAl & & \\
\hline IFRM & $(2,9)$ & & ACHAIN & \\
\hline IMEM & $(300)$ & RLIB & & \\
\hline INDOS & $(50,50,5)$ & DATA2 & & \\
\hline IOFNUC & $(50)$ & DATAl & & \\
\hline IT & $(2)$ & & RL IBIN & \\
\hline $\mathrm{K}$ & (1) & & ZEROI & \\
\hline KORG & (5) & & MAIN, INSET, OUTPUT, OAPAGE, & SETDAT \\
\hline KORGA & (5) & & MAIN, DFREAD, SETDAT & \\
\hline KORGLS & (5) & & MAIN, DFREAD, SETDAT & \\
\hline KORGW & (5) & & MAIN, DFREAD, SETDAT & \\
\hline MAXD & (5) & MXTIM & MAIN & \\
\hline MAXTIM & $(5)$ & MXTIM & & \\
\hline NCHN & $(300)$ & RL IB & IDNUC & \\
\hline NFLAG & $(300)$ & & MAIN, IDNUC, SETDAT & \\
\hline NFLAGC & $(200)$ & & MAIN, IDNUC, SETDAT & \\
\hline NOFNUC & $(200)$ & RL IB & & \\
\hline NSOLD & $(5,50)$ & & MAIN, SETDAT & \\
\hline NTR & $(5,50)$ & & MAIN, INSET, OAPAGE, SETDAT & \\
\hline ONA & $(5)$ & & OUTPUT & \\
\hline ONAME & $(23)$ & & OUTPUT, QAPAGE & \\
\hline 0 & $(50)$ & & MAIN, SETDAT & \\
\hline OAPR & $(50)$ & & MAIN, OAPAGE; SETDAT & \\
\hline OI & $(50)$ & & MAIN, SETDAT & \\
\hline QJ & $(50)$ & & MAIN, SETDAT & \\
\hline QK & $(50)$ & THIRDS & & \\
\hline SOILCN & $(50)$ & DATAI & PNTO & \\
\hline TIT20 & $(13)$ & TITLR & & \\
\hline
\end{tabular}


Tabie 4.3-1. MAXII Data Arrays (Continued)

\begin{tabular}{|c|c|c|c|}
\hline Array Name & $\begin{array}{l}\text { Number of } \\
\text { Elements }\end{array}$ & $\begin{array}{l}\text { Common } \\
\text { Block }\end{array}$ & Module Location \\
\hline $\begin{array}{l}\text { TIT21 } \\
\text { TIT22 } \\
\text { TIT24 } \\
\text { TIT25 } \\
\text { TIT27 } \\
\text { TITLDI } \\
\text { TITLEI } \\
\text { TITLR } \\
\text { TR } \\
X\end{array}$ & $\begin{array}{l}(13) \\
(13) \\
(13) \\
(13) \\
(13) \\
(15) \\
(20) \\
(20) \\
(300) \\
(100000)\end{array}$ & $\begin{array}{l}\text { TITLR } \\
\text { TITLR } \\
\text { TITLR } \\
\text { TITLR } \\
\text { TITLR } \\
\text { JUNK } \\
\text { RL IB }\end{array}$ & $\begin{array}{l}\text { MAIN, OAPAGE } \\
\text { MAIN, OAPAGE, RLIBIN } \\
\text { MAIN }\end{array}$ \\
\hline
\end{tabular}

Table 43-2. ONSITE Data Arrays

\begin{tabular}{|c|c|c|c|}
\hline Array Name & $\begin{array}{l}\text { Number of } \\
\text { Elements }\end{array}$ & $\begin{array}{l}\text { Common } \\
\text { Block }\end{array}$ & Module Loca \\
\hline A & $(300)$ & & RADIN \\
\hline ANS & (2) & & OPTION \\
\hline AWI & $(100)$ & INV & \\
\hline $\mathrm{CL}$ & (3) & & RADIN \\
\hline $\mathrm{E}$ & $(300)$ & & RADIN \\
\hline ELTI & $(100)$ & INV & \\
\hline EXTFAC & $(2,4)$ & & ONSITE \\
\hline GNAME & (2) & & ONSITE, MODIF, GROUP \\
\hline IDORG & (5) & & RADIN \\
\hline Is & (2) & & RADIN \\
\hline KORG & (5) & VARYBL & \\
\hline NS & $(5,300)$ & & RADIN \\
\hline NSOLD & $(5,100)$ & INV & \\
\hline NVU & (4) & DESC & \\
\hline NVUNIT & (4) & VARVBL & \\
\hline ORG & (23) & & RADIN \\
\hline 0 & $(100)$ & INV & \\
\hline OI & $(100)$ & INV & \\
\hline QJ & $(100)$ & INV & \\
\hline ok & $(100)$ & INV & \\
\hline TITL & (20) & DESC & \\
\hline UNITS & $(2,3)$ & DESC & \\
\hline WHERE & $(3,2)$ & & QUANTI \\
\hline
\end{tabular}


Table 4.3-3. MAXIl Common Block Definition and Usage

\begin{tabular}{l} 
Common \\
Block \\
Name \\
\hline
\end{tabular}

Variables

$\begin{array}{ll}\text { ELTO(50) } & \text { IFOD } \\ \text { AWO(50) } & \text { IARG } \\ \text { IOFNUC(50) } & \text { IWAT } \\ \text { NONUC } & \text { DK }(2,50) \\ \text { IFRM }(2,50) & \text { RIRR } \\ \text { AL }(50) & \text { RPF } \\ \operatorname{AM}(50) & \text { XMLF } \\ \operatorname{SOILCN}(50) & \text { DILF } \\ \operatorname{ICHN} & \text { IMO } \\ \operatorname{AMI}(50) & \text { DEN } \\ \operatorname{AMJ}(50) & \text { IEXT }\end{array}$

AMJ $(50)$
Used by Module

DATAl
MAIN

AIRDIS

ANDOS

DFREAD

INSET

OUTPUT

PADOS

QAPAGE

SETDAT

SOLCON

WATER
$\operatorname{DFDOS}(50,50,5)$

$\operatorname{AIDOS}(50,50,5)$

$\operatorname{INDOS}(50,50,5)$

DEXT (50)

$\operatorname{ARGF}(50,50,5)$

$\operatorname{ARDW}(50,50,5)$

$\operatorname{DEDXT}(50)$

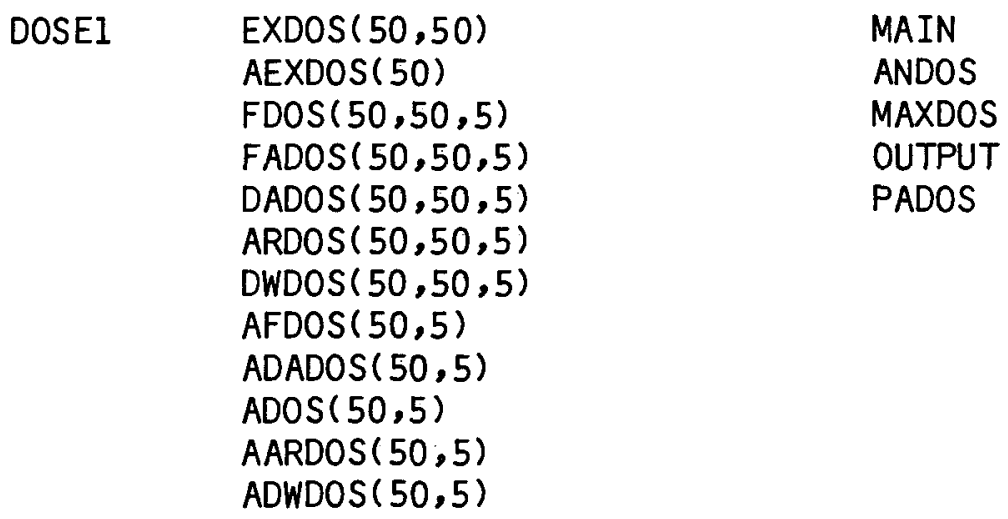

MAIN

ANDOS

MAXDOS

OUTPUT

PADOS

MAIN

INSET

PADOS

SETDAT 
Table 4.3-3. MAXII Common Block Definftion and Usage (Continued)

Common
Block
Name

FREAD
Variables

NYRL

NYRS

NORGL

NORGS

NISOL

NISOS

NYRW

NYRA

NORGW

NORGA

NISOW

NISOA
Used by Module

MAIN

DFREAD

SETDAT

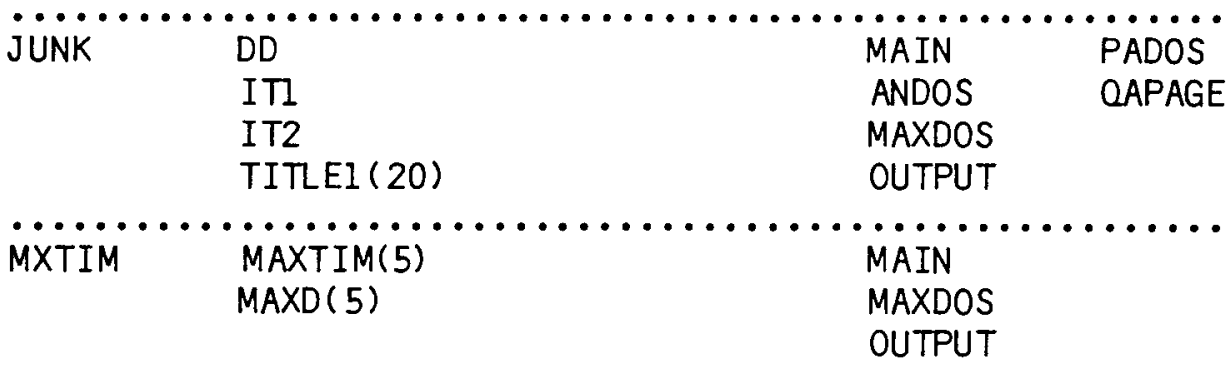

\begin{tabular}{|c|c|c|c|c|}
\hline LIB & $\begin{array}{l}\operatorname{ELT}(300) \\
\text { AW }(300) \\
\operatorname{TR}(300) \\
\text { NUC } \\
\text { NCHN }(300) \\
\text { NOFNUC }(200)\end{array}$ & $\begin{array}{l}\operatorname{NCHST}(200) \\
\operatorname{IFR}(2,300) \\
\operatorname{DKF}(2,300) \\
\operatorname{IMEM}(300) \\
\operatorname{NCH}\end{array}$ & $\begin{array}{l}\text { MAIN } \\
\text { RL IBIN } \\
\text { SETDAT }\end{array}$ & \\
\hline$\ddot{\text { THIRDS}}$ & $\begin{array}{l}\dddot{O K}(50) \\
\text { AML }(50) \\
\text { XOSITE }\end{array}$ & $\begin{array}{l}\text { IAIR } \\
\text { IDKAIR } \\
\text { IBLOW }\end{array}$ & $\begin{array}{l}\text { MAIN } \\
\text { AIRDIS } \\
\text { PADOS }\end{array}$ & $\begin{array}{l}\text { OAPAGE } \\
\text { SETDAT }\end{array}$ \\
\hline$\ddot{I} \ddot{\pi} \dot{s}$ & $\begin{array}{l}\text { TIT20 }(13) \\
\text { TIT2I } \\
\text { TIT22(13) }\end{array}$ & $\begin{array}{l}\text { TIT24 }(13) \\
\text { TIT25 } \\
\text { TIT27 }(13)\end{array}$ & $\begin{array}{l}\text { DFREAD } \\
\text { OAPAGE }\end{array}$ & \\
\hline
\end{tabular}


Table 4.3-4. ONSITE Common Block Definition and Usage

\begin{tabular}{|c|c|c|c|c|c|}
\hline \multirow{2}{*}{$\begin{array}{l}\text { Comenon } \\
\text { Block } \\
\text { Name } \\
\text { AREA }\end{array}$} & \multicolumn{2}{|c|}{ Yariables } & \multicolumn{3}{|c|}{ Used by Module } \\
\hline & $\begin{array}{l}\text { FRSIZ } \\
\text { AREAIN }\end{array}$ & AREAEX & $\begin{array}{l}\text { ONSITE } \\
\text { RITFIL }\end{array}$ & & \\
\hline$\ddot{D E S C}$ & $\begin{array}{l}\because \ddot{\operatorname{TIT}}(20) \cdots \\
\operatorname{UNITS}(2,3) \\
\operatorname{NVU}(4)\end{array}$ & $\cdots \cdots \cdots$ & $\begin{array}{l}\text { ONSITE } \\
\text { SCENR } \\
\text { MODIF } \\
\text { RADIN }\end{array}$ & $\begin{array}{l}\text { QUANTI } \\
\text { RITFIL } \\
\text { OPTION } \\
\text { INTRO }\end{array}$ & $\begin{array}{l}\text { CHANGE } \\
\text { SELECT } \\
\text { GROUP }\end{array}$ \\
\hline$\ddot{F L} \ddot{A G}$ & $\begin{array}{l}\text { ISUR } \\
\text { IRS } \\
\text { ILOC } \\
\text { INUT }\end{array}$ & $\ldots \ldots \ldots$ & $\begin{array}{l}\text { ONSITE } \\
\text { SCENR } \\
\text { MODIF } \\
\text { RADIN }\end{array}$ & $\begin{array}{l}\text { QUANTI } \\
\text { RITFIL } \\
\text { OPTION } \\
\text { INTRO }\end{array}$ & $\begin{array}{l}\text { CHANGE } \\
\text { SELECT } \\
\text { GROUP }\end{array}$ \\
\hline$\ddot{I N V}{ }^{\prime} \cdot$ & $\begin{array}{l}\ddot{N I N} \\
A W I(100) \\
\operatorname{NSOLD}(5,100) \\
Q(100) \\
Q I(100) \\
Q J(100)\end{array}$ & $\begin{array}{l}\text { ELTI } \\
\text { OK }(100)\end{array}$ & $\begin{array}{l}\text { ONSITE } \\
\text { SCENR } \\
\text { MODIF } \\
\text { RADIN } \\
\text { QUANTI } \\
\text { RITFIL }\end{array}$ & $\begin{array}{l}\text { INTRO } \\
\text { CHANGE } \\
\text { SELECT } \\
\text { GROUP } \\
\text { OPTION }\end{array}$ & $\cdots$ \\
\hline IOVAR & $\begin{array}{l}\text { SCRN } \\
\text { OUT } \\
\text { OUTFIL } \\
\text { KEY }\end{array}$ & 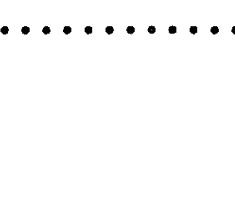 & $\begin{array}{l}\text { ONSITE } \\
\text { SCENR } \\
\text { MODIF } \\
\text { INTRO }\end{array}$ & $\begin{array}{l}\text { QUANTI } \\
\text { RITFIL } \\
\text { OPTION } \\
\text { CHANGE }\end{array}$ & $\begin{array}{l}\text { SËE } \\
\text { GROUP } \\
\text { GROUP }\end{array}$ \\
\hline V $\ddot{A R Y B L}$ & $\begin{array}{l}\text { IFOD } \\
\text { RPF } \\
\text { RF1 } \\
\text { IARG } \\
\text { IDKWAT } \\
\text { IAIR } \\
\text { IDKAIR } \\
\text { AGE } \\
\text { DEN } \\
\text { RINH } \\
\text { M3M2 } \\
\text { ITI } \\
\text { NORG } \\
\text { IOUT } \\
\text { RPF1 } \\
\text { XF } \\
\text { IRR } \\
\text { NVUNIT(4) }\end{array}$ & $\begin{array}{l}\text { RIRR } \\
\text { IMO } \\
\text { RF2 } \\
\text { IWAT } \\
\text { IEXT } \\
\text { XQSITE } \\
\text { XFACT } \\
\text { XDPT } \\
\text { XMLF } \\
\text { DILF } \\
\text { INTRUD } \\
\text { IT2 } \\
\text { KORG( 5) } \\
\text { NEXT } \\
\text { RPF2 } \\
\text { INHAL } \\
\text { SRDIL }\end{array}$ & $\begin{array}{l}\text { ONSITE } \\
\text { SCENR } \\
\text { MODIF } \\
\text { RADIN } \\
\text { OUANTI } \\
\text { RITFIL } \\
\text { OPTION } \\
\text { INTRO } \\
\text { CHANGE } \\
\text { SELECT } \\
\text { GROUP }\end{array}$ & & • \\
\hline
\end{tabular}




\begin{tabular}{|c|c|c|c|}
\hline $\begin{array}{l}\text { Constant } \\
\text { Name } \\
\end{array}$ & Constant Value & $\begin{array}{l}\text { Module } \\
\text { Lecation }\end{array}$ & Description \\
\hline ONAME $(n)$ & 'organ name' & $\begin{array}{l}\text { OUTPUT } \\
\text { OAPAGE }\end{array}$ & $\begin{array}{l}\text { Organ titles for report: 'organ } \\
\text { name' as it appears in Table } 4.5-3\end{array}$ \\
\hline Unnamed & $1.0 \times 10^{9}$ & AFACT & $\begin{array}{l}\text { Resuspension factor after } 17 \\
\text { years, in units of } \mathrm{m}^{-1} \text {, used with } \\
\text { Anspaugh model. (See Equation 2.7) }\end{array}$ \\
\hline Unnamed & 0.15 & MLOAD & $\begin{array}{l}\text { Correction factor for units } \\
\text { in PADOS with SOILCN in } \mathrm{pCi} / \mathrm{m}^{2} \text {. }\end{array}$ \\
\hline Unnamed & $3.15 \times 10^{4}$ & SOLCON & $\begin{array}{l}\text { Air concentration time and deposi- } \\
\text { tion velocity conversion factor: } \\
3.15 \times 10^{-15} \mathrm{sec} / \mathrm{yr} \times 1.0 \times 10^{-3} \\
\mathrm{~m} / \mathrm{sec} \text {. }\end{array}$ \\
\hline Unnamed & $3.175 \times 10^{4}$ & MAIN & $\begin{array}{l}\text { Air concentration conversion } \\
\text { factor from } \mathrm{Ci} / \mathrm{yr} \text { to } \mathrm{pCi} / \mathrm{m}^{3} \text {. }\end{array}$ \\
\hline Unnamed & $1.0 \times 10^{-4}$ & AFACT & $\begin{array}{l}\text { Resuspension factor - Anspaugh } \\
\text { model. (See Equation } 2.7 \text { ) }\end{array}$ \\
\hline Unnamed & -2.87 & AFACT & $\begin{array}{l}\text { Effective decay constant used in } \\
\text { the Anspaugh equation. (See } \\
\text { Equation } 2.7 \text { ) }\end{array}$ \\
\hline Unnamed & $5.844 \times 10^{-11}$ & PADOS & $\begin{array}{l}\text { Unit conversion factor: }(\mathrm{rem} / \mathrm{mrem} \\
(\mathrm{hr} / \mathrm{yr})(\mathrm{Ci} / \mathrm{pCi})\left(\mathrm{m}^{2} / 0.15 \mathrm{~m}^{3}\right) \text {. }\end{array}$ \\
\hline Unnamed & $1.0 \times 10^{-3}$ & PADOS & $\begin{array}{l}\text { Air deposition velocity for } \\
\text { all resuspended particles, } \mathrm{m} / \mathrm{sec} \text {. }\end{array}$ \\
\hline Unnamed & $2.635 \times 10^{6}$ & PADOS & Number of seconds in a month. \\
\hline Unnamed & 365.25 & SETDAT & Number of days in a year. \\
\hline Unnamed & 0.693 & SETDAT & Natural $\log$ of 2.0 \\
\hline Unnamed & 5 & MAIN & $\begin{array}{l}\text { Logical unit number of the input } \\
\text { file. }\end{array}$ \\
\hline Unnamed & 6 & $\begin{array}{l}\text { OAPAGE } \\
\text { OUTPUT } \\
\text { PNTO }\end{array}$ & $\begin{array}{l}\text { Logical unit number of the input } \\
\text { file. }\end{array}$ \\
\hline
\end{tabular}


Table 4.3-5. MAXIl Data Constants (Continued)

\begin{tabular}{|c|c|c|c|}
\hline $\begin{array}{l}\text { Constant } \\
\text { Name }\end{array}$ & Constant Value & $\begin{array}{l}\text { Module } \\
\text { Location }\end{array}$ & Description \\
\hline Unnamed & 10 & RL IBIN & $\begin{array}{l}\text { Logical unit number of the master } \\
\text { radionuclide library. }\end{array}$ \\
\hline Unnamed & 20 & DFREAD & $\begin{array}{l}\text { Logical unit number of the leaf- } \\
\text { mechanism dose rate factors file. }\end{array}$ \\
\hline Unnamed & 21 & DFREAD & $\begin{array}{l}\text { Logical unit number of the soil- } \\
\text { mechanism dose rate factors file. }\end{array}$ \\
\hline Unnamed & 22 & DFREAD & $\begin{array}{l}\text { Logical unit number of the surface } \\
\text { external exposure dose rate factors } \\
\text { file. }\end{array}$ \\
\hline Unnamed & 23 & INSET & $\begin{array}{l}\text { Logical unit number of the inhala- } \\
\text { tion dose rate factors file. }\end{array}$ \\
\hline Unnamed & 24 & DFREAD & $\begin{array}{l}\text { Logical unit number of the aquatic } \\
\text { foods dose rate factors file. }\end{array}$ \\
\hline Unnamed & 25 & DFREAD & $\begin{array}{l}\text { Logical unit number of the } \\
\text { drinking-water dose rate factors } \\
\text { file. }\end{array}$ \\
\hline Unnamed & 27 & DFREAD & $\begin{array}{l}\text { Logical unit number of the buried- } \\
\text { waste external-exposure dose rate } \\
\text { factors file. }\end{array}$ \\
\hline Unnamed & 30 & MAIN & $\begin{array}{l}\text { Logical unit number of the inven- } \\
\text { tory file. This is used only when } \\
\text { IBIO=l. }\end{array}$ \\
\hline Unnamed & 40 & OUTPUT & $\begin{array}{l}\text { Logical unit number of output } \\
\text { plot/summary file. This is used } \\
\text { only when IBIO=l. }\end{array}$ \\
\hline
\end{tabular}


Table 4.3-6. ONSITE Data Constants

\begin{tabular}{|c|c|c|c|}
\hline $\begin{array}{l}\text { Constant } \\
\text { Name }\end{array}$ & Constant Value & $\begin{array}{l}\text { Module } \\
\text { Location }\end{array}$ & Description \\
\hline SCRN & 1 & $\begin{array}{l}\text { ONSITE } \\
\text { CHANGE }\end{array}$ & $\begin{array}{l}\text { Logical unit number of the } \\
\text { computer terminal. }\end{array}$ \\
\hline OUT & 7 & ONSITE & $\begin{array}{l}\text { Logical unit number of the out- } \\
\text { put file from ONSITE. }\end{array}$ \\
\hline XFACT & $5.844 \mathrm{E}-11$ & SCENR & $\begin{array}{l}\text { Unit conversion factor: } \\
(\mathrm{hr} / \mathrm{yr} / \mathrm{mrem})(\mathrm{ci} / \mathrm{pCi}) \quad 0.15 \text {. }\end{array}$ \\
\hline DILF & 1.0 & SCENR & River dilution factor. \\
\hline INTRUD & 1 & SCENR & $\begin{array}{l}\text { Special inhalation model option } \\
\text { not manipulated by ONSITE. }\end{array}$ \\
\hline $\operatorname{UNITS}(2,3)$ & $\begin{array}{l}\text { "/square meter" } \\
\text { "/cubic meter" } \\
\text { "/Kg of soil" }\end{array}$ & ONSITE & $\begin{array}{l}\text { Source-term input units } \\
\text { corresponding to the index } \\
M 3 M 2 \text {. }\end{array}$ \\
\hline ORG (23) & "organ name" & RADIN & $\begin{array}{l}\text { Organ titles for transloca- } \\
\text { tion class review: "organ } \\
\text { name" arranged as indexed in } \\
\text { Table } 4.5-3 \text {. }\end{array}$ \\
\hline ANS (2) & $\begin{array}{l}"(N / Y) " \\
"(Y / N) "\end{array}$ & OPTION & $\begin{array}{l}\text { Default response logically } \\
\text { selected for pathway selec- } \\
\text { tion based on the value of } \\
\text { the option flag. }\end{array}$ \\
\hline EXTFAC & $\begin{array}{l}\text { "On Surface" } \\
\text { "Buried at } 0.5 \text { " } \\
\text { "Buried at } 1.0 \mathrm{m"} \\
\text { "Stored Waste" }\end{array}$ & ONSITE & $\begin{array}{l}\text { Description of waste location } \\
\text { for external exposure calcu- } \\
\text { lations. }\end{array}$ \\
\hline NVU & $\begin{array}{l}\text { "pCi" "mCi" } \\
\text { "Ci" "Ci" }\end{array}$ & ONSITE & $\begin{array}{l}\text { Description of input unit } \\
\text { selection for source term. }\end{array}$ \\
\hline NVUNIT & $\begin{array}{l}1.0 \\
1.0 \times 10^{3} \\
1.0 \times 10^{6} \\
1.0 \times 10^{9}\end{array}$ & ONSITE & $\begin{array}{l}\text { Source-term input units modi- } \\
\text { fication factor, corresponds } \\
\text { to constant NVU. }\end{array}$ \\
\hline
\end{tabular}




\subsection{Input File Organization}

The ONSITE computer program relieves the typical user of the need to be concerned with the detalis of input file organization. Only the Level 3 User (see Sections 2.2.2 and 3.1), that is the user who wishes to interact directly with the MAXIl program to set up unique scenarios, needs further information about the MAXIl program. The fol lowing descriptions will assist the Level 3 User in setting up proper input for the MAXIl code. The information in Section 2.4, Section 4.5, and this section will assist the Leve 13 User in appropriate parameter selection and organization.

The MAXIl execution file contains system commands to assign appropriate files from the data base and to run the MAXIl code. The file also contains MAXIl input; an identifying title, NAMELIST input, and the source term. The organization of the MAXIl execution file is detailed in Table 4.4-1.

MAXII uses the FORTRAN NAMELIST set INPUT for entering parameter values. For this set, the first NAMELIST record must be blank in column one; "\$INPUT" must be located in columns 2-8 and may optionally be fol lowed by data items. The data items are separated by commas and the 1 ast item must be fol lowed by "\$END". The data items must have one of the three following forms :

(1) Parameter Name $=$ Constant. The parameter name may be either subscripted or not.

(2) Array Name $=$ Set of Censtants (separated by commas). The number of constants may be less than, but not greater than, the number of elements in the array, and must be in the same order as the array is stored, i.e., the first subscript changes most rapidly.

(3) Subscripted Parameter = Set of Constants (separated by commas). The set of constants will be placed in consecutive array elements, starting with the element designated by the subscripted parameter.

Data items that are set via the NAMELIST statement are identified in Table 3.2.3-1 and Table 4.5-1 by the name of the set (e.g., INPUT) in the second column.

MAXIl can handle consecutive cases in an execution. Each case is preceded by an 80-character one- 1 ine title, and NAMELIST statements and parameters. The original inventory is used in al 1 subsequent cases. The parameter NEXT handles successive cases. The end of the run is signaled by a dummy title record and the NAMELIST INPUT parameter set to 4 . The output from the ONSITE sample problem interaction sessions are examples of MAXIl input file organization (see Figures in Section 3). 
Table 4.4-1. MAXII Execution File Organization

Eile Position

First nl lines

Following 1 ine

Next line

Following $n$ lines

Next 1 ine

Next NIN 1 ines

\section{Variable/Description/Format}

- Logical unit/file assignment statements to assign the master radionuclide file and selected dose rate factor flles for logical units 20-25 and logical unit 27 .

- System command to execute MAXII

- Identifying titie, up to 80 characters

- NAMELIST set INPUT as described above

- NIN (number of radionuclides, including daughters) (I5)

- IRR (number of years of irrigation prior to calculation) (I5)

- IBLOW (number of years contaminant blew onto site prior to calculation) (I5)

- For each radionuclide $n$, one line contains the following information:

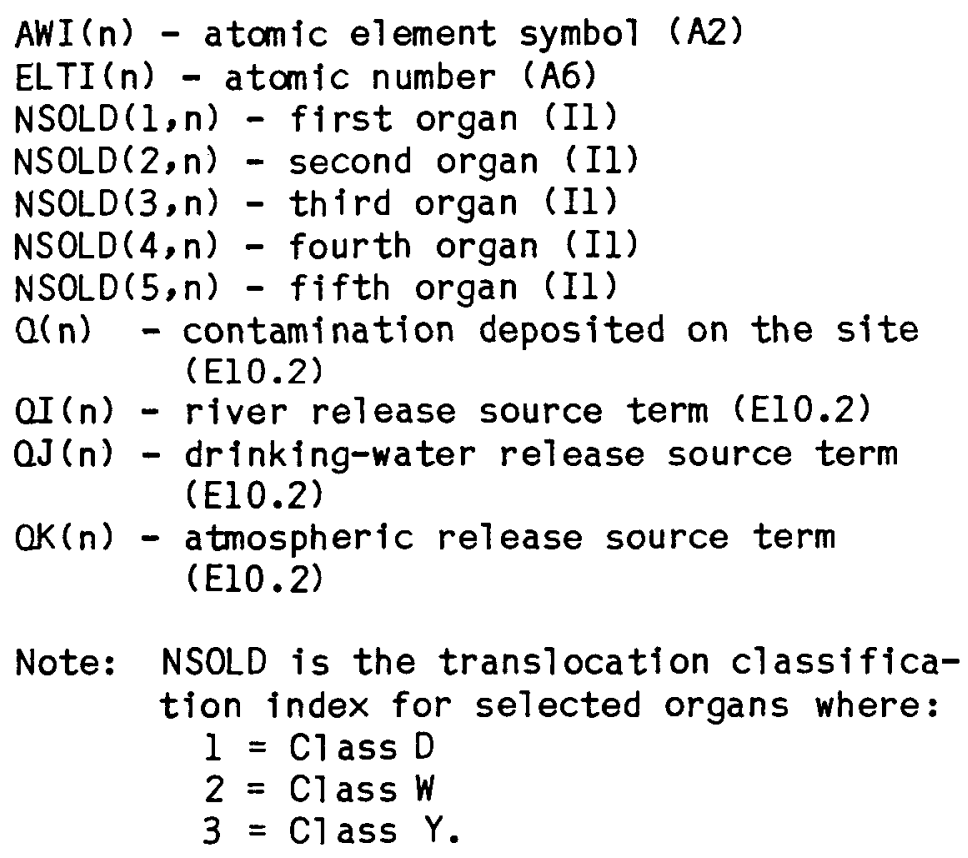

Note: NSOLD is the translocation classification index for selected organs where:

$1=C 1$ ass $D$

$2=C 1$ ass $W$

$3=$ Class $Y$. 


\subsection{Additional Parameter Descriptions}

The Level 3 User may utilize the MAXIl computer code for a wide range of applications. A primary criteria in the development of the scenarios and the ONSITE computer code is that the code package should be easy to use. Consequently, some of the options that have 1 ittle application to 1 owlevel waste storage are not manipulated by the ONSITE code. The Level 3 User may use these options and parameters when manually establ ishing MAXIl input files. MAXII parameters not manipulated by ONSITE are 1 isted and described in Table 4.5-1. Table 4.5-2 lists the organs used by the MAXIl code and the organ reference index associated with each organ.

Table 4.5-1. Additional Parameter Descriptions: MAXI1

\begin{tabular}{|c|c|c|c|}
\hline $\begin{array}{l}\text { Parameter } \\
\text { Name }\end{array}$ & $\begin{array}{l}\text { NAMELIST } \\
\text { Set/Number } \\
\text { Array } \\
\text { Elements }\end{array}$ & Data Type & Description \\
\hline DILF & INPUT & Real & $\begin{array}{l}\text { River dilution factor in units of } \\
\text { (1/yr) } 1 \text { to convert input river source } \\
\text { term of } p C i / y r \text { to } p C i / L \text {. } \\
\text { (Default value: } 1.0 \text { - no modification) }\end{array}$ \\
\hline IAIR & INPUT & Integer & $\begin{array}{l}\text { Will there by continuing atmospheric } \\
\text { deposition? } \\
0 \text { - no } \\
1 \text { - yes } \\
\text { (Default value: } 0)\end{array}$ \\
\hline IB IO & INPUT & Integer & $\begin{array}{l}\text { Not used in this application. } \\
\text { (Default value: } 0 \text { ) }\end{array}$ \\
\hline IBLOW & & Integer & $\begin{array}{l}\text { Number of years contaminants blew onto } \\
\text { the site prior to the beginning of the } \\
\text { dose calculation. } \\
\text { (Default value: } 0 \text { ) }\end{array}$ \\
\hline IBYR & & Integer & $\begin{array}{l}\text { Special input/output parameter not used } \\
\text { in this application. } \\
\text { (Default value: } 0 \text { ) }\end{array}$ \\
\hline IDKAIR & INPUT & Integer & $\begin{array}{l}\text { Decay the air-release source term for } \\
\text { IT2-IT years, starting at the begin- } \\
\text { ning of the scenario? } \\
0 \text { - no } \\
\begin{array}{ll}1 \text { - yes } \\
\text { (Default value: } & 0 \text { ) }\end{array}\end{array}$ \\
\hline
\end{tabular}


Table 4.5-1. Additional Parameter Descriptions: MAXIl (Continued)

\begin{tabular}{|c|c|c|c|}
\hline $\begin{array}{l}\text { Parameter } \\
\text { Name }\end{array}$ & $\begin{array}{c}\text { NAMELIST } \\
\text { Set/Number } \\
\text { Array } \\
\text { Elements }\end{array}$ & Data Type & Description \\
\hline IDKWAT & INPUT & Integer & $\begin{array}{l}\text { Decay the irrigation and aquatic food- } \\
\text { release term for IT2-IT1 years, } \\
\text { starting at the beginning of the } \\
\text { scenario? } \\
\quad 0 \text { - no } \\
\text { l-yes } \\
\text { (Default value: } 0)\end{array}$ \\
\hline INTRUD & INPUT & Integer & $\begin{array}{l}\text { Special inhalation model selection: } \\
0 \text { - model not selected } \\
\text { I - model selected (allows a one-year } \\
\text { exposure with annual doses) } \\
\text { (Default value: } 0\end{array}$ \\
\hline NEXT & INPUT & Integer & $\begin{array}{l}\text { Case control index: } \\
1 \text { - this is the first case: read } \\
1 \text { ibraries, NAMELIST INPUT, and } \\
\text { inventory; perform calculations } \\
\text { and prepare for following cases } \\
2 \text { - not used by MAXII } \\
3 \text { - this is a subsequent case; read } \\
\text { title and NAMELIST INPUT, perform } \\
\text { calculations, and prepare for } \\
\text { following case } \\
4 \text { - end execution; previous } \\
\text { title record was a dummy record } \\
5 \text { - } \text { special case handling not used in } \\
\text { this application. }\end{array}$ \\
\hline OK & $(100)$ & Real & $\begin{array}{l}\text { Atmospheric release source term in } \\
\mathrm{pCi} / \mathrm{yr} \text {. Not used in this application. }\end{array}$ \\
\hline XOSITE & INPUT & Real & $\begin{array}{l}\text { Chi/q value at the site. } \\
\text { (Default value: } 0.0 \text { ) }\end{array}$ \\
\hline XFACT & INPUT & Real & $\begin{array}{l}\text { This parameter has three functions: it } \\
\text { can be used to turn off the surface } \\
\text { external pathway (XFACT=0.); it can } \\
\text { modify the units of the surface } \\
\text { external DRF file assigned to logical } \\
\text { unit } 22 \text { allowing use of ISOSHLD } \\
\text { generated files (XFACT=1.0 for MAXI2 } \\
\text { generated file 22, XFACT }=5.844 E-11\end{array}$ \\
\hline
\end{tabular}


Table 4.5-1. Additional Parameter Descriptions: MAXIl (Continued)

\begin{tabular}{|c|c|c|c|}
\hline $\begin{array}{c}\text { Parameter } \\
\text { Name }\end{array}$ & $\begin{array}{c}\text { NAMELIST } \\
\text { Set/Number } \\
\text { Array } \\
\text { Elements }\end{array}$ & Data Type & Description \\
\hline$(\operatorname{con} t)$ & & & $\begin{array}{l}\text { for ISOSHLD generated file } 22 \text { ); and it } \\
\text { can modify the number of hours of } \\
\text { exposure per year (based on a ful } 1 \\
\text { year of exposure or } 8766 \mathrm{~h} / \mathrm{yr}=1.0 \text { ). } \\
\text { ONSITE uses the parameters ISUR, I22, } \\
\text { and XF } 2 \text { to simpl ify input of this } \\
\text { parameter. MAXIl will calculate XFACT } \\
\text { on } 7 \text { y if Val ues have been entered in } \\
\text { NAMELIST INPUT for ISUR, I22, and XF2. } \\
\text { This logic a l lows the user to enter a } \\
\text { value for XFACT through the NAMELIST } \\
\text { statement. }\end{array}$ \\
\hline
\end{tabular}

Table 4.5-2. Organ Selection

1 - Total body
2 - Body water
3 - Kidneys
4 - Liver
5 - Spleen
6 - Bone
7 - Fat
8 - Lungs

\author{
9 - Adrenals \\ 10 - Testes \\ 11 - Ovaries \\ 12 - Skin \\ 13 - Brain \\ 14 - Muscle \\ 15 - Prostrate \\ 16 - Thyroid
}

\author{
17 - Pancreas \\ 18 - Heart \\ 19 - GI tract \\ 20 - Stomach \\ 21 - Small intestine \\ 22 - Upper 1 arge intestine \\ 23 - Lower large intestine
}

\subsection{CDC Computer-Code Installation}

The installation of the ONSITE/MAXIl software package on the Control Data Corporation (CDC) computers at Brookhaven National Laboratories is discussed in this section. Computer operation-system interfacing on the CDC computers is 7 argely transparent to the user due to procedures included with this software package. These command level procedures are discussed in Section 4.6.1. Software security procedures established on the CDC are discussed in Section 4.6.2. Conversion of the computer codes for execution on the CDC is discussed in Section 4.6.3.

The ONSITE/MAXII software package is insta 1 led on the Brookhaven National Laboratory CDC 6600 (MFA) and CDC 7600 (MFZ) computers. The package has been modified to execute under INTERCOM Version 4 software control. The MFA computer uses the NOS/BE 1 operating system and the MFZ computer uses the SCOPE Version 2.1 operating system. The source code is compiled with the FTN5 FORTRAN compiler. The contents of the ONSITE/MAXI software 
packages are 1 isted in Table 4.6-1. Files residing on MFA have been backed up in duplicate on 1 ibrary tapes $\mathrm{K} 355$ and $\mathrm{Kl} 1916$. Files residing on MFZ have been backed up in duplicate on library tapes K1917 and K1918. Backup tapes were created with the DUMPF system command. MAXIl, MAXI2, and MAXI3 were developed on a UNIVAC $1100 / 70$ computer. The ONSITE computer code was developed on a Zenith-89 microcomputer. The software package was assembled, debugged, and tested on a $V A X-11 / 780$ computer.

\subsubsection{Command Level Procedures}

Three interactive Cyber Control Language (CCL) procedures have been written to handle most of the operating-system interface for the ONSITE/MAXII

Table 4.6-1. Contents of the ONSITE/MAXII Software Package

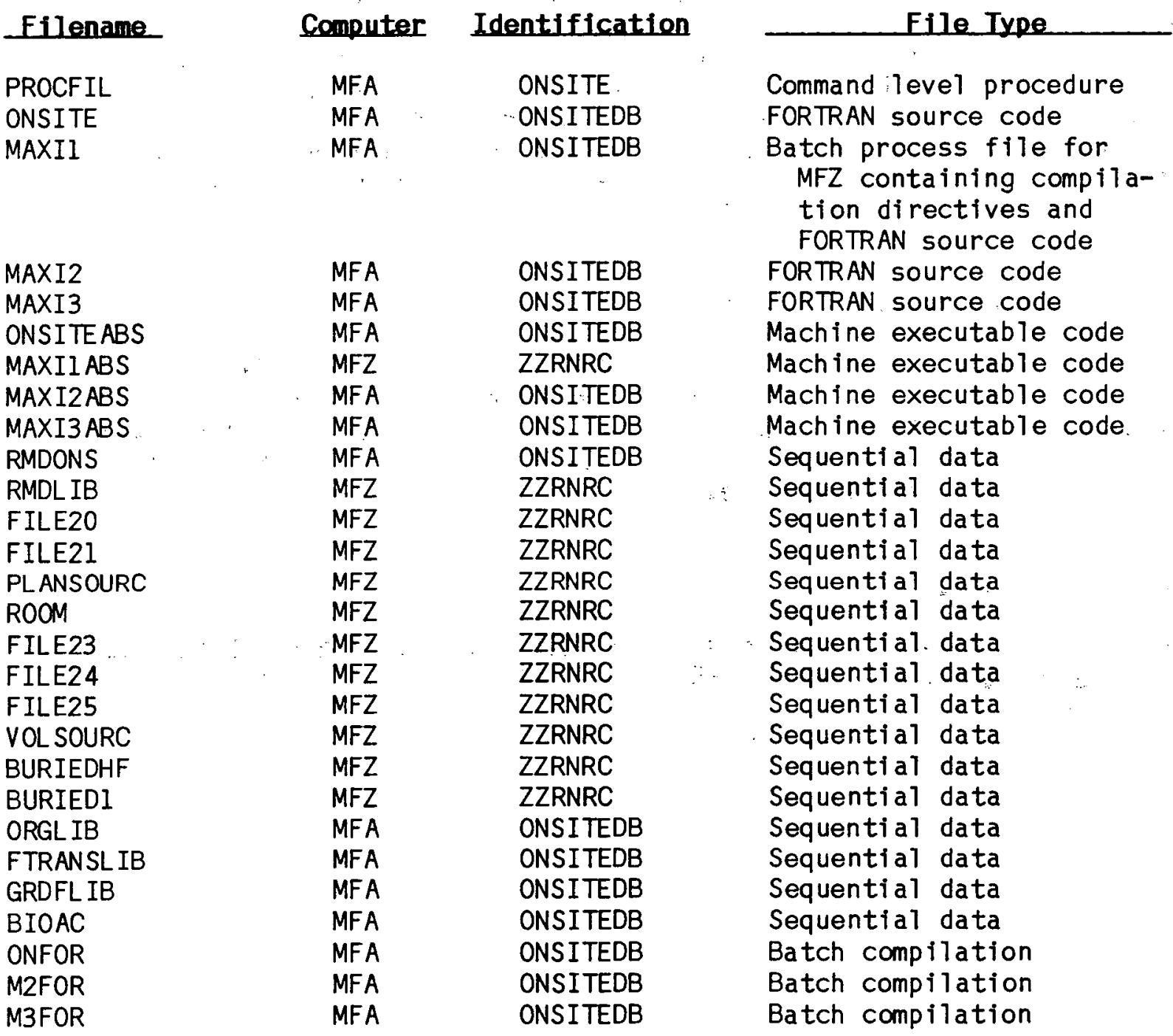


executions. Instructions for using these procedures are given in Section 3.1.1. The first CCL procedure, named $O N$, performs the necessary system-level commands to attach files, connect the files INPUT and OUTPUT to the terminal screen, and execute the ONSITE computer program. The second $\mathrm{CCL}$ procedure, named DONE, solicits a unique filename and a readprotection key from the user. DONE then catalogs the ONSITE-generated file with the user-supplied name, removes interim files from the user's work area, and disconnects the files INPUT and OUTPUT from the terminal screen. A third procedure, named SEND, routes an output file from the batch process output queue to the Remote Job Entry (RME) printer at the SS-056 Computer Operations Facility, Willste Building, Silver Spring, Maryland. A I isting of the file containing these procedures is located in Appendix 1.D.1.

\subsubsection{Software Security}

A1 1 files in the ONSITE/MAXIl software package have been protected against modification, extension, deletion, and performance of control functions by passwords. These passwords are not necessary for execution of any of the codes in the ONSITE/MAXIl software package. Requests for access to the passwords should be directed to the NRC Project Manager. Execution files created by ONSITE contain user identification and account information. These files are protected against read-access by a user-suppl ied password as discussed in Section 3.1.1.

\subsubsection{Computer-Code Conversion}

Most changes to the codes in the ONSITE/MAXIl software package were the result of minor syntax variations in the hardware and FORTRAN compilers. The only major change in the CDC version of the software package is the coding of the module RITFIL of the ONSITE computer code. A 1 isting of the CDC version of RITFIL is located in Appendix 1.D.2.

\subsection{References}

Chapin, N. 1974. "New Format for Flowcharts," Software-Practice and Experience, Vo1. 4, pp. 341-357, John Wiley and Sons Ltd., London, England. 


\section{APPENDIX $1 . A$}

\section{COMPUTER CODE LISTING - MAXII}




\section{APPENDIX 1.A COMPUTER CODE LISTING - MAXII}

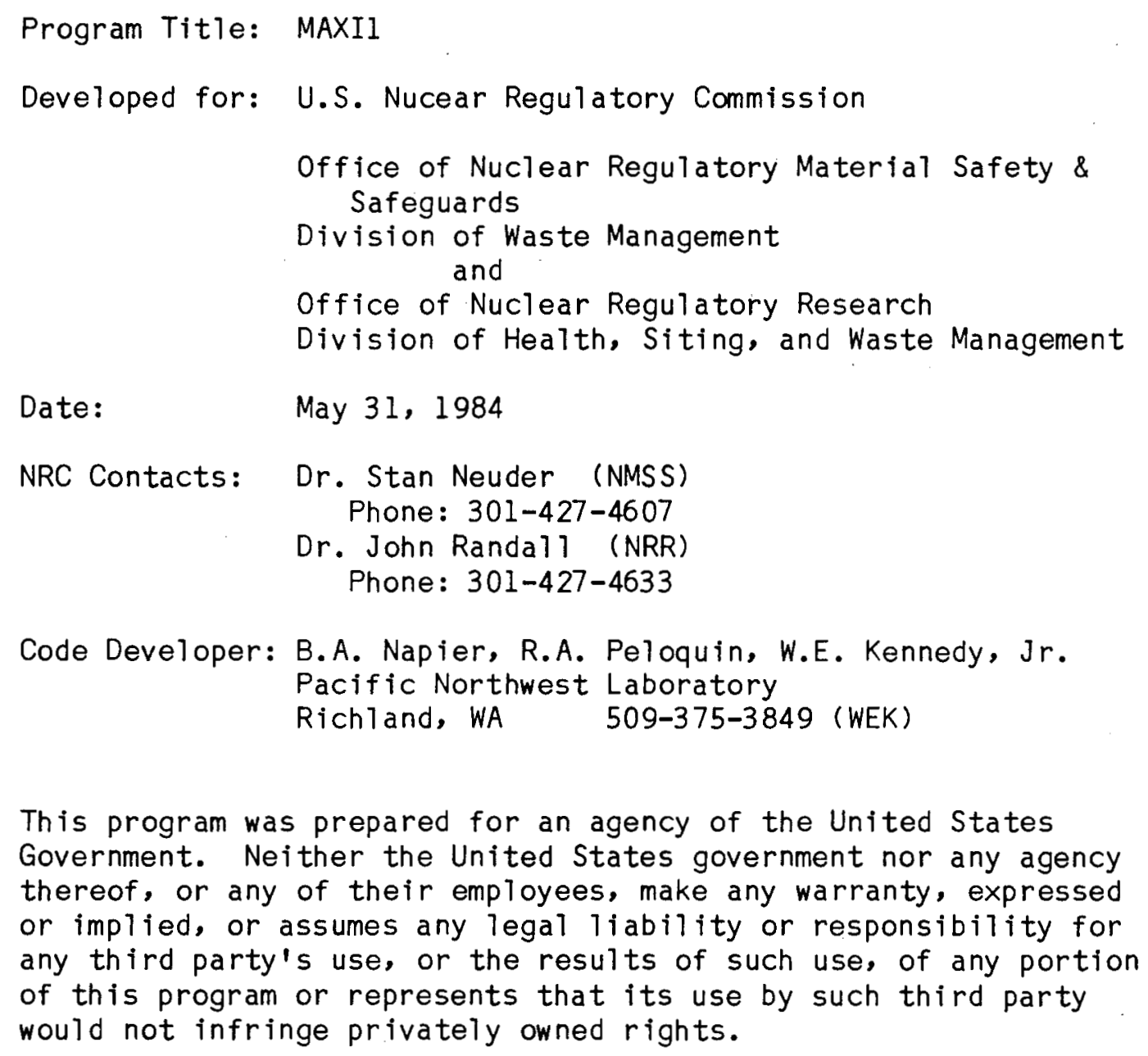




\section{APPENDIX I.A COMPUTER CODE LISTING - MAXII}

C

COMMON/THIRDS/OK (50), AML (50), XOSITE, IAIR, IDKAIR, IBLOW

COMMON/RL IB/ELT(300), AW(300), TR(300), NUC, NCH, NCHN(300), NOFNUC (200)

C

. ,NCHST (200), IFR $(2,300), \operatorname{DKF}(2,300), \operatorname{IMEM}(300)$

COMMON/DATAL/ELTO(50), AWO(50), IOFNUC (50), NONUC,DK(2,50), . $\operatorname{IFRM}(2,50), A L(50), A M(50), \operatorname{SOILCN}(50), \operatorname{ICHN}, \operatorname{AMI}(50), A M J(50)$,

C . IFOD, IARG, IWAT, RIRR, RPF, XMLF, DILF, IMO, DEN, IEXT

COMMON/DATA2/DFDOS $(50,50,5), \operatorname{AIDOS}(50,50,5), \operatorname{INDOS}(50,50,5)$, $. \operatorname{DEXT}(50), \operatorname{ARGF}(50,50,5), \operatorname{ARDW}(50,50,5), \operatorname{DEDXT}(50)$

C

COMMON/DOSEl/EXDOS $(50,50), \operatorname{AEXDOS}(50), \operatorname{FDOS}(50,50,5)$,

. $\operatorname{FADOS}(50,50,5), \operatorname{DADOS}(50,50,5)$,

. $\operatorname{ARDOS}(50,50,5), \operatorname{DWDOS}(50,50,5)$,

. $\operatorname{AFDOS}(50,5), \operatorname{ADADOS}(50,5), \operatorname{ADOS}(50,5)$,

. $\operatorname{AARDOS}(50,5), \operatorname{ADWDOS}(50,5)$

C

COMMON/MXTIM/MAXTIM( 5), MAXD (5)

C

COMMON/ JUNK/DDTT, ITI, IT2, TITLEI (20), TODAY, CLOCK

C

DIMENSION KORG $(5), \operatorname{NTR}(5,50), \operatorname{TITLR}(20), \operatorname{TITLDI}(15), \operatorname{NSOLD}(5,50)$

DIMENSION TITLIN(40)

DIMENSION Q(50), ELTI (50), AWI(50)

DIMENSION OI (50), OJ (50), OAPR (50)

DIMENSION NFLAG(300), NFLAGC(200)

C

C

CHARACTER AW*6, AWO*6, AWI*6

CHARACTER AWLS*6, AWX*6, AWAW*6, AWW*6, AWDX*6

CHARACTER DDTT*9, TODAY*10, CLOCK*10

REAL *4 INDOS

C

DATA AST / $1 * * 1 /$

C

C NAMELIST INPUT PARAMETERS

$\mathrm{C}$

NAMEL IST/INPUT/IEXT, XFACT, IOUT, ITI , IT2, KORG, NORG, XDPT, NEXT

., AGE, IFOD, IARG, IWAT, RIRR, RPF, XMLF, M3M2, DILF, IMO, DEN,

. RF1, RF2, RINH, INTRUD, IDKWAT, IAIR, XOSITE, IDKAIR,

- RPF1, RPF2, ISUR, I22, XF2, SRDIL, IBI0,

C

- FRSIZ, AREAIN, AREAEX, ION

C LAST TWO LINES OF NAMELIST INPUT SPECIFIC TO VAX ONSITE/BIOPORT

C VERSION

C

C MAXIMUM NUMBER OF RADIONUCLIDES THAT CAN BE CONSIDERED NMAX $=50$ 


\section{APPENDIX 1.A COMPUTER CODE LISTING - MAXII}

C GET DATE AND TIME

CALL DATE (TODAY)

CALL TIME (CLOCK)

C

C READ MASTER DATA LIBRARY FOR RADIONUCLIDE AND CHAIN DECAY DATA C

C

CALL RLIBIN(TITLR)

C

C READ CASE SPECIFIC INPUT

C

$\mathrm{DEN}=100$.

IMO $=6$

IFOD $=1$

I ARG $=1$

IWAT $=1$

IAIR $=1$

$X Q S I T E=0.0$

IDKAIR $=0$

RPF $=1$.

$\mathrm{RPF} 1=1.0$

RPF $2=0.0$

RIRR $=0.0$

$X M L F=0.01$

$M 3 M 2=0$

DILF $=1.0$

$A G E=-1.0$

IDKWAT $=0$

RIM $=1.0$

XDPT $=0.067$

$X F A C T=1.0$

ISUR $=1$

I22 $=1$

$X F 2=0.0$

ITI $=1$

RF $1=1.0$

RF2 $=0.0$

$\mathrm{RINH}=1.0$

IEXT $=0$

INTRUD $=0$

IT2 $=50$

C

SRDIL $=1.0$

$\operatorname{KORG}(1)=1$

$\operatorname{KORG}(2)=6$

$\operatorname{KORG}(3)=8$

$\operatorname{KORG}(4)=16$

$\operatorname{KORG}(5)=23$

$N O R G=5$ 


\section{APPENDIX 1.A COMPUTER CODE LISTING - MAXIl}

$\mathrm{IBIO}=0$

$I O N=0$

C

FRSIZ $=1.0$

AREAIN $=1.0$

AREAEX $=1.0$

C

C

C RPFI $=$ OLD RPF

C RPF2 $=$ FRACTION OF TOTAL DIET GROWN ON SITE

C RPF $=$ RPF 1 : IF RPF $2>0$. THEN RPF $=$ RPF $1 * R P F 2$

C ONLY RPF IS USED IN THE CALCULATION; RPFI, RPF2 USED FOR OA PAGE -RAP

C

C

C

C

C

C

$\mathrm{C}$

C

$\mathrm{C}$

C

ISUR, I22, AND XF2 ARE THE ONSITE PARAMETERS EQUIVELENT TO XFACT

ISUR = SURFACE CONTAMINATION (0-NOT CONSIDERED, 1-CONSIDERED)

I22 = INDEX OF SURFACE CONTAMINATION SOURCE (O-ISOSHLD, 2-MAXI2)

XF2 $=$ NO.OF HOURS/YEAR PERSON IS EXPOSED TO EXTERNAL CONTAMINATION

CODE LOGIC HAS BEEN ARRANGED SO THAT THE USER MAY STILL INPUT "XFACT"

THROUGH NAMELIST. XFACT WILL ONLY BE SET BY MAXII IF VALUES HAVE BEEN INPUT FOR ISUR, I22, AND XF1

$1 \operatorname{READ}(5,50, \mathrm{END}=99)$ TITLEl

READ (UNIT $=5, N M L=I N P U T, E R R=97$ )

IF (NEXT.EQ.4) GO TO 95

C

C

C

SET RIM VALUES BY M3M2

IF (M3M2.EQ.1) RIM=0.15

IF (M3M2.EQ.2) RIM=224.

$\mathrm{C}$

C IF ONSITE INPUT, SET XFACT BASED ON VALUES OF ISUR, I22, AND XF2

IF (ISUR .EQ. O) THEN

$X F A C T=0.0$

ELSE

IF (I22 .EQ. 0) XFACT $=5.844 \mathrm{E}-11$

IF (XF2 .GT. 0.) XFACT $=$ XFACT * $(X F 2 / 8766$.

ENDIF

C

C IF ONSITE, SET RPF ELSE SET RPFI=RPF

IF (RPF2 .GT. 0. ) THEN

$\mathrm{RPF}=\mathrm{RPF} 1 * \mathrm{RPF} 2$

ELSE

$\mathrm{RPFI}=\mathrm{RPF}$

$\mathrm{RPF2}=1.0$

ENDIF

C

C READ NEW ISOTOPE SELECTION

C NOTE: SUCCESSIVE CASES USE THE INITIAL INVENTORY 


\section{APPENDIX 1.A COMPUTER CODE LISTING - MAXII}

C IF NOT BIOPORT INPUT, DO STANDARD INVENTORY INPUT

IF (IBIO .NE. 1) THEN

C

IF (NEXT.EQ.3) GO TO 100

$\operatorname{READ}(5,200, E N D=99) \mathrm{NIN}$, IRR, IBLOW

C

IF (NIN.GT.NMAX.OR.NIN.LT.1) GO TO 98

$$
\operatorname{READ}(5,300, E N D=99)(E L T I(I), \operatorname{AWI}(I),(N S O L D(J, I), J=1,5), Q(I) \text {, }
$$

C

ELSE

C USE SPECIAL INVENTORY INPUT ROUTINE FROM BIOPORT

$\mathrm{C}$

$$
\begin{aligned}
& \text { IF (NEXT .EQ. 1) THEN } \\
& \text { FIRST TIME THROUGH }
\end{aligned}
$$

$\operatorname{READ}(5,201)$ IRR, IBLOW

$\operatorname{READ}(30,202) \quad($ TITL IN (IRAP), IRAP $=1,10)$

C PRINT 202, (TITIN (IRAP), IRAP $=1,40)$

ENDIF

C READ BIOPORT YEAR FOR REPORTS

READ $(30,205)$ IBYR

C PRINT 205, IBYR

C

C USE ALTERNATE INVENTORY INPUT (* SIGNALS END THIS YEAR)

C

$$
\begin{aligned}
& N I N=0 \\
& I=I
\end{aligned}
$$

C

153 CONTINUE

$$
\begin{aligned}
\operatorname{READ}(30,301, \operatorname{END}=99) & \operatorname{ELTI}(\mathrm{I}), \operatorname{AWI}(\mathrm{I}),(\operatorname{NSOLD}(\mathrm{J}, \mathrm{I}), \mathrm{J}=1,5), \\
& \mathrm{Q}(\mathrm{I}), \mathrm{OI}(\mathrm{I}), \mathrm{QJ}(\mathrm{I})
\end{aligned}
$$

C

C PRINT 8801, ELTI(I), AWI(I), Q(I), AST

C 8801 FORMAT (' AS READ: ',A4, ': ', A6, E10.3, ': ', A4, ': ')

C

C

IF (ELTI(I) .EQ. AST) GO TO 152

$I=I+I$

NIN $=$ NIN +1

GO TO 153

C

152 CONTINUE

ENDIF

DO $150 \quad I=1, N I N$

$Q(I)=Q(I) * S R D I L$

C

$150 \mathrm{OI}(I)=\mathrm{OI}(\mathrm{I}) * \mathrm{DILF}$ 


\section{APPENDIX 1.A COMPUTER CODE LISTING - MAXII}

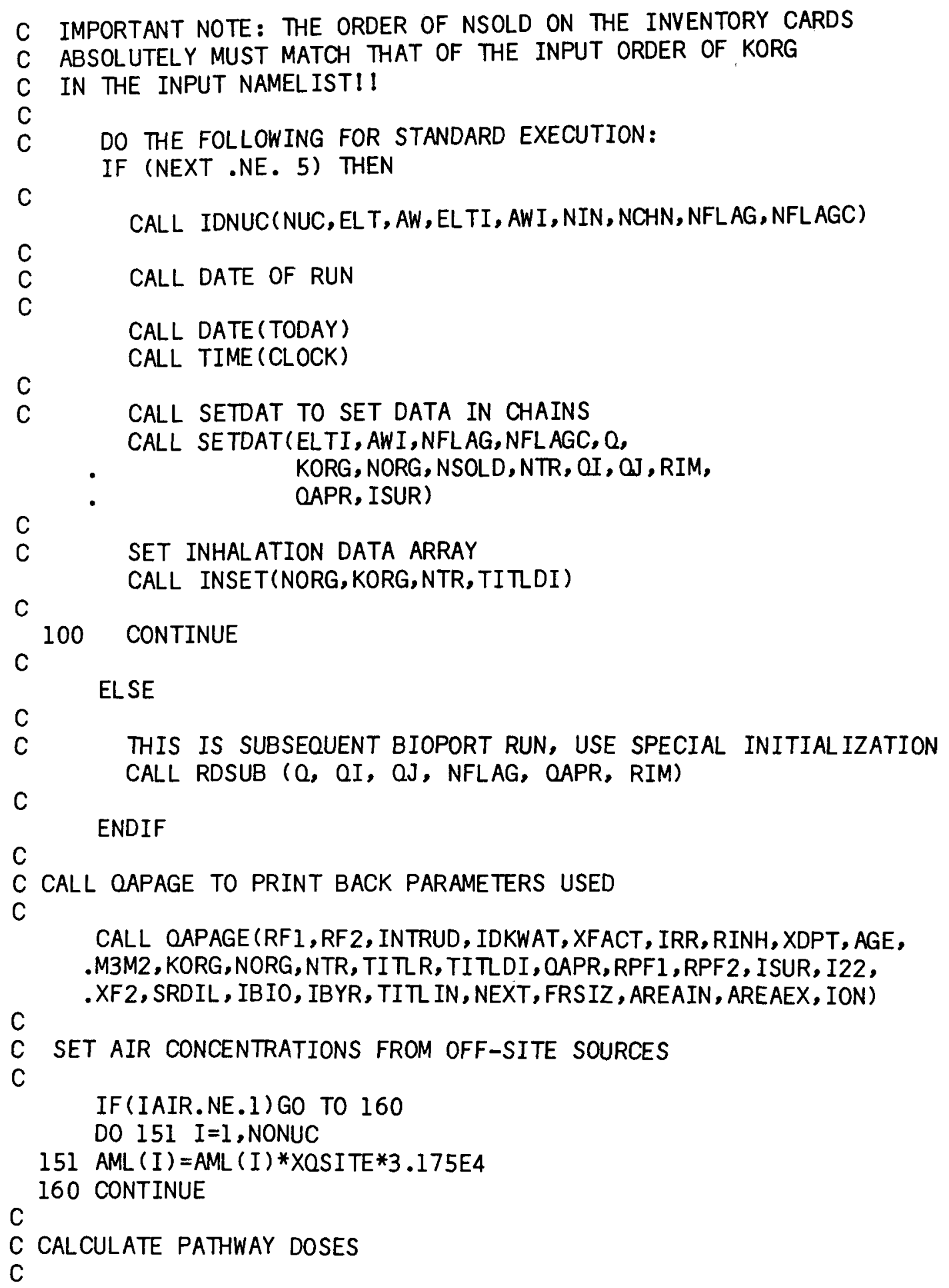

CALL OAPAGE (RF1, RF 2, INTRUD, IDKWAT, XFACT, IRR, RINH, XDPT, AGE, .M3M2, KORG, NORG, NTR, TITLR, TITLDI, OAPR, RPF1, RPF2, ISUR, I22, .XF2, SRDIL, IBIO, IBYR, TITL IN, NEXT, FRS IZ, AREAIN, AREAEX, ION) 


\section{APPENDIX 1.A COMPUTER CODE LISTING - MAXII}

C CALCULATE ANNUAL DOSES

C

CALL ANDOS(NORG)

C

C.DETERMINE MAXIMUM ANNUAL DOSE

C

CALL MAXDOS(NORG)

C

C PRINT OUTPUT RESULTS PAGE

C

CALL OUTPUT (NORG, IOUT, KORG, IBIO, IBYR, NEXT)

C

C RECOVER AML FOR FUTURE CASES

$\mathrm{C}$

IF (IAIR.NE. I) GO TO 180

DO $170 \quad I=1$, NONUC

$170 \mathrm{AML}(\mathrm{I})=\mathrm{AML}(\mathrm{I}) /(\mathrm{XQSITE} * 3.175 \mathrm{E} 4)$

180 CONTINUE

C

50 FORMAT (20A4)

200 FORMAT( 3 I5)

201 FORMAT ( 215$)$

202 FORMAT (20A4)

205 FORMAT $(1 X, I 5)$

300 FORMAT (A2, A6,5Il,4E10.2)

301 FORMAT ( $1 X, A 2, A 6,5 I 1,4 E 10.2)$

C

C IF(NEXT.GT.1) GO TO 1

GO TO 1

C

C

95 PRINT 400 STOP

99 PRINT 600

600 FORMAT(IH1,' DIAGNOSTIC 1: END OF FILE ON INPUT, STOP') STOP

97 PRINT 700

700 FORMAT(' DIAGNOSTIC 2: ERROR ON NAMELIST INPUT') STOP

98 PRINT 800, NIN, NMAX

800 FORMAT(IHI,' DIAGNOSTIC 3: ERROR IN NUMBER OF NUCLIDES ', ' 'INPUT, NONUC=1, I3, 'MAXIMUM ALLOWED IS, ' I4)

400 FORMAT(1HI, 'DIAGNOSTIC 4: END OF INPUT FOR THIS RUN, NORMAL ', 'TERMINATION')

$\mathrm{C}$

C

END 


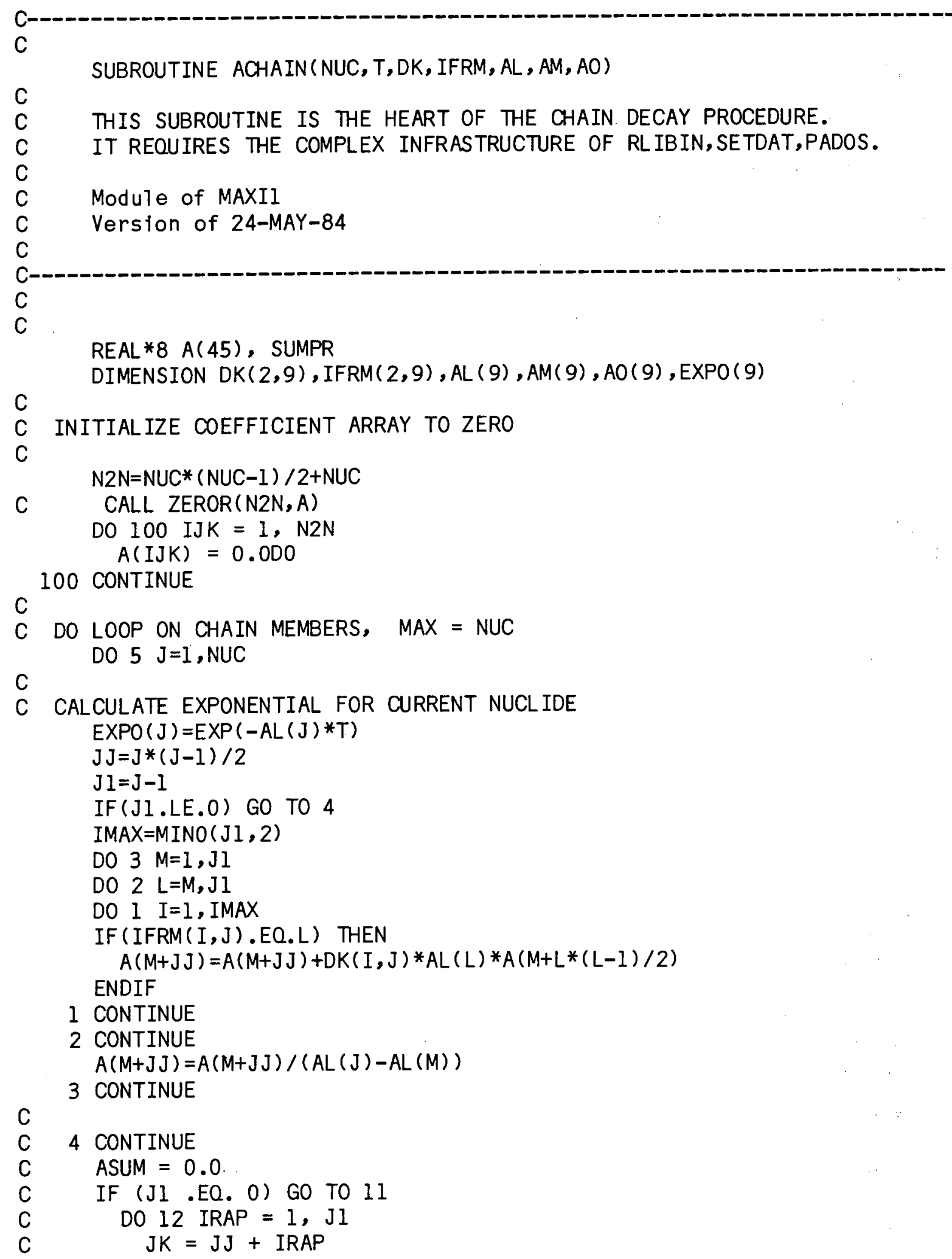




\section{APPENDIX 1.A COMPUTER CODE LISTING - MAXII}

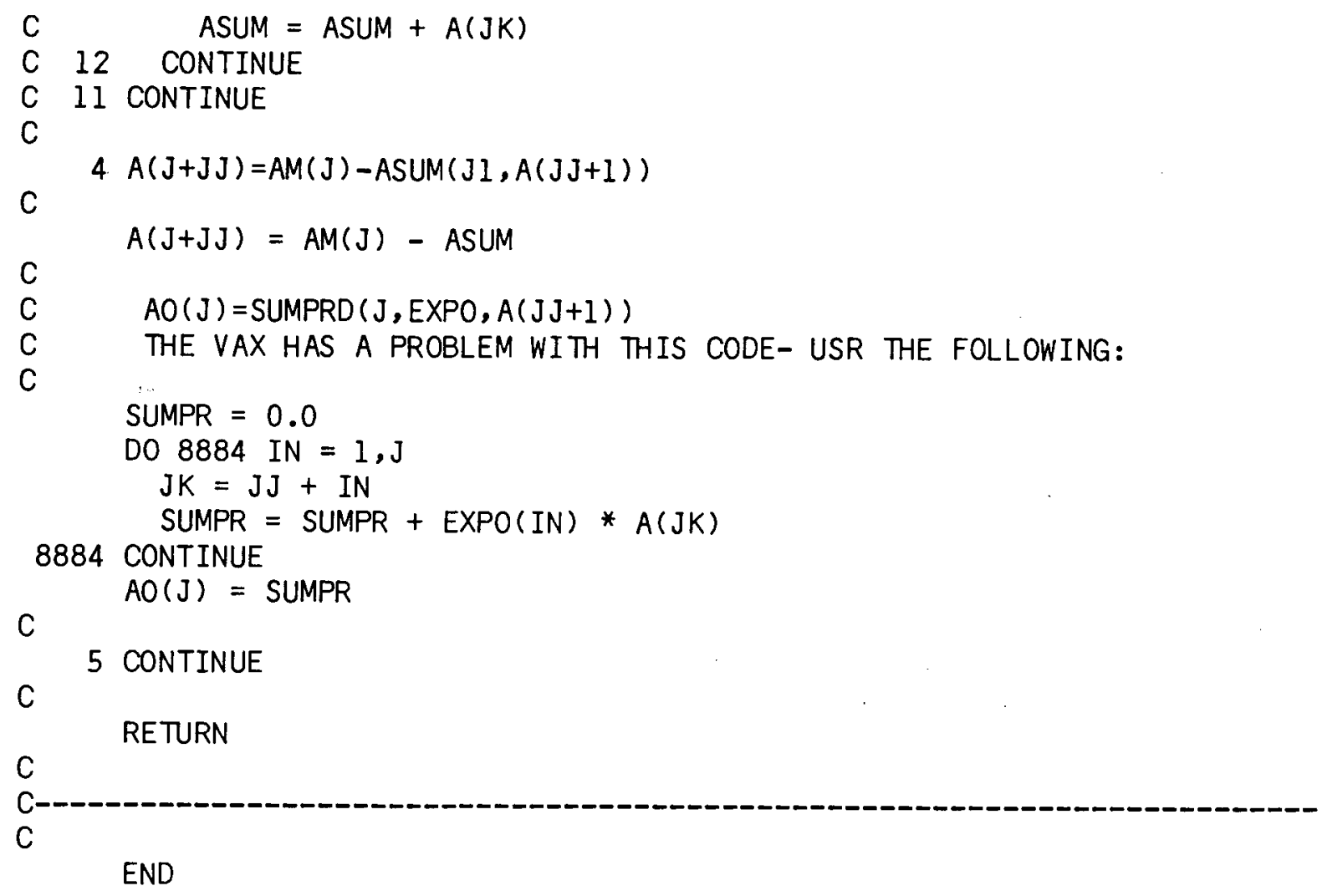




\section{APPENDIX 1.A COMPUTER CODE LISTING - MAXII}

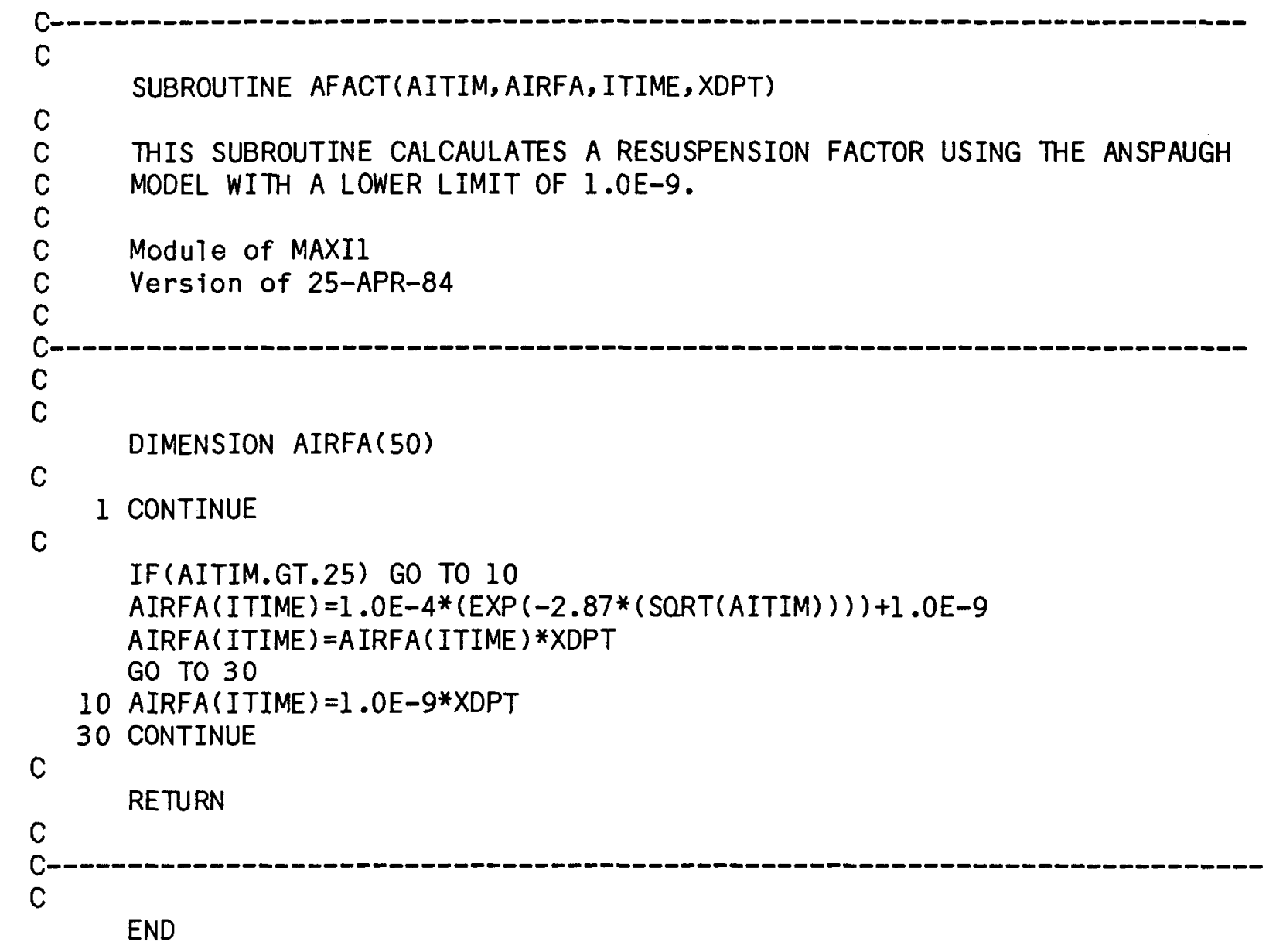




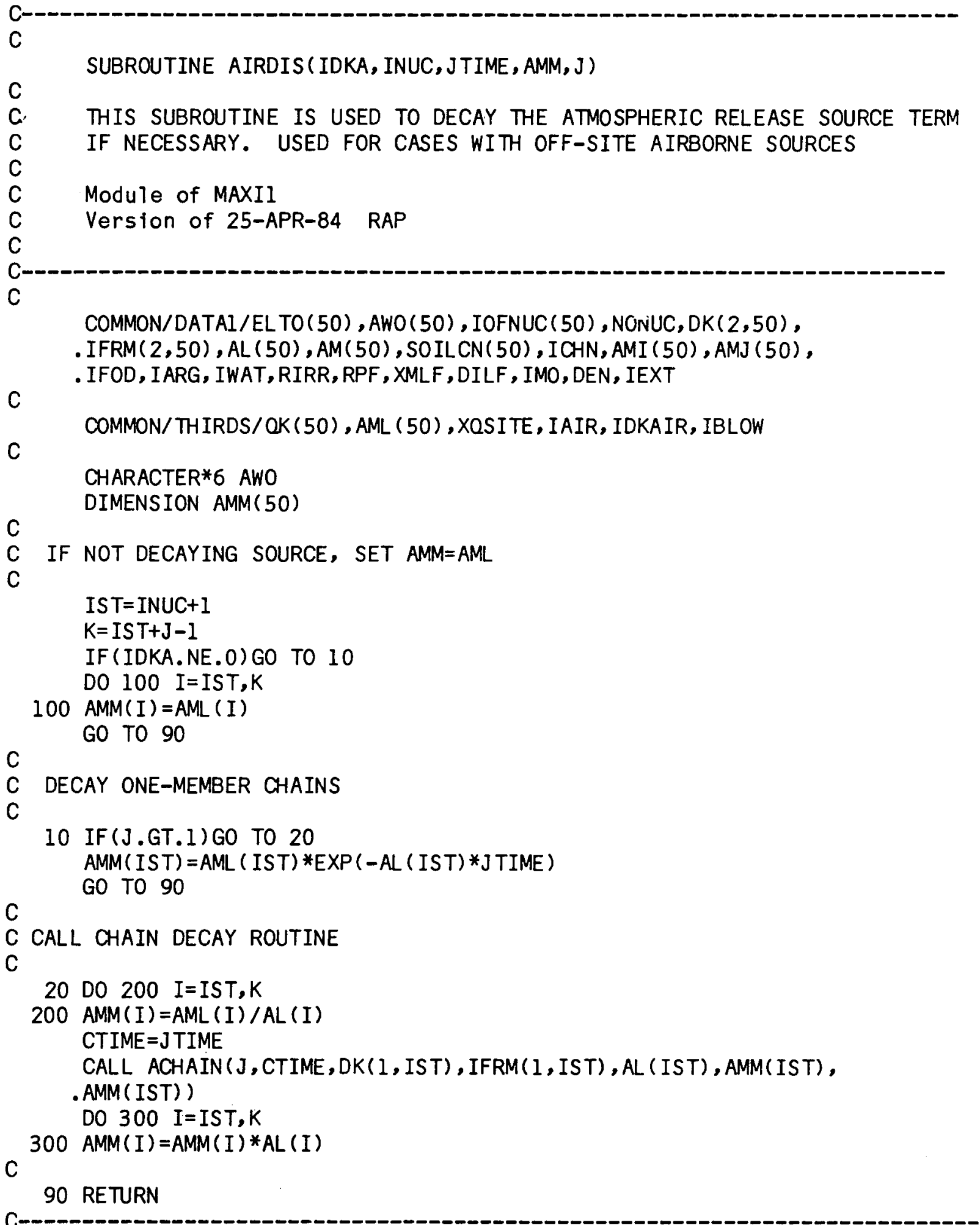

END 


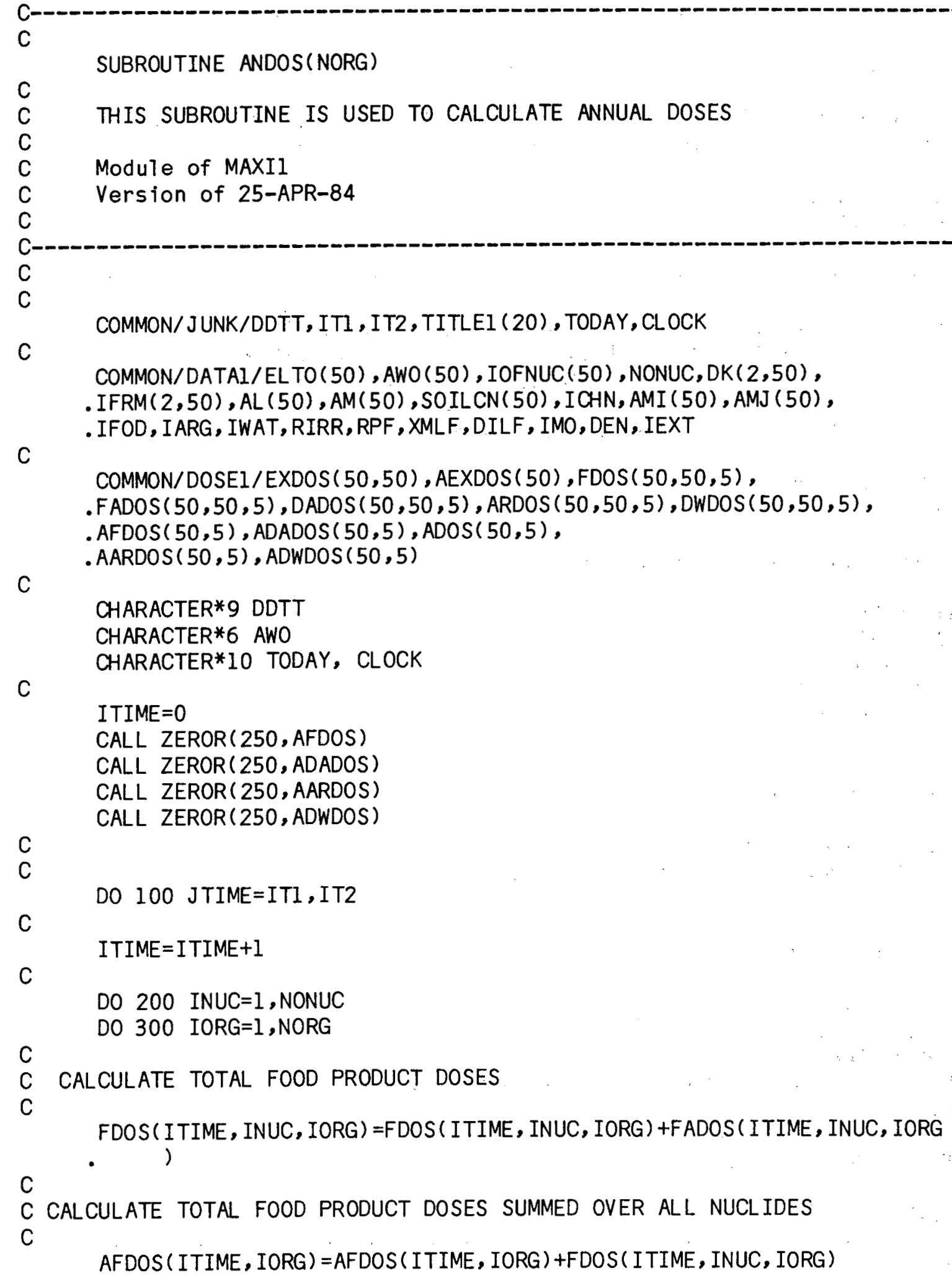


APPENDIX 1.A COMPUTER CODE LISTING - MAXII

C CALCULATE TOTAL INHALATION'DOSE SUMMED OVER ALL NUCLIDES

$\mathrm{C}$

ADADOS ( ITIME, IORG) =ADADOS ( ITIME , IORG) +DADOS( ITIME, INUC, IORG

C

C CALCULATE TOTAL AQUEOUS FOOD DOSES

C

AARDOS ( ITIME, IORG) $=$ AARDOS ( ITIME, IORG)

$\cdot$ +ARDOS ( ITIME, INUC, IORG)

C

C CALCULATE TOTAL DRINKING WATER DOSE

C

ADWDOS (ITIME, IORG) = ADWDOS (ITIME, IORG)

C

$$
\text { - } \quad \text { +DWDOS (ITIME, INUC, IORG) }
$$

300 CONTINUE

200 CONTINUE

$\mathrm{C}$

C

C CALCULATE ANNUAL DOSES

$\mathrm{C}$

C

DO 400 IORG $=1$, NORG

ADOS (ITIME, IORG) =AFDOS (ITIME, IORG) +ADADOS ( I TIME, IORG) + AEXDOS( I TIME

C )+AARDOS ( ITIME, IORG) + ADWDOS (ITIME, IORG)

400 CONTINUE

100 CONTINUE

$\mathrm{C}$

C DEBUG PRINT STATEMENT--

C ITIME $=0$

C DO 101 JTIME $=$ IT1, IT2

C ITIME $=$ ITIME +1

C PRINT 8881, JTIME, ( ADOS(ITIME, IORG), IORG=1, NORG)

C 8881 FORMAT( ' JTIME, ADOS: ', I4,5El0.3)

C 101 CONTINUE

C

C

RETURN

C

C

C

END 


\section{APPENDIX 1.A COMPUTER CODE LISTING - MAXII}

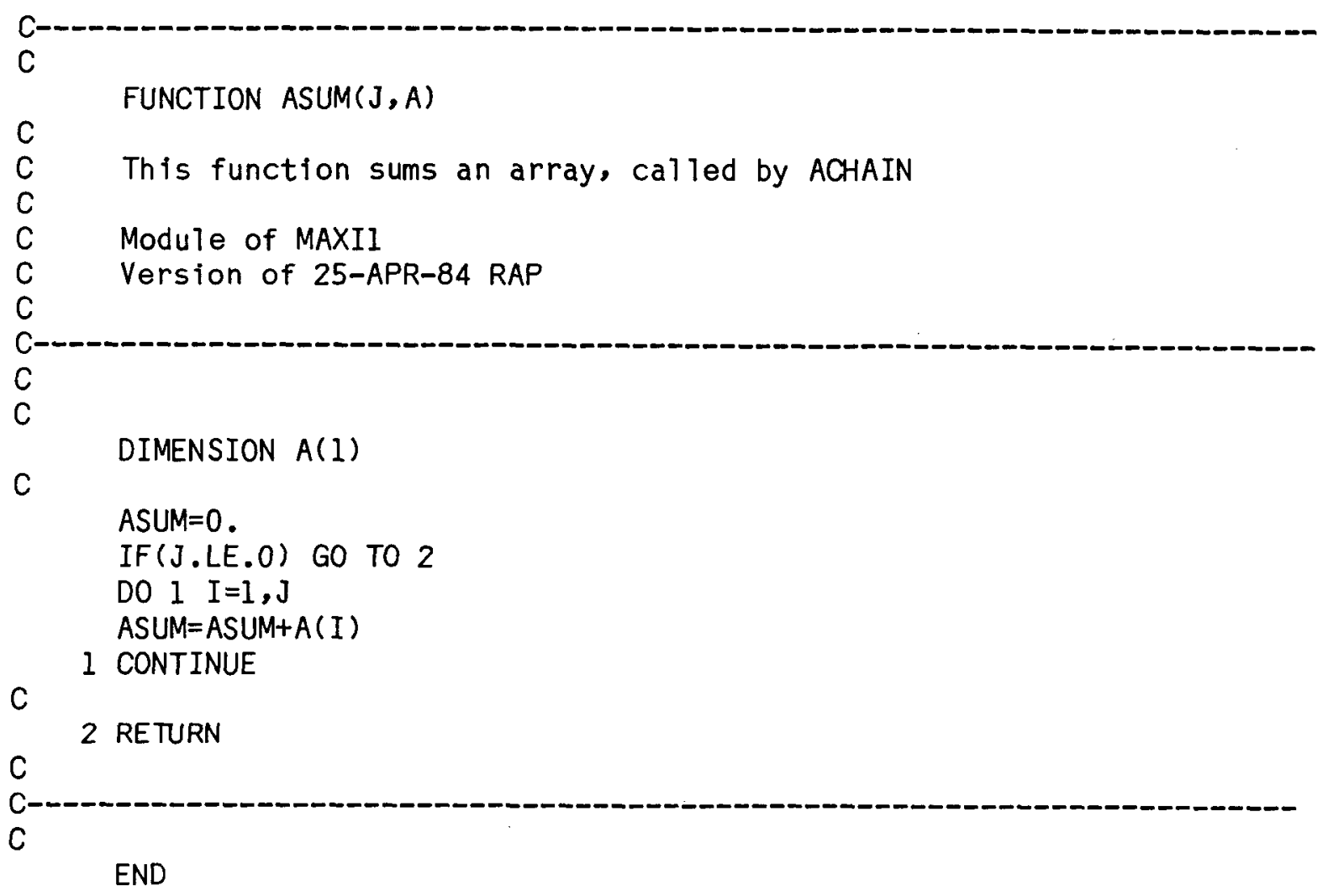




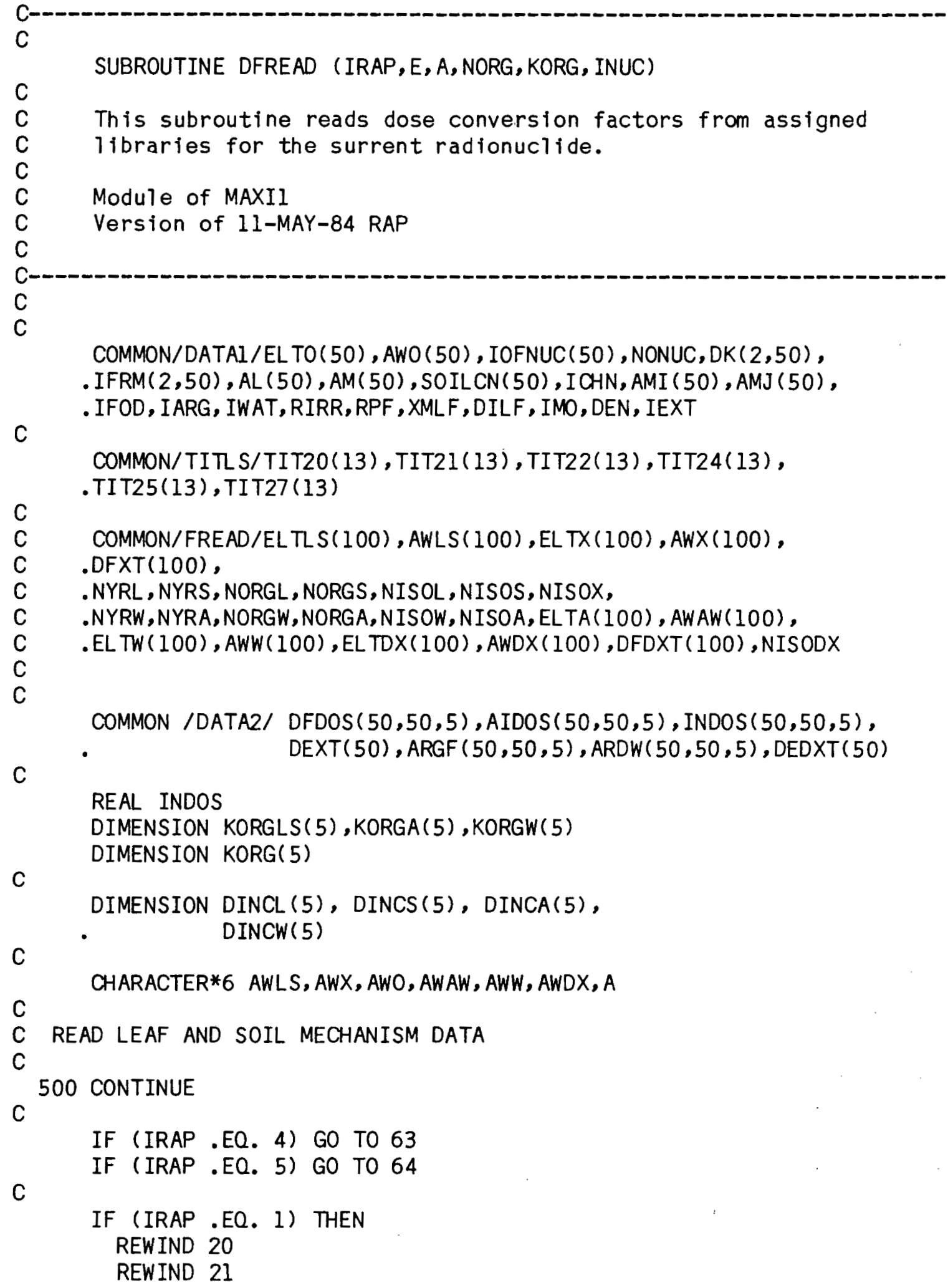


APPENDIX 1.A COMPUTER CODE LISTING - MAXII

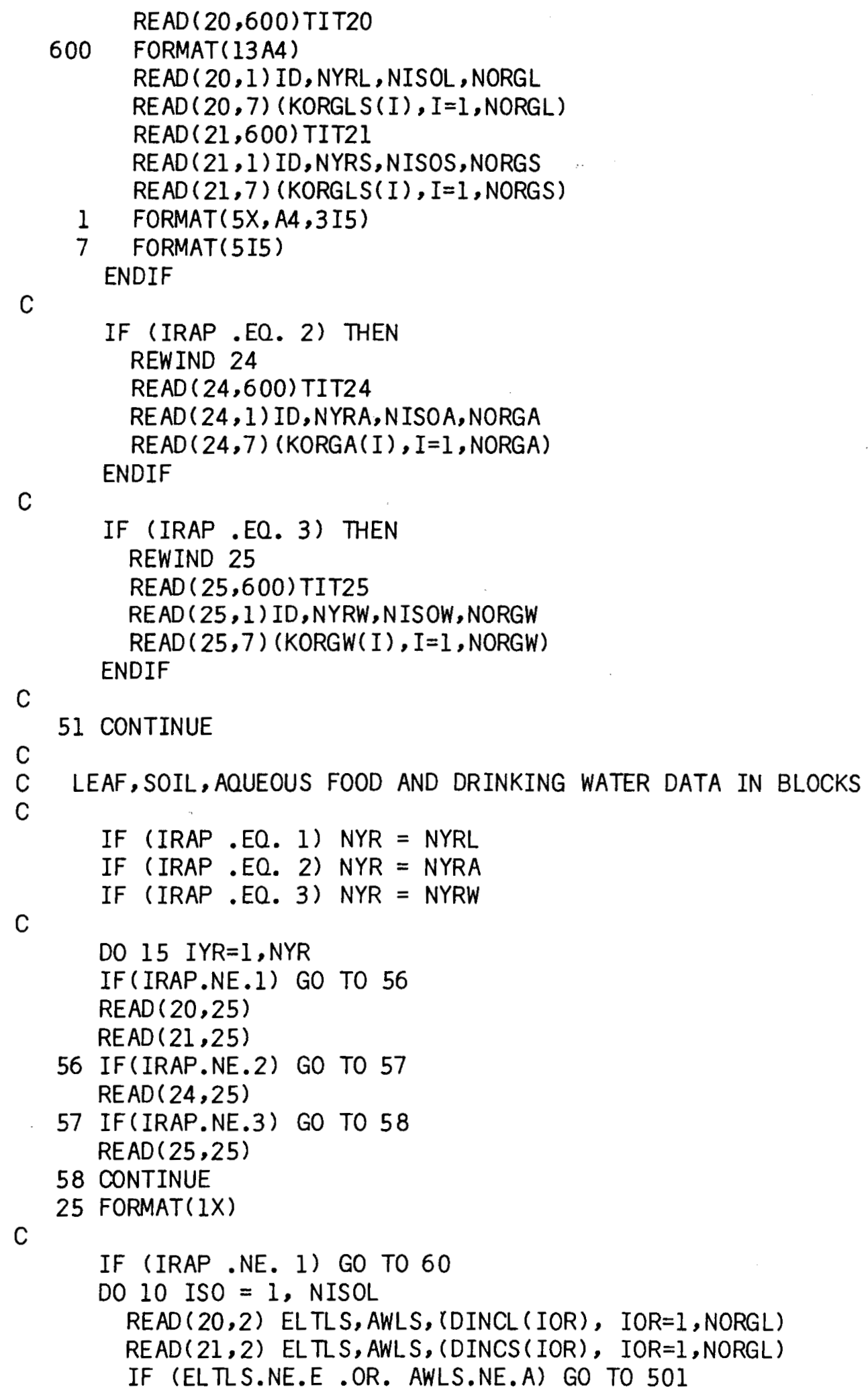


DO 502 IORG $=1$, NORG

DO 503 IOR $=1$, NORGL

IF (KORG (IORG).NE.KORGLS(IOR)) GO TO 504

DFDOS (IYR, INUC, IORG) =DINCS (IOR)

AIDOS ( IYR, INUC, IORG) $=$ DINCL (IOR)

504

503

CONTINUE

CONTINUE

502

CONTINUE

GO TO 15

501 CONTINUE

10 CONTINUE

60 CONTINUE

C

C

IF (IRAP .NE. 2) GO TO 61

DO 11 ISO $=1$, NISOA

$\operatorname{READ}(24,2)$ ELTA, AWAW, (DINCA(IOR), IOR=1, NORGA)

C WRITE $(6,8871)$ IYR, ELTA, AWAW, (DINCA (IOR), IOR=1, NORGA)

C 8871 FORMAT(// READ YR: ', I4,2X,A2, A6,2X,5E10.2)

IF (ELTA.NE.E .OR. AWAW.NE.A) GO TO 511

DO 512 IORG $=1$, NORG

DO 513 IOR = 1, NORGA

IF (KORG(IORG).NE.KORGA(IOR)) GO TO 514 ARGF (IYR, INUC, IORG) =DINCA (IOR)

C WRITE $(6,8870)$ IYR, INUC, IORG, ARGF (IYR, INUC, IORG)

C 8870

514

FORMAT(' IYR, INUC, IORG: 1,3 I5, 2X, IPE10.2)

513

512 CONTINUE CONTINUE

CONTINUE

GO TO 15

511 CONTINUE

11 CONTINUE

61 CONTINUE

c

IF (IRAP .NE. 3) GO TO 62

DO 12 ISO=l, NISOW

$\operatorname{READ}(25,2) \mathrm{ELTW}, A W W,(\mathrm{DINCW}(\mathrm{IOR}), I O R=1, N O R G W$ )

2 FORMAT (A2, A6,5E12.2)

IF (ELTW.NE.E .OR. AWW.NE.A) GO TO 521

DO 522 IORG $=1$, NORG

DO 523 IOR = 1, NORGW

IF (KORG (IORG). NE.KORGW(IOR)) GO TO 524

ARDW (IYR, INUC, IORG) $=D I N C W($ IOR)

524 CONTINUE

523 CONTINUE

522 CONTINUE

GO TO 15

521 CONTINUE 


\section{APPENDIX 1.A COMPUTER CODE LISTING - MAXII}

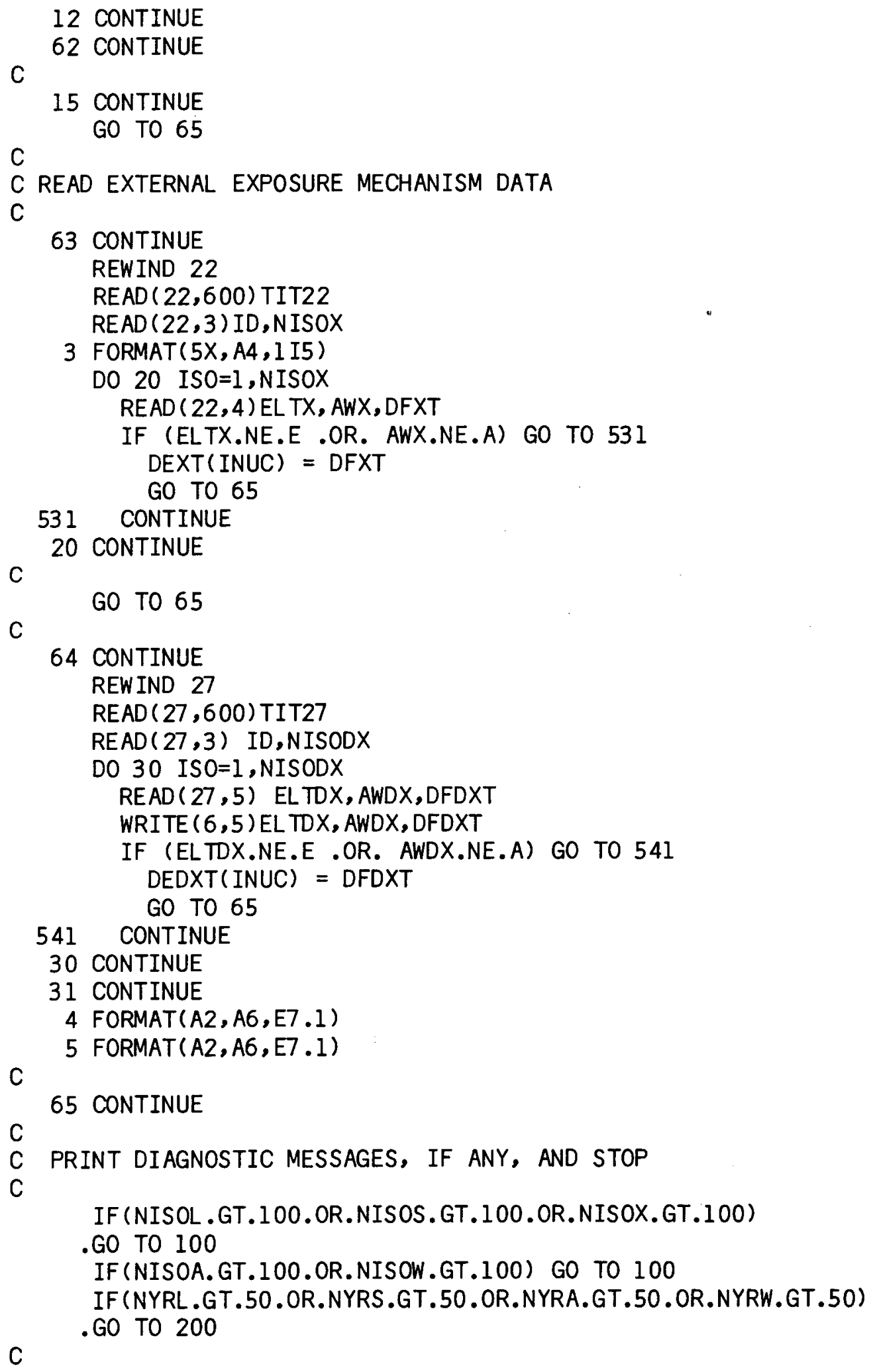


APPENDIX 1.A COMPUTER CODE LISTING - MAXII

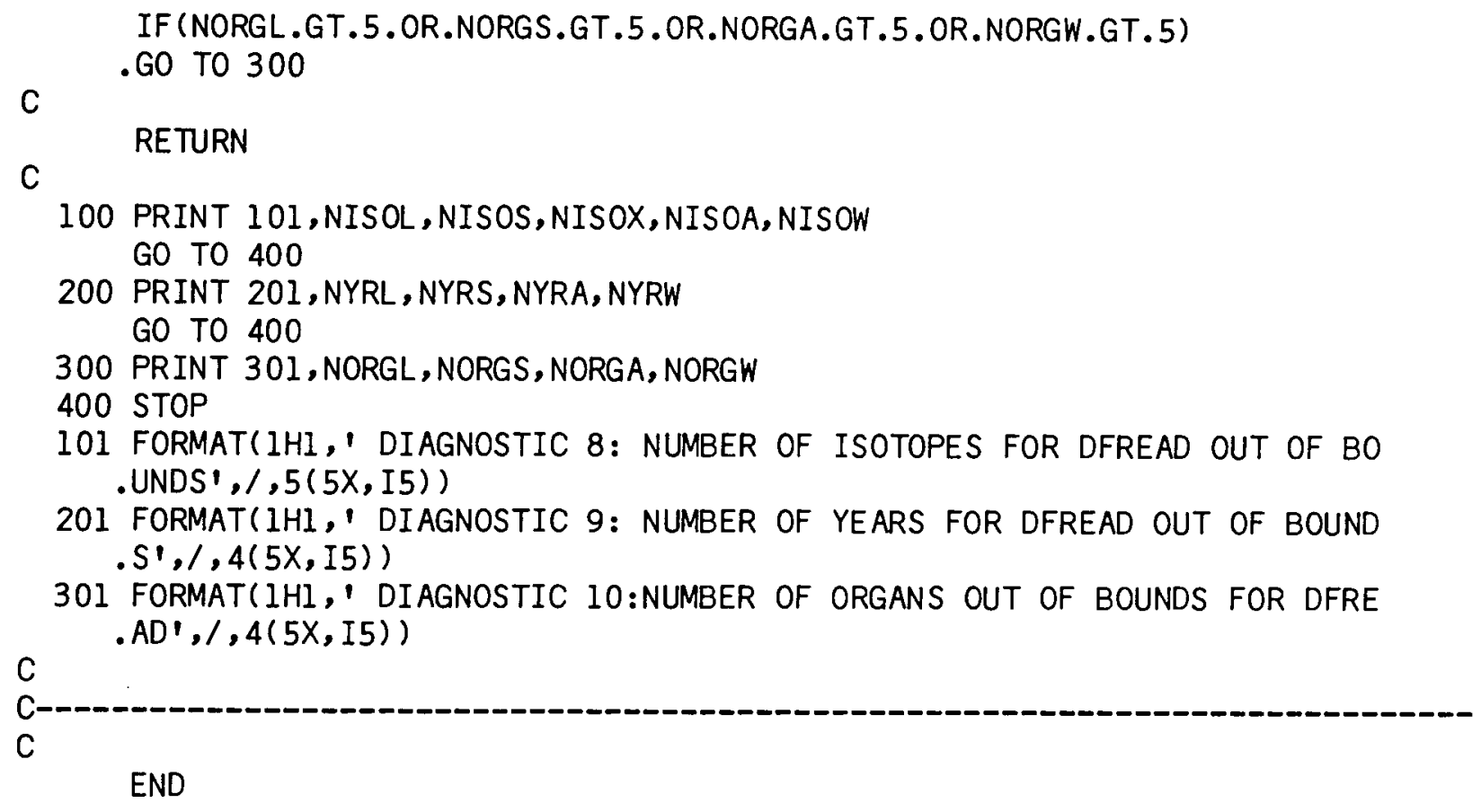


APPENDIX 1.A COMPUTER CODE LISTING - MAXIl

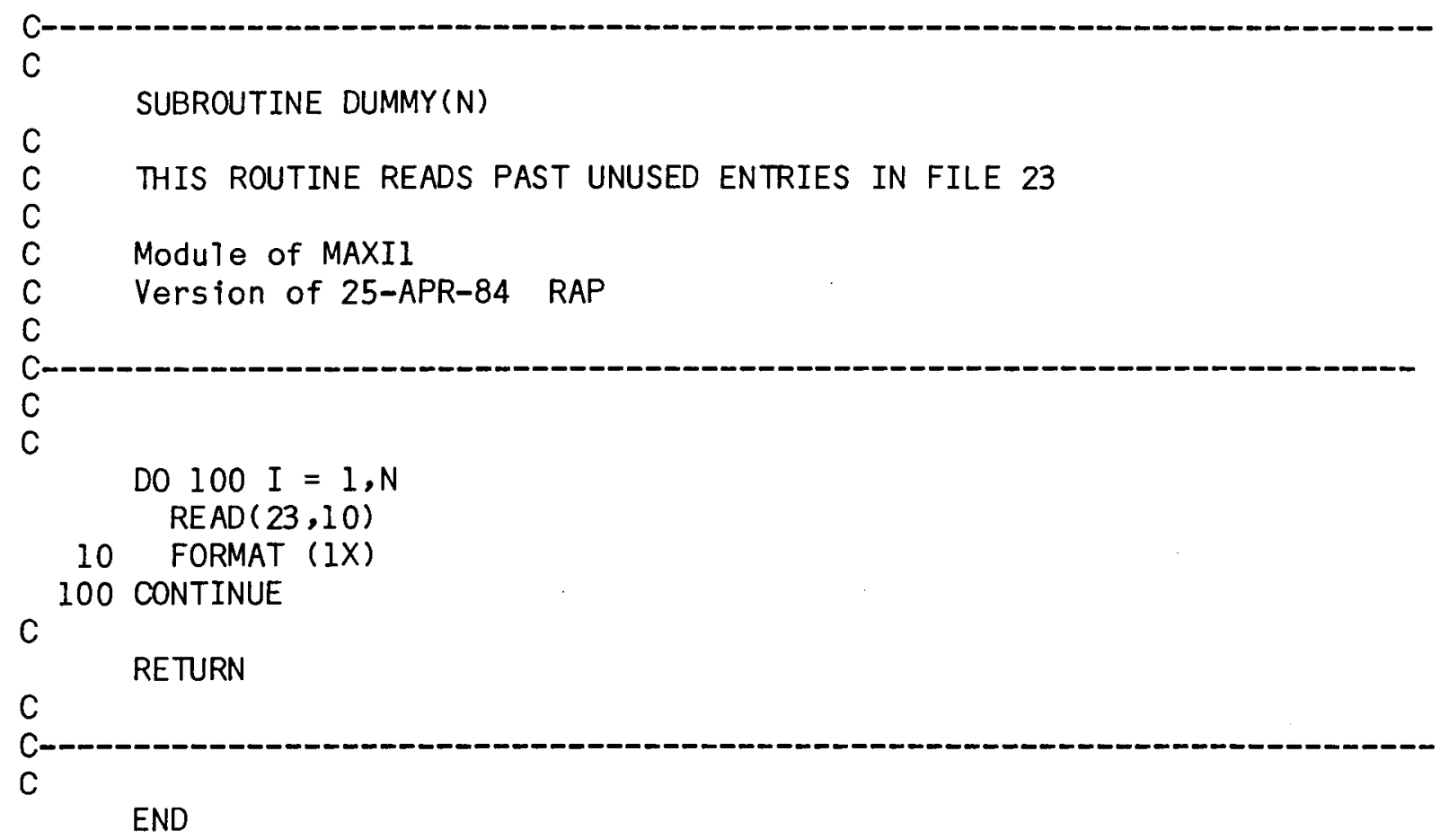


APPENDIX 1.A COMPUTER CODE LISTING - MAXII

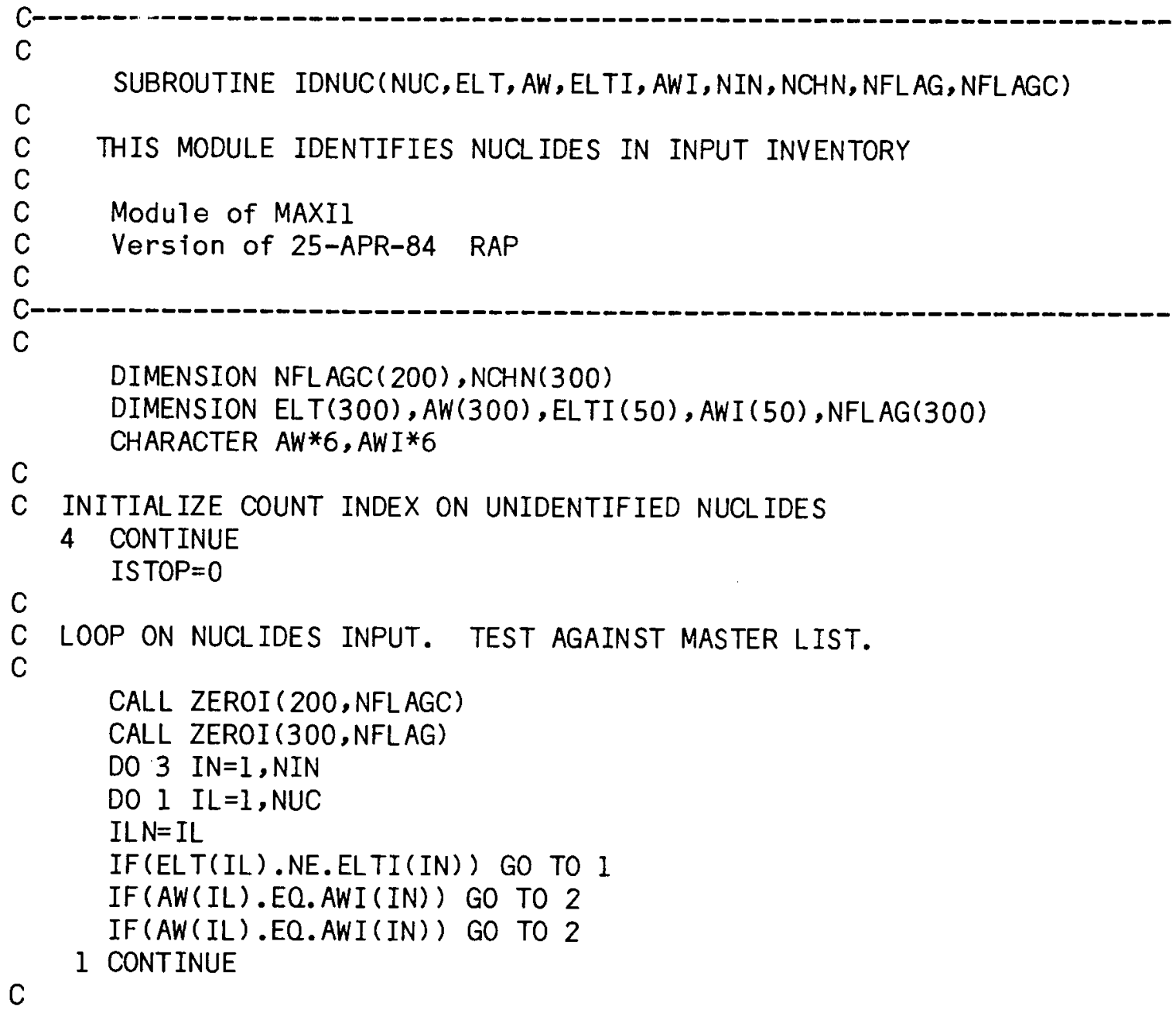

C NO MATCH IN LIBRARY FOR INPUT NUCLIDE. PRINT NAME OF UNKNOWN NUCL IDE ISTOP $=$ ISTOP+1

PRINT 100, ELTI(IN), AWI (IN)

GO TO 3

$2 N F L A G(I L)=I N$ $\operatorname{NFL~AGC}(N C H N(I L))=1$

3 CONTINUE IF ( ISTOP.LT.1) RETURN

C

C PRINT TOTAL NUMBER OF UNKNOWN NUCL IDES AND STOP.

C

PRINT 200, ISTOP

100 FORMAT(1HO,' DIAGNOSTIC 11: UNIDENTIFIED NUCLIDE ' , A2, A6)

200 FORMAT(IHO,' DIAGNOSTIC 12: THERE WERE UNIDENTIFIED NUCLIDES, ', ' ISTOP $=1$, I3) STOP

END 


\section{APPENDIX 1.A COMPUTER CODE LISTING - MAXII}

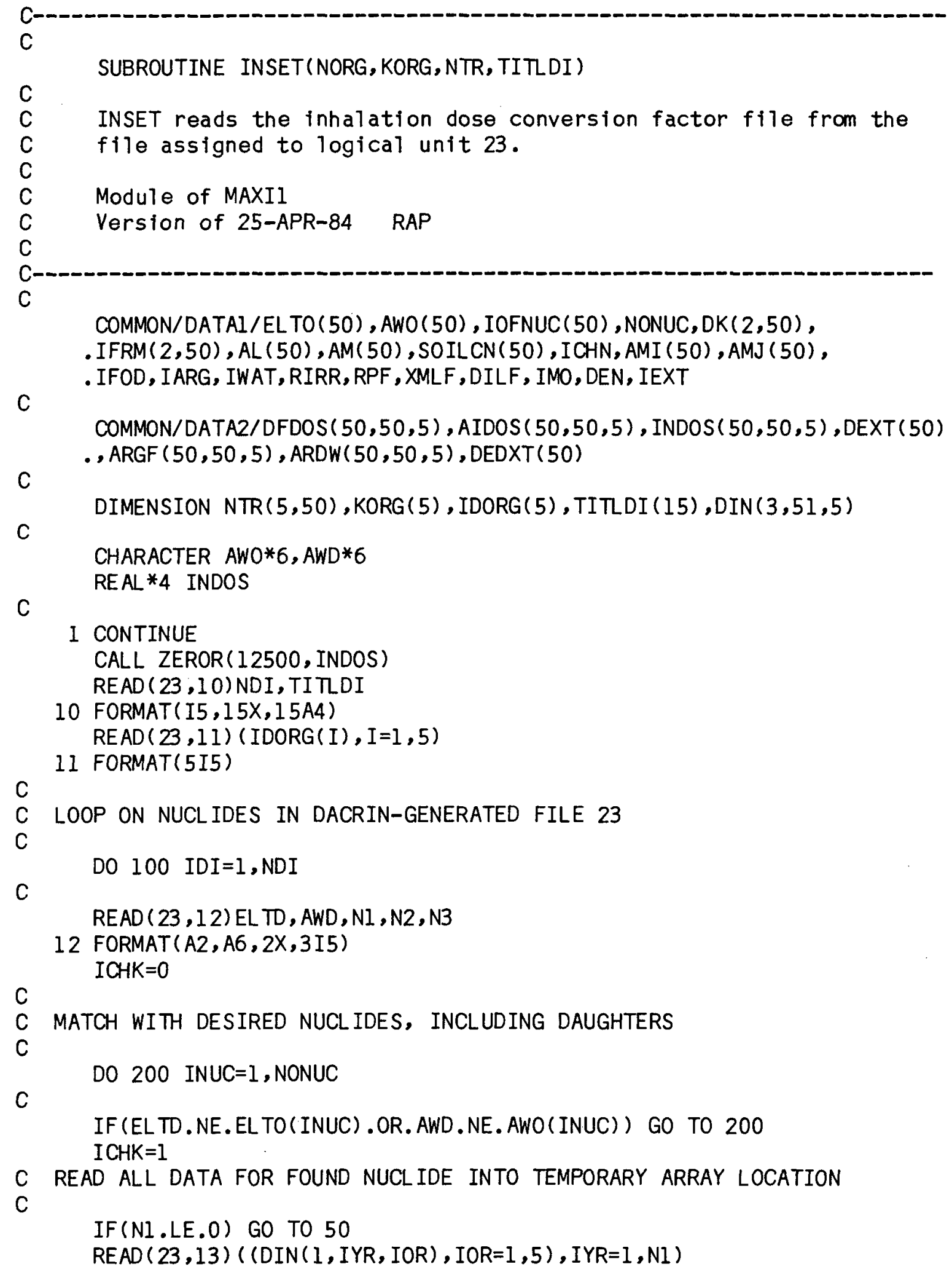

I CONTINUE

CALL ZEROR ( 12500, INDOS)

$\operatorname{READ}(23,10)$ NDI, TITLDI

10 FORMAT $(15,15 X, 15 A 4)$

$\operatorname{READ}(23,11)(\operatorname{IDORG}(\mathrm{I}), \mathrm{I}=1,5)$

11 FORMAT (5I5)

C

C LOOP ON NUCL IDES IN DACRIN-GENERATED FILE 23

C

C

DO 100 IDI $=1, N D I$

$\operatorname{READ}(23,12) \mathrm{EL} T \mathrm{~T}, \mathrm{AWD}, \mathrm{N1}, \mathrm{N2}, \mathrm{N3}$

12 FORMAT (A2, A6, 2X, 3I5)

ICHK $=0$

C

C MATCH WITH DESIRED NUCLIDES, INCLUDING DAUGHTERS

C

C

DO 200 INUC $=1$, NONUC

IF (ELTD. NE. EL TO(INUC) .OR. AWD. NE. AWO(INUC)) GO TO 200 ICHK=1

C READ ALL DATA FOR FOUND NUCL IDE INTO TEMPORARY ARRAY LOCATION

C

IF (NI.LE.0) GO TO 50

$\operatorname{READ}(23,13)((\operatorname{DIN}(1, \operatorname{IYR}, \operatorname{IOR}), \operatorname{IOR}=1,5), \operatorname{IYR}=1, \mathrm{~N} 1)$ 
APPENDIX I.A COMPUTER CODE LISTING - MAXII

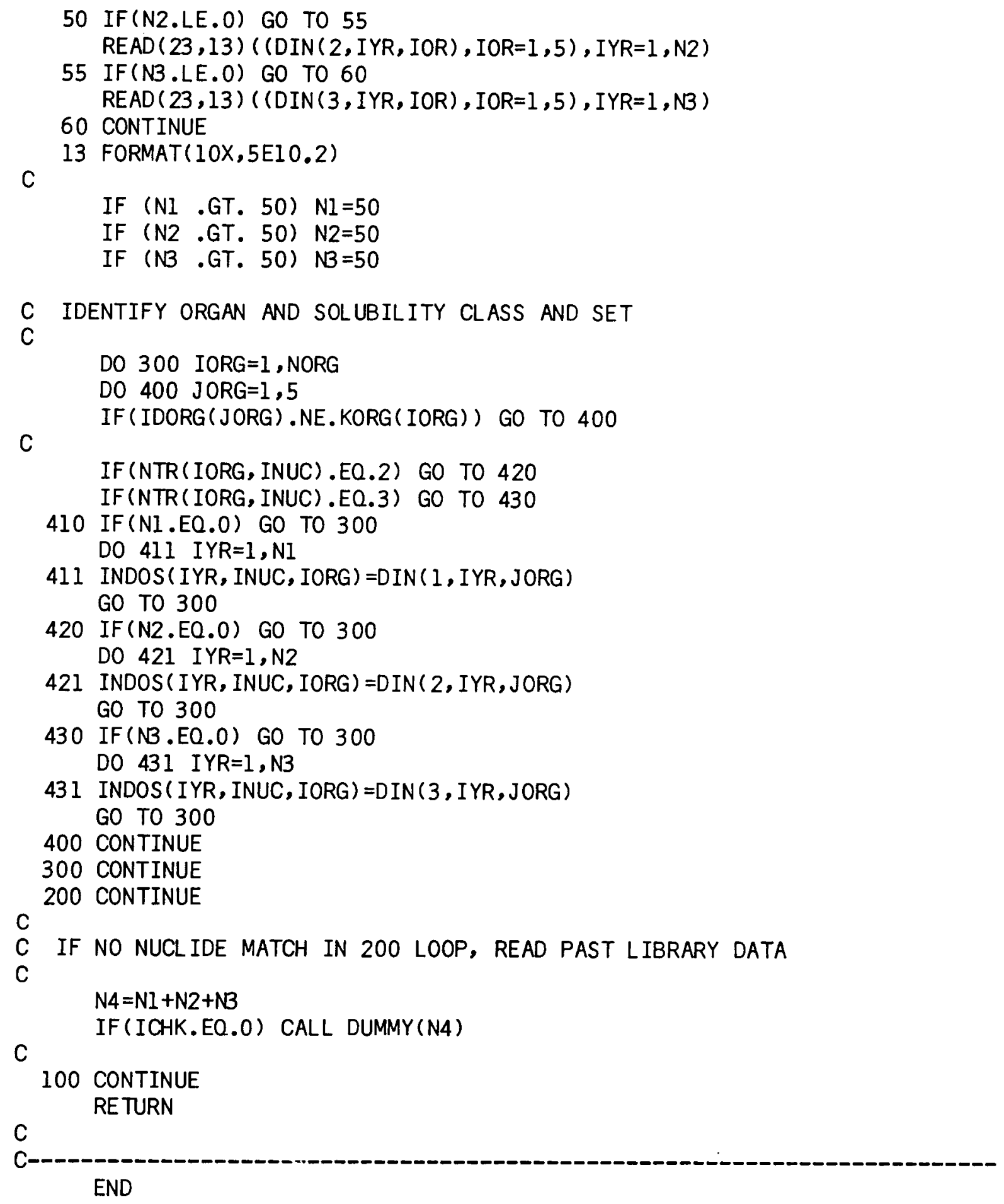




\section{APPENDIX 1.A COMPUTER CODE LISTING - MAXII}

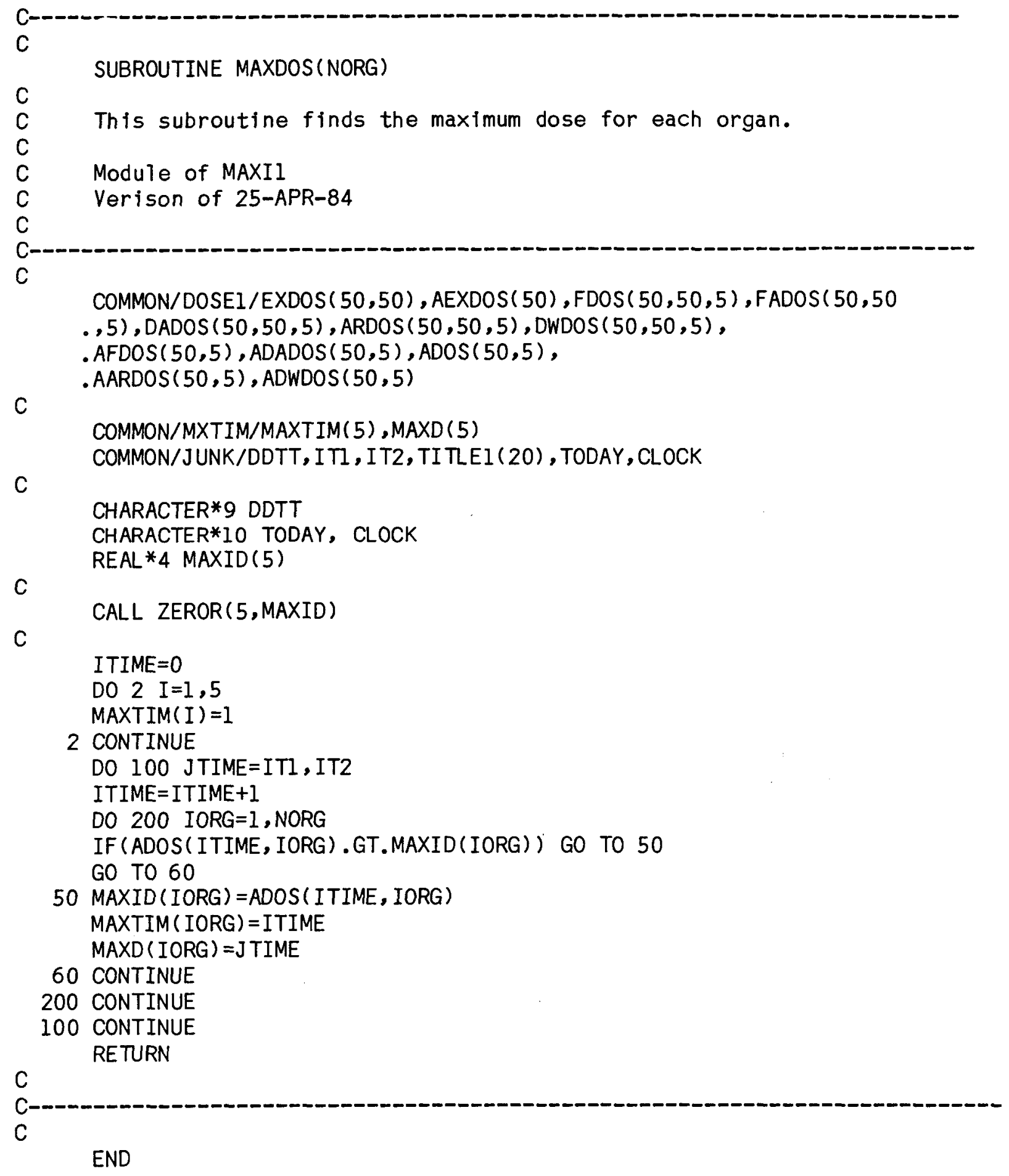

END 


\section{APPENDIX 1.A COMPUTER CODE LISTING - MAXII}

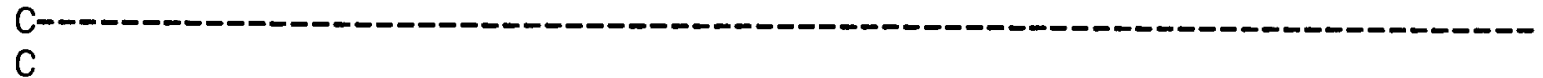

C

SUBROUTINE MLOAD(ITIME, DEN, XMLF, AIRFA)

C

C This subroutine calculates resuspension using the mass loading

C equation.

C

C Module of MAXIl

C Version of 25-APR-84 RAP

C

C

C

C

DIMENSION AIRFA(50)

C

1 CONTINUE

C

$\operatorname{AIRFA}($ ITIME $)=X M L F / D E N / 0.15$

C

RETURN

C

C-

C

END 


\section{APPENDIX 1.A COMPUTER CODE LISTING - MAXII}

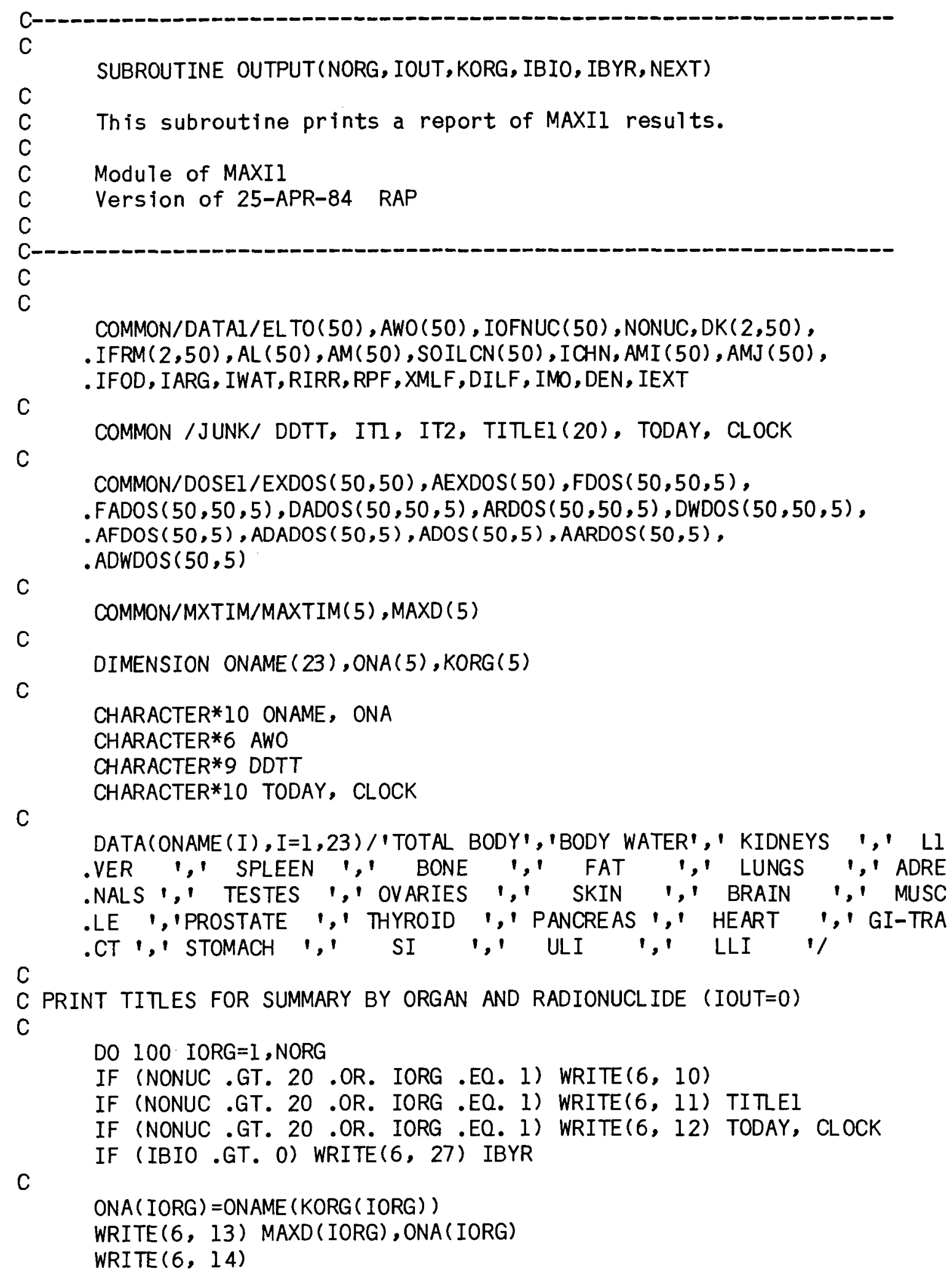




\section{APPENDIX 1.A COMPUTER CODE LISTING - MAXII}

DO 200 INUC $=1$, NONUC

$K=M A X T I M(I O R G)$

C

$A T E M P=A F D O S(K, I O R G)$

IPFD $=0$

C

IF (ATEMP . GT. 0.) IPFD $=F D O S(K$, INUC, IORG) $/ A T E M P * 100$

$A T E M P=A D A D O S(K, I O R G)$

IPDAD $=0$

C

IF (ATEMP .GT. 0.) IPDAD $=D A D O S(K$, INUC, IORG) $/$ ATEMP* 100

C

IPEX $=0$

IF (AEXDOS $(K)$.GT. 0.) IPEX $=\operatorname{EXDOS}(K, \operatorname{INUC}) / \operatorname{AEXDOS}(K) * 100$

ATEMP $=$ AARDOS $(K, I O R G)$

$I A R G=0$

IF (ATEMP .GT. 0.) IARG=ARDOS(K, INUC, IORG) /ATEMP* 100

C

ATEMP $=$ ADWDOS $(K$, IORG $)$

IDWD $=0$

C

IF (ATEMP .GT.0.) IDWD=DWDOS(K, INUC, IORG) /ATEMP*I00

WRITE (6, 15) EL TO(INUC), AWO (INUC), FDOS(K, INUC, IORG),

- IPFD, DADOS (K, INUC, IORG), IPDAD,

.EXDOS ( $K$, INUC), IPEX,

C

. ARDOS (K, INUC, IORG), IARG, DWDOS (K, INUC, IORG), IDWD

200 CONTINUE

C

IPAF $=0$

IPAD $=0$

IPAX $=0$

$I A G D=0$

IDWA $=0$

C

ATEMP $=\operatorname{ADOS}(K$, IORG $)$

C

IF (ATEMP.LE. O.) GO TO 201

IPAF $=$ AFDOS $(K$, IORG $) /$ ATEMP* 100

IPAD $=A D A D O S(K$, IORG $) / A T E M P * 100$

IPAX $=A E X D O S(K) / A T E M P * 100$

IAGD $=A A R D O S(K, I O R G) / A T E M P * 100$

IDW $A=A D W D O S(K$, IORG $) / A T E M P * 100$

C

201 CONTINUE

C

WRITE (6, 16) AFDOS(K,IORG), IPAF, ADADOS (K, IORG),

.IPAD, AEXDOS (K), IPAX,

. AARDOS (K, IORG), I AGD, ADWDOS (K, IORG), IDWA, ADOS (K, IORG) 


\section{APPENDIX 1.A COMPUTER CODE LISTING - MAXIl}

C

100 CONTINUE

10 FORMAT ( $1 \mathrm{HI})$

11 FORMAT $(4 X, 20 A 4)$

C

12 FORMAT(/,25X, 'MAXI, Version VAX2.2 25-APR-84', .' executed on ',AlO,' at ',AlO, '.')

C

13 FORMAT $(/, 1 X$, 'MAXIMUM ANNUAL DOSE SUMMARY FOR THE YEAR', . I5,' FOR', AI0)

14 FORMAT( $/ /, 28 X$, 'EXPOSURE PATHWAY',/,17X, 'INGESTION',1IX, .' INHALATION', IOX, 'EXTERNAL', .12X,' 'AOUATIC FOOD',8X, 'DRINKING WATER', $.1,1 X$, 'RADIONUCL IDE', $3 X$, $.5(1$ REM $1,9 X, 1 \% 1,5 X), /, 1 X, 12(1-1), 3 X, 5(16(1-1), 4 X), /)$

C

15 FORMAT ( $3 X, A 2, A 6,5 X, 5(1 P E 9.2 E 2,2 X, I 4,5 X))$

C

16 FORMAT( $1 X, 112(1-1), /, 5 X, '$ TOTAL S',6X, ' INGESTION',4X, 1\%' ', $.6 X, '$ INHAL ATION' $, 4 X, 1 \%$ ', 6X, 'EXTERNAL' $, 5 X, 1 \%$ ',

$.6 X, '$ AQUATIC FOOD',1X, $\% 1,5 X$, 'DRINKING WATER', $1 X$,

$.1 \% ', 6 \mathrm{X}$, 'TOTAL',

$. / /, 16 \mathrm{X}, 5(1 \mathrm{PE} 9.2 \mathrm{E} 2,2 \mathrm{X}, \mathrm{I} 4,5 \mathrm{X}), 1 \mathrm{PE} 9.2 \mathrm{E} 2)$

C

27 FORMAT(IX, 'DOSE RESULTING FROM CONCENTRATIONS AT YEAR ', I5, .' OF BIOPORT SIMULATION.' ')

C

$\mathrm{C}$

C PRINT DOSE BY ORGAN TO FILES FOR PLOTTING IF BIOPORT INPUT

C

IF (IBIO .EQ. 1) THEN

C

C

$$
\mathrm{IU}=40
$$

$$
\begin{aligned}
& \text { IF (NEXT .EQ. 1) THEN } \\
& \text { WRITE (IU,31) TITLEl, (ONA (IORG), IORG=1, NORG) }
\end{aligned}
$$
ENDIF

C WRITE (IU,32) IBYR, (ADOS(MAXTIM(IORG), IORG), IORG=1, NORG)

C ENDIF

C

31 FORMAT ( ' $, 20 A 4, / /, 1 X$, Year $\quad 1,5(2 X, A 10) /$

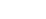

C

32 FORMAT (' $1, \operatorname{Il} 0,5(2 X, E 10.3))$

C

C 


\section{APPENDIX 1.A COMPUTER CODE LISTING - MAXII}

C TEST ON OUTPUT CLASS AND CONTINUE

C IF (IOUT.EQ.0) GO TO 999

C

C PRINT A TABULATION OF ANNUAL DOSES BY ORGAN (IOUT=1)

C

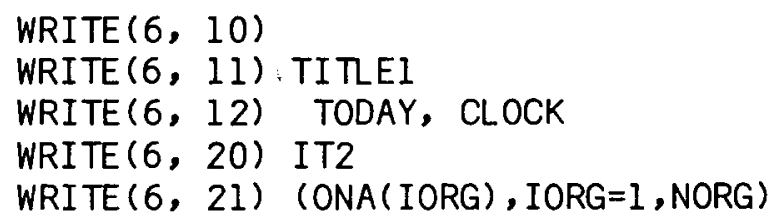

C

C LOOP ON YEARS AND ORGANS

C

ITIME $=0$

DO 300 JTIME $=$ IT, IT2

ITIME $=$ ITIME +1

WRITE $(6,22)$ JTIME, ( ADOS (ITIME, IORG), IORG =I, NORG)

300 CONTINUE

20 FORMAT $(/, 2 X$, 'ANNUAL DOSE SUMMARY FOR ', I5,' YEARS')

21 FORMAT $(2 X$, 'YEAR', $5 X, 5(A 10,2 X))$

22 FORMAT $(1 X, I 5,5 X, 5(1 P E 9.2 E 2,3 X))$

$\mathrm{C}$

C PRINT LONG OUTPUT BY PATHWAY, ORGAN, AND YEAR (IOUT.GT.1)

$\mathrm{C}$

IF(IOUT.LT.2)GO TO 999

ITIME $=0$

DO 500 JTIME $=$ IT1, IT2

ITIME $=$ ITIME+I

DO 600 IORG $=1$, NORG

C

C PRINT TITLES

C

WRITE $(6,10)$

WRITE $(6,11)$ TITLEI

WRITE $(6,12)$ TODAY, CLOCK

WRITE $(6,25)$ JTIME, ONA (IORG)

C

WRITE $(6,14)$

C LOOP ON RADIONUCLIDES

DO 700 INUC $=1$, NONUC

C

ATEMP $=$ AFDOS ( ITIME, IORG $)$

IPFD $=0$

IF (ATEMP .GT. 0.) IPFD=FDOS( ITIME, INUC, IORG)/ATEMP* 100

C

ATEMP=ADADOS $($ ITIME , IORG $)$

IPDAD $=0$

IF (ATEMP .GT. 0.) IPDAD=DADOS(ITIME, INUC, IORG) $/$ ATEMP* 100 
APPENDIX 1.A COMPUTER CODE LISTING - MAXII

ATEMP $=$ AEXDOS ( ITIME)

IPEX $=0$

IF (ATEMP .GT. 0.) IPEX=EXDOS (ITIME, INUC) /ATEMP*100

C

ATEMP $=$ AARDOS (ITIME, IORG)

$I A R G=0$

IF (ATEMP .GT. 0.) IARG=ARDOS(ITIME, INUC, IORG)/ATEMP*100

C

ATEMP $=$ ADWDOS (ITIME, IORG)

IDWD $=0$

C

IF (ATEMP .GT. 0.) IDWD=DWDOS(ITIME, INUC, IORG) /ATEMP*100

WRITE(6, 15) ELTO(INUC), AWO(INUC), FDOS( ITIME, INUC, IORG), .IPFD, DADOS (ITIME, INUC, IORG),

. IPDAD, EXDOS (ITIME, INUC), IPEX,

C

. ARDOS (ITIME, INUC, IORG), IARG, DWDOS (ITIME, INUC, IORG), IDWD

C

700 CONTINUE

$$
\begin{aligned}
& \text { IPAF }=0 \\
& \text { IPAD }=0 \\
& \text { IPAX }=0 \\
& \text { IAGD }=0 \\
& \text { IDWA }=0 \\
& \text { ATEMP }=\text { ADOS (ITIME, IORG) }
\end{aligned}
$$

C

IF (ATEMP .LE. O.) GO TO 701

IPAF $=$ AFDOS ( ITIME, IORG) / ATEMP* 100

IPAD $=$ ADADOS ( ITIME, IORG) $/$ ATEMP* 100

IPAX $=$ AEXDOS (ITIME) $/$ ATEMP* 100

I AGD $=$ AARDOS ( ITIME, IORG) /ATEMP* 100

IDWA=ADWDOS ( ITIME, IORG) /ATEMP* 100

701 CONTINUE

C

WRITE (6, 16) AFDOS (ITIME, IORG), IPAF, ADADOS( ITIME, IORG),

. IPAD, AEXDOS (ITIME), IPAX,

. AARDOS (ITIME, IORG), IAGD, ADWDOS (ITIME, IORG), IDWA,

. ADOS (ITIME, IORG)

600 CONTINUE

500 CONTINUE

25 FORMAT $(/, 13 \mathrm{X}, 1$ ANNUAL DOSE SUMMARY FOR YEAR', I5,1X,

' 'AND ORGAN', AlO)

C

999 CONTINUE

RETURN

C

C

END 


\section{APPENDIX 1.A COMPUTER CODE LISTING - MAXII}

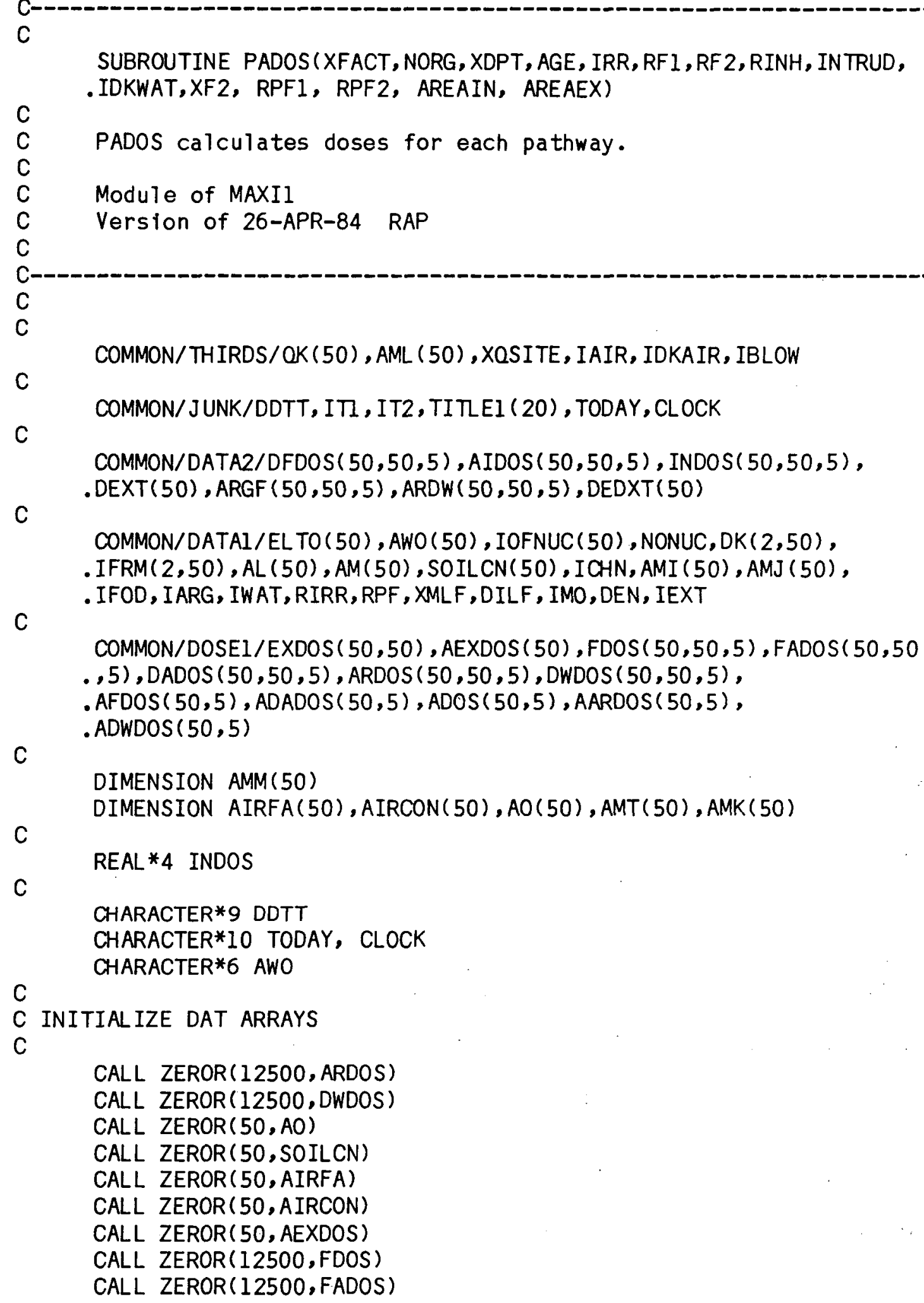

CALL ZEROR( 12500, ARDOS)

CALL ZEROR(12500,DWDOS)

CALL ZEROR $(50, A 0)$

CALL ZEROR (50,SOILCN)

CALL ZEROR(50,AIRFA)

CALL ZEROR (50,AIRCON)

CALL ZEROR (50,AEXDOS)

CALL ZEROR (12500,FDOS)

CALL ZEROR( 12500, FADOS) 


\section{APPENDIX 1.A COMPUTER CODE LISTING - MAXII}

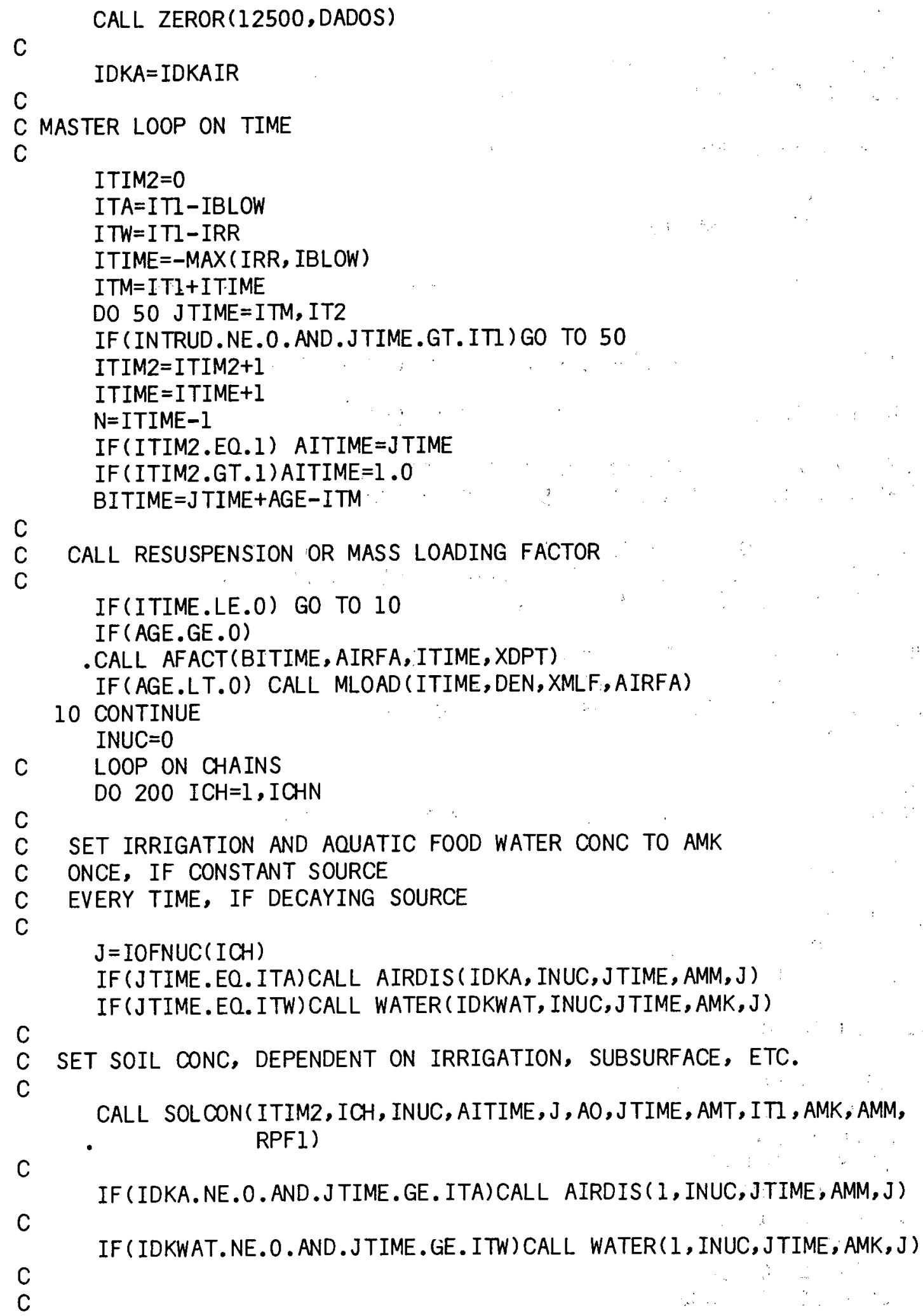




\section{APPENDIX 1.A COMPUTER CODE LISTING - MAXII}

C

DO $290 \mathrm{JNUC}=1, \mathrm{~J}$

INUC $=$ INUC+1

IF (JTIME.LT.ITI) GO TO 290

$\mathrm{C}$

C CALCULATE AIR CONCENTRATIONS

C

$A \operatorname{IRCON}($ INUC $)=S O I L C N($ INUC $) * A \operatorname{IRFA}($ ITIME $)+A M M($ INUC $)$

C

C CALCULATE EXTERNAL TOTAL BODY DOSES

C

EXDOS (ITIME, INUC) $=$ DEXT (INUC) *SOILCN (INUC)*XFACT*AREAEX

C WHERE 5.844E-l $1=(H R / Y R * R E M / M R E M * C I / P C I) / 0.15$

C

$\mathrm{C}$

C CALCULATE EXTERNAL DOSE SUMMED OVER ALL NUCL IDES AND DAUGHTERS

$\mathrm{C}$

AEXDOS (ITIME) $=$ AEXDOS ( ITIME $)+E X D O S($ ITIME, INUC)

C

C CALCULATE INTERNAL PATHWAY DOSES

$\mathrm{C}$

DO 300 IORG $=1$, NORG

$M=50-N$

DO 400 ITTIM=1,M

C

C

$$
\text { IR }=\text { ITTIM+N }
$$

FDOS ( ITTIM+N, INUC, IORG) =FDOS ( ITTIM+N, INUC, IORG) +DFDOS (ITTIM, INUC

., IORG)*SOILCN ( INUC) *RF 1*RPF $2 *$ AREAIN

.+DFDOS (ITTIM, INUC, IORG) *AMT ( INUC) *RF2*RPF2*AREAIN

C

FADOS ( ITTIM+N, INUC, IORG) $=$ FADOS (ITTIM+N, INUC, IORG) + AIDOS ( ITTIM, INUC . , IORG) *AIRCON ( INUC) *RPF2*AREAIN

C

C IRRIGATION LEAF DEPOSITION, AIR DEPOSITION VELOCITY IS ASSUMED

C TO BE IE-3 FOR ALL RESUSPENDED PARTICLES

C THIS REQUIRES A SPECIAL LIBRARY OF DEP VELOCITIES FOR FOOD FILGEN!!

C

IF(RIRR.LE.0.0)GO TO 500

C

FADOS (ITTIM+N, INUC, IORG) $=F A D O S($ ITTIM+N, INUC, IORG $)+$

. AIDOS ( ITTIM, INUC, IORG) *AMK ( INUC) *RIRR/2.635E6/1.0E-3*RPF 2

C 500 CONTINUE

C

DADOS ( ITTIM+N, INUC, IORG) $=$ DADOS ( ITTIM+N, INUC, IORG $)+$ INDOS ( ITTIM, INUC , IORG) *AIRCON (INUC) *RINH*AREAIN 


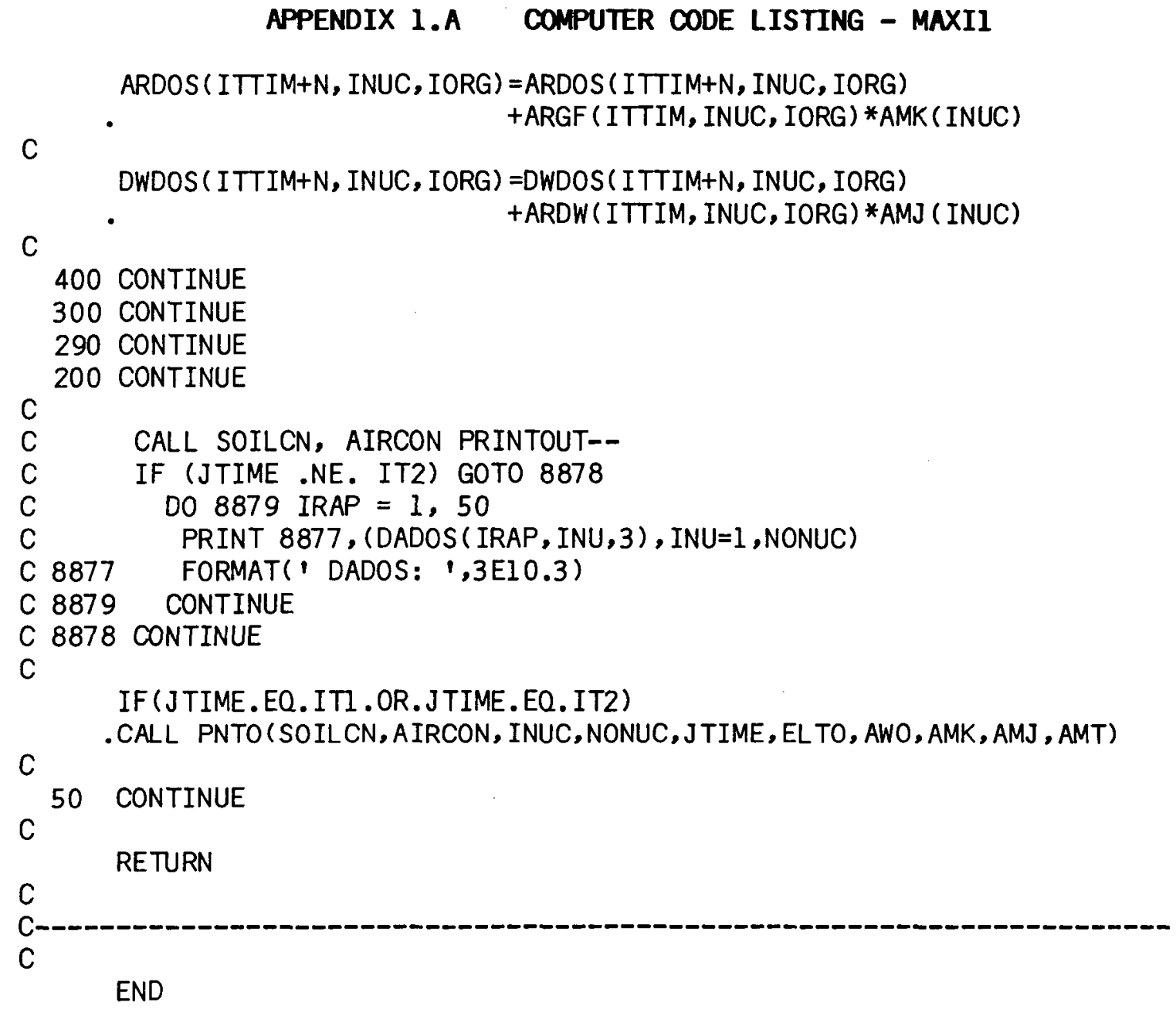

END 


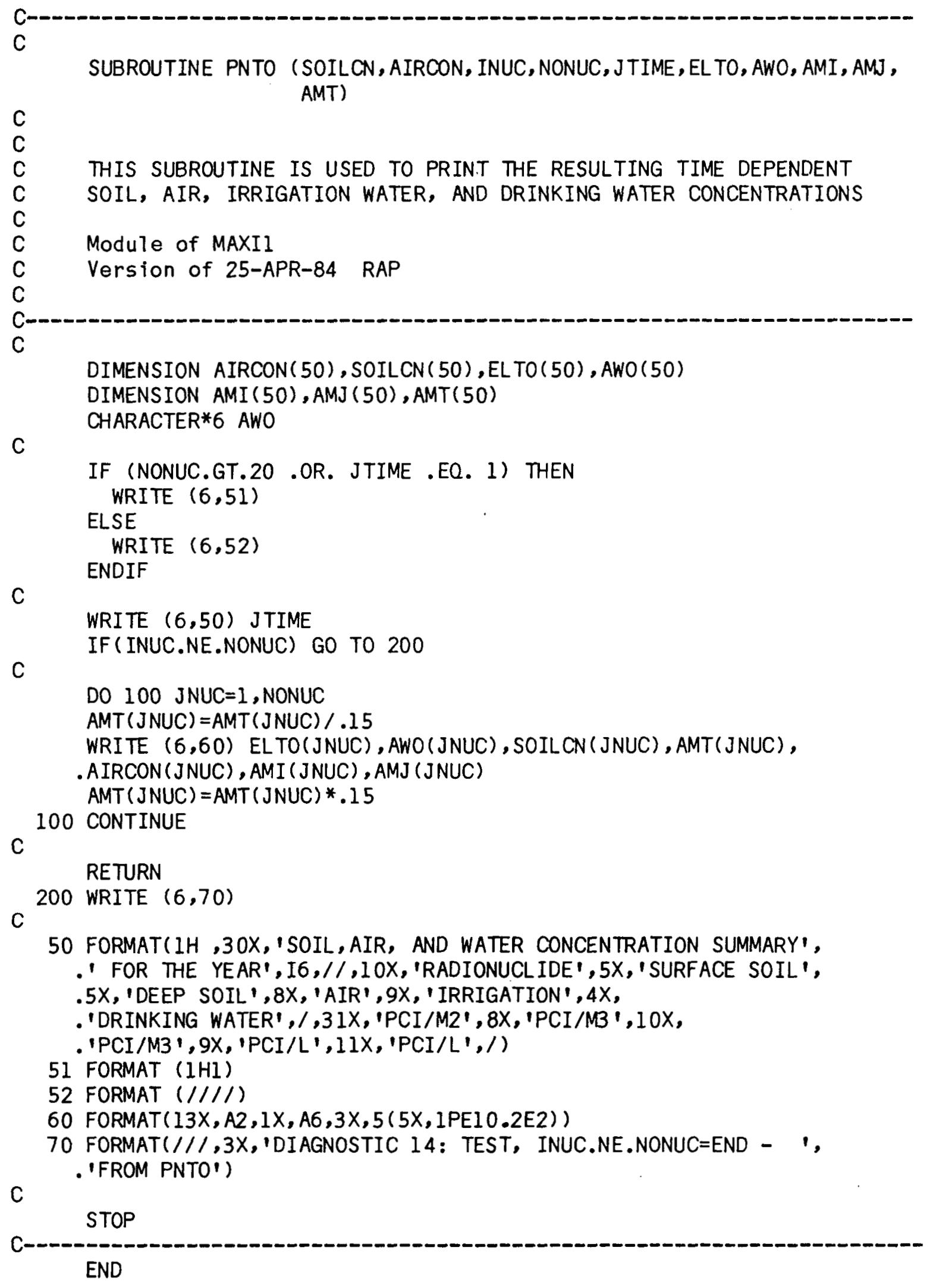




\section{APPENDIX 1.A COMPUTER CODE LISTING - MAXII}

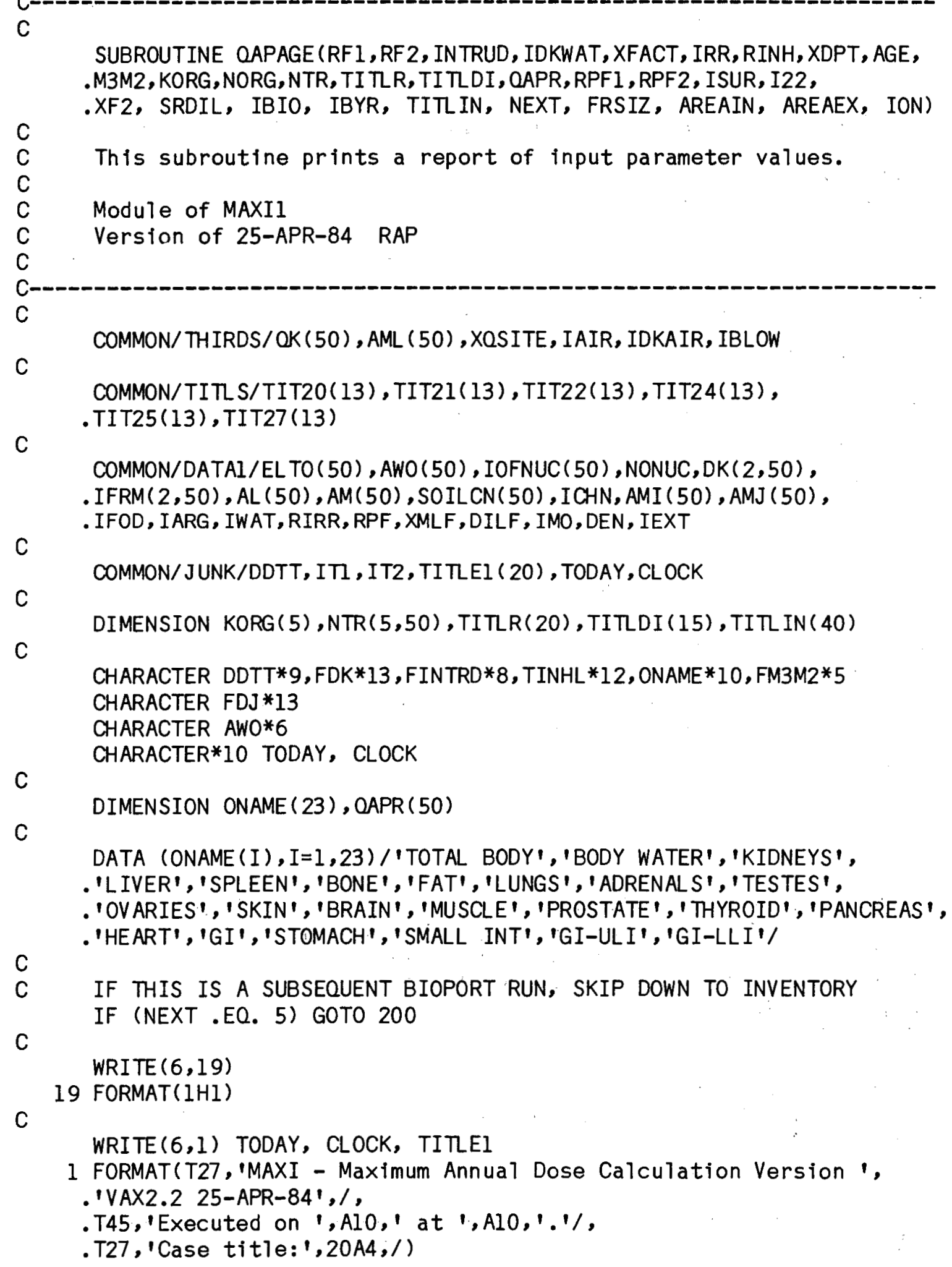




\section{APPENDIX 1.A COMPUTER CODE LISTING - MAXII}

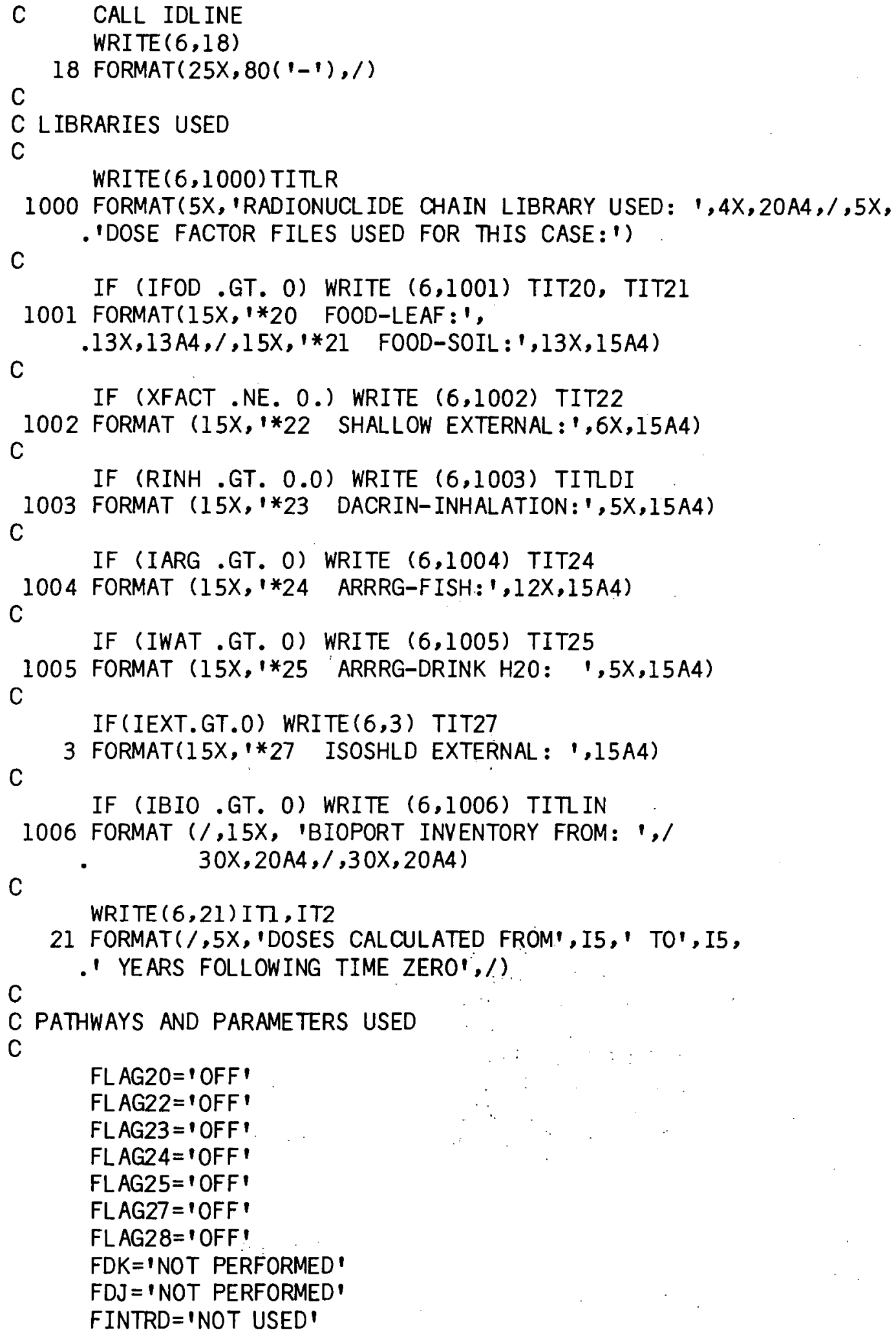


APPENDIX I.A COMPUTER CODE LISTING - MAXII

IF (IFOD.NE.0)FLAG20 $=10 \mathrm{~N}$,

IF (RINH.NE.0.0)FLAG23=ION '

IF (IARG.NE.0)FLAG24=ION '

IF (IWAT.NE.0)FLAG25 $=1 O N$,

IF (IEXT.NE.0)FLAG27=1ON '

IF (XFACT.NE.0.0)FLAG22=ION '

IF (IAIR.EQ.1)FLAG28 $=10 \mathrm{~N}$ '

IF ( INTRUD. NE.0) FINTRD $=$ IUSED

IF ( IDKWAT.NE.0) FDK = IPERFORMED

IF ( IDKAIR.EQ.I) FDJ = IPERFORMED

C

WRITE $(6,4)$ FLAG20, FL AG23, FLAG24, SRDIL, FLAG25, FDK, FLAG28, FDJ ,

.FLAG27, XQSITE, FLAG22, FINTRD

4 FORMAT( 5X, 'PATHWAYS INITIALIZED FOR DOSE CALCULATIONS: ', T65,

.'SPECIAL PARAMETERS INITIAL IZED: 1,/,15X, 'FARM PRODUCT INGESTION: ',

. T51, A3, $/, 15 X$, ' INHALATION OF RESUSPENDED MATERIAL : ', $A 3,1$

$,, 15 X, '$ AQUATIC FOODS INGESTION: ', T51, A3,

. T70,' INVENTORY DILUTION FACTOR: ', IPE9.2E2,/,

$.15 X, '$ DRINKING WATER INGESTION: ', T51; $A 3, T 70$, 'DECAY OF RIVER ',

' RELEASE SOURCE TERM ',Al3,/,

.15X, 'CONTINUING ATMOSPHERIC DEPOSITION 'A3,T70, 'DECAY OF ' ',

-'AIR RELEASE SOURCE TERM ',Al3,/,

$.15 X, '$ 'EXTERNAL FROM BURIED WASTES $1, T 51, A 3$,

.T70,'SITE X/O: ',IPE9.2E2,/

$.15 X, '$ EXTERNAL FROM SURFACE DEPOSITS:', T51,A3, 770 ,

C

-'SPECIAL INHALATION MODEL ',A8)

IF (ION .GT. 0) WRITE $(6,1055)$ FRSIZ, AREAIN, AREAEX

1055 FORMAT(T70,' 'SIZE OF THE SITE:',F9.5,' FRACTIONAL HECTARES'/,

.T70, 'INTERNAL PATHWAY AREA CORRECTION FACTOR:',IPE9.2E2/

.T70, 'EXTERNAL PATHWAY AREA CORRECTION FACTOR: ', IPE9.2E2)

$\mathrm{C}$

C FARM PRODUCT PARAMETERS

C

WRITE $(6,5)$ RF1, RIRR, RF 2, IMO, RPF 2,DILF, IRR

5 FORMAT( $101,4 X, 1 F A R M$ PRODUCT PARAMETERS USED: 1,1 ,

.15X, 'FRACTION OF ROOTS IN UPPER SOIL:',OPE10.2E2,

. T65, ' IRRIGATION RATE: ', IPE10.2E2,'L/M**2/MO',/

$.15 X$, 'FRACTION OF ROOTS IN BURIED WASTE',OPE9.2E2,

.T65, 'MONTHS PER YEAR IRRIGATED:', I5,/

.15X, 'FRACTION OF TOTAL DIET GROWN ON SITE: ',IPE10.2E2,

. T65, 'RIVER DILUTION FACTOR:', IPE10.2E2,'YYR/',/

.T65, 'YEARS OF IRRIGATION WITH CONTAMINATED WATER PRIOR TO',/

C

. T70,' THE DOSE CALCULATIONS:', I5)

C EXTERNAL PATH PARAMTERS

IF (FLAG22.EQ.'OFF' .AND. FLAG27 .EQ. 'OFF') GO TO 100

WRITE $(6,1060)$

1060 FORMAT ('O',4X, 'EXTERNAL EXPOSURE PARAMETERS USED: ') 


\section{APPENDIX 1.A COMPUTER CODE LISTING - MAXII}

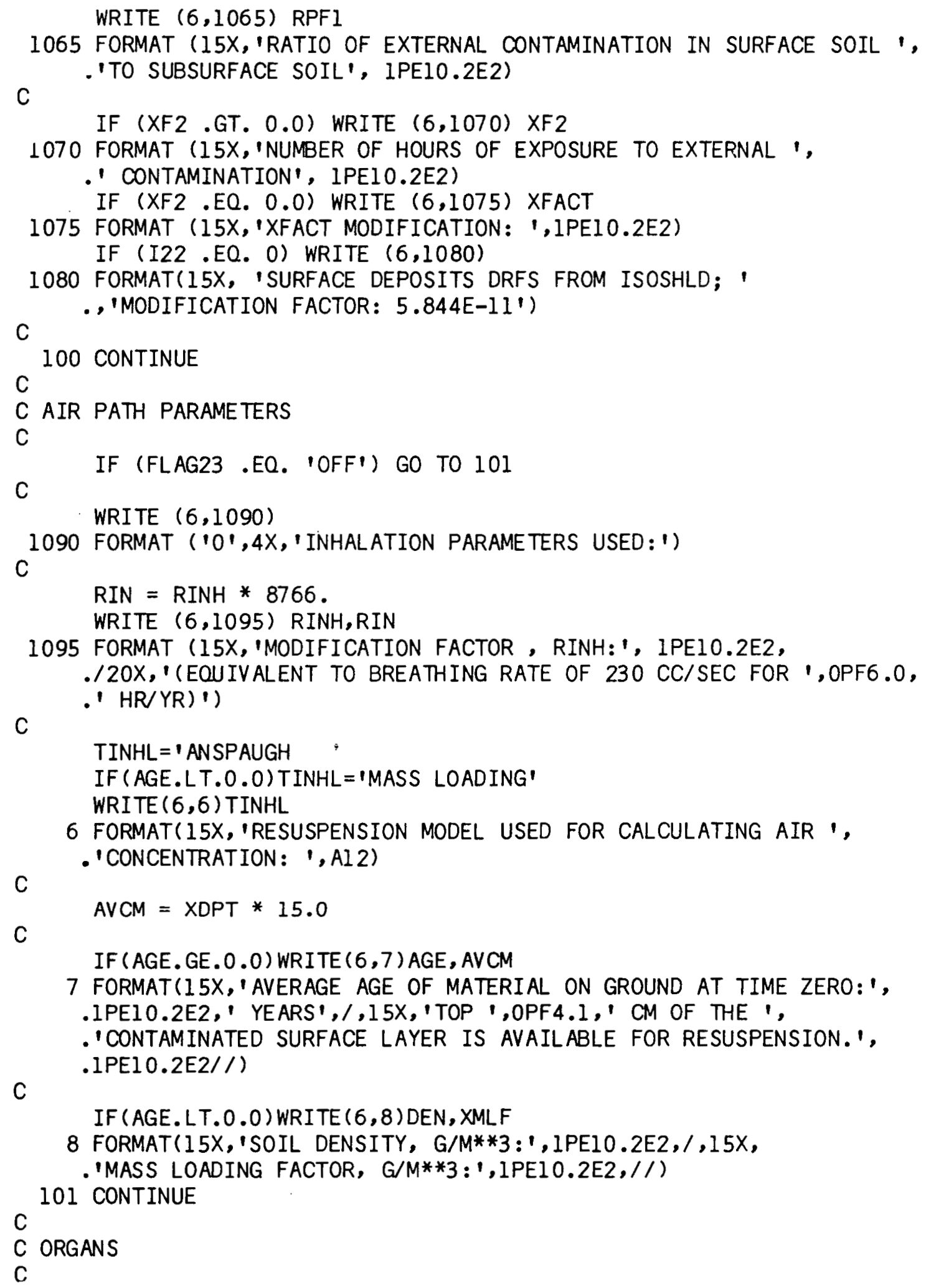




\section{APPENDIX 1.A COMPUTER CODE LISTING - MAXII}

WRITE $(6,9)$ (ONAME (KORG(I)), I=l, NORG)

9 FORMAT( 1 1,/

.5X, 'ORGANS FOR WHICH DOSES ARE CALCULATED (SAME ORDER AS',

.' SOLUBILITIES GIVEN BELOW): ',//,10X,5(10X,Al0))

C

C SIGN-OFF

WRITE $(6,10)$

10 FORMAT $(/ /, 20 X$, ' INPUT PREPARED BY', $25 X$, 'DATE' $, /, 37 X, 25(1=1), 4 X$, $.10(1=1), / /, 20 X, 1$ INPUT CHECKED BY $1,26 X, 1$ DATE $1,1,37 X, 25(1=1), 4 X$, $.10(1=1))$

C RELEASES

C

$I D=' Y R$ '

$I D L=I N T(D I L F)$

IF (IDL .EQ. I) ID = 'L '

C

\section{$F M 3 M 2=1 M * * 2) !$}

IF (M3M2. EQ.1) FM3M2 $=1 M * * 3)$ '

IF (M3M2.EQ. 2) FM3M2 $=1 K G$ )'

C

200 CONTINUE

C

IF (IBIO .GT. O) THEN WRITE $(6,1011)$ IBYR

1011 FORMAT ( 11 INVENTORY FOR YEAR ',I5,' OF BIOPORT SIMULATION. ') ELSE

WRITE $(6,1012)$

1012 FORMAT ('1')

ENDIF

C

WRITE $(6,11)$ FM3M2, ID

11 FORMAT(IH ,5X, 'RELEASE TERMS ', T56, 'SOIL SOURCE', T70, 'IRRIGAT',

.'ATION/AOUATIC', T92, 'DRINKING WATER', TI10,'ATM. RELEASE',/,

.10X, 'NUCL IDE', 10X, 'ORGAN SOLUBILITY CLASSES',5X, ' (PCI/', A5,10X,

.'(PCI/',AZ, ')', 9X,' (PCI/L)', IOX,' (CI/YR)',/)

C

DO $13 \mathrm{I}=1$, NONUC

WRITE $(6,12) \operatorname{ELTO}(I), \operatorname{AWO}(I),(N T R(J, I), J=1,5), \operatorname{OAPR}(I), \operatorname{AMI}(I), \operatorname{AMJ}(I)$ . AML (I)

12 FORMAT( $10 X, A 2,1 X, A 6,8 X, 5 I 4,4(8 X, 1 P E 10.2 E 2))$

13 CONTINUE

$\mathrm{C}$

C NOTE BOX

IF (NEXT .EQ. 5) GOTO 201

IBOX $=50-N O N U C$

IF (IBOX.LT.6) GO TO 20

WRITE $(6,14)$

14 FORMAT $(/, 20 X, 20(1 * 1)$, PLEASE NOTE ANY SPECIAL CONSIDERATIONS IN', ' THIS SPACE $1,20(1 * 1))$ 
APPENDIX 1.A COMPUTER CODE LISTING - MAXII

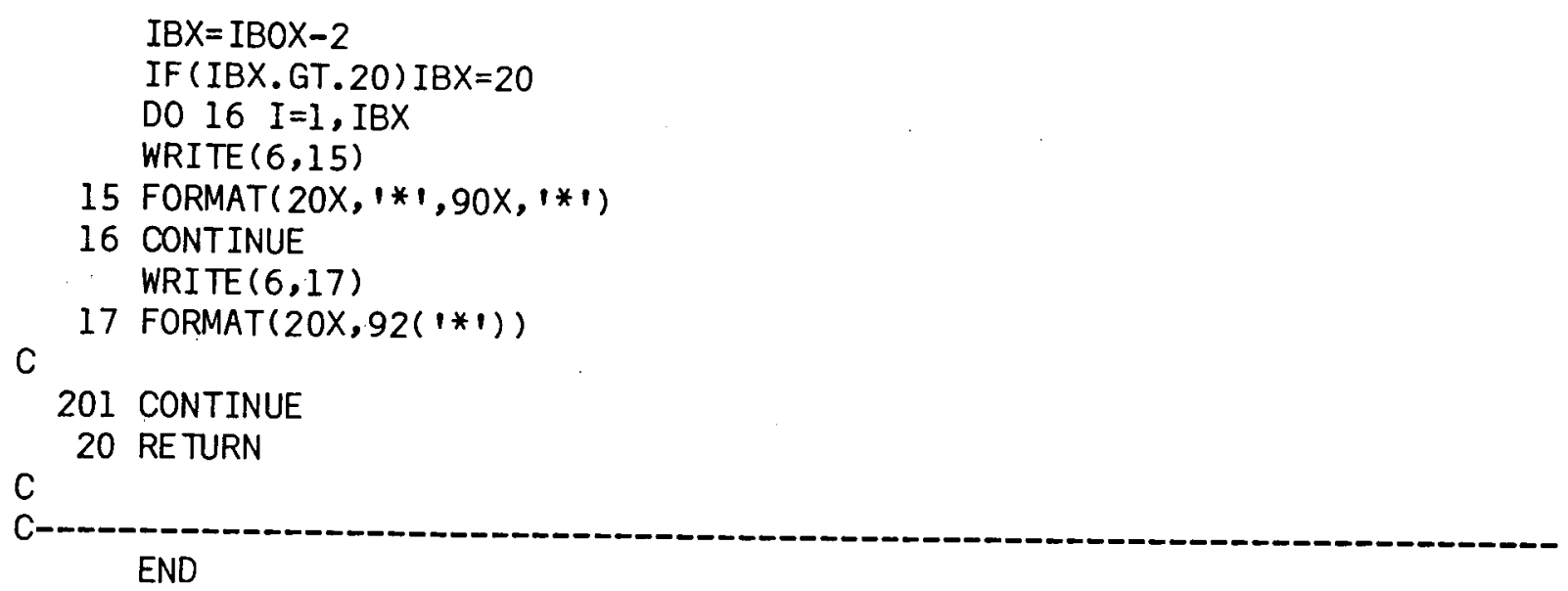




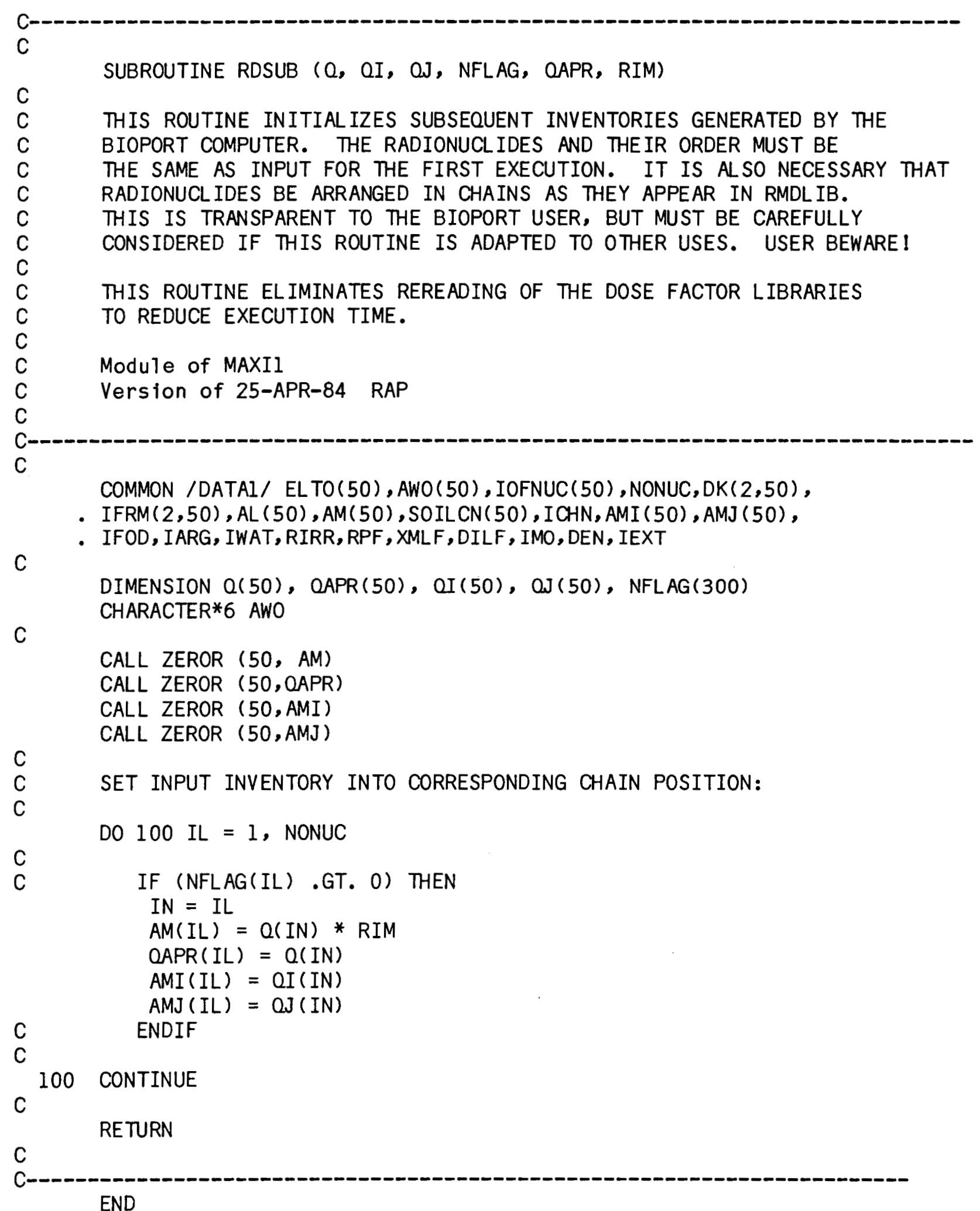




\section{APPENDIX 1.A COMPUTER CODE LISTING - MAXII}

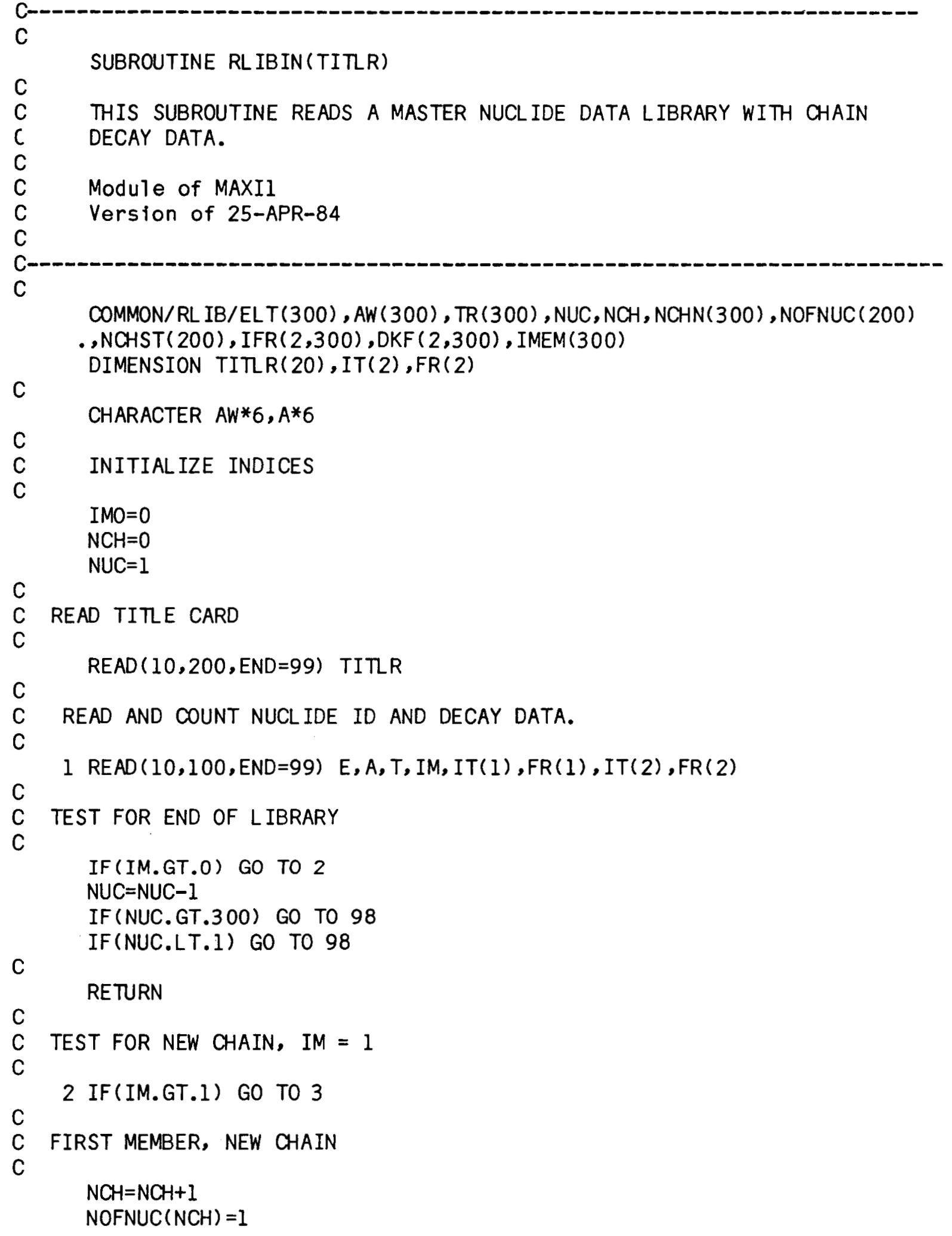




\section{APPENDIX I.A COMPUTER CODE LISTING - MAXII}

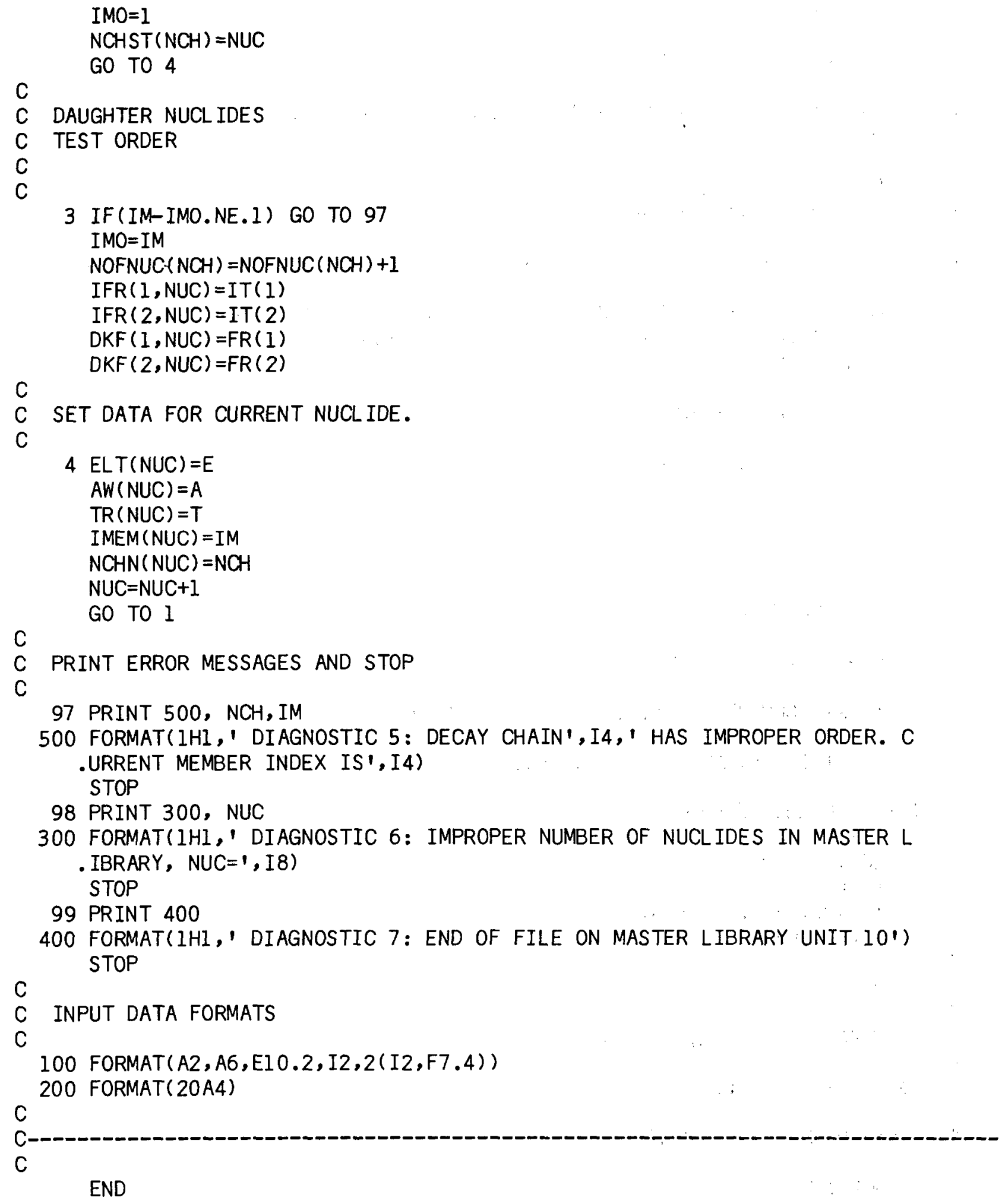

END 


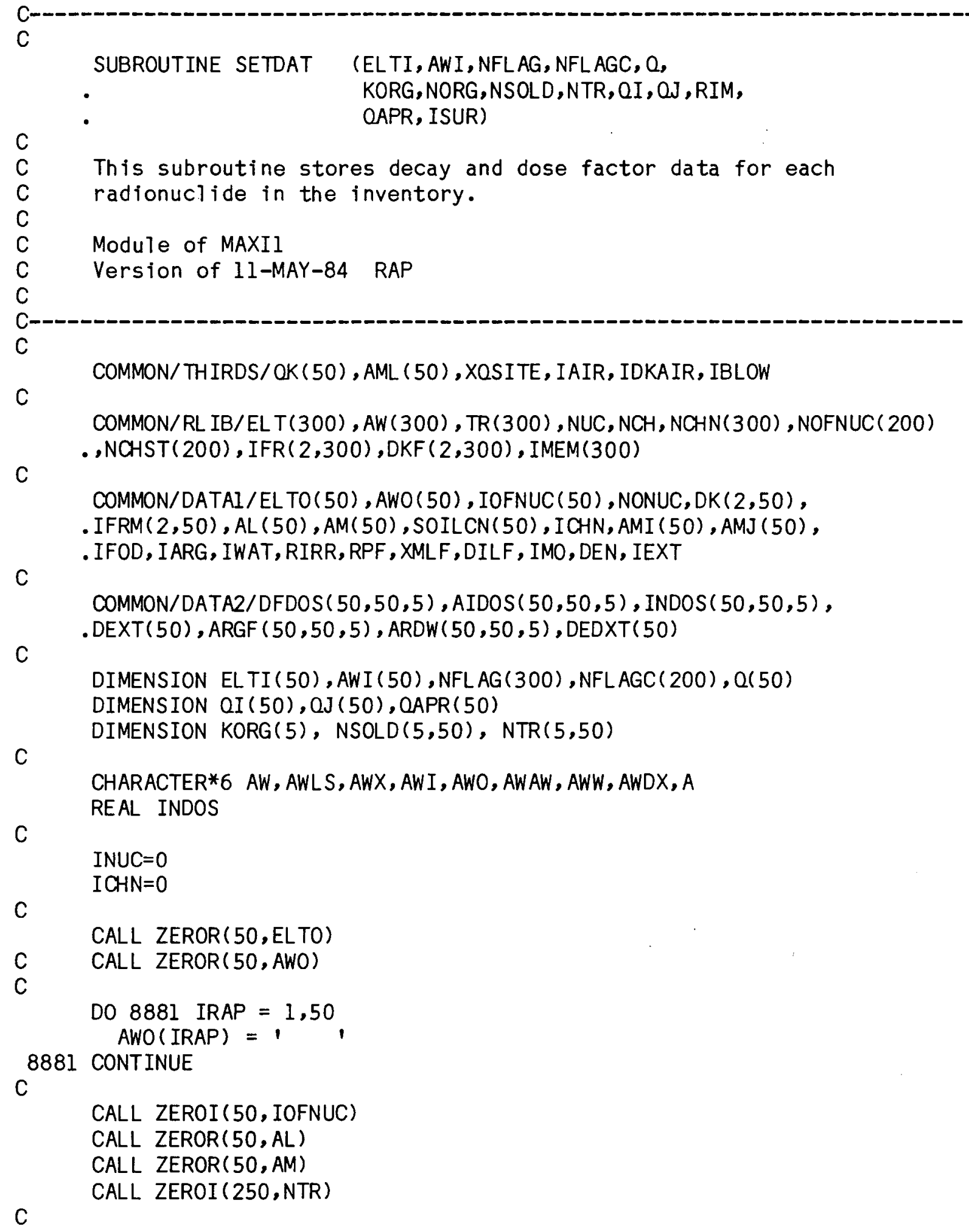

CALL ZEROI $(50$, IOFNUC)

CALL ZEROR $(50, A L)$

CALL ZEROR $(50, A M)$

CALL ZEROI $(250, N T R)$

C

C 


\section{APPENDIX 1.A COMPUTER CODE LISTIMG - MAXII}

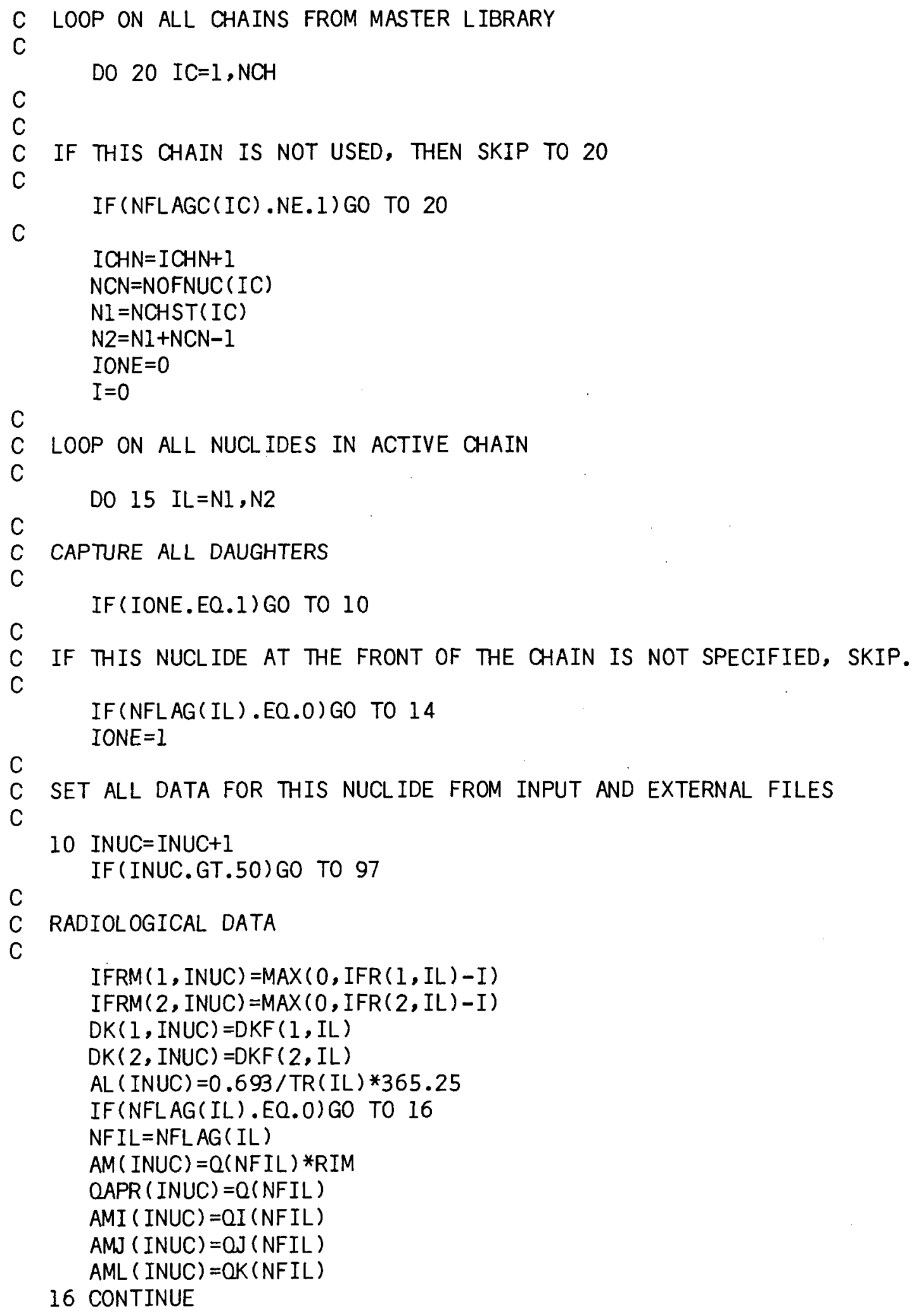


APPENDIX 1.A COMPUTER CODE LISTING - MAXII

C DEBUG PRINT STATEMENT--

C PRINT 8888, INUC, ELT(IL), AW(IL)

C 8888 FORMAT ( 1 INUC: ', I5, IX,A2,A6)

C

$\mathrm{ELTO}(\mathrm{INUC})=\mathrm{EL} T(\mathrm{IL})$

AWO $($ INUC $)=A W(I L)$

C

C ORGAN SOLUBILITY DATA--

DO 250 JORG $=1$, NORG

$250 N T R(J O R G, I N U C)=N S O L D(J O R G, N F I L)$

c

IRAP $=0$

$E=E L T O$ (INUC)

C

$A=A W O$ ( INUC)

C LEAF AND SOIL MECHANISM DATA

IF (IFOD .EQ. O) GO TO 30 IRAP $=1$

CALL DFREAD (IRAP, E, A, NORG, KORG, INUC)

30 CONTINUE

C

C AQUATIC FOOD DATA

IF (IARG .EQ. O) GO TO 40

IRAP $=2$

CALL DFREAD (IRAP, E, A, NORG, KORG, INUC)

40 CONTINUE

C

C DRINKING WATER DATA

IF (IWAT .EQ. O) GO iu vن

IRAP $=3$

CALL DFREAD (IRAP, E, A, NORG, KORG, INUC)

50 CONTINUE

C

C SURFACE EXTERNAL DATA

IF (ISUR .EQ. O) GO TO 60 IRAP $=4$

CALL DFREAD (IRAP, E, A, NORG, KORG, INUC)

60 CONTINUE

c

C BURIED/STORED DATA

IF (IEXT .EQ. 0) GO TO 70 IRAP $=5$

CALL DFREAD (IRAP, E, A, NORG, KORG, INUC)

70 CONTINUE

c

GO TO 15

C

C INCREMENT INDEX TO SKIP UNUSED CHAIN MEMBERS

14 I=IMEM( IL) 


\section{APPENDIX 1.A COMPUTER CODE LISTING - MAXII}

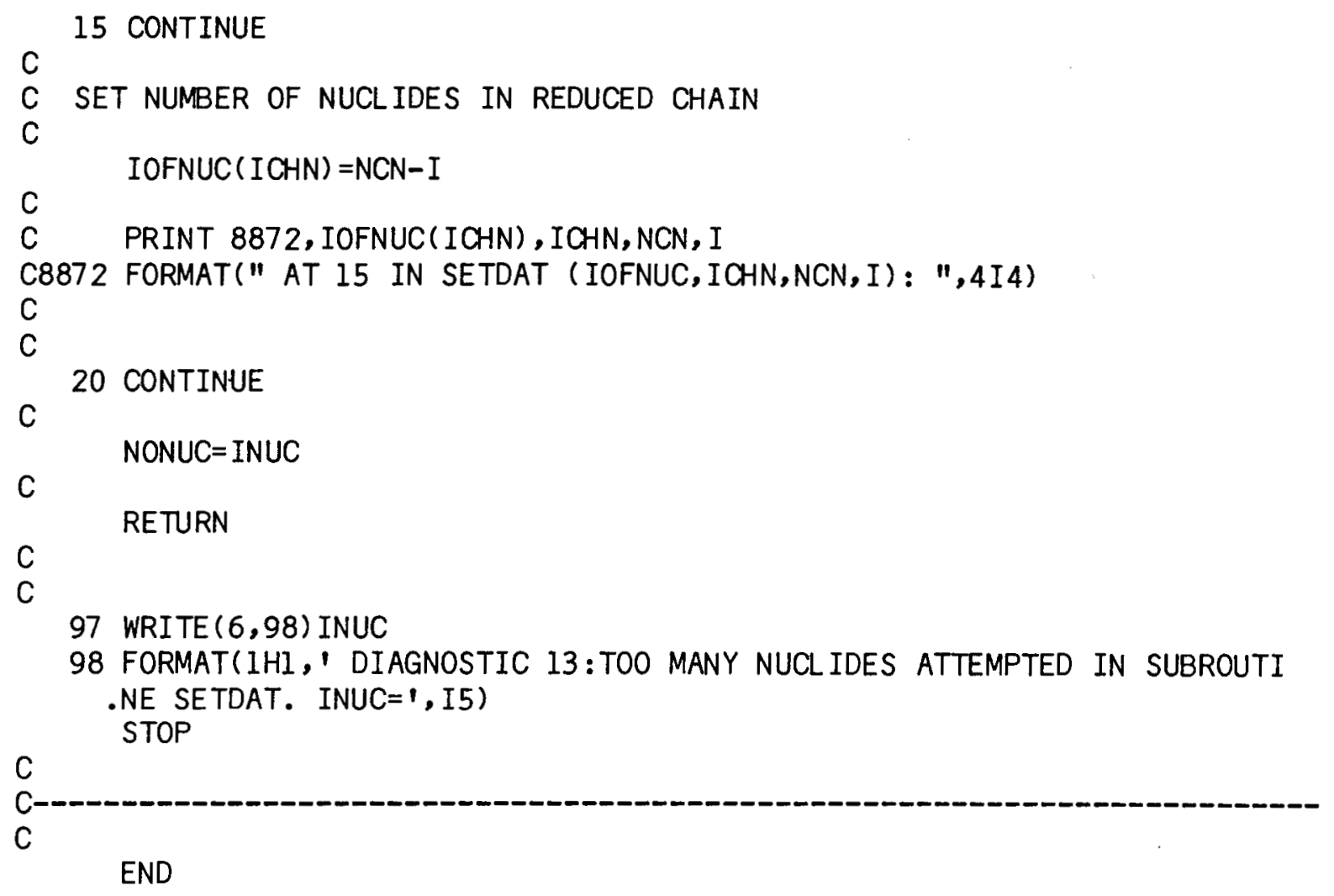




\section{APPENDIX 1.A COMPUTER CODE LISTING - MAXII}

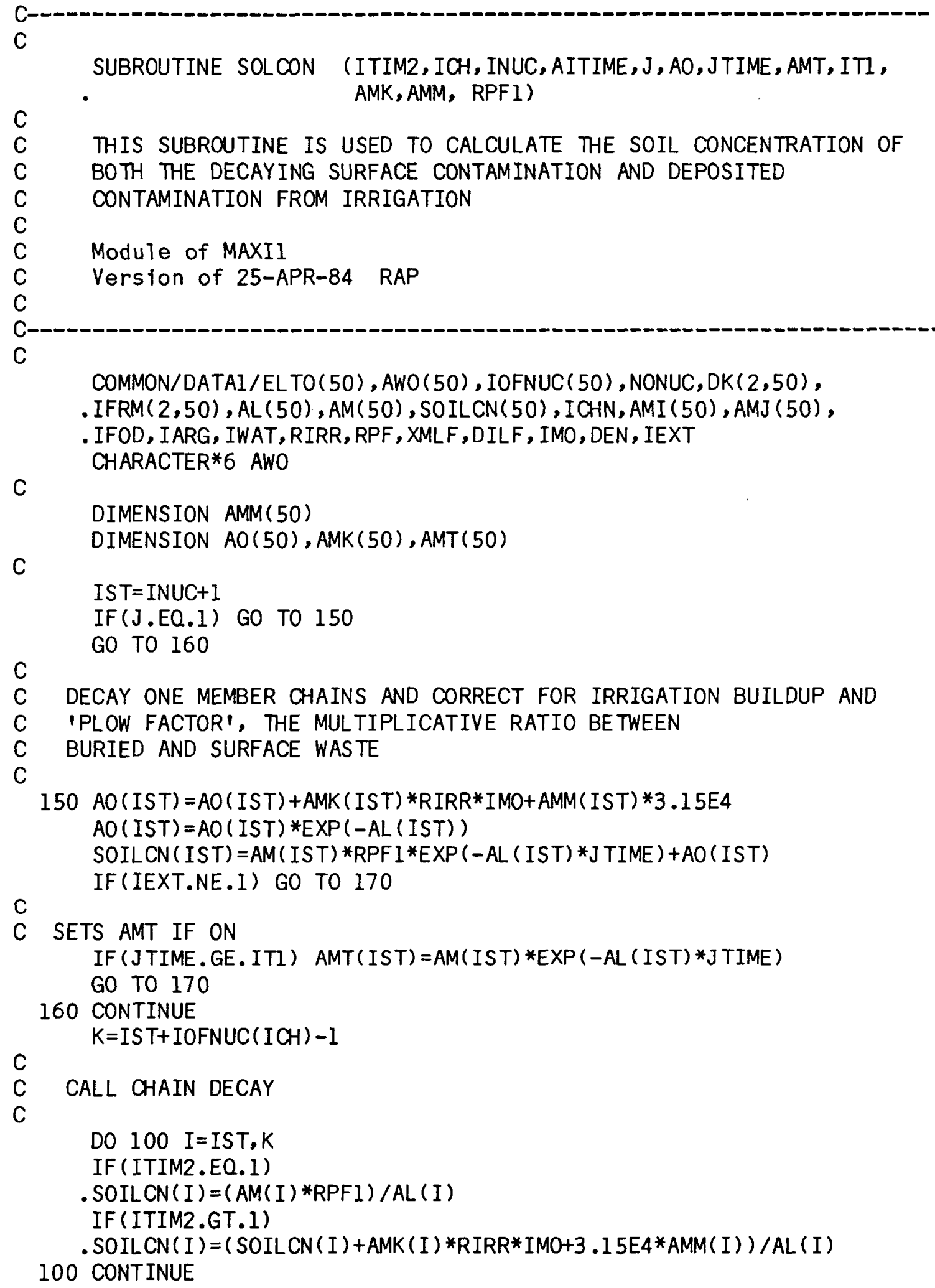




\section{APPENDIX 1.A COMPUTER CODE LISTING - MAXI1}

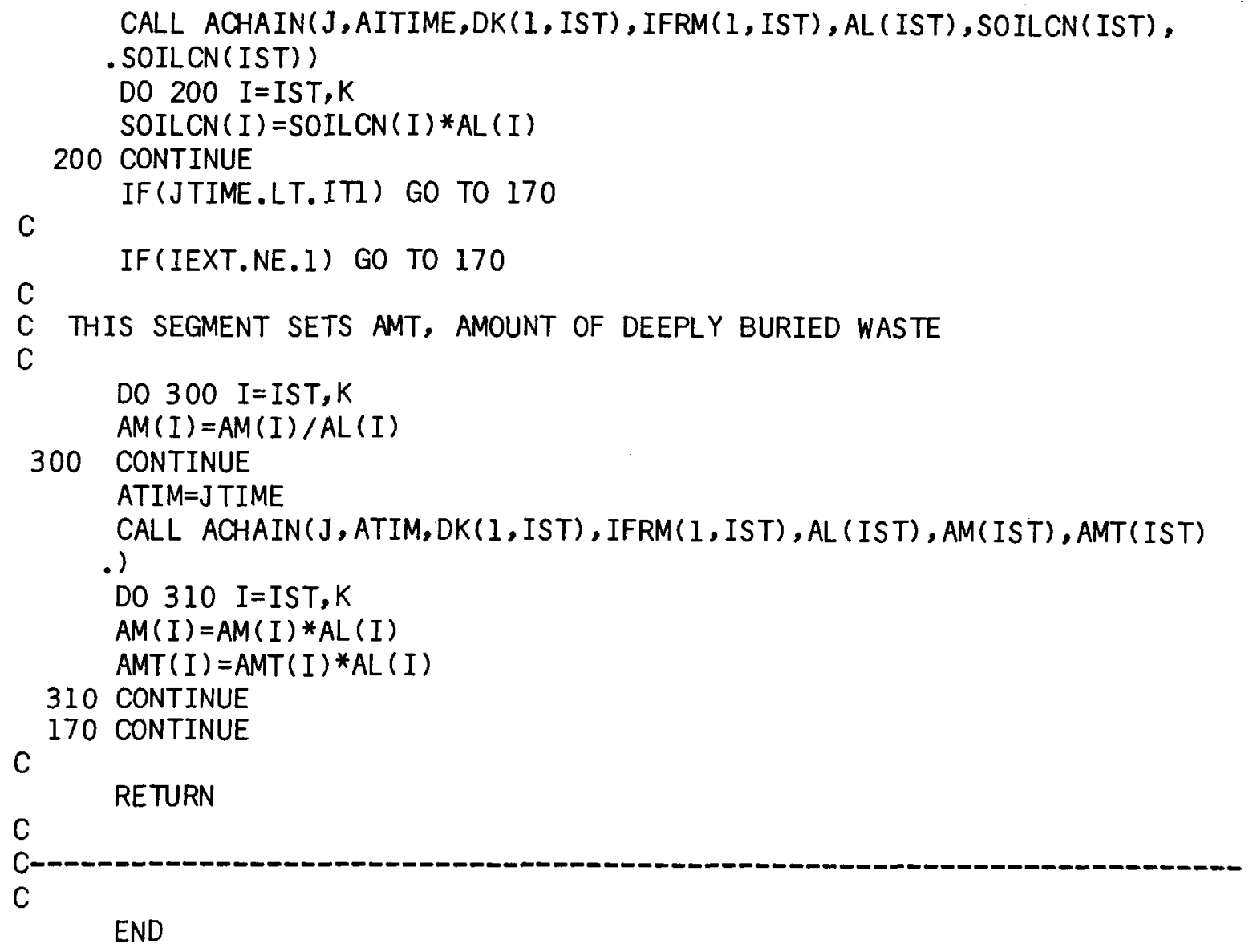


APPENDIX 1.A COMPUTER CODE LISTING - MAXII

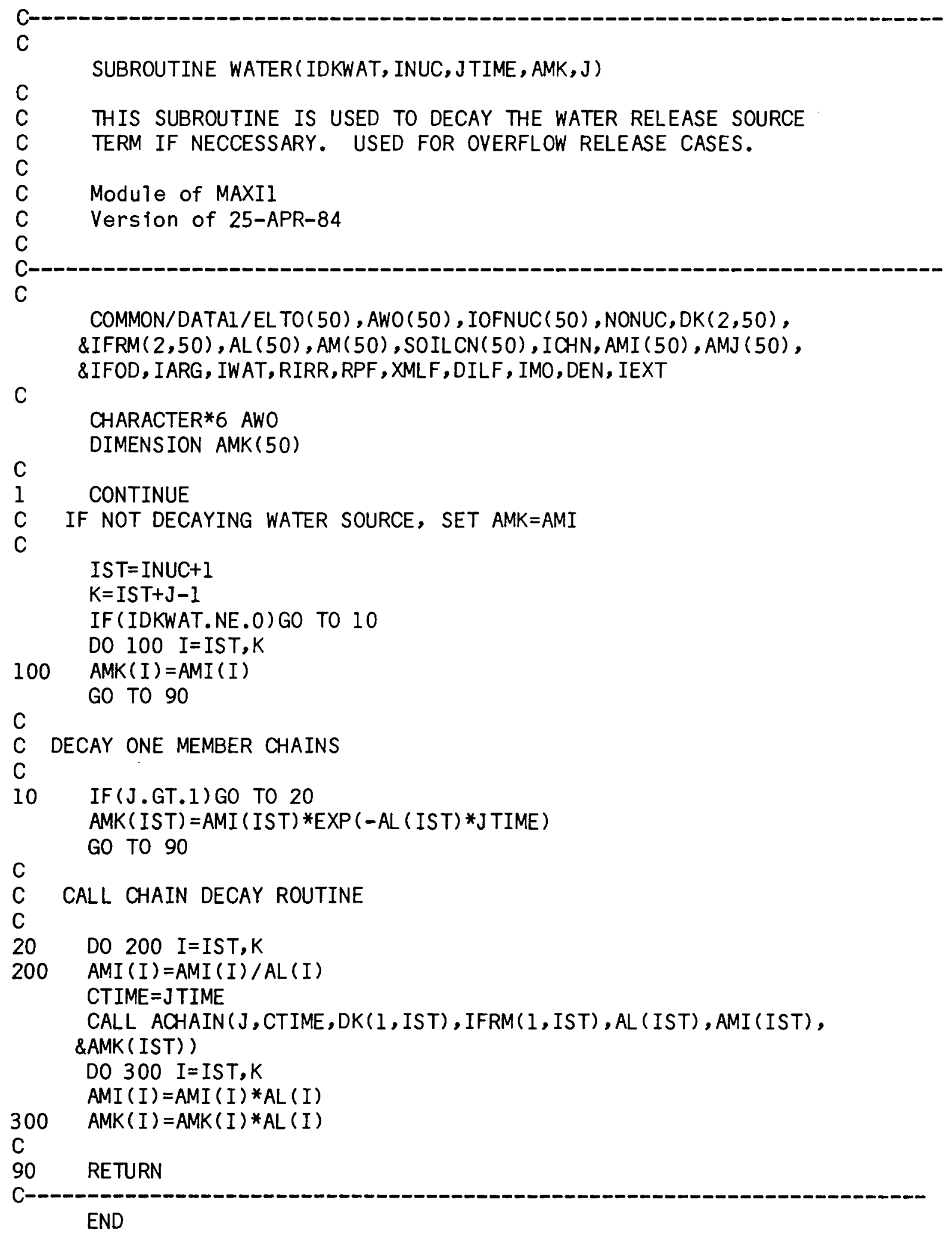




\section{APPENDIX 1.A COMPUTER CODE LISTING - MAXII}
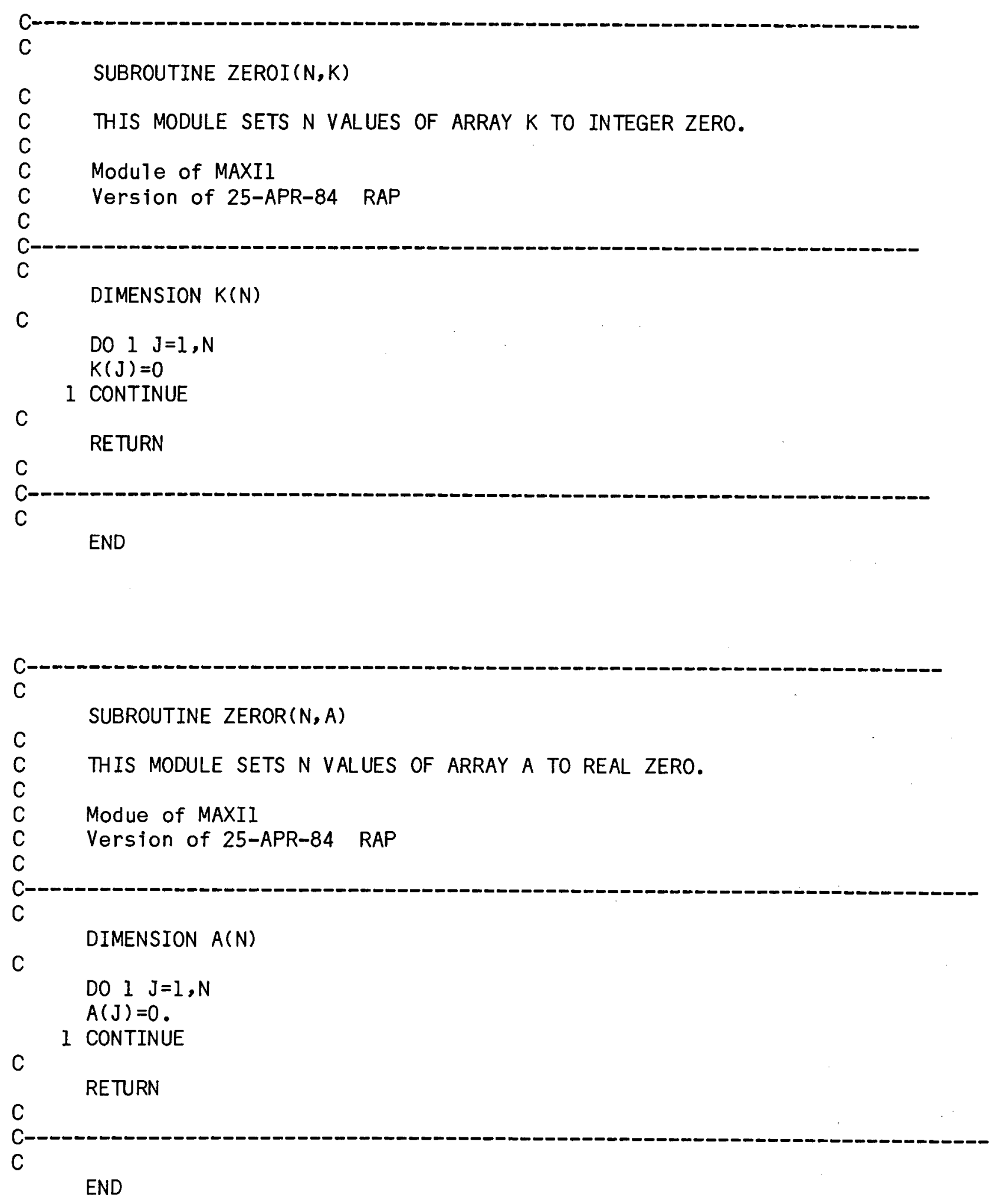


\section{APPENDIX 1.B COMPUTER CODE LISTING - ONSITE}

\section{Program Title: ONSITE}

Developed for: U.S. Nucear Regulatory Commission

Office of Nuclear Material Safety \& Safeguards

Division of Waste Management

Date: $\quad$ May 31,1984

NRC Contact: Dr. Stan Neuder

Phone: 301-427-4607

Code Developer: B.A. Napier, R.A. Peloquin, W.E. Kennedy, Jr. Pacific Northwest Laboratory

Richland, WA 509-375-3849 (WEK)

This program was prepared for an agency of the United States

Government. Neither the United States government nor any agency thereof, or any of their employees, make any warranty, expressed or implied, or assumes any legal liability or responsibility for any third party's use, or the results of such use, of any portion of this program or represents that its use by such third party would not infringe privately owned rights.

C

C-

C

C

C

ONSITE is the interactive user/system interface for the ONSITE

Disposal Version of the MAXIl computer code. ONSITE creates

a file containing the JCL and input stream for MAXII.

Version of 1-MAY-84 RAP

The program ONSITE includes the following modules:

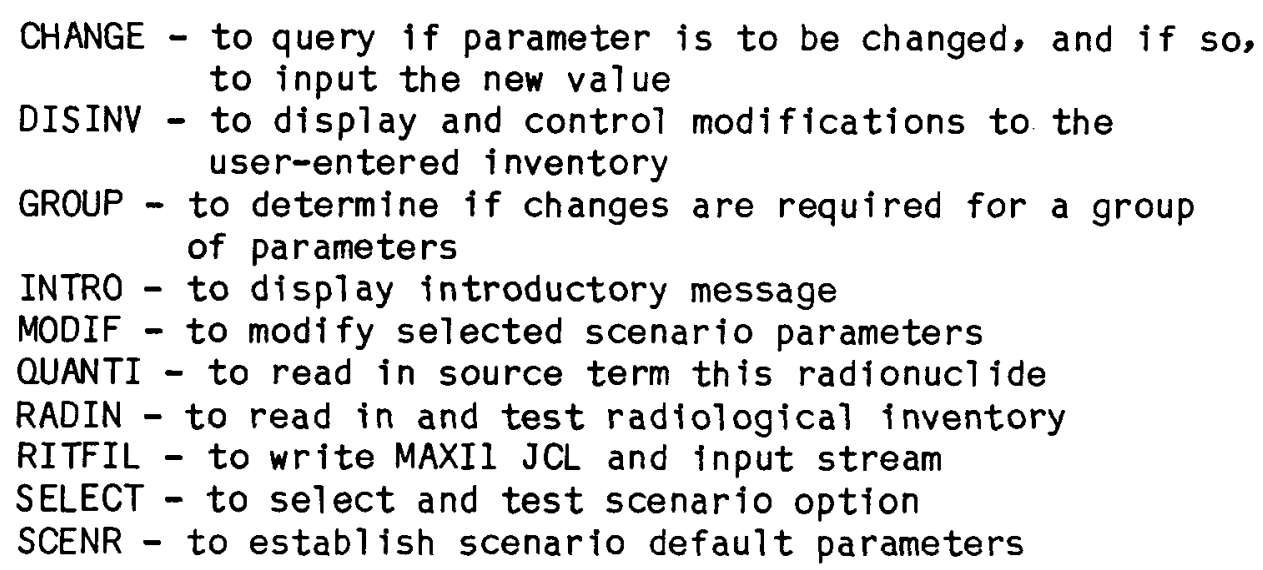




\section{APPENDIX 1.B COMPUTER CODE LISTING - ONSITE}

C

C

C

C

C

C

C

C

C

C

C

C

C

C

c

C

C

C

C

C

C

C

C

C

$\mathrm{c}$

C---- introduce program, describe scenarios to user, \& establish defaults ----

C

CALL INTRO

CALL SCENR

C

C---- input time and required parameters

C

WRITE (SCRN, 1100)

1100 FORMAT $(1,20(/), 1$,

- Enter a descriptive title to identify this case: ')

READ (KEY,110I) (TITL(I), I=1,20)

1101 FORMAT (20A4)
0 - no change requested

1 - change requested

0 - no change requested in this group

1 - change requested in this group

integer value

3 - double precision value

IX - CHANGE subrouotine passing parameter - integer value

Cassing parameter - maximum allowable integer inpu

GNAME (2) - Real*8 name of subgroup passed to GROUP

CHANGE subroutine passing parameter - real value

R8X _ CHANGE subroutine passing parameter - real*8 value

INCLUDE 'ONSITE.CMN'

DATA KEY, SCRN, OUT, IRS, IMOD, IBS $/ 5,6,7,1,0,1 /$

'Buried a', 't $0.5 \mathrm{~m}$ ',

'Buried a','t $1.0 \mathrm{~m}$ ',

'Stored w','aste I/

DATA NVU /'pCi ','UCi ','mCi ',' Ci '/

DATA NVUNIT $/ 1.0,1.0 \mathrm{E}+3,1.0 \mathrm{E}+6,1.0 \mathrm{E}+12 /$

'/cubic m','eter I,

$1 / \mathrm{Kg}$ of $\mathrm{s}^{1,10 i 1 \quad 1 /}$ 


\section{APPENDIX 1.B COMPUTER CODE LISTING - ONSIIE}

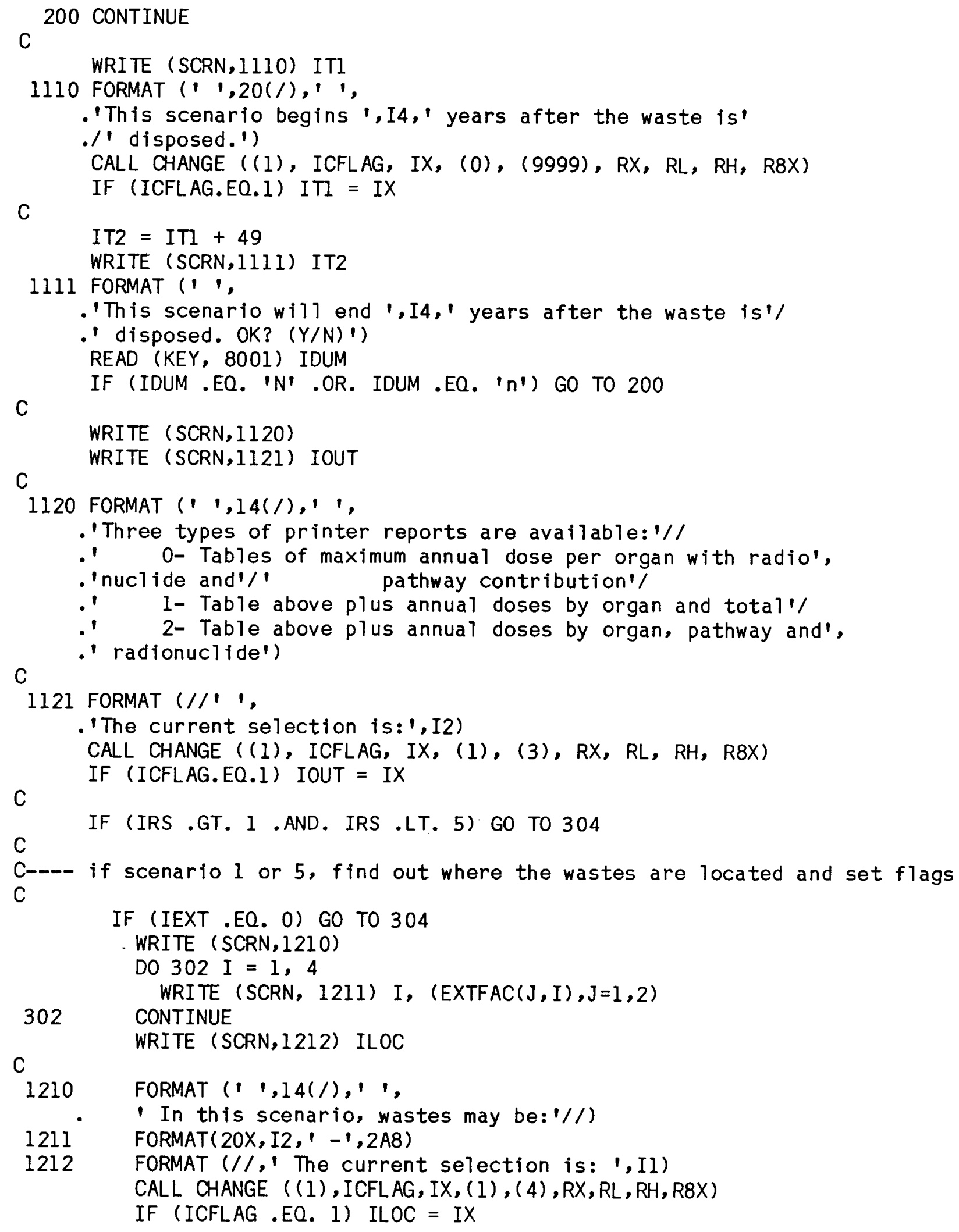




\section{APPENDIX 1.B COMPUTER CODE LISTING - ONSITE}

C

304 CONTINUE

C---- query if changes are desired to scenarios \& modify

C

IF (IRS .LT. 5) GO TO 111

$I M O D=1$

CALL OPTION

GO TO 100

111 CONTINUE

C

WRITE (SCRN,1001) IRS

1001 FORMAT (1,

$.14 X, 44(' \# 1) / / 14 X$, 'Do you wish to modify any parameter values for'

$. / 14 X, '$ Scenario ', Il, ' (N/Y) ?')

READ (KEY, 8001) IDUM

8001 FORMAT (AI)

WRITE (SCRN, 1002)

1002 FORMAT $(1,14(/))$

C

IF (IDUM .EQ. 'Y' .OR. IDUM .EQ. ' $y$ ') IMOD $=1$

100 CONTINUE

IF (IMOD .EQ. 1) CALL MODIF

C

C

C---- set area correction factor

C

400 CONTINUE

IF (IRS .EQ. 4) GO TO 401

C

C

1300 WRITE (SCRN,1300) FRSIZ

FORMAT ( $1,14(/), 1$,

- The size of the site in terms of fractional hectares'/

- ' (ie., $10000 \mathrm{sq} \mathrm{m}$ ), is ',IPGl0.3,1.')

CALL CHANGE ((2), ICFLAG, IX, IL, IH, RX, ( I.E-35), (1.E35), R8X)

IF (ICFLAG.EQ.1) FRSIZ = RX

C

C

WRITE (SCRN, 1301) FRSIZ

1301 FORMAT (////' ',

.The inventory will automatically be adjusted by the'/

- appropriate area correction factor for each exposure'/

C

- pathway based on a site size of ', IPG10.3, ' hectares. 1/)

C

$\operatorname{GNAME}(1)=$ ' the $a b^{\prime}$

$\operatorname{GNAME}(2)=$ 'ove $\quad$,

CALL GROUP (IGFLAG, GNAME)

C

IF (IGFLAG.EO.1) GO TO 400 


\section{APPENDIX 1.B COMPUTER CODE LISTING - ONSITE}

IF (FRSIZ .GE. 1.0) THEN

AREAIN $=1.0$

ELSE

IF (FRSIZ ,GE, 0.1) THEN

AREAIN $=0.75$

ELSE

IF (FRSIZ .GE. 0.02) THEN

AREAIN $=0.50$

ELSE

IF (FRSIZ .GE. 0.005) THEN

AREAIN $=0.25$

ELSE

AREAIN $=0.10$

ENDIF

ENDIF

ENDIF

ENDIF

C

IF (FRSIZ .GE. 0.125 ) THEN

AREAEX $=1.0$

ELSE

IF (FRSIZ . GE. 0.05) THEN

AREAEX $=2.7 *$ FRSIZ +0.67

ELSE

IF (FRSIZ . GE. 0.01) THEN

AREAEX $=6.5 *$ FRSIZ +0.48

ELSE

IF (FRSIZ . GE, 0.0025) THEN

AREAEX $=20.0 *$ FRSIZ +0.35

ELSE

AREAEX $=160.0 *$ FRSIZ

ENDIF

ENDIF

ENDIF

ENDIF

C

401 CONTINUE

C

C----- input ratio and inventory units

C

IF (ISUR .EQ. 1 .AND. IEXT .EQ. I) THEN

WRITE (SCRN, 1220) RPF1

1220 FORMAT (1 1,14(/), 1,

- This scenario assumes both surface contamination and"/

- ' contamination from buried or stored waste. What is"/

- ' the ratio of waste concentration in the surface to'/

- I subsurface soils? (Range $=0.0$ to 1.0$) \mathrm{l}$

- 'The current selection is: ', IPGI0.3)

CALL CHANGE ( (2), ICFLAG, IX, IL, IH, RX, (0.0), (1.0), R8X)

IF (ICFLAG .EQ. I) RPFI = RX 
APPENDIX 1.B COMPUTER CODE LISTING - ONSITE

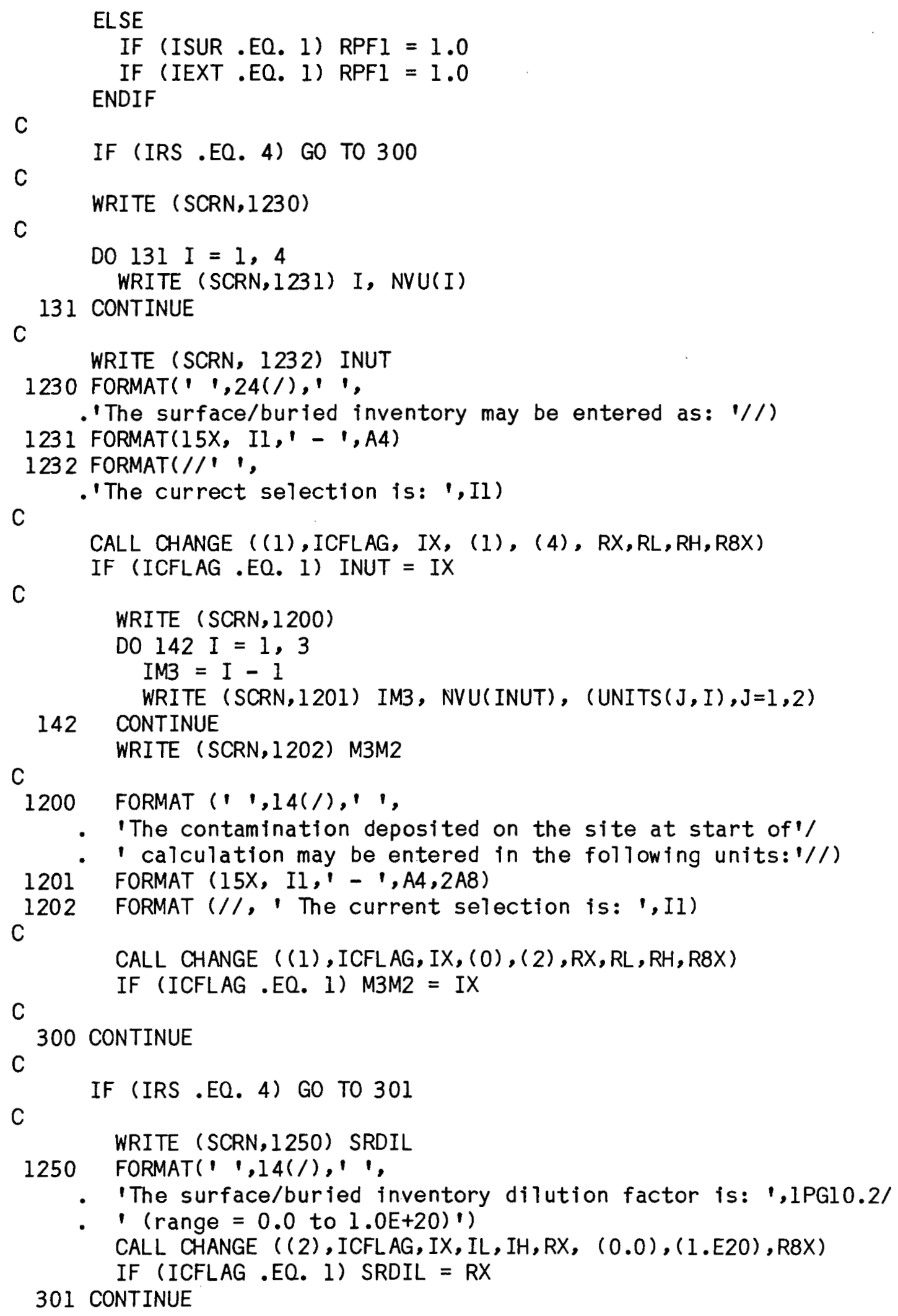




\section{APPENDIX 1.B COMPUTER CODE LISTING - ONSITE}

C--- allow user to review parameters before entering the inventory - - - C $\operatorname{GNAME}(1)=$ 'any of $t$ '

$\operatorname{GNAME}(2)=$ 'he above'

CALL GROUP (IGFLAG, GNAME)

IF (IGFLAG .EO. I) THEN

$I M O D=0$

GO TO 200

C ENDIF

C---- input inventory and write file

C

CALL RADIN

CALL DISINV

C

CALL RITFIL

C---- end of program

C

END 


\section{APPENDIX 1.B COMPUTER CODE LISTING - ONSITE}

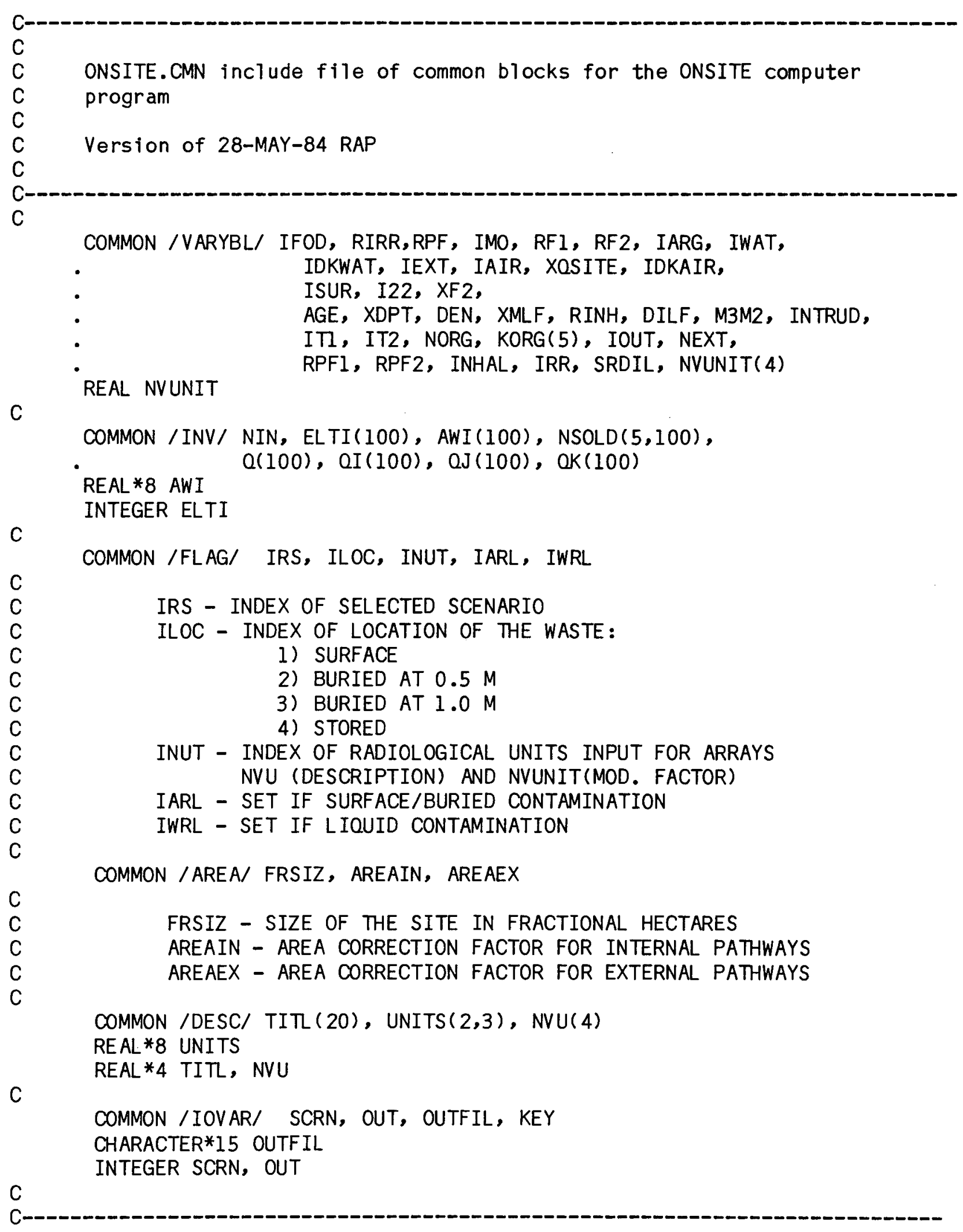


SUBROUTINE CHANGE (ITFLAG, ICFLAG, IX, IL, IH, RX, RL, RH, R8X)

CHANGE is called to query if parameter is to be changed, and if so, to input the new value and test if within the limits.

This subroutine will handle integer, real and alphanumeric input and will test the 7 imits on integer and real input. Alphanumeric input is read into the real*8 variable.

ICFLAG - CHANGE subroutine passing flag: (returned) 0 - no change requested 1 - change requested

ITFLAG - CHANGE subroutine passing flag: (received)

1 - integer value

2 - real value

3 - alphanumeric input - rea ${ }^{* 8}$

IX - new integer value (returned)

IH - maximum allowable integer input (received)

IL - minimum allowable integer input (received)

RX - new real value (returned)

$\mathrm{RH}$ - maximum allowable real input (received)

$\mathrm{RL}$ - minimum al lowable real input (received)

R8X - real*8 alphanumeric string input (returned)

Module of ONSITE

Version of 17-APR-84 RAP

$\mathrm{C}$

C

C

INCLUDE 'ONSITE.CMN'

REAL*8 R8X

C

ICFLAG $=0$

WRITE (SCRN, 1000)

1000 FORMAT $(/ /, 1,70(1-1), / /$

' Do you wish to change this value (N/Y)?')

READ (KEY, 8001) IY

8001 FORMAT (AI)

C

IF (IY .NE. 'Y' . AND. IY .NE. ' $y$ ') GO TO 700

C

100

ICFLAG $=1$

C

CONTINUE

C

FORMAT (' '/l Enter new value: ') 
APPENDIX 1.B COMPUTER CODE LISTING - ONSITE

C

200

C

$\mathrm{C}$

300

IF (ITFLAG .NE. 1) GO TO 200 $\operatorname{READ}(K E Y, *)$ IX

IF (IX .LT. IL .OR. IX .GT. IH) GO TO 100 GO TO 700

C

C

IF (ITFLAG .NE. 3) GO TO 400

IF (ITFLAG .NE. 2) GO TO 300 $\operatorname{READ}(K E Y, *)$ RX

IF (RX .LT. RL .OR. RX .GT. RH) GO TO 100 GO TO 700

CONTINUE READ (KEY, 8003) R8X

C

400 CONTINUE

700 CONTINUE

C

WRITE (SCRN, 1001)

1001 FORMAT $(1,24(/))$

c

RETURN

$\mathrm{C}$

C --- format statements -.--

C

8003 FORMAT (A8)

C

C

C

END integer input

reat input

rea $7 * 8$ alpha input 


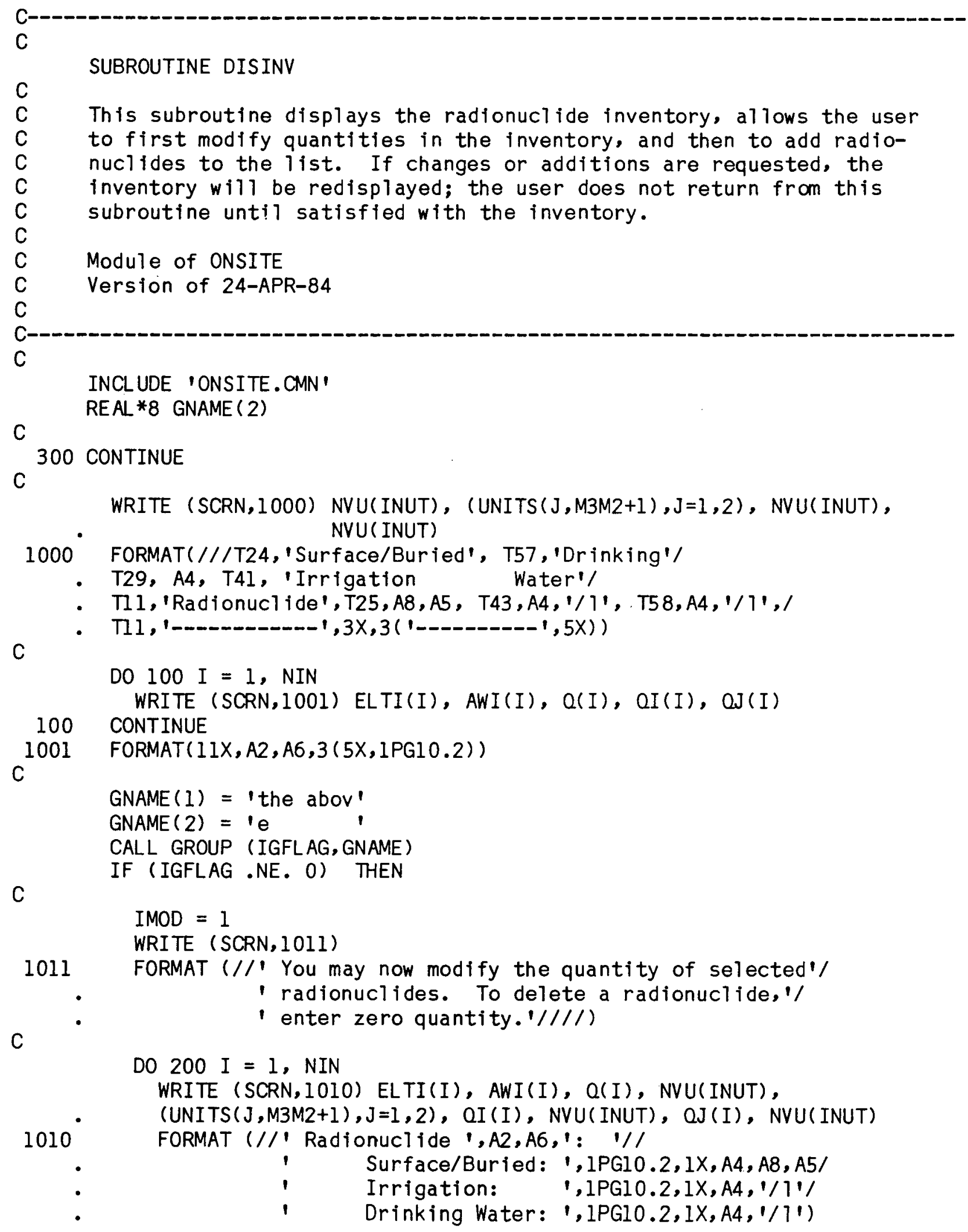


APPENDIX 1.B COMPUTER CODE LISTING - ONSITE

\section{CALL GROUP ( IGFLAG, GNAME)}

IF (IGFLAG .NE. O) CALL QUANTI (I)

200 CONTINUE

C

C

C ELSE

IMOD $=0$

C

C

ENDIF

C

WRITE (SCRN, 1020)

1020 FORMAT (///' Do you wish to add radionuclides to the above' ' inventory?')

READ (KEY,8001) IY

8001 FORMAT (AI)

C

IF (IY .EQ. 'Y' .OR. IY .EQ. ' $Y$ ') THEN $I M O D=1$

CALL RADIN

ENDIF

C

IF (IMOD .EQ. I) GO TO 300

C

C

RETURN

C

C

END 


\section{APPENDIX 1.B COMPUTER CODE LISTING - ONSITE}

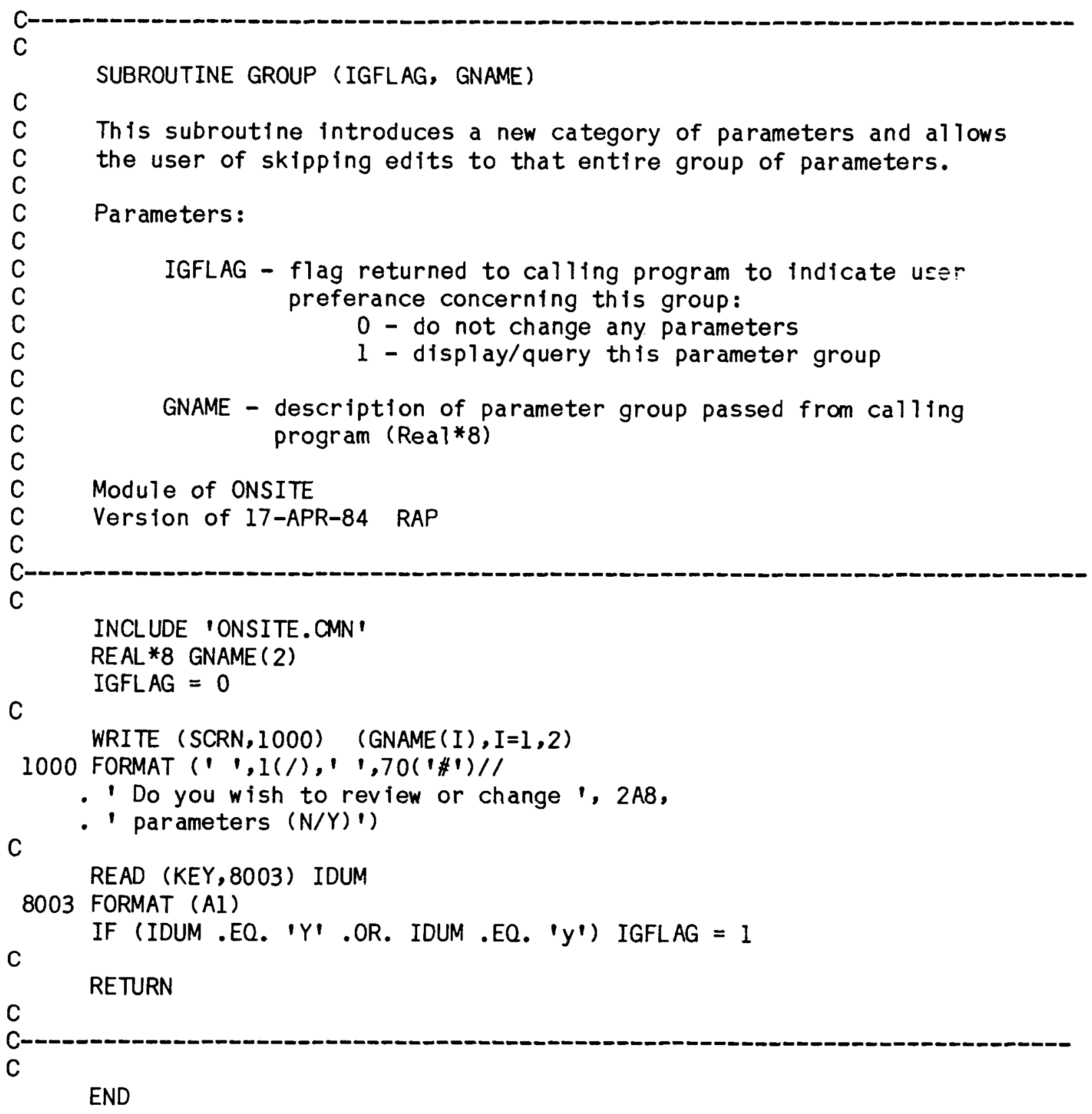




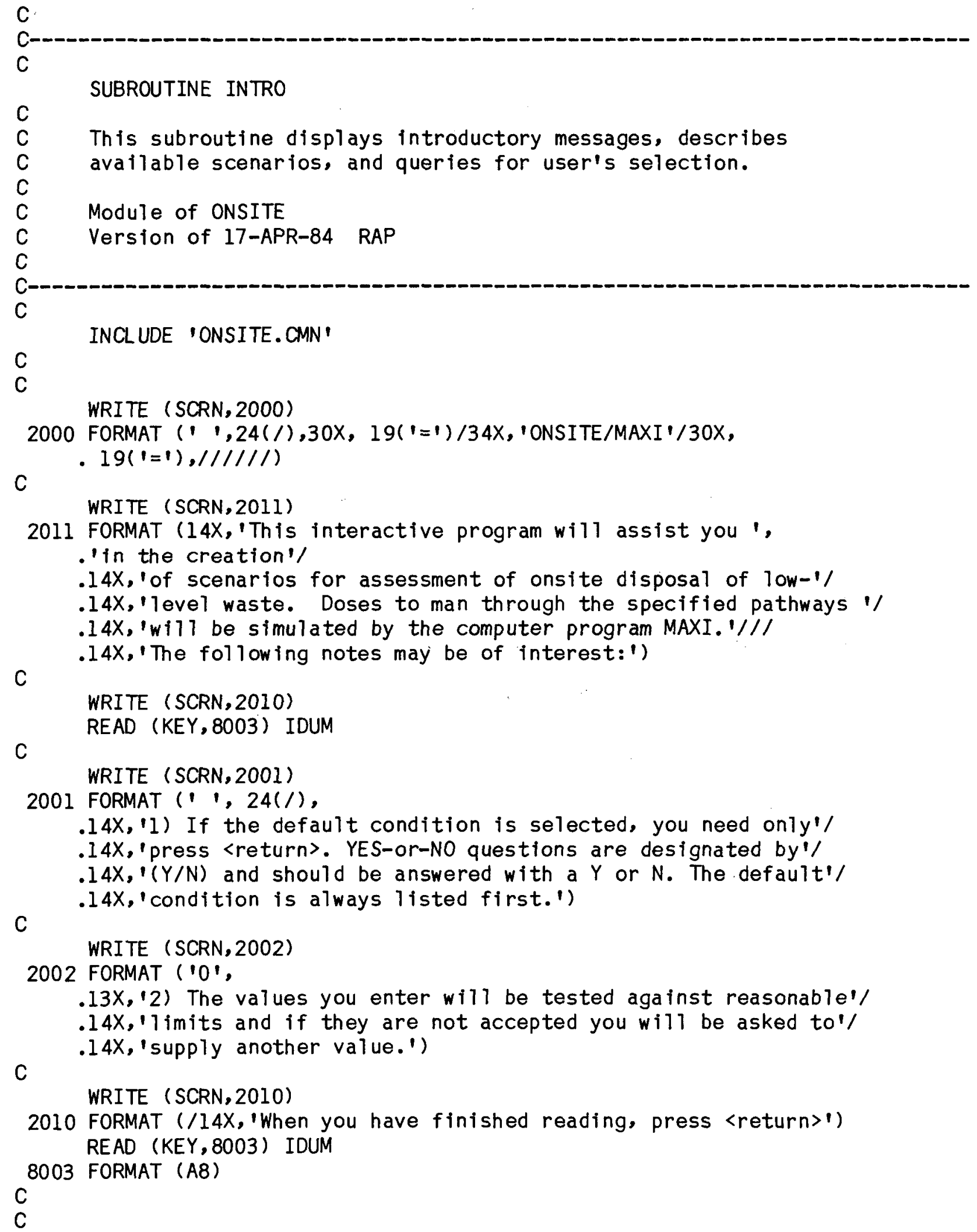




\section{APPENDIX 1.B COMPUTER CODE LISTING - ONSITE}

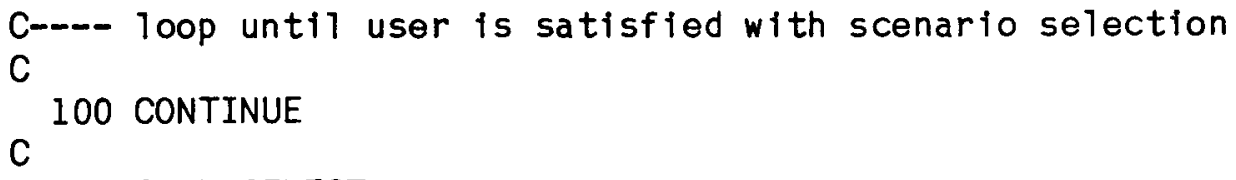

C

IF (IRS .EQ. I) WRITE (SCRN,2100)

2100 FORMAT $(1,24(/)$,

$.14 \mathrm{X}$, 'SCENARIO 1: External Exposure'//

$.14 X, 1$ This scenario can be used alone or as part of Scenarios $2 \%$

$.14 \mathrm{X}$, 'and 3. Occupational conditions of $2000 \mathrm{~h} / \mathrm{yr}$ of external'/

$.14 X$, 'exposure are assumed. Waste may be located on the surface, 1/

C

$.14 \mathrm{X}$, 'burled at $0.5 \mathrm{~m}$, buried at $1.0 \mathrm{~m}$, or stored.')

2200 FORMAT $(i, 24(/)$,

.14X, 'SCENARIO 2: External. Exposure plus Inhalation from Resus',

- 'pension'//

$.14 \mathrm{X}$, 'This scenario assumes surface contamination results over a'/

$.14 X, 11$ imited area. The scenario defaults to $2000 \mathrm{~h} / \mathrm{yr}$ exposure'/

$.14 X$, 'to surface contamination and inhalation. The Anspaugh')

IF (IRS .EQ. 2) WRITE (SCRN,2201)

2201 FORMAT ( $14 X$,

- 'resuspension mode 1 is used. User may define the fraction'/

$.14 X$, ' of soil in the top $15 \mathrm{~cm}$ containing buried waste (defaults'/

C

$.14 X$, to 0.2$) .1$ )

IF (IRS .EQ. 3) WRITE (SCRN, 2300)

2300 FORMAT $(1,24(/)$,

.14X, 'SCENARIO 3: Agricultural Activities'//

$.14 X$, This scenario assumes surface contamination (as in Scenario'/

$.14 X, 12$ ) with farming; defaults to $2000 \mathrm{~h} / \mathrm{yr}$ exposure to surface')

IF (IRS .EQ. 3) WRITE (SCRN, 230I)

2301 FORMAT (14X,

- 'contamination and inhalation. Anspaugh resuspension model'/

$.14 X, '$ is used. Scenario defaults to total diet of fruits, veg-'/

.14X, 'atables, and animal products grown on the site. The user'/

$.14 X, 1$ may specify the percentage of soil containing waste in the $/$

C $.14 \mathrm{X}$, 'top $15 \mathrm{~cm} .1$ )

IF (IRS .EQ. 4) WRITE (SCRN, 2400)

2400 FORMAT $(1,24(/)$,

$.14 X$, 'SCENARIO 4: Irrigation and Drinking Water'//

$.14 X$, 'This scenario accounts for the use of well or river water'/

$.14 X$, 'for irrigation and drinking. Assumes an irrigation rate')

IF (IRS .EQ. 4) WRITE (SCRN, 2401)

2401 FORMAT (14X,

- 'of $150 \mathrm{l} / \mathrm{sq} \mathrm{m} / \mathrm{mo}$ for 6 months. Defaults to Anspaugh model'/

$.14 \times$, 'for inhalation. Assumes total diet and 1.21 iters/day of'/

$.14 X$, 'drinking water. ') 


\section{APPENDIX 1.B COMPUTER CODE LISTING - ONSITE}

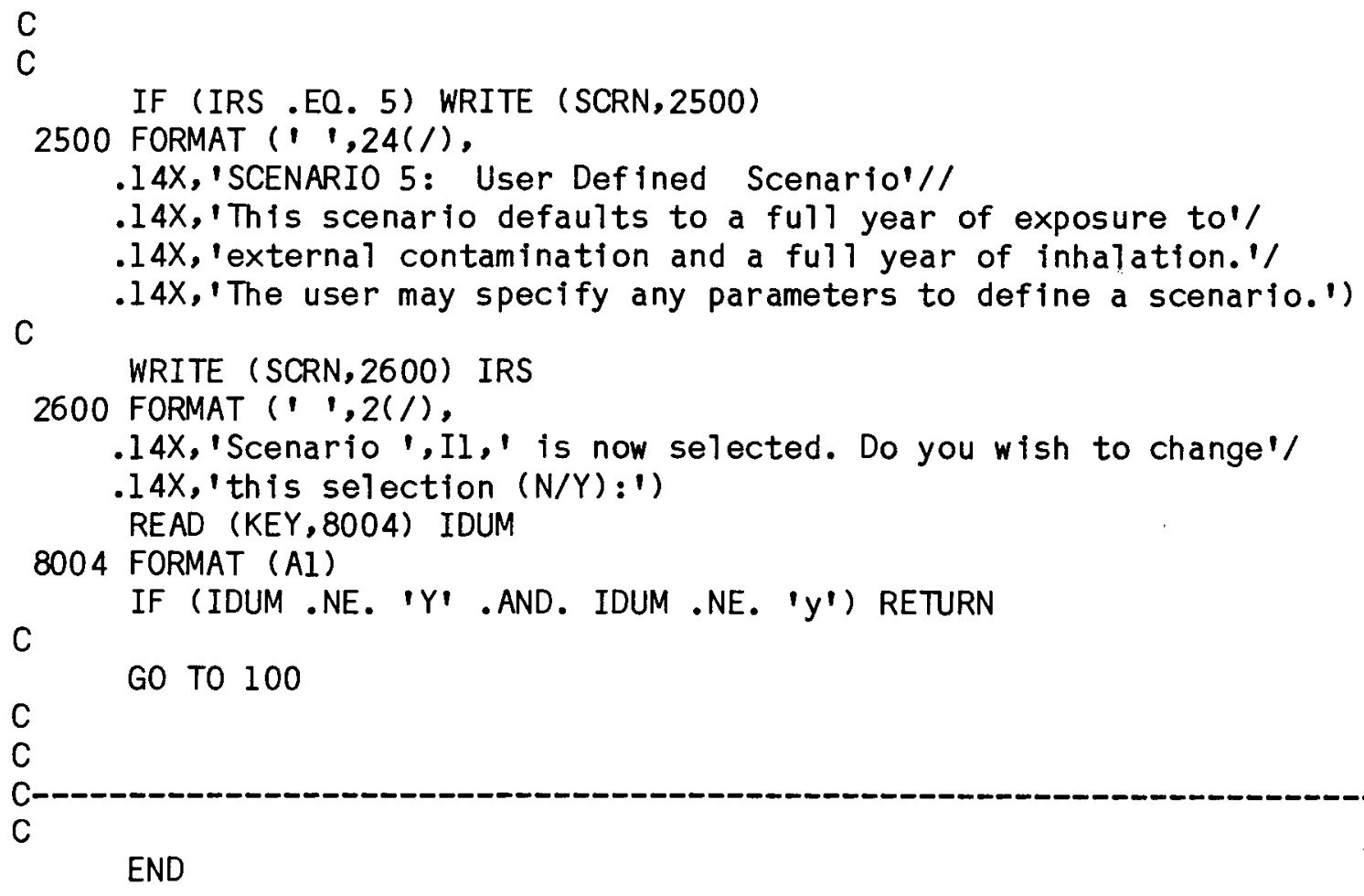

END 


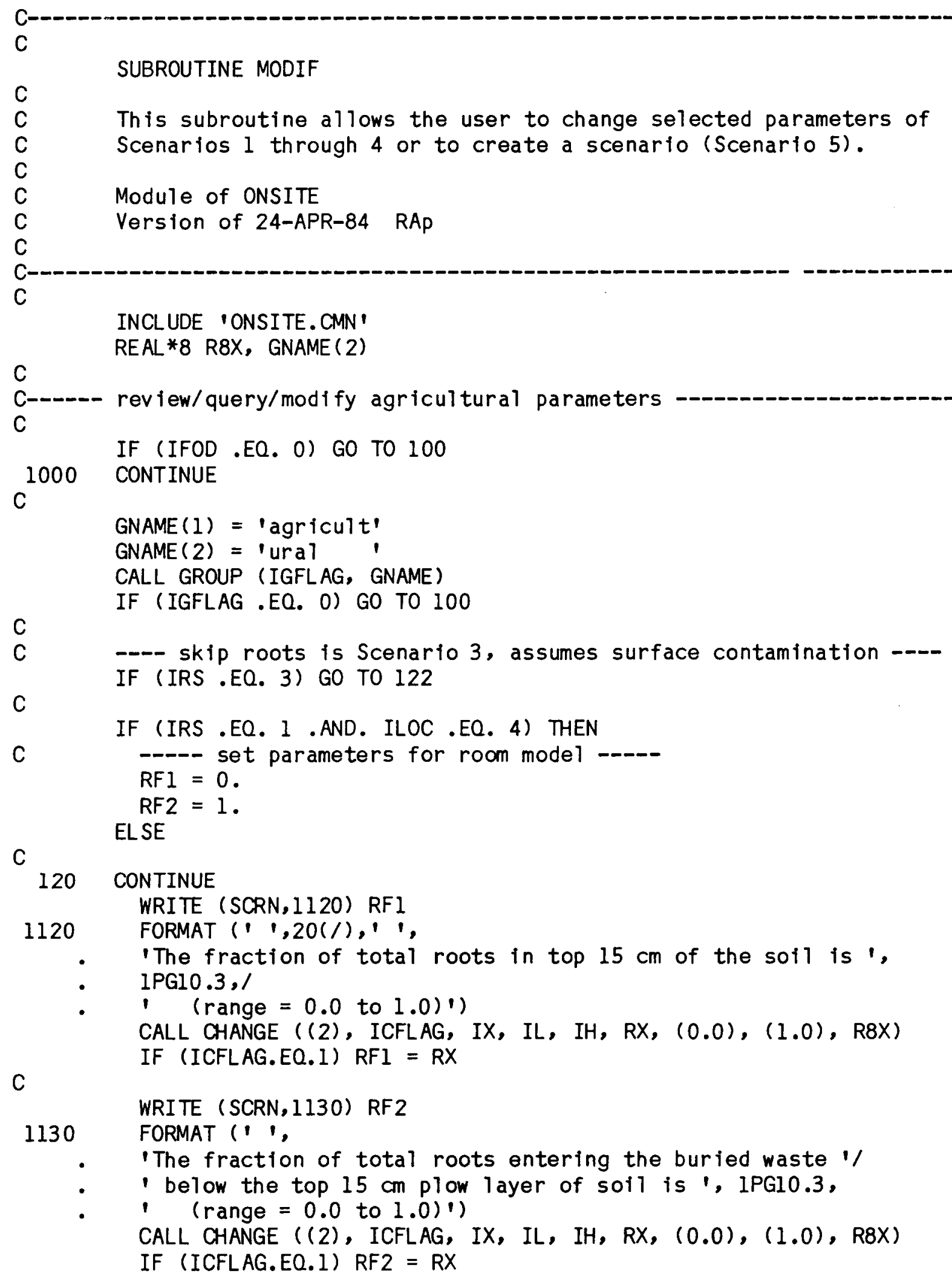




\section{APPENDIX 1.B COMPUTER CODE LISTING - ONSITE}

$\mathrm{RF}=\mathrm{RF} 1+\mathrm{RF} 2$

IF (RF .GT. 1.0) WRITE (SCRN,1140)

1140 FORMAT (///, I!! The previous two fraction cannot be greater ',

- 'than 1.0 : REENTER !!!')

IF (RF .GT. 1.0) GO TO 120

ENDIF

$\mathrm{C}$

122 CONTINUE

C

1160 FORMAT (' $1,20(/), 1$ ',

- The fraction of the total diet grown on the site' ',

- I is 1, IPGI0.3,1' (range $=0.0$ to 1.0 )'1)

CALL CHANGE ((2), ICFLAG, IX, IL, IH, RX, (0.0), (1.0), R8X)

IF (ICFLAG.EO.1) RPF2 = RX

C

IF (IWAT .EQ. 0) GOTO 100

WRITE (SCRN,1100) RIRR

1100 FORMAT (1 1,

- The irrigation rate in liters per square meter per month is ',

- $1 P G 10.3,1$

- 1 (range $=0.0$ to 1000.$) 1$ )

CALL CHANGE( ( 2$),$ ICFLAG, IX, IL, IH, RX, (0.0), (1000.0), R8X)

IF (ICFLAG.EQ.1) RIRR = RX

C

IF (RIRR .EQ. 0.0$)$ GO TO 110

WRITE (SCRN,1110) IMO

1110 FORMAT ( 1 ',

- The number of months per year that crops are irrigated is ',

- $\quad$ I2,1

- ' (range $=0$ to 12)')

CALL CHANGE ((1), ICFLAG, IX, (0), (12), RX, RL, RH, R8X)

IF (ICFLAG.EQ.1) IMO=IX

C

110 CONTINUE

WRITE (SCRN,1111) IRR

1111 FORMAT (' ',

- 'The number of years prior to the beginning of dose 1/

- ' calculations that irrigation accumulates radionuclides'/

- I is 1,I4,1 (range = 0 to 1000)' )

CALL CHANGE ( (1), ICFLAG, IX, (0), (1000), RX,RL,RH,R8X)

IF (ICFLAG.EQ.1) IRR=IX

C

100 CONTINUE

C

C

C---- review/query/modify external exposure parameters

C

C

IF (IEXT .EQ. 0 .AND. ISUR .EQ. 0) GO TO 200 


\section{APPENDIX 1.B COMPUTER CODE LISTING - ONSITE}

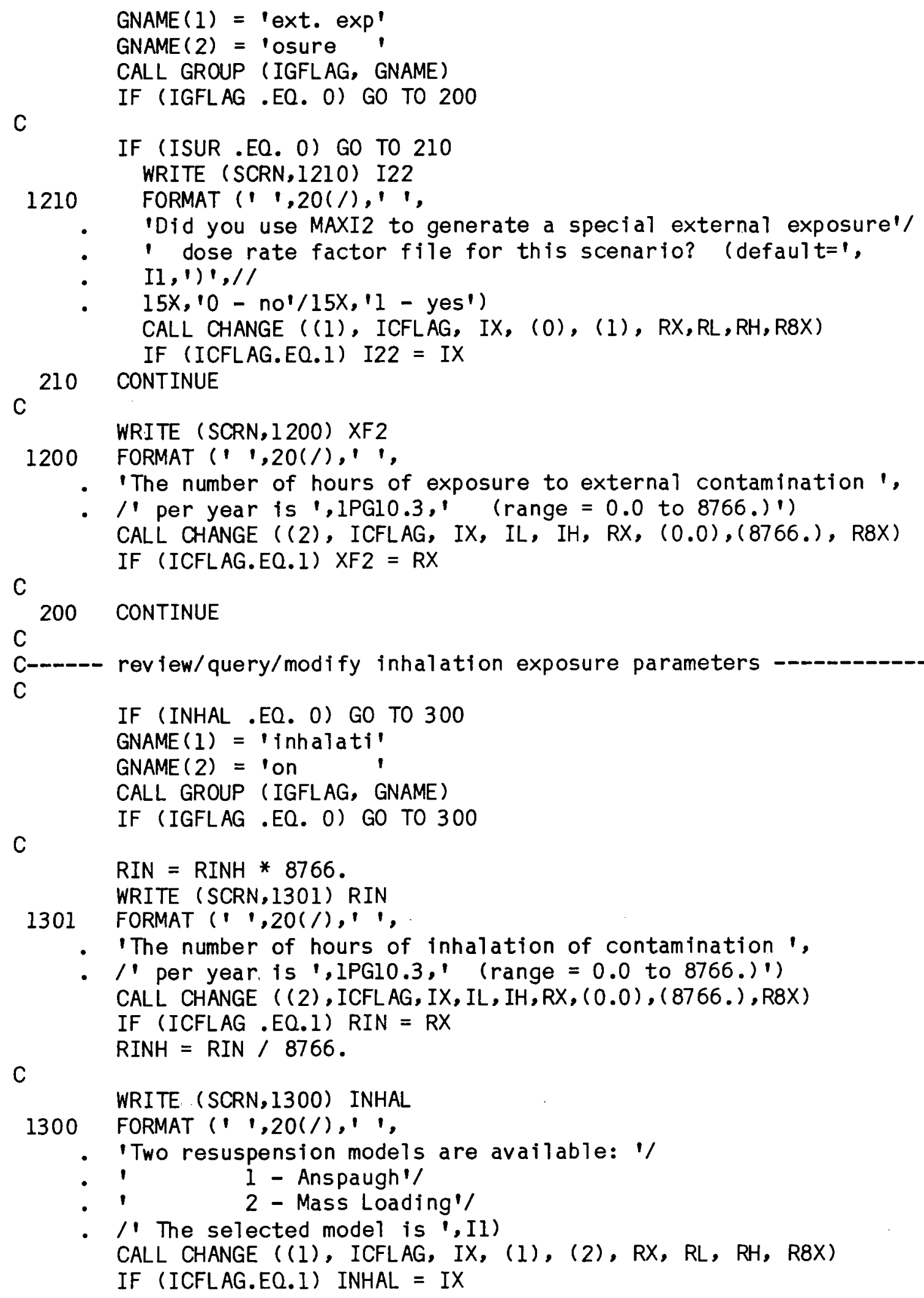




\section{APPENDIX 1.B COMPUTER CODE LISTING - ONSITE}

C

IF (INHAL .EQ. 2) GO TO 310

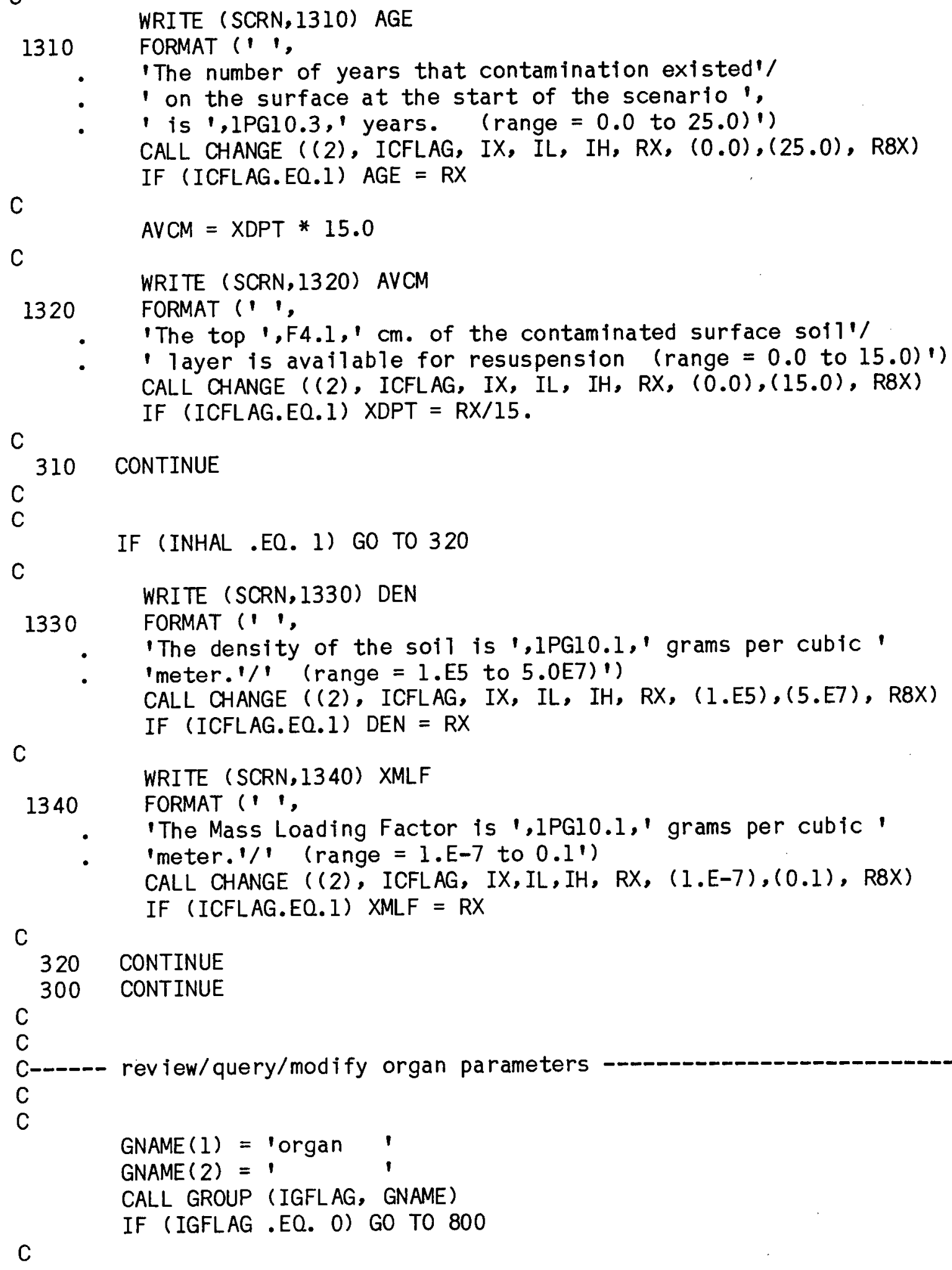




\section{APPENDIX 1.B COMPUTER CODE LISTING - ONSITE}

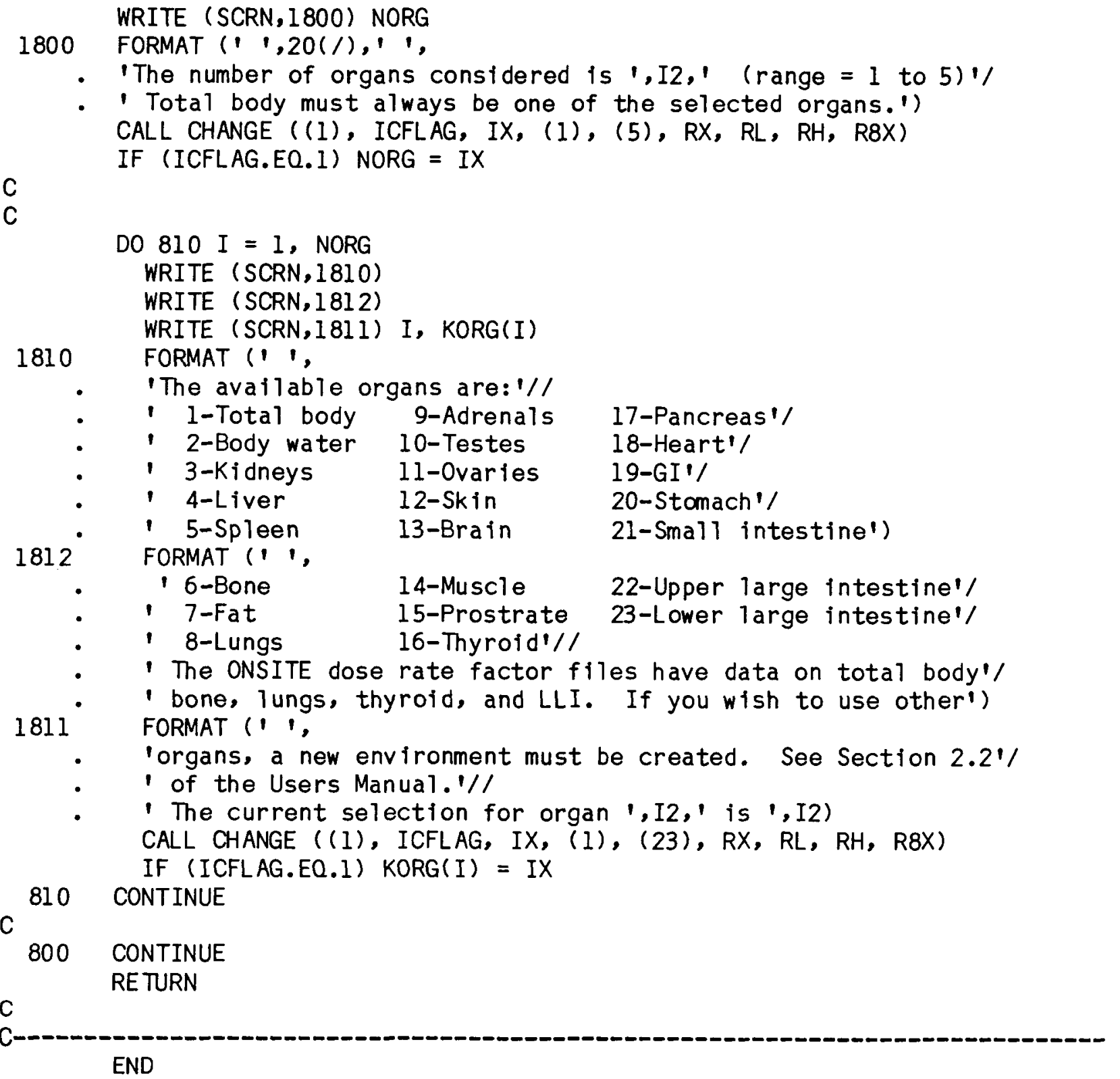




\section{APPENDIX 1.B COMPUTER CODE LISTING - ONSITE}

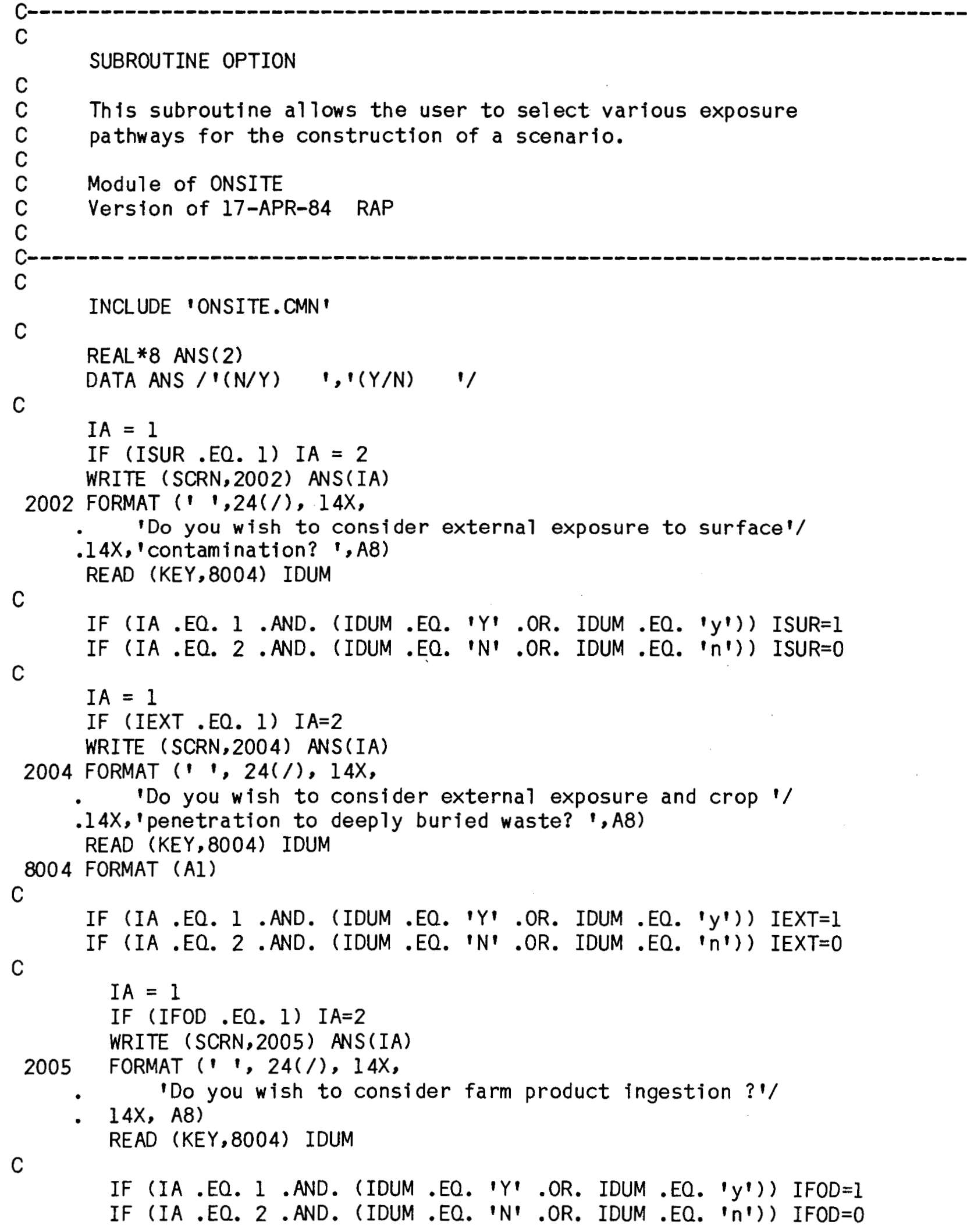




\section{APPENDIX 1.B COMPUTER CODE LISTING - ONSITE}
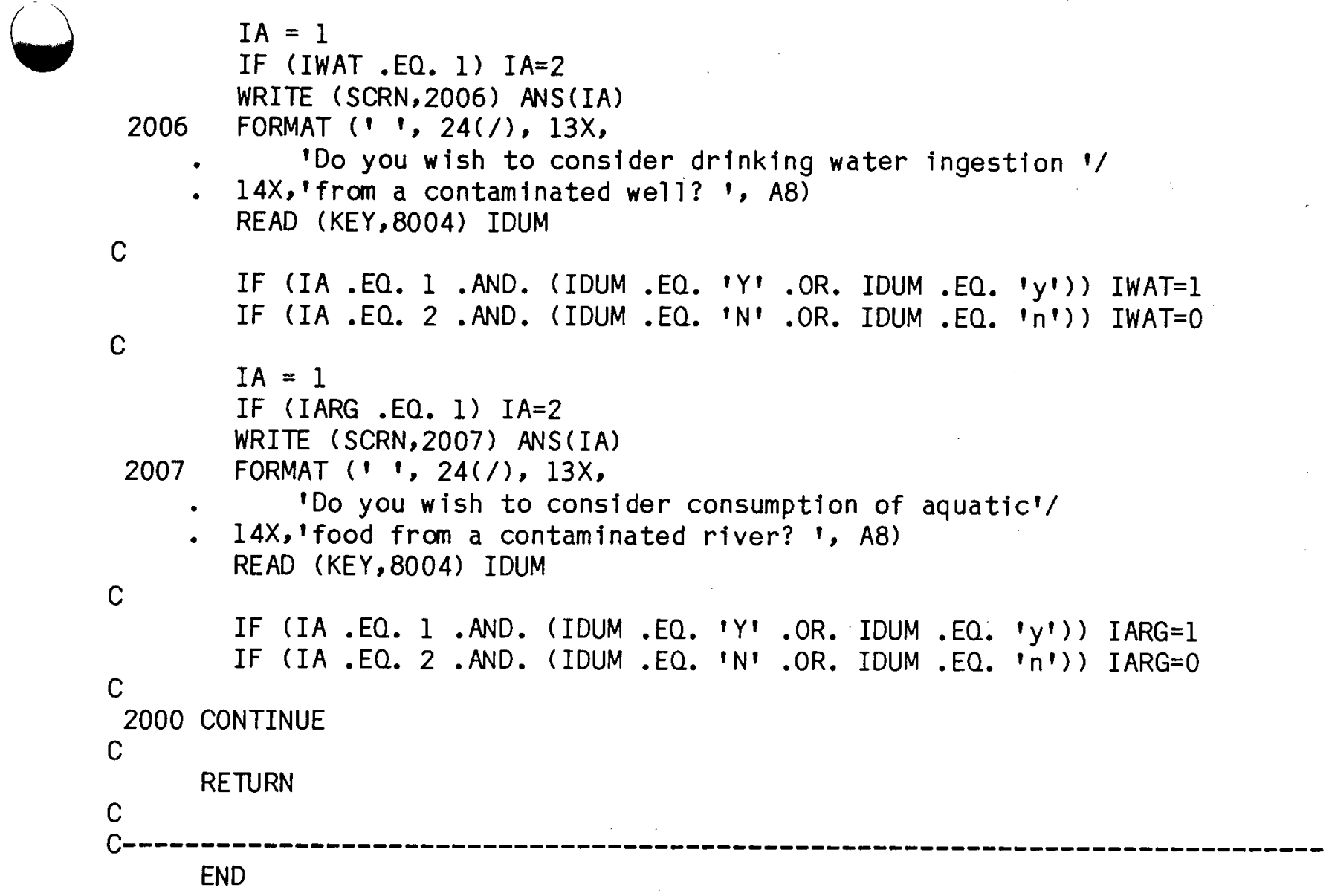


\section{APPENDIX 1.B COMPUTER CODE LISTING - ONSITE}

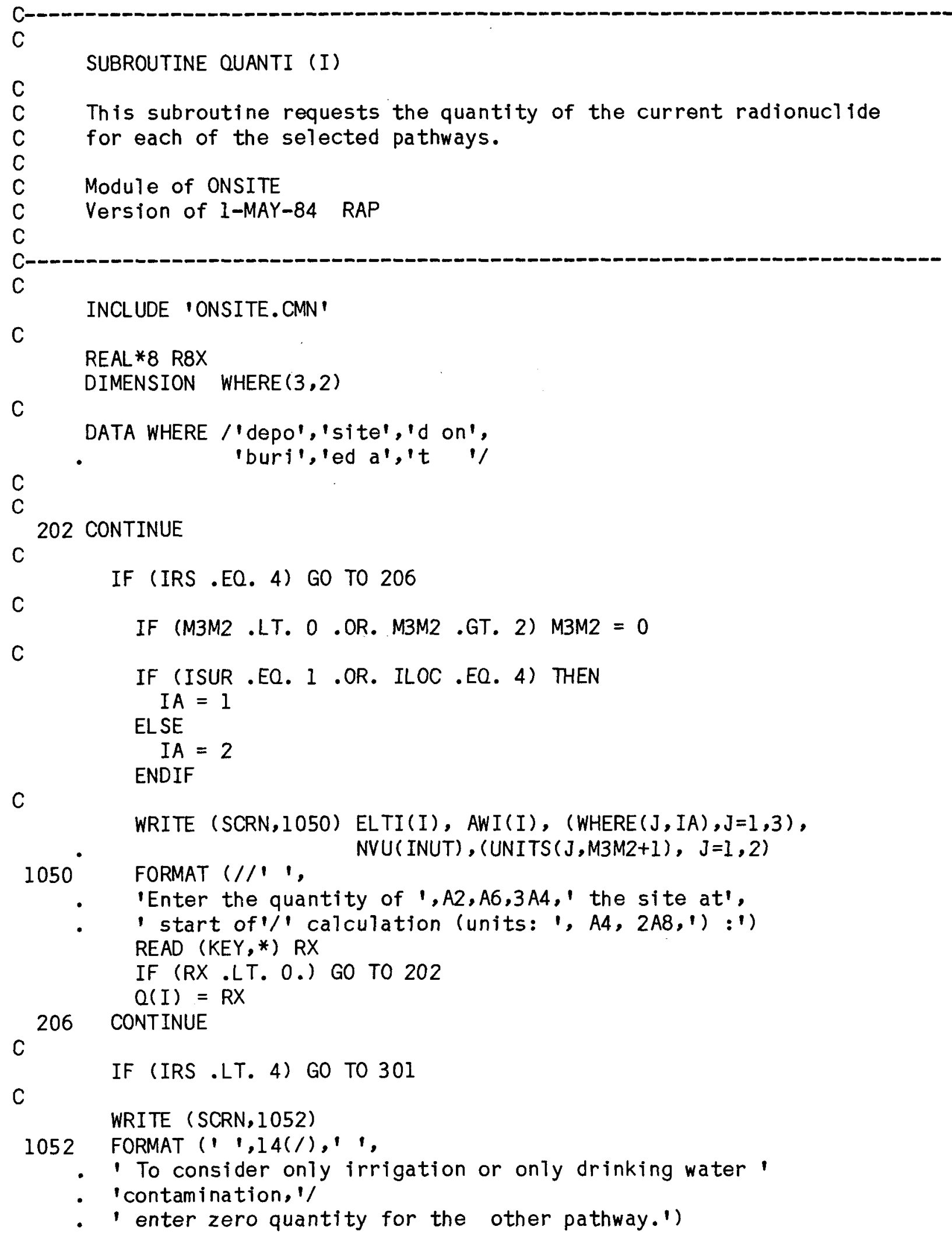




\section{APPENDIX 1.B COMPUTER CODE LISTING - ONSITE}

$C^{304}$ CONTINUE

WRITE (SCRN, 1060) ELTI(I), AWI(I)

1060 FORMAT (//' ',

- 'Enter the concentration of ',A2,A6,' in the irrigation ',

- 'water at start of'/' calculation (units: pCi/liter):')

C READ (KEY,*) RX

C

IF (RX .LT. O.) GO TO 304

$Q I(I)=R X$

IF (OI(I) .GT. O.) IWRL $=1$

C

302 CONTINUE

C

WRITE (SCRN,1070) ELTI(I), AWI(I)

1070 FORMAT (//' ',

- 'Enter the concentration of ' $, A 2, A 6, '$ in the drinking water',

- ' at start of $/ 1$ calculation (units: pCi/liter): ')

READ $(K E Y, *)$ RX

IF (RX .LT. 0.) GO TO 302

OJ $(I)=R X$

IF (OJ (I) .GT. 0.) IWRL =1

C

C

301 CONTINUE

C

C

RETURN

C

END 


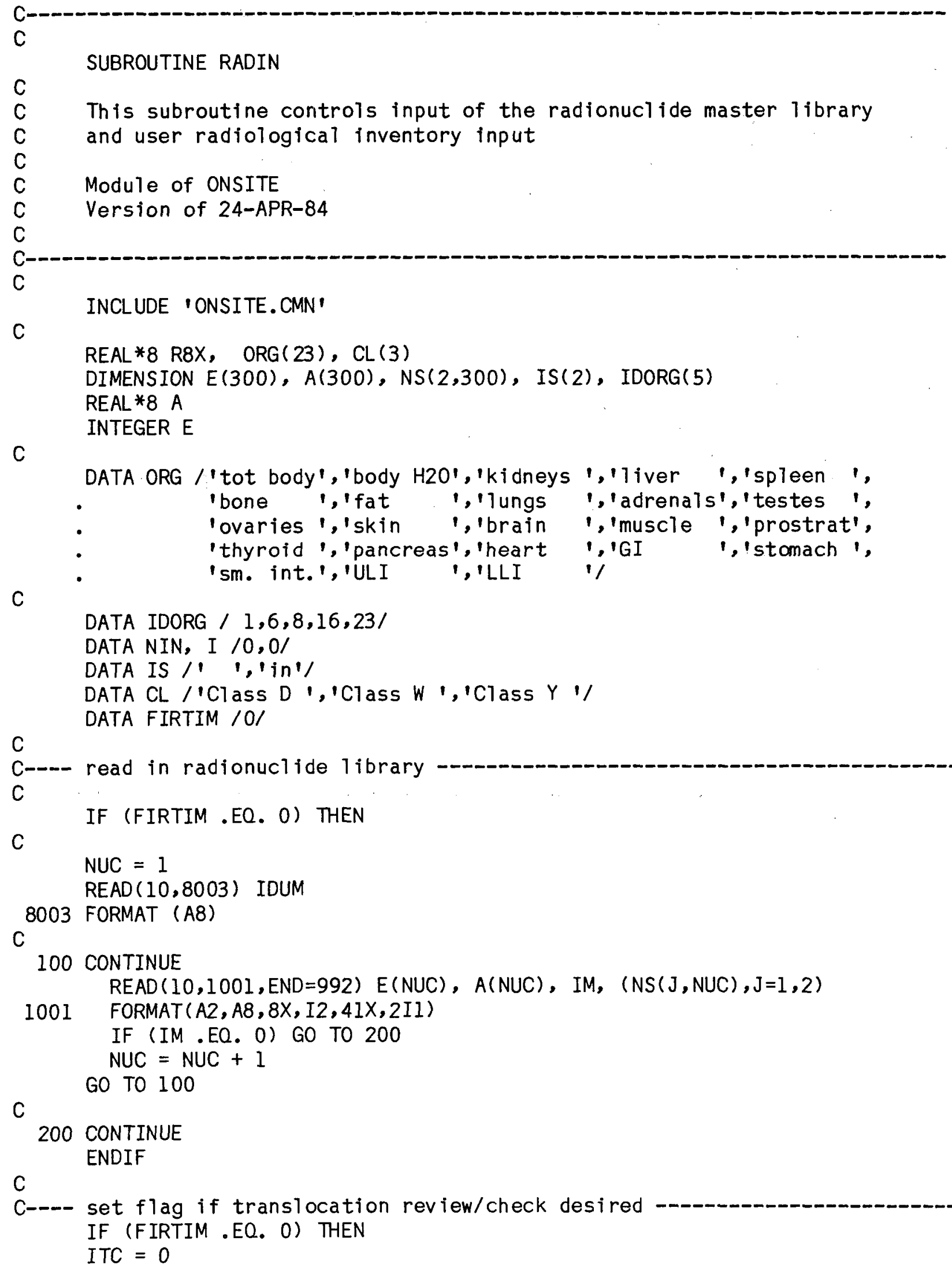




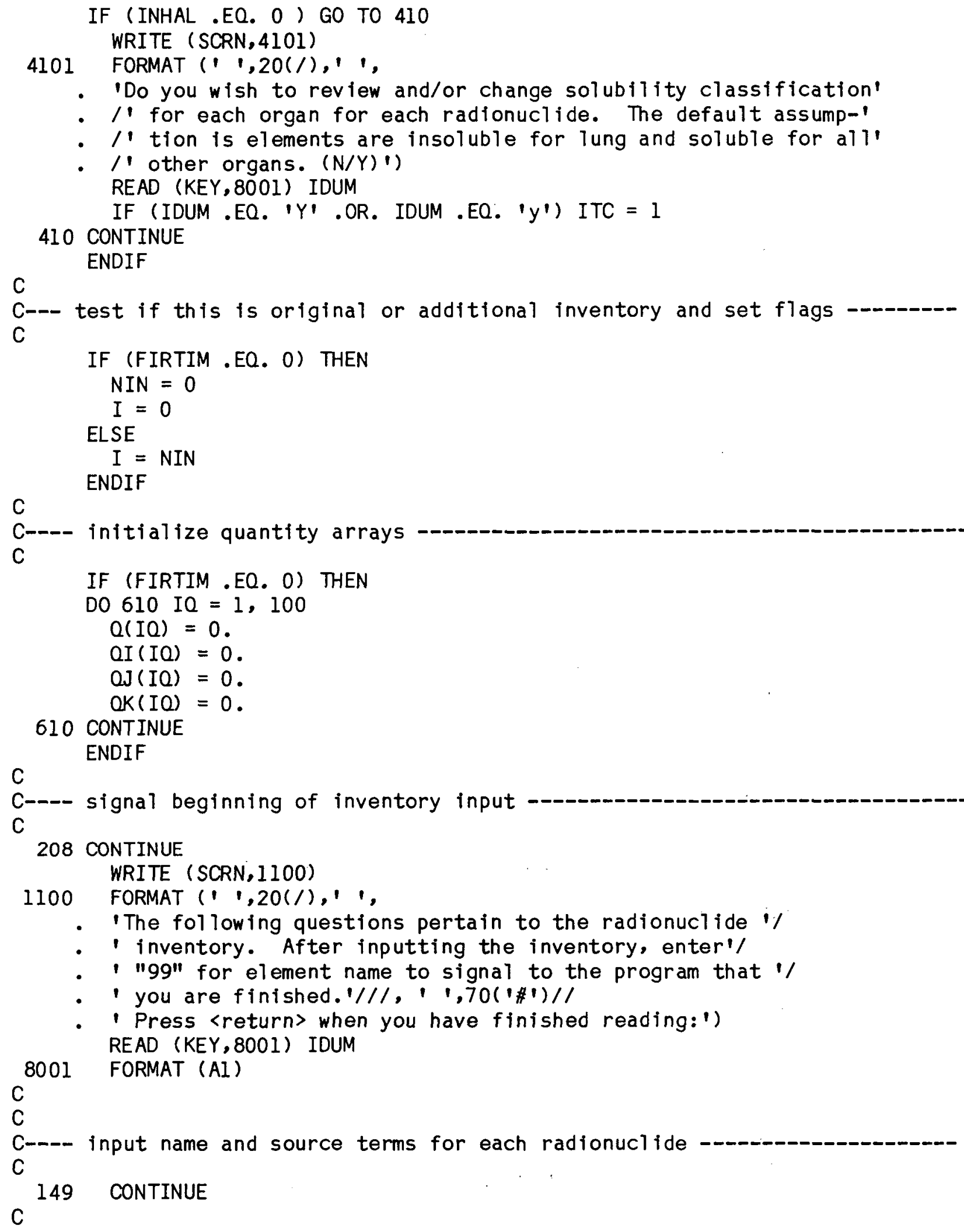




\section{APPENDIX 1.B COMPUTER CODE LISTING - ONSITE}

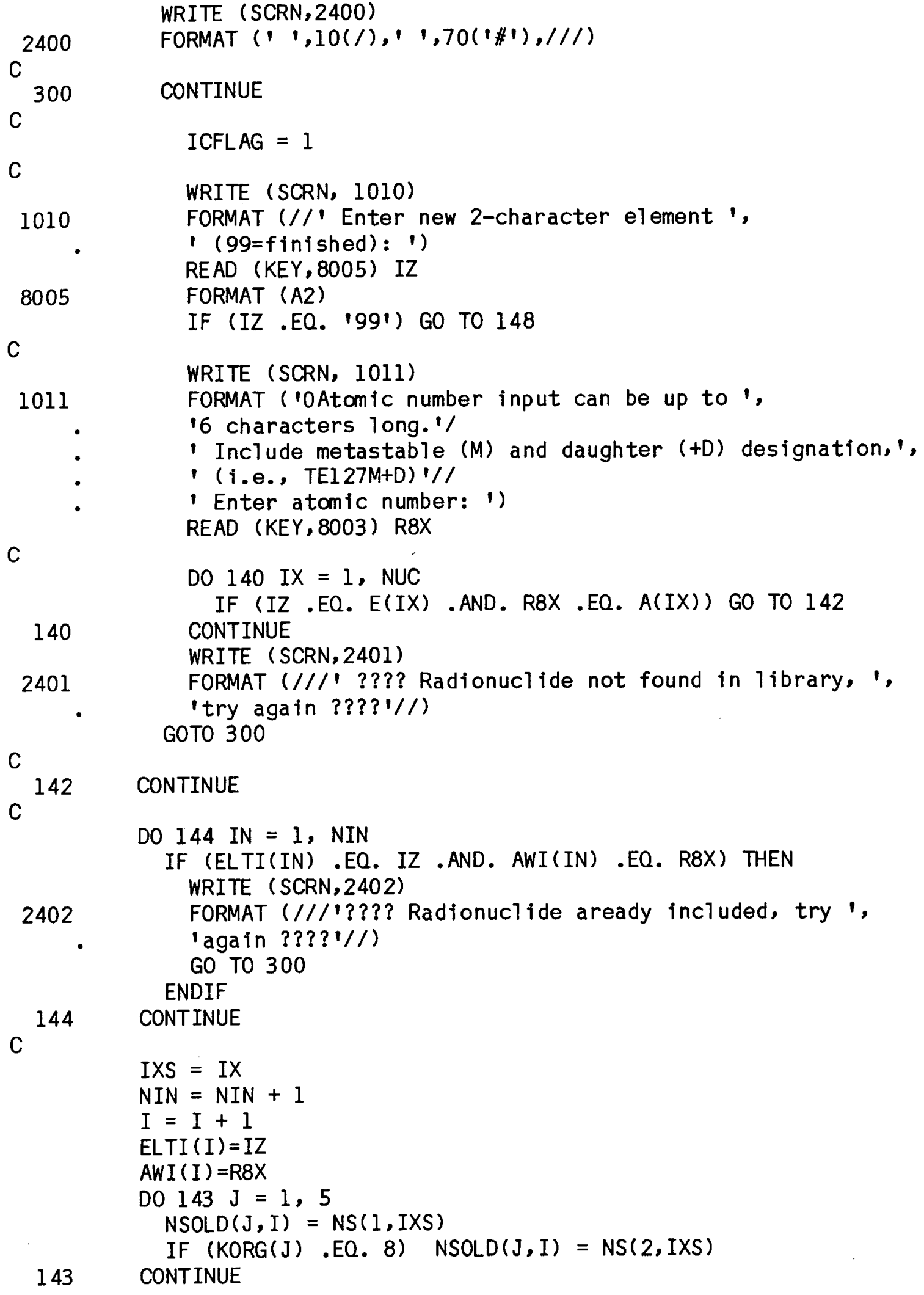


APPENDIX 1.B COMPUTER CODE LISTING - ONSITE

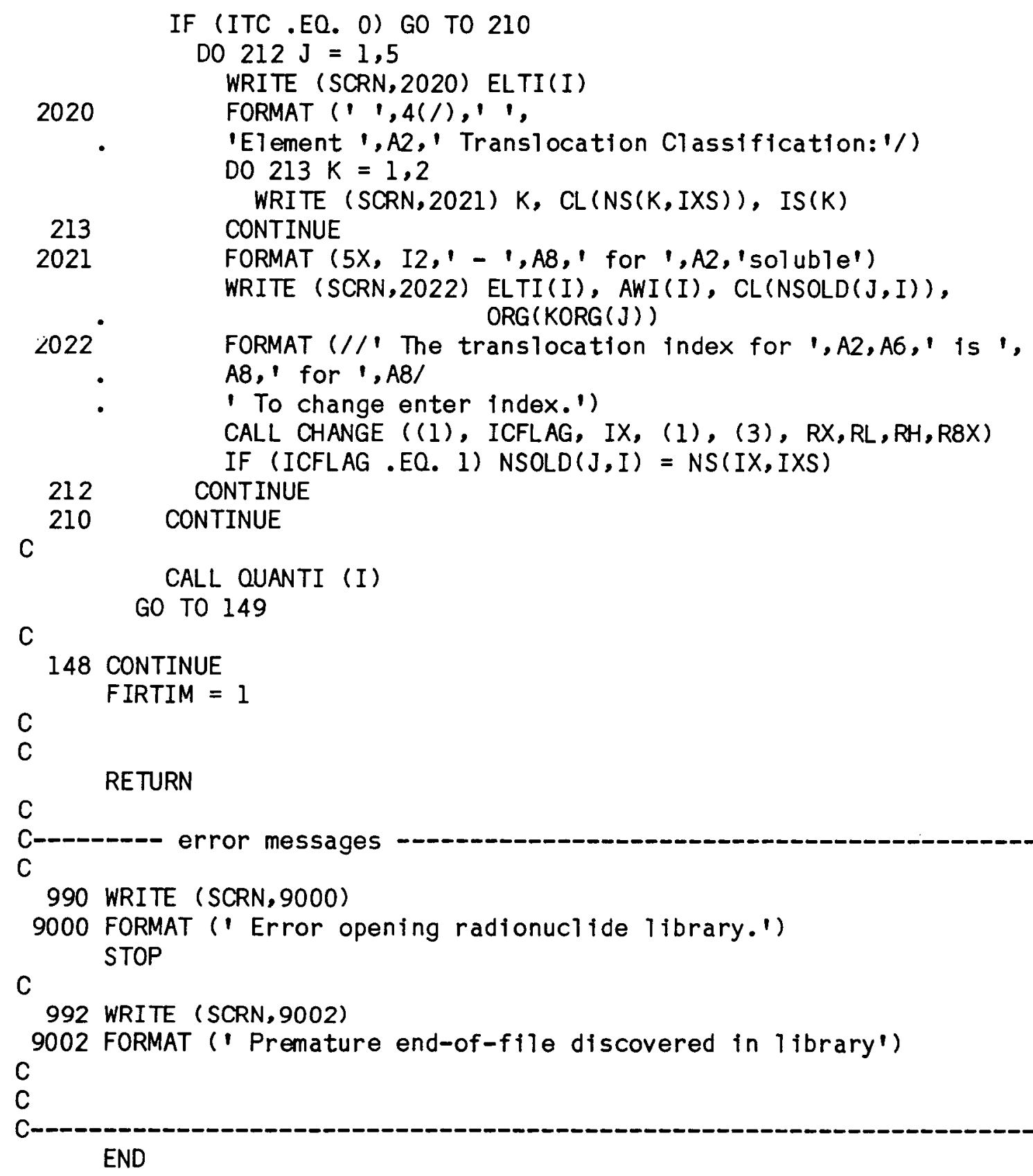




$$
\text { C }
$$

C

SUBROUTINE RITFIL

C This subroutine writes a file with input parameters and

C. system commands for MAXIl. RITFIL is called by the program

C ONSITE.

C

C Module of ONSITE

C Version of 1-MAY-84 RAP

C

C

INCLUDE 'ONSITE.CMN'

C

200 CONTINUE

C

C--- assign library files to logical unit devices

C

C IF (IFOD .GT. O) WRITE (OUT, 3010)

WRITE (OUT,3010)

3010 FORMAT ('ASSIGN [BIO.NEW]FILE20.DAT FORO20 /

(ASSIGN [BIO.NEW]FILE21.DAT FOR021')

$\mathrm{C}$

C IF (IARG .GT. 0) WRITE (OUT, 3020)

WRITE (OUT,3020)

3020 FORMAT ('ASSIGN [BIO.NEW]FILE24.DAT FORO24')

C

C IF (IWAT.GT. O) WRITE (OUT, 3030)

WRITE (OUT,3030)

3030 FORMAT ('ASSIGN [BIO.NEW]FILE25.DAT FORO25')

C

WRITE (OUT, 3040)

3040 FORMAT ('ASSIGN [BIO.NEW]PLANSOURC. SUR FORO22')

C

IF (ILOC .EQ. I) WRITE (OUT, 3044)

3044 FORMAT ('ASSIGN [BIO.NEW]VOLSOURC.SUR FORO27')

C

IF (ILOC .EQ. 2) WRITE (OUT, 3041)

3041 FORMAT ('ASSIGN [BIO.NEW]BURIEDHF.DAT FORO27')

C

IF (ILOC.EQ. 3) WRITE (OUT, 3042)

3042 FORMAT ('ASSIGN [BIO.NEW]BURIEDI.DAT FORO27')

C

IF (ILOC .EQ. 4) WRITE (OUT, 3043)

3043 FORMAT ('ASSIGN [BIO.NEW]ROOM.DAT FORO27')

C

WRITE (OUT, 3050)

3050 FORMAT ('ASSIGN [BIO.NEW]RMDLIB.DAT FORO10'/

' ASSIGN [BIO.NEW]FILE23.DAT FORO23') 


\section{APPENDIX 1.B COMPUTER CODE LISTING - ONSITE}

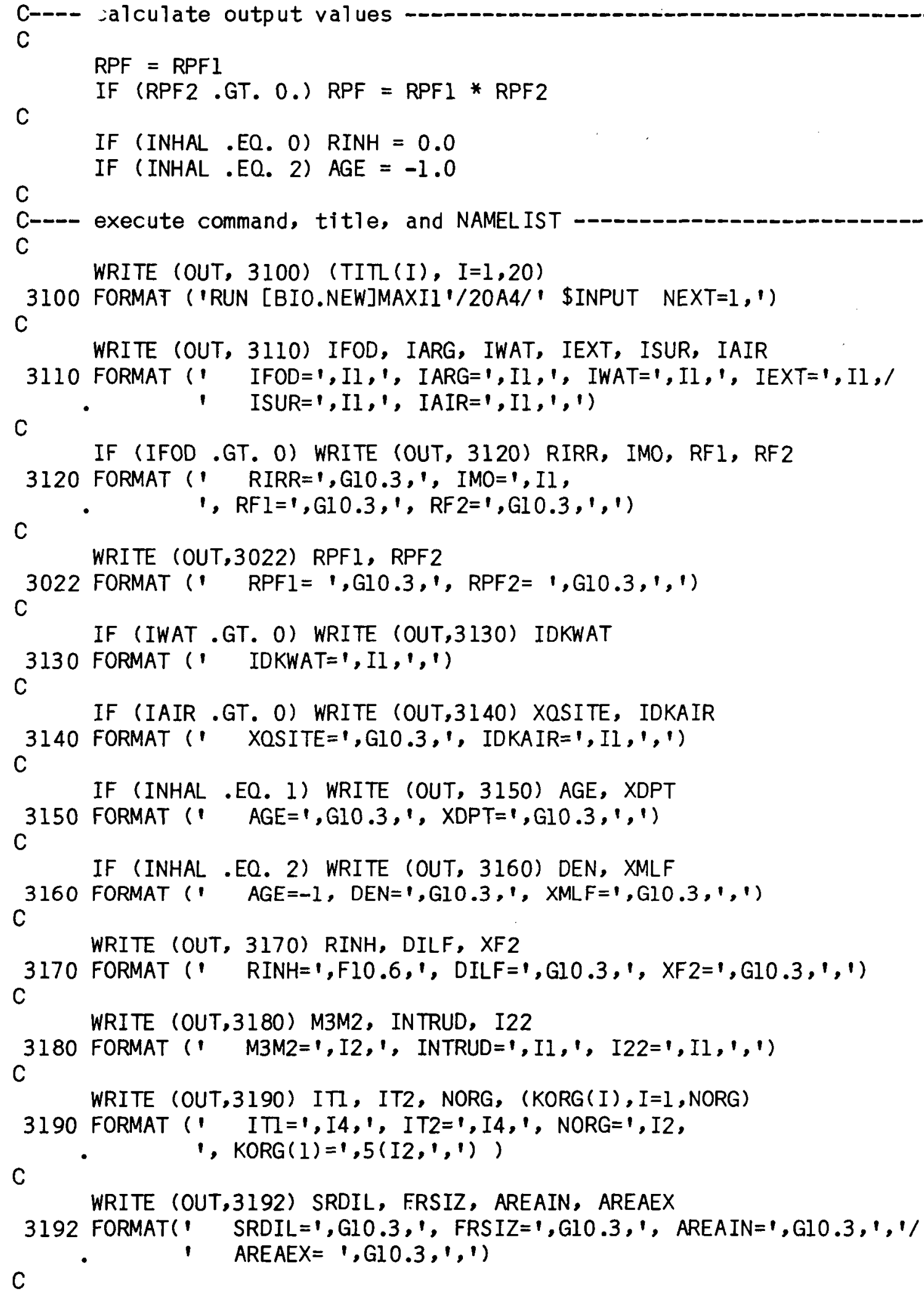




\section{APPENDIX 1.B COMPUTER CODE LISTING - ONSITE}

WRITE (OUT, 3200) IOUT

3200 FORMAT (' IOUT=1,I2, ', ION=1, \$END')

C

C--- adjust inventory to proper units and write to file

C

WRITE (OUT, 3300) NIN, IRR

3300 FORMAT (2I5)

C

DO $100 I=1$, NIN

$Q(I)=Q(I) *$ NVUNIT (INUT)

WRITE (OUT, 3400) ELTI(I), AWI(I), (NSOLD $(J, I), J=1,5)$,

$3400^{\circ}$ FORMAT (A2, A6,5Il,4(IPGI0.2))

100 CONTINUE

c

$\mathrm{C}$

RETURN

C

C--- error routines

C

992 WRITE (SCRN, 9920)

9920 FORMAT ('OError in opening output $f i l e '$ ')

GO TO 200

C

994 WRITE (SCRN,9940)

9940 FORMAT ('OError in closing output file')

STOP

C

C

END 


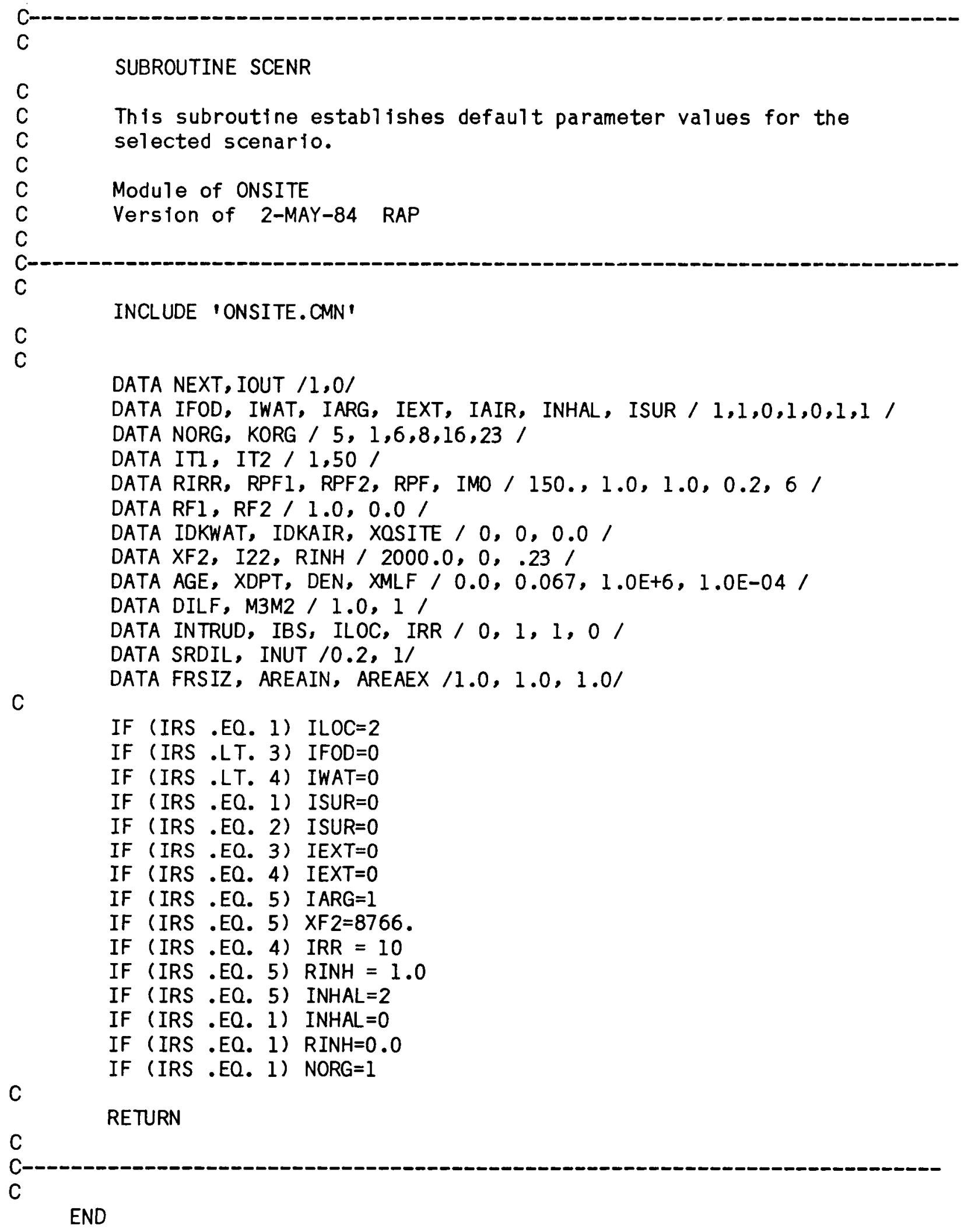




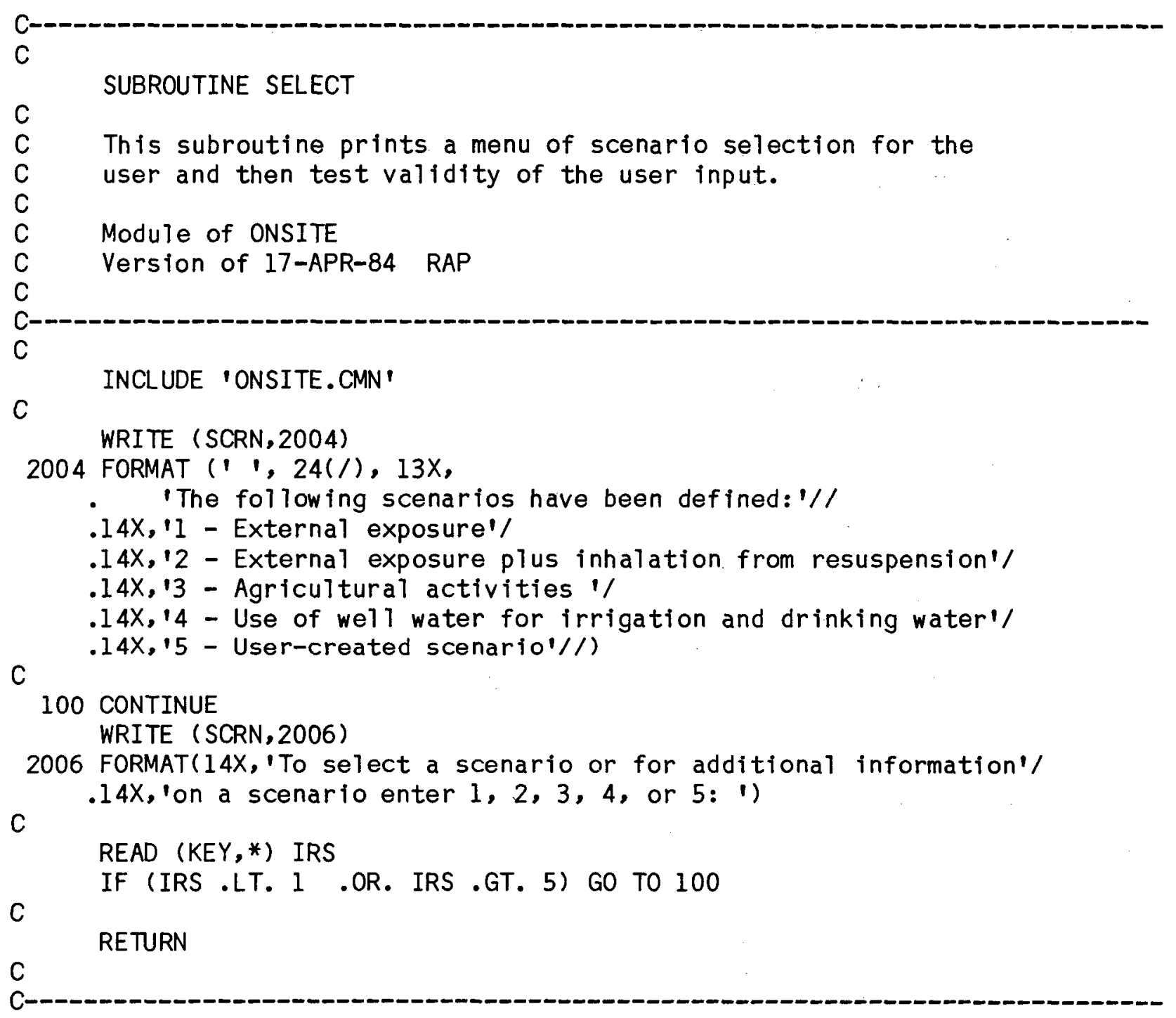

END 
APPENDIX $1 . \mathrm{B}$

COMPUTER CODE LISTING - ONSIIE 
APPENDIX $1 . \mathrm{C}$

\title{
ABBREVIATED DATA BASE LISTING
}

\author{
CONTENTS
}

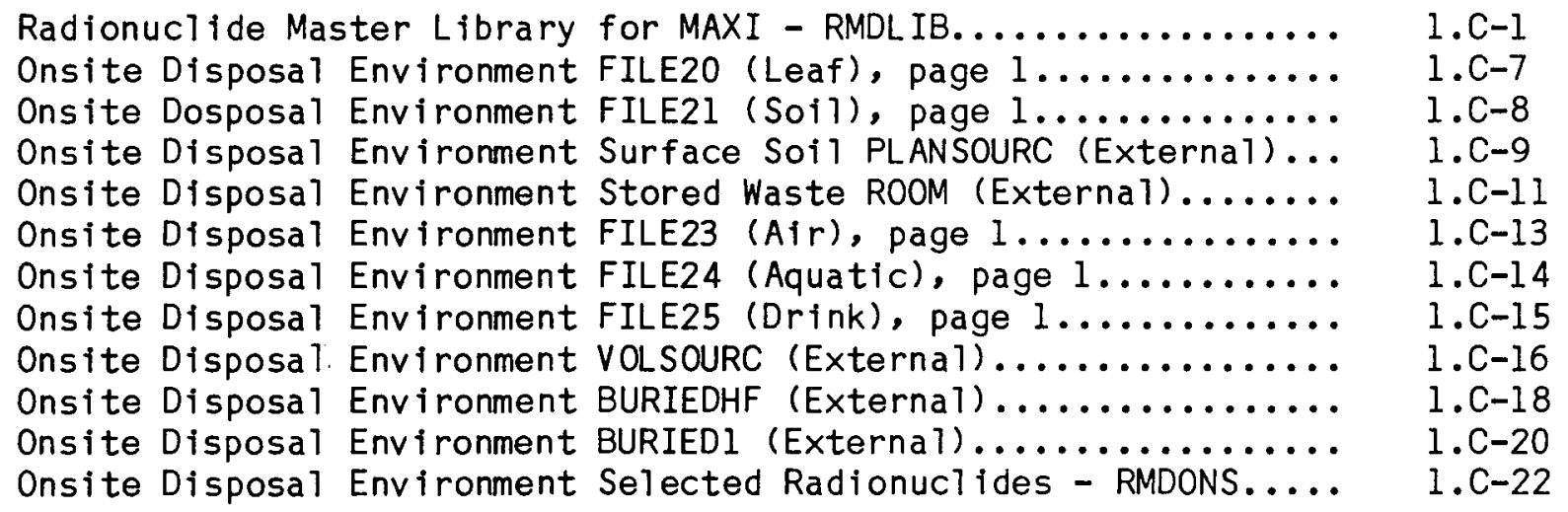




\section{Radionuclide Master Library for MAXI - RMDLIB}

RADIONUCLIDE MASTER DATA LIBRARY / W TRANSLOCATION CLASSES, 6-APR-84 RAP

H 3

BE10

C 14

$\mathrm{N} 13$

F 18

NA22

NA24

$P 32$

$P 33$

S 35

CL36

K 40

AR3 9

AR41

CA41

CA45

SC46

CR51

MN54

MN56

FE55

FE59

C057

C058

C060

NI5 9

NI63

NI65

CU64

ZN65

SE7 5

AS76

SE7 9

BR82

$\mathrm{BR} 83+\mathrm{D}$

BR84

SR85

KR90

KR91

RB86

RB8 9+D

SR89+D

SR90+D

SR91+D

SR92+D

$Y$ 91M+D

ZR93+D

ZR95+D

ZR97+D
$4.51 E+310$

$5.84 \mathrm{E}+8 \quad 10$

$2.091 E+610$

$6.92 \mathrm{E}-310$

$7.62 \mathrm{E}-210$

$9.50 \mathrm{E}+210$

6.25E-1 10

$1.43 \mathrm{E}+110$

$2.44 E+110$

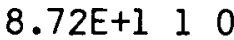

$1.1 E+8 \quad 10$

$4.67 \mathrm{Ell} 10$

$9.83 E+410$

7.61E-2 I 0

$5.11 E+7 \quad 10$

$2.77 \mathrm{E}+1$ 1 0

$8.38 \mathrm{E}+1$ 1 0

$2.77 E+110$

$3.12 \mathrm{E}+210$

$1.07 \mathrm{E}-110$

$9.86 \mathrm{E}+2$ I 0

$4.46 \mathrm{E}+110$

$2.71 E+210$

$7.08 \mathrm{E}+110$

$1.92 \mathrm{E}+3 \quad 10$

$2.74 E+710$

$3.51 E+410$

$1.05 \mathrm{E}-110$

$5.29 \mathrm{E}-1 \mathrm{l} \quad 0$

$2.44 E+2 ~ 10$

$1.2 \mathrm{E}+210$

$1.10 E+0110$

2.37E+7 10

$1.47 \mathrm{E}+010$

9.96E-2 10

$2.21 E-210$

$6.5 \mathrm{E}+110$

$3.74 \mathrm{E}-410$

$1.13 \mathrm{E}-410$

$1.87 \mathrm{E}+110$

$1.06 \mathrm{E}-210$

$5.06 \mathrm{E}+1$ I 0

$1.04 \mathrm{E}+410$

3.96E-1 l 0

$1.13 \mathrm{E}-110$

$3.45 \mathrm{E}-210$

$5.59 E+810$

$6.40 \mathrm{E}+1 \mathrm{I} 0$

$7.04 \mathrm{E}-110$

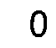

0

0

0

0

0

0

0

0

0

0

0

0

0

0

0

0

0

0

0

0

0

0

0

0

0

0

0

0

0

0

0

0

0

0

0

0

0

0

0

0

0

0

0

0

0
II

12

12

12

11

11

11

12

12

12

11

11

11

11

12

12

13

13

13

13

13

13

13

13

13

13

13

13

13

13

12

12

12

11

11

11

13

II

11

II

11

13

13

13

13

13

13

13.

13 
Radionuclide Master Library for MAXI - RMDLIB, continued

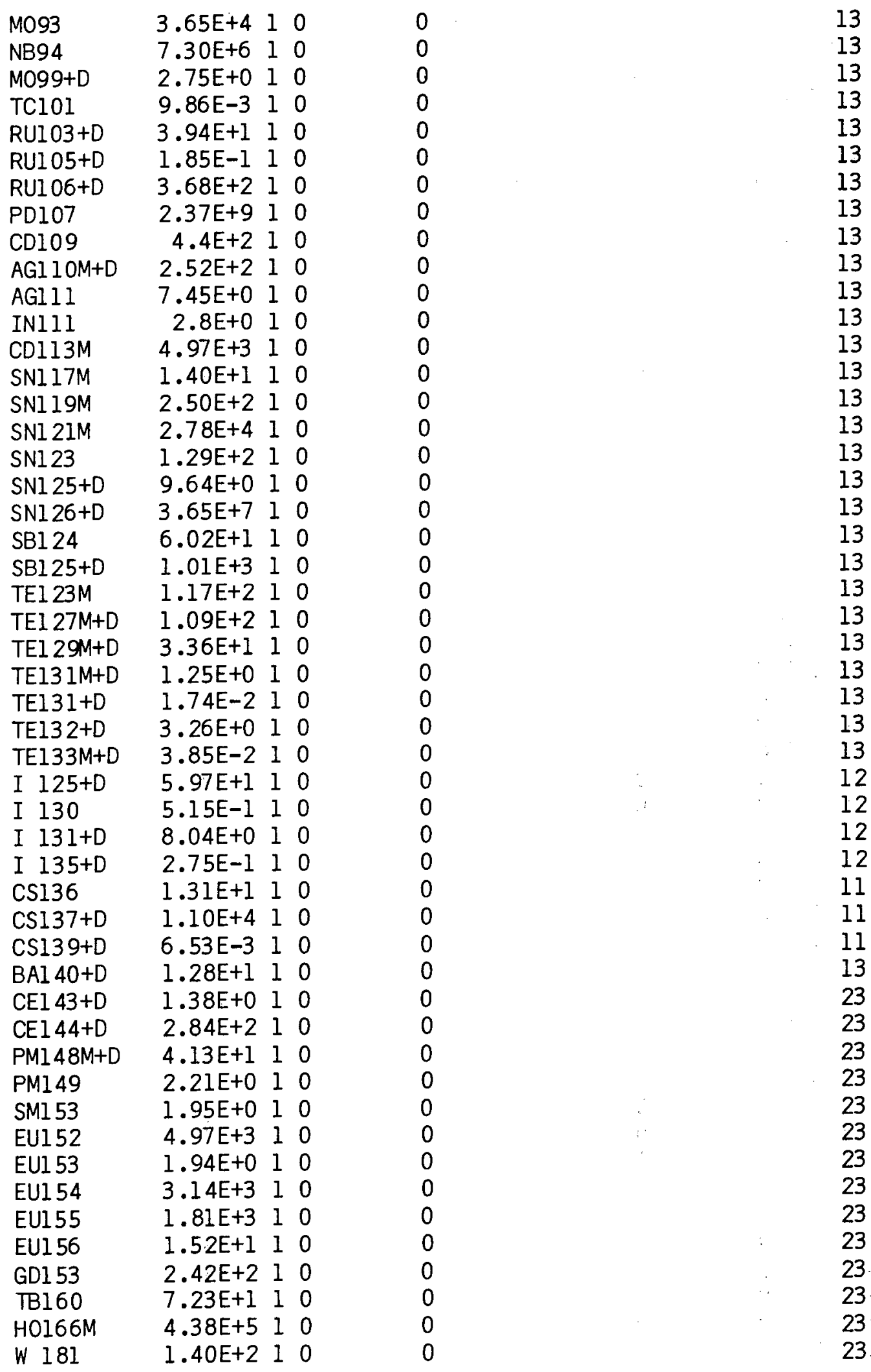


Radionuclide Master Library for MAXI - RMDLIB, continued

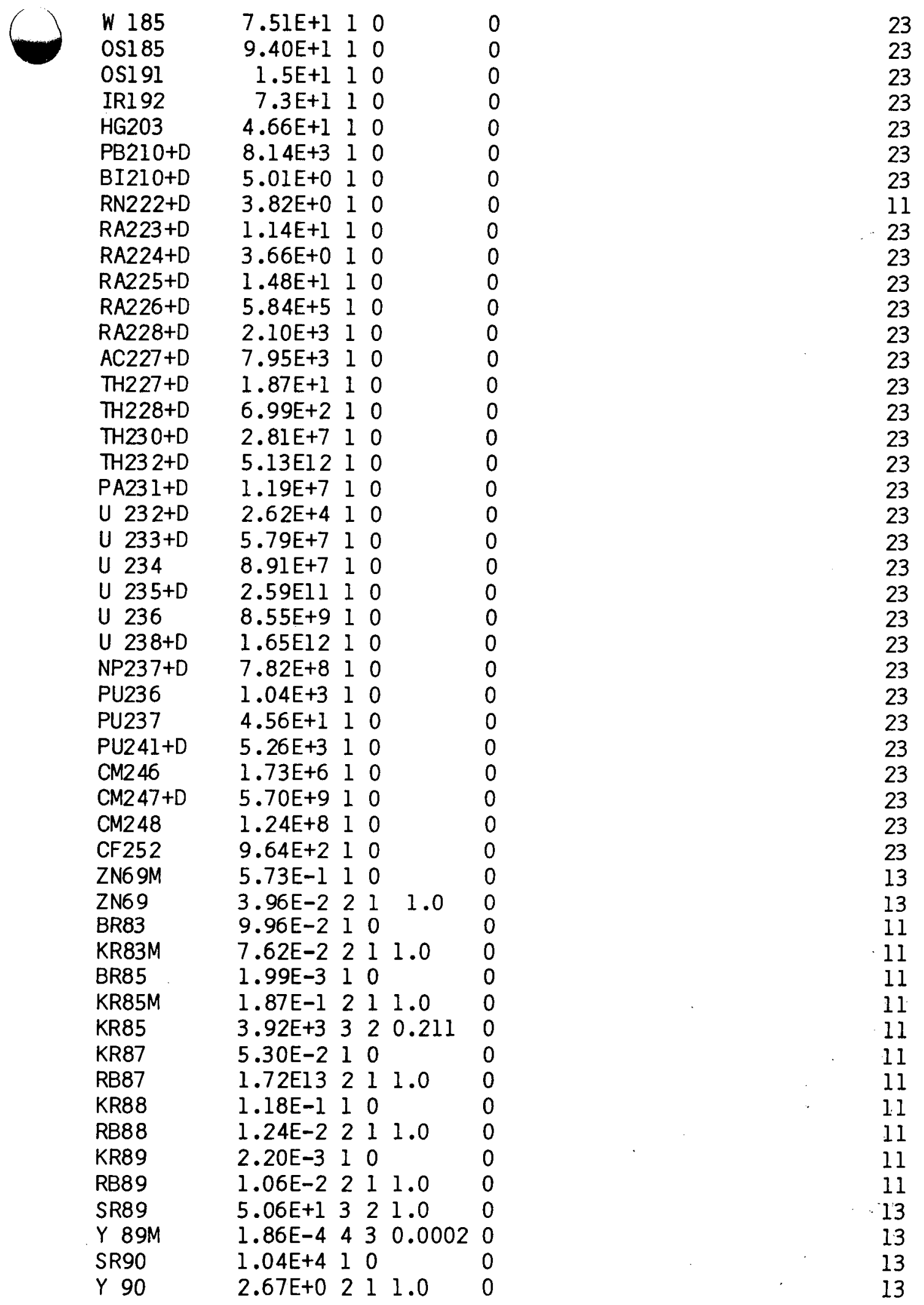


Radionuclide Master Library for MAXI - RMDLIB, continued

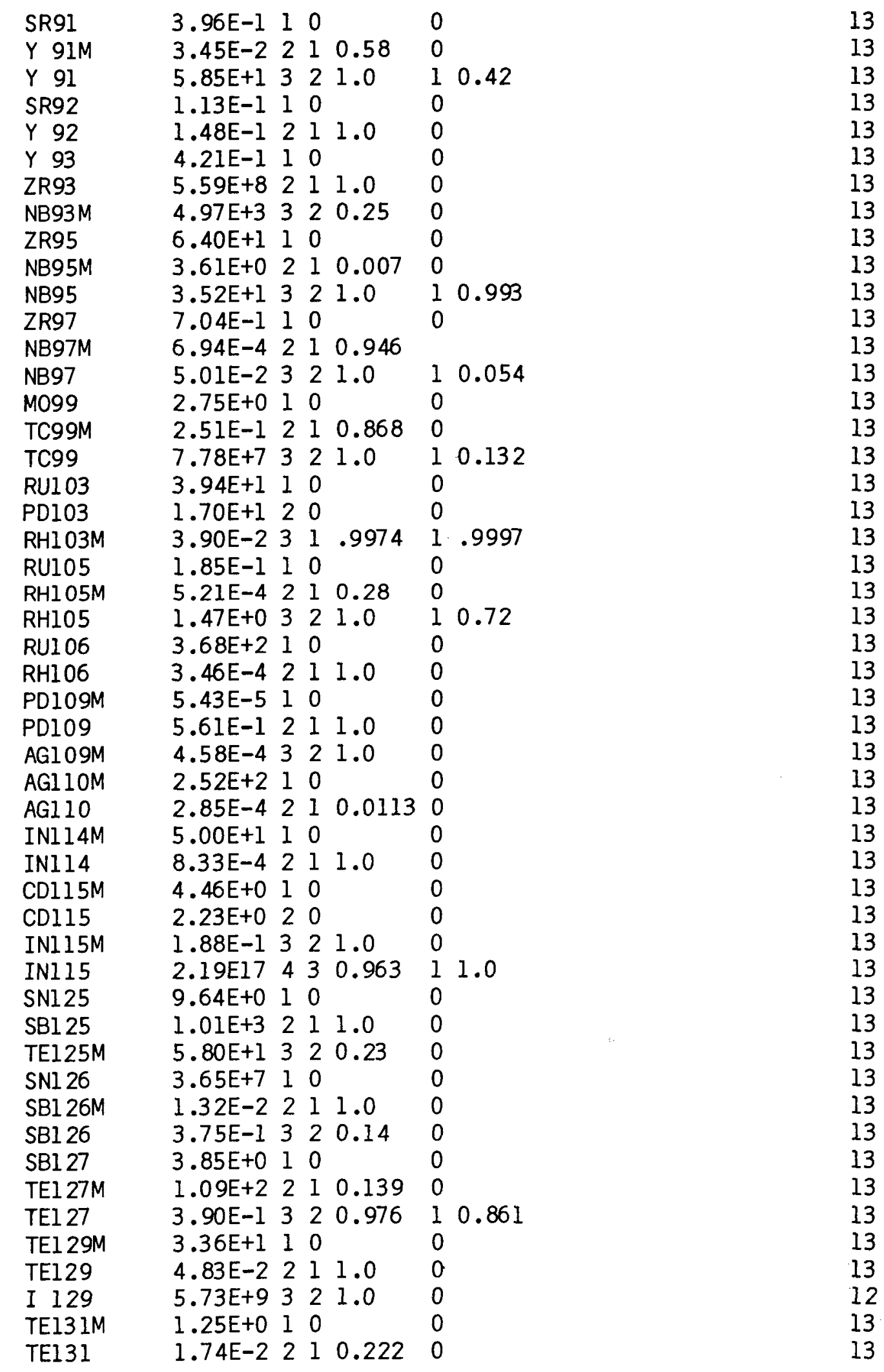


Radionuclide Master Library for MAXI - RMDLIB, continued

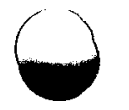

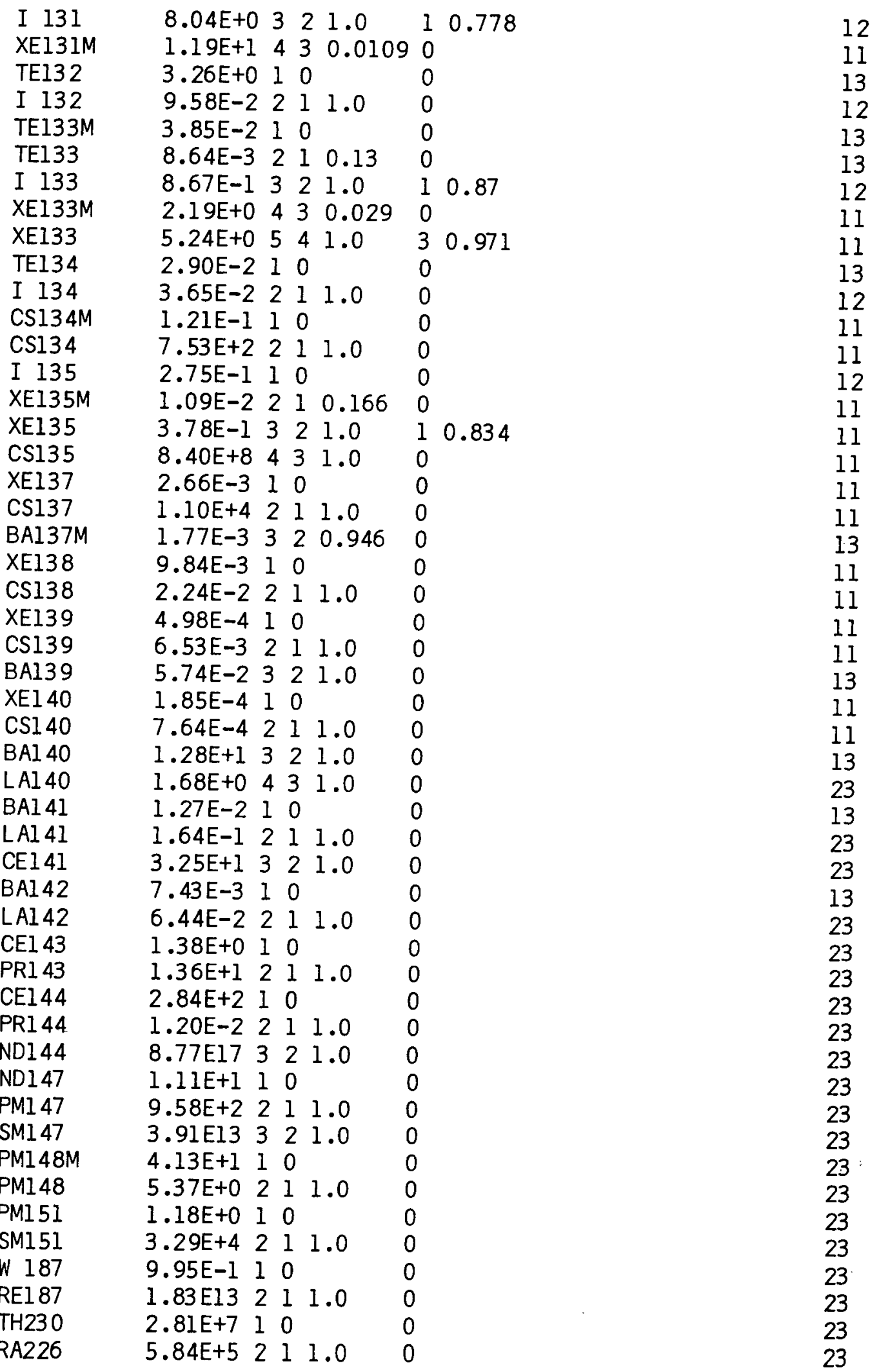


Radionuclide Master Library for MAXI - RMDLIB, continued

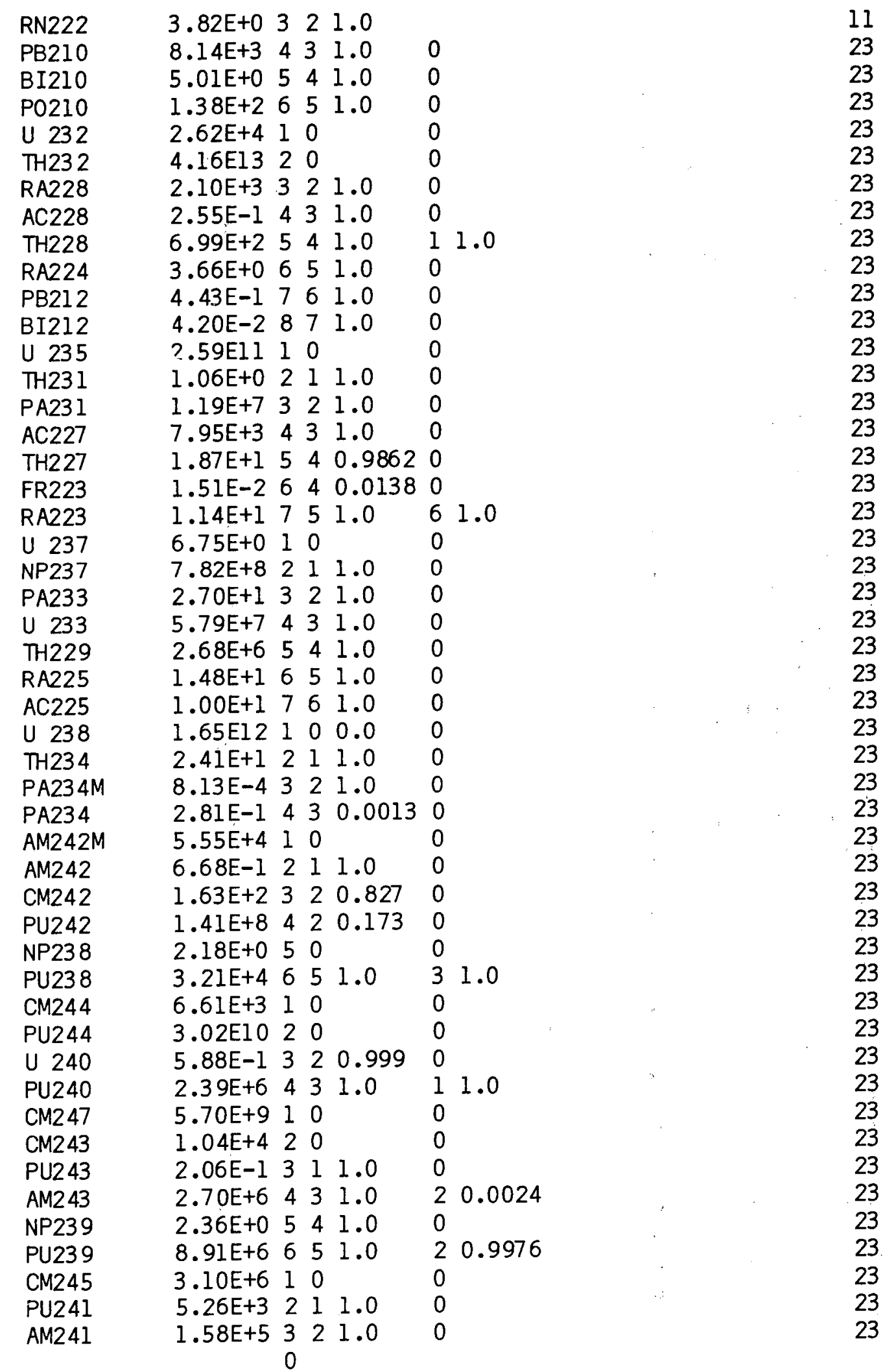


Onsite Disposal Environment FILE20 (Leaf), page 1

Leaf Incremental Dose Factors for ONSITE/BIOPORT Environment - 16-APR-84 RAP $\begin{array}{lrrrr}\text { LEAF } & 50 & 99 & 5 \\ 1 & 6 & 8 & 16 & 23\end{array}$

\begin{tabular}{|c|c|c|c|c|c|}
\hline H 3 & $1.44 \mathrm{E}-06$ & $0.00 E+00$ & $0.00 \mathrm{E}+00$ & $0.00 E+00$ & $0.00 \mathrm{E}+00$ \\
\hline 14 & $1.67 E-05$ & $7.31 E-05$ & $0.00 E+00$ & $0.00 E+00$ & $1.17 \mathrm{E}-05$ \\
\hline IA22 & $1.27 \mathrm{E}-03$ & $0.00 E+00$ & $0.00 \mathrm{E}+00$ & $0.00 E+00$ & $8.24 \mathrm{E}-04$ \\
\hline$P 32$ & $1.23 E-04$ & $3.18 E-03$ & $0.00 E+00$ & $0.00 E+00$ & $4.20 E-04$ \\
\hline P 33 & $3.14 \mathrm{E}-05$ & $8.46 E-04$ & $0.00 E+00$ & $0.00 \mathrm{E}+00$ & $6.83 E-05$ \\
\hline S 35 & $1.94 E-04$ & $4.31 E-04$ & $0.00 \mathrm{E}+00$ & $0.00 E+00$ & $0.00 E+00$ \\
\hline CL36 & $1.55 E+00$ & $0.00 E+00$ & $0.00 E+00$ & $0.00 E+00$ & $4.07 \mathrm{E}-01$ \\
\hline K 40 & $5.23 E+00$ & $0.00 \mathrm{E}+00$ & $0.00 \mathrm{E}+00$ & $0.00 E+00$ & $5.69 E-01$ \\
\hline CA45 & $1.90 \mathrm{E}-05$ & $8.57 E-04$ & $0.00 \mathrm{E}+00$ & $0.00 E+00$ & $6.85 E-05$ \\
\hline SC46 & $1.91 \mathrm{E}-08$ & $3.36 E-08$ & $0.00 E+00$ & $0.00 E+00$ & $3.91 E-04$ \\
\hline CR5l & $1.40 \mathrm{E}-08$ & $0.00 E+00$ & $2.88 \mathrm{E}-08$ & $8.33 E-09$ & $4.34 \mathrm{E}-06$ \\
\hline MN54 & $6.36 E-06$ & $0.00 E+00$ & $0.00 E+00$ & $0.00 E+00$ & $1.22 \mathrm{E}-04$ \\
\hline FE55 & $1.14 \mathrm{E}-06$ & $5.28 \mathrm{E}-06$ & $1.71 \mathrm{E}-06$ & $0.00 E+00$ & $1.31 E-05$ \\
\hline FE59 & $2.41 E-05$ & $2.79 E-05$ & $1.75 E-05$ & $0.00 \mathrm{E}+00$ & $2.94 \mathrm{E}-04$ \\
\hline $\mathrm{CO57}$ & $2.17 E-06$ & $0.00 E+00$ & $0.00 E+00$ & $0.00 \mathrm{E}+00$ & $3.82 E-05$ \\
\hline $\mathrm{CO60}$ & $3.68 \mathrm{E}-05$ & $0.00 E+00$ & $0.00 E+00$ & $0.00 E+00$ & $3.63 E-04$ \\
\hline NI59 & $3.47 \mathrm{E}-06$ & $1.77 \mathrm{E}-05$ & $0.00 E+00$ & $0.00 E+00$ & $9.76 \mathrm{E}-06$ \\
\hline NI63 & $9.45 \mathrm{E}-06$ & $2.41 E-04$ & $0.00 E+00$ & $0.00 \mathrm{E}+00$ & $2.66 \mathrm{E}-05$ \\
\hline ZN65 & $7.04 \mathrm{E}-05$ & $4.71 E-05$ & $0.00 E+00$ & $0.00 \mathrm{E}+00$ & $2.46 E-04$ \\
\hline SE75 & $2.85 E-04$ & $0.00 E+00$ & $0.00 E+00$ & $0.00 E+00$ & $0.00 E+00$ \\
\hline SR85 & $4.03 E-05$ & $3.34 \mathrm{E}-05$ & $0.00 E+00$ & $0.00 E+00$ & $0.00 E+00$ \\
\hline SR90+D & $4.29 E-04$ & $1.60 \mathrm{E}-03$ & $0.00 E+00$ & $0.00 E+00$ & $7.50 E-04$ \\
\hline M093 & $2.98 \mathrm{E}-06$ & $0.00 E+00$ & $0.00 \mathrm{E}+00$ & $0.00 \mathrm{E}+00$ & $2.04 \mathrm{E}-05$ \\
\hline NB94 & $1.12 \mathrm{E}-07$ & $0.00 E+00$ & $0.00 E+00$ & $0.00 E+00$ & $3.64 E-04$ \\
\hline RU1 06+D & $2.39 E-06$ & $1.83 E-05$ & $0.00 \mathrm{E}+00$ & $0.00 \mathrm{E}+00$ & $1.40 \mathrm{E}-03$ \\
\hline CD109 & $2.00 \mathrm{E}-07$ & $0.00 E+00$ & $0.00 E+00$ & $0.00 E+00$ & $0.00 E+00$ \\
\hline$A G 110 M+D$ & $3.86 E-06$ & $6.41 E-06$ & $0.00 E+00$ & $0.00 E+00$ & $3.01 E-03$ \\
\hline INIII & $1.20 \mathrm{E}-09$ & $2.18 \mathrm{E}-09$ & $0.00 E+00$ & $4.88 E-10$ & $9.84 E-06$ \\
\hline SB1 24 & $7.11 E-06$ & $1.68 \mathrm{E}-05$ & $1.38 \mathrm{E}-05$ & $4.71 E-08$ & $6.22 \mathrm{E}-04$ \\
\hline $\mathrm{SBl} 25+\mathrm{D}$ & $3.18 E-06$ & $1.04 E-05$ & $9.09 E-06$ & $1.56 \mathrm{E}-08$ & $1.91 \mathrm{E}-04$ \\
\hline I $125+D$ & $7.36 \mathrm{E}-05$ & $3.43 E-04$ & $0.00 E+00$ & $6.03 E-02$ & $8.66 E-06$ \\
\hline I $131+D$ & $3.05 E-05$ & $3.75 E-05$ & $0.00 E+00$ & $1.74 \mathrm{E}-02$ & $1.61 E-05$ \\
\hline CS137+D & $9.00 \mathrm{E}-04$ & $9.08 E-04$ & $1.43 E-04$ & $0.00 E+00$ & $4.93 E-05$ \\
\hline CEl 44+D & $8.24 E-08$ & $1.31 E-06$ & $0.00 E+00$ & $0.00 E+00$ & $1.29 \mathrm{E}-03$ \\
\hline EU152 & $6.03 E-08$ & $1.59 E-07$ & $0.00 E+00$ & $0.00 E+00$ & $2.25 \mathrm{E}-04$ \\
\hline EU154 & $8.72 \mathrm{E}-08$ & $5.58 \mathrm{E}-07$ & $0.00 E+00$ & $0.00 E+00$ & $4.80 E-04$ \\
\hline TB160 & $2.82 E-08$ & $2.24 E-07$ & $0.00 E+00$ & $0.00 \mathrm{E}+00$ & $3.10 E-04$ \\
\hline OS185 & $9.01 E-05$ & $0.00 E+00$ & $0.00 E+00$ & $0.00 \mathrm{E}+00$ & $3.18 E-03$ \\
\hline OS191 & $7.33 \mathrm{E}-06$ & $0.00 E+00$ & $0.00 E+00$ & $0.00 \mathrm{E}+00$ & $8.51 E-04$ \\
\hline IRI 92 & $8.51 E-06$ & $0.00 \mathrm{E}+00$ & $0.00 E+00$ & $0.00 E+00$ & $6.98 E-04$ \\
\hline HG2O3 & $2.35 \mathrm{E}-04$ & $0.00 E+00$ & $0.00 E+00$ & $0.00 E+00$ & $3.72 \mathrm{E}-04$ \\
\hline PB210+D & $3.82 E-04$ & $5.51 E-03$ & $0.00 E+00$ & $0.00 E+00$ & $4.43 E-04$ \\
\hline RA226+D & $3.34 \mathrm{E}-02$ & $3.36 \mathrm{E}-02$ & $0.00 E+00$ & $0.00 E+00$ & $2.83 E-03$ \\
\hline $\mathrm{TH} 228+\mathrm{D}$ & $2.12 E-05$ & $6.26 \mathrm{E}-04$ & $0.00 E+00$ & $0.00 E+00$ & $4.87 \mathrm{E}-03$ \\
\hline $\mathrm{TH} 230+\mathrm{D}$ & $5.11 E-06$ & $1.80 \mathrm{E}-04$ & $0.00 E+00$ & $0.00 E+00$ & $5.32 \mathrm{E}-04$ \\
\hline$T H 232+D$ & $6.62 E-06$ & $2.00 E-04$ & $0.00 E+00$ & $0.00 E+00$ & $4.53 E-04$ \\
\hline
\end{tabular}


Onsite Disposal Environment FILE21 (Soi 1), page 1

Soil Incremental Dose Factors for ONSITE/BIOPORT Environment - 16-APR-84 RAP
SOIL $50 \quad 99 \quad 55$ $\begin{array}{lllll}\text { SOIL } & 50 & 99 & 5 \\ & 6 & 8 & 16 & 23\end{array}$

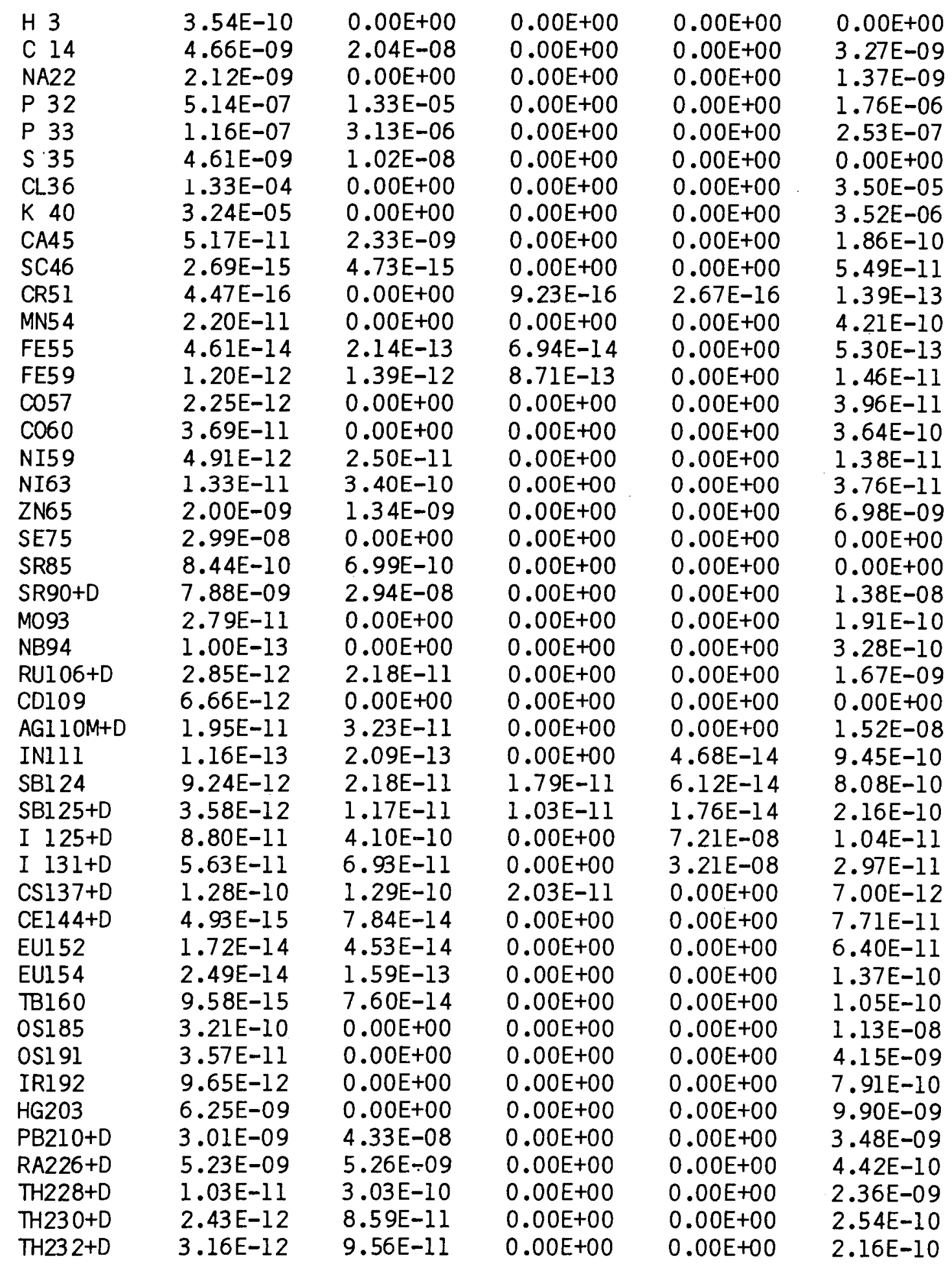


Onsite Disposal Environment Surface Soil PLANSOURC (External)

ONSITE/BIOPORT EXTERNAL DRFS FOR SURFACE (PLANE SOURCE) 10-APR-84 RAP PLAN 100
H 30.0
C $146.2 \mathrm{E}-04$
$\mathrm{NA} 22 \quad 4.3 \mathrm{E}+02$
P 32 9.2E-01
P $33 \quad 9.4 \mathrm{E}-01$
S $35 \quad 0.0$
CL36 2.8E-01
K $40 \quad 5.7 \mathrm{E}+0 \mathrm{I}$
CA45 2.8E-03
$\mathrm{SC} 46 \quad 7.2 \mathrm{E}+02$
CR51 1.1E+01
MN54 2.9E+02
FE55 0.0
FE59 4.0E+02
$\mathrm{CO57} 2.1 \mathrm{E}+01$
C060 8.6E+02
NI59 0.0
NI63 2.5E-14
ZN65 2.2E+02
SE75 9.2E+01
SR85 I.8E+02
SR90+D 1.9
M093 1.4
NB94 $5.3 \mathrm{E}+02$
RU106+D 8.9E+02
CD109 7.6
AGI IOM+DI . OE+03
INI11 $7.6 \mathrm{E}+01$
SBI24 $7.2 \mathrm{E}+02$
$\mathrm{SBl} 25+\mathrm{D}$ 1.7E+02
I $125+D \quad 8.8 \mathrm{E}-01$
I $131+\mathrm{D} 1.2 \mathrm{E}+02$
CS137+D 2.1E+02
CEl 44+D 1.7E+01
EU152 4.0E+02
EU154 4.3E+02
TB160 3.8E+02
OS185 2.5E+02
OSI $91 \quad 7.9$
IRI92 2.5E+02
$\mathrm{HG} 203$ 4.7E+OI
PB210+D 3.4E-01
RA226+D 1.3
$\mathrm{TH} 228+\mathrm{D} 3.3 \mathrm{E}+01$
TH230+D 1.3
$\mathrm{TH} 232+\mathrm{D} \quad 3.2 \mathrm{E}+02$
U $233+$ D 4.2
U 234 6.9E-02
U 235+D 8.9E+01 
Onsite Disposal Environment Surface Soll PLANSOURC (External), continued

$\begin{array}{ll}\text { U 238+D } & 5.0 \\ \text { NP237+D } & 6.6 E+01 \\ \text { PU241+D } & 1.1 \\ \text { SR89 } & 5.7 E-01 \\ \text { Y 89M } & 0.0 \\ \text { SR90 } & 3.0 E-02 \\ \text { Y 90 } & 1.9 \\ \text { M099 } & 4.8 E+01 \\ \text { TC99M } & 1.9 E+01 \\ \text { TC99 } & 4.0 E-03 \\ \text { RU103 } & 1.8 E+02 \\ \text { RH103M } & 5.1 E-02 \\ \text { PD103 } & 2.8 E-01 \\ \text { I 129 } & 4.3 E-01 \\ \text { CS134 } & 6.0 E+02 \\ \text { CS135 } & 1.3 E-03 \\ \text { CS137 } & 4.1 E-02 \\ \text { BA137M } & 2.2 E+02 \\ \text { CE141 } & 1.0 E+01 \\ \text { SM151 } & 2.4 E-04 \\ \text { U 235 } & 2.0 E+01 \\ \text { TH231 } & 1.3 \\ \text { PA231 } & 8.6 \\ \text { AC227 } & 1.3 E-02 \\ \text { TH227 } & 2.5 E+01 \\ \text { FR223 } & 7.6 \\ \text { RA223 } & 2.6 E+01 \\ \text { NP237 } & 1.9 \\ \text { PA233 } & 6.0 E+01 \\ \text { U 233 } & 4.2 E-03 \\ \text { TH229 } & 1.8 \\ \text { RA225 } & 6.8 E-01 \\ \text { AC225 } & 1.7 \\ \text { U 238 } & 9.8 E-03 \\ \text { TH234 } & 7.5 E-01 \\ \text { PA234M } & 2.9 \\ \text { PA234 } & 6.3 E+02 \\ \text { PU242 } & 8.1 E-04 \\ \text { NP238 } & 2.0 E+02 \\ \text { PU238 } & 2.9 E-03 \\ \text { CM244 } & 1.8 E-03 \\ \text { PU244 } & 6.8 E-07 \\ \text { U 240 } & 3.4 E-02 \\ \text { PU240 } & 2.7 E-03 \\ \text { CM243 } & 2.5 E+01 \\ \text { PU243 } & 2.7 \\ \text { AM243 } & 3.6 \\ \text { NP239 } & 2.9 E+01 \\ \text { PU239 } & 2.9 E-03 \\ \text { PU241 } & 2.9 E-12 \\ \text { AM241 } & 1.1 \\ & \end{array}$

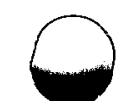

NP237+D 6.6E+01

PU241+D 1.1

SR89

$Y 89 \mathrm{M} \quad 0.0$

SR9O 3.0E-02

Y $90 \quad 1.9$

M099 4.8E+01

TC99M 1.9E+01

TC99 4.0E-03

RU103 1.8E+02

$\mathrm{RHI}$ 03M 5.1E-02

PDI03 2.8E-01

$4.3 E-01$

E +02

BAl37M 2.2E+02

CEI $41 \quad 1.0 E+01$

SMI51 2.4E-04

U $235 \quad 2.0 E+01$

TH231 1.3

PA231 8.6

AC227 $1.3 \mathrm{E}-02$

$\mathrm{TH} 227 \quad 2.5 \mathrm{E}+01$

FR223 7.6

$+01$

NP237 1.9

TH229 1.8

RA225 6.8E-01

AC225 1.7

U $238 \quad 9.8 \mathrm{E}-03$

TH234 7.5E-01

PA234M 2.9

PA234 6.3E+02

$8.1 E-04$

NP238 2.0E+02

2.9E-03

PU244 6.8E-07

U $240 \quad 3.4 \mathrm{E}-02$

PU2 40 2.7E-03

CM243 2.5E+01

PU243 2.7

AM2 $43 \quad 3.6$

NP239 2.9E+01

PU239 2.9E-03

AM241 1.1 


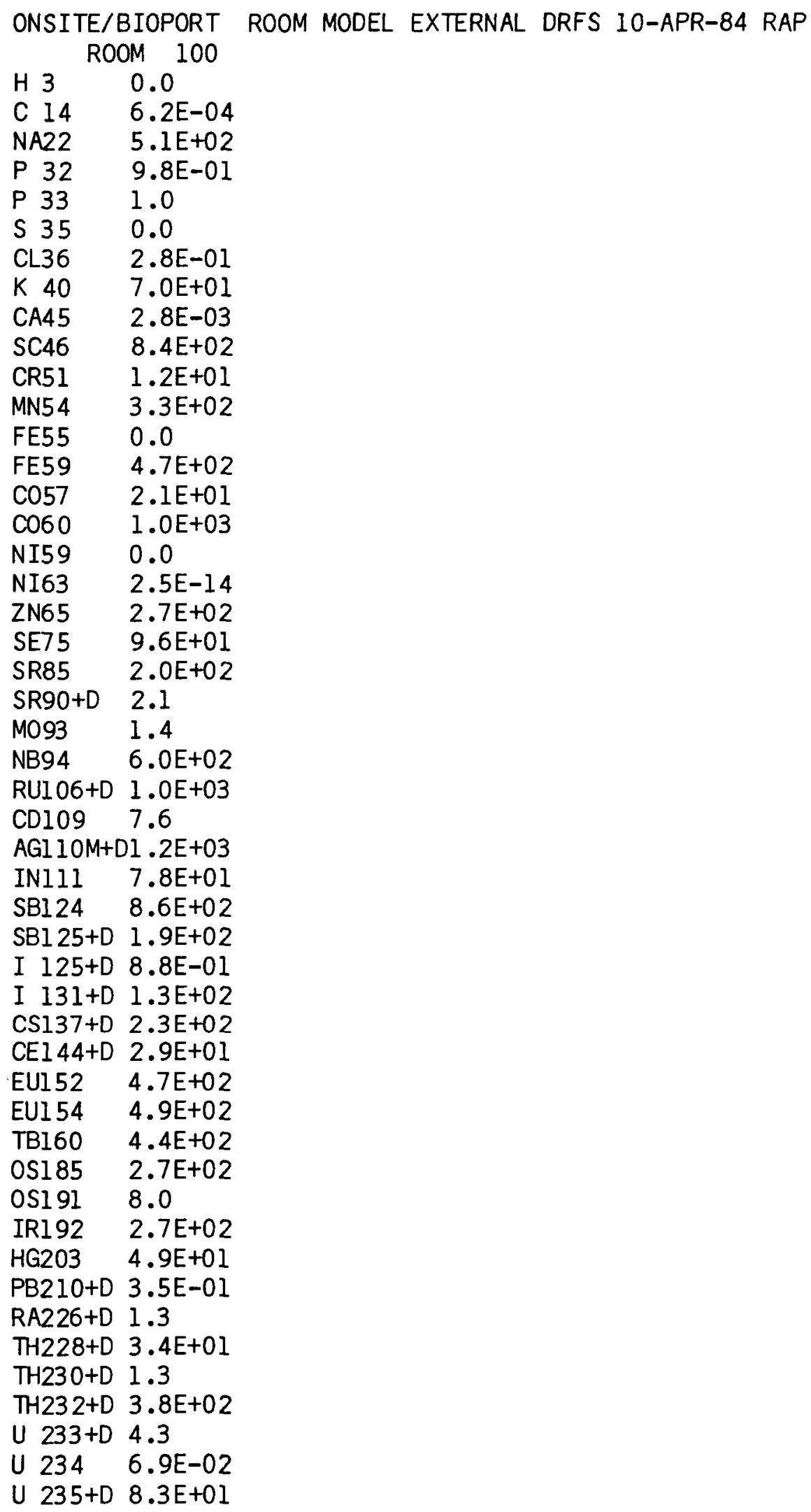


Onsite Disposal Environment Stored Waste ROOM (external), continued
U 238+D 5.6
NP237+D 7.1E+01
PU24I+D 1.1
SR89 $6.1 \mathrm{E}-01$
Y $89 \mathrm{M} \quad 0.0$
SR90 3.0E-02
Y $90 \quad 2.1$
M099 $\quad 5.4 \mathrm{E}+01$
TC99M $1.9 E+01$
TC99 4.0E-03
RU103 2.0E+02
$\mathrm{RH} 103 \mathrm{M}$ 5.1E-02
$\mathrm{PDI03} 2.8 \mathrm{E}-01$
I $129 \quad 4.3 \mathrm{E}-01$
CS134 6.7E+02
CS135 1.3E-03
CS137 4.2E-02
BAl37M 2.4E+02
CEl 41 1.0E+01
SM151 2.4E-04
U $235 \quad 2.0 \mathrm{E}+01$
TH23I 1.3
PA231 9.3
AC227 $1.3 \mathrm{E}-02$
TH227 2.6E+01
FR223 8.0
RA223 2.7E+01
NP237 2.0
PA233 6.5E+01
U 233 4.2E-03
TH229 1.9
RA225 6.8E-01
AC225 1.7
U $238 \quad 9.8 \mathrm{E}-03$
TH234 7.6E-01
PA234M 3.4
PA234 7.2E+02
PU242 8.1E-04
NP238 2.4E+02
PU238 2.9E-03
CM244 1.8E-03
PU244 6.8E-07
U $240 \quad 3.4 \mathrm{E}-02$
PU240 2.7E-03
CM243 2.6E+01
PU243 2.7
AM2 $43 \quad 3.6$
NP239 3.0E+01
PU239 2.9E-03
PU24I 2.9E-12
AM2 $41 \quad 1.1$ 
Onsite Disposal Environment FILE23 (Air), page 1

\begin{tabular}{|c|c|c|c|c|c|c|c|}
\hline 13 & & & IN ( & $S E$ & EN & E & \\
\hline & 1 & 6 & 16 & 23 & & & \\
\hline H 3 & & & 0 & 2 & & & \\
\hline $\mathrm{H}$ & 31 & 11 & $1.05 \mathrm{E}-06$ & .00 & $1.05 \mathrm{E}-06$ & $1.05 \mathrm{E}-06$ & .00 \\
\hline $\mathrm{H}$ & 31 & 12 & $5.32 E-08$ & .00 & $5.32 E-08$ & $5.32 E-08$ & .00 \\
\hline C 14 & & & 4 & 0 & & & \\
\hline C & 141 & 11 & $2.39 \mathrm{E}-06$ & $1.05 \mathrm{E}-05$ & $2.39 E-06$ & $2.39 E-06$ & $2.06 \mathrm{E}-06$ \\
\hline C & 141 & 12 & $1.01 \mathrm{E}-07$ & $1.97 \mathrm{E}-06$ & $1.01 E-07$ & $1.01 E-07$ & $1.23 E-10$ \\
\hline$C$ & 141 & 13 & .00 & $3.51 E-09$ & .00 & .00 & .00 \\
\hline C & 141 & 14 & .00 & 6.37 & .00 & .00 & .00 \\
\hline NA22 & & & 2 & 27 & & & \\
\hline A22 & & 11 & $7.25 \mathrm{E}-05$ & $0.00 \mathrm{E}+00$ & $5.01 E-05$ & $0.00 E+00$ & $1.15 \mathrm{E}-05$ \\
\hline A22 & & 12 & $3.33 E-06$ & $0.00 E+00$ & 9.9 & 0.00 & 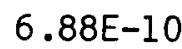 \\
\hline$A 22$ & & 21 & $6.82 \mathrm{E}-05$ & $0.00 \mathrm{E}+00$ & -03 & $E+00$ & \\
\hline NA22 & & 22 & $6.65 E-06$ & $0.00 \mathrm{E}+00$ & $5.32 E-04$ & $0.00 E+00$ & 1 \\
\hline VA22 & & 23 & $2.88 E-08$ & $0.00 E+00$ & $2.57 E-06$ & 0.00 & 09 \\
\hline $1 A 22$ & & 24 & $1.82 E-10$ & $0.00 \mathrm{E}+00$ & 1.2 & 0.00 & 3 \\
\hline NA22 & & 31 & $5.80 \mathrm{E}-05$ & $0.00 \mathrm{E}+00$ & 6.0 & 0.0 & -05 \\
\hline A22 & & 32 & $6.21 E-06$ & $0.00 E+00$ & 7.40 & 0.0 & 1 . \\
\hline A22 & & 33 & $1.84 E-06$ & $E+00$ & 3.4 & 0. & 8. \\
\hline A22 & & 34 & $9.47 \mathrm{E}-07$ & $E+00$ & -03 & 0. & 3. \\
\hline VA22 & & 35 & $4.96 \mathrm{E}-07$ & $E+00$ & .04 & 0. & 1. \\
\hline NA22 & & 36 & $2.65 \mathrm{E}-07$ & $0.00 E+00$ & -04 & -00 & $E-08$ \\
\hline NA22 & & 37 & $1.43 \mathrm{E}-07$ & $0.00 E+00$ & .04 & 0. & $5 E-08$ \\
\hline NA22 & & 38 & $E-08$ & $0.00 E+00$ & .05 & -00 & $E-08$ \\
\hline NA22 & & 39 & $4.36 \mathrm{E}-08$ & $0.00 E+00$ & 05 & 100 & $E-09$ \\
\hline NA22 & & 310 & $2.45 \mathrm{E}-08$ & $0.00 E+00$ & 05 & -00 & $9 E-09$ \\
\hline NA22 & & 311 & $:-08$ & $0.00 E+00$ & .06 & $E+00$ & $2 E-09$ \\
\hline NA22 & & 312 & $E-09$ & $0.00 E+00$ & .06 & +00 & $=-10$ \\
\hline NA22 & & 313 & 4. & $0.00 E+00$ & .06 & 00 & $E-10$ \\
\hline NA22 & & 314 & 2.6 & $0.00 E+00$ & & +00 & $E-10$ \\
\hline NA22 & & 315 & 1.5 & $0.00 E+00$ & .07 & $=+00$ & $E-11$ \\
\hline NA22 & & 316 & $E-10$ & $0.00 E+00$ & .07 & +00 & $E-11$ \\
\hline NA22 & & 317 & $E-10$ & $0.00 E+00$ & $6.71 E-08$ & $E+00$ & $1.46 \mathrm{E}-11$ \\
\hline NA22 & & 318 & $E-10$ & $0.00 E+00$ & -08 & too & $1.09 \mathrm{E}-11$ \\
\hline NA22 & & 319 & $E-10$ & $0.00 E+00$ & .08 & $:+00$ & $E+00$ \\
\hline NA22 & & 320 & $1.16 \mathrm{E}-10$ & $0.00 E+00$ & -09 & +00 & $E-12$ \\
\hline NA22 & & 321 & $E-11$ & $0.00 E+00$ & -09 & $E+00$ & $E+00$ \\
\hline $\mathrm{NA} 22$ & & 322 & $4 E-11$ & $0.00 E+00$ & $E-09$ & $E+00$ & $D E+00$ \\
\hline NA22 & & 323 & $2.18 \mathrm{E}-11$ & $0.00 E+00$ & +00 & +00 & $O E+O O$ \\
\hline NA22 & & 324 & $1.46 \mathrm{E}-11$ & $0.00 E+00$ & +00 & 100 & $O E+00$ \\
\hline NA22 & & 325 & $7.28 \mathrm{E}-12$ & $0.00 E+00$ & -09 & $0.00 E+00$ & $O E+00$ \\
\hline NA22 & & 326 & $7.28 \mathrm{E}-12$ & $0.00 E+00$ & -00 & +00 & $O E+00$ \\
\hline NA22 & & 327 & $7.28 \mathrm{E}-12$ & $0.00 E+00$ & $0.00 E+00$ & $0.00 E+00$ & $0.00 E+00$ \\
\hline P 32 & & & 2 & 2 & & & \\
\hline P 32 & & 11 & $3.79 E-05$ & $9.79 \mathrm{E}-04$ & & 0.0 & -05 \\
\hline P 32 & & 12 & $2.18 E-06$ & $5.89 E-05$ & $E-08$ & $0.00 E+00$ & E-09 \\
\hline P 32 & & 21 & $2.56 E-05$ & $6.62 \mathrm{E}-04$ & & $0.00 E+00$ & $6.96 E-05$ \\
\hline P 32 & & 22 & $1.57 \mathrm{E}-06$ & $4.24 E-05$ & 2.5 & $0.00 E+00$ & $2.90 E-07$ \\
\hline 32 & & 31 & $2.30 E-05$ & $5.95 E-04$ & $7.15 E-04$ & $0.00 E+00$ & $7.77 E-05$ \\
\hline
\end{tabular}


Onsite Disposal Environment FILE24 (Aquatic), page 1

Incremental Aquatic Foods Dose Factors - ONSITE/BIOPORT Env. - 16-APR-84 RAP $\begin{array}{lrrrr}\text { FISH } & 50 & 92 & 5 \\ 1 & 6 & 8 & 16 & 23\end{array}$

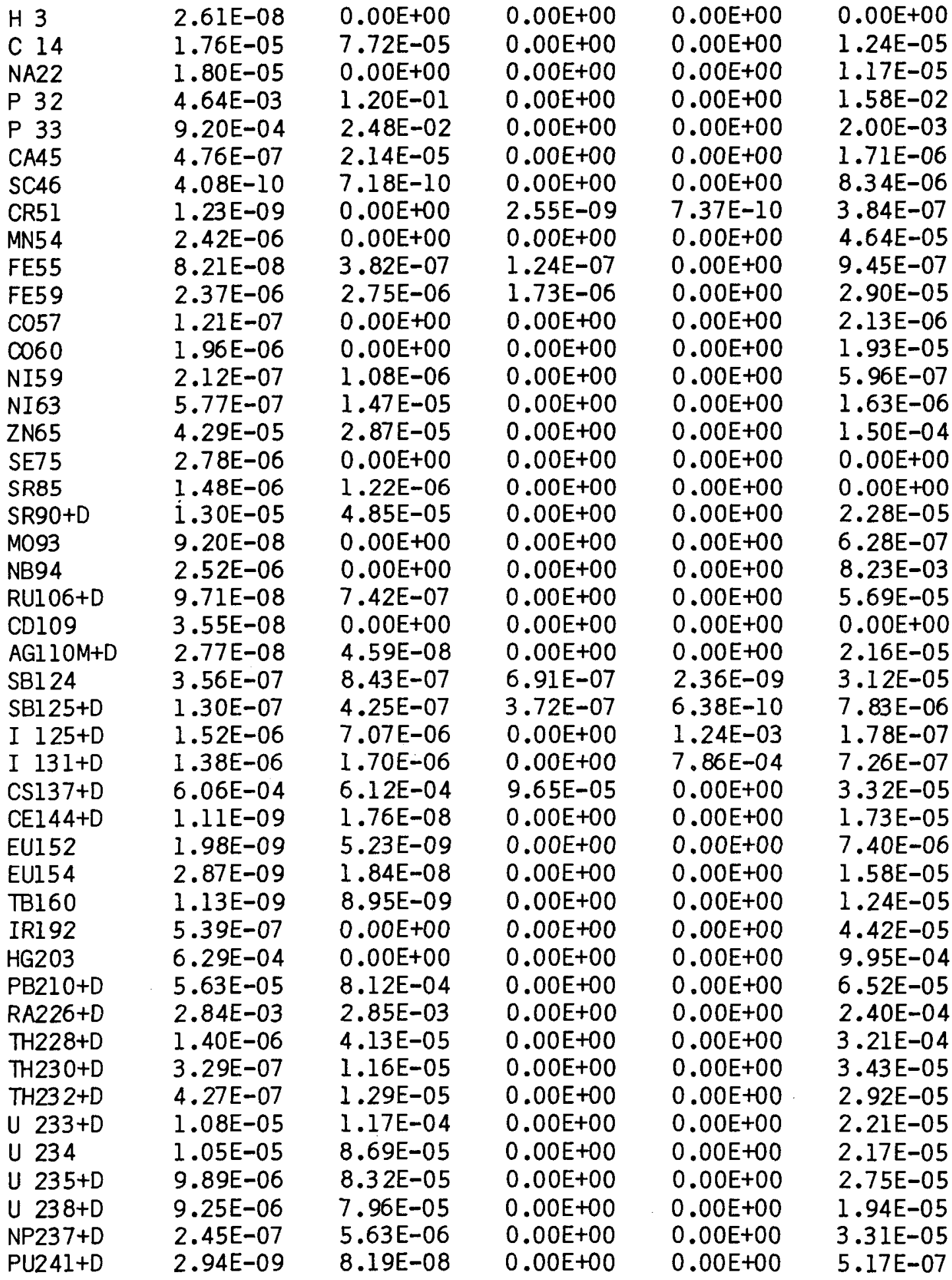


Onsite Disposal Environment FILE25 (Drink), page 1

Incremental Drinking Water Dose Factors - ONSITE/BIOPORT Env. 16-APR-84 RAP $\begin{array}{lrrrr}\mathrm{H} 2 \mathrm{O} & & 50 & 92 & 5 \\ 1 & 6 & 8 & 16 & 23\end{array}$

\begin{tabular}{|c|c|c|c|c|c|}
\hline H 3 & $2.57 E-08$ & $0.00 E+00$ & $0.00 E+00$ & $0.00 E+00$ & $0.00 E+00$ \\
\hline C 14 & $2.40 E-07$ & $1.05 \mathrm{E}-06$ & $0.00 E+00$ & $0.00 E+00$ & $1.68 \mathrm{E}-07$ \\
\hline NA22 & $6.54 \mathrm{E}-06$ & $0.00 \mathrm{E}+00$ & $0.00 E+00$ & $0.00 E+00$ & $4.24 E-06$ \\
\hline P 32 & $1.18 \mathrm{E}-06$ & $3.05 E-05$ & $0.00 E+00$ & $0.00 E+00$ & $4.02 \mathrm{E}-06$ \\
\hline P 33 & $2.34 \mathrm{E}-07$ & $6.29 E-06$ & $0.00 E+00$ & $0.00 E+00$ & $5.09 E-07$ \\
\hline CA45 & $1.15 E-07$ & $5.16 E-06$ & $0.00 \mathrm{E}+00$ & $0.00 \mathrm{E}+00$ & $4.12 \mathrm{E}-07$ \\
\hline SC46 & $3.70 E-10$ & $6.50 \mathrm{E}-10$ & $0.00 E+00$ & $0.00 E+00$ & $7.55 \mathrm{E}-06$ \\
\hline CR51 & $9.15 E-10$ & $0.00 E+00$ & $1.89 \mathrm{E}-09$ & $5.46 E-10$ & $2.84 \mathrm{E}-07$ \\
\hline MN54 & $1.78 \mathrm{E}-07$ & $0.00 E+00$ & $0.00 E+00$ & $0.00 E+00$ & $3.41 \mathrm{E}-06$ \\
\hline FE55 & $9.25 E-09$ & $4.30 E-08$ & $1.39 \mathrm{E}-08$ & $0.00 E+00$ & $1.06 \mathrm{E}-07$ \\
\hline FE59 & $2.68 E-07$ & $3.10 \mathrm{E}-07$ & $1.95 \mathrm{E}-07$ & $0.00 E+00$ & $3.26 \mathrm{E}-06$ \\
\hline $\cos 7$ & $2.45 E-08$ & $0.00 E+00$ & $0.00 E+00$ & $0.00 E+00$ & $4.31 E-07$ \\
\hline $\mathrm{CO60}$ & $3.97 \mathrm{E}-07$ & $0.00 E+00$ & $0.00 E+00$ & $0.00 E+00$ & $3.91 \mathrm{E}-06$ \\
\hline NI59 & $2.39 E-08$ & $1.22 E-07$ & $0.00 E+00$ & $0.00 E+00$ & $6.72 E-08$ \\
\hline NI63 & $6.50 E-08$ & $1.66 \mathrm{E}-06$ & $0.00 E+00$ & $0.00 E+00$ & $1.83 \mathrm{E}-07$ \\
\hline ZN65 & $5.38 \mathrm{E}-07$ & $3.60 \mathrm{E}-07$ & $0.00 E+00$ & $0.00 E+00$ & $1.88 \mathrm{E}-06$ \\
\hline SE75 & $6.40 \mathrm{E}-07$ & $0.00 E+00$ & $0.00 E+00$ & $0.00 E+00$ & $0.00 E+00$ \\
\hline SR85 & $4.39 \mathrm{E}-07$ & $3.63 E-07$ & $0.00 E+00$ & $0.00 E+00$ & $0.00 E+00$ \\
\hline SR90+D & $3.87 E-06$ & $1.44 \mathrm{E}-05$ & $0.00 E+00$ & $0.00 \mathrm{E}+00$ & $6.78 E-06$ \\
\hline M093 & $7.83 E-08$ & $0.00 E+00$ & $0.00 E+00$ & $0.00 E+00$ & $5.35 \mathrm{E}-07$ \\
\hline NB94 & $3.73 E-09$ & $0.00 \mathrm{E}+00$ & $0.00 E+00$ & $0.00 E+00$ & 1.22 \\
\hline RUI 06+D & $7.38 E-08$ & $5.64 E-07$ & $0.00 E+00$ & $0.00 E+00$ & $4.33 E-05$ \\
\hline CD109 & $5.68 \mathrm{E}-09$ & $0.00 E+00$ & $0.00 E+00$ & $0.00 E+00$ & $0.00 E+00$ \\
\hline$A G l 10 M+D$ & $2.63 E-08$ & $4.36 E-08$ & $0.00 E+00$ & $0.00 E+00$ & $2.05 E-05$ \\
\hline SBI 24 & $3.49 E-07$ & $8.27 E-07$ & $6.78 \mathrm{E}-07$ & $2.31 E-09$ & $3.06 \mathrm{E}-05$ \\
\hline SBl25+D & $1.27 \mathrm{E}-07$ & $4.16 E-07$ & $3.65 E-07$ & $6.25 \mathrm{E}-10$ & $7.68 \mathrm{E}-06$ \\
\hline I $125+D$ & $1.17 \mathrm{E}-06$ & $5.46 \mathrm{E}-06$ & $0.00 E+00$ & $9.60 E-04$ & $1.38 \mathrm{E}-07$ \\
\hline I $131+D$ & $1.06 \mathrm{E}-06$ & $1.31 E-06$ & $0.00 E+00$ & $6.07 E-04$ & $5.61 E-07$ \\
\hline $\mathrm{CS} 137+\mathrm{D}$ & $1.68 E-05$ & $1.70 \mathrm{E}-05$ & $2.68 \mathrm{E}-06$ & $0.00 E+00$ & $9.22 \mathrm{E}-07$ \\
\hline CEl 44+D & $1.03 E-09$ & $1.63 E-08$ & $0.00 E+00$ & $0.00 E+00$ & $1.60 \mathrm{E}-05$ \\
\hline EU152 & $6.68 E-10$ & $1.76 \mathrm{E}-09$ & $0.00 E+00$ & $0.00 E+00$ & $2.49 E-06$ \\
\hline EU154 & $9.67 \mathrm{E}-10$ & $6.19 E-09$ & $0.00 E+00$ & $0.00 E+00$ & $5.33 E-06$ \\
\hline TB160 & $3.80 E-10$ & $3.01 E-09$ & $0.00 E+00$ & $0.00 E+00$ & $4.17 E-06$ \\
\hline IRI 92 & $1.09 \mathrm{E}-07$ & $0.00 E+00$ & $0.00 E+00$ & $0.00 E+00$ & $8.95 E-06$ \\
\hline HG2O3 & $9.97 E-07$ & $0.00 E+00$ & $0.00 \mathrm{E}+00$ & $0.00 E+00$ & $1.58 \mathrm{E}-06$ \\
\hline PB210+D & $2.05 E-05$ & $2.95 E-04$ & $0.00 E+00$ & $0.00 E+00$ & $2.37 E-05$ \\
\hline RA226+D & $1.34 \mathrm{E}-03$ & $1.34 \mathrm{E}-03$ & $0.00 E+00$ & $0.00 E+00$ & $1.13 E-04$ \\
\hline $\mathrm{TH} 228+\mathrm{D}$ & $8.35 E-07$ & $2.46 \mathrm{E}-05$ & $0.00 E+00$ & $0.00 E+00$ & $1.92 \mathrm{E}-04$ \\
\hline $\mathrm{TH} 230+\mathrm{D}$ & $1.97 \mathrm{E}-07$ & $6.93 E-06$ & $0.00 E+00$ & $0.00 E+00$ & $2.05 E-05$ \\
\hline $\mathrm{TH} 232+\mathrm{D}$ & $2.55 E-07$ & $7.72 E-06$ & $0.00 E+00$ & $0.00 E+00$ & $1.74 E-05$ \\
\hline U $233+D$ & $1.03 E-05$ & $1.12 \mathrm{E}-04$ & $0.00 E+00$ & $0.00 E+00$ & $2.12 E-05$ \\
\hline U 234 & $1.01 \mathrm{E}-05$ & $8.31 E-05$ & $0.00 E+00$ & $0.00 E+00$ & $2.07 E-05$ \\
\hline U $235+D$ & $9.47 \mathrm{E}-06$ & $7.96 \mathrm{E}-05$ & $0.00 E+00$ & $0.00 E+00$ & $2.63 \mathrm{E}-05$ \\
\hline U $238+D$ & $8.85 \mathrm{E}-06$ & $7.62 \mathrm{E}-05$ & $0.00 E+00$ & $0.00 E+00$ & $1.86 \mathrm{E}-05$ \\
\hline $\mathrm{NP} 237+\mathrm{D}$ & $2.00 E-07$ & $4.59 E-06$ & $0.00 E+00$ & $0.00 E+00$ & $2.70 E-05$ \\
\hline PU2 41+D & $2.73 E-09$ & $7.59 E-08$ & $0.00 E+00$ & $0.00 \mathrm{E}+00$ & $4.80 E-07$ \\
\hline
\end{tabular}


Onsite Disposal Environment VOLSOURC (External)

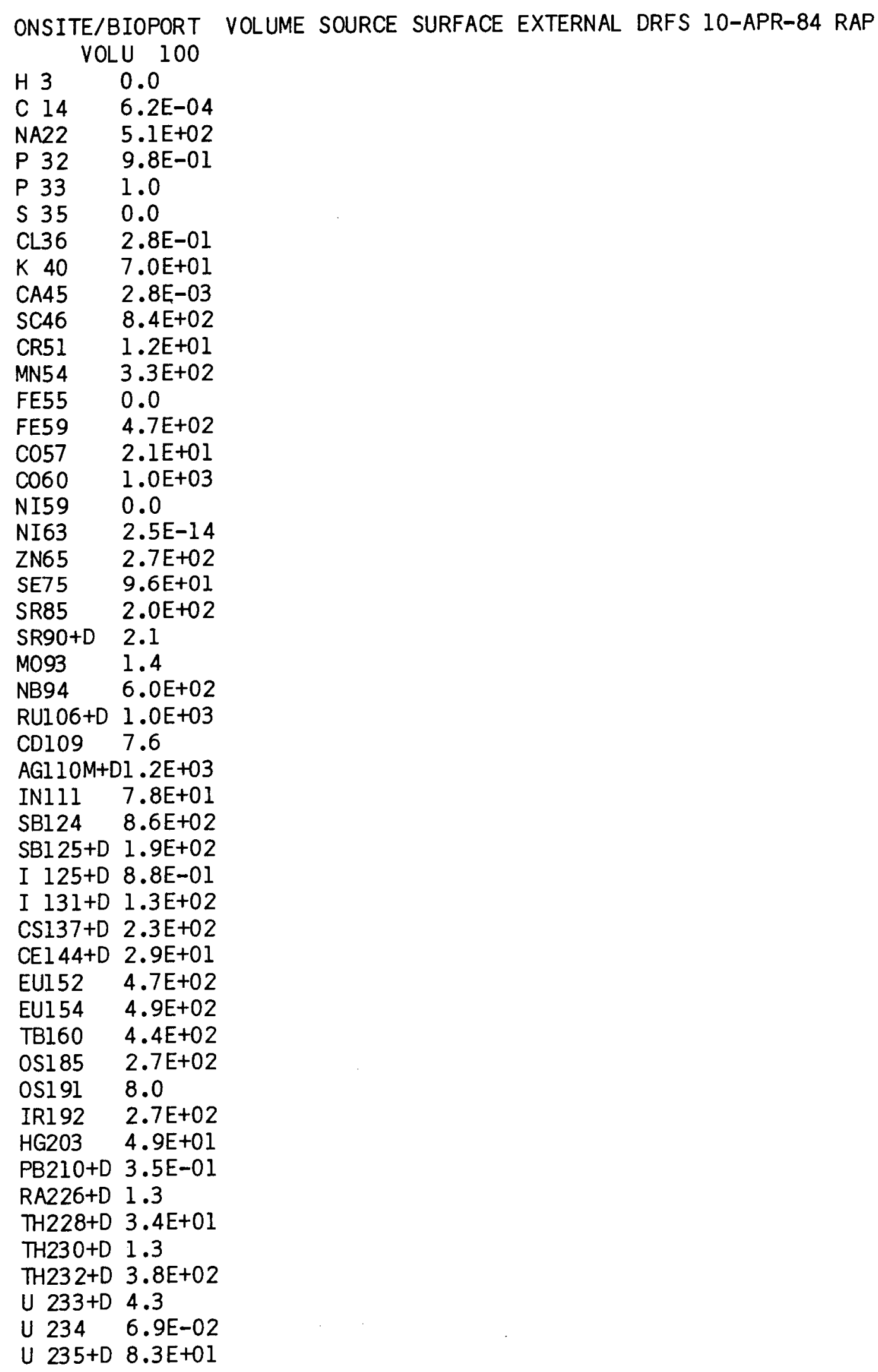


Onsite Disposal Environment VOLSOURC (External), continued
U 238+D 5.6
NP237+D 7.1E+01
PU241+D 1.1
SR89 6.1E-01
Y 89M 0.0
SR90 3.0E-02
$Y 90 \quad 2.1$
M099 5.4E+01
TC99M 1.9E+01
TC99 4.0E-03
RU103 2.0E +02
RH103M 5.1E-02
PD103 2.8E-01
I $1294.3 \mathrm{E}-01$
CS134 6.7E+02
CS135 1.3E-03
CS137 4.2E-02
BAl37M 2.4E+02
CEl 41 1.0E+01
SM151 2.4E-04
U $235 \quad 2.0 E+01$
TH231 1.3
PA231 9.3
AC227 $1.3 \mathrm{E}-02$
TH227 2.6E+01
FR223 8.0
RA223 2.7E+01
NP237 2.0
PA233 6.5E+01
U 233 4.2E-03
TH229 1.9
RA225 6.8E-01
AC225 1.7
U $238 \quad 9.8 \mathrm{E}-03$
$\mathrm{TH} 234 \quad 7.6 \mathrm{E}-01$
PA234M 3.4
PA234 7.2E +02
PU242 8.1E-04
NP238 2.4E+02
PU23 8 2.9E-03
CM244 1.8E-03
PU2 $44 \quad 6.8 E-07$
U $240 \quad 3.4 \mathrm{E}-02$
PU240 2.7E-03
CM2 $43 \quad 2.6 \mathrm{E}+01$
PU243 2.7
AM2 $43 \quad 3.6$
NP239 3.0E+01
PU239 2.9E-03
PU241 2.9E-12
AM241 1.1 
Onsite Disposal Environment BURIEDHF (External)

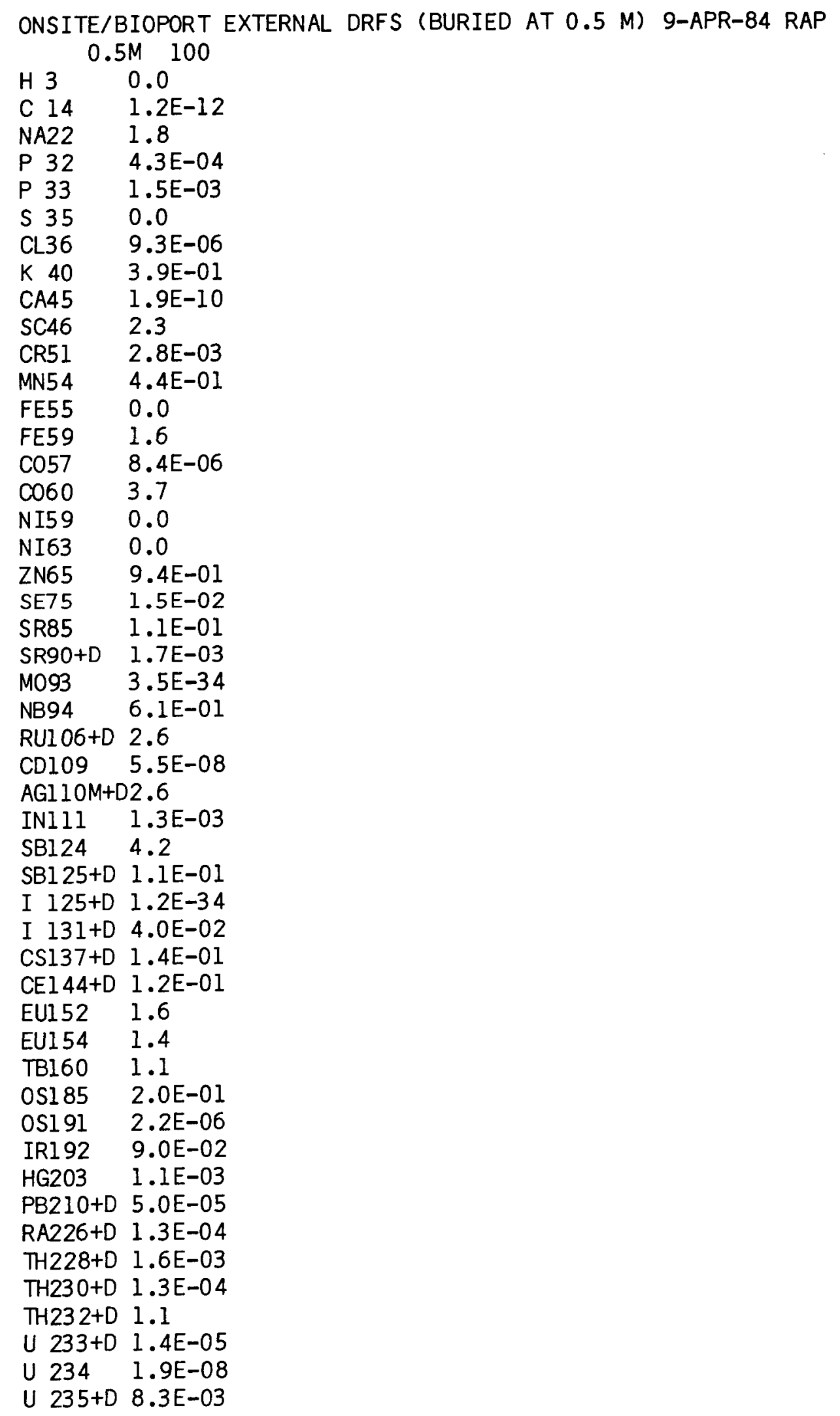


( U 238+D $1.2 \mathrm{E}-02$

NP237+D $1.6 \mathrm{E}-02$

PU24I+D 2.6E-09

SR89 1.8E-04

$Y$ 89M 0.0

SR90 5.5E-07

$Y 90 \quad 1.7 \mathrm{E}-03$

M099 4.4E-02

TC99M 7.6E-06

TC99 7.8E-10

RU103 1.1E-01

RHI 03M 2.8E-26

PDI03 9.3E-06

I $1296.3 \mathrm{E}-13$

CS134 8.0E-01

CS135 3.4E-11

CS137 4.4E-06

BAI37M 1.5E-01

CE1 $41 \quad 4.3 \mathrm{E}-06$

SM151 1.8E-19

U $235 \quad 8.7 E-05$

TH231 1.0E-07

PA23I 1.9E-03

AC227 4.3E-09

TH227 2.4E-03

FR223 2.2E-03

RA223 3.9E-03

NP237 2.7E-08

PA233 1.6E-02

U $233 \quad 6.5 \mathrm{E}-19$

TH229 7.1E-07

RA225 4.3E-09

AC225 1.4E-05

U $238 \quad 5.2 E-18$

$\mathrm{TH} 234 \quad 4.6 \mathrm{E}-08$

PA234M 9.1E-03

PA234 1.6

PU242 2.8E-27

NP238 7.5E-01

PU238 8.4E-10

CM244 6.2E-27

PU244 0 .

U 240 1.1E-13

PU240 8.4E-10

CM2 $43 \quad 3.5 \mathrm{E}-04$

PU243 2.1E-04

AM2 $43 \quad 8.5 \mathrm{E}-10$

NP239 7.9E-04

PU239 8.4E-10

PU241 0.0

AM2.41 2.6E-09 
Onsite Disposal Environment BURIEDl (Externa1)

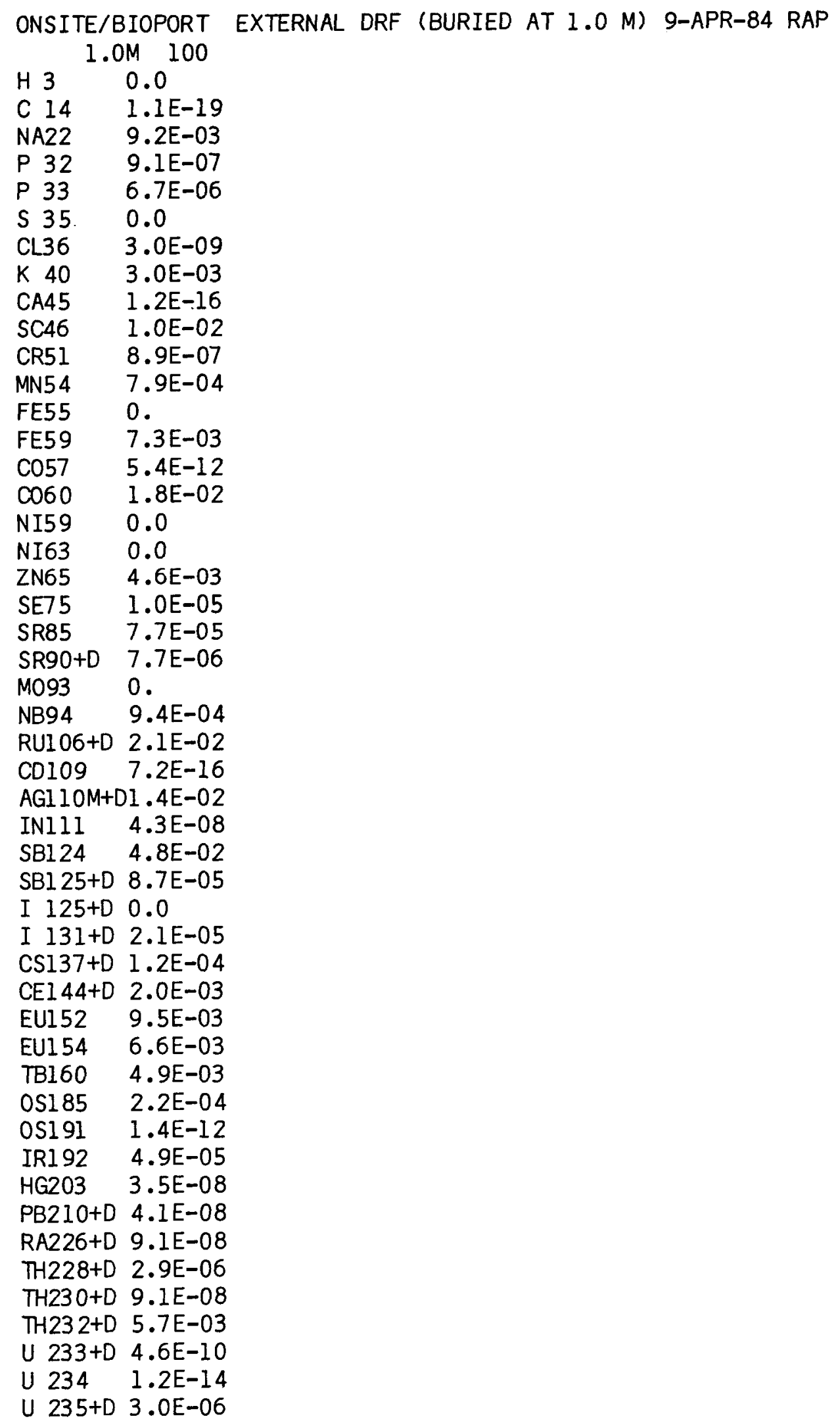




$\begin{array}{ll}\text { U 238+D } & 5.2 E-05 \\ \text { NP237+D } & 5.7 E-06 \\ \text { PU241+D } & 1.6 E-15 \\ \text { SR89 } & 2.8 E-07 \\ \text { Y 89M } & 0.0 \\ \text { SR90 } & 1.5 E-10 \\ \text { Y 90 } & 7.7 E-06 \\ \text { M099 } & 6.6 E-05 \\ \text { TC99M } & 4.9 E-12 \\ \text { TC99 } & 1.3 E-14 \\ \text { RU103 } & 7.9 E-05 \\ \text { RH103M } & 0.0 \\ \text { PD103 } & 3.0 E-09 \\ \text { I 129 } & 4.2 E-20 \\ \text { CS134 } & 2.1 E-03 \\ \text { CS135 } & 1.9 E-17 \\ \text { CS137 } & 4.1 E-09 \\ \text { BA137M } & 1.3 E-04 \\ \text { CE141 } & 9.3 E-11 \\ \text { SM151 } & 7.8 E-30 \\ \text { U 235 } & 2.6 E-09 \\ \text { TH231 } & 6.0 E-14 \\ \text { PA231 } & 6.0 E-07 \\ \text { AC227 } & 2.7 E-15 \\ \text { TH227 } & 6.5 E-07 \\ \text { FR223 } & 3.6 E-06 \\ \text { RA223 } & 1.7 E-06 \\ \text { NP237 } & 1.6 E-16 \\ \text { PA233 } & 5.7 E-06 \\ \text { U 233 } & 1.1 E-33 \\ \text { TH229 } & 4.6 E-13 \\ \text { RA225 } & 1.2 E-13 \\ \text { AC225 } & 4.6 E-10 \\ \text { U 238 } & 8.5 E-33 \\ \text { TH234 } & 1.6 E-14 \\ \text { PA234M } & 3.6 E-05 \\ \text { PA234 } & 8.2 E-03 \\ \text { PU242 } & 0.0 \\ \text { NP238 } & 3.2 E-03 \\ \text { PU238 } & 5.4 E-16 \\ \text { CM244 } & 0.0 \\ \text { PU244 } & 0.0 \\ \text { U 240 } & 6.4 E-21 \\ \text { PU240 } & 5.4 E-16 \\ \text { CM243 } & 1.1 E-08 \\ \text { PU243 } & 6.7 E-08 \\ \text { AM243 } & 4.3 E-19 \\ \text { NP239 } & 1.5 E-07 \\ \text { PU239 } & 5.4 E-16 \\ \text { PU241 } & 0 . \\ \text { AM241 } & 1.6 E-15 \\ & \\ \text { PU }\end{array}$


Onsite Disposal Environment Selected Radionuclides - RMDONS

\begin{tabular}{|c|c|c|c|c|c|}
\hline ONSITE/B & OPORT RAL & IONUCL IDE & MASTER DATA & LIBRARY 23-MAY-84 & RAP \\
\hline H 3 & $4.51 E+3$ & 10 & 0 & 4.8 & 11 \\
\hline C 14 & $2.091 E+6$ & 10 & 0 & 5.5 & 12 \\
\hline NA22 & $9.50 \mathrm{E}+2$ & 10 & 0 & $5.0 E-2$ & 11 \\
\hline$P 32$ & $1.43 E+1$ & 10 & 0 & $5.0 E+1$ & 12 \\
\hline P 33 & $2.44 \mathrm{E}+1$ & 10 & 0 & $5.0 E+1$ & 12 \\
\hline S 35 & $8.72 E+1$ & 10 & 0 & $5.9 E-1$ & 12 \\
\hline CL36 & $1.1 E+8$ & 10 & 0 & 5.0 & 11 \\
\hline $\mathrm{K} 40$ & $4.67 \mathrm{Ell}$ & 10 & 0 & $3.6 \mathrm{E}-1$ & 11 \\
\hline CA45 & $1.65 \mathrm{E}+2$ & 10 & 0 & $4.0 E-2$ & 12 \\
\hline $\mathrm{SC} 46$ & $6.5 \mathrm{E}+1$ & 10 & 0 & $1.1 E-3$ & 13 \\
\hline CR51 & $2.77 \mathrm{E}+1$ & 10 & 0 & $2.5 E-4$ & 13 \\
\hline MN5 4 & $3.12 E+2$ & 10 & 0 & $3.0 E-2$ & 13 \\
\hline FE5 5 & $9.86 E+2$ & 10 & 0 & $4.0 E-4$ & 13 \\
\hline FE59 & $4.46 E+1$ & 10 & 0 & $4.0 E-4$ & 13 \\
\hline C057 & $2.71 E+2$ & 10 & 0 & $9.4 E-3$ & 13 \\
\hline C060 & $1.92 E+3$ & 10 & 0 & $9.4 E-3$ & 13 \\
\hline NI59 & $2.74 \mathrm{E}+7$ & 10 & 0 & $1.9 E-2$ & 13 \\
\hline NI63 & $3.51 E+4$ & 10 & 0 & $1.9 E-2$ & 13 \\
\hline ZN65 & $2.44 E+2$ & 10 & 0 & $4.0 \mathrm{E}-1$ & 13 \\
\hline SE75 & $1.20 E+2$ & 10 & 0 & 1.3 & 12 \\
\hline SR85 & $6.5 \mathrm{E}+1$ & 10 & 0 & $2.0 \mathrm{E}-1$ & 13 \\
\hline SR90+D & $1.04 E+4$ & 10 & 0 & $2.0 E-1$ & 13 \\
\hline M093 & $3.65 E+4$ & 10 & 0 & $1.3 E-1$ & 13 \\
\hline NB94 & $7.30 E+6$ & 10 & 0 & $9.4 E-3$ & 13 \\
\hline RU106+D & $3.68 \mathrm{E}+2$ & 10 & 0 & $1.0 E-2$ & 13 \\
\hline CD109 & $4.40 E+2$ & 10 & 0 & $3.0 E-1$ & 13 \\
\hline$A G 110 M+D$ & $2.52 E+2$ & 10 & 0 & $1.5 \mathrm{E}-1$ & 13 \\
\hline IN11I & $2.8 \mathrm{E}+0$ & 10 & 0 & $2.5 E-1$ & 13 \\
\hline SBl 24 & $6.02 E+1$ & 10 & 0 & $1.1 \mathrm{E}-2$ & 13 \\
\hline SBl $25+D$ & $1.01 E+3$ & 10 & 0 & 1.1E-2 & 13 \\
\hline I $125+D$ & $5.97 E+1$ & 10 & 0 & $2.0 \mathrm{E}-2$ & 12 \\
\hline I $131+D$ & $8.04 E+0$ & 10 & 0 & $2.0 \mathrm{E}-2$ & 12 \\
\hline $\operatorname{CS} 137+D$ & $1.10 E+4$ & 10 & 0 & $2.0 E-3$ & 11 \\
\hline CEl 44+D & $2.84 E+2$ & 10 & 0 & $5.0 \mathrm{E}-4$ & 23 \\
\hline EU1 52 & $4.97 \mathrm{E}+3$ & 10 & 0 & $2.5 E-3$ & 23 \\
\hline EU154 & $3.14 \mathrm{E}+3$ & 10 & 0 & $2.5 E-3$ & 23 \\
\hline TB160 & $7.2 \mathrm{E}+1$ & 10 & 0 & $2.6 E-3$ & 23 \\
\hline OS185 & $9.40 \mathrm{E}+1$ & 10 & 0 & $5.0 \mathrm{E}-2$ & 23 \\
\hline OS191 & $1.5 \mathrm{E}+1$ & 10 & 0 & $5.0 E-2$ & 23 \\
\hline IRI 92 & $7.30 \mathrm{E}+1$ & 10 & 0 & $9.4 \mathrm{E}-3$ & 23 \\
\hline HG203 & $4.66 \mathrm{E}+1$ & 10 & 0 & $3.8 \mathrm{E}-1$ & 23 \\
\hline$P B 210+D$ & $8.14 E+3$ & 10 & 0 & $6.8 \mathrm{E}-2$ & 23 \\
\hline RA226+D & $5.84 E+5$ & $\begin{array}{ll}1 & 0\end{array}$ & 0 & $1.4 \mathrm{E}-3$ & 23 \\
\hline$T H 228+D$ & $6.97 E+2$ & 10 & 0 & $4.2 E-3$ & 23 \\
\hline$T H 230+D$ & $2.81 E+7$ & 10 & 0 & $4.2 \mathrm{E}-3$ & 23 \\
\hline$T H 232+D$ & $5.13 \mathrm{El} 2$ & 10 & 0 & $4 \cdot 2 \mathrm{E}-3$ & 23 \\
\hline$\cup 233+D$ & $5.79 \mathrm{E}+7$ & 10 & 0 & $2.5 E-3$ & 23 \\
\hline U 234 & $8.91 E+7$ & 10 & 0 & $2.5 E-3$ & 23 \\
\hline$U 235+D$ & $2.59 E I 1$ & 10 & 0 & $2.5 E-3$ & 23 \\
\hline U $238+D$ & $1.65 \mathrm{E} 12$ & 10 & 0 & $2.5 E-3$ & 23 \\
\hline
\end{tabular}


Onsite Disposal Environment Selected Radionuclides - RMDONS, continued

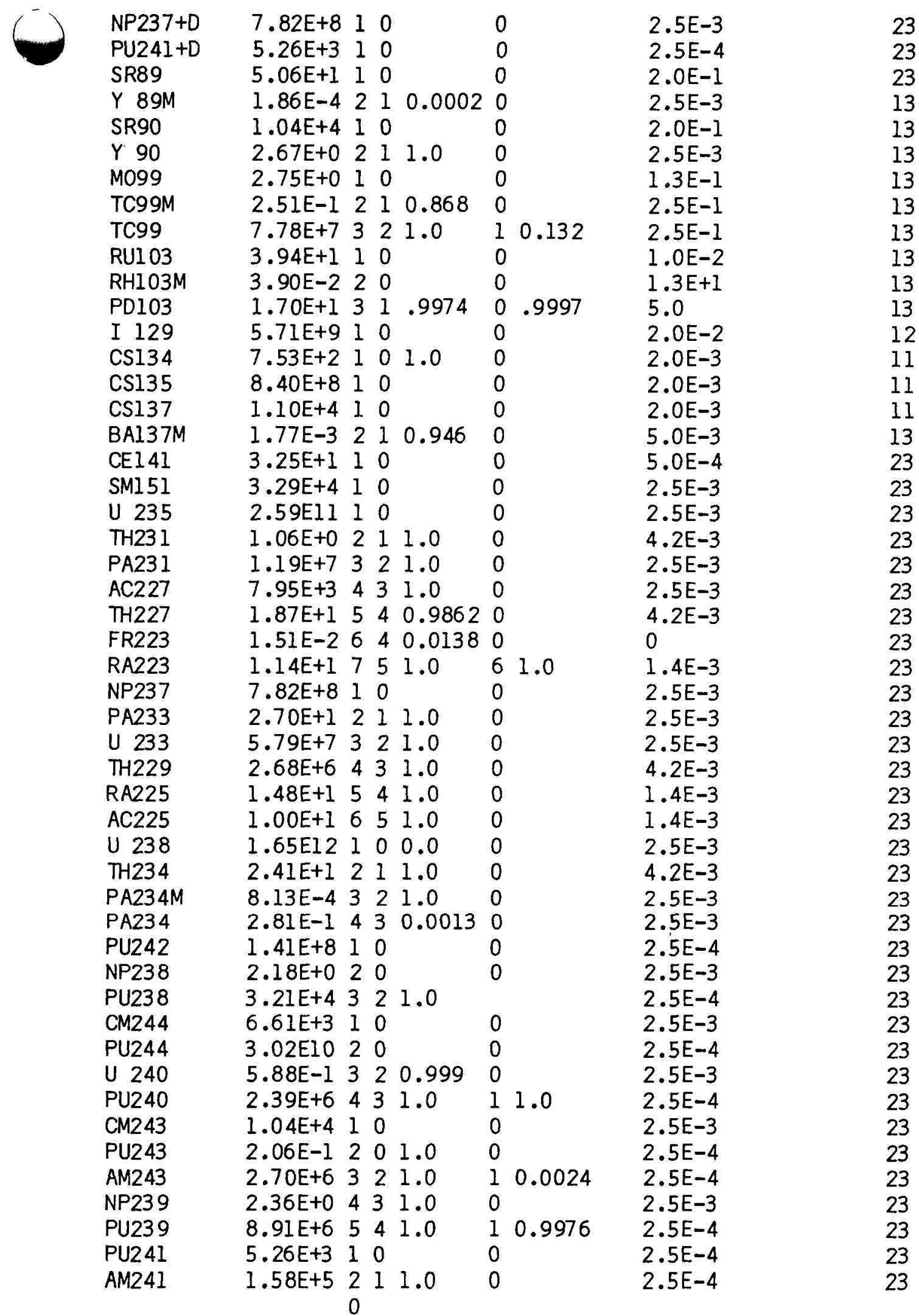


APPENDIX 1.0

CDC Computer Installation

\author{
CONTENTS
}

1.D.1 CDC Command Level Procedure - PROCFIL................ 1.D-1

1.D.2 CDC Version of the ONSITE module RITFIL............... 1.D-2 
.PROC,ON.

ATTACH, ABS, ONSITEABS, ID=0NSITEDB.

COPY, ABS, LGO.

RETURN, ABS.

ATTACH, TAPEI 0, RMDONS, ID $=0 N S I T E D B, M R=1$.

REWIND, TAPEI0.

CONNECT, OUTPUT.

CONNECT, INPUT.

CONNECT, TAPE5.

CONNECT, TAPE6.

REWIND, LGO.

LGO.

REVERT.

*EOR

.PROC,DONE*I, F"FILENAME FOR SCENARIO" $=\left({ }^{*} F\right)$,

$R^{\prime \prime R E A D ~ P A S S W O R D ~ F O R ~ F I L E " ~}=(* A)$.

CATALOG, TAPE7, $F, I D=O N S I T E, R P=10, R D=R$.

BATCH, TAPE7, INPUT, HERE.

RETURN, TAPE7.

RETURN, TAPEIO.

DISCONT, OUTPUT.

DISCONT, INPUT.

DISCONT, TAPE5.

DISCONT, TAPE6.

RETURN LGO.

FILES.

REVERT.

*EOR

.PROC, SEND*I, F"NAME OF OUTPUT FILE TO BE PRINTED:"=(*F), $N^{\prime \prime}$ IVE CHARACTER NAME TO IDENTIFY RUN" $=(* A)$.

$B A T C H, F, L O C A L$.

REQUEST, $X, * 0$.

REWIND, $F$.

COPY, $F, X$.

ROUTE $, X, D C=P R, F I D=* N, T I D=K T$.

RETURN $X$.

FILES.

REVERT.

*EOR

*EOF 
APPENDIX 1.D.2 CDC Version of the ONSITE Module RITFIL

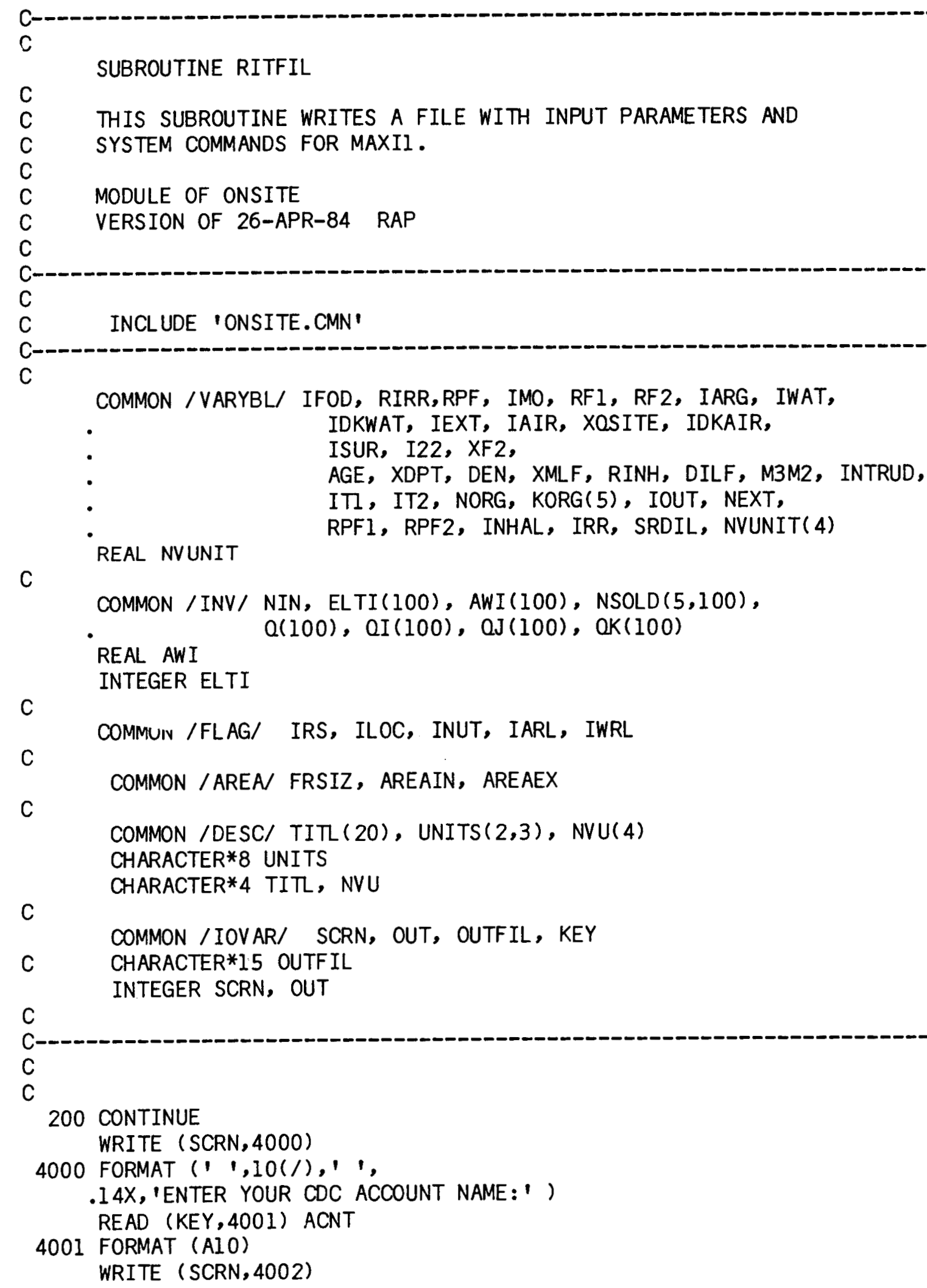


APPENDIX 1.D.2 CDC Version of the ONSITE Module RITFIL (Continued)

4002 FORMAT ('0', I 4X,' ENTER YOUR CDC PROBLEM NO:')

READ (KEY,4001) PRBLM

C

C--- INSERT JOB CONTROL RECORDS FOR BATCH PROCESSING

C

WRITE (OUT,3000) ACNT, ACNT, PRBLM, PRBLM

3000 FORMAT (A5,',STMFZ, CM160000,EC400, 177.1 '

.'ACCOUNT, ', A7, ', ', A4, ', ', A4, '.1'

C

C---- ASSIGN LIBRARY FILES TO LOGICAL UNIT DEVICES

C IF (IFOD .GT. O) WRITE (OUT, 3010)

WRITE (OUT,3010)

C

C 3010 FORMAT ('ASSIGN [BIO.NEW]FILE20.DAT FORO20'/

C ' 'ASSIGN [BIO.NEW]FILE21.DAT FORO21')

C

3010 FORMAT (' ATTACH, TAPE20,FILE20, ID=ZZRNRC. '

- ' ATTACH, TAPE21, FILE21, ID=ZZRNRC. 1/

1 REWIND, TAPE20."'

( REWIND, TAPE21.' )

C

C IF (IARG .GT. O) WRITE (OUT, 3020)

WRITE (OUT,3020)

C

C3020 FORMAT ('ASSIGN [BIO.NEW]FILE24.DAT FORO24')

3020 FORMAT ( ' ATTACH, TAPE24, FILE24, ID=ZZRNRC.'")

- REWIND, TAPE24. '1)

$\mathrm{C}$

C IF (IWAT .GT. O) WRITE (OUT, 3030)

WRITE (OUT,3030)

C

C3030 FORMAT ('ASSIGN [BIO. NEW]FILE25.DAT FORO25')

3030 FORMAT (" ATTACH, TAPE25,FILE25, ID=ZZRNRC."'

- REWIND, TAPE25.')

C

IF (ILOC .EQ. 4) THEN

WRITE (OUT, 3240)

ELSE

WRITE (OUT, 3040)

ENDIF

$\mathrm{C}$

C3240 FORMAT ('ASSIGN [BIO.NEW]ROOM.DAT FORO22')

3240 FORMAT (' ATTACH,TAPE22, ROOM, ID=ZZRNRC. " )

' REWIND, TAPE22.')

C

C3040 FORMAT ('ASSIGN [BIO.NEW]PLANSOURC. SUR FORO22')

3040 FORMAT (' ATTACH,TAPE22, PLANSOURC, ID =ZZRNRC. '

- REWTND, TAPE22.')

C 


\section{APPENDIX 1.D.2 CDC Version of the ONSITE Module RITFIL (Continued)}

IF (ILOC .EQ. 1) WRITE (OUT, 3044)

C3044 FORMAT ('ASSIGN [BIO.NEW] VOL SOURCE. SUR FORO27 ')

3044 FORMAT (' ATTACH, TAPE27, VOLSOURC, ID=ZZRNRC. '/

1 REWIND, TAPE27. ')

C

IF (ILOC .EQ. 2) WRITE (OUT, 3041)

C3041 FORMAT ('ASSIGN [BIO.NEW]BUR.IEDHF.DAT FORO 27')

3041 FORMAT (' ATTACH, TAPE27, BURIEDHF, ID=ZZRNRC.'"

' REWIND, TAPE27.')

C

IF (ILOC.EO. 3) WRITE (OUT, 3042)

C3042 FORMAT ('ASSIGN [BIO.NEW]BURIEDI.DAT FORO 27')

3042 FORMAT (' ATTACH, TAPE27, BURIED1, ID=ZZRNRC. ')

' REWIND, TAPE27.')

C

WRITE (OUT, 3050)

C

C3050 FORMAT ('ASSIGN [BIO.NEW]RMDLIB.DAT FORO10'/

C

'ASSIGN [BIO.NEW]FILE23.DAT FORO23')

3050 FORMAT (' ATTACH, TAPEI 0, RMDL IB, ID=ZZRNRC. ')

- ATTACH, TAPE23, FILE23, ID=ZZRNRC. '/

- $\quad$ REWIND, TAPE10.1\%

- $\quad$ REWIND, TAPE23.')

C

C

C---- CALCULATE OUTPUT VALUES

C

$\mathrm{RPF}=\mathrm{RPF} 1$

IF (INHAL .EQ. O) RINH $=0.0$

IF (INHAL .EQ. 2) AGE $=-1.0$

C

C

C---- EXECUTE COMMAND, TITLE, AND NAMELIST

C

C

C

WRITE (OUT, 3100)

C

C3100 FORMAT ('RUN [BIO.NEW]MAXII'/20A4/' \$INPUT NEXT=1,')

3100 FORMAT (' ATTACH, ABS, MAXII ABS, ID=ZZRNRC.')

- COPY, ABS, LGO. '/

- $\quad$ RETURN, ABS.' $/$

' MAP,OFF.' 1

- ATTACH,L IBI, FTN5L IB, CY=590.1/

- ATTACH, LIB2, SYSLIB7, CY $=590.1 \%$

- $\quad$ LIBRARY,LIBI,LIB2. $1 \%$

, LDSET,PRESET=ZERO. $1 \%$

- $\quad$ LGO.1) 


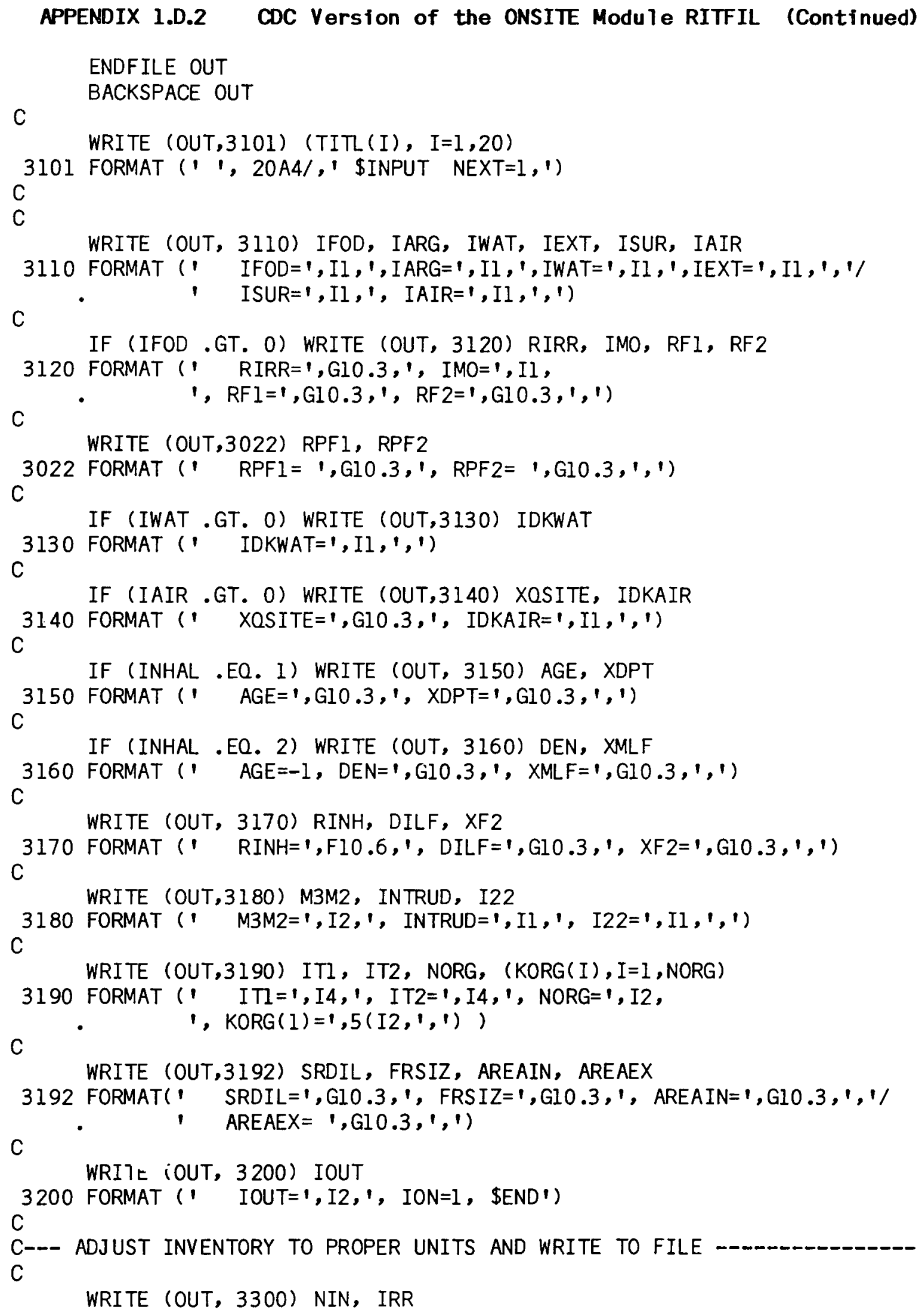


APPENDIX 1.D.2 CDC Version of the ONSITE Module RITFIL (Continued) 3300 FORMAT (2I5)

C

DO $100 \mathrm{I}=1, \mathrm{NIN}$

$Q(I)=Q(I) *$ NVUNIT(INUT)

WRITE (OUT, 3400) ELTI(I), AWI(I), (NSOLD(J,I),J=l,5),

3400 FORMAT $(A 2, A 6,5 \mathrm{II}, 4(1 \mathrm{PGI0.2)})$

100 CONTINUE

$\mathrm{C}$

C--- CLOSE FILE AND RETURN

C

ENDFILE OUT

CLOSE (UNIT=OUT)

C

RETURN

C

C--- ERROR ROUTINES

C

992 WRITE (SCRN,9920)

9920 FORMAT ('OERROR IN OPENING OUTPUT FILE')

GO TO 200

C

994 WRITE (SCRN,9940)

9940 FORMAT ('OERROR IN CLOSING OUTPUT FILE')

STOP

C

C

C

END 


\section{DISTRIBUTION}

No. of

Copies

OEFSITE

U.S. Nuclear Regulatory Commission

Division of Technical

Information and Document Control

7920 Norfolk Avenue

Bethesda, MD 20014

10 S. M. Neuder

U.S. Nuclear Regulatory Commission

Division of Waste Management Office of NMSS

Washington, DC 20555

J. D. Randa 11

U.S. Nuclear Regulatory

Commission

Mail Stop 1130 SS

Washington, DC 20555

Director, Office of NMSS

U.S. Nuclear Regulatory

Commission

Washington, DC 20555

Director, Division of Waste

Management

U.S. Nuclear Regulatory

Commission

Washington, DC 20555
No. of

Copies

QNSITE

50 Pacific Northwest Laboratory

J. B. Brown, Jr.

D. B. Cearlock

L. G. Faust

W. A. Glass

G. R. Hoenes

R. L. Kathren

W. E. Kennedy, Jr. (10)

L. T. Lakey

J. M. Latkovich

B. A. Napier (10)

R. A. Peloquin (10)

R. G. Schreckhise

J. M. Selby

J. K. Soldat

S. L. Stein

C. M. Unruh

Publishing Coordination (2)

Technical Information (5) 